\title{
Contributions to the \\ Palaeobiology of the Archosaurs (Reptilia: Diapsida) from the Bückeberg Formation ('Northwest German Wealden' \\ - Berriasian-Valanginian, Lower Cretaceous) of northern Germany
}

\begin{abstract}
Dissertation
zur Erlangung des mathematisch-naturwissenschaftlichen Doktorgrades

"Doctor rerum naturalium"

der Georg-August-Universität Göttingen

im Promotionsprogramm Geowissenschaften / Geographie

der Georg-August University School of Science (GAUSS)

vorgelegt von

Jahn Jochen Hornung
\end{abstract}

aus Freiburg im Breisgau

Göttingen 2013 


\section{Betreuungsausschuss:}

Prof. Dr. Joachim Reitner, Abteilung Geobiologie, Geowissenschaftliches Zentrum der Universität Göttingen

Dr. Mike Reich, Abteilung Geobiologie und Geowissenschaftliches Museum, Sammlungen und Geopark, Geowissenschaftliches Zentrum der Universität Göttingen

\section{Mitglieder der Prüfungskommission}

\section{Referent:}

Prof. Dr. Joachim Reitner, Abteilung Geobiologie, Geowissenschaftliches Zentrum der Universität Göttingen

\section{Korreferent:}

Dr. Mike Reich, Abteilung Geobiologie und Geowissenschaftliches Museum, Sammlungen und Geopark, Geowissenschaftliches Zentrum der Universität Göttingen

\section{Korreferentin:}

Dr. Annette Richter, Abteilung Naturkunde, Niedersächsisches Landesmuseum, Hannover

\section{Weitere Mitglieder der Prüfungskommission:}

PD Dr. Gernot Arp, Abteilung Geobiologie, Geowissenschaftliches Zentrum der Universität Göttingen

Dr. Cornelia Kurz, Museum für Naturkunde, Kassel

Prof. Dr. Volker Thiel, Abteilung Geobiologie, Geowissenschaftliches Zentrum der Universität Göttingen

PD Dr. Frank Wiese, Abteilung Geobiologie, Geowissenschaftliches Zentrum der Universität Göttingen 


\section{Table of Contents}

Chapter I - The 'German Wealden' and the Obernkirchen Sandstone - an introduction

Chapter IV - Vertebrate tracksites in the Obernkirchen Sandstone (late Berriasian, Early Cretaceous) of northwest Germany - their stratigraphical, palaeogeographical, palaeoecological, and historical context

Chapter V - Dinosaur tracks from the Berriasian Obernkirchen Sandstone on exhibit at the Göttingen University Geopark

Chapter VI - Metatetrapous valdensis Nopcsa, 1923 and the presence of ankylosaur tracks (Dinosauria: Thyreophora) in the Berriasian (Early Cretaceous) of northwestern Germany

Chapter VII - Ankylosaur remains from the Early Cretaceous (Valanginian) of Westphalia (northwestern Germany)

Chapter VIII - A new look into the periorbital morphology of Goniopholis (Mesoeucrocodylia: Neosuchia) and related forms

Chapter IX - Derived appendicular morphology in Early Cretaceous aquatic turtles evidenced by the track record

Chapter X - The first record of the pterosaur ichnogenus Purbeckopus in the late Berriasian (Early Cretaceous) of northwest Germany 
Chapter XI - Synopsis: Archosaurs during the dawn of the Cretaceous in Europe - the temporal and palaeobiogeographical context of the archosaur fauna from the

Outlook

Appendix A - Archosaur skeletal material from the Bückeberg Formation

Appendix B - Spatial and temporal distribution of archosaur fossils in the Bückeberg Formation 
To the memory of

Maximilian M. W. C. Ballerstedt

(1857-1945)

His efforts made this possible. 


\section{Abstract}

Fossil remains of archosaurs, the dominant clade of non-marine tetrapods during the Mesozoic, are known from the Berriasian to Lower Valanginian Bückeberg Formation (the "German Wealden") of northwestern Germany since the first half of the $19^{\text {th }}$ century. Since the 1880 s the formation became renown for the abundant occurrence of fossil vertebrate tracks, most of which have been left by dinosaurs. Despite being located within a crucial but poorly known interval of archosaur evolution, most of the material (especially the skeletal elements) has rarely been examined in the past.

The Bückeberg Formation predominantly consists of siliclastics deposited in the Lower Saxony Basin, an epicontinental basin ranging from the Netherlands in the west eastwards across northern into eastern Germany. The general palaeogeographical and palaeoenvironmental setting was that of a large freshwater lake which at least received inflow from rivers along its southern margin entering the basin in extensive deltaic systems. Episodically this lake communicated with the open Boreal Sea in the west, leading to the inflow of saline waters, which was, however, restricted to the western part of the basin during deposition of the lower part of the formation.

The present thesis provides a catalogue of archosaur material from the Bückeberg Formation which includes crocodilians (Pholidosauridae, Goniopholididae, Atoposauridae, Hylaeochampsidae), dinosaurs (Ankylosauria, Ornithopoda, Theropoda, Sauropoda) and pterosaurs. The specimens include skeletal material as well as abundant tracks.

Dinosaur tracksites of the Bückeberg Formation, some of which have produced material of impressive quality, are stratigraphically concentrated in the Obernkirchen Sandstone, a thin subunit within this formation. The Obernkirchen Sandstone represents mainly a sandy barrier to backbarrier and lagoonal setting within a limnic deltaic facies complex, which was deposited during the late Berriasian (Cypridea alta formosa ostracod subzone) in the southeast of the Lower Saxony Basin. A few tracksites occur more proximally in coeval fluvial deposits. Dinosaur footprint assemblages were produced by ornithopods, theropods, sauropods, ankylosaurs, and small, bipedal ornithischians (dryosaurids?). Other vertebrate tracks are those of turtles and, possibly, crocodilians. Due to the decrease in sandstone quarrying in recent decades, many old tracksites are inaccessible today. Additionally, historical descriptions of the tracks are of highly variable quality and often published in remote and today nearly unobtainable sources. A catalogue of 16 tracksites has been compiled from the literature and some new observations. Of these 16 tracksites, only five are still accessible and currently under study. Descriptions of each locality are provided, with a comprehensive compilation of existing data on lithofacies, stratigraphy, palaeogeography and palaeoecology of the Obernkirchen Sandstone and equivalent strata. A short review of the trackbearing lithofacies assemblage indicates that the outcrop areas have distinctly different facies and environments, and, therefore, track-bearing horizons can only be correlated stratigraphically between adjacent outcrops. For this reason, the identification of a megatracksite in the Obernkirchen Sandstone is currently regarded as premature and uncertain.

From the Bückeberg Formation, the first ichnotaxon ever attributed to a thyreophoran dinosaur, Metatetrapous valdensis, has been described in 1922/23. However, the subsequent loss of the 
original material made its identification, or the existence of this ichnotaxon at all, questionable for many subsequent authors. This situation was aggravated by the fact that there are only very brief original descriptions accompanied by a single drawing. A reconsideration of the original description recognises $M$. valdensis as a valid ichnotaxon, which, albeit showing great resemblence in pes morphology to similar ichnotaxa, stands out from them by a tetradactyle manus. It not only still holds its original systematic attribution, but has also sparked early hypotheses on the phylogeny of dinosaurs already in 1922, possibly for the first time based upon tracks. Two surviving natural hypichnial casts of ankylosaurian pes imprints from the same stratum cannot be straightforwardly identified with the type material due to a lack of documentation. However, comprehensive circumstantial evidence, including complete accordance in size and morphology among others, strongly supports such an association. The tracks confirm the presence of ankylosaurs in this lacustrine-deltaic setting as a very rare element of the local dinosaur fauna.

Ankylosaurs are also represented by skeletal material. A fragmentary cervico-pectoral lateral spine and partial humerus of an ankylosaur from the Early Cretaceous (early Valanginian) of Gronau in Westphalia (northwestern Germany) are described. The spine shows closest morphological similarities to the characteristic pectoral spines of Hylaeosaurus armatus from the late Valanginian of England. An extensive comparison of distal humeri among thyreophoran dinosaurs support systematic differences in the morphology of the distal condyli between Ankylosauria and Stegosauria and a referral of the Gronau specimen to the former. The humerus fragment indicates a rather small individual, probably in the size range of $H$. armatus, and both specimens are determined herein as ?Hylaeosaurus sp. A short overview of other purported ankylosaur material from the Berriasian-Valanginian of northwest Germany shows that otherwise only the tracks can be attributed to this clade with confidence at present.

Ornithopods are represented by extremely abundant tracks, representing various morphotypes of iguanodontians with functionally tridactyl pedes. A more basal type with impressions of a hallux was reported in older studies but could not yet been verified by material. The same is true for didactyl footprints described earlier. However, the morphotypes most probably represent several orthotaxa. This is supported by the rare osteological record which supports the presence of several taxa, representing different phylogenetic grades. Rare, smaller tracks may represent dryosaurids.

Recent studies have found the enigmatic small ornithischian Stenopelix valdensis to be a basal ceratopsian. This view is adopted here, supporting palaeogeographical ties of the Bückeberg Formation fauna with Asia during the Berriasian.

According to their track record, theropods were highly diverse and abundant in the Bückeberg Formation. The diversity of track morphotypes suggests the presence of various clades, however only one of them, Troodontidae, can be determined with some confidence. In contrast, the osteological record is sparse. It includes the holotype tooth of Altispinax dunkeri, which is of uncertain systematic position but shows potentially diagnostic characters.

Sauropods are rare. They are represented only in a single tracksite (though by a large number of tracks). Their skeletal record is restricted to several caudal vertebrae and a tooth from the Early Valanginian upper Bückeberg Formation, which show titanosauriform affinities.

Crocodilians are abundant and represented by well-preserved material. In a case study, the 
periorbital morphology of goniopholidids is discussed, exploring the diversity of patterns and the relevance of the data for phylogenetic studies. The revision of material focusses on Goniopholis spp. and closely related taxa from England, Germany, and Belgium, providing a comparative description of their interorbital morphology. Traditional interpretation of the interorbital elements in species of Goniopholis (G. simus, G. baryglyphaeus), where the frontal is interpreted as excluded from the orbit by a prefrontal-postorbital contact in the skull roof, is contested and clarified through the analysis of new specimens, including a morphometric analysis. In Goniopholis, failure to identify the palpebral and its subtle contact with the prefrontal has led to misinterpretation of elements and structures near the orbit, and the differential preservation/loss of palpebrals explains variability of the orbit in shape and orientation. In all European goniopholidids the frontal reaches the primary orbital border and there is no prefrontal-postorbital contact on the dorsal surface of the skull. Extensive contact of the palpebral with the primary orbital border creates a secondary (functional) orbital border, from which the frontal is excluded in most taxa. The condition is not exclusive of European goniopholidids and is paralleled by protosuchids, peirosaurids, and baurusuchids. At least four main morphological patterns are recognised, revealing a high diversity of European goniopholidids.

Other crocodilian material includes abundant and well-preserved material of the genus Pholidosaurus and rare material of atoposaurids and hylaeochampsids.

Pterosaurs are very rare. The skeletal record is confined to a few jaw and wing-phalanx fragments. The ichnological record includes a single specimen (manus impression) of Purbeckopus cf. penta-dactylus, which indicates the presence of a very large pterosaur (wing-span c. $6 \mathrm{~m}$ ). When compared to the English type material of $P$. pentadactylus, the specimen shows some differences which are mostly related to different properties of the substrate on which they have been left. These include the presence of an impression of the metacarpo-phalangeal joint of the wing finger, normally not present in tracks. Another remarkable feature are the rather short and rounded claws which seem more suitable for walking than for grasping or climbing.

The occurrences of Purbeckopus in England and Germany are related to different environments: the English locality was situated close to a brackish lagoon while the German site was placed in a limnic-deltaic system at the margin of a large freshwater lake. The ichnotaxon may be considered to have an ichnostratigraphical potential.

A review of 6 other Berriasian-Valanginian archosaur faunas from Europe (Denmark, England, France, Spain, Romania), integrating their stratigraphic, palaeogeographical, and palaeo-climatological context, and their comparison to the Bückeberg Formation fauna reveal patterns of diversity and vicariance during this important phase of archosaur history. Similarly the evolution of faunal patterns across the Jurassic/Cretaceous boundary in Europe is investigated. A critical discussion of taphonomical constraints across various local faunas and palaeoenvironments show, that the differences in diversity and diversity distribution (dominance of taxa) is strongly dependant from taphonomical filtering and the applied sampling method. Contrary to previous assumptions, when integrating a conservative estimation of dinosaur diversity based upon the track record from the earliest Cretaceous of Spain and Germany, only a slight decrease of overall dinosaur diversity at the 
beginning of the Cretaceous is considered, though a shift of dominance in the record of some groups is recognised. There is a lack of evidence for a massive, general "pauperisation" of the dinosaur fauna across the Jurassic/Cretaceous boundary in Europe, and these phenomena must be evaluated at a regional scale.

A novel approach is proposed for the analysis of habitat dominance based upon the abundance of tracks. Instead of a direct and indiscriminatory comparison of absolute track (footprint) numbers for each clade, a locality-based abundance (LBA) index is proposed. This index expresses the abundance of a clade as the ratio between the number of localities, in which a certain clade is present, to the total number of localities, assigned to the stratigraphic and regional context (SRC) that is investigated. The SRC has to be chosen to represent intervals that are characterized by stratigraphic, palaeoecological and taxonomical continuity, i.e. that it is inferred to represent a coherent ichnofauna. The LBA index is proposed to overcome adverse statistical effects by setting discrete extreme peaks of abundance into relation to a wider SRC (the ichnological equivalent of the "lagerstaetten effect", previously defined for fossil vertebrate diversity analyses by Benson et al. 2010).

Applying the LBA to the Obernkirchen Sandstone and Iberian Range (northeast Spain) Early Cretaceous dinosaur track assemblages reveal that in northern Germany ornithopods were dominant by during the late Berriasian at latest, while in Spain sauropods dominated herbivorous dinosaur communities into the Hauterivian, despite lower absolute numbers of sauropod tracks. Only in the Aptian ornithopods took over dominance in northeastern Iberia.

It emerges that an inclusion of most of the European Berriasian through Albian faunas in a "Greater Wealden" Fauna, as proposed earlier, proves problematic. At least two major and one minor faunal changes can be recognised between the Kimmeridgian and the Albian. These were however not strictly isochronous across Europe; e.g. as a typical Late Jurassic fauna probably survived in Iberia at least into the earliest Berriasian, while in central Europe a faunal hiatus is probably located at the Tithonian/Berriasian boundary.

The pre-Hauterivian faunas are characterized by a prevalence of inherited Late Jurassic elements. Immigration of Laurasian clades may have occurred during this time (ceratopsians, euhelopodid sauropods, ?microraptors) but these are mostly uncertain in exact dating and extent. In fact, in terms of higher-level clades, the pre-Hauterivian faunas blend very well with the Late Jurassic North American-Iberian-African faunas (the Laurafrican Fauna). The pattern of changes in biotope dominance between sauropods and ornithopods appear to be complex - a trend for an ornithopod faunal dominance is most evident in southern England and Germany, areas which were most severely affected by the Tithonian-Berriasian aridity crisis and may have lost temporarily their large herbivore faunas completely. In these regions, large-bodied ornithopods may have spread into trophic niches which were previously occupied by mid-level canopy browsing sauropods, especially diplodocids, in more humid lowlands after climate recovery. In other areas, e.g. in Spain and probably also in Denmark, sauropods remained to form a quantitatively important, if not exclusive faunal constituent deeply into the Early Cretaceous. In Spain relative sauropod dominance can be traced up to the Hauterivian and may have been supported by relatively dry conditions. Reasons for the apparently early Berriasian extinctions of diplodocids and turiasaurs are unclear as an 
immediate relationship of their total demise with the Tithonian-Berriasian aridity crisis cannot be found. However, their absence may be one of the most distinctive criteria to distinguish the genuine earliest Cretaceous archosaur faunas from the typical Late Jurassic faunas, and the latter can therefore be considered to have persisted into the early Berriasian in Iberia.

Basal Early Cretaceous and late Early Cretaceous faunas show major differences in composition which reflect the demise of several groups from Europe before the Barremian. According to these differences it seems suitable to characterise the European Berriasian-Hauterivian archosaur faunas as a distinct Purbeck-Hastings Fauna in contrast to the late Hauterivian-Albian Wealden Fauna. The former term alludes to the close relationship of Berriasian-early Valanginian (typical "Purbeckian") to mid-Valanginian-Hauterivian faunas, which are best represented in the Hastings Group (late Berriasian-Hauterivian) of England. A typical "Hastingian" element is the appearance of euhelopodid sauropods in this interval, which seems to show a stronger affinity to more humid environments shared by ornithopods. European-Asian interchange within the Purbeck-Hastings Fauna is evident by several clades, however, exact dating and directions of this interchange is mostly unclear. Assessing the relationships to North America is hampered by a stratigraphic hiatus between the Tithonian and the Barremian.

The Wealden Fauna shows some relationships to Asia and northern Africa, but is less comparable to North American faunas of the respective age. The changes in diversity and composition to the Purbeck-Hastings Fauna are marked, however, unfortunately the history of these changes is complicate to reconstruct in detail, especially for the large-bodied theropods due to the "theropod gap". Immigration from Africa may have played a role but can only be assessed safely for a few clades with some certainty due to an unclear palaeobiogeographical history of most groups. The most important immigrant clade may be represented by rebbachisaurid sauropods which flourished especially in southwestern Europe - co-occurring with rapidly evolving ornithopods while they continued to be rare towards the north.

Other groups of archosaurs are less informative than dinosaurs, though goniopholidid crocodilians show some evolution during this time, and limnic pholidosaurids may be restricted to Purbeckian-Hastingian faunas. The record of pterosaurs is too scarce for an assessment, though filter-feeding ctenochasmatids may have had an abundance maximum in late Laurafrican and early Purbeck-Hastingian faunas due to ecological circumstances.

An indisputable African influence on the European archosaur faunas after the Late Jurassic and before the late Hauterivian cannot be proven and the recently proposed concept of a basal Cretaceous "Eurogondwanan Fauna" cannot be substantiated on the basis of available data.

References on p. 13. 


\section{Introduction}

Archosaurs have been the dominant tetrapods in the Mesozoic, thriving in the water, on the land, and in the air. They were cosmopolitic, seized apex positions in continental trophic networks, and had a major impact on contemporaneous terrestrial ecosystems. However, their fossil record is comparatively sparse, often restricted to certain lithostratigraphic intervals favourable to their preservation, which leaves a patchy figure of their abundance, diversity, and distribution.

Such an interval is represented by the Berriasian - lowermost Valanginian Bückeberg Formation of northwestern Germany, a predominantly siliciclastic succession deposited in the epicontinental Lower Saxony Basin. The archosaur fauna and other vertebrates (e.g. turtles) are represented by abundant track material, some of exceptional quality, as well as less abundant skeletal material. Though subcomplete skeletal specimens are very rare, the preservation is otherwise very good, including e.g. three-dimensionally preserved skulls and physical preservation of internal skull cavities, although generally preserved only as highly detailed impressions.

The stratigraphic setting of the Bückeberg Formation falls into what can be conceived a "Dark Age" of archosaur evolutionary history between the better known Late Jurassic and the later Early Cretaceous (e.g. the English Wealden Supergroup) vertebrate faunas. Archosaur remains from the earliest part of the Early Cretaceous are, in most cases, fragmentary and isolated, though this time span represents an important phase of change in terrestrial ecosystems in conjunction with major evolutionary impulses for archosaurs (e. g. ornithischians, especially ornithopods, and the emergence of eusuchian crocodiles). It is also important in being affected by emergent palaeobiogeographic vicariance patterns among terrestrial vertebrates following the Jurassic Pangea break up, and especially the role of European vertebrate faunas as a link between Asian and Laurentian/Gondwanan faunal provinces is a matter of debate (see Chapter XI for details and references on these trends, problems, and implications).

In spite of its importance when compared to the contemporaneous scarce record and the fact that descriptions of material date back to the first half of the $19^{\text {th }}$ century (von Meyer 1841), studies on the vertebrate fauna from the Bückeberg Formation are relatively rare, mostly isolated in context and specimen-related (i. e. not concerned with wider faunal or palaeoecological aspects, see Fig. 0.1). This situation is probably aggravated by the fact, that a lot of available material was not studied in detail or published especially during the second half of the $20^{\text {th }}$ century. One possible reason for this neglect -besides the often incomplete nature of the material- is its mode of preservation. The most undistorted specimens are preserved in highly quartzose sandstones in which diagenetic processes have reduced the skeletal material to a soft whitish substance that cannot be preserved during preparation. Examination of these specimens therefore requires 
removal of this residual substance and casting of the very detailed cavities left in the host rock, yet casting has only been done for a small proportion of the available material.

However, investigation of the Bückeberg Formation archosaur fauna underwent some renaissance in recent years by an increased interest in the abundant tracksites, mainly produced by dinosaurs. Known at least since the late $19^{\text {th }}$ century, these tracks have been studied during the $20^{\text {th }}$ century mostly as isolated, though widespread occurrences and rarely in a wider context. The discovery of new, well preserved in situ tracksites since the turn of the millennium and advances in dinosaur ichnology have recently renewed the interest in the Bückeberg Formation vertebrate fauna.

The most important single source of information on archosaur palaeontology from the Bückeberg Formation is provided by the Ballerstedt Collection, kept at the University of Göttingen Geoscience Centre (GZG). Assembled by the teacher and amateur palaeontologist Max Ballerstedt (1857-1945), it was based upon the natural history collection of the school in which he worked, the Gymnasium Adolfinum in Bückeburg. It includes about 1200 specimens, most of which are vertebrates. Among those are pristine specimens of archosaurs, including important holotypes from the $19^{\text {th }}$ century. Shortly before his death, Max Ballerstedt presented his collection to the district of Schaumburg-Lippe and after a twisted history, it was finally put on permanent loan to the GZG in 1976 (for more details on the history of the Ballerstedt collection see Probst \& Windolf 1993, Hornung \& Reich 2007). With the exception of the holotypes of the dinosaur Stenopelix valdensis, the crocodilian Pholidosaurus schaumburgensis, and some of the track material (e.g. Ballerstedt 1905), none of the archosaur material from the Ballerstedt collection has been studied in detail before the beginning of this project (though it has been mentioned occasionally, e.g. by Salisbury et al. 1999).

Other museum collections also include considerable archosaur material, especially the Niedersächsische Landesmuseum, Hannover (NLMH), the Roemer- und Pelizaeus-Museum, Hildesheim (RPMH), and the Museum für Naturkunde, Berlin (MB), aside from smaller collections. By far, most of this material originates from outcrops which are not longer accessible and the quality of older descriptions (if present) or documentation varies on a wide range of scales.

The former negligence of this material spurred the initiation of an ongoing project to review and investigate upon this rich source of information. Beginning with a public exhibition of the Ballerstedt collection at the GZG in 2007, this task was quickly expanded to merge efforts with the renewed research works on recently studied in situ tracksites carried out by colleagues from the NLMH and other institutions. On the long term it is the goal of this project not only to study the archosaur record but to integrate ichnological, vertebrate and invertebrate palaeontological, as well as geological data to gain a wider insight into life and environment during the earliest Cretaceous in what was to become northern Germany. 


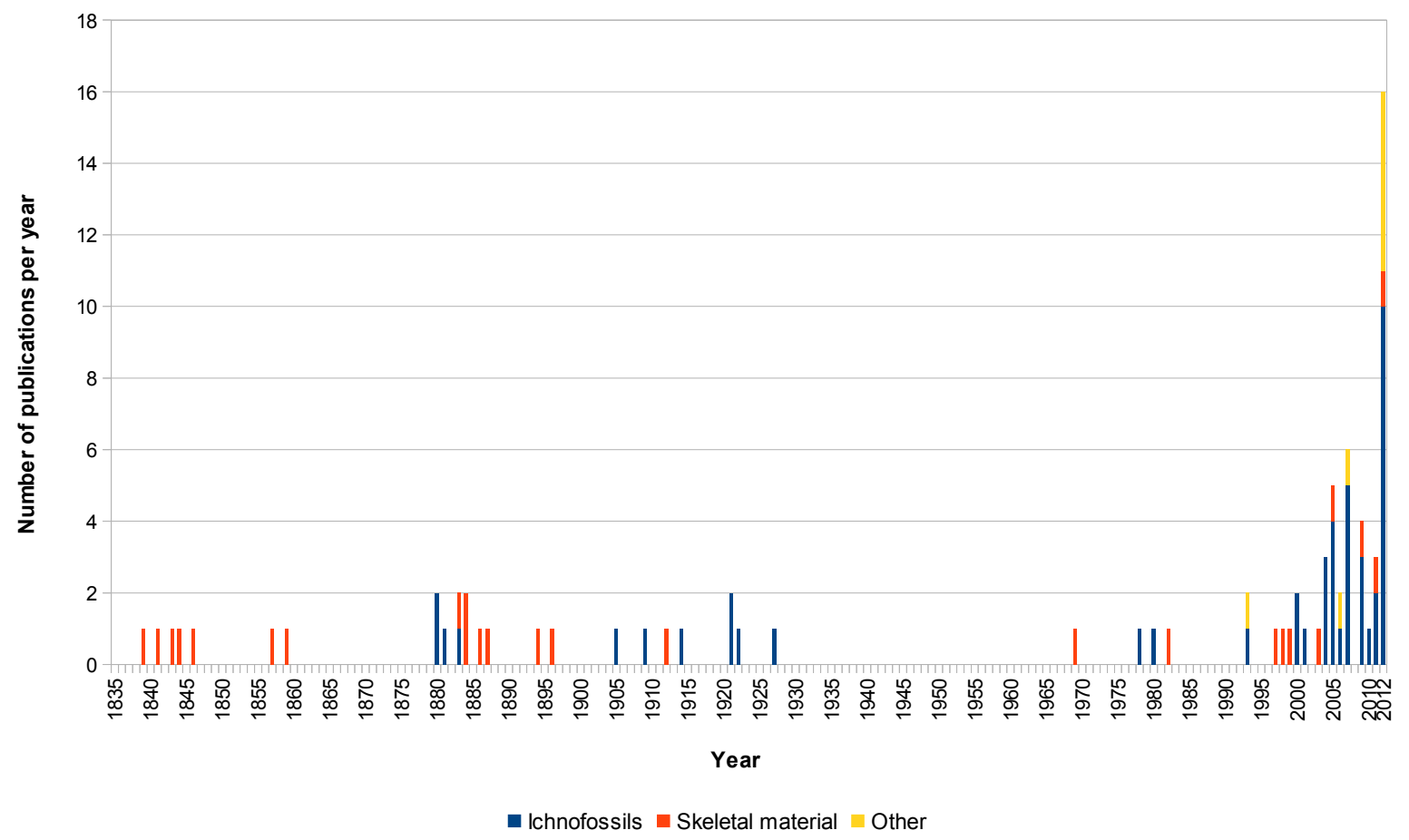

Fig. 0.1 Publications per year on archosaurs from the Bückeberg Formation, distinguished by basing upon track material, skeletal material, or dealing with archosaurs from this formation in another context (e.g. palaeoecological studies: "Other"). All types of publications were considered with the exception of popular accounts and those treating archosaur specimens only marginally.

Aims and scope

This thesis is a summary of the state of knowledge and some milestones this project has reached as of 2013 with a focus on the archosaur fauna. The richness of material and the strong variation in quality and detail of earlier studies required an intensive reassessment of historical accounts and sites. A major goal was the establishment of a database of the available, often uncatalogued archosaur material, which resulted in the identification of a number of taxa not previously known from this area, and provides insights into the status of often controversial historical reports.

The eleven chapters and two appendices of this thesis are grouped into four thematic complexes, including (1) introduction of the geological frame and palaeoenvironments with a re-evaluation of selected classical localities and a catalog of historical and present-day vertebrate tracksites (Chapters I to IV), (2) case-studies based upon ichnological and skeletal material, related to dinosaurs (Chapters V to VII), crocodilians (Chapters VIII and IX), and pterosaurs (Chapter X), (3) a synopsis and outlook (Chapter XI), and (4) a data appendix (Appendices A and B). 
- Chapter I provides a brief introduction into the geology, stratigraphy and palaeoenvironments of the "German Wealden" (Bückeberg Formation).

- Chapter II gives a redescription of the historical Wölpinghausen locality which produced the earliest finds of dinosaur tracks from Germany in the 1880s.

- Chapter III gives a short redescription and overview of the historical Harrl hill localities near Bückeburg, where most of the material from the Ballerstedt collection was excavated.

- Chapter IV presents a catalog of vertebrate tracksites known from the Bückeberg Formation with an extensive discussion of their geological setting, stratigraphy, ichnological inventory, history of investigation and present-day condition.

- Chapter $V$ describes two specimens of large track-bearing sandstone slabs exhibiting a diverse dinosaur ichnoassemblage, including ornithopod and theropod tracks.

- Chapter VI discusses the history of the ankylosaur ichnotaxon Metatetrapous valdensis from the Harrl hill locality and further ankylosaur track material from the Ballerstedt collection.

- Chapter VII describes isolated ankylosaur skeletal material from the Bückeberg Formation of Gronau in Westfalen.

- Chapter VIII discusses cranial features in Goniopholis simus, a crocodilian from the Bückeberg Formation and the Purbeck Limestone Group of England, and related taxa.

- Chapter IX describes an exceptionally preserved turtle footprint, which provides insights into the appendicular morphology of Berriasian turtles and allows the discussion of diagnostic criteria in the distinction between turtle and crocodilian manus impressions.

- Chapter $X$ describes the first record of the pterosaur ichnotaxon Purbeckopus cf. pentadactylus from the Bückeberg Formation.

- Chapter XI discusses synoptically the archosaur fauna of the Bückeberg Formation and compares it to other Early Cretaceous archosaur faunas, its palaeogeographical context as well as its palaeoenvironments and taphonomical implications. A review of diversity and other factors of these faunas across the Jurassic/Cretaceous boundary and throughout the Early Cretaceous is provided.

- An Outlook proposes future research approaches. 
- Appendix A provides an annotated catalog of all studied archosaur skeletal material with notes on some outstanding or historically important specimens and taxa.

- Appendix $B$ is a catalog of all known archosaur localities from the Bückeberg Formation, listed by regions.

Aside from Chapter XI and the data appendices, all chapters have been published, are accepted for publication, or are at least submitted for publication (in collaboration with other authors). Beside of this, a number of works have been published (mostly abstracts, Hornung \& Reich 2006, 2007, 2012; Hornung et al. 2009, 2011, Böhme et al. 2012, Reich et al. 2012, Richter et al. 2012) related to the Bückeberg Formation archosaur fauna, which were not included here.

\section{Acknowledgments}

Over the years, many people have helped and supported, in various ways, the task of completing this work, to which I want to express my sincerest gratitude.

First of all, I wish to thank my academic teachers, the principal supervisors Dr. Mike Reich, Prof. Dr. Joachim Reitner (both University of Göttingen), and Dr. Annette Richter (Niedersächsisches Landesmuseum Hannover), as well as the board of examiners, Dr. Cornelia Kurz (Museum für Naturkunde, Kassel), PD Dr. Gernot Arp, PD Dr. Frank Wiese, and Prof. Dr. Volker Thiel (all University of Göttingen).

Some of the chapters in this thesis are from papers produced in collaboration with colleagues from the "German Wealden“ Research Group as well as from abroad. I wish to thank all my esteemed colleagues, including Dr. Marco Brandalise de Andrade (formerly Bristol), Annina Böhme (Hannover), Torsten van der Lubbe (formerly Hannover), Dr. Mike Reich, Dr. Annette Richter, and Sven Sachs (Engelskirchen) for their fruitful collaboration and cooperation.

A number of curators and persons in equal positions supported this work by granting access or loan of specimens under their care and/or providing valuable information, including Dr. Angela Milner (formerly London), Dr. Markus Bertling (Münster), Rolf-Bernd de Groot ( $\dagger$, Obernkirchen), Dr. Hilary Ketchum (London), Nils Knötschke (Münchehagen), Dr. Cornelia Kurz (Kassel), Dr. Annette Richter (Hannover), Dr. Daniela Schwarz-Wings (Berlin), Dr. Lorna Steel (London), Dr. Anke Twachtmann-Schlichter (Bückeburg), Dr. Thomas Wiese (Hannover), and Dr. Jürgen Vespermann (Hildesheim).

Additional professional support (e. g. in form of reviews, discussions etc.) is outlined in the acknowledgment sections of the relevant chapters. 
Finally, there is this unmeasurable amount of professional, technical and personal, material, immaterial and emotional support and kindness I have received from a large number of people, colleagues, friends, and family over the years during which this work was completed, for which I am and will be ongoing grateful. By no way regarding this list as complete, I wish to thank with deep gratitude the following friends and colleagues: Annina Böhme, Eric Bondzio, Thomas Daniel, Jan Feddersen, Udo Frerichs, Dr. Alexander Gehler, Jana Gerowski, Patricia Grubbe, Karin Hiir, Cornelia Hundertmark, Gerhard Hundertmark, Julien Kimmig, Thomas Kluge, Julia König, Dr. Cornelia Kurz, Diana Magens, Dr. Philipp Nikolai, Anna Radon-Wolf, Maik Raddatz, Lea Rausch, Dr. Mike Reich, Dr. Annette Richter, Stefan Reiss, Vanessa Roden, Katrin Sachs, Sven Sachs, Willy Seewald, Ole Schirmer, Nils Schlüter, Nina Schulze, Michael Sosnitza, Tanja Stegemann, Uwe Stratmann, PD Dr. Frank Wiese, Dr. Oliver Wings, Nico Wolf,

and my parents, Niels and Maria.

My former employer for many years, DEEP. Underground Engineering GmbH (Bad Zwischenahn), is acknowledged for its supportive attitude towards my academic off-the-job training.

This work was self-funded with partial support by a grant from the European Union SYNTHESYS program (project GB-TAF-4204).

\section{Editorial note}

This thesis represents a summary of nearly six years (Oct. 2007-May 2013) of studying archosaur fossils from the Lower Cretaceous Bückeberg Formation in northwestern Germany and their palaeoenvironments. At present (May 2013), most of its chapters are either published, accepted for publication, or submitted to peer-reviewed journals. Due to these circumstances, the style of the chapters may vary slightly according to requirements of the respective publishers and the fact that most of them are the result of collaboration with a number of different colleagues. For the same reason there is some repetition in several chapters and there are individual reference lists at the end of most individual chapters. The long time-span of preparation also means that some very few, minor details may appear contradictorily from chapter to chapter, as the knowledge of specimens etc. increased, partly revealing more details. This results from the obligation of individual chapters to be faithful to the published or submitted works, therefore representing the state of knowledge at the moment of their publication or submission. 


\section{References for Abstract and Introduction}

Ballerstedt, M. 1905. Über Saurierfährten der Wealdenformation Bückeburgs. Naturwissenschaftliche Wochenschrift, Neue Folge, 4(31): 481-485.

Benson, R. J. B., Butler, R. J., Lindgren, J. \& Smith. A. S. 2010. Mesozoic marine tetrapod diversity: mass extinctions and temporal heterogeneity in geological megabiases affecting vertebrates. Proceedings of the Royal Society, B, 277: 829834.

Böhme, A., Reich, M., Hornung, J.J. \& Karl, H.-V. 2012. Excursion Guide C1: Northern 'German Wealden'- the collection of the Göttingen University. In: Richter, A., \& Reich, M. (eds.): Dinosaur Tracks 2011. An International Symposium, Obernkirchen, April 14-17, 2011. Abstract Volume and Field Guide to Excursions: 151-168, Göttingen: UniversitätsVerlag.

Hornung, J.J. \& Reich, M. 2006. The "Wealden" collection of Max Ballerstedt (1857-1945) - undisclosed treasures from the Early Cretaceous of northwestern Germany. Berichte des Instituts für Geowissenschaften, Christian-AlbrechtsUniversität, Kiel, 22: 40-41.

Hornung, J.J. \& Reich, M. 2007. Krokodile, Schildkröten \& Dinosaurier. Die "Wealden"-Sammlung der Universität Göttingen. FOSSILIEN, 1/2007: 32-36.

Hornung, J. J. \& Reich, M. 2012. The croc puzzle: a fairly complete specimen of Goniopholis (Mesoeucrocodylia: Goniopholididae) from the Bückeberg Formation (Berriasian) of Bückeburg, northern Germany. In: Richter, A., \& Reich, M. (eds.): Dinosaur Tracks 2011. An International Symposium, Obernkirchen, April 14-17, 2011. Abstract Volume and Field Guide to Excursions: 26, Göttingen: Universitäts-Verlag.

Hornung, J. J., Andrade, M. B. de \& Reich, M. 2009. Are Goniopholis crassidens and G. simus different species of crocodilians? New postcranial evidence solving a taxonomic riddle. Journal of Vertebrate Paleontology, 29 (Suppl. to 3): 117A.

Hornung, J.J., Böhme, A. \& Reich, M. 2011. The hypodigm of the theropod ichnotaxon "Bueckeburgichnus" maximus Kuhn, 1958 and its type status. Beiträge zur Paläontologie, 32: 56-57.

Meyer, H. von 1841. Pholidosaurus schaumburgensis, ein Saurus aus dem Sandstein der Wald-Formation NordDeutschlands. Neues Jahrbuch für Mineralogie, Geognosie, Geologie und Petrefakten-Kunde, 1841: 443-445.

Probst, E. \& Windolf, R. 1993. Dinosaurier in Deutschland. 320 pp., München: Bertelsmann.

Reich, M., Böhme, A., Hornung, J.J. \& Karl, H.-V. 2012. The 'Wealden' collection of the Göttingen University. In: Richter, A. \& Reich, M. (eds.): Dinosaur Tracks 2011. An International Symposium, Obernkirchen, April 14-17, 2011. Abstract Volume and Field Guide to Excursions: 51, Göttingen: Universitäts-Verlag.

Richter, A., Hornung, J.J., Böhme, A. \& Stratmann, U. 2012. Excursion Guide A1: Obernkirchen Sandstone Quarries - A Natural Workstone Lagerstaette and a Dinosaur Tracksite. In: Richter, A. \& Reich, M. (eds.): Dinosaur Tracks 2011. An International Symposium, Obernkirchen, April 14-17, 2011. Abstract Volume and Field Guide to Excursions: 73-100, Göttingen: Universitäts-Verlag.

Salisbury, S. W., Willis, P. M. A., Peitz, S. \& Sander, P. M. 1999. The crocodilian Goniopholis simus from the Lower Cretaceous of north-western Germany. Special Papers in Palaeontology, 60: 121-148. 
Introduction 


\section{Chapter I}

The 'German Wealden' and the Obernkirchen Sandstone

- an Introduction 
Published in:

Richter, A., \& Reich, M. (eds.): Dinosaur Tracks 2011. An International Symposium, Obernkirchen, April 14-17, 2011. Abstract Volume and Field Guide to Excursions: 61-72, Göttingen (Universitäts-Verlag) [2012]. Open access:

http://webdoc.sub.gwdg.de/univerlag/2013/Dinotracks.pdf

\title{
The 'German Wealden' and the Obernkirchen Sandstone - an Introduction
}

\author{
JAHN J. HORNUNG ${ }^{1}$, ANNINA BÖHME ${ }^{1,3}$, and MIKE REICH ${ }^{1,2}$ \\ ${ }^{1}$ Department of Geobiology, Geoscience Centre of the University of Göttingen, Göttingen, Germany \\ ${ }^{2}$ Geoscience Museum of the University of Göttingen, Göttingen, Germany \\ ${ }^{3}$ Hannover State Museum, Hannover, Germany
}

The so-called 'German Wealden' succession in northwestern Germany has benefited the region with important resources for centuries. The high quality working and dressing stones of the Obernkirchen Sandstone were valued in uncounted buildings across Europe and the world (Graupner 1977; Broschinski 2004), the quartzose sandstone were used as raw material for the production of glass (Krumsiek 1981), and the thin intercalated coals were mined from medieval times up to the 1960ies (Graupner 1980). In modern times, the bituminous shales became economically interesting as a hydrocarbon play (Berner et al. 2010; Berner 2011), and - last but not least - the dinosaur tracks boosted the geotouristical potential of the region on a grand scale.

The excursions described in this field-guide will reach in the area W and SW of Hannover (Fig. I.1). In order to set the stage for the more detailed outcrop descriptions below, we here provide a short introduction into the terminology, stratigraphy, palaeogeography, and palaeoclimatology of this Early Cretaceous treasure trove. However, it has to be kept in mind that many aspects are not yet studied in depth and there are many more questions to solve. For a more extensive introduction, overview of dinosaur track localities throughout the formation, and additional references please refer to Hornung, Böhme et al. (2012a).

\section{What is the 'German Wealden'?}

The term 'German Wealden' (i.e. here the 'northwest German Wealden') is used for an informal stratigraphic concept, to describe a succession of continental, predominantly siliciclastic deposits of earliest Cretaceous age in northwestern Germany. It is in use since the early $19^{\text {th }}$ century (Hoffmann 1830) and was coined following the observation that lithofacies and fossil content of this succession was quite similar to the Early Cretaceous sediments in southeastern England known as 'Wealden beds'.

Refined stratigraphic work has since shown that the 'German Wealden' in fact is mid-Berriasian to early Valanginian in age (e.g. Kemper 1973; Casey et al. 1975), while the English Wealden Supergroup ranges from the late Berriasian through lower Aptian. Therefore the 'German Wealden' correlates chronostratigraphically more tightly with the English Purbeck Group (Allen \& Wimbledon 1991). 
Allen (1955) restricted the use of the term „Wealden“ to the English deposits and proposed „Wealden facies“ for successions of similar age and genesis across western and central Europe. 'German Wealden' became therefore obsolete as a formal stratigraphic term and was superseded by the Bückeberg Formation (Casey et al. 1975). It is further used to characterize a Berriasian, limnic to brackish, continental facies complex exposed in northwestern Germany. However, Wolburg (1949) introduced a sixfold lithostratigraphical subdivision (Wealden 1 to 6) which is still in use in recent works.

Fig. I.1 Location of the outcrops described in this field-guide. Mountainous areas are shaded. A2: Federal highway BAB2.

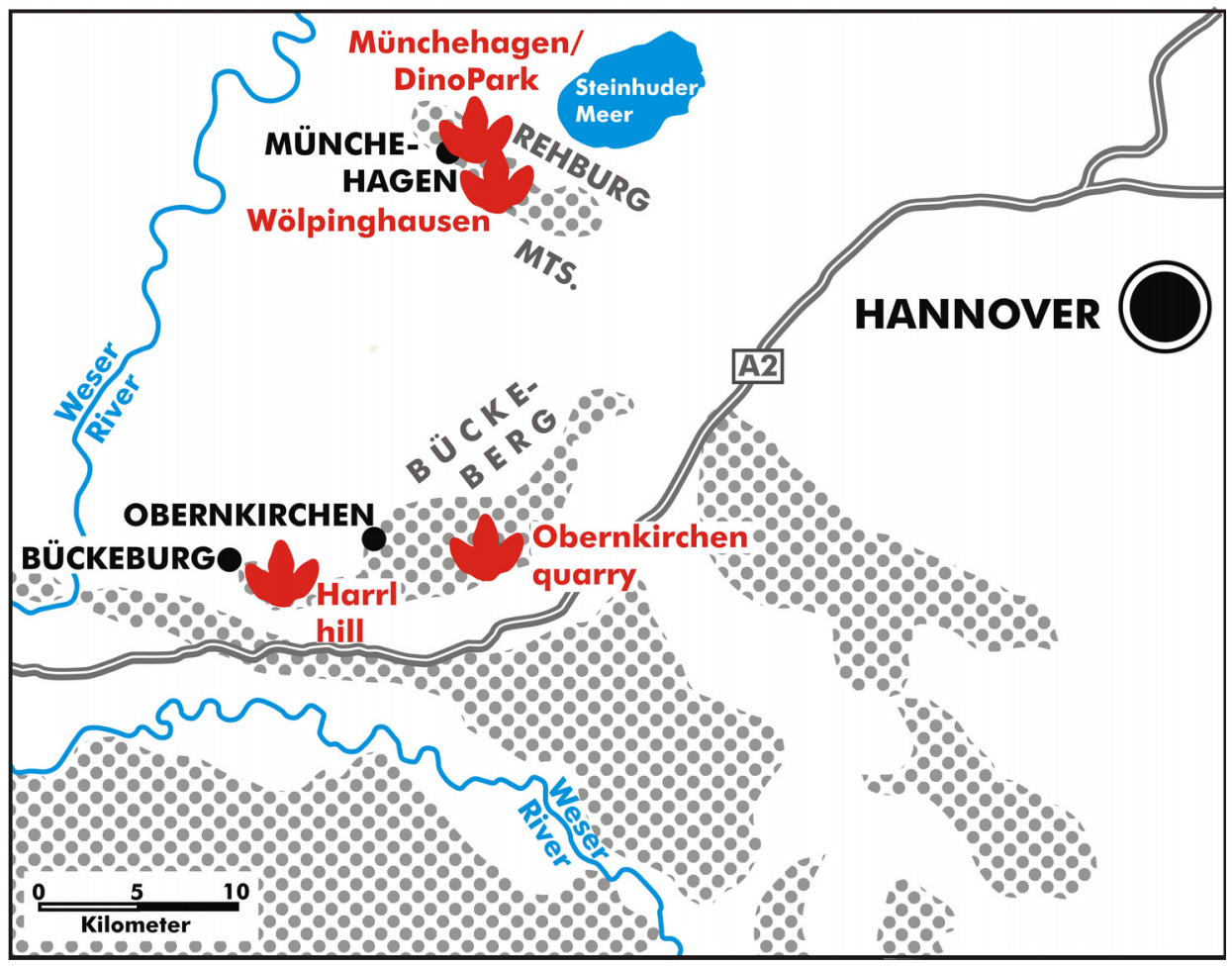

\section{Stratigraphy}

The Bückeberg Formation (Fig. I.2) is covered by younger Cretaceous and Cenozoic deposits across most of its extend. The most important outcrops are located in southern Lower Saxony in mountainous areas between Hannover in the E and the River Weser in the W and S. Smaller exposures exist also in North-Rhine Westphalia.

The Bückeberg Formation encompasses two members, the lower Obernkirchen Member (Wealden 1 to 4) and the upper Osterwald Member (Wealden 5 and 6). In the depocentre of the formation it consists mainly of up to 500-700 m of claystones and black-shales with rarely intercalated sideritic carbonates and coquinas. Coarser-grained (sandy) marginal sedimentary bodies prograded from the margins of the basin especially along its southern and eastern fringes (Kemper 1973; Mutterlose 1997a), including the dinosaur track-bearing Obernkirchen Sandstone.

The predominantly limnic origin of this formation hampers an idle correlation with the marine Early Cretaceous and its biostratigraphy is based upon ostracods (e.g. Martin 1940; Wolburg 1949, 


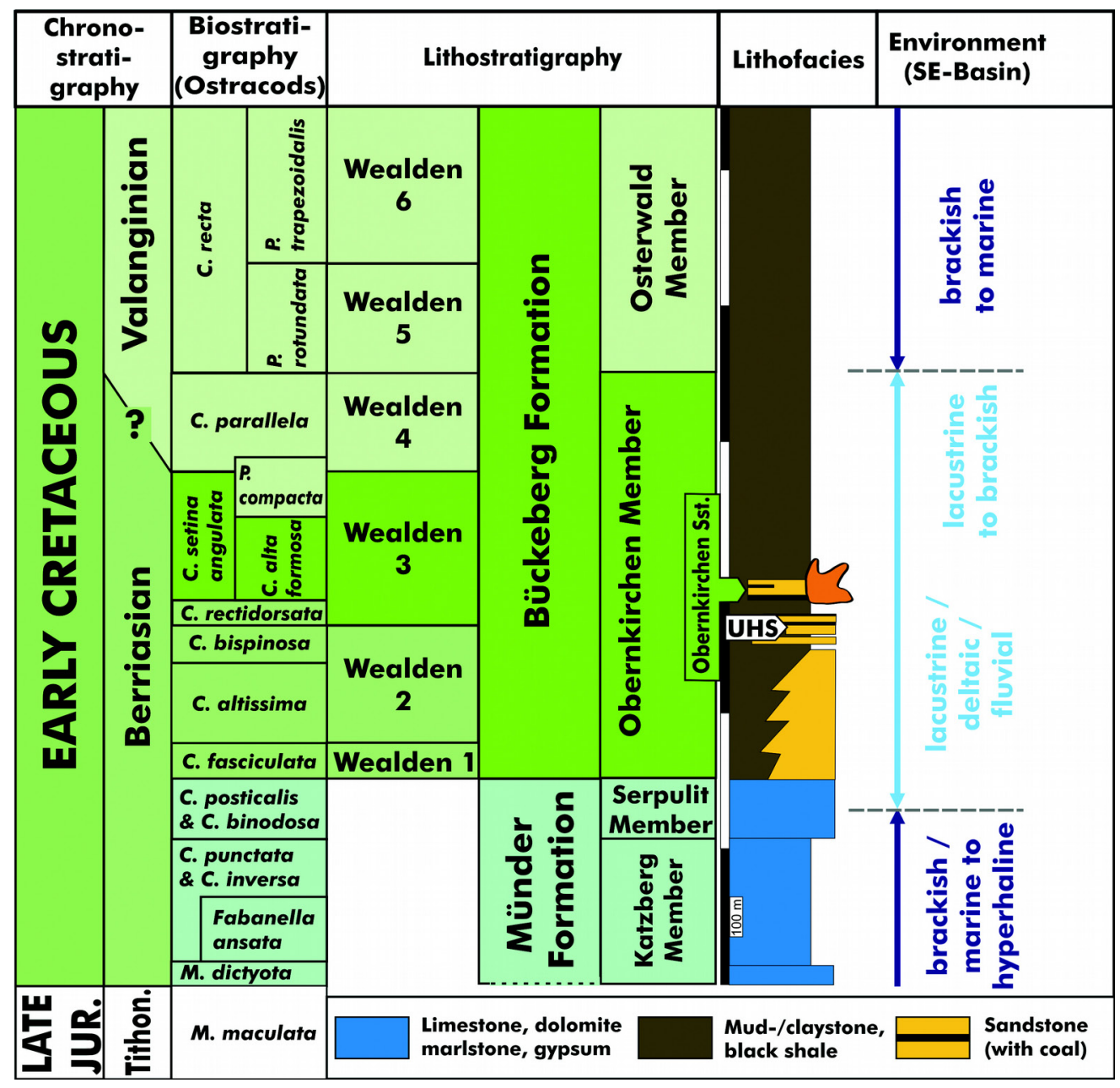

Fig. I.2 Stratigraphy of the Berriasian and early Valanginian in the southeastern Lower Saxony Basin. Ostracods: $C$. = Cypridea, M. = Macrodentina, $P .=$ Pachycytheridea. (after Kemper 1973; Strauss et al. 1993; Elstner \& Mutterlose 1996; Gramann et al. 1997; and Mutterlose 1997a, 2000, modified).

1959), charophytes (Schudack 1996), and palynomorphs (e.g. Dörhöfer 1977; Strauss et al. 1993; Pelzer 1998).

The Bückeberg Formation overlies the Münder Formation, which was correlated in the classic literature with the English Purbeck and considered Late Jurassic in age. However, the current concept (Strauss et al. 1993; Elstner \& Mutterlose 1996; Hoedemaeker \& Herngreen 2003) indicates the Jurassic/Cretaceous boundary within the Münder Formation, the upper part of which has been deposited during the early Berriasian. The Berriasian/Valanginian boundary is not well defined in the continental succession, but is considered at or near the boundary between the Obernkirchen and Osterwald Members. The Bückeberg Formation is concordantly overlain by Valanginian marine deposits (Platylenticeras Beds; Mutterlose 1997b).

The deposition of the Bückeberg Formation is modeled to have lasted about 3.4 myr (Berner 2011). Depending on the placement of the Berriasian/Valanginian boundary (140.2 $\pm 3.0 \mathrm{ma}$; Ogg et al. 2008) at the base of the Osterwald Member or alternatively at the base of Wealden 4 , the 
absolute age of the Bückeberg Formation is assumed to 142.0-138.6 \pm 3.0) ma, or 142.4-139.0 $( \pm 3.0)$ ma, respectively.

The dinosaur tracks occur in the Obernkirchen Sandstone, a thin marginal succession. Typically it consists of thin- to thick-bedded, structureless, horizontally or cross-stratified, quartzose sandstone, interbedded with thin layers of clay- to siltstone, and coal seams. There are some inconsistencies and ambiguities in the use of this term as a lithostratigraphical unit, as several outcrops of unconfirmed isochrony and depositional history have been considered to represent the Obernkirchen Sandstone (Hornung, Böhme et al. 2012a). In the widest sense it might encompass two coal-bearing sandstone tongues at the southeastern basin margin, separated by some tens of metres of pelites. They are exposed in the Bückeberge, the adjacent Harrl hill area, as well as in the Rehburg Mountains, c. $15 \mathrm{~km}$ to the N. These sandstone intercalations are often termed 'Unterer Hauptsandstein' and 'Oberer Hauptsandstein' ('lower main sandstone' and 'upper main sandstone'), respectively. Dinosaur tracks are limited so far to the thicker 'Oberer Hauptsandstein', which is considered the Obernkirchen Sandstone sensu stricto. In this guide we use the term Obernkirchen Sandstone according to the latter scheme (Fig. I.2). In an even more restrictive use, the Obernkirchen Sandstone may be confined to the central Bückeberge type region.

The Obernkirchen Sandstone correlates to the Cypridea alta formosa ostracod subzone (Wealden 3) and is therefore late Berriasian in age (Elstner \& Mutterlose 1996; Mutterlose 1997b).

\section{Palaeogeography and Palaeoclimate}

The Bückeberg Formation was deposited in the Lower Saxony Basin (LSB), a southern subbasin of the North German Basin that stretches from the Netherlands in the W across most of northern Germany (Figs. I.3-I.4). Subsidence of the basin began during the Late Jurassic and terminated by inversion in early Late Cretaceous (Betz et al. 1987; Bachmann \& Grosse 1989). The surrounding uplands were probably of low relief, not reaching more than a few hundred metres in altitude (Abbink et al. 2001).

After local highstand and marine flooding of most of the incipient LSB during the Late Jurassic (e.g. Gramann et al. 1997; Kästner et al. 2008) a major fall in sea level and early basin subsidence led to isolated, shrinking perimarine water bodies in the developing LSB during deposition of the Tithonian through earliest Berriasian Münder Formation. Increasing precipitation during the earliest Berriasian resulted in reduced salinities and peripheral haloclinal stratification of the lagoons in peripheral areas (Hils Embayment), though a marine connection still existed (Arp \& Mennerich 2008). With onset of the Bückeberg Formation, the water body in the basin was oligohaline (Mutterlose \& Bornemann 2000; Berner 2011). Corg-rich claystones and shales in the basin centre indicate a dysoxic hypolimnion in the deepest parts of the lake (Berner et al. 2010).

The history of the lake level is not well known yet, but the continuity of fine-grained sediments in the central LSB indicates a permanent presence throughout the Berriasian. River systems drained into the lake. Two of them on the southern basin margin are documented by extensive deltaic deposits. The western drainage formed the Osnabrück Delta (Lill \& Riegel 1991; Pelzer et al. 1992; 


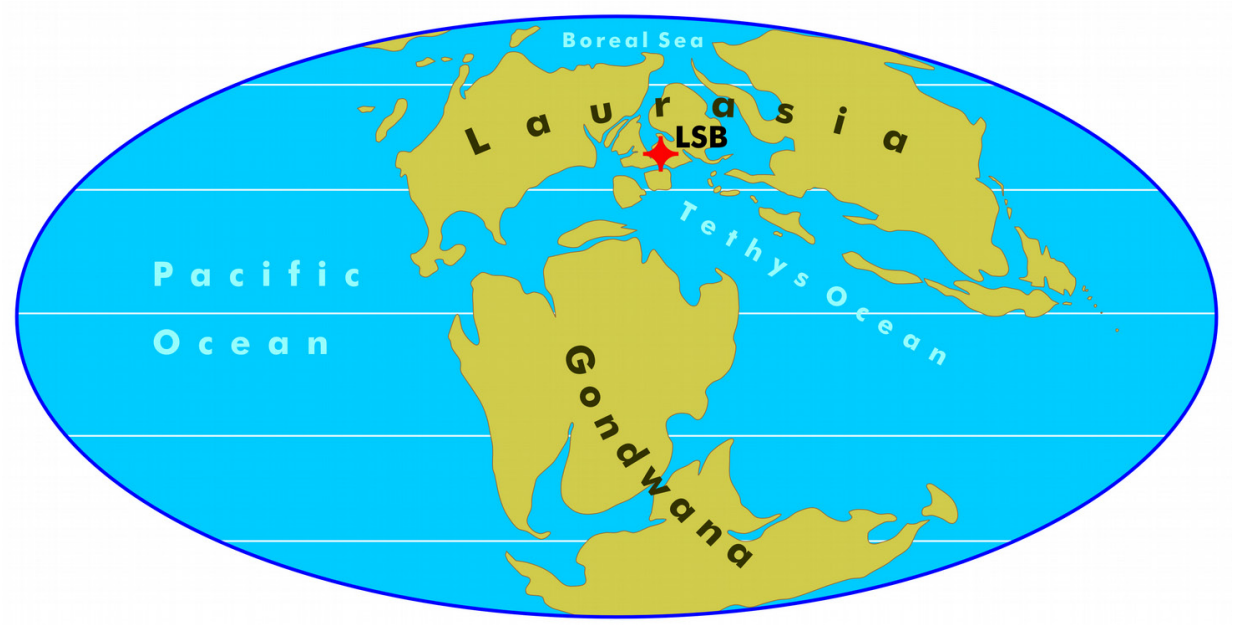

Fig. I.3 Global Berriasian palaeogeography with the position of the Lower Saxony Basin (LSB) (after Scotese 2002, modified).

Wilde \& Schultka 1996), while the eastern one occupied the Hils Embayment, an southern emargination of the LSB (Kauenhowen 1927). Progradation of the river resulted in the deposition of a complex barrier and delta system W of Hannover, including the Obernkirchen Sandstone (Pelzer 1998). The most proximal areas of the Hils Embayment (Hils, Osterwald Mountains) were filled with fluvial and perifluvial deposits (Pelzer 1984; Pelzer et al. 1992) which also yielded dinosaur tracks (Naumann 1927). The delta system consisted of a complex array of subenvironments, as represented in various lithofacies. These include barrier-related deposits, lagoonal and swamp facies, and various types of mouth-bar complexes (Pelzer 1998; Hornung, Böhme et al. 2012a; Richter, Hornung et al. 2012; Hornung, Böhme \& Reich 2012b; Wings et al. 2012; Hornung, Böhme \& Reich 2012c; Böhme, Reich et al. 2012; Hornung \& Reich 2012). The formation and preservation of the barrier facies was probably related to landward transport of sand during storm events under during a transgressing lake level and by wind-induced SW-NE longshore currents (Pelzer et al. 1992; Pelzer 1998).

The lake basin communicated with the North German Basin extension via a gateway in the $\mathrm{W}$ and SW (in the Netherlands). Sea level rises and tectonic modifications of the basin geometry resulted in several short-term incursions of marine waters into the lake (e.g. Berner 2011). During deposition of the lower and middle Obernkirchen Member, these were confined to the western part, resulting in an W-E decreasing salinity gradient throughout the basin (Mutterlose \& Bornemann 2000). Increasing eustatic sea level rise and local tectonics during the latest Berriasian and early Valanginian (Wealden 4 to 6) resulted in ingression and brackish conditions within the LSB (Elstner \& Mutterlose 1996; Mutterlose \& Bornemann 2000), which concluded in marine flooding during the Valanginian (Mutterlose 1997a).

During the Berriasian, the LSB was situated at c. $32^{\circ}-33^{\circ} \mathrm{N}$ palaeolatitude. Palaeoclimatological models (Pelzer \& Wilde 1987; Abbink et al. 2001) postulate a rapid change from hot-arid climate during the latest Jurassic (evaporites within the Münder Formation) towards a warm-humid 

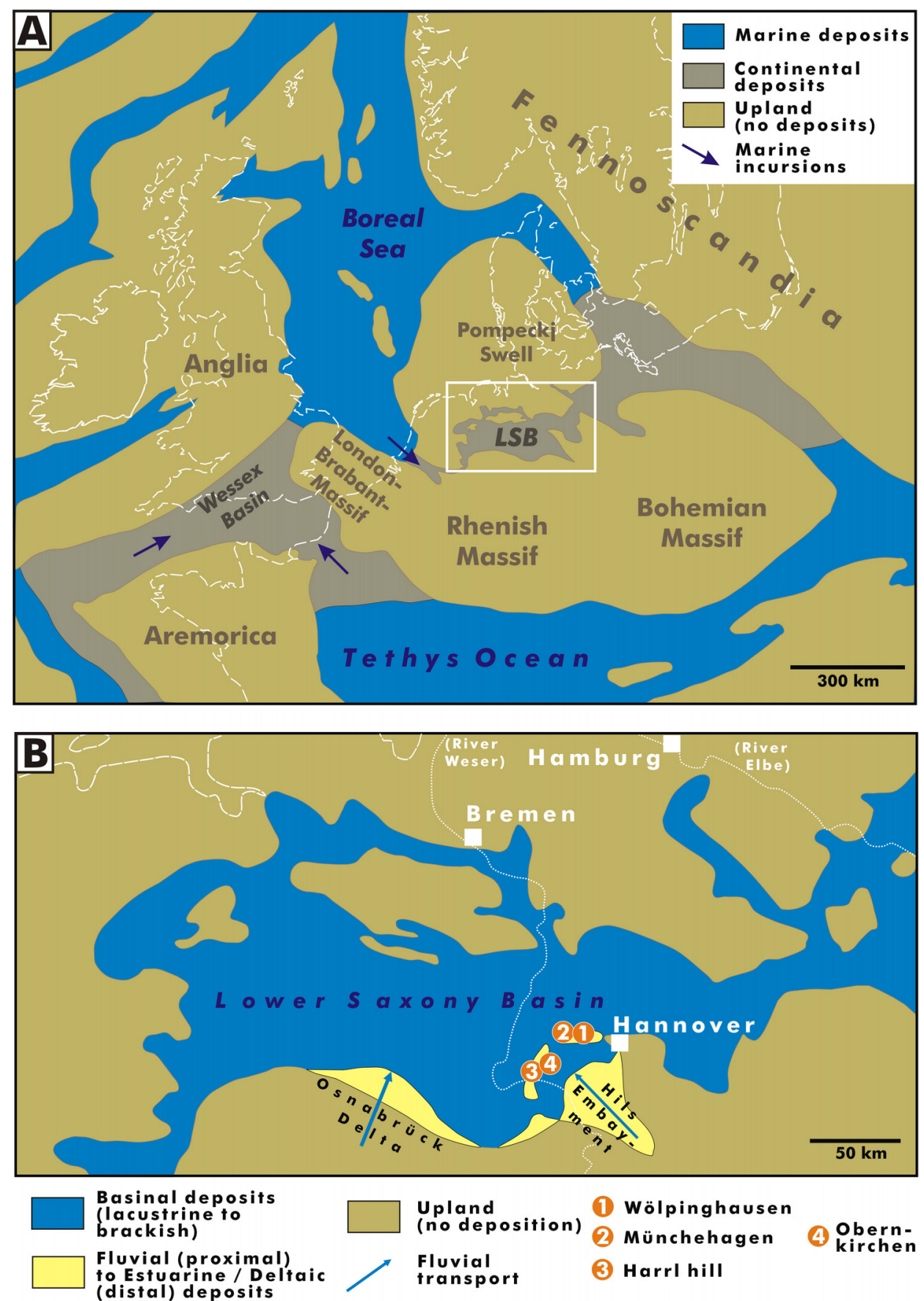

Fig. I.4 Regional palaeogeography of the Lower Saxony Basin (LSB) during the Berriasian. (A) Setting in the central European context, the roughly coeval Purbeck Limestone Group was deposited mainly in the Wessex Basin (after Mutterlose 1997a, modified). (B) Basin palaeogeography with the position of delta systems along the southern basin margin and the trackway localities (after Schott et al. 1967, 1969; Kemper 1973, modified).

subtropical to paratropical climate in the lowermost Berriasian (brackish to lacustrine deposits in the upper Münder Formation). Seasonal droughts and storm events became more abundant during late Berriasian/earliest Valanginian times. 


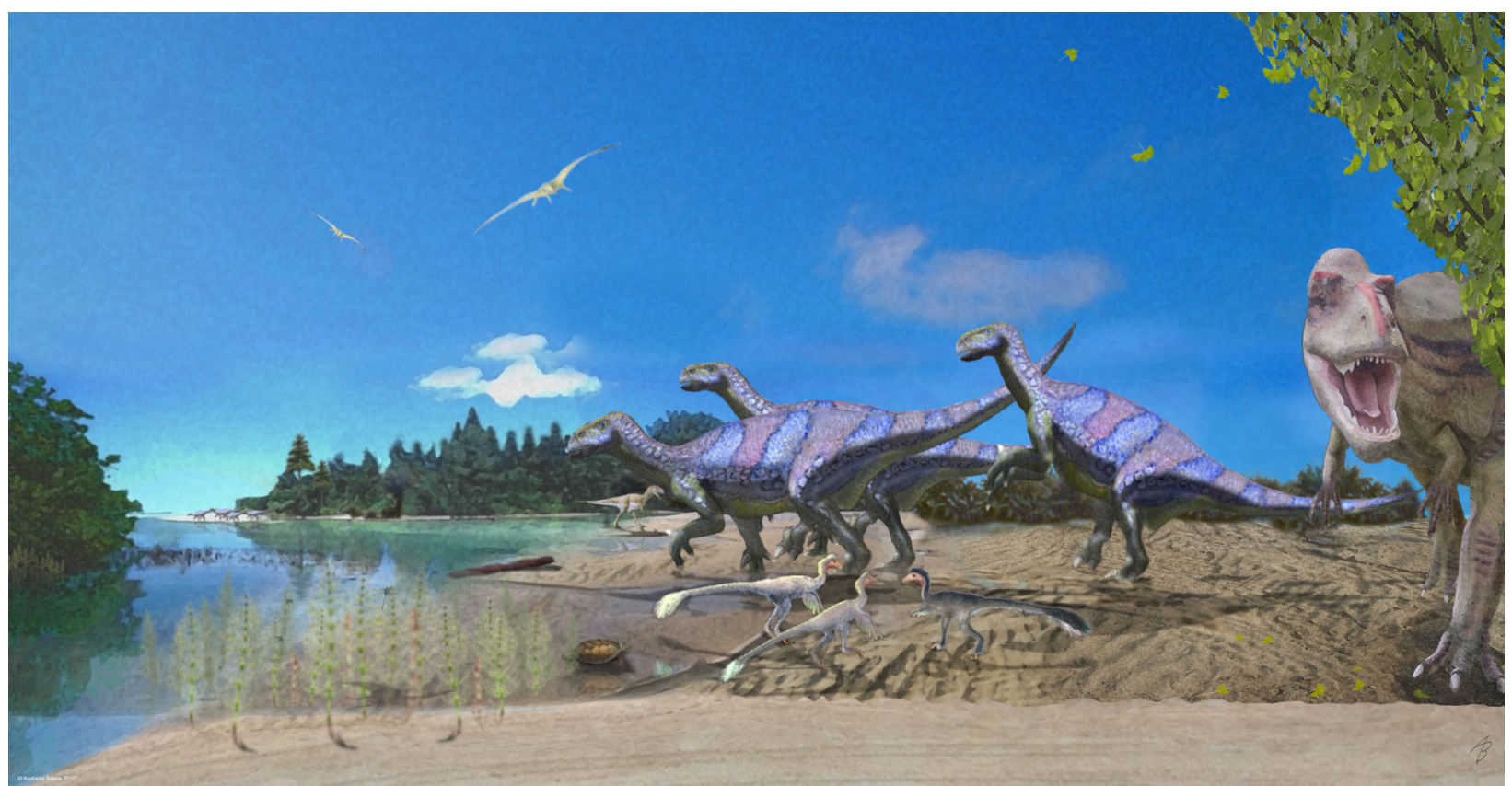

Fig. I.5 Life and environments of the Obernkirchen Sandstone. Illustration by A. Basse.

The deltaic and alluvial plains fringing the rivers support a rich and lush vegetation which may have had the character of rain- and swamp forests (Pelzer 1984, 1998; Abbink et al. 2001). The forests were dominated by conifers, ginkgoes, and arborescent ferns. Drier areas and probably the hinterland were covered by a more open, savannah-like vegetation comprising cycads and bennettitales. Shrub-like vegetation was composed mainly of various ferns. The areas of active deposition and sediment transport (mouth-bars, barriers) supported only a pioneer vegetation dominated by shrub-like horsetails.

\section{Vertebrate Fossil Preservation and Taphonomy}

In the sandstone facies rapid deposition of the highly matured, fine-grained sand resulted often in a very high quality of preservation of morphological detail, especially in fossil vertebrates. The sand invaded quickly nearly every cavity of bones and shells, supporting the three-dimensional preservation of even very delicate structures. However, due to the carbonate-depleted geochemistry of the Obernkirchen Sandstone, the original bone substance was transformed diagenetically into a soft, argillaceous matter. Fossil-bearing sandstone slabs commonly split through this substance, which cannot be preserved and freed from the much harder encasing sandstone. It has to be removed and an artificial cast of the remaining, highly detailed cavities has to be made. Historically, casts were made with plaster, while today casts are made with highly detailing, flexible silicone.

In contrast, fossils from the argillaceous and carbonate facies are preserved as fully mineralized specimens, which are, though generally well preserved, often affected by pyrite efflorescence.

The track record clearly shows that a broad diversity of dinosaur taxa, including iguanodontian ornithopods, ankylosaurs, sauropods, and a broad variety of theropods, crossed the delta and 
barrier system in the Hils Embayment (Fig. I.5). In opposite to the very abundant tracks, and with exception of the articulated postcranium of Stenopelix valdensis, there are only a few scattered bone remains of dinosaurs known from the Obernkirchen Sandstone and equivalents. As other reptile groups (turtles, crocodiles) are abundant and often well preserved, this represents probably primary bias rather than a gap in the record. The presence of the dinosaurs was probably migratorial as they used the emerged mouth-bars and barriers as a passage to trespass along the southern and southeastern shore of the LSB.

\section{References}

Abbink, O.; Targarona, J.; Brinkhuis, H. \& Visscher, H. (2001): Late Jurassic to earliest Cretaceous palaeoclimatic evolution of the southern North Sea. Global and Planetary Change 30 (3-4): 231-256.

Allen, P. (1955): Age of the Wealden in North-Western Europe. Geological Magazin 92 (4): 265-281.

Allen, P. \& Wimbledon, W. A. (1991): Correlation of NW European Purbeck-Wealden (nonmarine Lower Cretaceous) as seen from the English type-areas. Cretaceous Research 12 (5): 511-526.

Arp, G. \& Mennerich, C. (2008): Ostracod associations, palaeoenvironment and cyclicity of Purbeck-type sediments of the Münder Formation (Lower Cretaceous, Hils Syncline, N-Germany). In Mischke, S. \& Holmes, J. A. (eds.): Applications of lacustrine and marginal-marine Ostracoda to palaeoenvironmental reconstruction, $15^{\text {th }}$ International Symposium on Ostracoda. Palaeogeography, Palaeoclimatology, Palaeoecology 246 (3-4): 230-249.

Bachmann, G. H. \& Grosse, S. (1989): Struktur und Entstehung des Norddeutschen Beckens - geologische und geophysikalische Interpretation einer verbesserten Bouguer-Schwerekarte. In Das Norddeutsche Becken. Geophysikalische und geologische Untersuchungen des tieferen Untergrundes: Vorträge. Veröffentlichungen der Niedersächsischen Akademie der Geowissenschaften 2: 23-47.

Berner, U. (2011): The German Wealden, an Unconventional Hydrocarbon Play? Erdöl, Erdgas, Kohle 127 (7/8): 303-306.

Berner, U.; Kahl, T. \& Scheeder, G. (2010): Hydrocarbon potential of sediments of the German Wealden Basin. Oil Gas. European Magazine II/2010: 80-84.

Betz, D.; Führer, F.; Greiner, G. \& Plein, E. (1987): Evolution of the Lower Saxony Basin. Tectonophysics 137 (1-4): 127-170.

Böhme, A.; Reich, M.; Hornung, J. J. \& Karl, H.-V. (2012): Excursion Guide C1: Northern 'German Wealden' - the collection of the Göttingen University. In Richter, A. \& Reich, M. (eds.): Dinosaur Tracks 2011. An International Symposium, Obernkirchen, April 14-17, 2011. Abstract Volume and Field Guide to Excursions, 151-167; Göttingen (UniversitätsVerlag).

Broschinski, A. (2004): Exkursion 3: Der Obernkirchner Sandstein - Naturwerkstein und Fossilfundgrube der Unterkreide. In Reitner, J.; Reich, M. \& Schmidt, G. (eds.): Geobiologie 2. 74. Jahrestagung der Paläontologischen Gesellschaft in Göttingen 02. bis 08. Oktober 2004. Exkursionen und Workshops, 53-72; Göttingen (Universitäts-Verlag). 
Casey, R.; Allen, P.; Dörhöfer, G.; Gramann, F.; Hughes, N. F.; Kemper, E.; Rawson, P. F. \& Surlyk, F. (1975): Stratigraphical subdivision of the Jurassic-Cretaceous boundary beds in NW Germany. Newsletters on Stratigraphy 4 (1): 4-5.

Dörhöfer, G. (1977): Palynologie und Stratigraphie der Bückeberg-Formation (Berriasium, Valanginium) in der Hilsmulde (Nordwest-Deutschland). Geologisches Jahrbuch (Reihe A: Allgemeine und regionale Geologie BR Deutschland und Nachbargebiete, Tektonik, Stratigraphie, Palaeontologie) 42: 3-122.

Elstner, F. \& Mutterlose, J. (1996): The Lower Cretaceous (Berriasian and Valanginian) in NW Germany. Cretaceous Research 17 (1): 119-133.

Gramann, F.; Heunisch, C.; Klassen, H.; Kockel, F.; Dulce, G.; Harms, F.-J.; Katschorek, T.; Mönnig, E.; Schudack, M.; Schudack, U.; Thies, D. \& Weiss, M. (1997): Das Niedersächsische Oberjura-Becken - Ergebnisse interdisziplinärer Zusammenarbeit. Zeitschrift der Deutschen Geologischen Gesellschaft 148 (2):165-236.

Graupner, A. (1977): Natursteine an hannoverschen Bauwerken. Hannoversche Geschichtsblätter 35: 103-152.

Graupner, A. (1980): Der Berrias-Steinkohlenbergbau in Niedersachsen 1945-1963. Veröffentlichungen des niedersächsischen Instituts für Landeskunde und Landesentwicklung an der Universität Göttingen. Forschungen zur niedersächsischen Landeskunde 116: 184 pp.

Hoedemaeker, P. J. \& Herngreen, G. F. W. (2003): Correlation of Tethyan and Boreal Berriasian-Barremian Strata with emphasis on strata in the subsurface of the Netherlands. Cretaceous Research 24 (3): 253-275.

Hoffmann, F. (1830): Uebersicht der orographischen und geognostischen Verhältnisse vom nordwestlichen Deutschland. xxiv +676 pp.; Leipzig (J. A. Barth).

Hornung, J. J.; Böhme, A., Lubbe, T. van der; Reich, M. \& Richter, A. (2012a): Vertebrate tracksites in the Obernkirchen Sandstone (late Berriasian, Early Cretaceous) of northwest Germany - their stratigraphical, palaeogeographical, palaeoecological, and historical context. Paläontologische Zeitschrift 86 (3): 231-267.

Hornung, J. J.; Böhme, A. \& Reich, M. (2012b): Excursion Guide A2: Harrl hill near Bückeburg. In Richter, A. \& Reich, M. (eds.): Dinosaur Tracks 2011. An International Symposium, Obernkirchen, April 14-17, 2011. Abstract Volume and Field Guide to Excursions, 101-112; Göttingen (Universitäts-Verlag).

Hornung, J. J.; Böhme, A. \& Reich, M. (2012c): Excursion Guide B2: Wölpinghausen. In Richter, A. \& Reich, M. (eds.): Dinosaur Tracks 2011. An International Symposium, Obernkirchen, April 14-17, 2011. Abstract Volume and Field Guide to Excursions, 143-149; Göttingen (Universitäts-Verlag).

Hornung, J. J. \& Reich, M. (2012): Excursion Guide C2: Dinosaur tracks from the Berriasian Obernkirchen Sandstone on exhibit at the Göttingen University Geopark. In Richter, A. \& Reich, M. (eds.): Dinosaur Tracks 2011. An International Symposium, Obernkirchen, April 14-17, 2011. Abstract Volume and Field Guide to Excursions, 169-187; Göttingen (Universitäts-Verlag). 
Kästner, M.; Schülke, I. \& Winsemann, J. (2008): Facies architecture of a Late Jurassic carbonate ramp: the Korallenoolith of the Lower Saxony Basin. International Journal of Earth Sciences 97 (5): 991-1011.

Kauenhowen, W. (1927): Die Faziesverhältnisse und ihre Beziehung zur Erdölbildung an der Wende Jura-Kreide in Nordwestdeutschland. Neues Jahrbuch für Mineralogie etc. (B: Geologie und Paläontologie), Beilagen-Band 58: 215-272.

Kemper, E. (1973): Das Berrias (tiefe Unterkreide) in NW-Deutschland. Geologisches Jahrbuch (A: Allgemeine und regionale Geologie BR Deutschland und Nachbargebiete, Tektonik, Stratigraphie, Paläontologie) 9: 47-67.

Krumsiek, R. (1981): Obernkirchen. Chronik einer alten Stadt. 176 pp. Obernkirchen (Stadtverwaltung).

Lill, K. \& Riegel, W. (1991): Ein fluviatil dominiertes Delta im „Unteren Wealden“ (Berrias, Bueckeberg-Folge) von Borgloh/Kloster Ösede, Osnabrücker Hügelland, Niedersachsen). Bericht der Naturhistorischen Gesellschaft Hannover 133: 221-255.

Martin, G. P. R. (1940): Ostracoden des norddeutschen Purbeck und Wealden. Senckenbergiana 22: 275-361.

Mutterlose, J. (1997a): Lower Cretaceous. In Mutterlose, J.; Wippich, M. G. E. \& Geisen, M. (eds.): Cretaceous Depositional Environments of NW Germany. Bochumer Geologische und Geotechnische Arbeiten 46: 7-12.

Mutterlose, J. (1997b): Münchehagen quarry. In Mutterlose, J.; Wippich, M. G. E. \& Geisen, M. (eds.): Cretaceous Depositional Environments of NW Germany. Bochumer Geologische und Geotechnische Arbeiten 46: 123-128.

Mutterlose, J. (2000): Unterkreide im Niedersächsischen Becken. In Stratigraphische Kommission Deutschlands (ed.): Die Kreide der Bundesrepublik Deutschland. Courier Forschungsinstitut Senckenberg 226: 79-101.

Mutterlose, J. \& Bornemann, A. (2000): Distribution and facies patterns of Lower Cretaceous sediments in northern Germany: a review. Cretaceous Research 21 (6): 733-759.

Naumann, E. (1927): Blatt Eldagsen, Nr. 2088. Erläuterungen zur geologischen Karte von Preußen und benachbarten deutschen Ländern 265: 57 pp.

Ogg, J. G.; Ogg, G. \& Gradstein, F. M. (2008): The Concise Geological Timescale. 150 pp.; Cambridge (Cambridge University Press).

Pelzer, G. (1984): Cross section through a fluvial environment in the Wealden of Northwest Germany. In Reif, W-E. \& Westphal, F. (eds.): Short papers. Third symposium on Mesozoic terrestrial ecosystems, 181-186; Tübingen (Attempto Verlag).

Pelzer, G. (1998): Sedimentologie und Palynologie der Wealden-Fazies im Hannoverschen Bergland. Courier Forschungsinstitut Senckenberg 207: 211 pp.

Pelzer, G. \& Wilde, V. (1987): Klimatische Tendenzen während der Ablagerung der Wealden-Fazies in Nordwesteuropa. 
Geologisches Jahrbuch (A: Allgemeine und regionale Geologie BR Deutschland und Nachbargebiete, Tektonik, Stratigraphie, Paläontologie) 96: 239-263.

Pelzer, G.; Riegel, W. \& Wilde, V. (1992): Depositional controls on the Lower Cretaceous Wealden coals of northwest Germany. In McCabe, P. J. \& Parrish, J. T. (eds.): Controls on the Distribution and Quality of Cretaceous Coals. Geological Society of America, Special Paper 267: 227-244.

Richter, A.; Hornung, J. J.; Böhme, A. \& Stratmann, U. (2012): Excursion Guide A1: Obernkirchen sandstone Quarries - A Natural Workstone Lagerstaette and a Dinosaur Tracksite. In Richter, A. \& Reich, M. (eds.): Dinosaur Tracks 2011. An International Symposium, Obernkirchen, April 14-17, 2011. Abstract Volume and Field Guide to Excursions, 73-99; Göttingen (Universitäts-Verlag).

Schott, W.; Jaritz, W.; Kockel, F.; Sames, C. W.; Stackelberg, U. von; Stets, J.; Stoppel, D.; Baldschuhn, R. \& Krampe, K.-D. (1967): Paläogeographische Karten von Nordwestdeutschland im Maßstab 1:200000. In Bundesanstalt für Bodenforschung (ed.): Paläogeographischer Atlas der Unterkreide von Nordwest-Deutschland mit einer Übersichtsdarstellung des nördlichen Mitteleuropa, 289 pp.; Hannover (Bundesanstalt für Bodenforschung).

Schott, W.; Jaritz, W.; Kockel, F.; Sames, C. W.; Stackelberg, U. von; Stets, J.; Stoppel, D.; Baldschuhn, R. \& Krampe, K.-D. (1969): Erläuterungen. In Bundesanstalt für Bodenforschung (ed.): Paläogeographischer Atlas der Unterkreide von Nordwest-Deutschland mit einer Übersichtsdarstellung des nördlichen Mitteleuropa, 315 pp.; Hannover (Bundesanstalt für Bodenforschung).

Schudack, M. (1996): Die Charophyten des Niedersächsischen Beckens (Oberjura-Berriasium): Lokalzonierung, überregionale Korrelation und Palökologie. Neues Jahrbuch für Geologie und Paläontologie, Abhandlungen 200 (1/2): 27-52.

Scotese, C. R. (2002): PALEOMAP Project. http://www.scotese.com [last access June 2012]

Strauss, C.; Elstner, F.; Du Chène, J.; Mutterlose, J.; Reiser, H. \& Brandt, K.-H. (1993): New micropalaeontological and palynological evidence on stratigraphic position of the "German Wealden" in NW-Germany. Zitteliana 20: 389-401.

Wilde, V. \& Schultka, S. (1996): Die sandige Wealden-Fazies (Bückeberg-Formation, Berrias, Unterkreide) am Westrand eines Schüttungskörpers bei Osnabrück (NW-Deutschland). Neues Jahrbuch für Geologie und Paläontologie, Abhandlungen 199 (2): 249-268.

Wings, O.; Falk, D.; Knötschke, N. \& Richter, A. (2012): Excursion Guide B1: The Early Cretaceous Dinosaur Trackways in Münchehagen (Lower Saxony, Germany) - The Natural Monument 'Saurierfährten Münchehagen' and the adjacent Wesling Quarry. In Richter, A. \& Reich, M. (eds.): Dinosaur Tracks 2011. An International Symposium, Obernkirchen, April 14-17, 2011. Abstract Volume and Field Guide to Excursions, 113-142; Göttingen (Universitäts-Verlag).

Wolburg, J. (1949): Ergebnisse der Biostratigraphie nach Ostracoden im nordwestdeutschen Wealden. In Bentz, A. (ed.): Erdöl und Tektonik in Nordwestdeutschland, 349-360; Hannover (Amt für Bodenforschung).

Wolburg, J. (1959): Die Cyprideen des NW-deutschen Wealden. Senckenbergiana Lethaea 40 (3/4): 223-315. 
Chapter II

Wölpinghausen tracksite 
Published in:

Richter, A. \& Reich, M. (eds.): Dinosaur Tracks 2011. An International Symposium, Obernkirchen, April 14-17, 2011. Abstract Volume and Field Guide to Excursions: 143-150, Göttingen (Universitäts-Verlag) [2012]. Open access: http://webdoc.sub.gwdg.de/univerlag/2013/Dinotracks.pdf

\section{Wölpinghausen}

JAHN J. HORNUNG ${ }^{1}$, ANNINA BÖHME ${ }^{1,3}$ and MIKE REICH ${ }^{1,2}$

${ }^{1}$ Department of Geobiology, Geoscience Centre of the University of Göttingen, Göttingen, Germany

${ }^{2}$ Geoscience Museum of the University of Göttingen, Göttingen, Germany

${ }^{3}$ Hannover State Museum, Hannover, Germany

In the summer of 1879, the small village of Wölpinghausen, located c. $35 \mathrm{~km}$ WNW of Hannover, became the place where dinosaur tracks in Germany were scientifically investigated for the first time. During the summer of this year, the geologist Carl F. Struckmann (1833-1898, Fig. 1A) from Hannover undertook extensive excavations of dinosaur tracks in a nearby quarry.

Struckmann's detailed reports were published in 1880 (Fig. II.1B), but they were predated by a short protocol notice from a meeting of the 'Deutsche Geologische Gesellschaft', in which a sketch of giant footprints from the 'Rehburg area', sent by the mining engineer Fritz F. von Dücker, was presented. It is not clear, if von Dücker referred to the same material than Struckmann, but the latter was not mentioned in the note. The sketch led Wilhelm Dames to the assumption that the tracks were left by a dinosaur (Hauchecorne in Beyrich et al. 1879; Dames in Beyrich et al. 1879; see Hornung et al. 2012). However, Struckmann was definitely the first to substantiate these conclusions by a scientific description (Struckmann 1880a, 1880b). In autumn of 1879, the excavation of these giant tracks had already spawned strong public curiosity, and Struckmann met this interest with public talks and various newspaper articles. Referring to the pioneering works of Beckles (1852, 1854) from the English Wealden, Struckmann finally assigned the tracks to the ornithopod Iguanodon. This was further substantiated when he sent a plaster cast to Louis Dollo (1857-1931) in Brussels, who at this time investigated the famous Iguanodon assemblage from Bernissart, Belgium. Dollo (1883) noticed the perfect fit between the pedal skeleton of Iguanodon and the track cast and confirmed Struckmann's observations. The tracks also supported Dollo's new reconstruction of this animal as having a bipedal stance. Unfortunately, the exact geographical and geological context of the tracksite was only described in short by Struckmann.

\section{Old Quarries}

The area between Wölpinghausen and Münchehagen (Fig. II.2) is densely spotted with old, abandoned sandstone quarries; however, no significant outcrops are preserved today. The tracksite quarry belonged to the property of A. Spörl. The exact site of this quarry is currently unknown, but it was described as located 'below the Wilhelmsthurm', the latter being a touristical look-out on top 

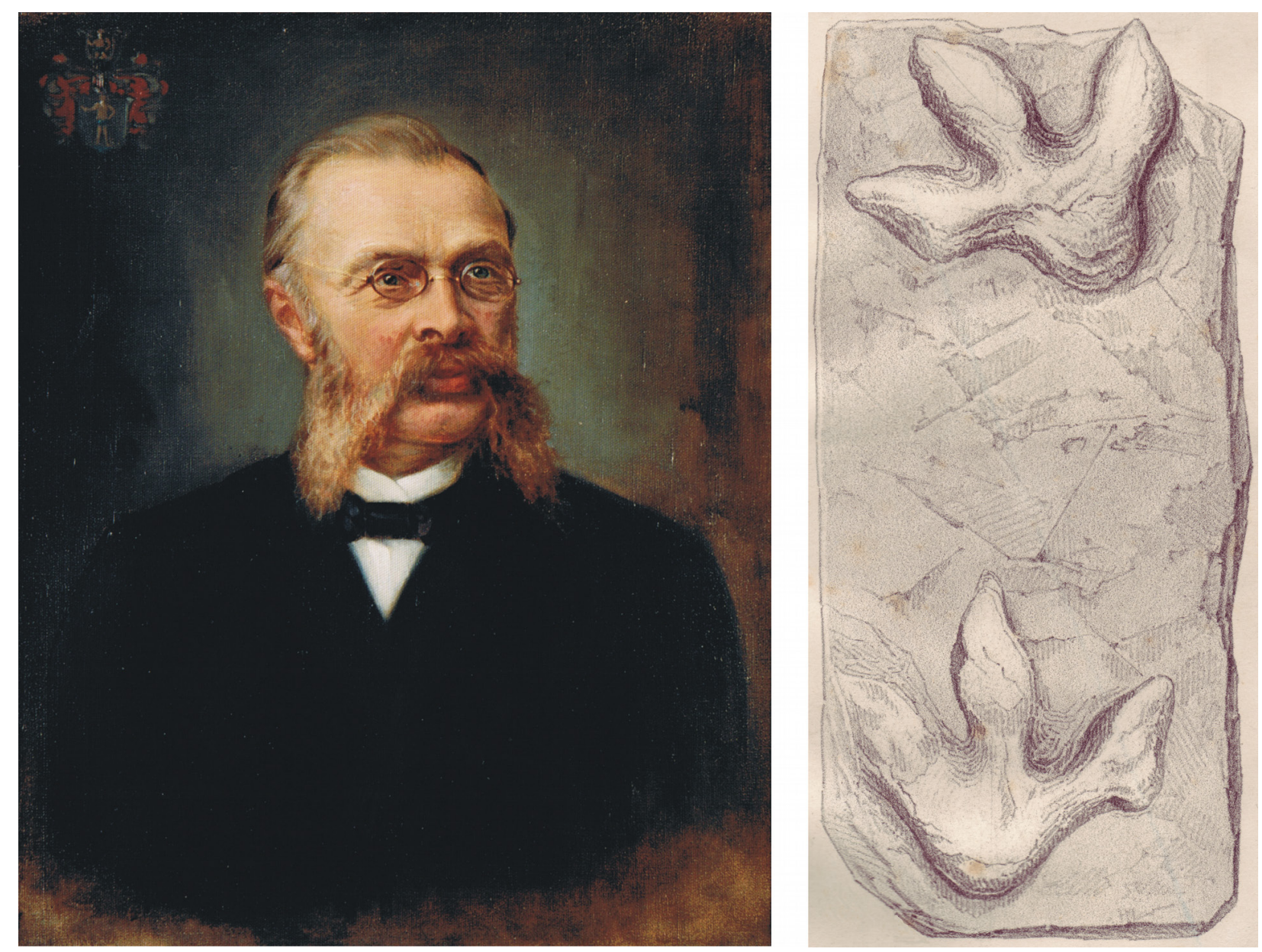

Fig. II.1 (A) Carl E. F. Struckmann (1833-1898), discoverer of the first dinosaur tracks in Germany (courtesy of the Naturhistorische Gesellschaft Hannover). (B) Slab with two pes impressions (natural hypichnial casts) of an iguanodontian ornithopod from the Obernkirchen Sandstone near Wölpinghausen as figured by Struckmann (1880b: pl. IV, fig. 1). The collection of Struckmann was donated in part to the Göttingen University (GZG) as well as purchased after his death by the Hannover Provincial Museum (today NLMH). Unfortunately, this specimen cannot longer be traced in any of both collections.

of the Wölpinghäuser Berg, c. $1.5 \mathrm{~km} \mathrm{NW}$ of Wölpinghausen. Therefore, a location between the small settlement of Berghol and the Wilhelmsturm is most probable. Struckmann recovered c. 40 dinosaur footprints from two horizons near the base of a c. $6 \mathrm{~m}$ thick succession in 40-60 cm thick sandstone beds. The tridactyl tracks reached footlengths of $60 \mathrm{~cm}$. They were preserved as hypichnial casts as well as epichnial reliefs. Struckmann did not provide further descriptions or measurements of trackways. He collected an unknown number of the tracks as isolated slabs; the largest specimens contained two consecutive footsteps (Fig. II.1B). At least two single hypichnial casts are still preserved at the Lower Saxony State Museum (NLMH 105.746, NLMH 105.747; see Hornung et al. 2012), representing the oldest historically published find of a dinosaur track from Germany still preserved in a public collection. A large slab of sandstone with many dinosaur tracks (at the Göttingen Geoscience Museum, GZG.IF.00100, see Hornung \& Reich 2012) also originates from Wölpinghausen, and was a donation of the Principality of Schaumburg-Lippe to the GeorgAugust University in 1880. 


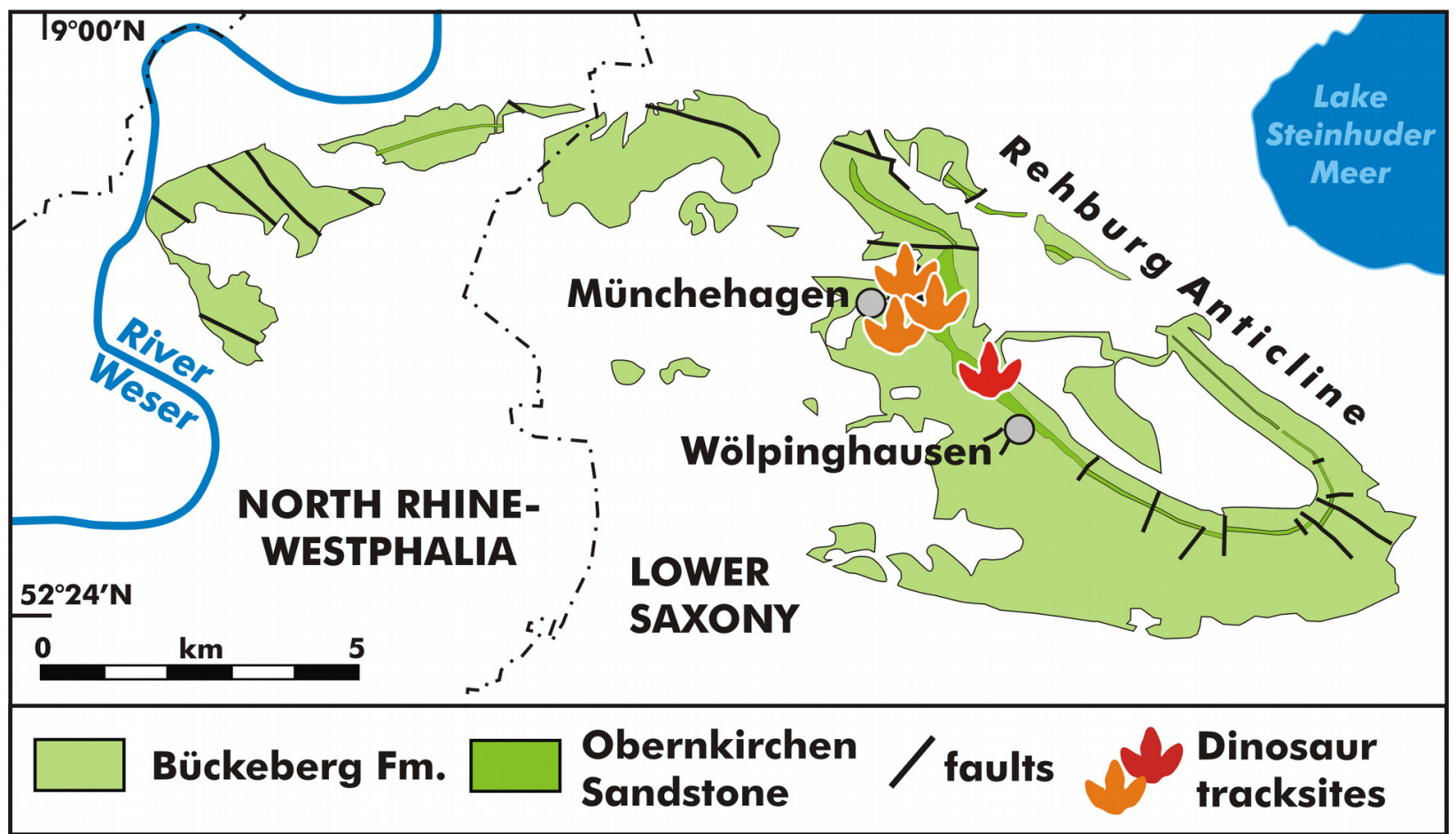

Fig. II.2 Simplified geological map of the Rehburg Anticline with outcrop of the Bückeberg Formation (after LBEG 2009, modified). The tracksites near Münchehagen (orange, see Wings et al. 2012) and the historical site close to Wölping-hausen (red) are marked.

\section{Lithofacies and Cretaceous Environments}

The small quarries around Wölpinghausen exploited the local equivalent of the Obernkirchen Sandstone, locally also known as Rehburg Sandstone or 'Hauptsandstein' ('main sandstone'). The sandstone, embedded between older and younger lacustrine shales is exposed on the southern flank of the Rehburg Anticline (Fig. II.2). This c. $7 \mathrm{~km}$ long, SE-NW striking saddle structure on the southern side of the Steinhuder Meer lake was probably formed by halotectonic uplift triggered by evaporites of the earliest Cretaceous Münder Formation (Jordan 1979). The hard, erosion-resistant, quartzose sandstone, reaching a thickness of 10 to $12 \mathrm{~m}$, forms a topographic ridge around most of the western, southern and southeastern perimeter of the anticline, protecting the softer sediments of the saddle core (Kaufmann et al. 1980). Between Münchehagen and Wölpinghausen, the strata have a dip of c. 25 degrees in southwesterly direction.

Today, solely a 2-3 $\mathrm{m}$ high ledge is exposed for $>60 \mathrm{~m}$ in SE-NW direction immediately below the Wilhelmsturm (Fig. II.3). This exposure apparently represents what remains of a largely infilled quarry.

As Struckmann's track horizons occurred in the lower part of the sandstone succession, the strata exposed today below the Wilhelmsturm cannot be correlated with these. They are also more thinly bedded, slightly younger and represent the uppermost layers of the sandstone preserved in the area. The lithofacies consists of thin- to medium-bedded, coarse- to fine-grained, mostly moderately to well-sorted sandstones with lenticular to sheet-like bedding-geometry. 


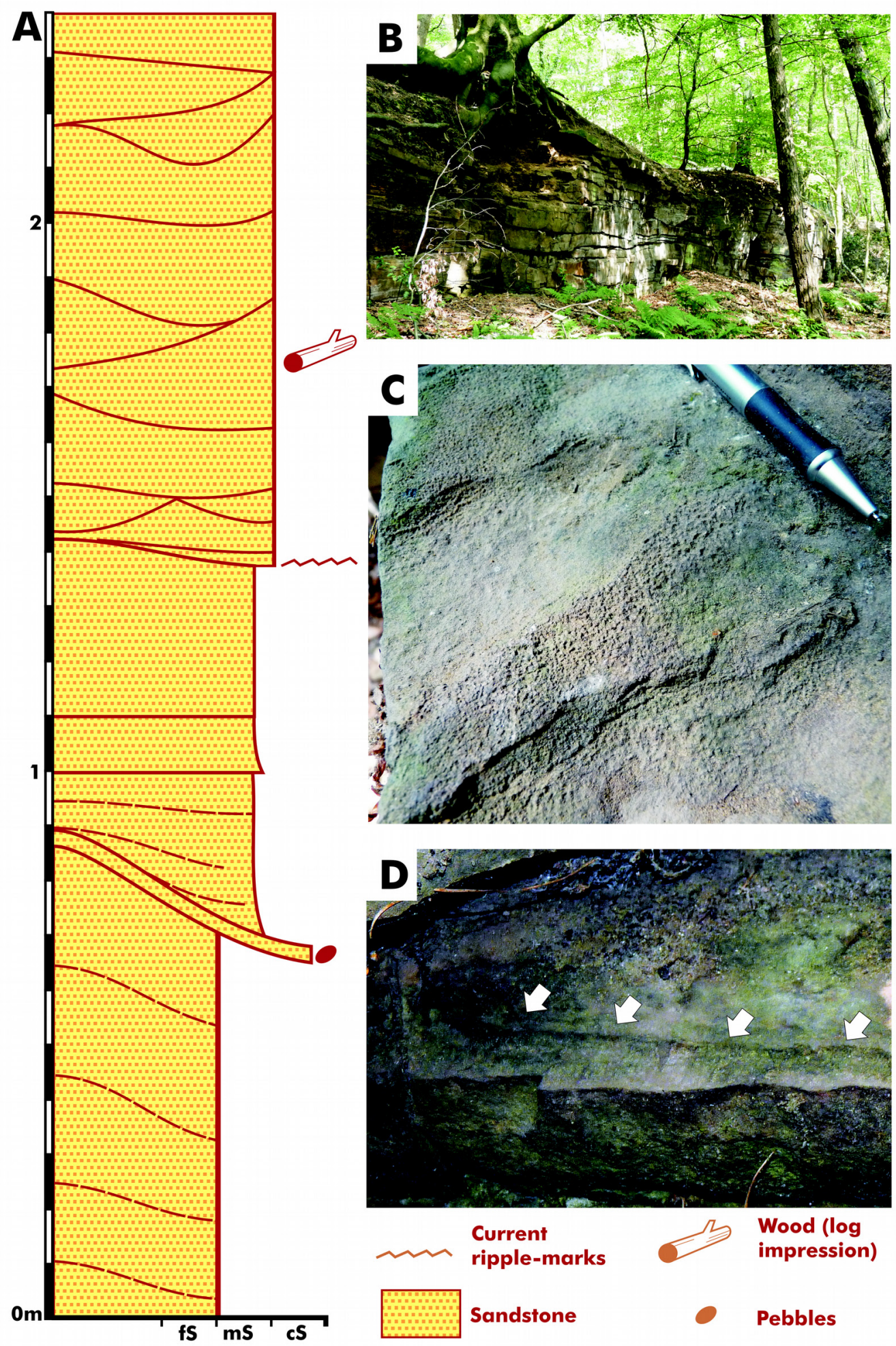

Fig. II.3 Wölpinghausen, quarry below the Wilhelmsturm. Obernkirchen Sandstone, Obernkirchen Member, Bückeberg Formation. (A) Lithological log. (B) Outcrop, looking towards NE. (C) Current ripple-marks with degraded crest tops and reticulate strucures probably related to desiccation of emergent microbial mats. (D) Wood fragment (log impression, arrows), c. $40 \mathrm{~cm}$ long. Abbreviations: fS: fine-grained sandstone, mS: medium-grained sandstone, cS: coarse-grained sandstone. 
The succession comprises at least three fining-upward cycles (Fig. II.3A). The best preserved cycle starts with a 2-3 cm thick basal lag consisting of a coarse-grained sandstone with isolated small (3-4 mm) quartz pebbles. This lag overlies an irregular bounding surface and is overlain by thin- to medium bedded, fining-upward, medium- to fine-grained, structureless sandstone, deposited in convex-down, lenticular (up to $8 \mathrm{~m}$ wide, $0.4 \mathrm{~m}$ thick), concordant bedsets, passing upwards into laterally thinning sheet-like beds (Fig. II.3B). This cycle terminates with a surface covered by unidirectional current ripple marks. The ripple crests show truncation, collapsed flanks, and a reticular, irregular surface pattern, while the ripple troughs are smooth and well preserved (Fig. II.3C). The next cycle starts with a c. $1 \mathrm{~m}$ thick coset of structureless, medium-grained sandstone. The single beds were deposited in convex-down, lenticular beds $(0.3->5 \mathrm{~m}$ wide, $0.05-$ $0.15 \mathrm{~m}$ thick). This unit contains a c. $40 \mathrm{~cm}$ long wood log impression (Fig. II.3D), the only fossil encountered in this outcrop.

The irregular bounding surfaces, coarse basal lag and lenticular bed-geometry indicate cyclical erosive events, which resulted in the formation of shallow channels, subsequently filled by deposits from sediment-laden stream flows (e.g. Mutti et al. 2000). Following the filling of the channels, unconfined flows formed small mouth bars. The apparent lack of internal textures within the sandstone may be a secondary effect due to a poor granulometric contrast or result from very quick deposition from hyperconcentrated flows during rapid deceleration. The formation of current ripples at the top indicates a decrease of sediment concentration during waning flow stage. Crest degradation and collapse evidences a partial emergence of the ripple-marked surfaces. The reticulated pattern on top of the ripple crests is similar to that formed by emerged and dried-up microbial mats (Schieber et al. 2007; Bose \& Chafetz 2009).

The lithofacies indicates an environmental setting in a river terminal channel mouth with a very shallow basinward depth gradient, resulting in the formation of extensive shallow-water mouth bar sandflats (e.g. Wright 1977). Fluctuating discharge, e.g. due to seasonal floods, resulted in rapid erosion and remobilization of matured sands. The direction of the channels and ripple marks on laterally unconfined beds indicate northwesterly to northeasterly flow directions. During falling flood stages and flow stagnation, ripple marked surfaces were colonized and stabilized by matbuilding microbes. Local emergence is evidenced by degraded ripple crests and dried-up microbial mats with a few mm of water still covering the ripple grooves.

\section{Summary}

From the data currently available, it appears that the dinosaur tracks from the southern flank of the Rehburg Anticline (including those from the Münchehagen sites, Wings et al. 2012) were exclusively found in the lower part of the main sandstone succession. The facies of these deposits were interpreted as shallow-water lagoonal and barrier sand deposits which were mobilized by storm events (Pelzer 1998; Hornung et al. 2012). The upper part exposed below the Wilhelmsturm preserves a distalmost fluvial facies and shows a change of environment throughout the deposition of the sandstone unit. At Münchehagen, the uppermost deposits have not been studied in detail yet. 
However, at least the base of one isolated channel incised into the lower track-bearing sandstone and filled with large-scale cross-stratified sandstone was reported from the Dino-Park tracksite (Fischer 1998). This might represent a fluvial channel deeply incised from the base of the upper unit.

The outcrop below the Wilhelmsturm shows once again that the Obernkirchen Sandstone and its lateral equivalents have to be considered polygenetic, with rapid lateral and vertical facies changes (see Pelzer 1998; Hornung et al. 2012), though they represent only a relatively thin interval within the up to $700 \mathrm{~m}$ thick pelite-dominated Bückeberg Formation. A detailed study of this variability will provide insight into the various environments which were roamed by the late Berriasian dinosaur communities.

\section{Acknowledgments}

We thank V. J. Roden, Darmstadt, for checking the English spelling of a first draft.

\section{References}

Beckles, S. H. (1852): On the Ornithoidichnites of the Wealden. Quarterly Journal of the Geological Society of London 8 (1-2): 396-397.

Beckles, S. H. (1854): On the Ornithoidichnites of the Wealden. Quarterly Journal of the Geological Society of London 10 (12): 456-464.

Beyrich, H. E.; Websky, W. \& Speyer, O. (1879): 2. Protokoll der December-Sitzung. Zeitschrift der Deutschen Geologischen Gesellschaft 31: 798-804.

Bose, S. \& Chafetz, H. S. (2009): Topographic control on distribution of modern microbially induced sedimentary structures (MISS): A case study from Texas coast. Sedimentary Geology 213 (3-4): 136-149.

Dollo, L. (1883): Troisième note sur les dinosauriens de Bernissart. Bulletin du Musée Royal de d'Histoire Naturelle de Belgique 2: 85-126.

Fischer, R. (1998): Die Saurierfährten im Naturdenkmal Münchehagen. Mitteilungen aus dem geologischen Institut der Universität Hannover 37: 3-59.

Hornung, J. J. \& Reich, M. (2012): Excursion Guide C2: Dinosaur tracks from the Berriasian Obernkirchen Sandstone on exhibit at the Göttingen University Geopark. In Richter, A. \& Reich, M. (eds.): Dinosaur Tracks 2011. An International Symposium, Obernkirchen, April 14-17, 2011. Abstract Volume and Field Guide to Excursions, 169-187; Göttingen (Universitäts-Verlag). 
Hornung, J. J.; Böhme, A., Lubbe, T. van der; Reich, M. \& Richter, A. (2012): Vertebrate tracksites in the Obernkirchen Sandstone (late Berriasian, Early Cretaceous) of northwest Germany - their stratigraphical, palaeogeographical, palaeoecological, and historical context. Paläontologische Zeitschrift 86 (3): 231-267.

Jordan, H. (1979): Blatt Rehburg, Nr. 3521. In Niedersächsisches Landesamt für Bodenforschung (ed.): Erläuterungen zur Geologischen Karte von Niedersachsen (1 : 25 000): 134 pp.; Hannover (Landesamt für Bodenforschung).

Kaufmann, R.; Oppermann, H.-U. \& Petsch, K. (1980): Zur Entwicklung der tiefen Unterkreide (Berrias/Valangin) im Süden des Rehburger Sattels unter besonderer Berücksichtigung der Tongrube Sachsenhagen. Ballerstedtiana 3: 5-27.

LBEG [Landesamt für Bergbau, Energie und Geologie Niedersachsen] (2009): Cardomap server. http://memas01.lbeg.de/lucidamap/index.asp [last accessed 02 July 2009]

Mutti, E.; Tinterri, R.; di Biase, D:; Fava, L.; Mavilla, N.; Angella, S. \& Calabrese, L. (2000): Delta-front facies associations of ancient flood-dominated fluvio-deltaic systems. Revista de la Sociedad Geológica de España 12 (2): 165-190.

Pelzer, G. (1998): Sedimentologie und Palynologie der Wealden-Fazies im Hannoverschen Bergland. Courier Forschungsinstitut Senckenberg 207: 211 pp.

Schieber, J.; Bose, P.; Eriksson, P. G.; Banerjee, S.; Sarkar, S.; Altermann, W. \& Catuneanu, O. (eds., 2007): Atlas of Microbial Mat Features Preserved within the Siliciclastic Rock Record. 324 pp.; Amsterdam (Elsevier).

Struckmann, C. (1880a): Die Wealden-Bildungen der Umgebung von Hannover. Eine geognostisch-paläontologischstatistische Darstellung. viii + 122 pp.; Hannover (Hahn).

Struckmann, C. (1880b): Vorläufige Nachricht über das Vorkommen großer, vogelähnlicher Thierfährten (Ornithoidichnites) im Hastingssandsteine von Bad Rehburg bei Hannover. Neues Jahrbuch für Mineralogie, Geologie und Paläontologie [1880] (1): 125-128.

Wings, O.; Falk, D.; Knötschke, N. \& Richter, A. (2012): Excursion Guide B1: The Early Cretaceous Dinosaur Trackways in Münchehagen (Lower Saxony, Germany) - The Natural Monument 'Saurierfährten Münchehagen' and the adjacent Wesling Quarry. In Richter, A. \& Reich, M. (eds.): Dinosaur Tracks 2011. An International Symposium, Obernkirchen, April 14-17, 2011. Abstract Volume and Field Guide to Excursions, 113-142; Göttingen (Universitäts-Verlag).

Wright, L. D. (1977): Sediment transport and deposition at river mouths: A synthesis. Geological Society of America, Bulletin 88 (6): 857-868. 
Chapter III

Harrl hill tracksites 
Published in:

Richter, A. \& Reich, M. (eds.): Dinosaur Tracks 2011. An International Symposium, Obernkirchen, April 14-17, 2011.

Abstract Volume and Field Guide to Excursions: 101-112, Göttingen (Universitäts-Verlag) [2012]. Open access:

http://webdoc.sub.gwdg.de/univerlag/2013/Dinotracks.pdf

\section{Harrl hill near Bückeburg}

JAHN J. HORNUNG ${ }^{1}$ ANNINA BÖHME ${ }^{1,3}$, and MIKE REICH ${ }^{1,2}$

${ }^{1}$ Department of Geobiology, Geoscience Centre, Georg-August University of Göttingen, Germany

${ }^{2}$ Museum, Collections \& Geopark, Geoscience Centre, Georg-August University of Göttingen, Germany

${ }^{3}$ Lower Saxony State Museum, Hannover, Germany

The Harrl hill, located c. $2 \mathrm{~km}$ east of Bückeburg (Hornung, Böhme, Reich 2012a: fig. 1, here Chapter I: Fig. I.1), is established as a Cretaceous vertebrate locality since the early $19^{\text {th }}$ century. The quarries on the hill were the private property of the Princes of Schaumburg-Lippe. Therefore they are also known as "Fürstliche Steinbrüche" ("comital quarries"). The dynasty of Schaumburg-Lippe used the stones to build their château at Bückeburg as well as other buildings in the region.

Today the quarries are abandoned, partly backfilled or flooded and protected by conservation laws.

Fossils from the Harrl hill were possibly known for centuries to the quarry workers. That these finds were brought to the eyes of the then still nascent science of vertebrate palaeontology was due to the efforts of another local institution: the Adolfinum grammar school (see Böhme et al. 2012). This school was founded during the $17^{\text {th }}$ century and soon became the institution in charge of the comital natural history collection. Especially thanks to the efforts of principal Wilhelm Burchard (1804-1887), important vertebrate fossils found on the Harrl hill in the first half of the $19^{\text {th }}$ century were brought to the attention of Hermann von Meyer (1801-1869), an early, very prominent authority in this field. Von Meyer $(1841,1857,1859)$ published the first descriptions of a crocodile from the German "Wealden" (Pholidosaurus schaumburgensis) and of a tremendously complete small dinosaur (Stenopelix valdensis), whose articulated skeleton only missed the head. At the time of its description, Stenopelix was the most complete dinosaur known, although it was not yet identified as such.

During the second half of the $19^{\text {th }}$ century, the scientific interest for the Adolfinum natural history collection dwindled somewhat, until a new enthusiast entered the stage: Max Ballerstedt (1857-1945), then teacher at the Adolfinum. Ballerstedt's palaeontological research began sometime before the turn of the century and yielded first results when he published on dinosaur tracks he had unearthed at the Harrl hill between 1900 and 1905 (Ballerstedt 1905). Dinosaur tracks were first mentioned very briefly from the Harrl by Grabbe (1881), but from his description their nature becomes not very clear. Ballerstedt was the first to provide figures and some descriptions, including discussions on the trackmakers.

The quarries on the Harrl hill were operated on an "on-demand“ basis and Ballerstedt (1921a) reported that the working activities had declined since the middle of the $19^{\text {th }}$ century. However, 
Ballerstedts efforts to collect fossils were probably aided by increased production activities, following an extensive building programme at nearby Bad Eilsen, initiated by Adolf II. (1883-1936), the last reigning Prince of Schaumburg-Lippe, between 1911 and 1918 (vom Hofe 2006).

\section{Lithofacies and Cretaceous Environments}

Today the exposures at the Harrl hill show a succession of more than 12 meters of sand- to claystones, dipping steeply in northeasterly directions. The erosion resistant, tectonically tilted sandstone, interbedded in soft pelites, formed the shape of the ridge-like hill, which stretches therefore roughly parallel to the strike direction of the beds. Two outcrops, a small pit closer to the town of Bückeburg, and a large quarry, situated c. $350 \mathrm{~m}$ to the E, expose the deposits. The smaller outcrop (Fig. III.1) has previously been studied by Pelzer (1998) and Grupe (1933) provided a short overview of the whole section.

The succession begins with a c. $8 \mathrm{~m}$ thick unit of $\mathrm{cm}$ - to $\mathrm{dm}$-thick, fine-grained, massive, horizontally or planar cross-stratified sandstone, deposited in laterally and vertically stacked, shallowly lenticular erosive features. These features are simple scour-and-fill-structures, up to tens of meters wide and commonly less than $0.5 \mathrm{~m}$ deep. Bounding surfaces of a higher order separate cosets up to several meters in thickness which occasionally show thickening-upward trends. Towards the top this unit increasingly contains finer-grained, partly silty, massive, plane- or flaser bedded, and current-ripple cross-laminated sandstones. At the small, western outcrop the upper part of this unit was studied in detail (Figs. 1A-B). From about $2.1 \mathrm{~m}$ below the coal seam, thinlybedded massive to ripple cross-laminated, partly silty-clayey fine-grained sandstone contain root horizons in some levels. The successions shows an overall fining-upward trend.

The lower unit is concluded by a $5-10 \mathrm{~cm}$ thick coal seam (seam "no. 2" of Grupe (1933), Fig. III.1C).

The upper unit begins with thin, massive, current-ripple cross-laminated, or wavy bedded, finegrained, partly silty sandstones with abundant plant-remains. The sandstone forms isolated, lenticular, convex-up bedforms, several meters wide and up to $0.3 \mathrm{~m}$ thick. The internal bedsurfaces are concordant to the surface of the bedforms. The bedforms are overlain without marked erosion by a $0.4-0.5 \mathrm{~m}$ thick complex of fine-grained, massive sandstone, deposited in very shallow, laterally extensive, lenticular erosional features (up to $>5 \mathrm{~m}$ wide and $0.15 \mathrm{~m}$ thick). The infill of these features often begin with a lag consisting of numerous wood logs, preserved as impressions up to $50 \mathrm{~cm}$ long (Fig. III.1D), and a few but relatively large $(3-5 \mathrm{~cm})$ bivalve resting traces (Lockeia isp.) are preserved at the base of the unit.

The following c. $2 \mathrm{~m}$ of the log are composed of fining- and thinning-upward, massive, predominantly thinly-bedded fine-grained sandstones. With decreasing bed-thickness (from 15 to 1 $\mathrm{cm}$ ) the abundance of thin clay drapes on the bed boundaries increase upwards. The thinly-bedded layers (5 to $1 \mathrm{~cm}$ thickness) show mass-occurrences of small Lockeia isp. and occasional doublevalved neomiodontid bivalves. Incised in the top of this unit, a small convex-down, lenticular erosional feature is filled with trough cross-stratified medium-grained sandstone, containing 


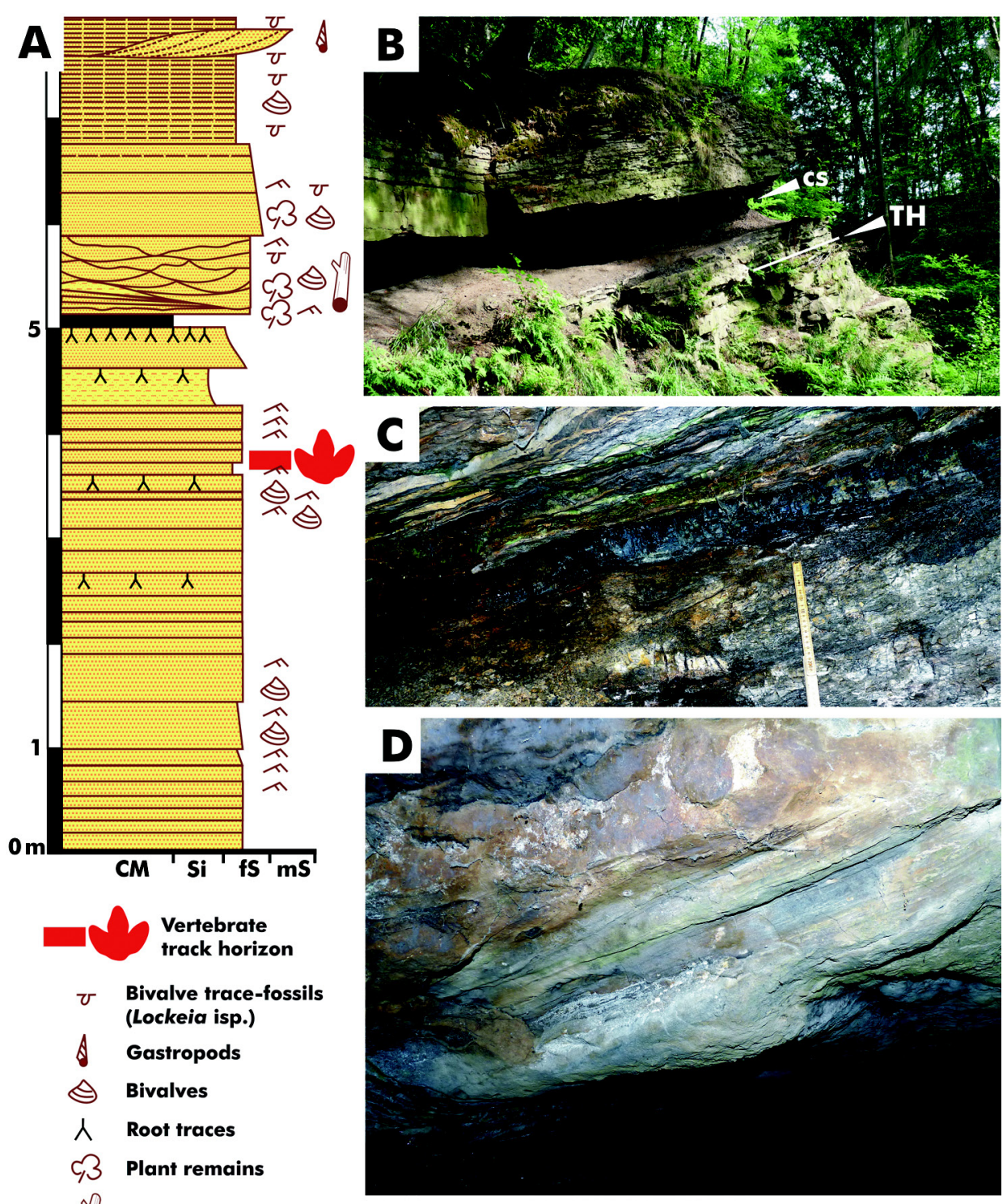

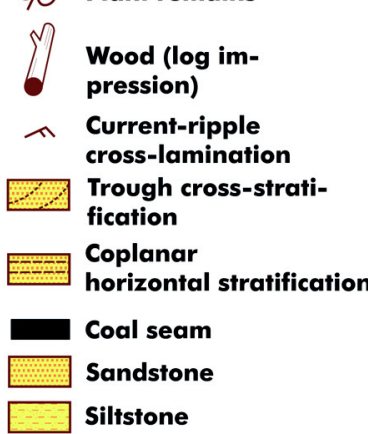

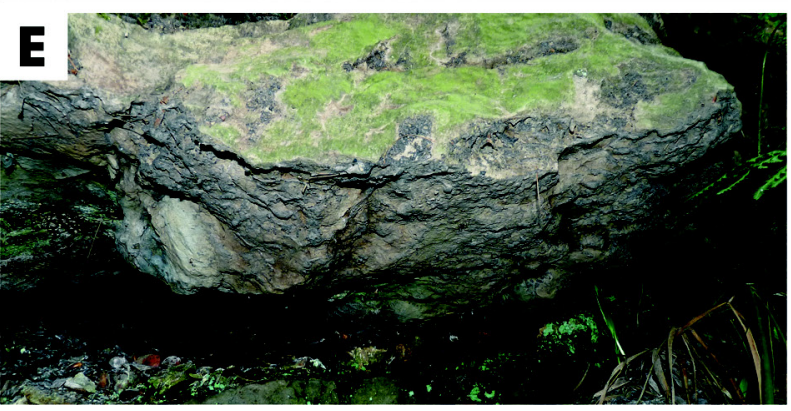

Fig. III.1 Harrl hill near Bückeburg, western quarry, Obernkirchen Sandstone. (A) Lithological log. CM: claystone/mudstone, Si: siltstone, fS: fine-grained sandstone, $\mathrm{mS}$ : medium-grained sandstone (B) Overview of outcrop, exposed thickness c. 8 m, cs: coal seam, TH: track horizon. (C) Coal seam. (D) Accumulation of wood fragments, preserved as flattened impressions at the base of sandstone scour-fills, overlying the coal seam. Length of $\log$ fragments $\mathrm{C} .40 \mathrm{~cm}$. (E) Hypichnial cast of a massive, tridactyle footprint, probably of an iguandontian ornithopod. Width of picture c. $60 \mathrm{~cm}$. 
numerous plant fragments, neomiodontids and gastropods.

Overlying the former unit, a similar succession of thin-bedded sandstones with abundant Lockeia follow after a distinctive erosive boundary. At the large outcrop to the east the same boundary surface can be traced which is overlain by southeastwardly thickening and coarsening sandstone, while the underlying beds tend to be finer-grained and thinner-bedded. This suggests a fan-shaped architecture of both units with fan-diameters in the size range of several 100 meters.

This succession was preliminary interpreted by Pelzer (1998) as tidal channel deposits. However, there is no lithofacies texture indicative of bidirectional currents, which would evidence astronomically controlled tidal cycles. Though storm-induced tides may form unidirectional flow deposits in inlets and breaches, the succession is obviously to complex and records to many different lithofacies to be unified as result of a single event.

The lower part of the section shows quite homogenous facies of beds with marked erosive bases, deposited from turbulent flows. They form complex fills within wide multistorey channels and are interpreted as proximal sandy mouth bar deposits. The presence of flaser and wavy bedding in some of these beds indicate fluctuating flow strength (e.g. Martin 2000), probably related to seasonally changing discharge. Under peak-efflux the stoss-sides of these bars commonly underwent extensive scouring, when the flow-depth is reduced by accumulating sediment (Wright 1977; Van Dijk et al. 2009). Rooting and vertebrate tracks towards the top shows decreasing flowenergy and very shallow water depth.

Dense rooting in the bed underlying the coal seam indicates dense surface colonization by plants and a distinct ochre coloration as well as high content of clay minerals point toward an initial pedogenesis in this horizon. The coal was probably formed under transgressive conditions, drowning the vegetation and forming a peat-bog swamp (Pelzer 1998).

The succession overlying the coal is interpreted as distal mouth bar deposits, forming lobes of thinly-bedded sand interbedded by finer-grained basinal sediments. The sand-sheets have been extensively exploited by neomiodontid bivalves, which left the abundant Lockeia traces. Near the base of the unit, a slightly more proximal facies is intercalated including a bed with a basal lag of plant debris, wood logs, and intraclasts. Near the top, channelizing and erosive truncation indicates a regressive stage.

\section{Fauna and Flora in the sandstone of the Harrl hill}

Due to incomplete records it is not entirely clear for any specimen in the Ballerstedt collection if it was found on the Harrl hill or in the nearby Bückeberg (Obernkirchen area). This situation will hopefully be improved by the painstaking evaluation of Ballerstedt's personal archive, also kept in Göttingen. His digging and acquisitions at least yielded a number of turtles and crocodiles from the Harrl as well as a large number of vertebrate tracks, invertebrates and plants.

(1) Vertebrates - Among the vast number of turtle specimens in the Ballerstedt collection the situation regarding the origin of specimens is currently especially confusing. About seven species 
are known from the Bückeberg Formation (Karl et al. 2007a, 2007b, 2012) and it can be anticipated, that at least Pleurosternon bullockii, Ballerstedtia bueckebergensis, and Hylaeochelys menkei (cf. Karl, Staesche et al. 2007), three very common, basal cryptodirans, occur at the Harrl hill. Turtles from the Obernkirchen Sandstone are nearly exclusively known from their shells (impressions and moulds, see Böhme et al. 2012), while skulls are entirely missing, despite the abundance of this group. Among the Ballerstedt collection, recently a well preserved manus track hypichnium, left by a swimming or 'bottom-walking' large turtle, was recognized (Hornung, Karl \& Reich 2012; Fig. III.2A).

Crocodilians (e.g. von Meyer 1841; Koken 1886, 1887; Salisbury et al. 1999; Hornung, Andrade et al. 2009; Andrade \& Hornung 2011) include two rather abundant mesoeucrocodylian genera: the short-snouted Goniopholis and the long-snouted Pholidosaurus. The latter is represented by the holotype of P. schaumburgensis (Fig. III.2B) and a number of skulls and postcranial elements, some of which evidently were found in the Harrl quarries. Though already identified by Koken (1886) in the Obernkirchen Sandstone, numerous specimens of Goniopholis in the Ballerstedt collection remained undescribed (the origin of the well preserved skull at the Goldfuss Museum, University of Bonn, described by Salisbury et al. 1999 is unknown). Recently a skull and large part of the postcranium was reidentified on several blocks dispersed among the collection (Hornung, Andrade et al. 2009; Andrade \& Hornung 2011; Hornung \& Reich 2012). This specimen was found before 1925, most probably at the Harrl hill, and is figured in part (skull) in Böhme et al. (2012).

The holotype of Stenopelix valdensis still remaines the only reasonably complete dinosaur from the Obernkirchen Sandstone (Figs. 2C-D). Identified as a dinosaur for the first time by Koken $(1887)^{1}$, the lack of a skull of this small, bipedal ornithischian led to a great number of hypotheses about its relationships. It was considered a basal 'hypsilophodontid', a primitive pachycephalosaur or a psittacosaurid ceratopsian. The latest thorough revision of the specimen (Butler \& Sullivan 2009) came to the conclusion that it is best regarded a marginocephalian of uncertain affinities. However, a recent more inclusive cladistic analysis (Butler et al. 2011) found it to be a very basal ceratopsian, closely related to the Upper Jurassic Yinlong downsi from China.

Other dinosaur remains include isolated bones and bone fragments of which at least an

Fig. III.2 Reptiles and reptile tracks from the Obernkirchen Sandstone at the Harrl hill. (A) Turtle manus impression, GZG.BA.0116, natural hypichnial cast (see Hornung, Karl \& Reich 2012; Chapter IX). (B) Pholidosaurus schaumburgensis von Meyer, 1841, holotype GZG.BA.0047a. Dorsal vertebral series (natural impression) of a pholidosaurid crocodile. Laterally to the transverse processes impressions of the outer margin of the dorsal osteodermal shield are also visible in situ. (C-D) Stenopelix valdensis von Meyer, 1857, holotype GZG.BA.0048a-b. Postcranial skeleton (slab and counter-slab, natural impressions) of a small, basal (?)ceratopsian dinosaur. (E) Iguanodontian ornithopod footprint, GZG.BA.0866. Natural hypichnial cast of the right pes. (F) 'Bueckeburgichnus' maximus Kuhn, 1958, ichnotopotypoid, GZG.BA.0930. Natural hypichnial cast of the left pes. See Hornung, Böhme \& Reich 2012a). (G) Ankylosaur footprint, GZG.BA.0050. Natural hypichnial cast of left pes, possibly part of the ichnoholotype of Metatetrapous valdensis Nopcsa, 1923. See Hornung, König \& Reich (2012). Scale bars: $10 \mathrm{~cm}$.

1 Corrigendum: It was Huxley (1870: Quaterly Journal of the Geological Society, Scientific Memoirs, 3: 487509) who pointed out the dinosaurian affinities of S. valdensis for the first time, though Koken (loc. cit.) was the first to provide a thorough revision of the specimen. 


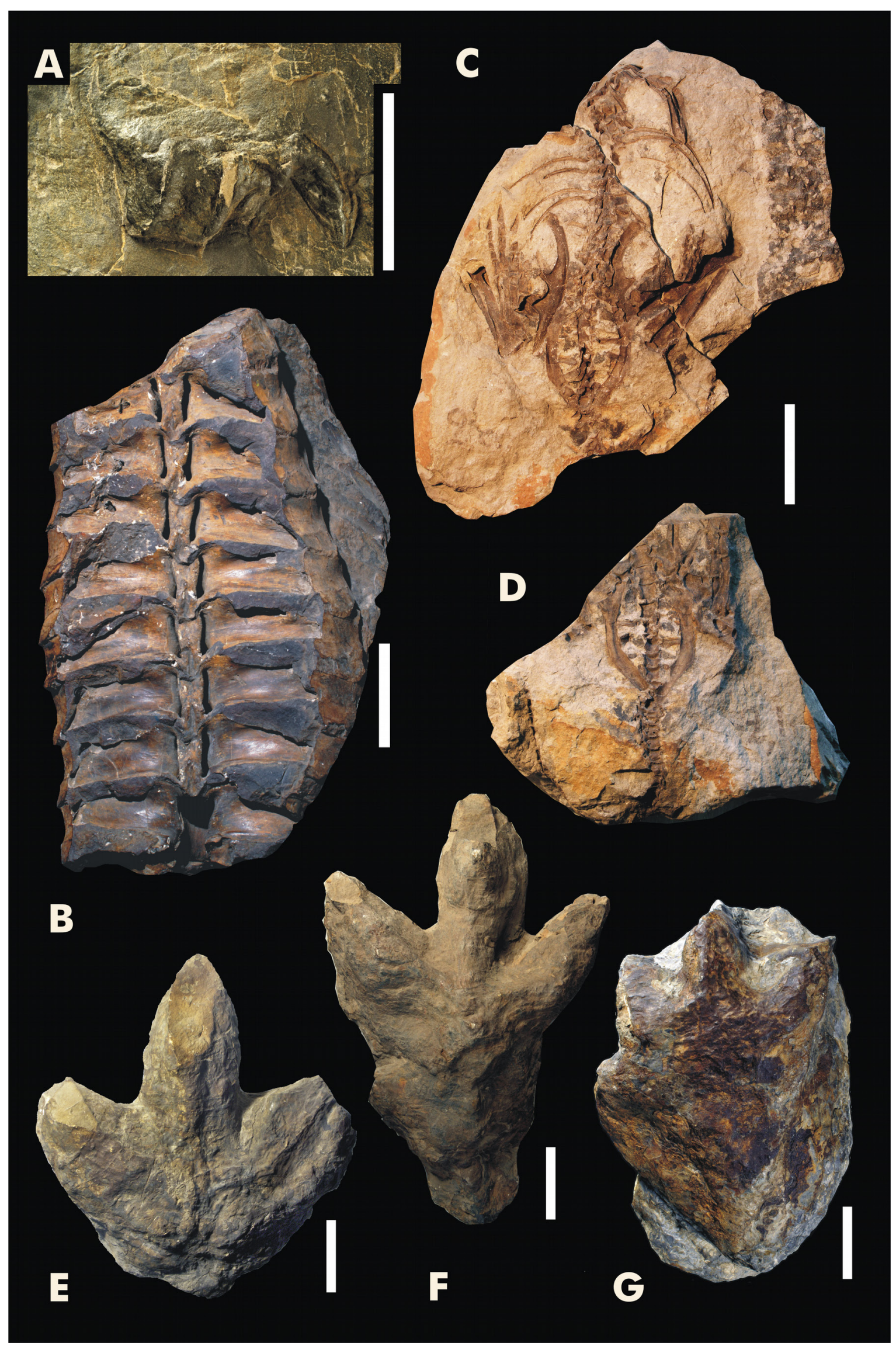


iguanodontian pubis was found on the Harrl hill (letter of M. Ballerstedt to O. Abel, 2 Feb 1922; see Karl \& Tichy 2007: 288f.)

The dinosaur tracks include those of the ubiquitous iguanodontian ornithopods (Ballerstedt 1905, 1914; Fig. III.2E) but also those of a large theropod (Fig. III.2F). The latter, described already by Ballerstedt (1905), were identified as those of a carnivorous dinosaur ("Megalosaurus") by Abel (1935) and finally named Bueckeburgichnus maximus (Fig. III.2F, see Kuhn 1958, Lockley 2000, Thulborn 2001, Hornung, Böhme \& Reich 2012b). Later he found massive, didactyle tracks, which he compared to the didactyle foot of an ostrich and named Struthopus schaumburgensis (see Ballerstedt, 1921b). These tracks have been disputed later - i.e. Abel (1935) argued that they have been left by an ornithopod with severed foot, missing a toe. As Ballerstedt's descriptions were based on isolated hypichnial casts, it was also proposed that they represent incompletely preserved ornithopod tracks. Unfortunately, the original material could not be relocated yet (minor parts of the collection went lost between 1945 and 1976).

In 1921 Ballerstedt discovered a new type of track, left by a quadrupedal animal. He shortly described the specimen and concluded that it was left by a "secondarily quadrupedal" dinosaur (Ballerstedt 1921a, 1922). This track was named Metatetrapous valdensis and correctly identified as that of an armoured ornithischian (thyreophoran) by Nopcsa (1923). Being the first thyreophoran (more precisely ankylosaurian) trackway ever identified, it was considered lost by many authorities over the decades (e.g. Haubold 1974). However, in 2007 we were able to identify two hypichnial casts of the pes imprint of an ankylosaur which may belong to the original material (Hornung, König \& Reich 2012; Chapter VI; Fig. III.2G).

According to Grupe (1933) dinosaur tracks are confined to the section below the coal seam. A track horizon presumed by Pelzer (1998) to be present about $0.9 \mathrm{~m}$ below the coal seam was confirmed (pers. obs. 2011, Figs. 1A-B, E). The tracks (of which large-sized tridactyle pes impressions of (?) ornithopods were identified in the field) were left in an about $10 \mathrm{~cm}$ thick, dark-grey, silty, flasery, current-ripple cross-laminated sandstone and cast by a yellow, massive, fine-grained sandstone. This lithology is congruent with that observable on isolated hypichnial casts from the Ballerstedt collection, supporting an identification of this track-level with that described by the latter. In places the bed shows intensive internal contortion which is interpreted as dinoturbation.

Ballerstedt's material also included the manus track of a large pterosaur (Purbeckopus cf. pentadactylus), which shows close similarity to contemporaneous material from southern England, is preserved only as a plaster cast which was presented by Ballerstedt to Othenio Abel (1875-1946) in 1935. The latter left the specimen in Göttingen, when he returned to Austria for retirement in 1940. This ichnological evidence is especially important as other records of pterosaurs from the Obernkirchen Sandstone are still a bias. The size of the track indicates an animal with a wingspan of about 6 m (Hornung \& Reich 2011; Chapter X).

(2) Invertebrates - at the Harrl hill are mostly represented by bivalves and gastropods. The bivalves belong to the family Neomiodontidae, which indicate freshwater or brachyhaline conditions (Huckriede 1967). The gastropods include Viviparidae, which are also indicative of freshwater. Several levels are strongly bioturbated by shallowly burrowing neomiodontids, leaving very abundant Lockeia isp. trace-fossils. 
(3) Plants - The palaeoflora is mostly documented by abundant root-traces of various types (Pelzer 1998). Immediately above the coal-seam a lag of wooden trunks, preserved as flattened impressions, is present, and Ballerstedt (in Grupe 1933) noted the occurrence of the tree-fern Tempskya in this layer. Silicified fragments of pseudo-stems of this genus are abundantly present in his collection.

\section{Outlook}

This overview on the historical outcrops at the Harrl hill is far from being complete. Research to be undertaken in the future include a more detailed interpretation of the facies and environment, as well as a stratigraphical correlation with other outcrops of the Obernkirchen Sandstone. The latter may be faciliated by the recognition of a major erosive boundary surface near the top of the outcrop, a similar discontinuity has been found in the Bückeberge (Dietrich 1927; pers. obs.) and in the Rehburg Mountains (Fischer 1998; Hornung, Böhme et al. 2012c). It is probably related to a significant drop in the lake level and can potentially serve as a cornerstone for a future sequencestratigraphical framework of the Obernkirchen Sandstone.

\section{References}

Abel, O. (1935): Vorzeitliche Lebensspuren. xv + 664 pp.; Jena (Fischer).

Andrade, M. B. de \& Hornung, J. J. (2011): A new look into the periorbital morphology of Goniopholis (Mesoeucrocodylia: Neosuchia) and related forms. Journal of Vertebrate Paleontology 31 (2): 352-368.

Ballerstedt, M. (1905): Über Saurierfährten der Wealdenformation Bückeburgs. Naturwissenschaftliche Wochenschrift (Neue Folge) 4 (31): 481-485.

Ballerstedt, M. (1914): Bemerkungen zu den älteren Berichten über Saurierfährten im Wealdensandstein und Behandlung einer neuen, aus 5 Fußabdrücken bestehenden Spur. Centralblatt für Mineralogie, Geologie und Paläontologie [1914] (2): 48-64.

Ballerstedt, M. (1921a): Dinosaurierfährten im Wealdensandstein des Harrl bei Bückeburg und eine zur Zeit freiliegende Spur eine „vierfüßigen“ plumpen Dinosauriers. Zeitschrift der Deutschen Geologischen Gesellschaft 72: 231-233.

Ballerstedt, M. (1921b): Zwei große, zweizehige Fährten hochbeiniger Bipeden aus dem Wealdensandstein bei Bückeburg. Zeitschrift der Deutschen Geologischen Gesellschaft, Monatsberichte 73B: 76-91.

Ballerstedt, M. (1922): Über Schreckensaurier und ihre Fußspuren. Kosmos 19 (3): 77-80.

Böhme, A.; Reich, M.; Hornung, J. J. \& Karl, H.-V. (2012): Excursion Guide C1: Northern 'German Wealden' - the collection of the Göttingen University. In Richter, A. \& Reich, M. (eds.): Dinosaur Tracks 2011. An International Symposium, Obernkirchen, April 14-17, 2011. Abstract Volume and Field Guide to Excursions, 151-167; Göttingen (Universitäts-Verlag). 
Butler, R. J. \& Sullivan, R. M. (2009): The phylogenetic position of the ornithischian dinosaur Stenopelix valdensis from the Lower Cretaceous of Germany and the early fossil record of Pachycephalosauria. Acta Palaeontologica Polonica 54 (1): 21-34.

Butler, R. J.; Liyong, L.; Jun, C. \& Godefroit, P. (2011): The postcranial osteology and phylogenetic position of the small ornithischian dinosaur Changchunsaurus parvus from the Quantou Formation (Cretaceous: Aptian-Cenomanian) of Jilin Province, north-eastern China. Palaeontology 54 (3): 667-683.

Dietrich, O. W. (1927): Über Fährten ornithopodider Saurier im Oberkirchner Sandstein. Zeitschrift der Deutschen Geologischen Gesellschaft 78 [for 1926] (4): 614-621.

Fischer, R. (1998): Die Saurierfährten im Naturdenkmal Münchehagen. Mitteilungen aus dem geologischen Institut der Universität Hannover 37: 3-59.

Grabbe, H. (1881): Neue Funde von Saurier-Fährten im Wealdensandsteine des Bückeberges. Verhandlungen des naturhistorischen Vereines der preussischen Rheinlande und Westfalens, Correspondenzblatt 38 (1): 161-164. [= Vierte Folge 8]

Grupe, 0. (1933): Blatt Bückeburg, Nr. 2017. Erläuterungen zur geologischen Karte von Preußen und benachbarter deutscher Länder, Lieferung 330: 69 pp.

Haubold, H. (1974): Die fossilen Saurierfährten. Die Neue Brehm-Bücherei 479. 168 pp.; Wittenberg (Ziemsen).

Hofe, A. vom (2006): Vier Prinzen zu Schaumburg-Lippe und das parallele Unrechtssystem. 390 pp.; Madrid (Vierprinzen, S.L.).

Hornung, J. J.; Andrade, M. B. de \& Reich, M. (2009): Are Goniopholis crassidens and G. simus different species of crocodilians? New postcranial evidence solving a taxonomic riddle. In $69^{\text {th }}$ Annual Meeting Society of Vertebrate Paleontology and the $57^{\text {th }}$ Symposium of Vertebrate Palaeontology and Comparative Anatomy (SVPCA), University of Bristol, Bristol, United Kingdom, September 23-26, 2009. Journal of Vertebrate Paleontology 29 (3) [suppl.]: p. 117A.

Hornung, J. J.; Böhme, A. \& Reich, M. (2012a): Excursion Guides A-C: The 'German Wealden' and the Obernkirchen Sandstone - an Introduction. In Richter, A. \& Reich, M. (eds.): Dinosaur Tracks 2011. An International Symposium, Obernkirchen, April 14-17, 2011. Abstract Volume and Field Guide to Excursions, 62-72; Göttingen (Universitäts-Verlag).

Hornung, J. J.; Böhme, A. \& Reich, M. (2012b): The type material of the theropod ichnotaxon "Bueckeburgichnus" maximus Kuhn, 1958 - reconsidered. In Richter, A. \& Reich, M. (eds.): Dinosaur Tracks 2011. An International Symposium, Obernkirchen, April 14-17, 2011. Abstract Volume and Field Guide to Excursions, p. 27; Göttingen (Universitäts-Verlag).

Hornung, J. J.; Böhme, A. \& Reich, M. (2012c): Excursion Guide B2: Wölpinghausen. In Richter, A.; Hübner, T. R. \& Reich, M. (eds.): Dinosaur Tracks 2011. An International Symposium, Obernkirchen, April 14-17, 2011. Abstract Volume and Field Guide to Excursions, 143-149; Göttingen (Universitäts-Verlag).

Hornung, J. J.; Karl, H.-V. \& Reich, M. (2012): A well-preserved isolated turtle footprint from the lowermost Cretaceous (Berriasian) of northern Germany. In Richter, A. \& Reich, M. (eds.): Dinosaur Tracks 2011. An International Symposium, Obernkirchen, April 14-17, 2011. Abstract Volume and Field Guide to Excursions, p. 28; Göttingen (Universitäts-Verlag).

Hornung, J. J.; König, J. \& Reich, M. (2012): The type material of the ankylosaurian ichnospecies Metatetrapous valdensis Nopcsa, 1923 (Early Cretaceous, northern Germany). In Richter, A. \& Reich, M. (eds.): Dinosaur Tracks 2011. An International Symposium, Obernkirchen, April 14-17, 2011. Abstract Volume and Field Guide to Excursions, p. 29; 
Göttingen (Universitäts-Verlag).

Hornung, J. J. \& Reich, M. (2011): The first record of a pterosaur ichnite from the lower Bückeberg Formation (Early Cretaceous) of Bückeburg, Lower Saxony, northern Germany. In Nagel, D. (ed.): 82. Jahrestagung der Paläontologischen Gesellschaft in Wien, Abstract Volume. Beiträge zur Paläontologie 32: 55-56.

Hornung, J. J. \& Reich, M. (2012): The croc puzzle: a fairly complete specimen of Goniopholis (Mesoeucrocodylia: Goniopholididae) from the Bückeberg Formation (Berriasian) of Bückeburg, northern Germany. In Richter, A. \& Reich, M. (eds.): Dinosaur Tracks 2011. An International Symposium, Obernkirchen, April 14-17, 2011. Abstract Volume and Field Guide to Excursions, p. 26; Göttingen (Universitäts-Verlag).

Huckriede, R. (1967): Molluskenfaunen mit limnischen und brackischen Elementen aus Jura, Serpulit und Wealden NWDeutschlands und ihre paläogeographische Bedeutung. Beihefte zum Geologischen Jahrbuch 67: 263 pp.

Karl, H.-V. \& Tichy, G. (2007): Zur frühen Geschichte der Paläocheloniologie von Schaumburg-Lippe. Die Rolle des Gymnasial-Professors Max Ballerstedt in der Naturwissenschaft. Berichte zur Wissenschaftsgeschichte 27: 285-296.

Karl, H.-V.; Gehler, A.; Roden, V. J. \& Reich, M. (2007a): Die Schildkröten des nordwestdeutschen „Wealden“ (Unter-Kreide: Berriasium) und ihre Paläoökologie. In Elicki, O. \& Schneider, J. W. (eds.): Fossile Ökosysteme. 77. Jahrestagung der Paläontologischen Gesellschaft. Kurzfassungen der Vorträge und Poster. Wissenschaftliche Mitteilungen, Institut für Geologie, TU Bergakademie Freiberg 36: 64-65.

Karl, H.-V.; Gröning, E.; Brauckmann, C. \& Reich, M. (2012): Ballerstedtia bueckebergensis, a new turtle from the Early Cretaceous Wealden facies of Germany (Testudines: Pleurosternidae). In Karl, H.-V. (ed.): Turtle faunal changes in Central Europe and related areas. Studia Palaeocheloniologica IV: 47-60. [= Studia geológica Salmanticensia, Volumen especial 9]

Karl, H.-V.; Staesche, U.; Tichy, G.; Lehmann, J. \& Peitz, S. (2007): Systematik der Schildkröten (Anapsida: Chelonii) aus Oberjura und Unterkreide von Nordwestdeutschland. In Staesche, U. (coord.): Fossile Schildkröten aus vier Ländern in drei Kontinenten. Geologisches Jahrbuch (B: Regionale Geologie Ausland) 98: 5-89.

Koken, E. (1886): Vorkommen fossiler Crocodiliden in den Wealdenbildungen Norddeutschlands und über die Systematik der mesozoischen Crocodiliden. Zeitschrift der Deutschen Geologischen Gesellschaft 38: 664-670.

Koken, E. (1887): Die Dinosaurier, Crocodiliden und Sauropterygier des norddeutschen Wealden. Palaeontologische Abhandlungen 3 (5): 1-111.

Kuhn, O. (1958): Die Fährten der vorzeitlichen Amphibien und Reptilien. 64 pp.; Bamberg (Meisenbach).

Lockley, M. G. (2000): An amended description of the theropod footprint Bueckeburgichnus maximus Kuhn 1958, and its bearing on the megalosaur tracks debate. Ichnos 7 (3): 217-225.

Martin, A. J. (2000): Flaser and wavy bedding in ephemeral streams: a modern and an ancient example. Sedimentary Geology 136 (1-2): 1-5.

Meyer, H. von (1841): Pholidosaurus schaumburgensis, ein Saurus aus dem Sandstein der Wald-Formation NordDeutschlands. Neues Jahrbuch für Mineralogie, Geognosie, Geologie und Petrefakten-Kunde [for 1841]: 443-445.

Meyer, H. von (1857): Beiträge zur näheren Kenntnis fossiler Reptilien. Neues Jahrbuch für Mineralogie, Geologie und Paläontologie [for 1857]: 532-543. 
Meyer, H. von (1859): Stenopelix Valdensis, ein Reptil aus der Wealden-Formation Deutschlands. Palaeontographica 7 (1): 25-34.

Nopcsa, F. (1923): Die Familien der Reptilien. Fortschritte der Geologie und Paläontologie 1 (2): 210 pp.

Pelzer, G. (1998): Sedimentologie und Palynologie der Wealden-Fazies im Hannoverschen Bergland. Courier Forschungsinstitut Senckenberg 207: 211 pp.

Salisbury, S. W.; Willis, P. M. A.; Peitz, S. \& Sander, P. M. (1999): The crocodilian Goniopholis simus from the Lower Cretaceous of north-western Germany. In Unwin, D. M. (ed.): Cretaceous fossil vertebrates. Special Papers in Palaeontology 60: 121-148.

Thulborn, R. A. (2001): History and nomenclature of the theropod dinosaur tracks Bueckeburgichnus and Megalosauripus. Ichnos 8 (3-4): 207-222.

Van Dijk, M.; Postma, G. \& Kleinhans, M. G. (2009): Autocyclic behaviour of fan-deltas: an analogue experimental study. Sedimentology 56 (5): 1569-1589.

Wright, L. D. (1977): Sediment transport and deposition at river mouths: A synthesis. Geological Society of America, Bulletin 88 (6): 857-868. 
Chapter IV

Vertebrate tracksites in the Obernkirchen Sandstone (late Berriasian, Early Cretaceous) of northwest Germany - their stratigraphical, palaeogeographical, palaeoecological, and historical context 
Published in:

Paläontologische Zeitschrift, 86: 231-267 [2012]. Open access: DOI: 10.1007/s12542-012-0131-7

Vertebrate tracksites in the Obernkirchen Sandstone (late Berriasian, Early Cretaceous) of northwest Germany - their stratigraphical, palaeogeographical, palaeoecological, and historical context

\title{
JAHN J. HORNUNG ${ }^{1}$, ANNINA BÖHME ${ }^{1}$, TORSTEN VAN DER LUBBE ${ }^{2}$, MIKE REICH ${ }^{3}$, and ANNETTE RICHTER $^{2}$
}

${ }^{1}$ Geowissenschaftliches Zentrum, Abt. Geobiologie, Georg-August-Universität Göttingen, Goldschmidtstr. 3, 37077 Göttingen, Germany

${ }^{2}$ Niedersächsisches Landesmuseum Hannover, Willy-Brandt-Allee 5, 30169 Hannover, Germany

${ }^{3}$ Geowissenschaftliches Zentrum, Museum, Sammlungen and Geopark, Georg-August-Universität Göttingen, Goldschmidtstr. 1-5, 37077 Göttingen, Germany

\begin{abstract}
The northern German Lower Cretaceous Bückeberg Formation yields numerous dinosaur tracksites, some of which have produced material of impressive quality. Stratigraphically, the localities are concentrated in the Obernkirchen Sandstone, a thin subunit within this formation. The Obernkirchen Sandstone represents mainly a sandy barrier to back-barrier and lagoonal setting within a limnic deltaic facies complex, which was deposited during the late Berriasian (Cypridea alta formosa ostracod subzone) in the southeast of the Lower Saxony Basin, northwest Germany. A few tracksites occur more proximally in coeval fluvial deposits. Dinosaur footprint assemblages were left by ornithopods, theropods, sauropods, ankylosaurs, and small, bipedal ornithischians. Other vertebrate tracks are those of turtles and, possibly, crocodilians. Due to the decrease in sandstone quarrying in recent decades, many old tracksites are inaccessible today. Additionally, historical descriptions of the tracks were of highly variable quality and often published in remote and today nearly unobtainable sources. Here we provide a catalogue of 13 tracksites compiled from the literature and some new observations. Of these 13 tracksites, only five are still accessible and currently under study. Descriptions of each locality are provided, with a comprehensive compilation of existing data on lithofacies, stratigraphy, palaeogeography and palaeoecology of the Obernkirchen Sandstone and equivalent strata. A short review of the track-bearing lithofacies assemblage indicates that the outcrop areas have distinctly different facies and environments, and, therefore, track-bearing horizons can only be correlated stratigraphically between adjacent outcrops. For this reason, the identification of a megatracksite in the Obernkirchen Sandstone is currently regarded as premature and uncertain.
\end{abstract}




\section{Kurzfassung}

Die unterkretazische Bückeberg-Formation Nordwest-Deutschlands ist reich an Fundstellen von Dinosaurierfährten, von denen einige hervorragend erhaltenes Material lieferten. Diese Fundstellen sind stratigraphisch auf ein geringmächtiges Intervall, den Obernkirchen-Sandstein, konzentriert. Der Obernkirchen-Sandstein repräsentiert eine sandige Barrieren- und Lagunen-Fazies innerhalb eines limnisch-deltaischen Fazieskomplexes, der während des späten Berriasiums (Cypridea alta formosa Ostrakoden-Subzone) im Südosten des Niedersächsischen Beckens abgelagert wurde. Einige Fährtenfundstellen liegen auch in etwas proximaleren, gleichaltrigen, fluviatilen Ablagerungen. Erzeuger der Dinosaurierfährten waren Ornithopoden, Theropoden, Sauropoden, Ankylosaurier sowie kleine, bipede Ornithischia. Weitere Wirbeltier-Fährten wurden von Schildkröten und möglicherweise Krokodilen hinterlassen. Aufgrund des Rückgangs im SandsteinAbbau im Verlauf der vergangenen Jahrzehnte sind viele der alten Fährten-Fundstellen heute nicht mehr aufgeschlossen. Historische Beschreibungen sind von unterschiedlicher Qualität und häufig nur in schwer erhältlichen Quellen publiziert. Hier präsentieren wir einen Katalog mit 13 Fundstellen, zusammengestellt aus Literaturquellen und neuen Untersuchungen. Nur fünf Fundstellen sind heute noch zugänglich und derzeit Gegenstand weiterer Forschungen. Sämtliche Fundstellen werden vorgestellt und der Kenntnisstand über Lithofazies, Stratigraphie, Paläogeographie und Paläoökologie des Obernkirchener Sandsteins zusammengefasst. LithofaziesDaten zeigen, dass eine feinstratigraphische Korrelation individueller Horizonte innerhalb des Sandstein-Komplexes nur zwischen sehr eng benachbarten Aufschlüssen möglich ist und deutliche Faziesunterschiede zwischen den Fährtenvorkommen bestehen. Daher erscheint die derzeitige Datengrundlage als nicht hinreichend, um den Obernkirchen-Sandstein in seiner Gesamtheit als Megatracksite zu charakterisieren.

\section{Introduction}

The Berriasian Bückeberg Formation is well-known for its wealth of dinosaur tracks (Ballerstedt 1905; Dietrich 1927; Lehmann 1978), but their documentation is mostly confined to isolated specimens or localities. Important discoveries of the last two decades are mostly reported in general overviews or abstracts (Wings et al. 2005a; Lehmann 2006; Lehmann et al. 2006; A. Richter et al. 2007; U. Richter et al. 2007; Richter et al. 2009; Richter 2007; Böhme et al. 2009; van der Lubbe et al. 2009).

Nearly all tracksites from the Bückeberg Formation are located stratigraphically within the Obernkirchen Sandstone, a thin subunit exposed in the northern and western vicinities of Hannover. At least since early medieval times, this sandstone has been a valued dressing stone and building material. Intensive quarrying since the 11th century AD led to the use of the nearly pure quartzose sandstone in hundreds of buildings and monuments across northern Germany, Europe, 
and in places as far abroad as Jakarta, Indonesia (Hamm 1938; Graupner 1977; Harnack 1989; Broschinski 2004). Since the beginning of the 19th century, this formation became increasingly well-known as a lagerstaette for rare but well-preserved Cretaceous vertebrates, including turtles, crocodiles, and dinosaurs (e.g. Roemer 1836; von Meyer 1841, 1857, 1859; von Meyer in Dunker 1846).

Although extremely abundant and probably known to quarry workers for centuries, reliable accounts of dinosaur tracks were not reported before the middle of the 19th century. According to Grabbe (1881), the mining supervisor Heidtmeier reported the occurrence of a trail of consecutive tracks more than $100 \mathrm{~m}$ long which was uncovered in a quarry near Wendthagen in the 1850s. Unfortunately, there are no other records of this find.

In 1879, the first dinosaur tracks reported from Germany rather sneaked into the scientific record. At the December meeting of the Deutsche Geologische Gesellschaft (German Geological Society), held on 3 December 1879, in Berlin, Wilhelm Hauchecorne presented a letter and a drawing by mining engineer Fritz F. von Dücker, in which he reported the discovery of "bird tracks" in the Bad Rehburg area. At the same meeting, Wilhelm Dames commented that these tracks were very similar to those from the English Wealden, which had been identified as dinosaur tracks shortly before. Both contributions consisted of a single sentence each, included in the published proceedings of the meeting (Dames in Beyrich et al. 1879; Hauchecorne in Beyrich et al. 1879).

The geologist Carl Struckmann was the first researcher to provide a scientific description of these tracks. During the summer of 1879, more tracks were found at Wölpinghausen (Rehburg mountains, see locality 4 below) and immediately vividly discussed in local press reports (Anonymous 1879a, b). These early discussions, led mostly by Struckmann, centred around a "birdlike" animal as a potential trackmaker. This view was not left unchallenged-in fact, the ornithologist Wilhelm Pralle suggested the tridactyl imprints had been made by the mani (!) of giant anurans (Anonymous 1879b). In 1880, Struckmann substantiated his results and published the first papers on the "Ornithoidichnites", referring them to the dinosaur Iguanodon (Struckmann 1880a, b).

To corroborate his identification, Struckmann sent a gypsum cast of one of the tracks to Louis Dollo, in Brussels, who was the most important authority on Iguanodon at the time, and was studying the famous "herd" of this dinosaur found at the Bernissart coal mine in 1878. Dollo (1883: 113) reported a perfect match of this track with the pedal skeleton of a specimen he identified as Iguanodon mantelli.

At least two specimens of Struckmann's material are still preserved in the Niedersächsisches Landesmuseum, Hannover. One right pes impression of a large ornithopod (NLMH 105.747, Fig. IV.1) can be identified as the specimen which was deemed an exception by him, as he believed it was tetradactyl instead of tridactyl (Struckmann 1880a: 99, pl. V, fig. 1; here Fig. IV.1b). This identification of the specimen seems to be well substantiated, although the figure by Struckmann was quite schematic in some details and the proportions of the footprint and the supposed "hallux" seems not to have been depicted entirely correctly by him. Subsequent studies (e.g. Grabbe 1883; Koken 1887; Ballerstedt 1914; Dietrich 1927) doubted the interpretation of the "hallux". The specimen as preserved today (Fig. IV.1a) supports the observation by Ballerstedt (1914) that the "first digit" is in fact a poorly preserved footprint over-stepped and deformed by the large, typically 


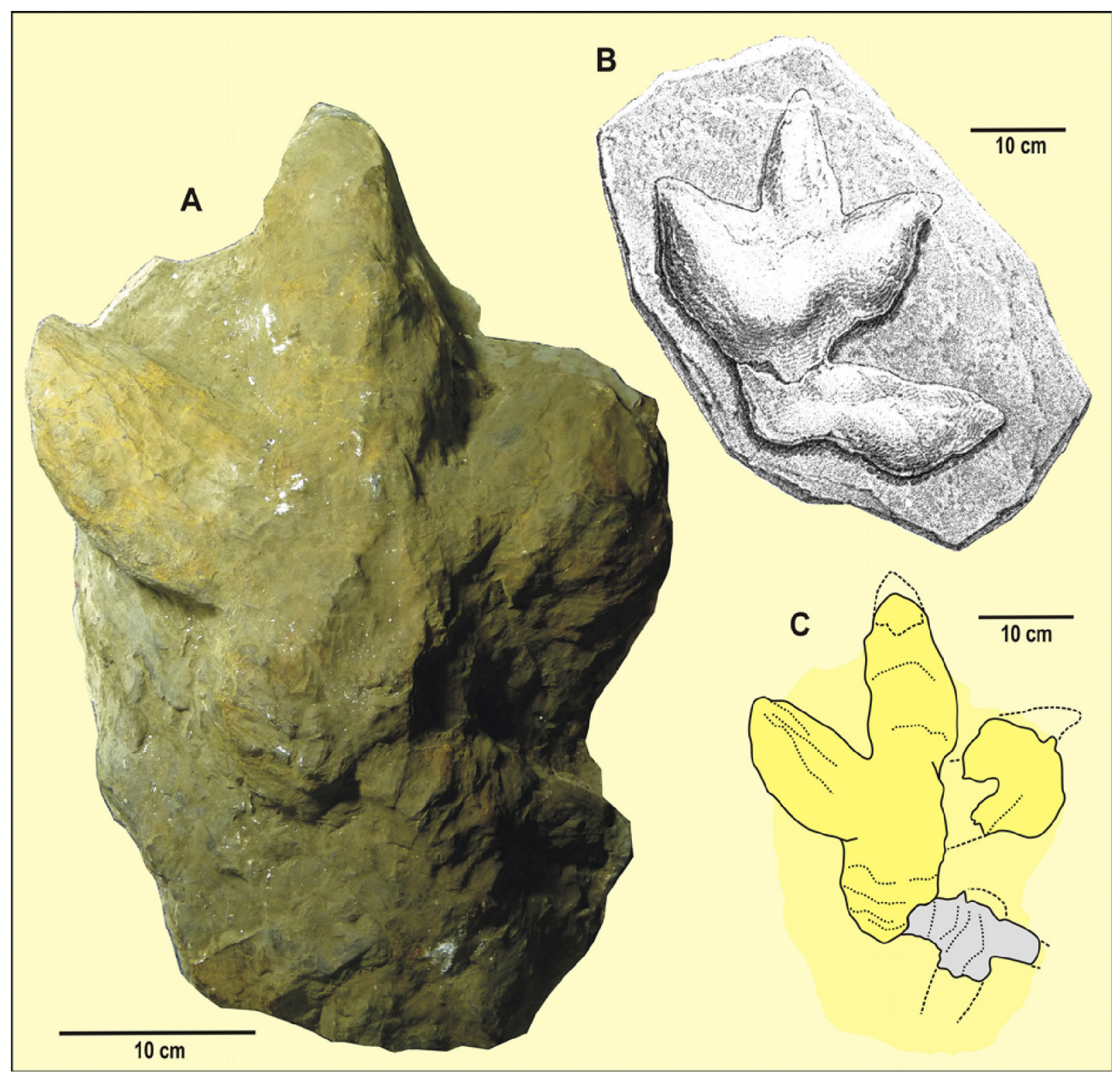

Fig. IV.1 Right pes impression (hypichnial relief) of a large ornithopod (NLMH 105.747), Bückeberg Formation, Obernkirchen Member, Obernkirchen Sandstone. Most probably an original specimen of Struckmann (1880a), collected in the summer of 1879 from the quarry of A. Spörl near Wölpinghausen, Rehburg Mountains, Lower Saxony (locality 4). This is, historically, the first footprint to be identified as having been left by a dinosaur in Germany and is still preserved in a public collection. a Specimen as preserved today; b Specimen as drawn by Struckmann (1880: pl. $\mathrm{V}$, fig. 1). The structure below the footprint was interpreted as a hallux impression by C. Struckmann. This interpretation was rejected by subsequent scientists; c New interpretation of the specimen (drawing). The greyshaded structure is interpreted as the remains of a much smaller tridactyl(?) footprint, overstepped by the ornithopod heading in the opposite direction. 
tridactyl, ornithopod footprint (Fig. IV.1c). It is the historically oldest find of a dinosaur track from Germany still preserved in a public collection. Identification of the second specimen (NLMH 105.746) is not as straightforward, because it cannot be directly identified as one of those depicted by Struckmann. However, he collected far more material than he figured, and the size, proportions, and morphological details of the specimen suggest that it belonged to a trackway from which he figured two other, subsequent footsteps, preserved on a single sandstone slab which is currently lost (Struckmann 1880a: 98-99, pl. IV, fig. 1, 1880b: 127, pl. IV).

Struckmann's discoveries were followed shortly by those of Grabbe $(1881,1883)$, who identified dinosaur tracks in many localities in the Bückeberge and Harrl areas.

Over the following decades, numerous reports were published of tracksites in the outcrop area of the Obernkirchen Sandstone. Most of these appeared in hard-to-obtain local journals, some of them even in newspapers, and they are almost exclusively written in the German language. Additionally, in many cases, the original material was considered lost, hampering modern revisions (Haubold 1971, 1974, 1984; Lockley 2000; Thulborn 2001).

The historical collection of the Gymnasium Adolfinum Bückeburg and the Max Ballerstedt private collection are highly important in investigations of Berriasian dinosaur tracks from Germany. Although a few specimens from these collections date back to the 1840s, the bulk of the material was collected between ca 1900 and 1940 by the teacher and amateur palaeontologist Max Ballerstedt (1857-1945). The collection includes a large number of footprints (mostly natural casts), some of which were original specimens of Ballerstedt's publications (see also Thulborn 2001). However, after Ballerstedt's death in 1945, the collection suffered from lack of care and attendance shortly after World War II (Probst and Windolf 1993; Hornung and Reich 2007). Most of what survived is stored in the collections of the Geoscience Centre of the University of Göttingen. A detailed inventory or catalogue of the Ballerstedt collection is currently incomplete. In an ongoing project, this gap is to be filled and many of Ballerstedt's specimens, thought to be lost, have recently been located and are, in fact, not lost (Hornung and Reich 2006, 2007; Hornung et al. 2007).

In addition to classical works and material, new evidence has been gathered from the Obernkirchen Sandstone, beginning with the discovery of sauropod tracks in 1979 (Hendricks 1981; Fischer 1998) and culminating in continuing excavations at several localities, immensely increasing the amount of data (A. Richter et al. 2007; U. Richter et al. 2007; Richter et al. 2009; Böhme et al. 2009; van der Lubbe et al. 2009).

The objective of this paper is to comprehensively survey of the known localities of vertebrate tracks in the Obernkirchen Sandstone and to provide an up-to-date account of the stratigraphical and palaeoenvironmental data of this remarkable formation. This should serve as easy access to older locality descriptions and as a basis for further investigation of ichnological issues in this formation. The identification of these occurrences as a megatracksite in the Obernkirchen Sandstone (as proposed by Diedrich 2004) is also discussed. 
Abbreviations

Institutional abbreviations BGR Bundesanstalt für Geowissenschaften und Rohstoffe, Hannover, Germany; GPMH Geologisch-Paläontologisches Museum, Universität Hamburg, Germany; GZG Geowissenschaftliches Zentrum, Georg-August-Universität Göttingen, Germany; NLMH Niedersächsisches Landesmuseum, Hannover, Germany.

Palaeogeographical and stratigraphical abbreviations DP: 'Dachplatte', hf: Hauptflöz (main coal seam), LSB: Lower Saxony Basin (Niedersächsisches Becken), OHS: Oberer Hauptsandstein (Obernkirchen Sandstone sensu stricto), UHS: Unterer Hauptsandstein.

General abbreviations H: Hochwert (northing, Gauss-Krüger coordinate system), R: Rechtswert (easting, Gauss-Krüger coordinate system).

\section{Geology and environment of the Bückeberg Formation}

Exposure and stratigraphy

The Bückeberg Formation is buried beneath younger deposits across wide areas of Lower Saxony but is exposed in local uplifts, for example the mountainous areas of the Bückeberge, the Deister, the Rehburg Mountains, the southeastern Süntel, the Osterwald, and the Hils mountains (Fig. IV.2). South and west of the Weser Valley, it has been completely eroded. The Obernkirchen Sandstone forms a thin interval within the Obernkirchen Member, the lower member of the Bückeberg Formation, stretching in a SW to NE striking belt between the River Weser in the west and Hannover in the east. In most areas where outcrops of Obernkirchen Sandstone are revealed it was quarried, especially for high-quality building stones. Additionally, thin coal seams are intercalated with the sandstones and have been mined in shallow subsurface mines since the 13th century AD until the 1960s (Falke 1944; Graupner 1980). However, following the decline of both industries, mining has been completely abandoned and quarrying substantially reduced, leading to a decrease in accessible outcrops.

The Bückeberg Formation (Casey et al. 1975, traditionally referred to as the 'German Wealden', Hoffmann 1830, Fig. IV.3) comprises the middle Berriasian through early Valanginian sedimentary infill of the Lower Saxony Basin (LSB, Fig. IV.4). It is underlain by evaporitic marlstones of the Tithonian through lower Berriasian Münder Formation and overlain by Valanginian marine deposits (Kemper 1973; Strauss et al. 1993; Mutterlose 1997a, 2000). The predominantly limnic nature of the Bückeberg Formation hampers exact correlation with the marine Berriasian outside the basin (Mutterlose 1997a). Internal correlation is provided by ostracod biostratigraphy (Wolburg 1949, 1959; Elstner and Mutterlose 1996). Older lithostratigraphical schemes use a subdivision into six units (W[ealden]1 to W6, Wolburg 1949). Current schemes (Elstner and Mutterlose 1996; Mutterlose 1997a, 2000) use subdivision into a basal Obernkirchen Member (corresponding to the W1 to W4) and the overlying Osterwald Member (W5 to W6). 


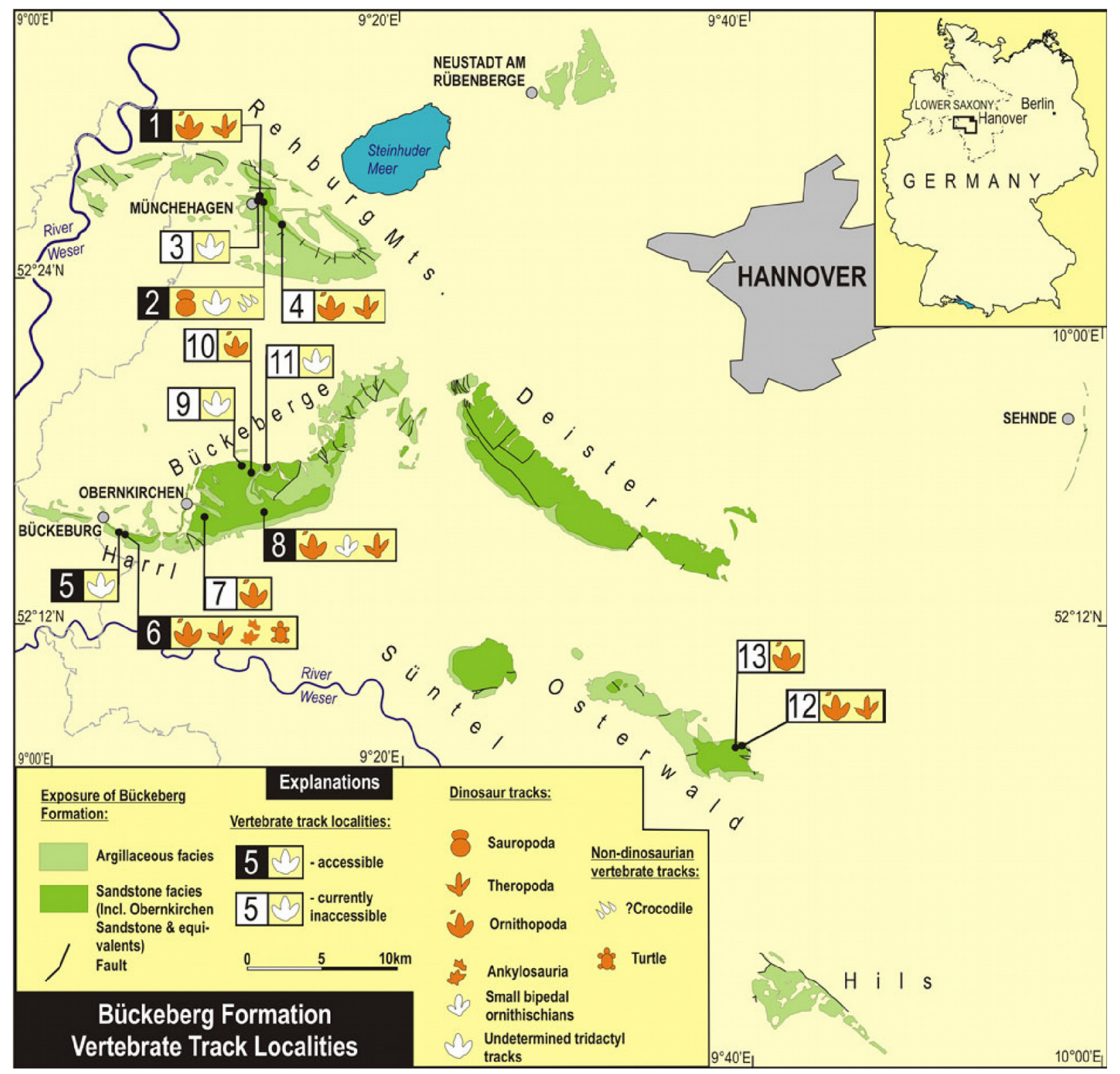

Fig. IV.2 Distribution of vertebrate tracksites in the Bückeberg Formation. Numbers refer to the locality numbers in the text.

The Obernkirchen Member can be subdivided into a fine-grained argillaceous basin facies and a marginal, sandy facies. The fine-grained basinal facies reaches a thickness of up to $700 \mathrm{~m}$ in the basin centre. It consists of siltstones, mudstones, and black shales. In the entire succession, thin carbonate layers are occasionally interbedded, mostly composed of mollusc coquinas (Neomiodon spp. and gastropods).

The marginal facies attains a thickness of up to $200 \mathrm{~m}$ along the southeastern basin margin, and accumulates especially in two sedimentary wedges (Fig. IV.4), an eastern one in the Hannover area and a western one in the Osnabrück area (North Rhine-Westphalia, Kauenhowen 1927). The western sediment wedge (Riegel and Lill 1988; Lill and Riegel 1991; Wilde and Schultka 1996) has so far yielded only one tridactyl cast (hypichnium), found in a field near Hilter-Borgloh (Anonymous 
Fig. IV.3 Stratigraphy, lithofacies, and environment of the basal Early Cretaceous in NW Germany. Ostracods: C. $=$ Cypridea, $M .=$ Macrodentina, $P$. = Pachycytheridea. After Kemper 1973; Strauss et al. 1993; Elstner and Mutterlose 1996; Gramann et al. 1997; Mutterlose 1997a, 2000; and others, modified.

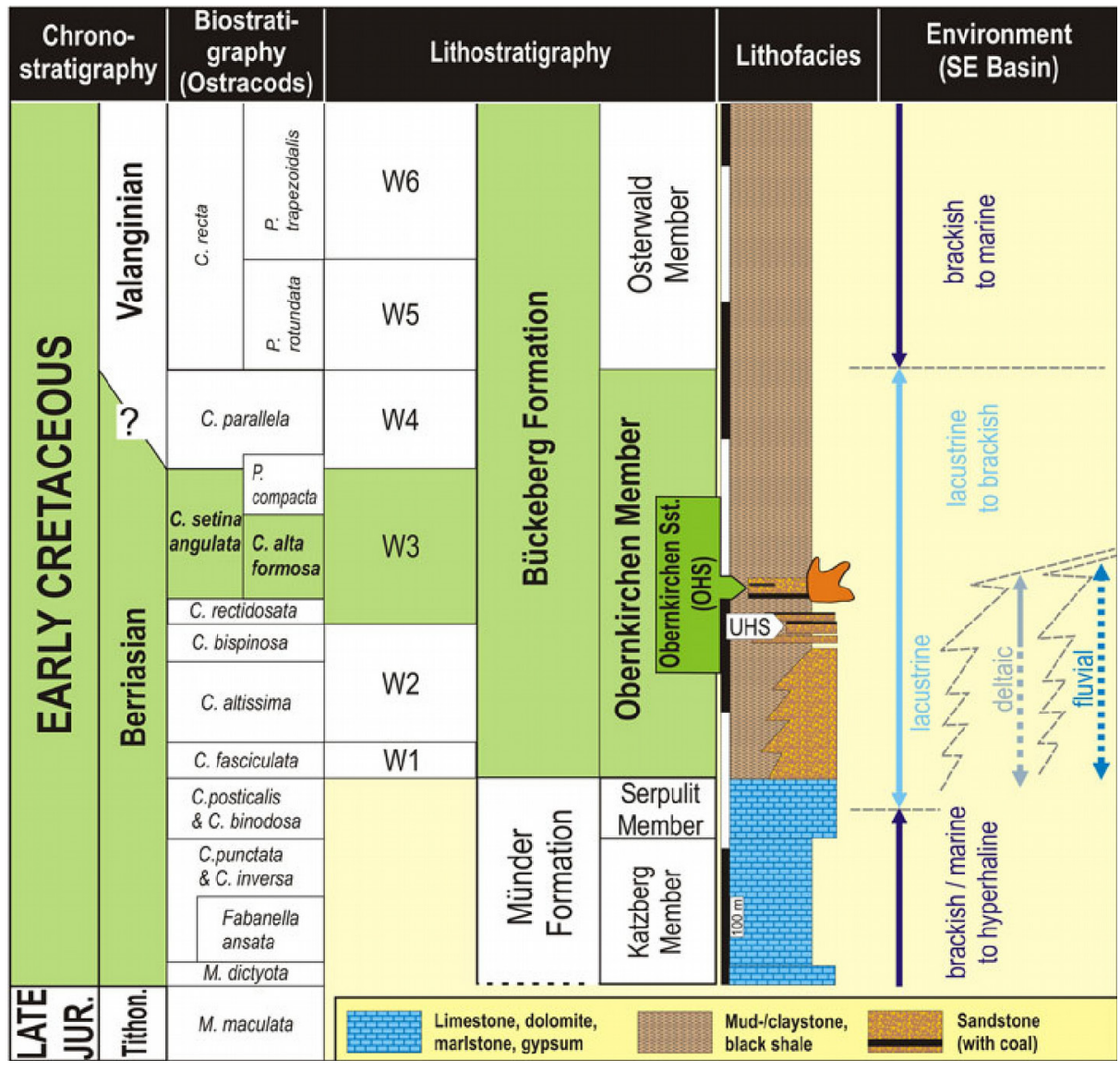

Fig. IV.4 Berriasian palaeogeography (after Schott et al. 1967, 1969; Kemper 1973, Pelzer 1998, modified) and vertebrate tracksite occurrences in the Lower Saxony Basin.

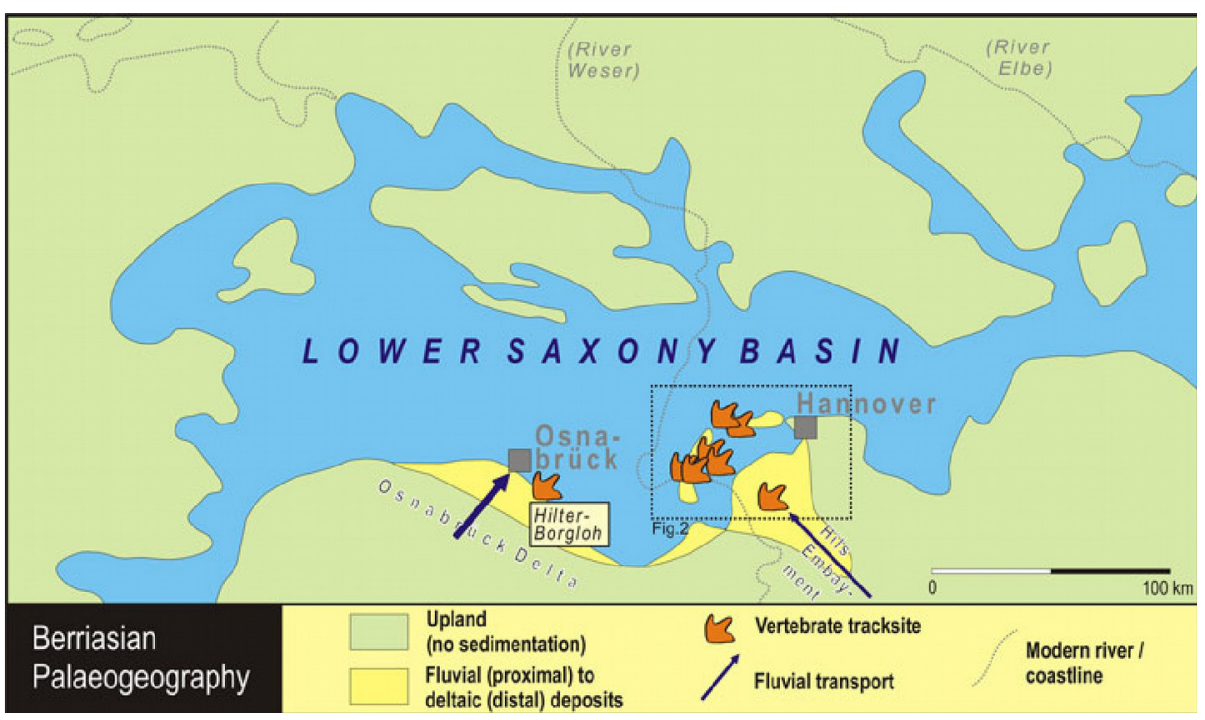

2005). This single, yet undescribed record suggests that the southwestern part of the basin margin may also be a significant source of dinosaur tracks. However, all other finds are from the eastern wedge, and the discussion herein will be restricted to this region.

The eastern sediment wedge fills a southeastern extension of the LSB, the Hils Embayment (Fig. IV.4). Its distalmost outreaches consist of two sandstone tongues, a lower one (Unterer 
Hauptsandstein, UHS, Figs. IV.3, IV.5) and an upper one (Oberer Hauptsandstein, OHS, Figs. IV.3, IV.5, IV.6b), separated by 10-25 m of fine-grained sediments. The UHS attains a thickness of 2-5 m, the OHS of 10-20 m. Proximally, along a SE-NW trending depositional axis, an increasing number of thin sandstone layers become intercalated below, between, and above the UHS and OHS. The OHS is equivalent to the Obernkirchen Sandstone sensu stricto and the latter term is used herein exclusively as a synonym of the OHS.

Thin intercalated coal seams are common throughout the Obernkirchen Sandstone and its equivalents, including the Osterwald and Hils mountains (Falke 1944; Graupner 1980; Pelzer et al. 1992). They were used in early attempts at detailed intraformational lithostratigraphy of the sandstone succession across the Rehburg Mountains, Bückeberge, and Harrl hill (Grabbe 1883; Grupe 1933; Falke 1944; Graupner 1980). Up to five superimposed, cm to dm-thick coal seams have been reported intercalated with the sandstones (Figs. IV.5, IV.6). However, lateral correlation of these coal seams spanning wider distances is questionable. Only the most important Hauptflöz (main seam, hf in Figs. IV.5, IV.6) can be traced below the Obernkirchen Sandstone across the Bückeberge, where a prominent coal layer, up to $80 \mathrm{~cm}$ thick, is embedded at the base of the sandstone complex. A similar situation is present at the Rehburg Mountains, where the thickest seam is located at the base of the sandstone succession, suggesting a potential correlation. The coal seams in the outcrops at Harrl hill are intercalated within a different lithofacies succession and previous correlation attempts, for example that by Grupe (1933), are still very weakly supported.

In many outcrops and subsurface logs, the Hauptflöz is separated from the overlying Obernkirchen Sandstone by a 0.5-1.5 m fine-grained interval, the 'Dachplatte' (DP, Figs. IV.5, IV.6b). This unit is locally very fossiliferous and has yielded especially rich plant and vertebrate remains (Grabbe 1883; Dames 1884a).

The distal sandy complex correlates biostratigraphically with the Cypridea alta formosa ostracod subzone (upper Berriasian, Elstner and Mutterlose 1996) and is nested well within the lower part of W3. Diedrich (2004) assigned the upper part of the Obernkirchen Sandstone at the Obernkirchener Sandsteine GmbH quarry (locality 8) to the W4 (C. jonesi/C. parallela ostracod biozone). However, this is not in agreement with other stratigraphical schemes (Jordan 1979), and because Diedrich (2004) did not provide any data or rationales for his correlation, it is not followed herein.

South of Hannover, the sandy facies increasingly dominates and conglomerate layers are rarely intercalated (Struckmann 1880a). Because of the lack of adequate lithostratigraphical and biostratigraphical marker-beds, exact correlation of the UHS and OHS with the more proximal sandy beds toward the SE is not possible.

The overlying Osterwald Member shows a retrogradational facies trend with a margin-ward onlap of the fine-grained basin facies. A marginal, coarse-grained facies is restricted to the southeasternmost region of the Hils Embayment (Pelzer 1998). 


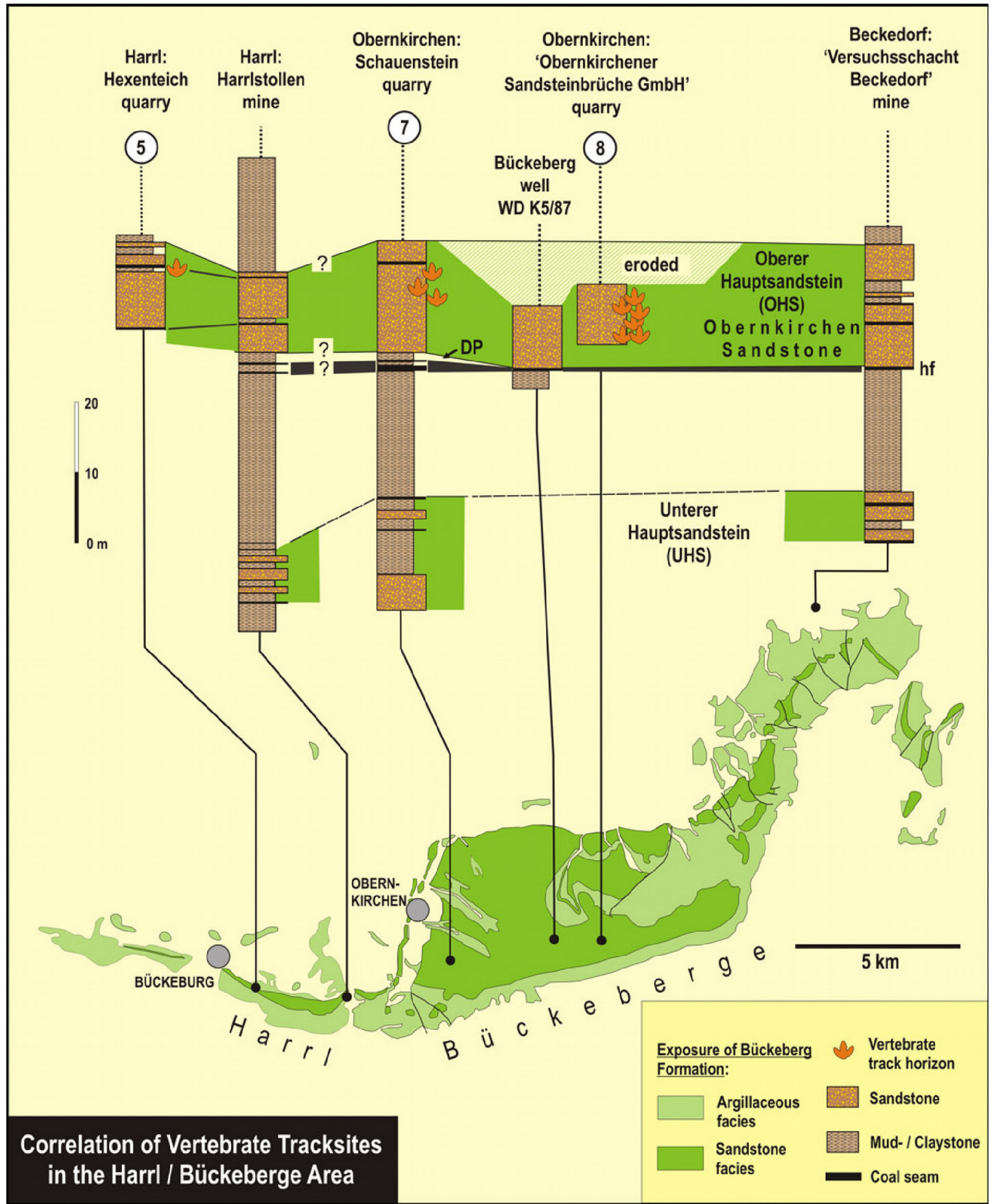

Fig. IV.5 Lithostratigraphical correlation of outcrops in the Bückeberge and Harrl areas. Note the weakly supported correlation of the track-bearing beds of Harrl hill with those of the central Bückeberge. Encircled numbers refer to locality numbers in text. Lithological data after Dietrich 1927, Grupe 1933, Pelzer 1998, and our own observations. 


\section{Palaeogeography}

The LSB (Fig. IV.4) is an adjacent subbasin of the North German Basin, which stretches across most of central northern Germany and westwards into the eastern part of The Netherlands (Schott et al. 1967, 1969). Its subsidence began during the Late Jurassic and continued into the early Late Cretaceous, when it was terminated by basin inversion (Betz et al. 1987; Bachmann and Grosse 1989).

Communication of the LSB with the main North German Basin was maintained only through narrow gateways in the SW, W, and E (Schott et al. 1967, 1969). The basin fill facies was governed primarily by eustatic sea level fluctuations and/or local tectonic opening of gateways which connected or unconnected the LSB from the Tethys and Boreal Ocean (Kemper 1973, 1992; Elstner and Mutterlose 1996; Mutterlose and Bornemann 2000). Following disconnection from marine influx, after deposition of the marine-brackish to hyperhaline upper Münder Formation (early Berriasian, Arp and Mennerich 2008), short-time ingressions occurred from the W and SW (Holland) during the latest W2 and throughout W3 (Elstner and Mutterlose 1996; Mutterlose and Bornemann 2000; Berner et al. 2010; Berner 2011) resulting in a W-E-decreasing salinity gradient across the LSB. The eastern part remained oligohaline until the latest Berriasian or earliest Valanginian (W4) when marine microfaunas occur temporarily in the eastern part of the basin also (Martin 1961a; Mutterlose and Bornemann 2000). On a secondary scale, the LSB facies and palaeogeography were controlled by autocyclical processes, including local tectonics (including halotectonics and subrosion of Permian evaporites), differential subsidence, and intra-basinal, climatically controlled base-level fluctuations during phases of disconnection from the global sealevel (Mutterlose and Bornemann 2000). These factors dominated the sedimentation within the LSB from the Jurassic/Cretaceous boundary well through the latest Berriasian.

After local highstand and marine flooding of most of the incipient LSB during the Late Jurassic (Gramann et al. 1997; Kästner et al. 2008), a major fall in sea level and early basin subsidence led to isolated, shrinking perimarine water bodies in the developing LSB during deposition of the Tithonian through earliest Berriasian Münder Formation. These beds were regarded as the equivalent of the English Purbeck beds in the 19th and early 20th century literature (Struckmann 1880a). The lower part of the Münder Formation is dominated by marlstones, locally evaporitic (Katzberg Member) and contains low-diversity faunal assemblages with dominant local biostromes of the sedentary polychaete Serpula coacervata (Blumenbach, 1803) and increasing influx of freshwater in the upper part of the Münder Formation (Serpulite Member, Borberg Member; Arp and Mennerich 2008).

During early to mid-Berriasian times, precipitation increased and a lacustrine water body began to spread in the basin centre, fed by river systems draining the basin margins and uplands (Pelzer 1987; Pelzer and Wilde 1987; Pelzer et al. 1992; Wilde et al. 1995). The river systems reached substantial dimensions with meandering beds and extensive belts of well-vegetated floodplain deposits, backswamps, and associated lakes, as documented by related deposits in the southeast of the LSB (Pelzer 1984; Pelzer et al. 1992). The relatively undisturbed succession of fine-grained deposits in the basin centre (Kemper 1973) suggests that a central lake was continuously present 


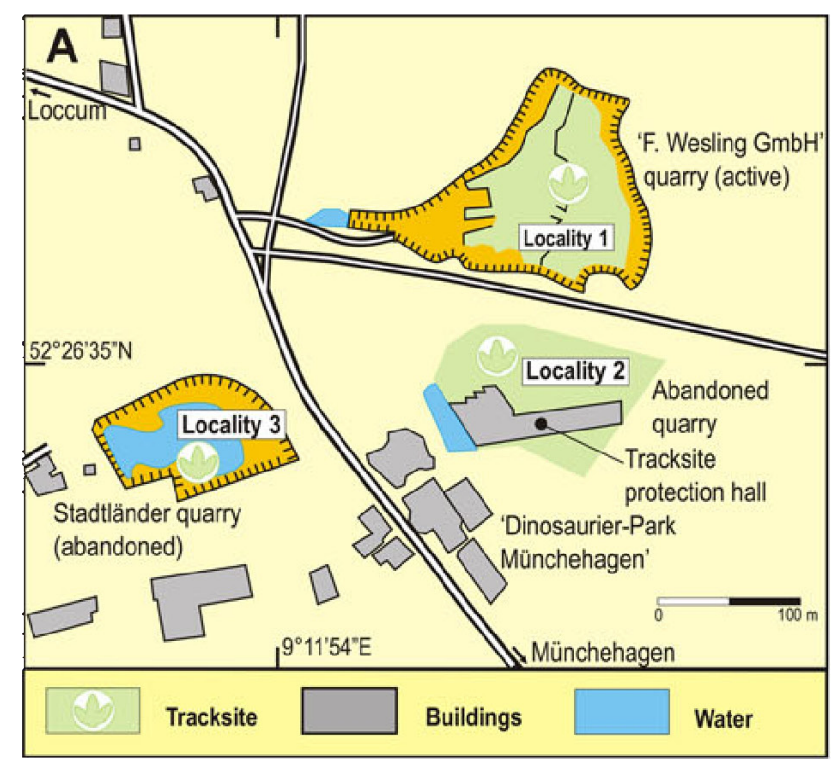

B

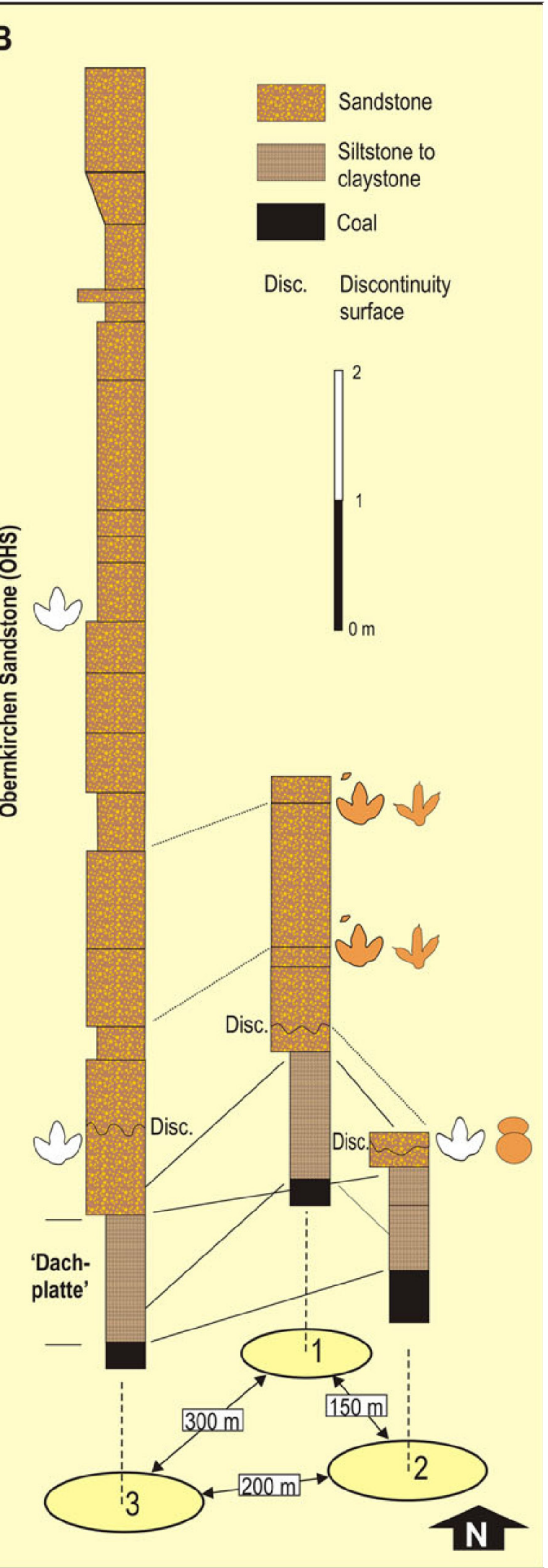

Fig. IV.6 a Geographical overview of the tracksites near Münchehagen (localities 1-3, Rehburg Mts.); b Simplified lithological logs of localities 1-3, showing lateral correlation and track horizons.

Lithological data after Wilde et al. 1995, Fischer 1998, Pelzer 1998, and our own observations. Track symbols are explained in Fig. IV.2. 
throughout the Berriasian. However, transgressive-regressive patterns of this lake are not well known. Transgressive sequences can be traced in parts of the succession and an overall expansion of the lake is assumed for most of its existence. The fluvial facies is exposed in the Hils and Osterwald mountains (Pelzer 1984, 1998; Pelzer et al. 1992; Riegel et al. 1986).

It is of importance to note that the vertebrate track-bearing deposits of the Obernkirchen Sandstone are all located within this limnic depositional system, contrary to a few publications (Diedrich 2004; Lockley et al. 2004) which regard this as marginal-marine in origin.

In the Osterwald mountains, fluvial large-scale cross-stratified, up to $12 \mathrm{~m}$ thick (channel-fill?) sandstones (Obernkirchen Member) are abruptly overlain by a thin conglomerate, interpreted as a transgressional beach deposit, passing upwards into perideltaic brackish-marine sediments (Osterwald Member; Waldeck 1969; Pelzer 1998). Palynological data suggest that the marginal river systems were still active in Valanginian times (Pelzer 1984) when the basin centre was reoccupied by marine waters because of eustatic sea level rise.

At least one fluvial system apparently occupied the axis of the Hils Embayment. The system terminated downstream in the Bückeburg-Bad Rehburg-Hannover area, where an extensive, shallow-water deltaic system (Kauenhowen 1927; Graupner 1980; Pelzer et al. 1992; Pelzer 1998) became established during the mid- to late Berriasian. This system is represented by the distal reaches of the Hannover sedimentary wedge. The sandstones and intercalated fine-grained sediments preserve a diverse assemblage of sedimentary facies, representing several subenvironments. Pelzer (1998) proposed a barrier/back-barrier setting for the Obernkirchen Sandstone with severe storm events as an important landward transport mechanism for reworked and matured terrigenous sand in this microtidal environment. Current work suggests that the Obernkirchen Sandstone encompasses several facies assemblages, including back-barrier storm deposits in the Rehburg Mountains and a landward deltaic succession in the southern and western Bückeberge (see the discussion below).

On the landward side of the lagoons, swamps existed, passing into peat-bogs and vegetated areas on emergent and stabilised interchannel and interlagoonal islands (Wilde et al. 1995; Pelzer et al. 1992; Pelzer 1998).

The dinosaurs apparently passed across the shore-face, back-barrier, deltaic and alluvial flats, and through shallow lagoonal waters. The preservation of multiple, vertically stacked barrier and lagoonal deposit successions within the Obernkirchen Sandstone and abundant interbedded palaeosols and authochthonous coal seams indicate a long-term net aggrading sedimentary regime under transgressive conditions, favouring also the preservation of vertebrate tracks. However, erosional discontinuities on a local scale have been reported in some outcrops (Fischer 1998; Pelzer 1998).

\section{Palaeoecology}

The only well-studied microfaunal group are the ostracodes, which provide the biostratigraphic 
framework of the non-marine Berriasian (Martin 1940, 1958, 1961b; Wolburg 1949, 1959, 1962, 1971; Schudack and Schudack 2009).

The invertebrate macrofauna in the lagoonal deposits is dominated by mollusc assemblages (predominantly Unionidae, Neomiodontidae and various gastropods; Dunker 1846, 1849; Struckmann 1880a; Huckriede 1967). Modern detailed taxonomic and diversity studies of these groups are still lacking. Abundant endobenthic invertebrate trace fossils (Schwennicke 1998) indicate normally oxygenated conditions for the lagoonal water bodies in the Münchehagen area.

Aquatic vertebrates are represented by elasmobranchians (hybodontoid, petalodontid, and neoselachian sharks) and several species of actinopterygian fishes, including members of Semionotiformes, Pycnodontiformes, Amiiformes, and Pholidophoriformes (Dunker 1846; Struckmann 1880a; Branco 1887; Martin and Weiler 1954; Schultze 1970; López-Arbarello et al. 2007, Nyhuis and Herbig 2009). A maximum of fish diversity is known from concentrated, tempestitic bone-beds, deposited in the Osterwald Member in the western, deeper basin (Nyhuis and Herbig 2009). In the southeastern, sandy facies of the Obernkirchen Member, the known fish fauna is so far confined to hybodontoid sharks (fin spines, teeth, and egg capsules) and semionotids (including some splendid specimens of "Lepidotes" mantelli Agassiz, 1833; see Branco 1887; LópezArbarello et al. 2007).

Plesiosaurs also inhabited the LSB, including Brancasaurus brancai Wegner, 1914 known from a rather complete skeleton from the Osterwald Member of Gronau/Westphalia (Wegner 1914). Isolated plesiosaur skeletal elements are furthermore known from various localities and facies (Koken 1887, 1896). Semiaquatic vertebrates are mostly represented by the very abundant and diverse turtles (at least seven species of basal cryptodirans; Grabbe 1884; Peitz 1998; Karl et al. 2007a, b) and by the common mesoeucrocodylian crocodile genera Goniopholis Owen, 1842 and Pholidosaurus von Meyer, 1841 (von Meyer in Dunker 1846; Koken 1883, 1886, 1887, 1896; Jaffé 1912; Edinger 1938; Salisbury et al. 1999).

The fauna of fluvial and alluvial environments is less well-known, although mollusc shell-beds and bone-bed layers are present (Pelzer 1984, 1998). Fine-grained overbank deposits preserved a few terrestrial arthropods, for example insects (Coleoptera) and possibly arachnids (Struckmann 1880a; Pelzer 1984; Pelzer et al. 1992).

The terrestrial vertebrate fauna was mainly composed of dinosaurs, but only the small ornithischian Stenopelix valdensis von Meyer, 1857 is represented by a largely complete, articulated postcranium (Schmidt 1969; Sues and Galton 1982; Butler and Sullivan 2009). Besides the track record, Ornithopoda, Ankylosauria, Theropoda, and Sauropoda have also been identified from isolated bone fragments (Dames 1884a, b; Koken 1887; Struckmann 1894; Sachs 1997; Windolf 1998; Hornung unpublished data).

A single specimen of pterosaur, the holotype of Ctenochasma roemeri von Meyer, 1851, was found in the Deister mountains. Although considered to be Late Jurassic in age, for example by Wellnhofer (1991), the information provided by von Meyer (1851) supports an origin from the Serpulite Member of the Münder Formation and therefore a basal Berriasian age, as suggested by Bennett (2007). So far no pterosaurs are known from the limnic mid- to late Berriasian deposits.

The palaeoflora is known from leaf impressions in fine-grained sediments, stem-impressions in 
Fig. IV.7 Typical dinosaur track-bearing lithofacies of the Obernkirchen Sandstone. a Thick-bedded, massive sandstone beds with oscillation ripple-marks at the top, intercalated by $\mathrm{mm}$ to $\mathrm{cm}$-thick sandy siltstone to claystone layers. In the foreground a large ornithopod track. The sandstone beds in the background have a thickness of 70$100 \mathrm{~cm}$. Münchehagen/F. Wesling GmbH quarry (ch) (locality 1), 2005; b Medium-bedded, partly amalgamated and channellised (ch) fine-grained sandstone beds, intercalated by $\mathrm{mm}$ to $\mathrm{cm}$-thick siltstone to claystone layers. Note the overall thinning-upward trend. The surface at the base of the image is the so-called "chicken yard" track horizon (Fig. IV.15). "Upper" and "lower unit" refer to a lithological subdivision, which can be traced between adjacent quarries at a local scale (see locality description for further details). Scale: $2 \mathrm{~m}$. Obernkirchen/Obernkirchener Sandsteinbru"che quarry (locality 8), 2009; c Channellised (ch), medium to thick-bedded sandstone, "lower unit", Obernkirchen/Obernkirchener Sandsteinbrüche quarry (locality 8), 2009; d Thin to medium-bedded, scoured, massive sandstone beds, overlain by a soft succession of sandy siltstone to mudstone and capped by a thin coalseam (cs). Pelzer (1998) tentatively identified a track horizon (TH) in this succession. Bückeburg/ abandoned quarry at the W' side of Harrl hill (locality 5), 2009.

sandy sediments, macro- and microremains from lignites, and root-traces, including strongly rooted palaeosol horizons, and, rarely, amber. Palynomorphs and macroremains indicate various floral communities, including pioneer, swamp and floodplain vegetation, and forested areas (Pelzer 1984, 1998; Pelzer et al. 1992). Aquatic plants are represented by dinoflagellates and charophytes (Schudack 1996; Pelzer 1998). Major terrestrial plant taxa include Coniferae, Equisetales, Ginkgophyta, Cycadophyta, Pteridophyta, Bryophyta, and Fungi (Lipps 1923; Mägdefrau and Rudolf 1969; Hiltermann 1949; Pelzer 1984, 1998; Riegel and Wilde 1984; Wilde and Heunisch 1990; Wilde 1991; Wilde et al. 1995). Various morphotypes of root-traces, rhizomes of Equisetales and log impressions are very common plant remains associated with the track-bearing sandy facies (Pelzer 1998).

\section{Facies and lithology of vertebrate track-bearing horizons}

The vast majority of vertebrate (mostly dinosaur) tracks from the Obernkirchen Member are from the limnic deltaic-estuarine deposits, more precisely from the OHS deltaic-estuarine sandstones. However, some tracks have also been described from the fluvial and alluvial facies in the Osterwald mountains (Naumann 1927).

Dinosaur track horizons in the deltaic-estuarine environment commonly occur in $\mathrm{mm}$ - to $\mathrm{dm}$ thick sandstone beds interlayered with $\mathrm{mm}$ - to cm-thick sandy or silty claystones and mudstones. The sandstones are often massive or internally ripple to large-scale cross-stratified, horizontally laminated or flaser-bedded with oscillation or unidirectional ripple-marks at the top. Thick-bedded sandstone layers are often composed of amalgamated sublayers.. Lithofacies data indicate that vertebrate tracks were left in various subenvironments of the deltaic-estuarine system. In the Münchehagen area (localities 1-3, Fig. IV.7a), the tracks were left on top of dm-thick sandstone beds, which have a slightly erosive base and a predominantly massive or diffusely horizontally stratified texture. The uppermost centimetres are wave-reworked and have well-preserved 

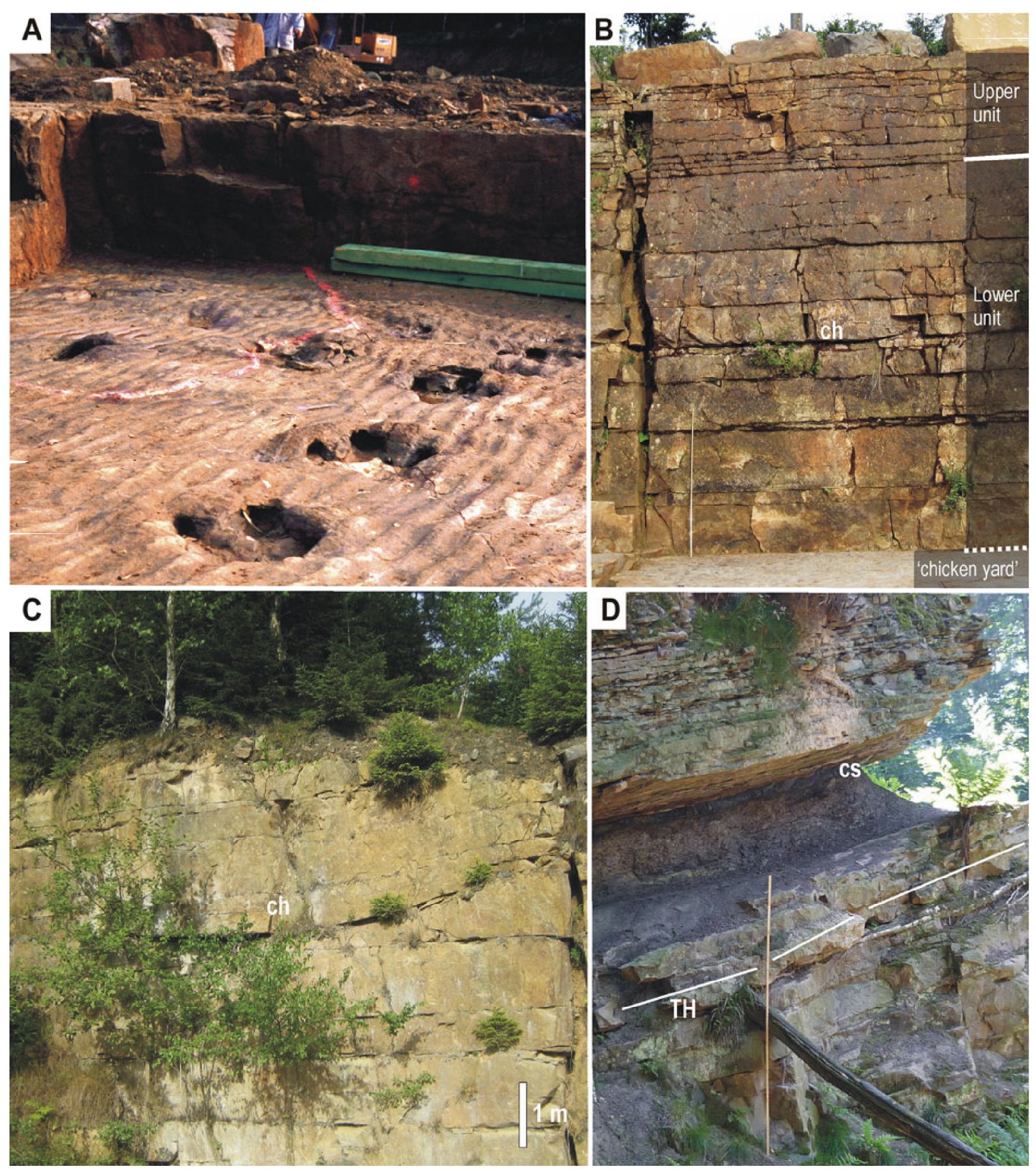

oscillation-ripple cross-lamination and intensive invertebrate bioturbation, overlain by $1-10 \mathrm{~cm}$ thick drapes of siltstones to mudstones. The thick bedding and massive texture indicates rapid deposition from voluminous highly concentrated density flows with limited turbulence at the flow base. The best preserved dinosaur tracks and ripple-marks occur at the contact between the top of sandstone beds and the base of relatively thick $(2-5 \mathrm{~cm})$ siltstones to claystones. These boundaries contain sub-millimetric, smooth, carbonaceous films covering the surface of the oscillation ripplemarked sandstones. The films are probably the remnants of microbial mats (Eriksson et al. 2007) 
which grew on the freshly deposited sand grounds before being covered by the subaqueous deposition of pelitic sediments. They probably helped to prediagenetically stabilize ichnia and sedimentary structures by providing increased cohesion. Stacked and partly amalgamated sandstone layers are in places separated by wavy-irregular, often laterally discontinuous boundary surfaces, often covered by very thin clay vails. Seen from above, these surfaces have a reticulated pattern of mm-wide grooves separated by sharp ridges. Similar structures have been described to be formed by desiccated microbial mats in ephemeral pools on supratidal sandbars in extant environments (Bose and Chafetz 2009). Together with extremely rare desiccation cracks these structures are indicative of temporary emersion of the sandy deposits.

These deposits are interpreted to be associated with storm-reworked barrier sands, splayed into back-barrier lagoons (Pelzer 1998). Such an event-based sedimentation is concordant with the presence of cluster-like colonies of fully grown, gregarious, infaunal unionoid bivalves (Fig. IV.8, see also Schwennicke 1998). Growth to several centimetres in shell-length required years to decades before the population was extinguished or forced to relocate by rapid burial. The $10^{1}$ to $10^{2} \mathrm{yr}$ frequency of high-energy deposition supports an association with severe storm events.

The lacustrine setting, in concordance with the absence of clear indicators of regular rhythmic tidal currents (e.g. herring-bone cross-stratification) and rarity of signs of sustained unidirectional currents, precludes astronomical tides as sediment-transport mechanism. However, storm-induced tides, piling water in shallow littoral regions as the Hils Embayment may explain temporal inundation of intertidal to supratidal areas after the deposition of storm-mobilized sediments. Subsequent desiccation of such isolated supratidal water bodies can explain the occurrence of features such as the reticulated microbial mat structures (compare Bose and Chafetz 2009).

The relative abundance of interspersed channel- and scour-fill sandstones, often containing roottraces and separated by knobby-irregular, clay-draped boundary surfaces at Obernkirchen (Bückeberge, locality 8, Fig. IV.7b, c) indicate a facies setting rather different from that at the Rehburg Mountains. The knobby surfaces are always associated to rooted horizons. These surfaces, which were first described as stacked palaeosols by Grupe (1931), are very similar to structures formed by desiccated microbial mats on vegetated, supratidal sandbars (Bose and Chafetz 2009). They indicate subaerial exposure which lasted long enough to enable the growth of a rather dense vegetation cover. Channel-fill deposits occasionally have large-scale trough cross-stratification and coarser-grained basal lags. Together with the diffusely horizontally stratified or structureless, laterally extensive sandstone beds, these observations suggest a shallow-water deltaic mouthbar complex, in which the tops of mouthbars became emersed and vegetated following the drop of the local water-table after periods of very strong, probably seasonal discharge. Dinosaur tracks occur on the top of channel complexes and on rooted-knobby surfaced and plain sandstone layers. The quality of track preservation varies substantially, but is generally inferior to that in the Münchehagen area. Track-covered surfaces were probably at least partially subaerially exposed and degraded because of the lack of a protective mud layer, vegetation growth, and surface modification by desiccating microbial mats (compare Marty et al. 2009).

At Harrl hill (localities 5 and 6, Fig. IV.7d), at least one track horizon is situated near the top of a thinning-upward, scoured sandstone succession, passing upwards into several dm of ripple cross- 


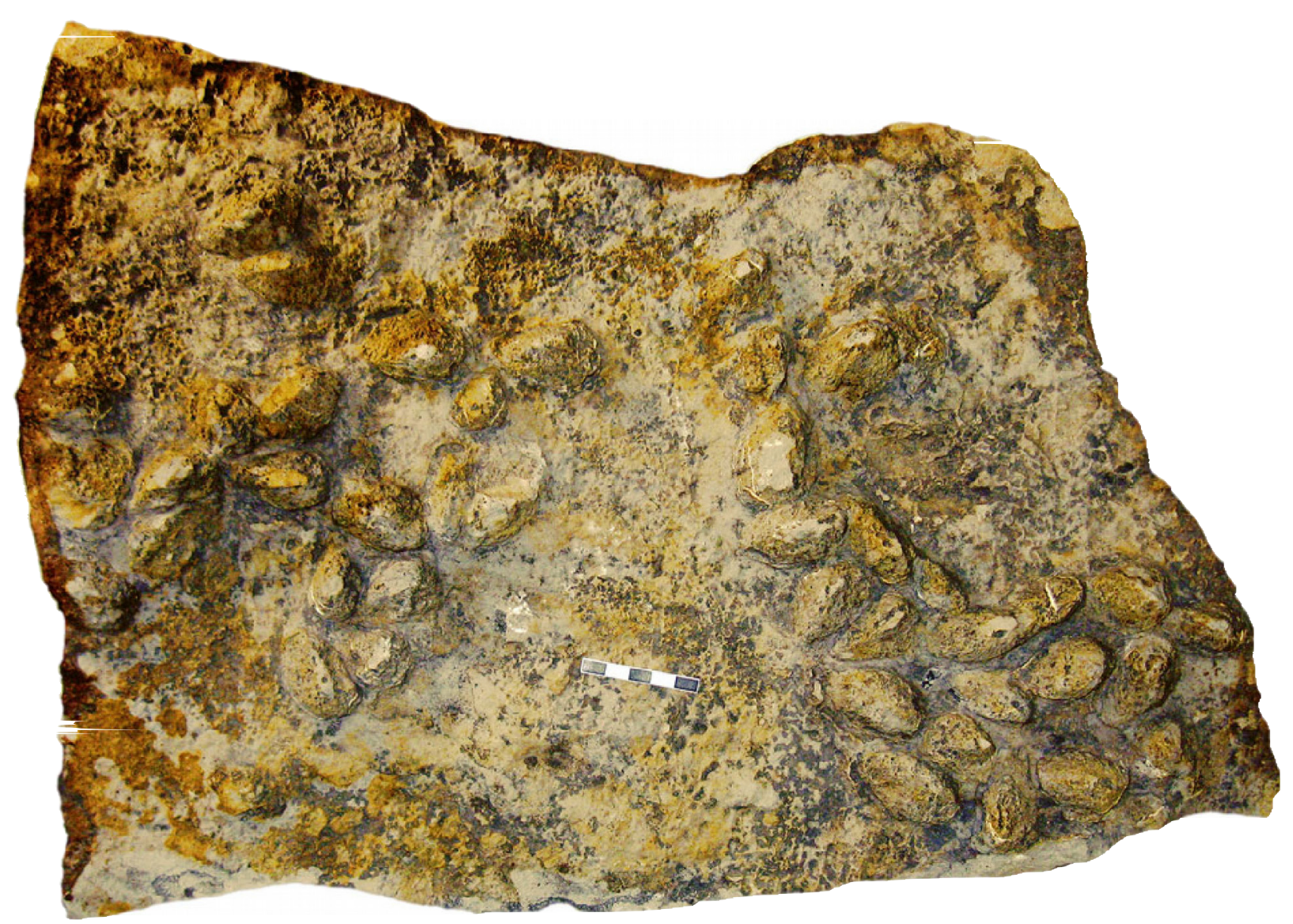

Fig. IV.8 Lockeia isp. (NLMH 105.745A), resting traces of unionid bivalve colony at the underside of a dm-thick, massive sandstone layer indicating sudden burial under rapidly deposited sediment after a prolonged period of undisturbed growth. Bückeberg Formation, Obernkirchen Member, Münchehagen/F. Wesling GmbH quarry (locality 1). Scale bar $5 \mathrm{~cm}$.

laminated siltstones to mudstones and capped by a coal seam (Pelzer 1998). The facies assemblage suggests an aggrading mouthbar under transgressive conditions, overlain by proximal shallowlagoon sediments, when the base-level rise forced retrogradation of the system or the mouthbar became inactive by avulsion. Finally, a peat-bog swamp became established under highstand conditions. The dinosaur tracks were left on top of the shallowly submerged mouthbar.

The dinosaur tracks from fluvial deposits at the Osterwald mountains (localities 12 and 13) are preserved at the base of medium-bedded, partly current-ripple cross-laminated sandstones, overlying partly coal-bearing clay- and mudstones rich in plant macrofossils (Naumann 1927). Crevasse-splay deposited sand probably rapidly covered the fine-grained overbank mud in which the tracks were made.

Tracks are commonly preserved as hyporeliefs on the lower surface of sandstone beds. The finegrained intervals are poorly inundated and the trackway impressions (positive epireliefs) are often destroyed during exposure if not preserved by artificial casting (Grabbe 1881; Hamm 1938; Lehmann 1978). However, this type of preservation may be over-represented in historical collections as it was logistically easier to collect blocks with isolated hypichnia than to remove the 
track-bearing layer. Thin mudstone intercalations support the preservation of epireliefs on an underlying sandstone surface either by penetration of the mud layer by the foot or by undertracks. Thinly bedded sandstones with intercalating mudstone laminae also favour the preservation of undertracks.

\section{Vertebrate track inventory of the Bückeberg Formation}

(Table IV.1)

As this work is not intended as a thorough ichnotaxonomical revision of the vertebrate ichnofauna, which will be given elsewhere, only a short overview and terminological framework for the locality section will be given here. Several dinosaur ichnotaxa have been formally established on the basis of material from the Bückeberg Formation; however, virtually none of these are correctly diagnosed or undisputed.

Table IV.1 Distribution, taxonomy, and abundance of dinosaur tracks across the localities discussed herein.

\begin{tabular}{|c|c|c|c|c|c|c|c|c|c|c|c|c|c|}
\hline \multirow{2}{*}{$\begin{array}{l}\text { Region } \\
\text { Locality }\end{array}$} & \multicolumn{4}{|c|}{ Rehburg Mountains } & \multicolumn{2}{|c|}{ Harrl hill } & \multicolumn{5}{|c|}{ Bückeberge } & \multicolumn{2}{|c|}{$\begin{array}{c}\text { Osterwald } \\
\text { Mts. }\end{array}$} \\
\hline & 1 & 2 & 3 & 4 & 5 & 6 & 7 & 8 & 9 & 10 & 11 & 12 & 13 \\
\hline SAUROPODA & & + & & $?$ & & & & & & & & & \\
\hline \multicolumn{14}{|l|}{ THEROPODA } \\
\hline $\begin{array}{l}\text { "Bueckeburgichnus } \\
\text { maximus" }\end{array}$ & & & & + & & + & & + & & & & & \\
\hline $\begin{array}{l}\text { „Megalosauripus" } \\
\text { isp. }\end{array}$ & & & + & + & & & & + & & & & + & \\
\hline $\begin{array}{l}\text { Didactyl } \\
\text { morphotype }\end{array}$ & & & & & & & & + & & & & & \\
\hline ORNITHOPODA & $?$ & & ++ & ++ & $?$ & ++ & ++ & ++ & & + & & + & + \\
\hline \multicolumn{14}{|l|}{ ANKYLOSAURIA } \\
\hline $\begin{array}{l}\text { Metatetrapous } \\
\text { valdensis }\end{array}$ & & & & & & + & & & & & & & \\
\hline $\begin{array}{l}\text { UNID. TRIDACTYL } \\
\text { DINOSAUR } \\
\text { TRACKS }\end{array}$ & & + & & & & & & + & + & & + & & \\
\hline CHELONIA & & & & & & + & & & & & & & \\
\hline CROCODYLIA & & & & & & & & $?$ & & & & & \\
\hline
\end{tabular}

Abundance: (+) rare to very rare, (++) abundant; (?) identification uncertain 
Sauropoda

(Fig. IV.9a)

Sauropod trackways (Fig. IV.9a) are known only from the "Dinosaurier-Park Münchehagen" open-air museum (locality 2; Hendricks 1981; Lockley et al. 2004). A new ichnotaxon, Rotundichnus muenchehagensis Hendricks, 1981, has been established for these tracks, but this has not found wide acceptance, because the tracks do not preserve many morphological details (Lockley et al. 1994, 2004; Wright 2005). Their general morphology is similar to that of the wide-gauge ichnogenus Brontopodus Farlow, Pittman and Hawthorne, 1989. Despite confirming its status as nomen dubium, Wright (2005) proposed characters to distinguish Rotundichnus from Brontopodus and denied the referral of the Münchehagen tracks to the latter. The main differences pointed out by Wright (2005) were subcircular manus impressions (narrowly arc-shaped in Brontopodus) and a manus width circa two times the manus length (nearly equal in Brontopodus). However, the manus impressions are more crescent-shaped in Rotundichnus than illustrated in Wright (2005: fig. 9.5J and 9.5G respectively, compare with Lockley et al. 2004: figs. 4-5 and to Fig. IV.9a herein).

An occurrence of Brontopodus isp. sauropod tracks at Harrl hill as indicated by Diedrich (2004: fig. 1) is not supported by previous reports or the original material.

Theropoda

(Figs. IV.9b, c, IV.16b, c, IV.18a, b)

Theropod tracks (Fig. IV.9b, c) are common in the LSB but have been misidentified as ornithopod tracks on various occasions. The first description of theropod tracks from the Obernkirchen Sandstone were given by Grabbe (1883: 20), who noted moderately sized tridactyl footprints (footlength ca $25-30 \mathrm{~cm}$ ) with an asymmetric metatarsal region and distinct claw marks. Unfortunately, he did not provide figures or a detailed locality (?Harrl hill). The first indisputable figures of theropod tracks were published by Ballerstedt (1905); these were from Harrl hill.

Theropod footprints occur in various size classes and morphotypes. One distinct morphotype is represented by large, functionally tridactyl footprints, which often preserve the small digit I on deep casts and show a broad, robust digit II (Fig. IV.9b). This morphotype has been named Bueckeburgichnus maximus Kuhn, 1958 (see Lockley 2000; Lockley et al. 2004). However, Thulborn (2001) reasonably argued that the ichnogenus Megalosauripus Lessertisseur, 1955 is available as a valid senior synonym of Bueckeburgichnus. We tentatively retain here the name 'Bueckeburgichnus' for the sake of distinction between those theropod tracks which have been included in the ichnotaxonomic concept of the ichnogenus Megalosauripus Lockley, Meyer and dos Santos, 1998 non Lessertisseur, 1955. Because a second morphotype of theropod tracks (Figs. IV.9c, IV.16b, IV.18a, b) is also consistent with the current definition of the latter (Lockley et al. 1998), we use here the name 'Megalosauripus' to distinguish these from 'Bueckeburgichnus'. However, both designations are unsatisfactory in the long term, and this plexus of theropod ichnotaxa is in desperate need of revision. 


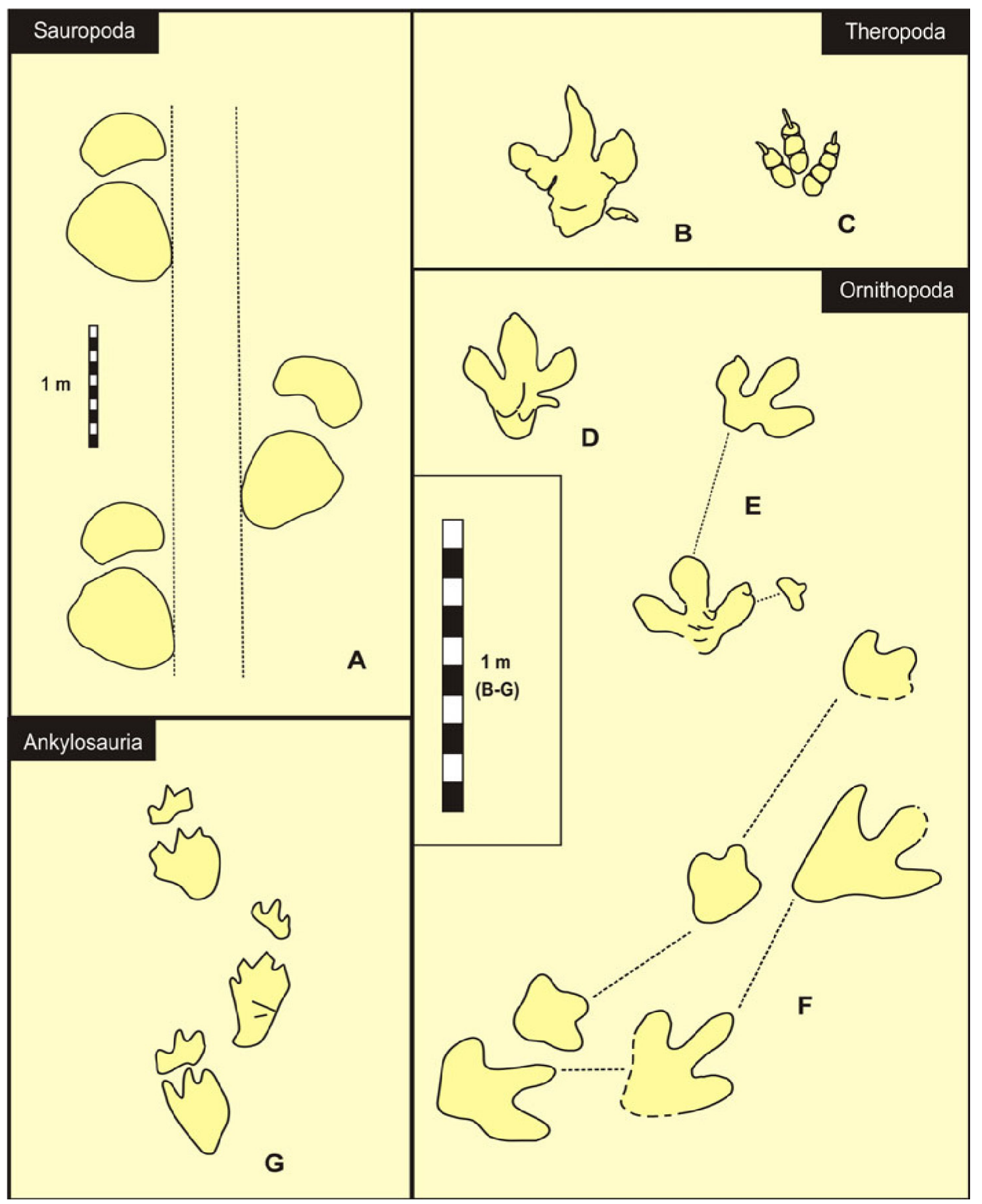

Fig. IV.9 Dinosaur track morphotypes from the Obernkirchen Sandstone. a Brontopodus isp. (= Rotundichnus muenchehagensis Hendricks, 1981), sauropod trackway, locality 2 (from Lockley et al. 2004, modified); b 'Bueckeburgichnus' maximus Kuhn, 1958, large theropod track, locality 6 (from Lockley 2000, modified); c 'Megalosauripus' isp., moderately sized theropod track, locality 8 (from Diedrich 2004, modified); $\mathbf{d}$ Large ornithopod pes track, the presence of a vestigial hallux in this track morphotype is questionable, locality 7 (after Dietrich 1927; Kuhn 1958, modified); e Large ornithopod trackway with manus imprint, locality 2 (from Lockley et al. 2004, modified); f Large ornithopod trackways, adult and sub-adultjjuvenile tracks, locality 8 (from Lehmann 1978, modified); g Metatetrapous valdensis Nopcsa, 1923, ankylosaur track, locality 6 (from Ballerstedt 1922, modified). Scale bar $1 \mathrm{~m}$, note different scale in $\mathbf{a}$ and $\mathbf{b}-\mathbf{g}$. 
Yet unpublished material includes other types of theropod tracks which will be listed as "theropod tracks" generally. These include recently discovered didactyl trackways at Obernkirchen, apparently left by theropods with a specialised sickle-shaped claw on digit II (probably troodontids, van der Lubbe et al. 2009, Fig. IV.16c).

Ornithopoda

(Figs. IV.1, IV.9d, e, f, IV.11, IV.12, IV.14, IV.16e, IV.17a, IV.18a, b, IV.19)

Ornithopods are by far the most abundant dinosaurs in the Bückeberg Formation ichnofauna (Fig. IV.9d, e, f). Even their earliest discoveries have been associated with the genus Iguanodon Mantell, 1825 from the Barremian through Aptian of southern England (Struckmann 1880a, b). Although Struckmann used the descriptive term "Ornithoidichnites" coined by Beckles (1852, 1854) for similar tracks from England, most subsequent authors addressed them simply as "Iguanodon tracks" or even as "Iguanodon" (Stechow 1909; Ballerstedt 1914; Lehmann 1978; Richter 2007). It had already been noted by Kuhn (1958) and others that such a designation is taxonomically incorrect, because:

1. it cannot be demonstrated positively that the (geologically younger) orthotaxon Iguanodon had produced the tracks; and

2. naming tracks by the same formal taxonomic group as their producer is only admissible for extant tracks.

Alternatively, the term "iguanodontid tracks" was also used (first by Grabbe 1881). However, this spelling is problematical too, because a monophyletic family Iguanodontidae was not recognised by recent analyses of ornithopod relationships (Norman 2004; Paul 2008; Butler et al. 2008). Nonetheless, attribution of the tracks to (a) relatively large-sized, basal member(s) of Iguanodontia (in the sense of crown-group Ornithopoda, e.g. Norman 2004) is, of course, indisputable.

More recent papers (Lehmann 2003, 2006; Diedrich 2004; U. Richter et al. 2007; Hornung and Reich 2007) recognised the ichnogenus Iguanodontipus Sarjeant, Delair and Lockley, 1998, however without a proper rationale for this assignment. As this ichnogenus was introduced by Sarjeant et al. (1998) for a distinct morphotype of tridactyl ornithopod tracks and not intended as a catch-all ichnotaxon for Lower Cretaceous iguanodontian tracks, its general use for the LSB large ornithopod tracks is rejected herein. Indeed the morphological diversity suggests the presence of at least 2-3 morphotypes among the large ornithopod tracks from the LSB (Hornung unpublished data). These include a new, recently discovered morphotype with two additional metapodial pad impressions at the foot base from Obernkirchen (Böhme et al. 2009, unpublished data).

Because of these complications, ornithopod tracks will not be further differentiated at ichnogenus level in the locality descriptions. Several observations on well-preserved trackways have shown that some of the large ornithopod trackmakers were quadrupedal and various 
ontogenetic stages are present (Lockley et al. 2004; Diedrich 2004; A. Richter et al. 2007; Böhme et al. 2009; Figs. IV.9e, f, IV.16e).

Ballerstedt $(1905,1921$ a) reported the existence of a didactyl ornithopod track which he named Struthopus schaumburgensis Ballerstedt, 1921. The location of the type material of this ichnotaxon is currently not known, but from the published figures it can be inferred that it is not identical to the newly discovered didactyl theropod tracks from Obernkirchen. Given the variation observed in ornithopod tracks from the Obernkirchen Sandstone, it is highly probable that $S$. schaumburgensis is an extramorphologically modified tridactyl track or one left by a pathological individual (as proposed, for example, by Abel 1935). In the latter case, Ballerstedt's ichnotaxon would be justified and valid; however, this can only be decided with the original material at hand.

Small bipedal ornithischians

(Fig. IV.16d)

Recently, small trackways, possibly left by bipedal cursorial ornithischians have been found at Obernkirchen (Fig. IV.16d). Their generalised morphology potentially agrees with various groups of ornithischians, including derived ornithopods, basal thyreophorans, and marginocephalians. Detailed studies of these tracks are in preparation.

Ankylosauria

(Fig. IV.9g)

The first trackway of a quadruped dinosaur from the Bückeberg Formation was described by Ballerstedt (1921b, 1922) from Harrl hill near Bückeburg (Fig. IV.9g). It was named Metatetrapous valdensis and identified as the trackway of a thyreophoran ornithischian by Nopcsa (1923). The validity and identity of this ichnotaxon were long doubted (Schmidt 1969; Haubold 1974), as the only known documentation of the trackway was a sketch by Ballerstedt (1922). However, recently some parts of the ichnoholotype have been identified from the Ballerstedt collection confirming the observations by Ballerstedt and Nopcsa and supporting its description as an ankylosaurian trackmaker (Hornung et al. 2007, unpublished data).

Non-dinosaurian vertebrate tracks

Non-dinosaurian vertebrate tracks are quite rare in the Bückeberg Formation. Recently, a wellpreserved cast of a manus imprint from a large turtle (possibly Hylaeochelys menkei) from the Harrl hill locality was identified in the Ballerstedt collection (Hornung et al. 2008). Diedrich (2004) noted scratch-marks (?swimming-track) made by a crocodilian from the Dinosaurier-Park Münchehagen open-air museum quarry but gave no further details or figures. 
A strong discrepancy in diversity and composition exists between the vertebrate fauna represented by tracks and by body fossils from the same lithological unit (Table IV.2). Crocodiles and turtles are very abundant (with a very scarce track record), whereas large ornithopods and theropods (for which an extremely abundant track record exists) are only represented by a few teeth and isolated bones (Dames 1884a, b; Koken 1887; Struckmann 1894; and unpublished material). This suggests high taphonomical control of both body and trace fossil preservation. The dinosaur tracks represent a local fauna at least temporarily autochthonous to the delta and shoal system (large ornithopods, theropods, rare sauropods, and ankylosaurs). Some body fossils (e.g. Stenopelix valdensis) are allochthonous components from other habitats, which must have existed in the catchment area of local fluvial systems.

Table IV.2 Fossil record and taphonomy of tetrapods from the Obernkirchen Sandstone .

\begin{tabular}{|c|c|c|c|}
\hline \multirow{2}{*}{$\begin{array}{l}\text { Fossil record: } \\
\text { Vertebrate Taxa: }\end{array}$} & \multicolumn{2}{|c|}{ Body fossils } & \multirow{2}{*}{$\begin{array}{l}\text { Trace fossils } \\
\text { Abundance }\end{array}$} \\
\hline & Preservation & Abundance & \\
\hline \multicolumn{4}{|l|}{ DINOSAURIA } \\
\hline - Sauropoda & (f) & + & + \\
\hline - Theropoda & (f) & + & ++ \\
\hline \multicolumn{4}{|l|}{ - Ornithischia } \\
\hline -- basal Iguanodontia & (f) & + & +++ \\
\hline -- Stenopelix valdensis & (a) & + & $?$ \\
\hline -- Ankylosauria & (f) & + & + \\
\hline CROCODYLIA & (a) & ++ & $?$ \\
\hline CHELONIA & (a) & +++ & + \\
\hline
\end{tabular}

Preservation coded as (a) articulated material, $(f)$ fragmentary and/or isolated material

Abundance: $(+)$ single specimen, extremely rare, $(++)$ few specimens, rare, $(+++)$ numerous specimens.

\section{Vertebrate tracksites in the Bückeberg Formation}

In the sections below, all data about the published dinosaur tracksites from the Obernkirchen Sandstone are compiled. Some emphasis is given to those localities which are currently not accessible and for which data are compiled from the dispersed literature. Localities with current excavation and research coverage are only rather briefly introduced, because their detailed description will be the objective of future work. The locality numbers refer to the map in Fig. IV.2.

It must be stressed that the rather deliberate use of locality names in the past may have led to confusion. For example, Diedrich (2004) distinguished between two tracksites in the Rehburg Mountains, "Bad Rehburg" (based on Struckmann 1880a, b and Stechow 1909) and "Münchehagen" (based upon Fischer 1998). In fact, Struckmann (1880a, b) referred to specimens found at Wölpinghausen (here locality 4) and Stechow (1909) and Fischer (1998) to material from Münchehagen. Bad Rehburg, situated $1.5 \mathrm{~km}$ E of Münchehagen, has not yielded any tracksite yet. 
Its use in the older references was because of its status as an administration centre (community of Rehburg-Loccum).

Localities 1 to 4: Rehburg Mountains

Three of the four known tracksites from the Rehburg Mountains (localities 1-3) are clustered in the immediate vicinity $\mathrm{E}$ of the town of Münchehagen. They expose nearly the same stratigraphical interval. At all three outcrops, the succession begins ca $1 \mathrm{~m}$ below the outcrop base with the Hauptflöz coal seam, which is overlain by a sandstone layer with a rugged, eroded surface on top. This discontinuity is found at the same level in all three outcrops (Wilde et al. 1995), and the boundary surface bears dinosaur tracks in two of them (localities 2 and 3). The overlying sandstones are laterally discontinuous and cannot be correlated with certainty.

1. Münchehagen/F. Wesling GmbH quarry (Figs. IV.6, IV.7a, IV.10, IV.11)

Coordinates N 52²6'37.39", E 9॰12'05.90"; R: 3513680, H: 5812380; 1:25000 German Topographical Map reference grid sheet 3521 Rehburg.

Stratigraphic position Lower part of Obernkirchen Sandstone, ca 3-5 m above Hauptflöz coal seam.

Track inventory Large and medium-sized ornithopods and theropods.

Remarks The quarry of the F. Wesling GmbH company exposes ca 6-7 $\mathrm{m}$ of 0.1-1 $\mathrm{m}$ thick sandstone, intercalated by $0.05-0.2 \mathrm{~m}$ thick mudstone and siltstone layers. Two horizons with wellpreserved trackways are present, separated by ca $2 \mathrm{~m}$ of sandstone. Abundant $(>15)$ ornithopod trackways left by bipedal and quadrupedal individuals in various ontogenetic stages were present on both track levels. Several of the animals walked subparallel to each other. One ornithopod trackway consisted of at least 57 steps (Fig. IV.11). Medium-sized theropods are represented by several trackways on both track horizons. The quarry is still in production; contemporaneous to the quarrying activities, systematic rescue excavations, surveys and casting have been carried out by the Dinosaurier-Park Münchehagen, the NLMH, and collaborating institutions since 2004. As not all track-bearing layers could be preserved, contemporaneously to the documentation of the track-site, a ca $20 \mathrm{~m} 2$-sized slab of the lower track horizon was removed in 2005 for a future exhibit at the GZG. Casts from the 2004-2005 excavation campaigns are stored at the NLMH. Other original material from this locality, already found before systematic excavation at the site began, is on exhibition at the nearby Dinosaurier-Park Münchehagen open-air museum (locality 2) and was partly figured by Lockley et al. (2004). Since 2010, newly excavated at locality 1, excellently preserved theropod and ornithopod trackways from the lower track horizon are reassembled and permanently exhibited in the Dinosaurier-Park Münchehagen protection hall, including currently (spring 2011) a >15 m long consecutive trackway of a medium-sized theropod.

References Athen et al. (2005); Wings et al. (2005a, b); Lehmann (2006); Lehmann et al. (2006); A. Richter et al. (2007); U. Richter et al. (2007); Richter (2007). 


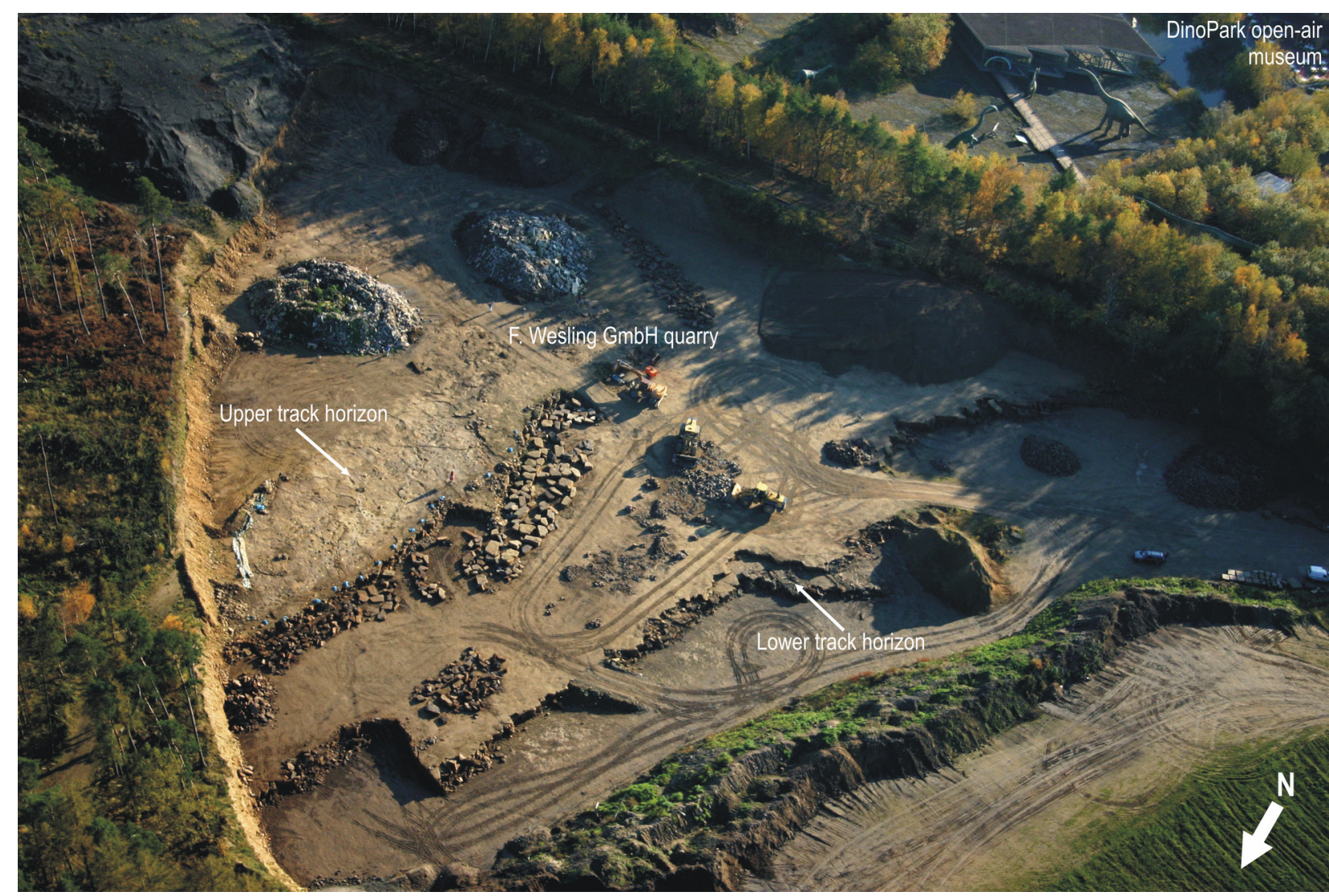

Fig. IV.10 Münchehagen, F. Wesling GmbH quarry (locality 1) and Dinosaurier-Park Münchehagen open-air museum (locality 2, compare Fig. IV.6a). Aerial view of the excavations and the exhibitions (in the upper right corner) in 2005. The tracks discovered in 1979 are partly protected by the building in the background. Photo by P. Nisi (NLMH).

2. Münchehagen/Dinosaurier-Park Münchehagen open-air museum (Figs. IV.6, IV.10)

Coordinates N 52²6'33.20", E 9¹2'02.51"; R: 3513720, H: 5812190; 1:25000 German Topographical Map reference grid sheet 3521 Rehburg.

Stratigraphic position Lower part of Obernkirchen Sandstone, ca $1 \mathrm{~m}$ above the Hauptflöz coal seam.

Track inventory Sauropods, unidentified tridactyl, bipedal dinosaur, ?crocodile swimming-track.

Remarks The outcrop exposes 7-8 $\mathrm{m}$ of thin- to thick-bedded sandstone, interbedded with $\mathrm{cm}$ thick mudstone to siltstone. The Hauptflöz coal seam was found in a core well ca $1 \mathrm{~m}$ below the sandstone layer forming the floor of the quarry (Fischer 1998).

256 individual footprints belong to eight sauropod trackways, seven of which are oriented roughly subparallel. 19 additional footprints form a single trackway of a large tridactyl biped on a single bedding surface. All tracks were pre-diagenetically eroded and further worn by postexcavational damage on the quarry floor before protection. Because of the poor preservation, the producer of the tridactyl track cannot be determined (Lockley et al. 2004). Diedrich (2004) reported "crocodile scratch-marks" from this locality but gave no further details or figure.

On discovery of these tracks in 1979, this tracksite enjoyed great public interest, because it was 


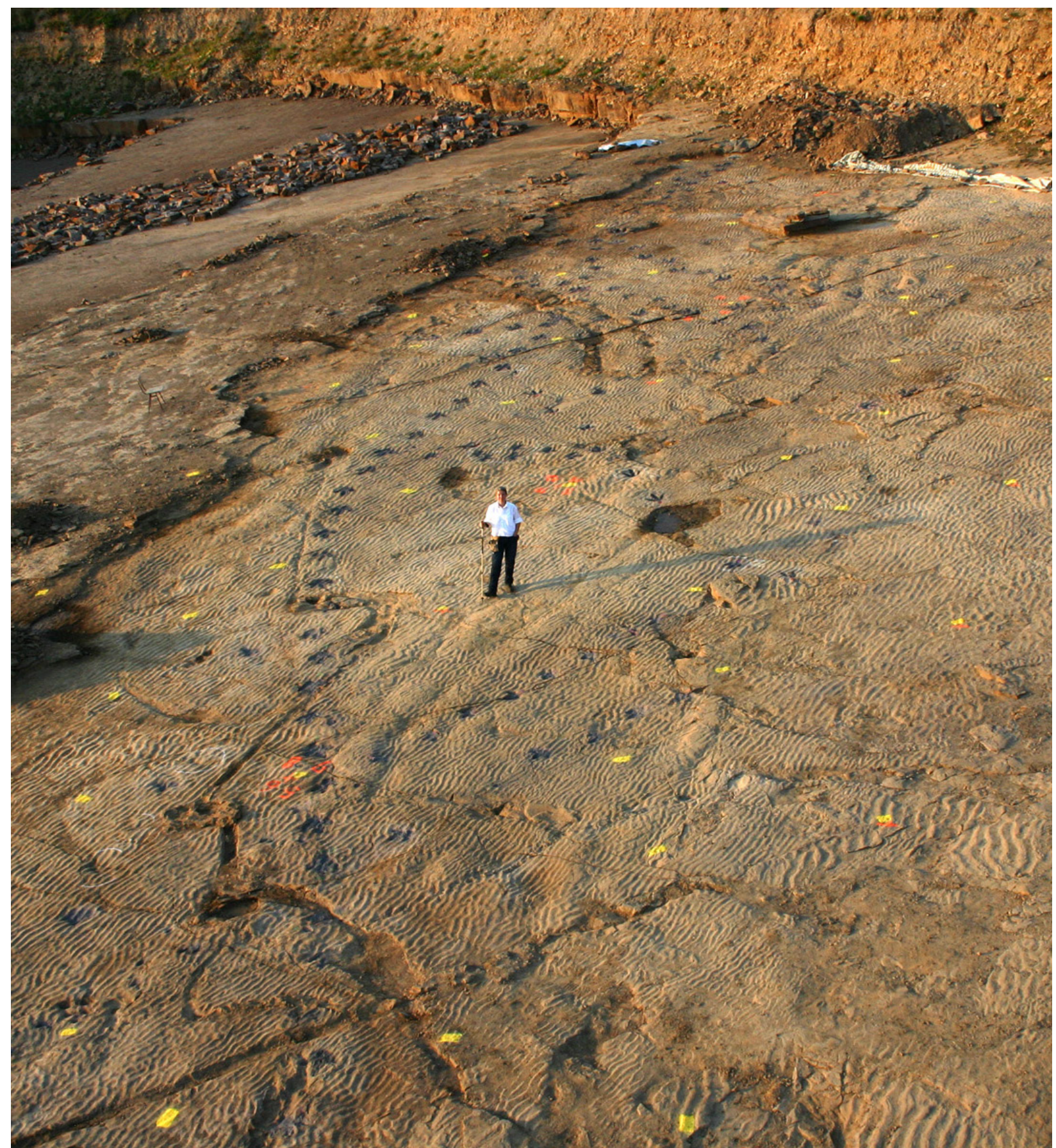

Fig. IV.11 Münchehagen/F. Wesling GmbH quarry (locality 1), upper track-horizon (large ornithopod trackways) during excavation in 2005. Note the long trackway on the left side and well-preserved oscillation ripple-marks. After documentation, this area was lost to quarry operations; view towards $\mathrm{N}$.

the first time since the 1920s that long and numerous in situ trackways of dinosaurs had been revealed. It was also the first time sauropod tracks, apparently left by a 'herd', had been identified from the Obernkirchen Sandstone (for overviews see Hendricks 1981; Probst and Windolf 1993; Fischer and Thies 1993, 2000; Fischer 1998). The tracks are protected by conservation law and form the centrepiece of the Dinosaurier-Park Münchehagen open-air museum. Some areas of the 
tracksite are sheltered and publicly accessible (see also Töneböhn and Kulle-Battermann 1989a, b, c). The tracks have been studied extensively by Hendricks (1981), Kleinschmidt (1986), Fischer (1998) and Lockley et al. (2004). Production in the quarry ceased in 1972.

References Hulke (1980); Hendricks (1981); Staesche (1981); Look (1986); Look et al. (1988); Kleinschmidt (1986); Fischer (1987, 1998); Meyer (1987); Fischer et al. (1988); Töneböhn and Kulle-Battermann (1989a, b, c), Fischer in Boenigk (1990); Probst and Windolf (1993); Fischer and Thies (1993, 2000); Haubold in Lockley (1993); Wilde et al. (1995); Mutterlose (1997b); Lockley and Meyer (2000); Lockley et al. (2004); Wright (2005); U. Richter (2007).

3. Münchehagen/Stadtländer quarry (Fig. IV.6)

Coordinates N 52²6'32.57", E 9¹1'51.37"; R: 3513540, H: 5812160; 1:25000 German Topographical Map reference grid sheet 3521 Rehburg.

Stratigraphic position Lower part of Obernkirchen Sandstone, ca $4 \mathrm{~m}$ above Hauptflöz coal seam.

Track inventory Large ornithopods(?).

Remarks The quarry exposed ca $9 \mathrm{~m}$ of medium- to thick-bedded sandstone, interbedded infrequently by cm-thick mudstone layers. Layers with accumulated shark-teeth, preserved as impressions, have been reported from this site.

Large tridactyl hypichnia, "probably made by Iguanodon", were observed by Wilde et al. (1995) and Pelzer (1998) at the basal horizon (corresponding to the track horizon in locality 2) and in a second horizon ca $3 \mathrm{~m}$ above the base of the outcrop. The quarry is abandoned, over-grown by vegetation, and partly water-filled.

References Wilde et al. (1995); Pelzer (1998).

\section{Wölpinghausen/Wölpinghäuser Berg (Figs. IV.1, IV.12)}

Coordinates Wölpinghäuser Berg (Wilhelmsturm), approx. N 52²5'44.22", E 9¹3'12.28"; R: 3515120, H: 5810660; 1:25000 German Topographical Map reference grid sheet 3521 Rehburg.

Stratigraphic position Obernkirchen Sandstone, exact level unknown.

Track inventory Large and medium-sized ornithopods, theropods.

Remarks The first scientifically described record of any dinosaur track from Germany was reported from this locality (Struckmann 1880a, b; Fig. IV.1). Struckmann reported the presence of ca 40 tridactyl, "bird-like" tracks of a biped at the quarry of A. Spörl, close to the Wilhelmsturm, ca $1.5 \mathrm{~km} \mathrm{NW}$ to the town of Wölpinghausen. For some of them the footlength was ca $60 \mathrm{~cm}$. Struckmann (1880a, b) provided depictions of isolated hypichnial casts corresponding to large ornithopod tracks, which he associated with the genus Iguanodon (Fig. IV.1b).

Unfortunately, geological information about the tracksite provided by Struckmann is very sparse. He noted the footprints from two 40-60 cm thick sandstone beds near the base of the quarry, exposing ca $6 \mathrm{~m}$ of Obernkirchen Sandstone. Today the quarry is abandoned and inaccessible.

The GZG houses a large sandstone slab from "Wölpinghausen" (donation of the Principality of Schaumburg-Lippe; mentioned in Schmidt 1959), lacking more precise locality information. The 


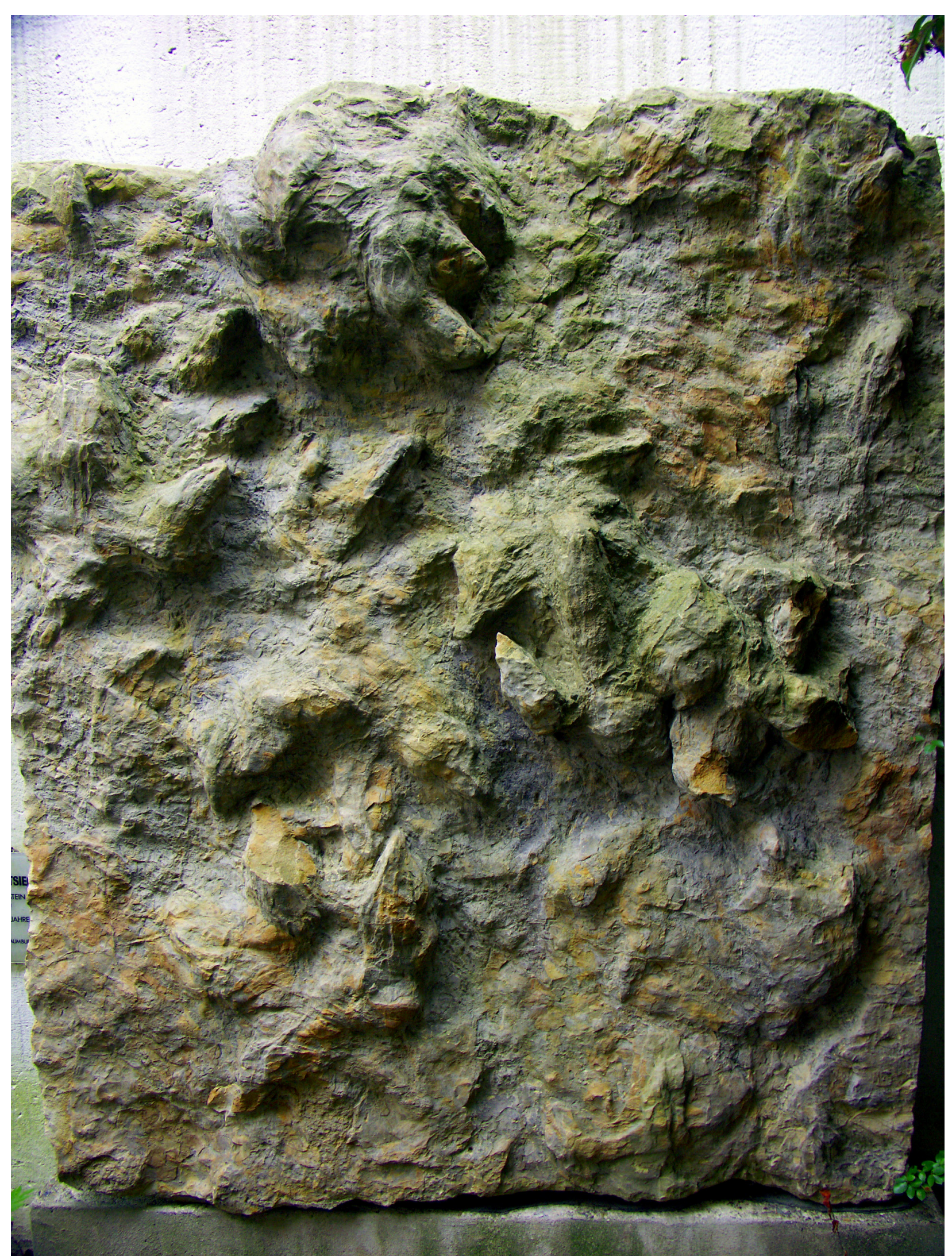


Fig. IV.12 Wölpinghausen (locality 4). Sandstone block with numerous ornithopod and theropod tracks (hypichnial casts, GZG.IF.00100). Size: ca $178 \times 150 \mathrm{~cm}$. On exhibition in the GZG Geopark, Göttingen (donation of the Principality of Schaumburg-Lippe, second half, nineteenth century).

lower surface is densely covered with hypichnia of mid-sized to large ornithopods and theropods, heading in various directions (Fig. IV.12).

References Struckmann (1880a, b); Schmidt (1959).

Localities 5 and 6: Bückeburg/Harrl hill

5. Bückeburg/Abandoned quarry on the W' side of Harrl hill (Fig. IV.7d)

Coordinates N 52¹5'03.70", E 903'50.71"; R: 35044670 H: 5790870; 1:25000 German Topographical Map reference grid sheet 3720 Bückeburg, ca $1.4 \mathrm{~km}$ SE of Bückeburg.

Stratigraphic position Upper part of Obernkirchen Sandstone.

Track inventory Tridactyl, bipedal dinosaurs.

Remarks The quarry exposed a ca $7.5 \mathrm{~m}$ thick succession showing a tripartite subdivision (Pelzer 1998; Fig. IV.7d). The lower, $>4.7 \mathrm{~m}$ thick succession consists of medium-bedded, scoured, and partly cross-stratified sandstone with root-traces in the upper part, overlain concordantly with ca $0.8 \mathrm{~m}$ of sandy siltstone and mudstone with ripple-mark cross-lamination and root horizons, topped by a thin coal-seam. The upper, ca $2 \mathrm{~m}$ thick unit consists of thin to medium-bedded, crossstratified, scoured, fine-grained sandstone, rich in molluscs (Neomiodontidae and unidentified gastropods), beginning with a basal coarse-grained horizon with intraformational rip-up clasts, wood impressions, and abundant large bivalve shallow-burrowing traces (Lockeia isp., personal observation).

Pelzer (1998) reported cross-sections of hypichnia in the quarry wall, near the base of the second unit, ca $1.3 \mathrm{~m}$ below the coal seam (Fig. IV.7d). The track-bearing horizon is probably equivalent to the track layer in nearby locality 6, excavated by Ballerstedt (e.g. 1905, 1921b). The quarry is abandoned and over-grown by vegetation, but still accessible (personal observation 08/2009).

References Pelzer (1998).

\section{Bückeburg/Hexenteich quarry}

Coordinates N 52¹5'01.16", E 904'07.62"; R: 3504770 H: 5790734; 1:25000 German Topographical Map reference grid sheet 3720 Bückeburg, ca 1.6 km SE of Bückeburg.

Stratigraphic position Upper part of Obernkirchen Sandstone.

Track inventory Large ornithopods (including Struthopus schaumburgensis Ballerstedt, 1921), theropods ('Bueckeburgichnus' maximus Kuhn, 1958), ankylosaurs (Metatetrapous valdensis Nopcsa, 1923), turtle footprint.

Remarks During the 19th century, this locality has yielded important body fossils, for example the holotypes of the crocodylian Pholidosaurus schaumburgensis and the dinosaur Stenopelix 
valdensis. First discoveries of tracks in the Harrl hill area date back to Grabbe $(1881,1883)$, but these lack detailed locality information. Around 1900, an extensive track horizon was discovered by Ballerstedt (1905). The material includes large ornithopods and large theropods, among them the type material of 'Bueckeburgichnus' maximus Kuhn, 1958 and Struthopus schaumburgensis Ballerstedt, 1921. Isolated hypichinia from this track horizon survived in the Ballerstedt collection at the GZG and in other places.

In 1921, Ballerstedt reported a trackway of a quadruped from the same locality and horizon (the first definite evidence of a quadruped known from the Obernkirchen Sandstone at the time). This trackway is, historically, the earliest named trackway attributed to an ankylosaur (Metatetrapous valdensis Nopcsa 1923; Hornung et al. 2007).

The strata exposed in this outcrop follow the strike direction of the strata from locality 5 , which is located only $350 \mathrm{~m}$ to the $\mathrm{W}$. The beds can be partly correlated between the two outcrops. The lower part of the exposed section consists of $>8 \mathrm{~m}$ of scoured, medium-bedded, partly crossstratified, fine- to medium-grained sandstone, overlain by ca $0.6 \mathrm{~m}$ of thin-bedded sandstone to mudstone, capped by a cm-thick coal seam. The coal is truncated erosively and overlain by ca $1.7 \mathrm{~m}$ of thin- to medium-bedded, fining-upward, cross-stratified sandstone that forms very gently dipping foresets. Above the sandstone, ca $1 \mathrm{~m}$ of siltstone to mudstone is followed by sandstone 0.5 m thick.

According to Grupe (1933), the succession is underlain by another thin coal seam and the base of the sandstone above the coal-seam is rich in stem-fragments of the pteridophyte Tempskya schimperi Corda, 1845 and contains rip-up coal clasts. The dinosaur tracks were confined to the section below the upper coal seam. The central section, including the coal seam and the underlying fine-grained deposits, correlates with the exposure at locality 5. The lithology of the track casts preserved at the GZG suggests that they were found in this subunit below the coal seam, from were Pelzer (1998) also reported track casts at locality 5.

The quarry near the Bückeburg Castle was owned by the Count of Schaumburg-Lippe in the 19th century. Therefore it was cited in older literature as "Fürstlicher Steinbruch" ("comital quarry") or simply as "the large quarry on the Harrl (hill)" (von Meyer 1841, 1857; Ballerstedt $1905,1914,1921 a, 1921 b, 1922$ ). Regular operations in the quarry ceased around 1870, and it was exploited only occasionally (on demand) into the first half of the 20th century (Ballerstedt 1921). Today the quarry is partly over-grown by vegetation and occupied by the 'Hexenteich' ('witch pond') but is still accessible (personal observation 08/2009).

References von Meyer (1841, 1857, 1859); Ballerstedt (1905, 1914, 1921a, b, 1922); Wegner (1913, 1926); Grupe (1933).

Localities 7 to 11: Bückeberge

7. Obernkirchen/Schauenstein glass factory quarry (Figs. IV.13, IV.14)

Coordinates N 52¹5'37.93", E 908'36.80"; R: 3509887 H: 5791918, 1:25000; German Topographical Map reference grid sheet 3720 Bückeburg, ca $1.5 \mathrm{~km}$ SE of Obernkirchen. 


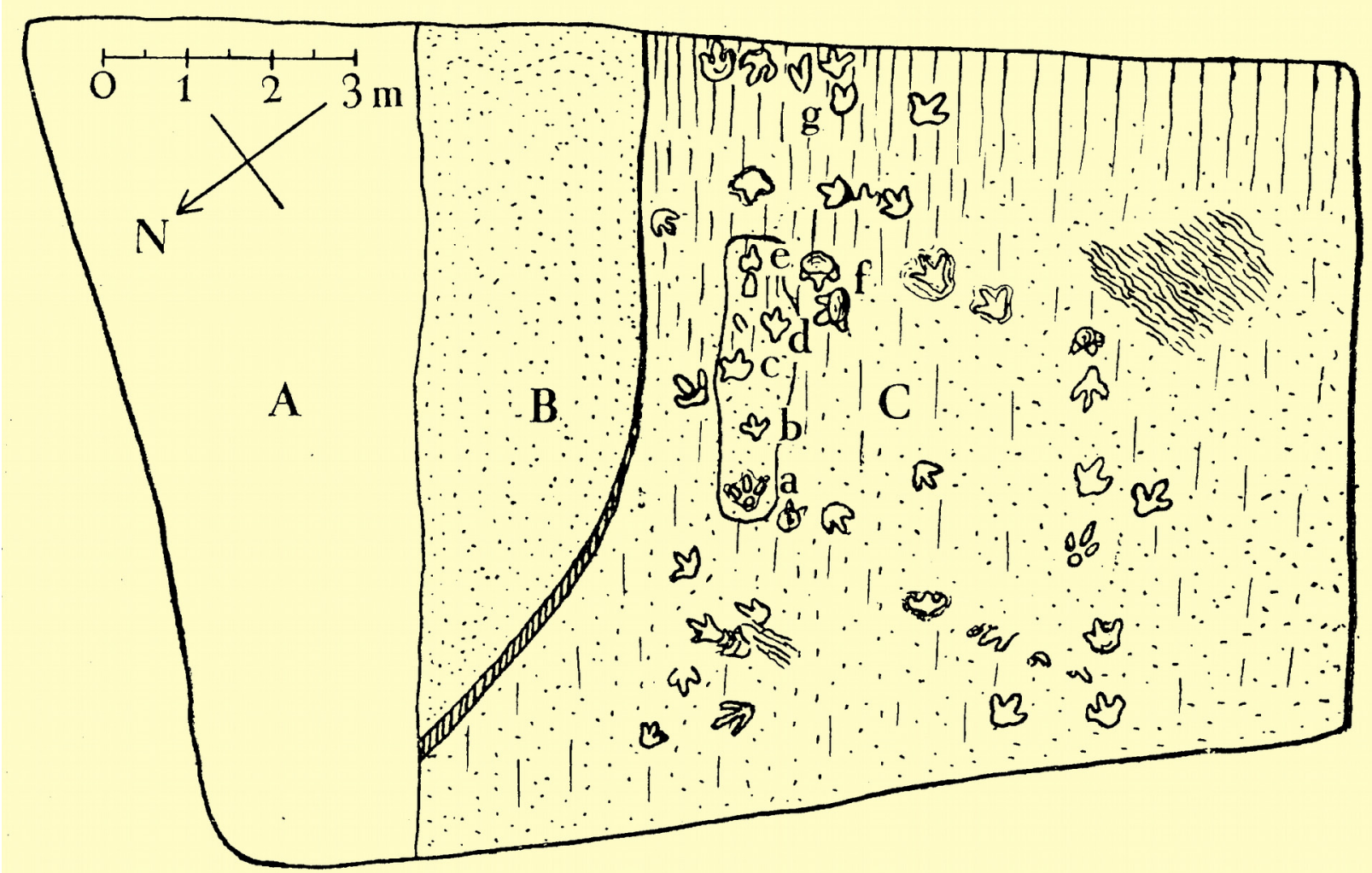

Fig. IV.13 Obernkirchen/Schauenstein glass factory quarry (locality 7). Uppermost track horizon as mapped by Dietrich 1927: fig. 1. A, B Covered areas of the track horizon; C track surface, sandstone with local oscillation ripplemarks; vertically striated areas were covered by some $\mathrm{cm}$ of mudstone, thinning in the stippled areas; a-e single trackway of a large ornithopod, $\mathrm{f}, \mathrm{g}$ various other tridactyl tracks.

Stratigraphic position Upper part of Obernkirchen Sandstone.

Track inventory Large ornithopods (tridactyl and tetradactyl(?) tracks).

Remarks Dietrich (1927) gave a short description of the locality as of June 1926 (Fig. IV.13): The succession shows a subdivision into two superimposed lithofacies. The upper, track-bearing lithofacies consists of thin- to medium-bedded, laterally irregular-continuous or lenticular, partly cross-stratified sandstone, intercalated with thin-bedded sandy mudstone. This succession was underlain by thick-bedded sandstone and overlain by a thin, discontinuous coal-seam. Dietrich (1927) reported a thickness of $12 \mathrm{~m}$, implying that this thickness referred to the upper, crossstratified horizon. However, comparison with other data from surrounding outcrops and the schematic log by Grupe (1933: fig. 1), suggest that this corresponded rather to the total exposed thickness in the quarry. The cross-stratified lithofacies (below the coal-seam) therefore accounts for $>3-4 \mathrm{~m}$ and the underlying thick-bedded facies for ca 8-9 $\mathrm{m}$, of which only the upper ca $5 \mathrm{~m}$ were exposed in the quarry. The underlying strata down to the UHS were identified from a well in the quarry area (Grupe 1933).

The quarry exposed at least three track horizons, one of which (from the upper lithological unit) was mapped in detail by Dietrich (1927). He identified approximately 40-45 individual tridactyl tracks but was unable to identify longer trackways of consecutive footsteps (Fig. IV.12). 


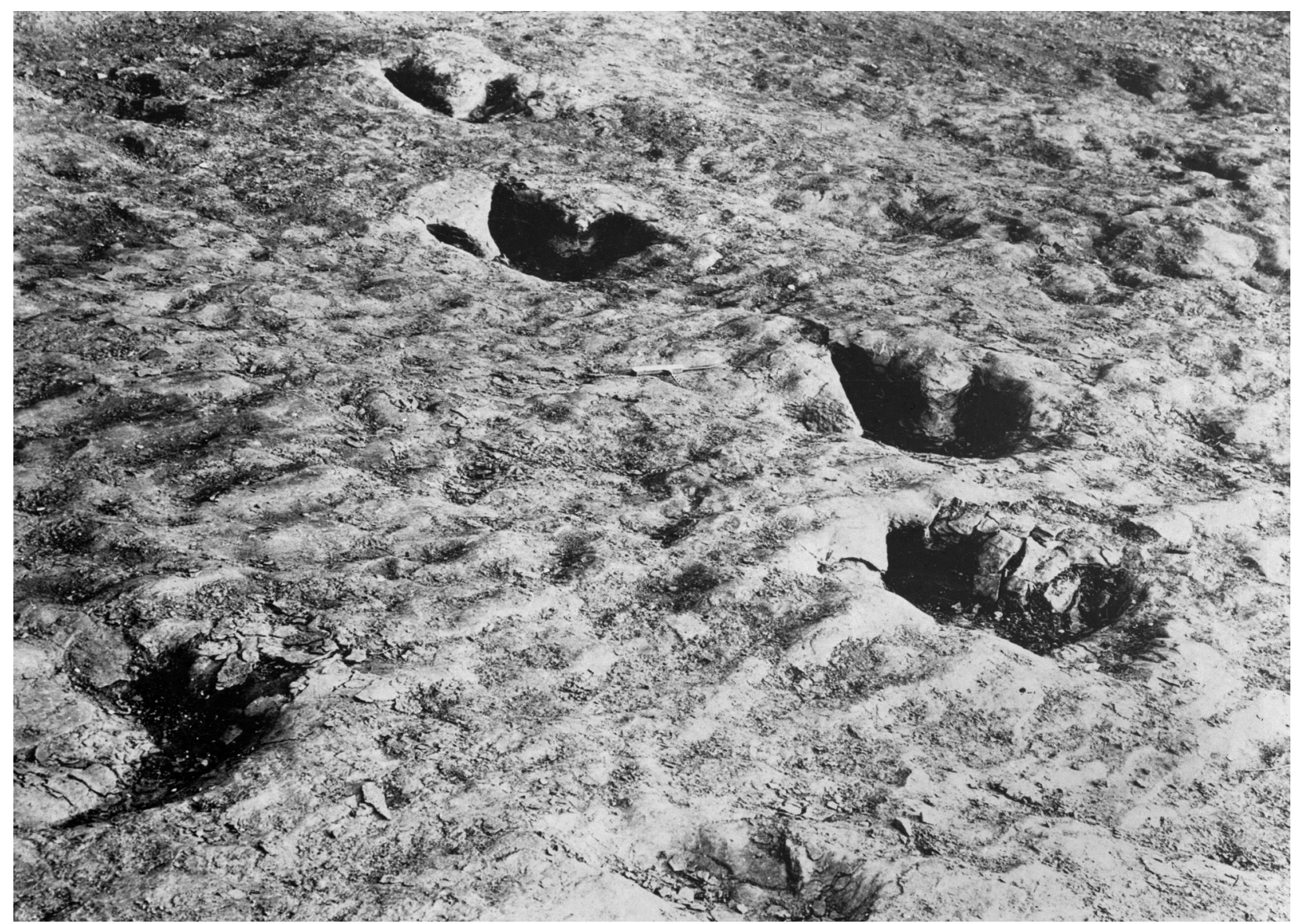

Fig. IV.14 Obernkirchen/Schauenstein glass factory quarry (locality 7). Large ornithopod trackway, foot length ca 35 cm, stride length ca $140 \mathrm{~cm}$. Photographed in 1925, measurements from Hamm 1957.

Hamm (1957) published a contemporary photograph, apparently showing a part of Dietrich's track horizon, and some measurements (Fig. IV.14).

The tracks were identified as having been produced by a single taxon of large ornithopods but their shape and quality strongly depends on the local thickness of the sandy mud in which the tracks were left. In some areas they were impressed through the mud-layer into relatively clean sand, where only subtle marks were left. From isolated hypichnia, Dietrich (1927) also figured an allegedly tetradactyl ornithopod pes print, which was named Wealdenichnites iguanodontoides by Kuhn (1958; Fig. IV.9d). The existence of this morphotype was questioned by Haubold $(1974,1984)$.

Based upon the vertical succession of lithofacies, the track-bearing section can be correlated with the upper part of the exposure in the nearby active quarry of the Obernkirchener Sandstein (locality 8, Fig. IV.5). The Schauenstein quarry was operated by the F.C.H. Heye glass manufacturing company from 1827. It is now abandoned and re-filled as an earth dump.

References Dietrich (1927); Grupe (1933); Hamm (1957).

8. Obernkirchen/Obernkirchener Sandsteinbrüche GmbH quarry (Figs. IV.7b, c, IV.15, IV.16)

Coordinates Main site: N 52¹5'45.02", E 9॰12'24.16"; R: 3514120 H: 5792220; nearby small, inactive quarry: N 52 15'37.22", E 9¹2'00.34"; R: 3513720, H: 5791940; 1:25000 German 


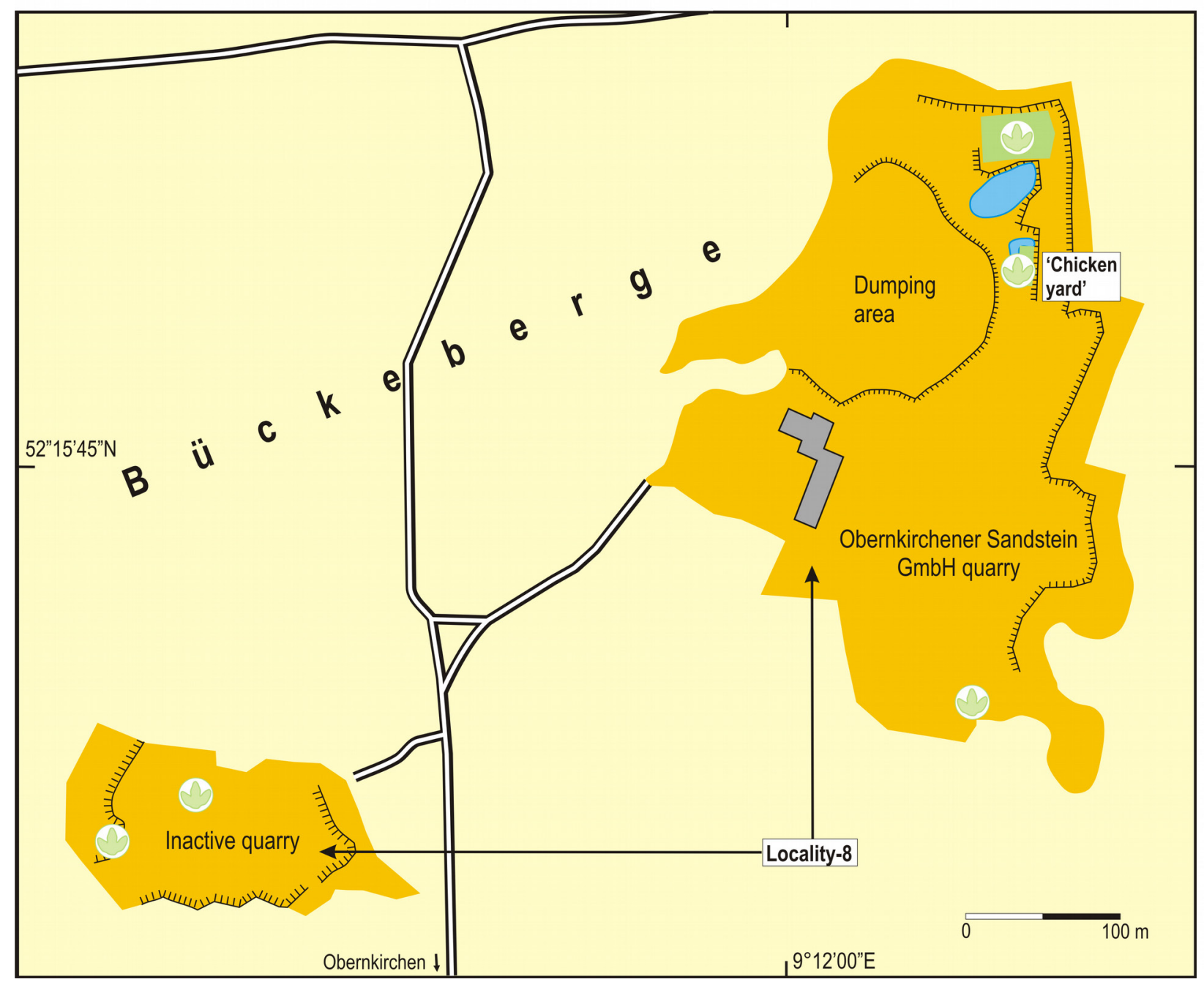

Fig. IV.15 Locality map of the Obernkirchener Sandsteinbrüche $\mathrm{GmbH}$ quarry (locality 8) figured by Diedrich (2004: figs. 2-3) is situated in the inactive quarry to the SW. Most other discoveries, including the excavations since 2006, were made in the large, active quarry. A map legend is given in Fig. IV.6a.

Topographical Map reference grid sheet 3721 Auetal, ca 5.3 km ESE of Obernkirchen.

Stratigraphic position Middle to upper part of Obernkirchen Sandstone.

Track inventory Small, bipedal ornithischians, several morphotypes of large ornithopods and theropods ('Bueckeburgichnus' maximus, 'Megalosauripus' isp., and didactyl tracks).

Remarks The active quarry of the Obernkirchener Sandsteinbrüche GmbH is currently the most important production site for the Obernkirchen Sandstone. The exposed section comprises more than $8 \mathrm{~m}$ and can be subdived into two vertically stacked lithofacies units (Fig. IV.7b). The lower, at least $6 \mathrm{~m}$ thick, unit consists of massive, locally channellised (Fig. IV.7c), thick bedded sandstone with irregular bedding surfaces, abundant rooted palaeosol horizons, and few cm-thick mudstone intervals. The upper unit comprises more than $2 \mathrm{~m}$ of scoured or channellised, lenticular, or planarbedded, laterally discontinuous sandstone, interbedded with $\mathrm{mm}$ - to $\mathrm{cm}$-thick mudstone layers.

At least six to seven track horizons are present: five to six in the lower lithofacies unit and one in the upper. The lowermost track level, ca 1.5-2 m above the base of the exposure, comprises 


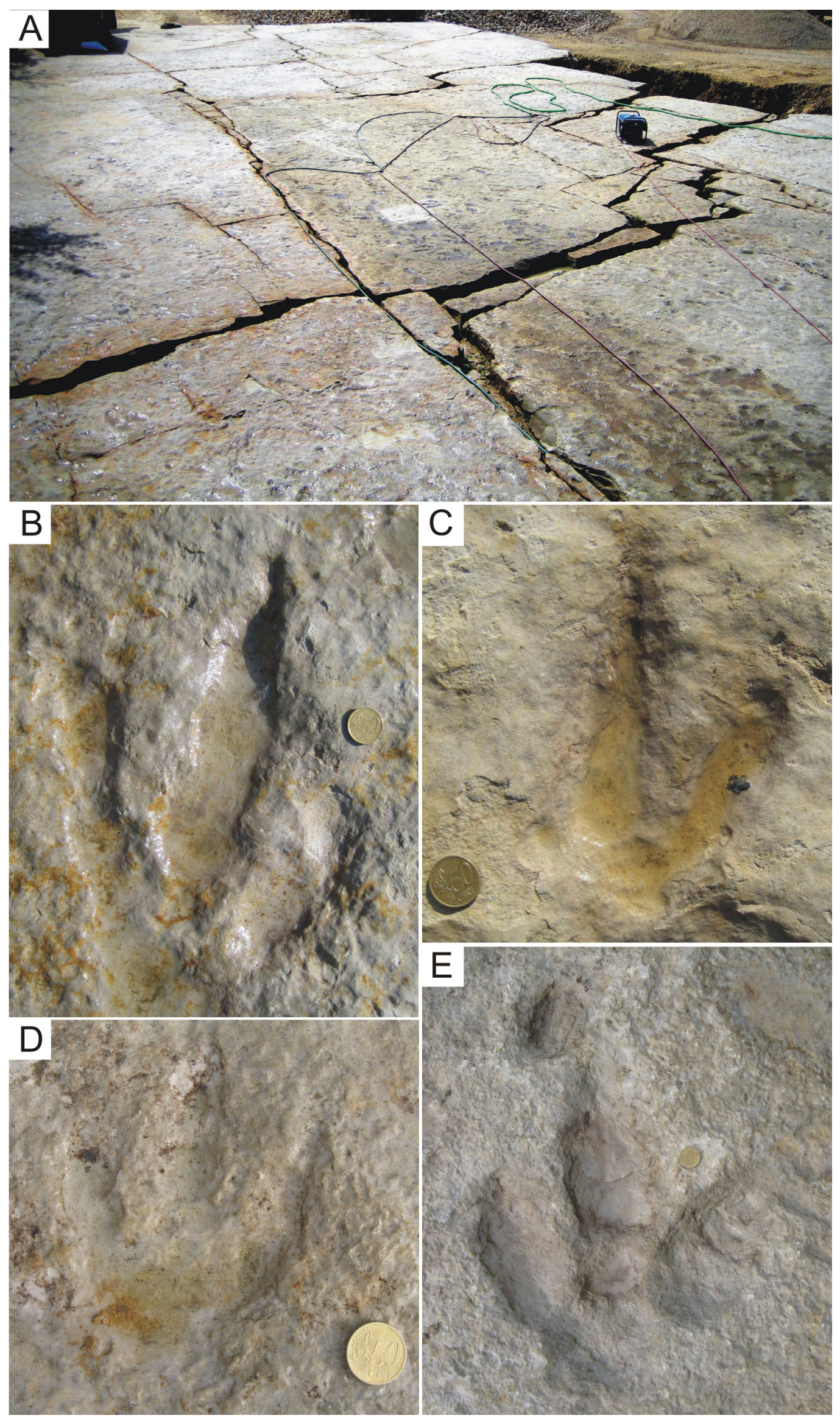


Fig. IV.16 Obernkirchen/Obernkirchener Sandsteinbrüche GmbH quarry (locality 8). The 'chicken yard' track horizon as excavated in 2008-2009. a Overview of the bedding surface with hundreds of dinosaur footprints, preserved as epichnial impressions; $\mathbf{b}$-e Examples of dinosaur footprint morphotypes preserved on the 'chicken yard' track surface; b cf. 'Megalosauripus' isp., moderately sized, tridactyl theropod pes track. Light shed from the right; c Small, didactyl theropod pes track, probably from a troodontid. Light shed from the right; $\mathbf{d}$ Small, biped ornithischian pes track. Light shed from the lower right; e Large ornithopod track, manus/pes-couple. Light shed from the left. Coin diameter in all figures $\mathrm{b}-\mathrm{e}$ is $24 \mathrm{~mm}$.

hundreds of tri- and didactyl theropod and tridactyl ornithopod tracks of different sizes and morphologies (Figs. IV.7b, IV.16a), some still showing long, superimposed trackways. This horizon, which was nicknamed 'chicken yard' during excavation (Richter et al. 2009; van der Lubbe et al. 2009), can be traced throughout wide areas in the northern, deepest part of the quarry. Circa $1 \mathrm{~m}$ above the "chicken yard" level, another track horizon, with large ornithopod tracks, has been recognised in a few places.

The uppermost track horizon within the lower unit at the active quarry contains large ornithopod tracks of a new morphotype yet to be described in detail (Böhme et al. 2009). The stratigraphically youngest track level at Obernkirchen is located within the upper unit. Finally, at least one horizon with ornithopod tracks has recently been found in the southern part of the active quarry. The exact stratigraphic position of this horizon has not yet been established, because this area is affected by some faulting, but it seems to be situated in the lower unit.

The track levels reported by Diedrich (2004) are not exposed in the main quarry but in a small, currently inactive quarry ca $500 \mathrm{~m}$ to the SW. We suppose that the bipartite lithofacies subdivision observed by Diedrich (2004: figs. 2-3) at this site corresponds to the lower and upper lithofacies units in the main quarry. Only his "track bed I" was found at the site, as indicated in Diedrich (2004), ca $2.5 \mathrm{~m}$ below the top of the lower lithological unit. A second track layer occurs ca $1 \mathrm{~m}$ lower in the succession than indicated in Diedrich (2004: fig. 3) and nearly $2 \mathrm{~m}$ below the position indicated in Diedrich (2004: fig. 2). Diedrich's "track bed II" could not be found in any of the positions given. In the same locality, isolated large ornithopod tracks were found at the top bed of the lower unit, indicating a third track level.

The gross lithostratigraphic succession in the Obernkirchener Sandsteinbrüche GmbH quarry is very similar to that in the Schauenstein glass factory quarry (locality 7, Dietrich 1927; Grupe 1933), and the boundary between the lower and upper subunits may correlate. Unfortunately, no coal seam is exposed in the former in direct succession with the track horizons. However, a 10-30 cm thick seam (probably the Hauptflöz seam) is tectonically uplifted in the southeastern area of the quarry in relation to the main part, suggesting that it underlies the lower facies unit. The presence of the Hauptflöz coal seam ca $11 \mathrm{~m}$ below the ground level (ca 2-4 m below the quarry base level) is also confirmed by various wells drilled in the vicinity of the quarry (LBEG 2009).

In recent years, especially since 2006, the dinosaur track inventory (Fig. IV.16b-e) of this location has been shown to be of enormous richness in quantity and diversity. U. Lehmann (1978) provided the first extensive description of ornithopod tracks from the Obernkirchen Sandstone since Ballerstedt's era based upon a large track slab from this locality (now at the GPMH). Diedrich 
(2004) described a large track slab with ornithopod and theropod ('Megalosauripus' isp.) tracks, discovered in 1987. Haderer and Neef (2004) reported new material of 'Bueckeburgichnus' maximus from this locality, for the first time since the discovery of Ballerstedt's (1905) original material found near Bückeburg. However, the specimen, kept at the NLMH, is very poorly preserved, and its theropod assignment is disputable (personal observation, TvdL, AR). Isolated large slabs at the quarry dump area also preserved large theropod imprints referable to 'Bueckeburgichnus' (personal observation, JJH, MR).

Systematic excavations of the NLMH since 2006 have continuously yielded new finds, among others spectacular mass occurrences of theropod tracks, including didactyl footprints, presumably of troodontids (van der Lubbe et al. 2009). At least four to six ichnotaxa occur at Obernkirchen, partially in the same track layers, therefore providing the highest known diversity of any tracksite in the Obernkirchen Sandstone. Large ornithopods are represented by several trackways (Böhme et al. 2009) including those that indicate quadrupedal individuals (adult and subadult).

A proposal for the partial conservation and public exhibition of this site is under development.

References Broschinski (2004); Diedrich (2004); Haderer and Neef (2004); Lehmann (2003, 2006); Richter and Stratmann (2007); Böhme et al. (2009); van der Lubbe et al. (2009); Richter et al. (2009).

\section{Nienstädt/“Dreier's quarry"}

Coordinates Exact locality unknown. Probably SE to the town of Nienstädt, 1:25000 German Topographical Map reference grid sheet 3721 Auetal.

Stratigraphic position Unknown position within Obernkirchen Sandstone.

Track inventory Tridactyl, bipedal dinosaurs.

Remarks Grabbe (1881) reported moderately sized (footlength 32.9-37.9 cm) apparently tridactyl tracks of a biped of "distinct habitus". They were characterised by a "very broad 'toe base'" and "triangular toes" of which the middle one was the shortest. Although he provided some measurements, his description-lacking an illustration-is not sufficient to gain a clear picture of this type of tracks. The allegedly short digit III is incongruent to mesaxonic, tridactyl dinosaur pes anatomy and suggests either misinterpretation or an epigenetic modification of the track.

The small, now probably vanished quarry could no longer be located with certainty but was situated SE of the vicinity of Nienstädt.

References Grabbe (1881).

\section{Nienstädt: Liekwegen/Brandshof quarry (Fig. IV.17)}

Coordinates Approx. N 52¹7'06.50", E 9¹1'25.70"; R: 3512950 H: 5794670; 1:25000 German Topographical Map reference grid sheet 3721 Auetal, ca $1.8 \mathrm{~km}$ SE of Nienstädt.

Stratigraphic position Unknown position within Obernkirchen Sandstone.

Track inventory Large ornithopods.

Remarks Grabbe (1883) reported large ornithopod tracks (footlength 47-48 cm) from this locality, but did not provide any details on the geology or stratigraphy of this, now inaccessible, site. He excavated more that 10 consecutive footprints, forming a trail. 


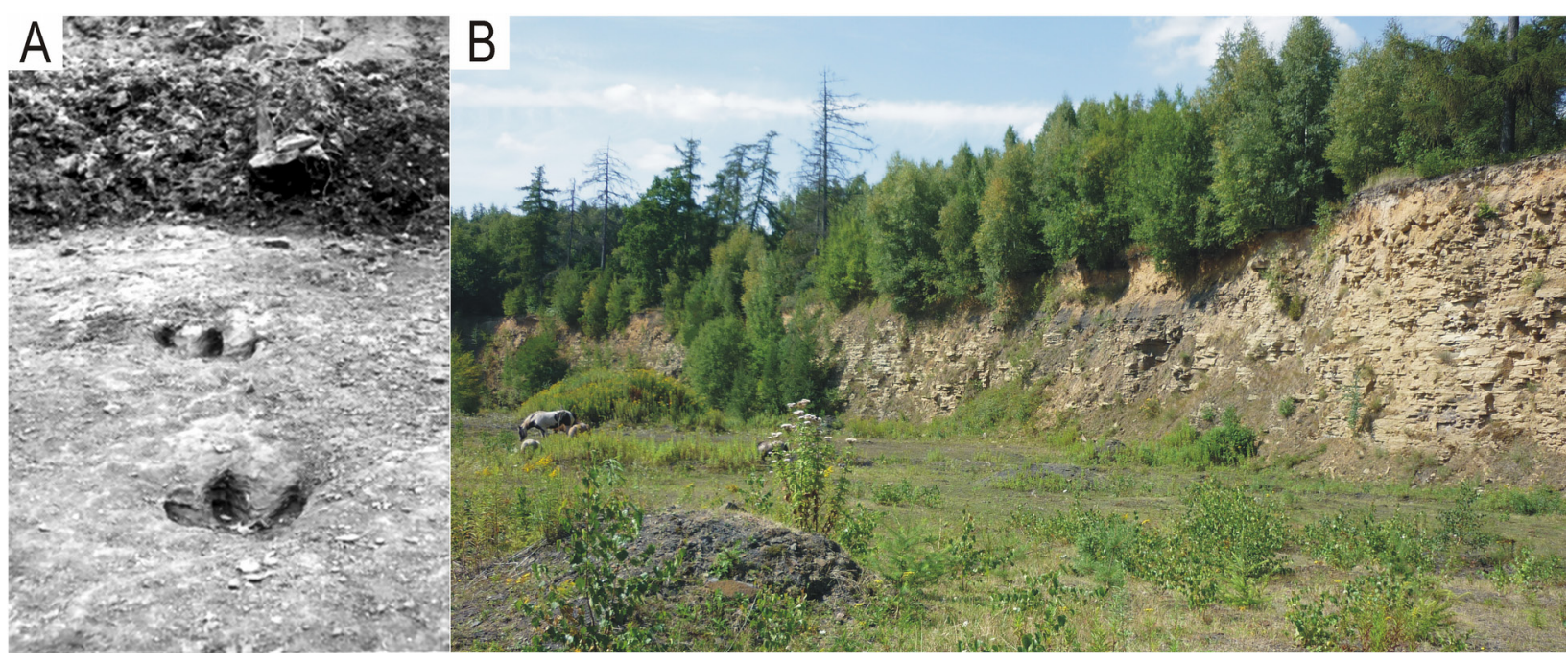

Fig. IV.17 Liekwegen/Brandshof quarry. a Tridactyl pes track, exact size unknown. Historical photography, ca 19401945, GZG museum archive; b Present exposure of the quarry. The base of the quarry consists of sideritic shales with bivalve coquinas, overlain by medium-bedded sandstone. Height of exposure ca 6-7 m, 2009.

An unpublished historical photograph from the 1940s (Fig. IV.17), labelled "LiekwegenWendthagen quarry", shows a tridactyl track of a biped consisting of two pes imprints, preserved as an epichnial relief on an irregular sandstone surface. The morphology and proportions of the track suggest an ornithopod trackmaker. The photograph from the Ballerstedt archive was probably taken at the Brandshof quarry, because of this was the largest quarry in the area and still in production in the mid-20th century. Only a small part of the former quarry is still accessible, exposing ca 4-5 m of thinning-upward, medium to thinly bedded sandstone. In some places the floor of the quarry consists of sideritic claystone with neomiodontid coquinas underlying the sandstone.

References Grabbe (1883).

\section{Wendthagen/“Maier's quarry”}

Coordinates Exact locality unknown. In the vicinity of the town of Wendthagen, 1:25000 German Topographical Map reference grid sheet 3721 Auetal.

Stratigraphic position Lower or middle part of Obernkirchen Sandstone.

Track inventory Large bipedal dinosaurs.

Remarks Grabbe (1881) recorded an oral report by mining supervisor Heidtmeier that a ca 100 $\mathrm{m}$ long trail of large footprints was found "well below the top" of the Obernkirchen Sandstone ca 1850-1860. The tracks were preserved as an epirelief. This is the oldest rather detailed and reliable account of dinosaur tracks from Germany. The tracks were no longer preserved at the time of Grabbe's investigations.

References Grabbe (1881). 
Fig. IV.18 Osterwald/Ahrensberg area. Bückeberg Formation, fluvial equivalent of Obernkirchen Member. a Track slab with two, overstepping, large ornithopod trackways (lower part) and theropod footprint (upper right). Parts of a second theropod footprint are located at the upper margin of the slab. Epichnial relief, lowangle light from upper right slab-size approximately $210 \mathrm{~cm} \times 162 \mathrm{~cm}$, BGR unnumbered; b Right and left ornithopod foot-prints, the trackmakers walked in opposite directions, detail of a; $c$ Left theropod footprint, detail of $\mathbf{a}$. Scale bar $30 \mathrm{~cm}$ (in a), $10 \mathrm{~cm}$ (in $\mathbf{b}$ and c)

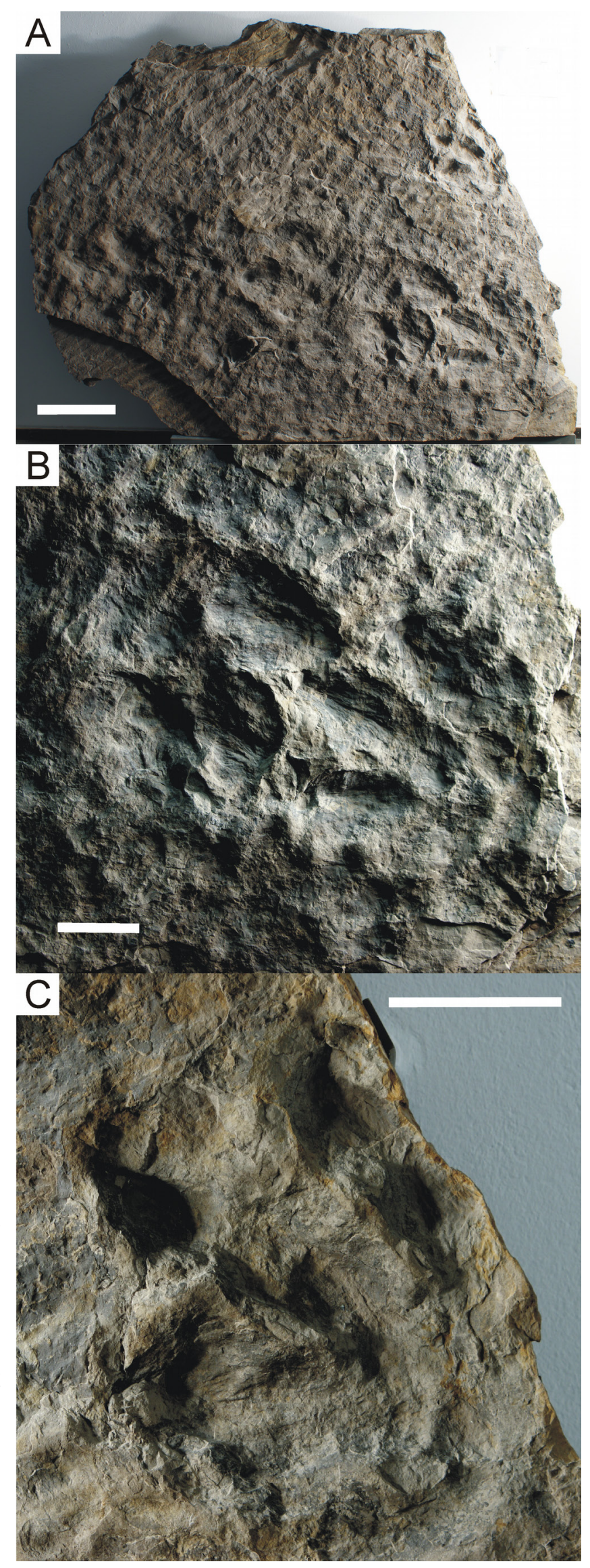


Localities 12 and 13: Osterwald

Tracksites in the Osterwald mountains are located in the more proximal, fluvial and alluvial deposits of the Obernkirchen Member (Pelzer et al. 1992; Pelzer 1998). These deposits cannot be correlated in detail with those of the Obernkirchen Sandstone sensu stricto or dated more precisely than middle or late Berriasian. They are overlain by Valanginian brackish deposits (Osterwald Member).

12. Osterwald/Quarry $450 \mathrm{~m}$ south of Ahrensberg mountain (Fig. IV.18)

Coordinates N52 ${ }^{\circ}$ '30.27", E 9० 38'58.70"; R: 3544640 H: 5777050; 1:25,000 German Topographical Map reference grid sheet 3823 Coppenbrügge (formerly Eldagsen as in Naumann 1927), ca $2 \mathrm{~km} \mathrm{NE}$ to the town of Osterwald.

Stratigraphic position Upper(?) Obernkirchen Member.

Track inventory Large ornithopods, theropods.

Remarks Naumann (1927) indicated an unspecified number of large, tridactyl hypichnia at the base of a $2.1 \mathrm{~m}$ thick sandstone layer interbedded within a ca $23 \mathrm{~m}$ thick series of alternating sandstone, mudstone, and claystone rich in plant macrofossils and minor coal seams. The succession is located well below the boundary to the Osterwald Member and probably slightly older than that in nearby locality 13. The track horizons in both localities cannot be correlated lithostratigraphically. The lithofacies and flora suggest a peri-fluvial environment with fine-grained sediments and coal settled in oxbow-lakes and back-swamps, while coarser-grained sedimentary bodies represent channel-fills, natural levees, and crevasse-splay fans (compare Pelzer 1984).

Naumann (1927: 29) explicitly associated the tracks with Iguanodon and reported the recovery of two individual footprints, one with a foot-length of $52 \mathrm{~cm}$ and a foot-width of $42 \mathrm{~cm}$. The quarry is abandoned and over-grown by vegetation.

A ca $2.10 \mathrm{~m} \times 1.62 \mathrm{~m}$ large slab (Fig. IV.18) of thinly bedded, fine-grained, bioturbated, current ripple-marked sandstone was recovered from the Osterwald/Ahrensberg area (exact provenance unknown) during the 1970s and is now kept at the Bundesanstalt für Geowissenschaften und Rohstoffe, Hannover (BGR). The slab shows three mid-sized ornithopod footprints (footlength ca 30 $\mathrm{cm}$ ), forming the section of a trackway, and a single well-preserved left footprint of a mid-sized theropod (footlength ca $31 \mathrm{~cm}$ ). The tracks are preserved as epichnia. The small fragment of a second (right) theropod footprint is probably preserved at the upper margin of the slab.

References Naumann (1927).

13. Osterwald/Kaiserblick (Fig. IV.19)

Coordinates N52 7'38.08", E 9० 39'16.00"; R: 3544950 H: 5777260; 1:25000 German Topographical Map reference grid sheet 3823 Coppenbrügge (formerly Eldagsen as in Naumann 1927), ca $2.4 \mathrm{~km}$ NE to the town of Osterwald.

Stratigraphic position Upper(?) Obernkirchen Member.

Track inventory Large tridactyl tracks (?Ornithopoda).

Remarks From an abandoned quarry, ca 500 m ESE of the Ahrensberg, Naumann (1927) noted 


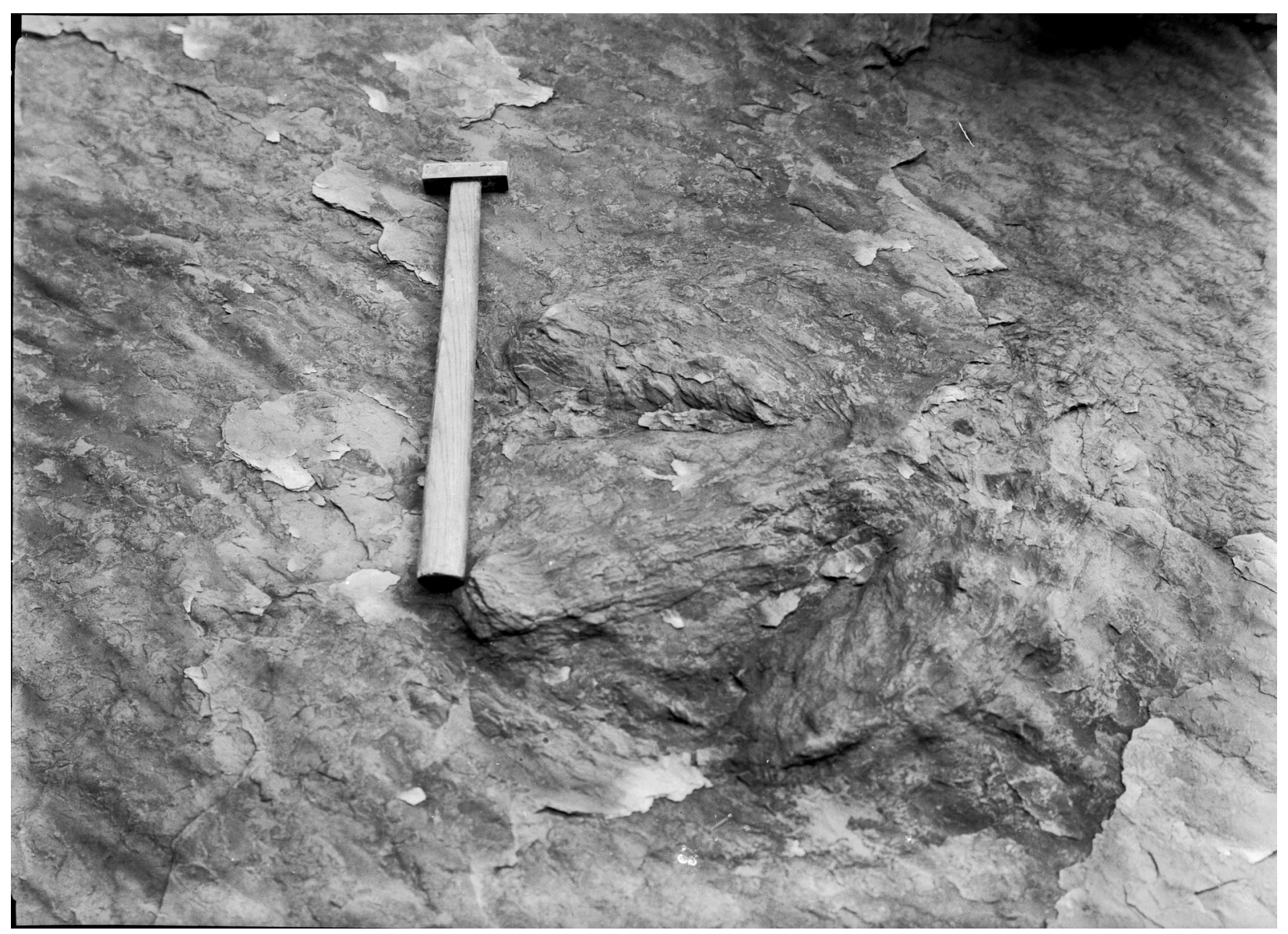

Fig. IV.19 Osterwald/Kaiserblick (locality 13). Large ornithopod track (hypichnial cast). Historical photograph, 1930 by F. Hamm (from Barner 1931).

"Iguanodon-tracks" near the base of a sandstone package, embedded in a ca 20 m thick succession of sandstone, mudstone, and claystone, and minor coal seams. It is probably slightly younger than that in nearby locality 12 . The lithofacies data provided by Naumann are scarcer than in locality 12 but suggest a similar environmental setting. The quarry is abandoned and over-grown by vegetation.

Barner (1931) published a photograph from the tracksite, taken around 1925 (Fig. IV.19).

References Naumann (1927); Barner (1931).

\section{The Obernkirchen Sandstone dinosaur track localities- a megatracksite?}

Diedrich (2004) listed several of the above mentioned dinosaur tracksites (localities 2, 4, 6, 8) as forming a "central European Berriasian megatracksite". This argument was mainly based on the (rough) stratigraphical and lithofacial correlation of these localities and the assumed lateral connection of the track-bearing lithological units.

Generally, a megatracksite is strictly defined as a regionally extensive, single track-bearing horizon, or a very thin package of horizons over a large area in the order of hundreds or thousands 
of square kilometres (Lockley and Pittman 1989; Lockley 1991a). Almost all of the established megatracksites are formed by track-bearing strata not exceeding $1 \mathrm{~m}$ in thickness (Lockley 1997). An exception is provided by the Dakota Sandstone megatracksite (the "dinosaur freeway", Lockley et al. 1992), which consists of several track horizons, encompassing a total thickness of ca $10 \mathrm{~m}$. Regional correlation of the track horizon(s) requires very sound stratigraphic control, as provided, for example, by vertical relationships to major sequence boundaries in clastic sequences or laterally extensive bed-by-bed correlation in carbonate platform successions (Lockley 1991b; Meyer 1993; Kvale et al. 2001).

Such tight stratigraphic control is not available for the Obernkirchen Sandstone tracksites. Although in many locations several trackway horizons are present, these cannot be correlated laterally over more than a few square kilometers at best (Figs. IV.5, IV.6b). The sandstone beds on which the tracks were preserved are often laterally discontinuous, sometimes even at outcrop scale, and lithofacies assemblages differ among the outcrop regions.

Truncated channel-fill deposits indicate the presence of intraformational discontinuities above the track-level in the Münchehagen quarry (Fischer 1998). A discontinuity at regional scale was also reported from the western Obernkirchen area by Dietrich (1927) and Grupe (1933) and observed in the Obernkirchener Sandsteinbrüche GmbH quarries (personal observation).

As already discussed, major differences exist between the lithofacies assemblages at the Rehburg Mountains and the Bückeberge. Although both systems were probably genetically coupled on a wider time scale, a strict isochrony of the barrier deposits in the northwest and the deltaic succession in the southwest-and especially of the dinosaur track horizons within both-cannot be demonstrated at present. Although similar in facies, again such a correlation cannot be made between the occurrences at Harrl hill and the Bückeberge. Therefore, identification of the Obernkirchen Sandstone as a megatracksite currently seems premature and rather uncertain.

\section{Conclusions}

13 dinosaur tracksites have been identified in the Obernkirchen Sandstone (Obernkirchen Member, Bückeberg Formation, Late Berriasian) in the southeastern part of the Lower Saxony Basin, eight of which are no longer accessible. A survey of available geological and ichnological data on these localities shows a database of quite inhomogeneous quality.

Correlations to current facies models (Pelzer 1998) for the Obernkirchen Sandstone and equivalents show that eleven tracksites are located in a distal coastal barrier/deltaic facies assemblage.

The presence of dinosaur tracks spans a number of facies types, indicating a range of local environments. Track occurrences in the Münchehagen area are linked to heterolithic successions, reflecting re-occurring high-energy depositional events interrupting long-term calm suspension settling. These events have a local reoccurrence frequency of at least $10^{1}$ to $10^{2} \mathrm{yrs}$, and are related to storm events carrying matured littoral barrier sands into back-barrier lagoons. Dinosaurs must have frequently passed through shallow areas of these lagoons and along barriers and shoals. 
At Obernkirchen (Bückeberge), many of the track levels occur at the top of sandbars, which show indications of subaerial exposure and plant coverage. The laterally continuous beds are vertically and laterally intercalated with channel-fill sandstones in places, suggesting a net aggrading, temporarily emergent mouthbar complex. At Harrl hill, well-preserved dinosaur tracks occur on what is interpreted as a submerging mouthbar surface.

Because of association of various facies assemblages, lateral inconsistency, and a lack of stratigraphic correlation of the track-bearing horizons in the Obernkirchen Sandstone, its characterisation as a megatracksite (Diedrich 2004) is currently regarded as speculative.

Two tracksites occur at the Osterwald mountains in more proximal equivalents of the Obernkirchen Sandstone, represented by perifluvial overbank deposits further inland.

Vertebrate clades represented by tracks include Ornithopoda, small, bipedal ornithischians, Ankylosauria, Theropoda, Sauropoda, turtles, and possibly crocodiles. Large ornithopods are most abundant and probably present in all localities, followed in abundance by theropods (five localities), sauropods, ankylosaurs, turtles and crocodiles (one locality each). Several ichnotaxa have been established for these tracks, but, with the exception of Metatetrapous valdensis Nopcsa, 1923 (Ankylosauria; Hornung et al. 2007), none is properly defined at present. There are two or three morphotypes (partly related to different ontogenetic stages) of large ornithopod tracks and at least three morphotypes of theropods (corresponding to different clades). Ornithopod and theropod tracks occur in large numbers in several localities.

A strong discrepancy in diversity and composition exists between the vertebrate fauna represented by tracks and by body fossils from the same lithological unit. This suggests high local vicariance and taphonomical control of both body and trace fossil preservation. The dinosaur tracks represent a local fauna at least temporarily autochthonous to the estuary and shoal system. The nearly total absence of articulated or associated material from these groups suggests that their presence in this environment was probably non-permanent and migratorial.

\section{Acknowledgments}

The following people provided valuable discussions and logistic help: H. Schwanke (GZG), M. Sosnitza (retired, formerly GZG), T. Stegemann (GZG), H.-V. Karl (Weimar/GZG), J. König (GZG), M. Raddatz (Halle/S.), and U. Staesche (Hannover). T. Wiese (BGR) is thanked for providing access to material in his care. V. J. Roden (formerly GZG) is acknowledged for checking the English spelling and grammar. The current excavation projects in the Obernkirchen Sandstone would not be possible without ongoing and generous support by the owners and crew of the quarry operations. We cordially thank F. Wesling sen. (Ferdinand Wesling GmbH \& Co. KG and Dinosaurier-Park Münchehagen GmbH \& Co. KG, Rehburg-Loccum), K. Köster (Obernkirchener Sandsteinbrüche $\mathrm{GmbH}$, Obernkirchen), and B. Wolter (retired, formerly Dinosaurier-Park Münchehagen) for their cooperation in our research work, and for their willingness to allow public access to and preservation of the dinosaur tracks found on their property. F. Klebe and L. Seidel (Landkreis Schaumburg-Lippe) also provided interest in and support of conservation of the tracks. The 
research at Münchehagen is strongly assisted by the team of the "Dinosaurier-Park Münchehagen" open-air museum headed by N. Knötschke. The support by many others was vital to the excavation projects, including M. Schmitz (formerly NLMH, currently Naturhistorisches Museum, Mainz), A. Basse (Bremen), and U. Richter (Hannover), and the volunteer team, joined on a regular basis by U. Stratmann, O. Gerke, U. Picht, G. Picht, J. Picht, C. Weimann, and L. Weimann and hundreds of shortterm volunteers who have spent thousands of working-hours uncovering the tracksites at Münchehagen and Obernkirchen since 2004. Colleagues from other research institutions also cooperated in various stages of the project, including $M$. Wiggenhagen (Institut für Photogrammetrie und Geoinformation, Leibniz-Universität Hannover, Hannover), M. Fischmann, and K. Grobe (Fachbereich Design und Medien, Fachhochschule Hannover, Hannover), O. Wings (Museum für Naturkunde, Humboldt-Universität zu Berlin), J. Lepper (formerly BGR), C. Heunisch, and F. Luppold (Landesamt für Bergbau, Energie und Geologie, Hannover), J. Lehmann (Geowissenschaftliche Sammlung, Universität Bremen), and O. Kullmer (Forschungsinstitut und Naturmuseum Senckenberg, Frankfurt am Main). All of these people are warmly acknowledged for their efforts. We also thank Richard J. Butler (München) and Oliver Wings (Münchehagen/Berlin) for reviewing the manuscript and providing helpful comments to improve the paper.

\section{References}

Abel, 0. 1935. Vorzeitliche Lebensspuren. xv+664 pp., Jena: Fischer.

Agassiz, L. 1833. Recherches sur les poissons fossiles. Volume I. xlix+188 pp., Neuchâtel: Auteur.

Anonymous. 1879a. [Naturhistorische Gesellschaft...]. Hannoverscher Courier 23 (10023, morning issue; 09 Nov 1879): without pagination. [Newspaper report].

Anonymous. 1879b. Local-Nachrichten, Naturhistorische Gesellschaft [...]. Hannoverscher Courier 23 (10039, evening issue; 19 Nov 1879): 4-5. [Newspaper report].

Anonymous. 2005. Saurierfährte in der Borgloher Schweiz entdeckt. 130 Millionen Jahre alter Abdruck stammt von einem Dreizeher. Landkreis Osnabrück, Pressemitteilung vom 07.09.2005. http://www.landkreisosnabrueck.de/verwaltung-europa-politik/pressestelle/pressearchiv/3.html?

kategorie=0\&month=9\&type=search\&view=search\&year=2005 [last accessed: 09 Feb 2009].

Arp, G., and C. Mennerich (2008) Ostracod associations, palaeoenvironment and cyclicity of Purbeck-type sediments of the Münder Formation (Lower Cretaceous, Hils Syncline, N-Germany). In Applications of lacustrine and marginal-marine Ostracoda to palaeoenvironmental reconstruction, 15th International Symposium on Ostracoda, eds. S. Mischke, and J. A. Holmes. Palaeogeography, Palaeoclimatology, Palaeoecology 246(3-4): 230-249.

Athen, K., O. Wings, and A. Broschinski. 2005. Wildwechsel von 140 Millionen Jahren. Dinosaurierspuren führen ins Niedersächsische Landesmuseum nach Hannover. Museum Aktuell 118(9): 6-8.

Bachmann, G.H., and S. Grosse. 1989. Struktur und Entstehung des Norddeutschen Beckens-geologische und geophysikalische Interpretation einer verbesserten Bouguer-Schwerekarte. In Das Norddeutsche Becken. 
Geophysikalische und geologische Untersuchungen des tieferen Untergrundes: Vorträge. Niedersächsische Akademie der Geowissenschaften, Veröffentlichungen 2: 23-47.

Ballerstedt, M. 1905. Über Saurierfährten der Wealdenformation Bückeburgs. Naturwissenschaftliche Wochenschrift (Neue Folge) 4(31): 481-485.

Ballerstedt, M. 1914. Bemerkungen zu den älteren Berichten über Saurierfährten im Wealdensandstein und Behandlung einer neuen, aus 5 Fußabdrücken bestehenden Spur. Centralblatt für Mineralogie, Geologie und Paläontologie 1914(2): 48-64.

Ballerstedt, M. 1921a. Zwei große, zweizehige Fährten hochbeiniger Bipeden aus dem Wealdensandstein bei Bückeburg. Zeitschrift der Deutschen Geologischen Gesellschaft, Monatsberichte 73B: 76-91.

Ballerstedt, M. 1921b. Dinosaurierfährten im Wealdensandstein des Harrl bei Bückeburg und eine zur Zeit freiliegenden Spur eines „vierfüßigen“plumpen Dinosauriers. Zeitschrift der Deutschen Geologischen Gesellschaft 72: 231-233.

Ballerstedt, M. 1922. Über Schreckensaurier und ihre Fußspuren. Kosmos 19(3): 77-80.

Barner, W. 1931. Unsere Heimat Band 1: Das Land zwischen Hildesheimer Wald und Ith. xi+571 pp., Hildesheim: Lax.

Beckles, S.H. 1852. On the Ornithoidichnites of the Wealden. Quarterly Journal of the Geological Society 8(1-2): 396-397.

Beckles, S.H. 1854. On the Ornithoidichnites of the Wealden. Quarterly Journal of the Geological Society 10(1-2): 456-464.

Bennett, S.C. 2007. A review of the pterosaur Ctenochasma: Taxonomy and ontogeny. Neues Jahrbuch für Geologie und Paläontologie, Abhandlungen 245(1): 23-31.

Berner, U. 2011. The German Wealden, an unconventional hydrocarbon play? Erdöl, Erdgas, Kohle 127(7/8): 303-306.

Berner, U., T. Kahl, and G. Scheeder. 2010. Hydrocarbon potential of sediments of the German Wealden Basin. Oil Gas. European Magazine II/2010: 80-84.

Betz, D., F. Führer, G. Greiner, and E. Plein. 1987. Evolution of the Lower Saxony Basin. Tectonophysics 137(1-4): 127-170.

Beyrich, H.E., W. Websky, and O. Speyer. 1879. 2. Protokoll der December-Sitzung. Zeitschift der Deutschen Geologischen Gesellschaft 31: 798-804.

Blumenbach, J.F. 1803. Specimen archaeologiae telluris terrarumque inprimis Hannoveranarum. Göttingen: H. Dieterich.

Boenigk, G. 1990. Geologie im Niedersächsischen Landesmuseum Hannover. Hannover: Niedersächsisches Landesmuseum.

Böhme, A., U. Stratmann, M. Wiggenhagen, T. van der Lubbe, and A. Richter. 2009. New tracks on the rock: Parallel trackways of a new type of Iguanodontipus-Caririchnium-like morphology from the Lower Cretaceous sandstones of Obernkirchen, northern Germany. Journal of Vertebrate Paleontology 29(3): 66A.

Bose, S., and H.S. Chafetz. 2009. Topographic control on distribution of modern microbially induced sedimentary structures (MISS): A case study from Texas coast. Sedimentary Geology 213: 136-149.

Branco, W. 1887. Beiträge zur Kenntnis der Gattung Lepidotus. Abhandlungen zur geologischen Specialkarte von Preußen 
und den thüringischen Staaten 7(4): 84 pp.

Broschinski, A. 2004. Exkursion 3: Der Obernkirchner Sandstein-Naturwerkstein und Fossilfundgrube der Unterkreide. In Geobiologie 2. 74. Jahrestagung der Paläontologischen Gesellschaft in Göttingen 02. bis 08. Oktober 2004. Exkursionen und Workshops, eds. J. Reitner, M. Reich, and G. Schmidt, 53-72, Göttingen: Universitäts-Verlag.

Butler, R.J., and R.M. Sullivan. 2009. The phylogenetic position of the ornithischian dinosaur Stenopelix valdensis from the Lower Cretaceous of Germany and the early fossil record of Pachycephalosauria. Acta Palaeontologica Polonica 54(1): 21-34.

Butler, R.J., P. Upchurch, and D.B. Norman. 2008. The phylogeny of the ornithischian dinosaurs. Journal of Systematic Palaeontology 6: 1-40.

Casey, R., P. Allen, G. Dörhöfer, F. Gramann, N.F. Hughes, E. Kemper, P.F. Rawson, and F. Surlyk. 1975. Stratigraphical subdivision of the Jurassic-Cretaceous boundary beds in NW Germany. Newsletters on Stratigraphy 4(1): 4-5.

Corda, A.J. 1845. Beiträge zur Flora der Vorwelt. Prag: Calve.

Dames, W. 1884a. Megalosaurus dunkeri. Sitzungsberichte der Gesellschaft naturforschender Freunde zu Berlin (1884) (10): 186-188.

Dames, W. 1884b. Über ein Humerusfragment eines Dinosauriers welches im Liegenden des Hauptflötzes im Marienschacht auf der Körssen bei Stadthagen gefunden wurde. Zeitschrift der Deutschen Geologischen Gesellschaft 36: 186-187.

Diedrich, C. 2004. New important iguanodontid and theropod trackways of the tracksite Obernkirchen in the Berriasian of NW Germany and megatracksite concept of Central Europe. Ichnos 11(3): 215-228.

Dietrich, O.W. 1927. Über Fährten ornithopodider Saurier im Oberkirchner Sandstein Sandstein. Zeitschrift der Deutschen Geologischen Gesellschaft 78: 614-621.

Dollo, L. 1883. Troisième note sur les dinosauriens de Bernissart. Bulletin du Musée Royal de d'Histoire Naturelle de Belgique 2: 85-126.

Dunker, W. 1846. Monographie der Norddeutschen Wealdenbildung: ein Beitrag zur Geognosie und Naturgeschichte der Vorwelt. Braunschweig: Oehme and Müller.

Dunker, W. 1849. Ueber den norddeutschen sogenannten Wälderthon und dessen Versteinerungen. Studien des Göttingischen Vereins Bergmännischer Freunde 5(2): 105-185.

Edinger, T. 1938. Über Steinkerne von Hirn- und Ohr-Höhlen der Mesosuchier Goniopholis und Pholidosaurus aus dem Bückeburger Wealden. Acta Zoologica 19(3): 467-505.

Elstner, F., and J. Mutterlose. 1996. The Lower Cretaceous (Berriasian and Valanginian) in NW Germany. Cretaceous Research 17(1): 119-133.

Eriksson, P.G., J. Schieber, E. Bouougri, G. Gerdes, H. Porada, S. Banerjee, P.K. Bose, and S. Sakar. 2007. Classification of structures left by microbial mats in their host sediments. In Atlas of microbial mat features preserved within the clastic rock record, ed. J. Schieber, J. Bose, P.K. Eriksson, B.G. Banerjee, S. Sarkar, W. Altermann, and O. Catunaeau, 3952. Amsterdam: Elsevier. 
Falke, H. 1944. Der Wealden-Steinkohlenbergbau in Niedersachsen. Veröffentlichungen des Provinzialinstituts für Landesplanung und niedersächsische Landes- und Volksforschung Hannover-Göttingen (A: Forschungen zur Landesund Volkskunde, I: Natur und Wirtschaft) 23: 130 pp.

Farlow, J.O., J.G. Pittman, and M. Hawthorne. 1989. Brontopodus birdi, Lower Cretaceous sauropod footprints from the U.S. Gulf Coastal Plain. In Dinosaur tracks and traces, ed. D.D. Gillette, and M.G. Lockley, 371-394. Cambridge: Cambridge University Press.

Fischer, R. 1987. Exkursion V-1. Bedeutende paläontologische Lokalitäten im östlichen Niedersachsen. In 57. Jahrestagung der Paläontologischen Gesellschaft, Exkursionsführer Harz und Harzvorland, 2-26, Clausthal-Zellerfeld: Institut für Geologie und Paläontologie.

Fischer, R. 1998. Die Saurierfährten im Naturdenkmal Münchehagen. Mitteilungen aus dem geologischen Institut der Universität Hannover 37: 3-59.

Fischer, R., and D. Thies. 1993. Das Dinosaurier-Freilichtmuseum Münchehagen und das Naturdenkmal „Saurierfährten“, 1st ed., 60 pp., Rehburg-Loccum.

Fischer, R., and D. Thies. 2000. Das Dinosaurier-Freilichtmuseum Münchehagen und das Naturdenkmal „Saurierfährten“, 2nd ed. Rehburg-Loccum: Dino-Park Münchehagen.

Fischer, R., S. Kulle-Battermann, and R. Töhneböhn. 1988. Das “Naturdenkmal Saurierfährten Münchehagen”. Natur und Museum 118(12): 385-392.

Grabbe, H. 1881. Neue Funde von Saurier-Fährten im Wealdensandsteine des Bückeberges. Verhandlungen des naturhistorischen Vereines der preussischen Rheinlande und Westfalens, Correspondenzblatt 38(1): 161-164. (=Vierte Folge volume 8).

Grabbe, H. 1883. Die Schaumburg-Lippe’sche Wealden-Mulde. Doctoral thesis, University of Göttingen, 61 pp., Bückeburg: Grimme.

Grabbe, H. 1884. Beitrag zur Kenntnis der Schildkröten des deutschen Wealden. Zeitschrift der Deutschen geologischen Gesellschaft 36: 17-28.

Gramann, F., C. Heunisch, H. Klassen, F. Kockel, G. Dulce, F.-J. Harms, T. Katschorek, E. Mönnig, M. Schudack, U. Schudack, D. Thies, and M. Weiss. 1997. Das Niedersächsische Oberjura-Becken-Ergebnisse interdisziplinärer Zusammenarbeit. Zeitschrift der Deutschen Geologischen Gesellschaft 148(2): 165-236.

Graupner, A. 1977. Natursteine an hannoverschen Bauwerken. Hannoversche Geschichtsblätter 35: 103-152.

Graupner, A. 1980. Der Berrias-Steinkohlenbergbau in Niedersachsen 1945-1963. Veröffentlichungen des niedersächsischen Instituts für Landeskunde und Landesentwicklung an der Universität Göttingen. Forschungen zur niedersächsischen Landeskunde 116: 184 pp.

Grupe, 0. 1931. Über Wurzelböden im Wealdensandstein der Bückeberge und ihre Bedeutung für den Rhythmus dynamischer Vorgänge. Zeitschrift der Deutschen Geologischen Gesellschaft 83: 224-234.

Grupe, 0. 1933. Blatt Bückeburg, Nr. 2017. Erläuterungen zur geologischen Karte von Preußen und benachbarter deutscher Länder, Lieferung 330: 69 pp. 
Haderer, F., and C. Neef. 2004. Ein weiterer Nachweis der Theropodenfährte Bueckeburgichnus aus dem Obernkirchener Sandstein von Nordwestdeutschland. Bericht der Naturhistorischen Gesellschaft Hannover 146: 1-6.

Hamm, F. 1938. Einführung in Niedersachsens Erdgeschichte. 333 pp., Hildesheim and Leipzig: Lax.

Hamm, F. 1957. Letzte Spuren großer Landechsen in Niedersachsen. Niedersachsen Zeitschrift für Kultur, Geschichte, Heimat und Natur 3: 209-212.

Harnack, I. 1989. Der 'Bremer Stein'—Ein Stein macht Geschichte. Begleitheft zur Sonderausstellung im Übersee-Museum vom 5.2. bis 2.4.1989. Bremen: Übersee-Museum.

Haubold, H. 1971. Ichnia Amphibiorum et Reptiliorum fossilium. Handbuch der Paläoherpetologie 18: 124 pp.

Haubold, H. 1974. Die fossilen Saurierfährten. Die neue Brehm-Bücherei 479: 168 pp., Wittenberg: Ziemsen.

Haubold, H. 1984. Saurierfährten. Die neue Brehm-Bücherei 479: 231 pp., Wittenberg Lutherstadt: Ziemsen.

Hendricks, A. 1981. Die Saurierfährten von Münchehagen bei Rehburg-Loccum (NW-Deutschland). Abhandlungen aus dem Landesmuseum für Naturkunde zu Münster in Westfalen 43: 1-22.

Hiltermann, H. 1949. Funde von bernsteinartigen Harzen in der Unterkreide Nordwestdeutschlands. Schriften des Naturwissenschaftlichen Vereins für Schleswig-Holstein 24(1): 70-73.

Hoffmann, F. 1830. Uebersicht der orographischen und geognostischen Verhältnisse vom nordwestlichen Deutschland. Leipzig: J.A. Barth.

Hornung, J.J., and M. Reich. 2006. The "Wealden” collection of Max Ballerstedt (1857-1945) - undisclosed treasures from the Early Cretaceous of northwestern Germany. In 76. Jahrestagung der Paläontologischen Gesellschaft. Kiel, 28.-30. August 2006. Beitragskurzfassungen. Berichte-Reports des Instituts für Geowissenschaften, Christian-AlbrechtsUniversität Kiel 22:40-41.

Hornung, J.J., and M. Reich. 2007. Krokodile, Schildkröten \& Dinosaurier. Die "Wealden"-Sammlung der Universität Göttingen. Fossilien 24(1): 32-36.

Hornung, J.J., J. König, and M. Reich. 2007. Rediscovered type material of the ankylosaurian ichnospecies Metatetrapous valdensis Nopcsa, 1923 (Early Cretaceous, NW Germany). In Fossile Ökosysteme. 77. Jahrestagung der Paläontologischen Gesellschaft. Kurzfassungen der Vorträge und Poster, eds. O. Elicki, and J.W. Schneider. Wissenschaftliche Mitteilungen, Institut für Geologie, TU Bergakademie Freiberg 36: 59-60.

Hornung, J.J., Karl, H.-V., and Reich, M. 2008. An exquisitely preserved turtle footprint from the Berriasian (lowermost Cretaceous) of northwestern Germany. In Jahrestagung der Paläontologischen Gesellschaft. 8.-10. September 2008, Erlangen, eds. S.B. Löffler, and A. Freiwald. Erlanger geologische Abhandlungen, Sonderband 6: 91-92.

Huckriede, R. 1967. Molluskenfaunen mit limnischen und brackischen Elementen aus Jura, Serpulit und Wealden NWDeutschlands und ihre paläogeographische Bedeutung. Beihefte zum Geologischen Jahrbuch 67: 263 pp.

Hulke, R. 1980. Mit raumgreifenden Schritten stapfte der Dinosaurier über das Meer-Ufer. Die Harke (29 Nov 1980), without pagination, Nienburg/Weser. (local newspaper). 
Jaffé, G. 1912. Über Pholidosaurusreste aus dem Naturhistorischen Museum in Lübeck. Mitteilungen der Geographischen Gesellschaft und des Naturhistorischen Museums in Lübeck (Zweite Reihe) 25: 1-10.

Jordan, H. 1979. Erläuterungen zu Blatt Nr. 3521 Rehburg. In Geologische Karte von Niedersachsen, ed. Niedersächsisches Landesamt für Bodenforschung, 134 pp., Hannover: Landesamt für Bodenforschung.

Kästner, M., I. Schülke, and J. Winsemann. 2008. Facies architecture of a Late Jurassic carbonate ramp: the Korallenoolith of the Lower Saxony Basin. International Journal of Earth Sciences 97(5): 991-1011.

Karl, H.-V., A. Gehler, V.J. Roden, and M. Reich. 2007a. Die Schildkröten des nordwestdeutschen “Wealden” (Unter-Kreide: Berriasium) und ihre Paläoökologie. In Fossile Ökosysteme. 77. Jahrestagung der Paläontologischen Gesellschaft. Kurzfassungen der Vorträge und Poster, eds. O. Elicki, and J.W. Schneider. Wissenschaftliche Mitteilungen, Institut für Geologie, TU Bergakademie Freiberg 36:64-65.

Karl, H.-V., U. Staesche, G. Tichy, and S. Peitz. 2007b. Systematik der Schildkröten (Anapsida: Chelonii) aus Oberjura und Unterkreide von Nordwestdeutschland. In Fossile Schildkröten aus vier Ländern in drei Kontinenten, coord. U. Staesche. Geologisches Jahrbuch (B: Regionale Geologie Ausland) 98: 5-89.

Kauenhowen, W. 1927. Die Faziesverhältnisse und ihre Beziehung zur Erdölbildung an der Wende Jura - Kreide in Nordwestdeutschland. Neues Jahrbuch für Mineralogie etc. (B: Geologie und Paläontologie), Beilagen-Band 58: 215272.

Kemper, E. 1973. Das Berrias (tiefe Unterkreide) in NW-Deutschland. Geologisches Jahrbuch (A: Allgemeine und regionale Geologie BR Deutschland und Nachbargebiete, Tektonik, Stratigraphie, Paläontologie) 9: 47-67.

Kemper, E. 1992. Die tiefe Unterkreide im Vechte-Dinkel-Gebiet (westliches Niedersächsisches Becken). Losser: Stichting het Starinmonument te Losser.

Kleinschmidt, G. 1986. Die Dinosaurierspuren der Bückeberg-Formation in den Rehburger Bergen bei Münchehagen (NWDeutschland). Unpublished Diploma thesis, University of Münster, 108 pp., Münster.

Koken, E. 1883. Die Reptilien der norddeutschen unteren Kreide. Zeitschrift der Deutschen Geologischen Gesellschaft 35: 735-827.

Koken, E. 1886. Vorkommen fossiler Crocodiliden in den Wealdenbildungen Norddeutschlands und über die Systematik der mesozoischen Crocodiliden. Zeitschrift der Deutschen Geologischen Gesellschaft 38: 664-670.

Koken, E. 1887. Die Dinosaurier, Crocodiliden und Sauropterygier des norddeutschen Wealden. Palaeontologische Abhandlungen 3(5): 1-111.

Koken, E. 1896. Die Reptilien des norddeutschen Wealden. Nachtrag. Palaeontologische Abhandlungen 7: 119-126. (=N.F. $3(2))$.

Kuhn, O. 1958. Die Fährten der vorzeitlichen Amphibien und Reptilien. Bamberg: Meisenbach.

Kvale, E.P., A.D. Johnson, D.L. Mickelson, K. Keller, L.C. Furer, and A.W. Archer. 2001. Middle Jurassic (Bajocian and Bathonian) Dinosaur Megatracksites, Big Horn Basin, Wyoming, U.S.A. Palaios 16(3): 233-254.

LBEG [Landesamt für Bergbau, Energie und Geologie Niedersachsen] 2009. Cardomap server, http://memas01.lbeg.de/lucidamap/index.asp [last accessed 02 Jul 2009]. 
Lehmann, J. 2003. Dinosaurierfährten aus dem Obernkirchener Sandstein (Unterkreide, Berriasium) in der Geowissenschaftlichen Sammlung der Universität Bremen. Abhandlungen des Naturwissenschaftlichen Vereins zu Bremen 45: 473-486.

Lehmann, J. 2006. Dinosaurier-Spuren einer vergangenen Welt. Münchehagen, der Bremer Stein und die Saurierfährten. Haus der Wissenschaft e. V. 3: 1-91.

Lehmann, J., M. Krogmann, U. Richter, and A. Broschinski. 2006. Neue Dinosaurierfährten vom Rang eines Naturdenkmals in den Sandsteinen der Bückeberg Formation (Unterkreide, Berriasium) von Münchehagen, Niedersachsen. Abhandlungen des Naturwissenschaftlichen Vereins zu Bremen 46: 27-37.

Lehmann, U. 1978. Eine Platte mit Fährten von Iguanodon aus dem Obernkirchener Sandstein (Wealden). Mitteilungen aus dem Geologisch-Paläontologischen Institut der Universität Hamburg 48: 101-114.

Lessertisseur, J. 1955. Traces fossiles d'activite animale et leur signification paleobiologique. Mémoires de la Société Géologique de France (Nouvelle Série) 34(74): 1-148.

Lill, K., and W. Riegel. 1991. Ein fluviatil dominiertes Delta im „Unteren Wealden“(Berrias, Bueckeberg-Folge) von Borgloh/Kloster Ösede, Osnabrücker Hügelland, Niedersachsen). Bericht der Naturhistorischen Gesellschaft Hannover 133: 221-255.

Lipps, T. 1923. Ueber die Unter-Kreide-Flora Nordwest-Deutschlands, besonders die Flora des Barrémien von Hildesheim. Botanisches Archiv 4(5): 329-381.

Lockley, M.G. 1991a. Tracking Dinosaurs: A new Look at an Ancient World. Cambridge, MA: Cambridge University Press.

Lockley, M.G. 1991b. The Moab Megatracksite: A preliminary description and discussion of millions of Middle Jurassic tracks in eastern Utah. In Guidebook for Dinosaur Quarries and Tracksites Tour, Western Colorado and Eastern Utah, ed. W.R. Averett, 59-65. Grand Junction, C0: Museum of Western Colorado.

Lockley, M.G. 1993. Auf den Spuren der Dinosaurier. Dinosaurierfährten-Eine Expedition in die Vergangenheit. Basel: Birkhäuser.

Lockley, M.G. 1997. The paleoecological and paleoenvironmental utility of Dinosaur tracks. In The complete Dinosaur, ed. J.O. Farlow, and M.K. Brett-Surman, 554-578. Bloomington, IN: Indiana University Press.

Lockley, M.G. 2000. An amended description of the theropod footprint Bueckeburgichnus maximus Kuhn 1958, and its bearing on the megalosaur tracks debate. Ichnos 7(3): 217-225.

Lockley, M.G., and C.A. Meyer. 2000. Dinosaur tracks and other fossil footprints of Europe. New York: Columbia University Press.

Lockley, M.G., and J.G. Pittman. 1989. The megatracksite phenomenon: Implications for paleoecology, evolution and stratigraphy. Journal of Vertebrate Paleontology 9(3): 30A.

Lockley, M.G., A. Hunt, J. Holbrook, M. Matsukawa, and C. Meyer. 1992. The dinosaur freeway: A preliminary report on the Cretaceous megatracksite, Dakota Group, Rocky Mountain Front Range and High Plains, Colorado, Oklahoma and New Mexico. In Mesozoic of the Western Interior, ed. R. M. Flores. SEPM Midyear Meeting Field Guidebook (1992): 39-54, Fort Collins, Colo. [Theme Meeting 17.-19.08.1992, Rocky Mountain Section SEPM]. 
Lockley, M.G., J.O. Farlow, and C.A. Meyer. 1994. Brontopodus and Parabrontopodus ichnogen. nov. and the significance of wide- and narrow-gauge sauropod trackways. Gaia 10: 135-145.

Lockley, M.G., C.A. Meyer, and V.F. dos Santos. 1998. Megalosauripus and the problematic concept of megalosaur footprints. In Aspects of Theropod Paleobiology, eds. B.P. Pélaez-Moreno, T. Holtz jr., J.L. Sanz, and J. Moratalla. Gaia 15:313-337.

Lockley, M.G., J.L. Wright, and D. Thies. 2004. Some observations on the dinosaur tracks at Münchehagen (Lower Cretaceous), Germany. Ichnos 11(3-4): 261-274.

Look, E.-R. 1986. Dinosaurierfährten von Münchehagen im Landkreis Nienburg, 15 pp., Nienburg.

Look, E.-R., S. Kulle-Battermann, and R. Töneböhn. 1988. Die Dinosaurierfährten von Münchehagen (Landkreis Nienburg/Weser) im Naturpark "Steinhuder Meer", 20 pp., Hannover: Naturhistorische Gesellschaft.

López-Arbarello, A., M. Reich, and A. Gehler. 2007. New specimen of "Lepidotes" mantelli Agassiz, 1833 from the German "Wealden" and the taxonomy of the giant "Lepidotes" of Europe. In Fossile Ökosysteme. 77. Jahrestagung der Paläontologischen Gesellschaft. Kurzfassungen der Vorträge und Poster, eds. O. Elicki, and J.W. Schneider. Wissenschaftliche Mitteilungen, Institut für Geologie, TU Bergakademie Freiberg 36: p. 92.

Mägdefrau, K., and H. Rudolf. 1969. Morphologie und Histologie der Nadel der Conifere Abietites linkii (Roem.) Dunk. aus dem Wealden des Hils. Neues Jahrbuch für Geologie und Paläontologie, Monatshefte 5: 288-298.

Mantell, G.A. 1825. Notice on the Iguanodon, a newly discovered Fossil Reptile, from the Sandstone of Tilgate Forest, in Sussex. Philosophical Transactions of the Royal Society of London 115(2): 179-186.

Martin, G.P.R. 1940. Ostracoden des norddeutschen Purbeck und Wealden. Senckenbergiana 22: 275-361.

Martin, G.P.R. 1958. Über die systematische Stellung der Gattung Cypridea Bosquet (Ostracoda), nebst Beschreibung der Wealden-Basis-Ostracode C. buxtorfi n. sp. Neues Jahrbuch für Geologie und Paläontologie, Monatshefte 7: 312-320.

Martin, G.P.R. 1961a. Eine marine Mikrofauna im Wealden von Emlichheim (Emsland, NW-Deutschland. Palaeontographica (A. Paläozoologie, Stratigraphie) 116: 105-120.

Martin, G.P.R. 1961b. Die Gattung Fabanella n. g. (Ostracoda) im NW-deutschen Malm und Wealden. Senckenbergiana Lethaea 42(3/4): 181-195.

Martin, G.P.R., and W. Weiler. 1954. Fisch-Otolithen aus dem deutschen Mesozoikum (Dogger bis Wealden). Senckenbergiana Lethaea 35(3/4): 119-182.

Marty, D., A. Strasser, and C.A. Meyer. 2009. Formation and taphonomy of human footprints in microbial mats of presentday tidal-flat environments: Implications for the study of fossil footprints. Ichnos 16(1-2): 127-142.

Meyer, C.A. 1993. A sauropod dinosaur megatracksite from the Late Jurassic of northern Switzerland. Ichnos 3(1): 29-38.

Meyer, D. 1987. Naturdenkmal Saurierfährten von Münchehagen. Fossilien 4(3): 142-143.

Mutterlose, J. 1997a. Lower Cretaceous. In Cretaceous Depositional Environments of NW Germany, eds. J. Mutterlose, M.G.E. Wippich, and M. Geisen. Bochumer Geologische und Geotechnische Arbeiten 46: 7-12. 
Mutterlose, J. 1997b. Münchehagen quarry. In Cretaceous depositional environments of NW Germany, eds. J. Mutterlose, M.G.E. Wippich, and M. Geisen. Bochumer Geologische und Geotechnische Arbeiten 46: 123-128.

Mutterlose, J. 2000. Unterkreide im Niedersächsischen Becken. In Die Kreide der Bundesrepublik Deutschland, ed. Stratigraphische Kommission Deutschlands. Courier Forschungsinstitut Senckenberg 226: 79-101.

Mutterlose, J., and A. Bornemann. 2000. Distribution and facies patterns of Lower Cretaceous sediments in northern Germany: a review. Cretaceous Research 21(6): 733-759.

Naumann, E. 1927. Blatt Eldagsen, Nr. 2088. Erläuterungen zur geologischen Karte von Preußen und benachbarten deutschen Ländern 265: 57 pp.

Nopcsa, F. 1923. Die Familien der Reptilien. Fortschritte der Geologie und Palaeontologie 1 (2): 210 pp.

Norman, D.B. 2004. Basal Iguanodontia. In The Dinosauria, ed. D.B. Weishampel, P. Dodson, and H. Osmolska, $413-437$. Berkeley, CA: University of California Press.

Nyhuis, C. and H.-G. Herbig. 2009. Ichthyolithe aus dem Berriasium von Gronau/Westfalen (westliches Niedersächsisches Kreidebecken)-Rekonstruktion einer trophischen Kette aus sturmkondensierten Bonebeds. In Paläontologie Schlüssel zur Evolution. 79. Jahrestagung der Paläontologischen Gesellschaft. Kurzfassungen der Tagungsbeiträge, eds. T. Martin, and S.I. Kaiser. Terra Nostra. Schriften der Alfred-Wegener-Stiftung 2009/3: p. 85.

Owen, R. 1842. Report on British Fossil Reptiles. Part II. Report of the Annual Meeting of the British Association for the Advancement of Science 12: 60-204.

Paul, G. 2008. A revised taxonomy of the iguanodont dinosaur genera and species. Cretaceous Research 29(2): $192-216$.

Pelzer, G. 1984. Cross section through a fluvial environment in the Wealden of Northwest Germany. In Short papers. Third symposium on Mesozoic terrestrial ecosystems, ed. W.-E. Reif, and F. Westphal, 181-186. Tübingen: Attempto Verlag.

Pelzer, G. 1987. Transition from fluvial to littoral environments in the Wealden facies (lower most Cretaceous) of Northwest Germany. In Short papers. 4. Symposium on Mesozoic Terrestrial Ecosystems, eds. P.J. Currie, and E.H. Koster. Occasional Paper of the Tyrell Museum of Palaeontology 3: 177-182.

Pelzer, G. 1998. Sedimentologie und Palynologie der Wealden-Fazies im Hannoverschen Bergland. Courier Forschungsinstitut Senckenberg 207: 211 pp.

Pelzer, G., and V. Wilde. 1987. Klimatische Tendenzen während der Ablagerung der Wealden-Fazies in Nordwesteuropa. Geologisches Jahrbuch (A: Allgemeine und regionale Geologie BR Deutschland und Nachbargebiete, Tektonik, Stratigraphie, Paläontologie) 96: 239-263.

Pelzer, G., Riegel, W., and V. Wilde. 1992. Depositional controls on the Lower Cretaceous Wealden coals of northwest Germany. In Controls on the Distribution and Quality of Cretaceous Coals, eds. P.J. McCabe, and J.T. Parrish. Geological Society of America, Special Paper 267: 227-244.

Peitz, S. 1998. Schildkröten der deutschen Wealden-Fazies - Ein Einblick in die Ballerstedtsche Sammlung. In 2. Treffen der deutschsprachigen Paläoherpetologen, Tübingen 27.02.-01.03.1998. Extended Abstracts, eds. M.W. Maisch, and A.T. Matzke, 12-18, Tübingen.

Probst, E., and R. Windolf. 1993. Dinosaurier in Deutschland. München: Bertelsmann. 
Richter, A., and U. Stratmann. 2007. Obernkirchener Sandsteinbrüche auf dem Bückeberg. Naturwerksteine und Fossilien der Unterkreidezeit. In Niedersächsisches Landesamt für Bergbau, Energie und Geologie, Geotope 109: 2 pp., Hannover. available online at http://www.lbeg.de/extras/geologie/downloads/geotope/Nr_109_obernkirchen_bueckeberg.pdf [last accessed 24 Feb 2009].

Richter, A., O. Wings, U. Richter, and N. Knötschke. 2007. "Happy Feet": A new Lower Cretaceous dinosaur tracksite from Münchehagen, Germany. Journal of Vertebrate Paleontology 27(3): 134A.

Richter, A., A. Böhme, and T. van der Lubbe. 2009. “Chicken Run”: A new unusual, heavily dinoturbated tracksite from the Lower Cretaceous sandstones of Obernkirchen, northern Germany. Journal of Vertebrate Paleontology 29(3): 171A.

Richter, U. 2007. Dinosaurier-Freilichtmuseum und Naturdenkmal Saurierfährten Münchehagen. Rehburg-Loccum: DinoPark Münchehagen.

Richter, U., A. Richter, and J. Lehmann. 2007. Fährtensucher auf der Dinospur in den Rehburger Bergen. Fossilien 24(1): 11-20.

Riegel, W., and K. Lill. 1988. Geologische und sedimentologische Untersuchungen im Berrias von Borgloh/Kloster Ösede (Osnabrücker Hügelland, Niedersachsen). Nachrichten der Deutschen Geologischen Gesellschaft 39: 78-79.

Riegel, W., and V. Wilde. 1984. Biota and sedimentology of a fluvial environment in the Wealden of Northwest Germany; implications for ecosystem reconstruction. In Short papers. Third symposium on Mesozoic terrestrial ecosystems, ed. W.-E. Reif, and F. Westphal, 199-200. Tübingen: Attempto Verlag.

Riegel, W., G. Pelzer, and V. Wilde. 1986. Erste Ergebnisse einer paläobotanischen Grabung in der fluviatilen WealdenFazies des Osterwaldes bei Hannover. Courier Forschungs-Institut Senckenberg 86: 137-170.

Roemer, F.A. 1836. Die Versteinerungen des Norddeutschen Oolithen-Gebirges. Hannover: Hahn.

Sachs, S. 1997. Erster Nachweis eines gepanzerten Dinosauriers (Reptilia, Ornithischia, Thyreophora) aus der Unterkreide von Gronau in Westfalen. Neues Jahrbuch für Geologie und Paläontologie, Monatshefte 1: 56-64.

Salisbury, S.W., Willis, P.M.A., Peitz, S., and Sander, P.M. 1999. The crocodilian Goniopholis simus from the Lower Cretaceous of north-western Germany. In Cretaceous fossil vertebrates, D.M. Unwin. Special Papers in Palaeontology, 60: 121-148.

Sarjeant, W.A.S., J.B. Delair, and M.G. Lockley. 1998. The footprints of Iguanodon: a History and taxonomic study. Ichnos 6(3): 183-202.

Schmidt, H. 1959. Die Cornberger Fährten im Rahmen der Vierfüßler-Entwicklung. Abhandlungen des Hessischen Landesamtes für Bodenforschung 28: $137 \mathrm{pp}$.

Schmidt, H. 1969. Stenopelix valdensis H. v. Meyer, der kleine Dinosaurier des norddeutschen Wealden. Paläontologische Zeitschrift 43(3-4): 194-198.

Schott, W., W. Jaritz, F. Kockel, C.W. Sames, U. von Stackelberg, J. Stets, D. Stoppel, R. Baldschuhn, and K.-D. Krampe. 1967. Paläogeographische Karten von Nordwestdeutschland im Maßstab 1:200000. In Paläogeographischer Atlas der Unterkreide von Nordwest-Deutschland mit einer Übersichtsdarstellung des nördlichen Mitteleuropa, ed. Bundesanstalt für Bodenforschung, 289 pp., Hannover: Bundesanstalt für Bodenforschung. 
Schott, W., W. Jaritz, F. Kockel, C.W.Sames, U. von Stackelberg, J. Stets, D. Stoppel, R. Baldschuhn, and K.-D. Krampe. 1969. Erläuterungen. In: Bundesanstalt für Bodenforschung (ed.): Paläogeographischer Atlas der Unterkreide von NordwestDeutschland mit einer Übersichtsdarstellung des nördlichen Mitteleuropa. 315 pp., Hannover: Bundesanstalt für Bodenforschung.

Schudack, M. 1996. Die Charophyten des Niedersächsischen Beckens (Oberjura - Berriasium): Lokalzonierung, überregionale Korrelation und Palökologie. Neues Jahrbuch für Geologie und Paläontologie, Abhandlungen 200(1/2): $27-52$.

Schudack, U., and M. Schudack. 2009. On the taxonomy of the species Cypridea setina Anderson, 1939 and Cypridea laevigata Dunker, 1846 (Ostracoda, Crustacea) from the Early Cretaceous of Europe-a special note on systematical inconsistencies. Berliner paläobiologische Abhandlungen 10: 311-320.

Schultze, H.-P. 1970. Indaginilepis rhombifera n. gen. et n. sp., ein altertümlicher Palaeoniscoide (Pisces, Actinopterygii) aus dem Wealden von Norddeutschland. Paläontologische Zeitschrift 44(1-2): 10-24.

Schwennicke, T. 1998. Sedimenttexturen und Lebensspuren der Sohlbank des Naturdenkmals "Saurierfährten Münchehagen". Mitteilungen aus dem geologischen Institut der Universität Hannover 37: 61-102.

Staesche, U. 1981. Die Saurierfährten von Münchehagen. Führer zu vor- und frühgeschichtlichen Denkmälern 49: 146149.

Stechow, E. 1909. Neue Funde von Iguanodon-Fährten. Centralblatt für Mineralogie, Geologie und Paläontologie (1909): $700-705$.

Strauss, C., F. Elstner, J. Du Chène, J. Mutterlose, H. Reiser, and K.-H. Brandt. 1993. New micropalaeontological and palynological evidence on stratigraphic position of the "German Wealden" in NW-Germany. Zitteliana 20: 389-401.

Struckmann, C. 1880a. Die Wealden-Bildung der Umgebung von Hannover. Eine geognostisch-paläontologisch-statistische Darstellung. Hannover: Hahn.

Struckmann, C. 1880b. Vorläufige Nachricht über das Vorkommen großer, vogelähnlicher Thierfährten (Ornithoidichnites) im Hastingssandsteine von Bad Rehburg bei Hannover. Neues Jahrbuch für Mineralogie, Geologie und Paläontologie 1: 125-128.

Struckmann, C. 1894. Über einen Zahn des Iguanodon aus dem Wealden von Sehnde bei Lehrte. Zeitschrift der Deutschen Geologischen Gesellschaft 156: 828-831.

Sues, H.-D., and P.M. Galton. 1982. The systematic position of Stenopelix valdensis (Reptilia: Ornithischia) from the Wealden of north-western Germany. Palaeontographica (A: Paläozoologie, Stratigraphie) 178: 183-190.

Thulborn, R.A. 2001. History and nomenclature of the theropod dinosaur tracks Bueckeburgichnus and Megalosauripus. Ichnos 8(3-4): 207-222.

Töneböhn, R., and S. Kulle-Battermann. 1989a. Die Dinosaurierfährten von Münchehagen. Teil A. Zur Paläontologie der Saurierfährten von Münchehagen. Unpublished report, 108 pp., Nienburg/Weser: Amt für Regionalplanung.

Töneböhn, R., and S. Kulle-Battermann. 1989b. Die Dinosaurierfährten von Münchehagen. Teil B. Maßnahmen zum Erhalt des Naturdenkmals "Saurierfährten Münchehagen". Unpublished report, 70 pp., Nienburg/Weser: Amt für 
Regionalplanung.

Töneböhn, R., and S. Kulle-Battermann. 1989c. Die Dinosaurierfährten von Münchehagen. Teil C. Vorschläge zur weiteren musealen Gestaltung des Naturdenkmals "Saurierfährten Münchehagen". Unpublished report, 70 pp., Nienburg/Weser: Amt für Regionalplanung.

van der Lubbe, T., A. Richter, and A. Böhme. 2009. Velociraptor's sisters: First report of troodontid tracks from the Lower Cretaceous of northern Germany. Jounal of Vertebrate Paleontology 29(3): 194A.

von Meyer, H. 1841. Pholidosaurus schaumburgensis, ein Saurus aus dem Sandstein der Wald-Formation NordDeutschlands. Neues Jahrbuch für Mineralogie, Geognosie, Geologie und Petrefakten-Kunde 1841: 443-445.

von Meyer, H. 1846. Reptilien aus der Wealdenformation Norddeutschlands. In: Dunker, W. (ed.): Monographie der Norddeutschen Wealdenbildung: ein Beitrag zur Geognosie und Naturgeschichte der Vorwelt. 70-83, Braunschweig.

von Meyer, H. 1851. Ctenochasma Roemeri. Palaeontographica 2(3): 82.

von Meyer, H. 1857. Beiträge zur näheren Kenntnis fossiler Reptilien. Neues Jahrbuch für Mineralogie, Geologie und Paläontologie (1857): 532-543.

von Meyer, H. 1859. Stenopelix Valdensis, ein Reptil aus der Wealden-Formation Deutschlands. Palaeontographica 7(1): 25-34.

Waldeck, H. 1969. Gefügeuntersuchungen in Wealdenkonglomeraten des Osterwaldes und Nesselberges südlich Hannover. Geologisches Jahrbuch 87: 229-275.

Wegner, T. 1913. Geologie Westfalens und der angrenzenden Gebiete, 1st ed. Paderborn: Schöningh.

Wegner, T. 1914. Brancasaurus brancai n. gen. n. sp., ein Elasmosauride aus dem Wealden Westfalens. In Wilhelm Branca zum siebzigsten Geburtstage, 9. Sept. 1914. Eine Festschrift seiner Schüler, ed. F. Schöndorf, 235-305, Leipzig: Borntraeger.

Wegner, T. 1926. Geologie Westfalens und der angrenzenden Gebiete, 2nd ed. Paderborn: Schöningh.

Wellnhofer, P. 1991. The illustrated Encyclopedia of Pterosaurs. New York: Crecent Books.

Wilde, V. 1991. Tritaenia (al. Abietites) linkii (Roemer) Mägdefrau \& Rudolf (Coniferae inc. sed.) und ihr Vorkommen in der Wealden-Fazies der unteren Kreide von Nordwestdeutschland. Neues Jahrbuch für Geologie und Paläontologie, Abhandlungen 183(1-3):363-374.

Wilde, V., and C. Heunisch. 1990. Auftreten und Erhaltung von Moosen im Mesozoikum (Keuper und Wealden) Nordwestdeutschlands. Nachrichten der Deutschen Geologischen Gesellschaft 43: 155.

Wilde, V., and S. Schultka. 1996. Die sandige Wealden-Fazies (Bückeberg-Formation, Berrias, Unterkreide) am Westrand eines Schüttungskörpers bei Osnabrück (NW-Deutschland). Neues Jahrbuch für Geologie und Paläontologie, Abhandlungen 199(2): 249-268.

Wilde, V., D. Thies, and W. Riegel. 1995. Exkursion D. Terrestrische Paläo-Ökologie im Wealden des Hannoverschen Berglandes. In Geologie und Paläontologie im Raum Hildesheim. Exkursionen aus Anlaß der 65. Jahrestagung der Paläontologischen Gesellschaft in Hildesheim 1995, eds. M. Boetzkes, and J. Vespermann. Terra Nostra. Schriften der 
Alfred-Wegener-Stiftung 95/5: 125-151.

Windolf, R. 1998. Dinosaurierfunde in Niedersachsen. Arbeitskreis Paläontologie Hannover 26(1): 1-7.

Wings, O., N. Schulze, N. Knötschke, and A. Broschinski. 2005a. Neue Dinosaurierfährten aus der Niedersächsischen Unterkreide. GMit, Geowissenschaftliche Mitteilungen 20: 33-35.

Wings, O., A. Broschinski, and N. Knötschke. 2005b. New theropod and ornithopod dinosaur trackways from the Berriasian of Münchehagen (Lower Saxony, Germany. In Current Research in Vertebrate Palaeontology 3rd Annual Meeting of the European Association of Vertebrate Palaeontologists (EAVP). Kaupia. Darmstädter Beiträge zur Naturgeschichte 14: 105.

Wolburg, J. 1949. Ergebnisse der Biostratigraphie nach Ostracoden im nordwestdeutschen Wealden. In Erdöl und Tektonik in Nordwestdeutschland, ed. A. Bentz, 349-360. Hannover: Amt für Bodenforschung.

Wolburg, J. 1959. Die Cyprideen des NW-deutschen Wealden. Senckenbergiana Lethaea 40(3/4): 223-315.

Wolburg, J. 1962. Zur Taxionomie und Nomenklatur einiger im Handbuch „Leitfossilien der Mikropalaeontologie“(1962) dargestellten Wealden-Ostracoden. Senckenbergiana Lethaea 43(6): 529-532.

Wolburg, J. 1971. Zur Taxonomie und Nomenklatur einiger Wealden-Ostracoden. Senckenbergiana Lethaea 52(1): 39-46.

Wright, J.L. 2005. Steps in understanding sauropod biology: The importance of sauropod tracks. In The sauropodsEvolution and paleobiology, ed. K.C. Rogers, and J.A. Wilson, 252-284. Berkeley, CA: University of California Press. 


\section{Addendum (2013) to Chapter IV}

After publication in print of Chapter IV in early 2012, the author became knowledge of the unpublished doctoral thesis by Jürgens (1972), who described numerous outcrops in the Obernkirchen Sandstone, many of which are not longer accessible, and reported four localities with dinosaur tracks. He gave no detailed description or figure of the tracks but mentioned them generally to be di- or tridactyl, up to $30 \mathrm{~cm}$ long and produced by an ,iguanodontian“.

- He confirmed the occurrence of tracks at locality 6 (Harrl hill).

- He (for the first time) reported tracks from the quarries of the Obernkirchen Sandstein $\mathrm{GmbH}$ at the Bückeberg (locality 8), both in the active eastern, as well as in the currently inactive western outcrop.

- Another tracksite was listed in a quarry between Nienstädt and Liekwegen, which is no longer in existence (completely infilled). It is possible that this locality is identical either to locality 9 or 10, the exact position of which are unknown. The locality is listed and mapped in Appendix B (Fig. B.1, p. 352) as locality C-9b.

- The fourth locality was at the Rodenberger Höhe in the Deister Mountains, described and mapped in Appendix B (Fig. B.1, p. 353) as locality C-17.

Additionally an isolated ornithopod footprint is known from a locality south of WennigsenBredenbeck, also in the Deister Mountains (see Appendix B: locality C-18, Fig. B.1, p. 353).

The latter two records are especially interesting as dinosaur tracks from the Deister Mountains have been mentioned widespread in popular accounts, however, reliable data on true finds were hard to obtain.

Ole Schirmer, Hannover, is thanked for making me aware of the thesis and the specimen from Wennigsen-Bredenbeck.

\section{References}

Jürgens, U. 1972. Sedimentologie der Wealden-Sandsteine im Hannoverschen Bergland (NW-Deutschland), Unpublished Doctoral Thesis. Hamburg: Universität Hamburg. 


\section{Chapter V}

Dinosaur tracks from the Berriasian Obernkirchen Sandstone on exhibit at the Göttingen University Geopark 
Published in:

Richter, A. \& Reich, M. (eds.): Dinosaur Tracks 2011. An International Symposium, Obernkirchen, April 14-17, 2011. Abstract Volume and Field Guide to Excursions: 169-187, Göttingen (Universitäts-Verlag) [2012]. Open access: http://webdoc.sub.gwdg.de/univerlag/2013/Dinotracks.pdf

\title{
Dinosaur tracks from the Berriasian Obernkirchen Sandstone on exhibit at the Göt- tingen University Geopark
}

\author{
JAHN J. HORNUNG ${ }^{1 *} \&$ MIKE REICH ${ }^{1,2^{*}}$ \\ ${ }^{1}$ Department of Geobiology, Geoscience Centre of the University of Göttingen, Göttingen, Germany \\ ${ }^{2}$ Geoscience Museum of the University of Göttingen, Göttingen, Germany
}

The collections of the Geoscience Centre at the University of Göttingen (GZG) includes two large blocks derived from the Obernkirchen Sandstone, both displaying a number of dinosaur tracks. The larger specimen is on public exhibit in the Geopark (Reich et al. 2009; Reich 2012) outside the GZG building. The smaller one is presently stored in a courtyard and not accessible to the public.

Data on the provenance of the blocks are scarce. The larger slab (GZG.IF.00100) was a donation by the Prince of Schaumburg-Lippe to the Georg-August University of Göttingen in 1880 (July 27; Fig. V.1). It originates from Wölpinghausen and is one of the few specimens still preserved from the area from which Struckmann (1880a, 1880b) described the first dinosaur tracks from the Obernkirchen Sandstone (Hornung, Böhme \& Reich 2012d). It was shortly mentioned, but not described, by Schmidt (1959).

The origin of the second specimen is entirely unknown. The yellowish colour of the sandstone is similar to material from the Bückeberg (Obernkirchen area) but this cannot be regarded unambiguous.

\section{The large block - GZG.IF.00100 (Figs. V.2-V.6, Table V.1)}

The block is $178 \mathrm{~cm}$ long, $150 \mathrm{~cm}$ wide, and consists of a 28-32 cm thick, massive, fine-grained sandstone layer (Fig. V.2). On the underside the tracks are preserved as hypichnial casts (reliefs). The tracks, preserved as undertracks, were impressed in a thin, sandy-clayey mudstone layer which is preserved in some patches. Its thickness varies slightly and thins in some areas to 1-2 mm. Sandfilled mudcracks in this layer evidence desiccation of the muddy bed. In one corner patches of a 1-2 cm thick layer of sandstone, casting current ripple marks, underlie the mudstone layer, representing the oldest preserved stratum. The asymmetrical ripple marks had sinusoidal crests. The palaeo-flow direction indicated by the ripple-marks is shown in Fig. V.2B. The top also contains the impression of a c. $5 \mathrm{~cm}$ long wood fragment.

At least 19 individual tracks are recognisable on the slab, ranging in preservation quality from 
good to vague. Many tracks show terrace-like lineation on the lower surface which can be interpreted as microfaults, formed due to the strain exerted by the foot to the substrate and/or subsequent track margin collapse after removal of the foot. There is also evidence of multiple overstepping and faintly preserved irregularities that suggest originally an even higher abundance of tracks. Due to the size of the trackmakers and partial overstepping, a maximum of two consecutive footprints are recorded in individual trackways. For most of the tracks no preceding or succeeding steps can be identified.

The block presents an unusual abundance and diversity of different morphotypes, referable to ornithopods as well as to theropods. The broad range of preservation quality suggests a certain time-span and history of the substrate condition (water content, e.g. Manning 2004) for the accumulation of the tracks. However, the interplay of trackmaker size, substrate condition and track preservation is complex and not easy to decipher without tight control of the relevant parameters ('goldilocks' effect', Falkingham et al. 2011). At least the track surface records a spot of activity of a number of different dinosaur taxa. The tracks have two main directions, juxtaposed by about $180^{\circ}$ of heading to each other (Fig. V.3B).

For the purpose of description the individual tracks are numbered 1 to 19 according to Figure V.2B. Trackways are additionally marked I and II. Other remarkable features discussed below are labeled A to $\mathrm{C}$.

\section{Systematic ichnology I}

Basic measurements were taken according to Figure V.3A, summarised in Table V.1, and Figure V.4. All described specimens originate from the Obernkirchen Member, Bückeberg Formation (late Berriasian) of Lower Saxony.

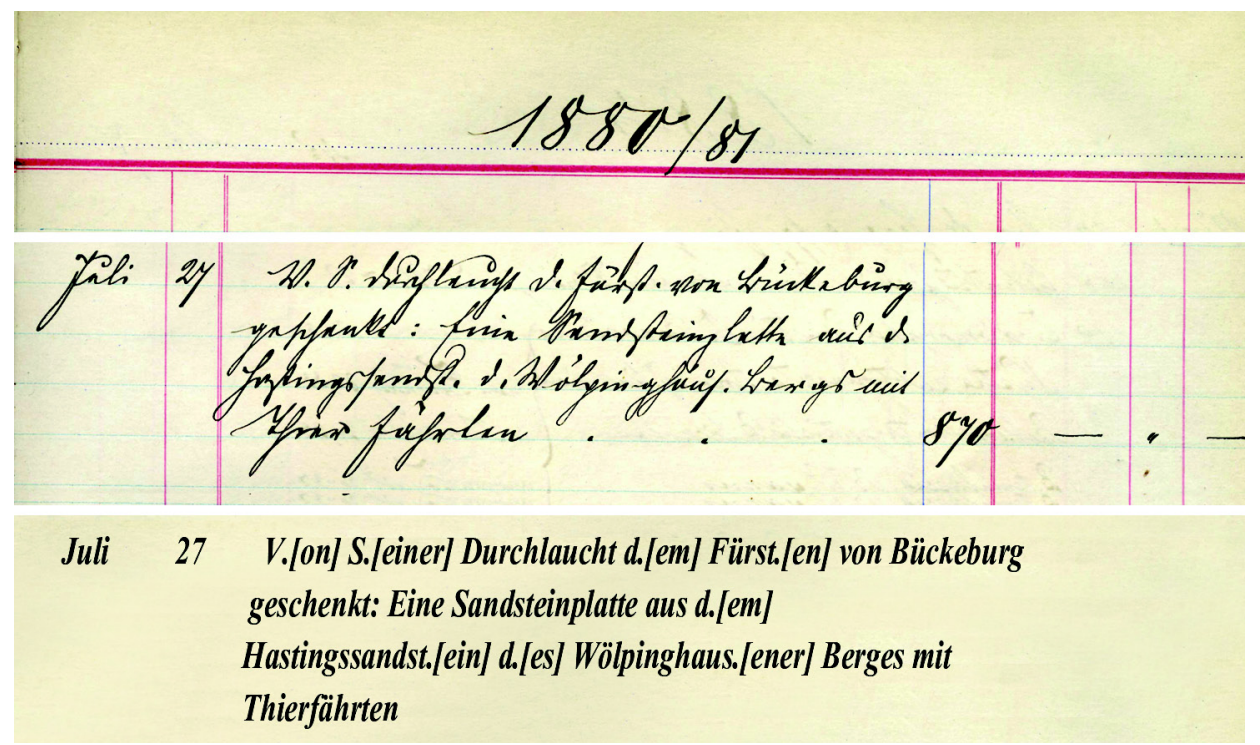

Fig. V.1 Inventory entry concerning the Obernkirchen Sandstone slab GZG.IF.00100 donated to the Göttingen University: "July $27^{\text {th }}$, 1880, donated by His Serenity Prince of Bückeburg [Principality of Schaumburg-Lippe]. A sandstone slab from the Hastings sandstone of the Wölpinghausen mountain with animal tracks" [loose translation]. 
Dinosauria Owen, 1842

Ornithischia Seeley, 1887

Ornithopoda Marsh, 1881

\section{Ichnogenus Dinehichnus Lockley, dos Santos, Meyer \& Hunt, 1998 \\ Dinehichnus isp.}

Figs. V.2, V.6B

Material - left pes impression: track 11, right pes impression: track 12.

Description and remarks - Two pes impressions of markedly different preservation quality. Track 11 is the cast of a deeply impressed tridactyl left pes, showing no trace of a hallux. The pes is symmetrically mesaxonic with a moderate toe divarication (Fig. V.4). There are no claw-marks. Digit II is represented by a single, triangular pad impression. Digit III, being distinctly longer than II and IV, forms a subcylindrical impression, which is slightly broadening towards its rounded apex. Very indistinct indentions may indicate the presence of three interphalangeal pads. Digit IV is largely overstepped by track 7. However, it can be observed, that it is slightly longer than digit I and has a broad, rounded apex similar to digit III. At the base of the digits, and well separated from them, a centrally located, ovate metatarsophalangeal pad is deeply impressed. Track 12 consists only of the weak impresssions of digit III and IV, but they are very similar in shape, divarication and size to track 11. According to their relative position and size it seems possible that tracks 11 and 12 belong to a single trackway. However the strong differences in the deepness of impression suggest that their arrangement is either coincidentally and they have been formed at different occasions under different substrate conditions, or that the substrate characteristics were markedly different in short distance.

The symmetrical shape, quadripartite appearance with very prominent metatarsophalangeal pad, and the blunt, subtriangular to subcylindrical digits, are in good accordance to the characteristics of Dinehichnus socialis Lockley, dos Santos, Meyer \& Hunt, 1998 from the Upper Jurassic of Utah, U.S.A. (Lockley et al. 1998a). However, the size is markedly larger than in D. socialis which has average foot lengths between 10 and 20 centimeters. On the other hand, the size range in D. socialis was considered quite large, with the largest specimen from Utah measuring $28 \mathrm{~cm}$ (Lockley et al. 1998a, Lockley \& Wright 2001), approaching therefore the size of the Wölpinghausen tracks. The latter can therefore be attributed to this ichnogenus. Similar tracks have also been reported from the Upper Jurassic and Lower Cretaceous of Spain and the Upper Jurassic of Poland (e.g. Gierliński et al. 2009).

Dinehichnus is commonly attributed to a basal iguanodontian (i.e. dryosaurid for small specimens, 'camptosaurian' for larger examples) trackmaker. In some occurrences of tentatively referred specimens a short hallux is impressed, which is in closer compliance to the pes morphology in Camptosaurus than in dryosaurids (Gierliński et al. 2009). The deeply impressed track 11 lacking a hallux suggests that digit I was strongly reduced or absent in the trackmaker. However, it is by far too large to have been left by a dryosaurid. It is therefore hypothesised that the Wölpinghausen tracks have been left by a relatively large-bodied basal iguanodontian, which is 
morphologically intermediate between the relatively narrow- and long-footed 'camptosaurs' and more derived, broad-footed, tridactyl ankylopollexians. The Wölpinghausen slab seems to indicate that taxa representing both phylogenetic grades (see below for advanced ankylopollexians) lived sympatrically during the Berriasian in Central Europe.

The evidence of a missing hallux even in deeply impressed specimens of large Dinehichnus, in conjunction with the tridactyly of the type material, evokes the question, whether tetradactyl specimens should be definitly excluded from the ichnogenus. However, a deeper investigation on this topic is beyond the scope of this contribution.

Table V.1 GZG.IF.00100, measurements of tracks. The heading refers to the polar grid in Fig. V.2B, see Fig. V.3A for explanation of morphometric indices.

\begin{tabular}{|c|c|c|c|c|c|c|c|c|c|c|c|c|}
\hline $\begin{array}{c}\text { Track } \\
\text { - } \\
\text { way }\end{array}$ & $\begin{array}{c}\text { Step } \\
\text { length } \\
{[\mathrm{cm}]}\end{array}$ & $\begin{array}{c}\text { Track } \\
\text { no. }\end{array}$ & Determination & $\begin{array}{l}\text { Auto- } \\
\text { podium }\end{array}$ & $\begin{array}{c}\text { FL } \\
{[\mathrm{cm}]}\end{array}$ & $\begin{array}{l}\text { FW } \\
{[\mathrm{cm}]}\end{array}$ & $\begin{array}{l}\text { L-II } \\
{[\mathrm{cm}]}\end{array}$ & $\begin{array}{l}\text { L-III } \\
{[\mathrm{cm}]}\end{array}$ & $\begin{array}{l}\text { L-IV } \\
{[\mathrm{cm}]}\end{array}$ & $\begin{array}{c}\operatorname{div}_{\text {II-III }} \\
{\left[^{\circ}\right]}\end{array}$ & $\begin{array}{c}\operatorname{div}_{\text {III- }} \\
\text { IV } \\
{\left[{ }^{\circ}\right]}\end{array}$ & $\begin{array}{l}\text { Head- } \\
\text { ing }\left[^{\circ}\right]\end{array}$ \\
\hline \multirow{2}{*}{ I } & \multirow{2}{*}{80} & 1 & $\begin{array}{c}\text { Ornithopod isp. } \\
1\end{array}$ & pes, 1 & 40 & 41 & 35 & 40 & 34 & 42 & 40 & 344 \\
\hline & & 2 & $\begin{array}{l}\text { Ornithopod isp. } \\
1\end{array}$ & pes, $r$ & 39 & 41 & 35 & 39 & $?$ & $? 55$ & 55 & 5 \\
\hline \multirow{5}{*}{ II } & \multirow{5}{*}{82} & 3 & Ornithopod isp. & pes, $\mathrm{r}$ & 34 & 36 & 23 & 29 & 21 & 40 & 35 & 177 \\
\hline & & 4 & $\begin{array}{c}\text { Ornithopod isp. } \\
1\end{array}$ & pes, 1 & 41 & 42 & 38 & 41 & 36 & 37 & 43 & 183 \\
\hline & & 5 & Ornithopod isp. 1 & pes & $?$ & $?$ & $?$ & $?$ & $?$ & $?$ & $?$ & 172 \\
\hline & & 6 & Ornithopod isp. 1 & pes, $\mathrm{r}$ & 31 & 32 & 26 & 31 & 23 & 47 & 50 & 185 \\
\hline & & 7 & Ornithopod isp. 1 & pes & 35 & 36 & $?$ & 35 & $?$ & 68 & 90 & 120 \\
\hline \multirow[t]{12}{*}{ I } & & 8 & $\begin{array}{c}\text { Ornithopod isp. } \\
1\end{array}$ & manus, 1 & 8 & 15 & $\mathrm{n} / \mathrm{a}$ & $\mathrm{n} / \mathrm{a}$ & $\mathrm{n} / \mathrm{a}$ & $\mathrm{n} / \mathrm{a}$ & $\mathrm{n} / \mathrm{a}$ & $\mathrm{n} / \mathrm{a}$ \\
\hline & & 9 & Iguanodontipus isp. & pes, ?r & 30 & $>22$ & 24 & 30 & $?$ & 25 & $?$ & 357 \\
\hline & & 10 & Iguanodontipus isp. & pes, ?l & 22.5 & $>19$ & 18.5 & 22.5 & $?$ & 30 & $?$ & 45 \\
\hline & & 11 & Dinebichnus isp. & pes, $\mathrm{r}$ & 39 & 32.5 & 31 & 39 & $>28$ & 35 & 35 & 347 \\
\hline & & 12 & Dinehichnus isp. & pes & 32 & $>28$ & ? & 32 & 29 & $?$ & ? & 20 \\
\hline & & 13 & Theropod isp. 2 & pes, 1 & 30 & 27.5 & 22 & 30 & 27 & 27 & 35 & 32 \\
\hline & & 14 & Theropod isp. 2 & pes, ?r & $?$ & $\sim 26$ & $?$ & ? & $?$ & $?$ & $?$ & 36 \\
\hline & & 15 & ?Theropod isp. 2 & pes, ?r & $>18$ & $? 22$ & $>10$ & $>18$ & $>15$ & 42 & ? & 215 \\
\hline & & 16 & indet. & pes, ?r & 27 & $?$ & $?$ & 22 & 17 & $?$ & $?$ & 80 \\
\hline & & 17 & indet. & pes & $>30$ & $?$ & $?$ & $?$ & $?$ & 35 & $?$ & 200 \\
\hline & & 18 & indet. & pes & 31 & $>34$ & $?$ & ? & $?$ & $?$ & ? & 5 \\
\hline & & 19 & indet. & pes & $?$ & ? & $?$ & ? & $?$ & ? & ? & $?$ \\
\hline
\end{tabular}




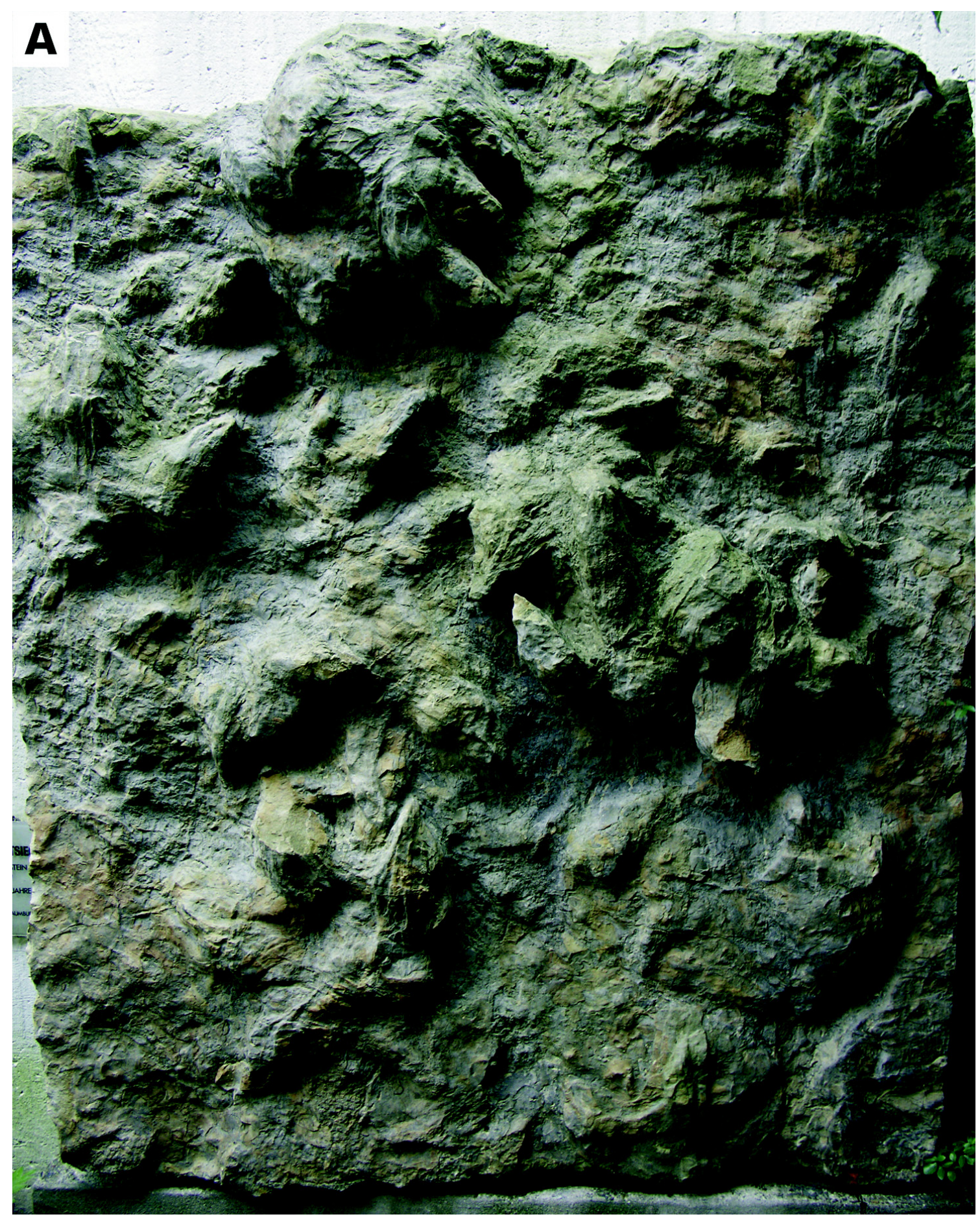

Fig. V.2 Large block (GZG.IF.00100) with numerous dinosaur tracks from the Obernkirchen Sandstone near Wölpinghausen, donated by the Principality of Schaumburg-Lippe in 1880 to the Göttingen University, and on exhibit at the Göttingen University Geopark. $\Delta$ (A) Photograph. (B) Interpretative drawing. The polar grid provides the reference for the directional measurements in Fig. V.3B. 

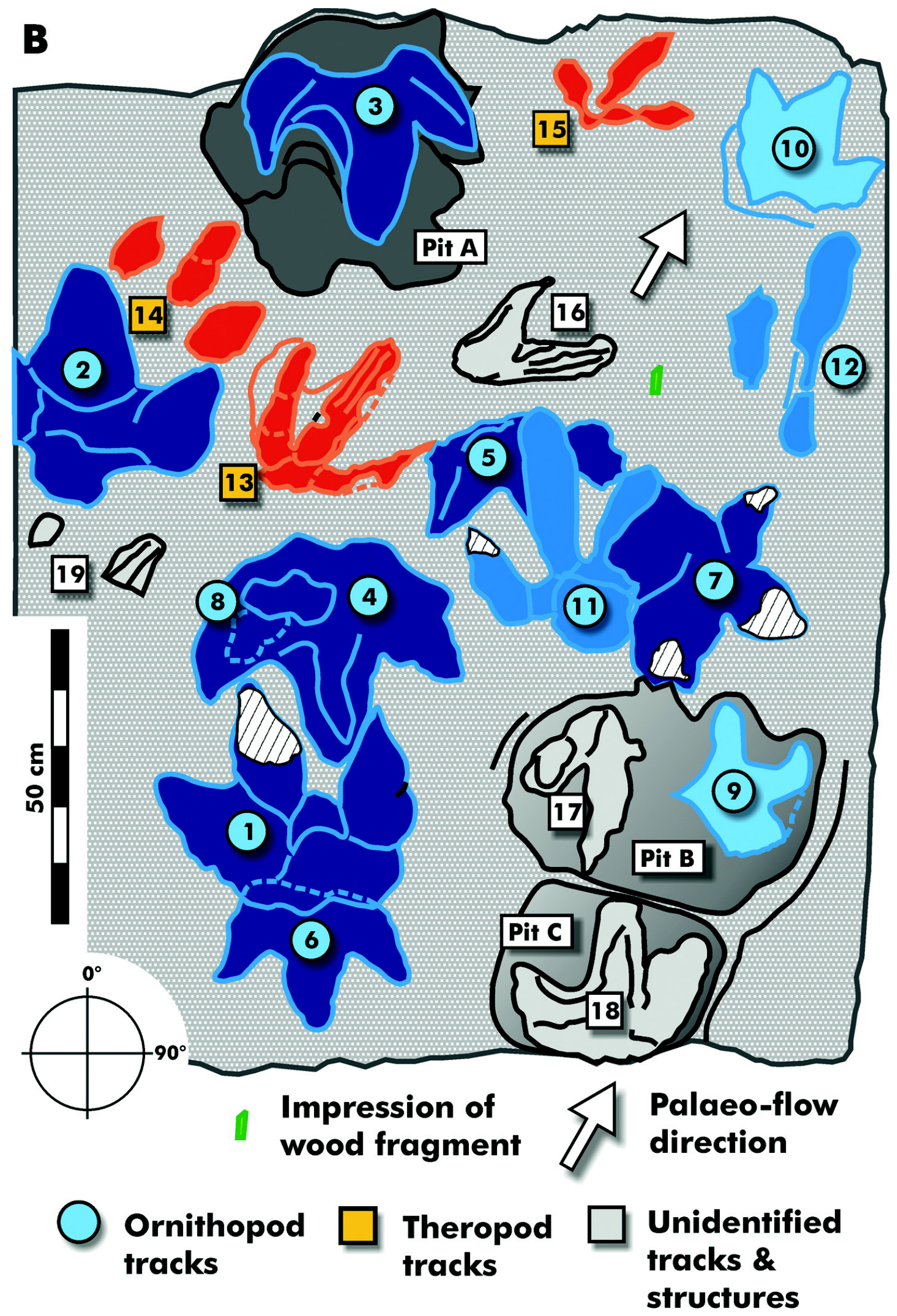
Fig. V.3 (A) Measurements as in Table V.1. (B) Diagram of orientation of the tracks on GZG.IF.00100. Two juxtaposed main directions are evident. Note that the directions are relative to the polar grid in Fig. V.2B, as the original orientation of the track block is unknown.
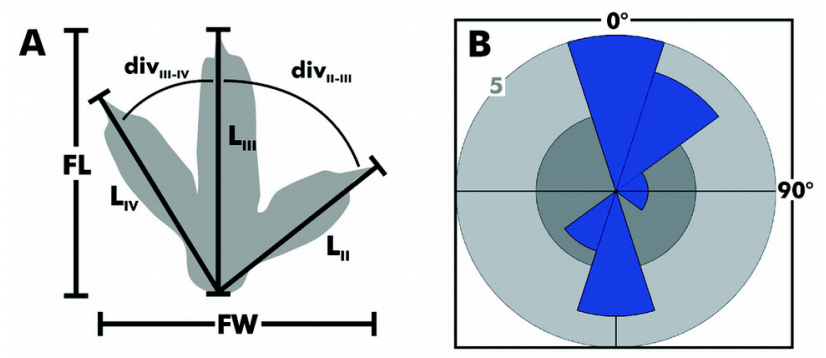

\section{Ichnogenus Iguanodontipus Sarjeant, Delair \& Lockley, 1998 Iguanodontipus isp.}

Figs. V.2, V.6A

Material - pes impressions: tracks 9, 10.

Description and remarks - Two isolated, moderately to poorly preserved pes impressions. Tridactyl, digits short, straight, stubby and resembling an isosceles triangle in outline. Distal metapodophalangeal pad impression ('heel') long (nearly as long as free digit III in track 8) and with posteriorly rounded margin.

Sarjeant et al. (1998) introduced the ichnogenus Iguanodontipus for tracks from the Berriasian Purbeck Group of southern England. This was an attempt to formalise the previously rather informally termed track morphotype associated with the ornithopod Iguanodon. However, the authors explicitly stated, that the new taxon was not intended as a kind of waste-basked ichnotaxon for the abundant 'Iguanodon-tracks' in England and elsewhere but to embrace only tracks of the defined morphology. The diagnosis of the type ichnospecies Iguanodontipus burreyi Sarjeant, Delair \& Lockley, 1998 was based upon a trackway left by a rather small individual with stubby digits and a broad and long metapodophalangeal pad impression. Its morphology closely approaches that of the two tracks here under discussion but not that of the more common, much larger tracks which are often also summarised under this ichnotaxon (e.g. Diedrich 2004, Pollard \& Radley 2011: textfig. 34.6d, and see below).

Herein we follow the original concept of Iguanodontipus as established by Sarjeant et al. (1998) and expanded by Meyer \& Thüring (2003) and restrict the identification of this ichnotaxon to tracks 9 and 10 on GZG.IF.00100. These are also similar to tracks identified as Iguanodontipus isp. from the Oncala Group (Berriasian) of Soria (Spain; Pascual-Arribas et al. 2009) and from the Late Jurassic of Porto Escada (Portugal, Antunes \& Mateus 2003).

Ichnogen. et ichnosp. indet. 1

Figs. V.2, V.5

Material - left and right pes impressions (consecutive steps): tracks $1+2$ (trackway I) and 3+4 
Fig. V.4 Histograms of digit divarications of tracks preserved on GZG.IF.00100 and GZG.IF.00101. (A) Digit II/III-divarication, (B) digit III/IV-divarication.

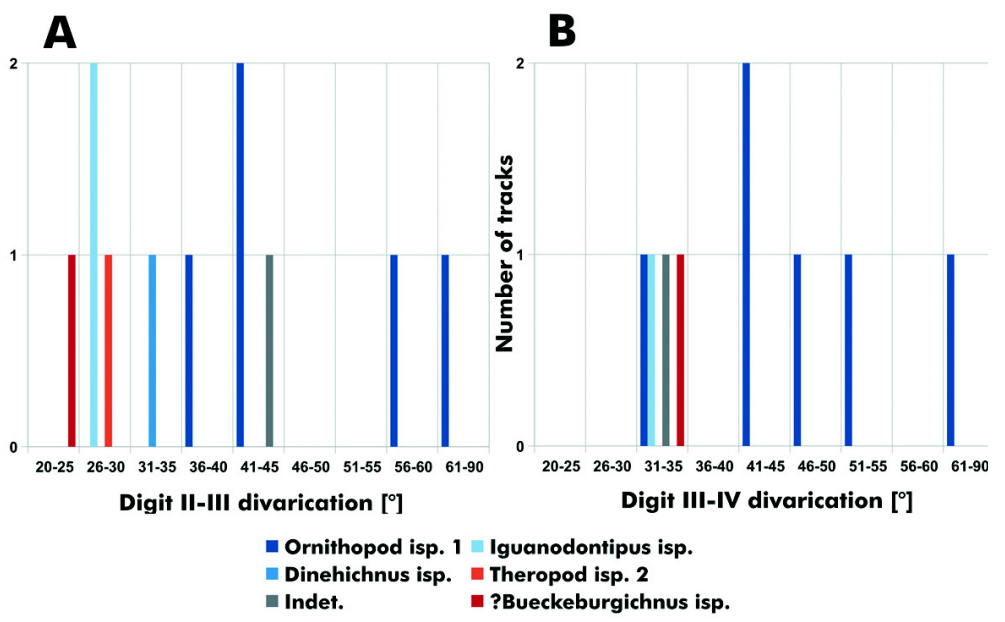

(trackway II), left pes impressions: tracks 5, 6, 7, (?) manus impression: track 8 (probably to trackway I).

Description and remarks - At least seven, good to poorly preserved pes impressions, four represent two pairs of consecutive left and right steps (trackways I, II). The trackways show a placement of the pedes nearly in a straight line (exact pace angulations cannot be measured). The pes seem to have been oriented slightly laterally but this is not sure as both trackways seem to have been left during a change of walking direction. If it is referable to trackway I, the manus impression is located anteriorly and slightly laterally to the pes. Tridactyl, large and massive, digit III longer than digits I and II, digits 'fleshy', cone- to pear-shaped, often constricted at the base of the free digits. Digits pointed but without distinct claws, and moderately to strongly splayed (Fig. V.3). Metapodophalangeal pad short (except in very deeply impressed tracks, e.g. 2, 7) and posteriorly squared-off. In trackways the feet are placed almost in line with the digits being slightly turned medially. Track 8 is a sharply and deeply impressed transversally subtriangular, peanut-shaped structure, c. $15 \mathrm{~cm}$ wide. In comparison with other occurrences (e.g. Lockley \& Wright 2001) it can be interpreted as a manus impression. It slightly overlaps a similar imprint, which is interpreted to result from a first attempt of the animal to place its manus on the ground, which was followed immediately by the second and final attempt, located slightly anterolaterally to the first. The manus imprints are superimposed to the older and less well preserved pes track 4. Their position suggest, that they were made by the left manus and belong to trackway I.

This morphotype is the most common large ornithopod track from the Obernkirchen Sandstone and known in great abundance from many localities (Hornung, Böhme et al. 2012). This includes the pioneering finds by Struckmann (1880a, 1880b) from Wölpinghausen. Though it has been identified as being referable to Iguanodontipus in some publications it does not match the original diagnosis of this ichnogenus as stated above. Its ichnotaxonomic placement must be kept open, as there is a yet unresolved plexus of ichnogenera defining often very similar track morphotypes, including e.g. Amblydactylus Sternberg, 1932, Wealdenichnites Kuhn, 1958, Caririchnium Leonardi, 1984 among others. Its producer was probably a heavily built basal iguanodontian reaching a body length of up to $8 \mathrm{~m}$. 


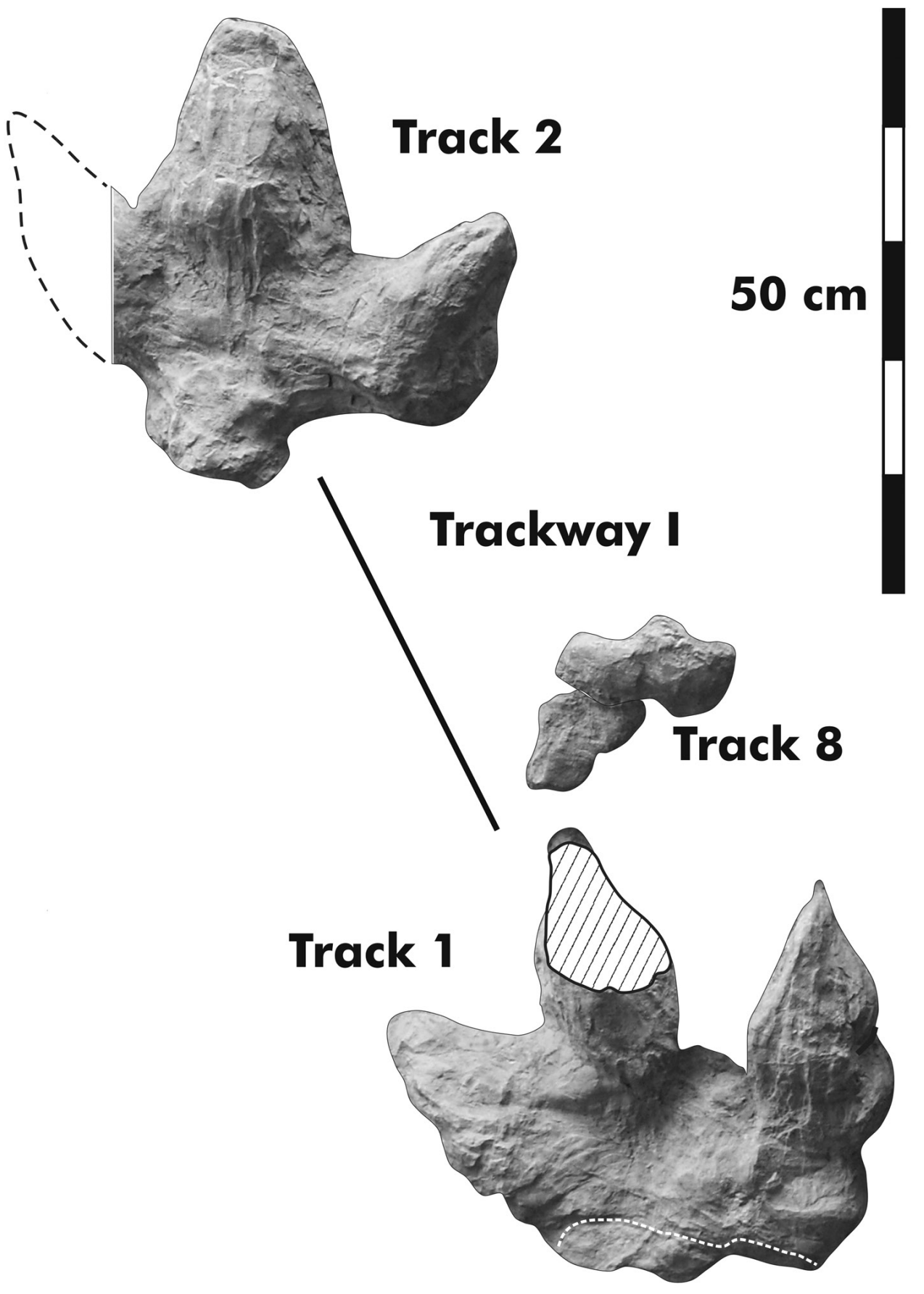

Fig. V.5 Ornithopod ichnospecies 1, trackway I (hypichnia), tracks 1 (left pes), 2 (right pes), 8 (left manus), GZG.IF.00100. Note that the manus (track 8) was apparently impressed two times, the upper right impression is deeper and more pronounced. 

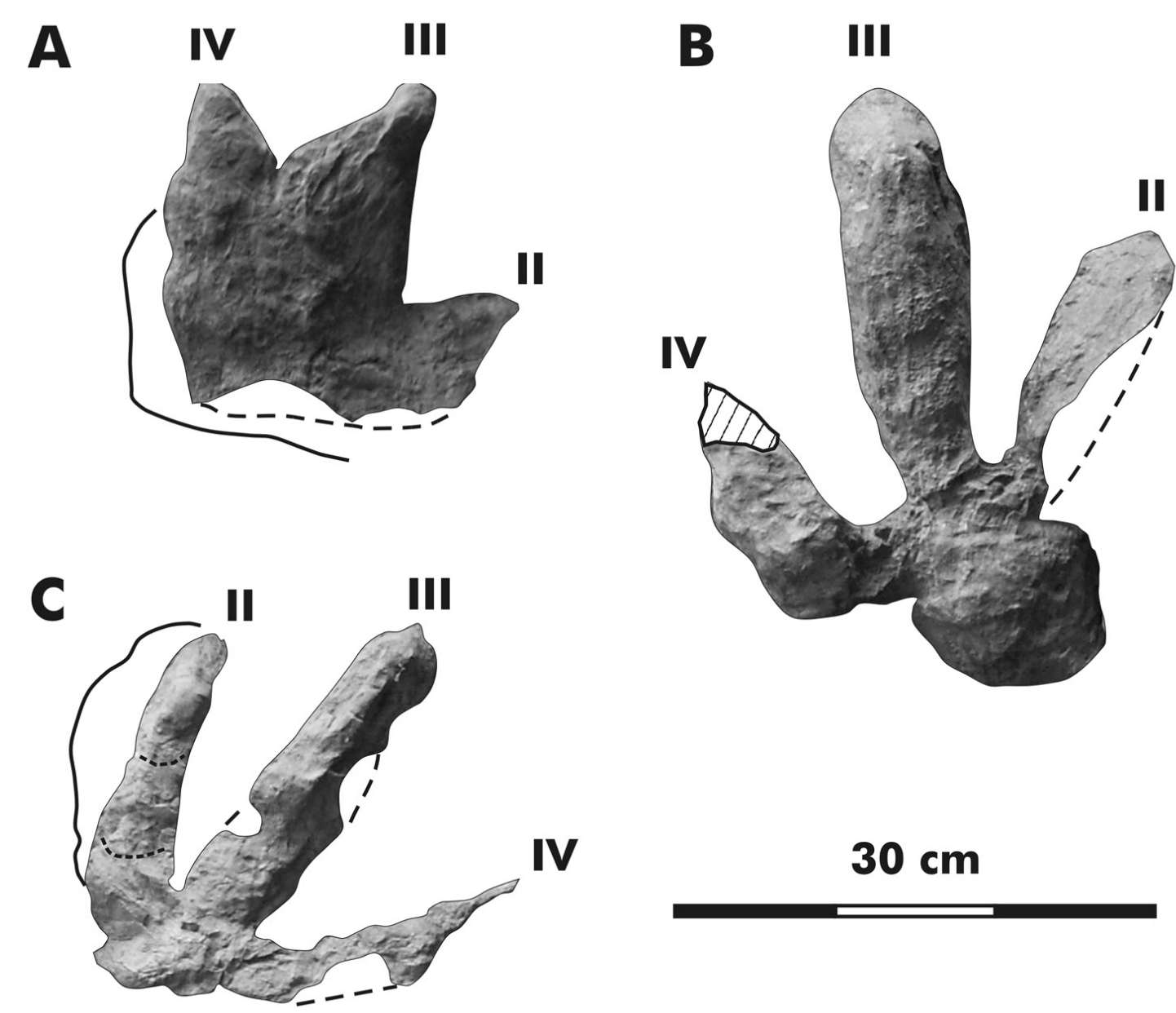

$\mathbf{V}$

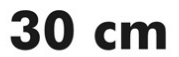

Fig. V.6 Ornithopod and theropod tracks (hypichnia) from GZG.IF.00100. (A) Iguanodontipus isp., track 10 (right pes), (B) Dinehichnus isp., track 11 (right pes), (C) theropod ichnospecies 2, track 13 (left pes).

\author{
Saurischia Seeley, 1887 \\ Theropoda Marsh, 1881
}

ichnogen. et ichnosp. indet. 2

Figs. V.2, V.6B

Material - Isolated pes impressions: tracks 13, 14, ?15.

Description and remarks - The two tracks attributable to this theropod morphotype are moderately to poorly preserved. In both tridactyl, mesaxonic tracks the digits are much stronger impressed than the metatarsal region, suggesting a fast locomotion.

Track 13, a right pes impression, which is the best preserved one, clearly shows the clear asymmetry in the 'heel' region typical for theropod footprints. The digits are splayed moderately (Fig. V.4). Interphalangeal pads are nearly indistiguishable, though this condition is clearly the 
result of preservation and not of pes anatomy. Digit IV probably possessed four interphalangeal pads, their number on the other digits cannot be assessed. All digits taper apically but only on digit II a faint claw-mark can be identified. Digits II and IV are subequal in length but distinctly shorter than digit III.

Track 14 consists only of the impressions of the distal digits of a (?)left pes. This specimen shows a claw-mark on digit IV. Track 15 is very poorly preserved but its asymmetry suggests a theropod trackmaker, too.

This morphotype is similar in size and proportions to well preserved theropod tracks from the same formation at Obernkirchen by Diedrich (2004, on exhibit in the Doberg Museum, Bünde). They also show the overall morphology of the complex of track morphotypes often referred to as Megalosauripus sensu Lockley et al. (1998b). In the light of only mediocre preservation, a twisted theropod track taxonomy and evidently high diversity of theropod ichnotaxa in the Obernkirchen Member (e.g. van der Lubbe et al. 2009; Richter et al. 2009, 2012), the Wölpinghausen examples are kept here in open nomenclature.

Dinosauria Owen, 1842

ichnogen. et ichnosp. indet. ('tridactyl tracks')

Fig. V.2

Material - Isolated pes impressions: tracks 16, 17, 18, 19.

Remarks - At least three tracks of parts of tracks cannot be determined safely as they are deformed or otherwise extramorphologically damaged.

Other morphological features on GZG.IF.00100

Fig. V.2

Material - Three 'pits' (preserved as hypichnial bulges): A, B, C.

Remarks - Aside of the unequivocal dinosaur tracks on the underside of the slab, three large, rounded bulges occur, which represent the cast of pit-like structures on the original surface. Pit/bulge A can be most easily explained as a multiple overstepping of tridactyl tracks. The casts of digits are clearly visible, sticking out from the periphery of the bulge. The youngest track (track 3 ) is reasonably well preserved.

The origins of structures B and C are less obvious. They consist of two transversally elliptical, rather shallow depressions, which are sharply delimited. The larger structure B partly indents structure $\mathrm{C}$. On one side the bulges are delimited by a broad groove, which branches between both bulges. This most probably represent a displacement rim. Tridactyl tracks located within the pits/bulges (tracks 9, 16, 18) show various amounts of deformation, increasing towards the middle of the structures. These deformations suggest that the pits were formed after the tridactyl tracks 
and were deformed largely by vertical compression (local shear failure, Manning 2004).

A possible explanation of these structures would be an interpretation as sauropod manus/pes tracks. Sauropod tracks are known from one site at Münchehagen (Hendricks 1981; Fischer 1998; Lockley et al. 2004). However the lack of more detailed features and the presence of other, possibly anorganic, pit-like features in the Obernkirchen Sandstone ('Hauptsandstein') (Kaufmann et al. 1980; Fischer 1998) leave open alternative interpretations.

The small block - GZG.IF.00101 (Figs. V.4, V.7, Table V.2)

The smaller track slab from an unknown locality (in Lower Saxony) consists of a block of massive, fine-grained sandstone, $120 \mathrm{~cm}$ high, $86 \mathrm{~cm}$ wide, and 26 to $29 \mathrm{~cm}$ thick. Its lower surface preserves an (inverted) relief, which records an interesting history of deposition.

The oldest layer (which is not longer preserved) formed a surface with a slight slope towards a gentle depression on the right side of the slab (as on Fig. V.7). This surface emerged and desiccation cracks were formed on it. The next phase was dominated by the cut of a shallow, $4-5 \mathrm{~cm}$ deep channel into this surface which opened towards the right into the depression. The steep bank of this channel is preserved on the lower left area of the slab and shows failure and collapse due to oversteepening. The bottom of the channel was covered by an apparently thin sheet of sand which formed current ripple marks that confirm a flow from the left to the right, and are preserved as cast on the lower surface of the subsequent bed. This phase of deposition ended with a new thin layer of fine-grained sediment, which dried-up and formed desiccation cracks. The well-preserved mudcrack casts on the underside of track 22 suggests that it has been left on the mud layer before its final emersion and cracking, and is therefore older than tracks 20 and 21 . Another c. $1 \mathrm{~cm}$ thick sandstone sheet covered this layer and cast the ripple-marks and desiccation-cracks. Tracks 20 and 21 have been originally formed on top of the thin sandstone layer and were transmitted as undertracks. Finally the tracks, channel and any other relief were filled-up by deposition of the main c. $25 \mathrm{~cm}$ thick sandstone layer, which is massive at its base and ripple cross-laminated a few $\mathrm{cm}$ below its top.

Table V.2 GZG.IF.00101, measurements of tracks. See Fig. V.3A for explanation of morphometric indices.

\begin{tabular}{cccccccccc}
\hline $\begin{array}{c}\text { Track } \\
\text { no. }\end{array}$ & Determination & $\begin{array}{c}\text { Auto- } \\
\text { podium }\end{array}$ & $\begin{array}{c}\text { FL } \\
{[\mathbf{c m}]}\end{array}$ & $\begin{array}{c}\text { FW } \\
{[\mathbf{c m}]}\end{array}$ & $\begin{array}{c}\text { L-II } \\
{[\mathbf{c m}]}\end{array}$ & $\begin{array}{c}\text { L-III } \\
{[\mathbf{c m}]}\end{array}$ & $\begin{array}{c}\text { L-IV } \\
{[\mathbf{c m}]}\end{array}$ & $\begin{array}{c}\operatorname{div}_{\text {II- }} \\
{\left[{ }^{\circ}\right]}\end{array}$ & $\begin{array}{c}\operatorname{div}_{\text {III- }} \\
{\left[{ }^{\circ}\right]}\end{array}$ \\
\hline $\mathbf{2 0}$ & ?'Bueckeburgichnus' isp. & pes, $\mathrm{r}$ & 25 & $>22$ & $?$ & 25 & 26 & $?$ & 35 \\
$\mathbf{2 1}$ & ?'Bueckeburgichnus' isp. & pes, ?1 & $?$ & $?$ & $?$ & $?$ & $?$ & $?$ & $?$ \\
$\mathbf{2 2}$ & ?'Bueckeburgichnus' isp. & pes, 1 & 35 & 33 & 25 & 34 & 27 & 25 & 35 \\
\hline
\end{tabular}




\title{
Systematic ichnology II
}

\author{
Dinosauria Owen, 1842 \\ Ornithischia Seeley, 1887 \\ Theropoda Marsh, 1881 \\ Ichnogenus 'Bueckeburgichnus' Kuhn, 1958 \\ ?'Bueckeburgichnus' isp.
}

Fig. V.7

Material - Two consecutive pes impressions (both incomplete, trackway III): tracks 20, 21, one complete, isolated pes impression: track 22.

Description and remarks - The block preserves the hypichnia of three tracks, apparently left by the same species of trackmaker. Track 22 is the best preserved and provides most information on morphology. The tracks are tridactyl and mesaxonic with moderate digital divarication. Digit III shows three indistinct interphalangeal pads. Three interdigital pads can also be discerned on digit IV. Digit II is broader than the other digits and conically shaped; separate interphalangeal pads cannot be discerned. The metatarsal region shows an asymmetry at the base of digits II and IV. The digits are pointed apically and bear a claw-mark at least in digit IV (track 20), less distinct in digit III (tracks 20 and 22), and possibly digit II (track 22).

Tracks 20 and 21 form a trackway, consisting of a right pes impression (track 20) and the posteromedial part of the subsequent left pes impression (track 21). The tracks are arranged in a straight line and the feet were slightly turned inwardly. The short step length (c. $45 \mathrm{~cm}$ ) indicates slow locomotion speed.

Track 22 shows a short slip-face in its 'heel'-region.

The morphology of the tracks, including the claw-marks and metatarsal asymmetry, clearly indicate a theropod trackmaker. Some characteristics are congruent with the problematic ichnogenus 'Bueckeburgichnus' (Lockley 2000, Thulborn 2001, Hornung, Böhme \& Reich 2012a), most important the broad, triangular, fleshy digit II. The lack of a hallux impression, reported from the type ichnospecies 'B.' maximus Kuhn, 1958, is explainable by the shallow impression depth of the tracks in GZG.IF.00101. Another difference is the size, which is considerably smaller than in the 'B.' maximus type material. It seems reasonable that the trackmaker of tracks 20 to 22 was closely related to or an ontogenetically younger specimen of the producer of 'B.' maximus. Aside of the occurrences in the Berriasian Obernkirchen Member, 'Bueckeburgichnus' has so far only been reported from the Berriasian-Valanginian and Aptian of Spain (e.g. Canudo et al. 2005).

\section{Discussion}

Especially the abundance and diversity of tracks on GZG.IF.00100 provide a very valuable insight in the dinosaur fauna of the Obernkirchen Member. Iguanodontipus isp. and ornithopod 

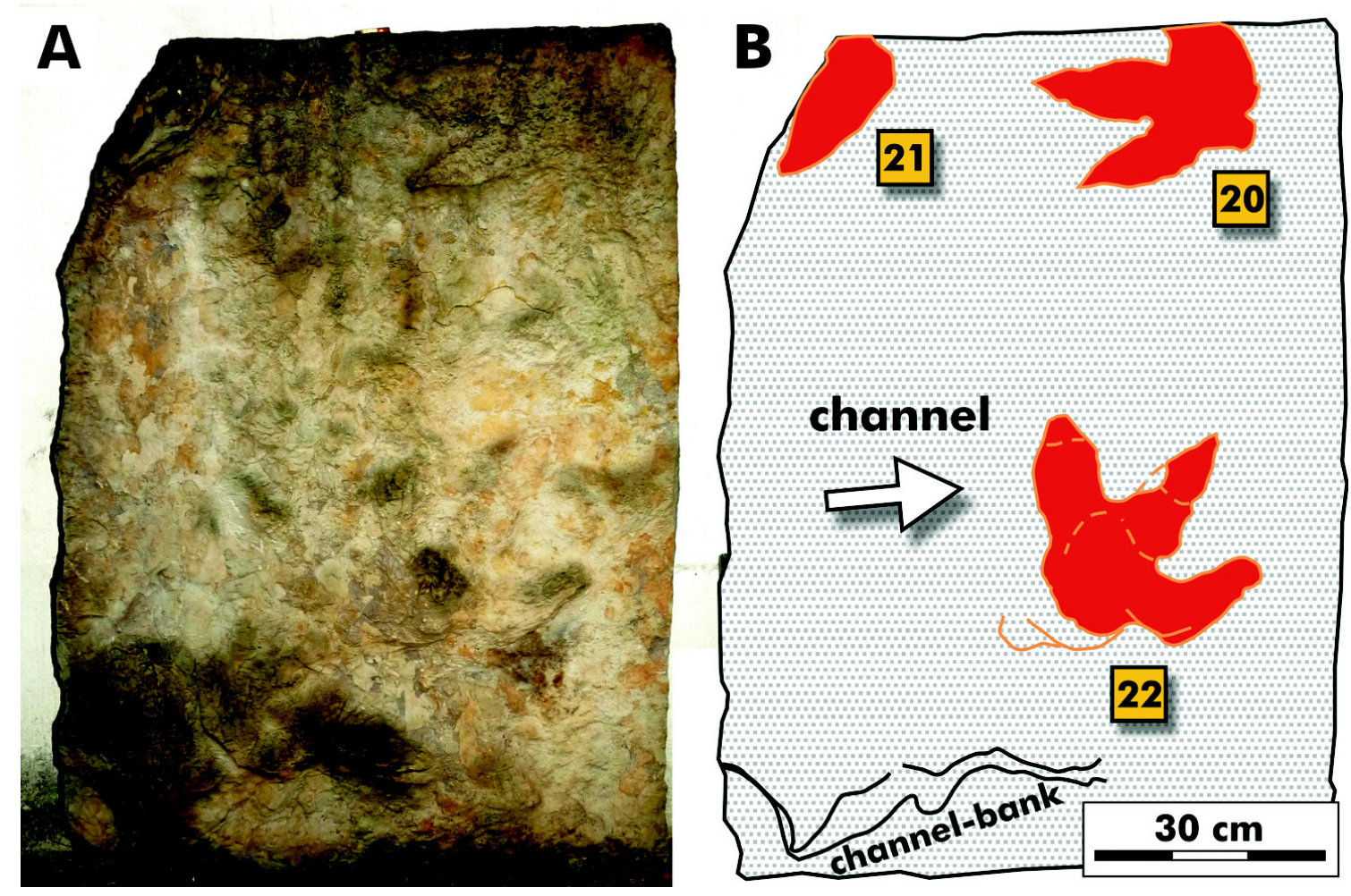

Fig. V.7 Block with three theropod tracks (?'Bueckeburgichnus' isp.) from the Obernkirchen Sandstone from an unknown locality in Lower Saxony, GZG.IF.00101. Symbols and colour-coding as in Fig. V.2B.

ichnospecies 1 represent morphotypes common to the local ichnofauna (e.g. Struckmann 1880a, 1880b; Dietrich 1927; Lehmann 1978; Lockley \& Wright 2001; Hornung, Böhme et al. 2012). As far as known at present, typical Iguanodontipus tracks occur exclusively associated to the larger morphotype (e.g. Lehmann 1978), and it will require further investigations whether both morphotypes may represent different ontogenetic stages of the same orthotaxon. As evidenced by the manus morphology, the trackmaker of ichnospecies 1 was a member of the Styracosterna Sereno, 1986. This clade is characterised by a specialised manus, in which only digits II to IV are used for quadrupedal locomotion and were conjoined in a single skin envelope. Digit I was reduced to a defensive 'thumb spine' and digit $\mathrm{V}$ was specialised as a grasping organ and both did normally not contact the ground. The structure formed by digits II to IV left the subtriangular impressions (Wright 1999). Recent analysis has shown that earliest members of Styracosterna occurred in the Late Jurassic [Cumnoria prestwichii (Hulke, 1880) from the Kimmeridgian; McDonald et al. 2010], however these are rather gracile animals. In contrast, the Berriasian tracks from the Bückeberg Formation and elsewhere clearly show that an evolution towards massive, large-bodied forms have taken place as early as the Jurassic-Cretaceous boundary - an intervall very poorly represented by osteological remains.

Such an important transition in the iguanodontian bauplan during the Berriasian is additionally underscored by the occurrence of large-sized Dinehichnus isp. This type of track is commonly 
associated with very basal, 'camptosaur'-grade iguanodontians, though the lack of a hallux impression indicates some advancement in pes morphology towards more derived iguanodontians. These tracks document the sympatric co-occurrence of very basal and more advanced iguanodontians in the Berriasian of Central Europe.

The theropod track record supports a considerable diversity of this clade, as has shown in other localities. Whether even sauropods can be added to the ichnocoenosis cannot be decided finally. The ichnological and sedimentological record of GZG.IF.00100 documents the formation of tracks over a considerable amount of time under changing substrate conditions. The sedimentary record commences with a thin sand layer, deposited under unidirectional flow conditions (current ripple marks). Flow-direction was about $45^{\circ}$ respective to the baseline of the slab and subparallel to one of the main directions of the tracks. The flow waned subsequently and a thin layer of fine-grained material settled subaqueously. Dinosaurs crossed the site through this quite and shallow waterbody which increasingly dried-up. Finally the tracks were covered by a new sand deposit.

The heading of the tracks is not random, most tracks follow a main direction or its juxtaposed heading. This orientation, together with the taxonomical diversity and the apparent accumulation of tracks over a considerable time-span indicates, that the slab represents an area of dinosaur crossing' and probably a bypass region suited well for passage.

Unfortunately the preserved material does not allow a certain conclusion on the exact stratigraphic origin of the specimen. However, the still existent outcrops at Wölpinghausen expose only the uppermost parts of the local equivalent of the Obernkirchen Sandstone (Hornung, Böhme \& Reich 2012d). The lithofacies at these outcrops is mostly represented by medium to thinly bedded, partly channelised, fluvial sandstones. It seems more reasonable that the slab originates from the deeper (today inaccessible) parts of the section, where also the first tracks have been found by Struckmann (1880a).

\section{Acknowledgements}

We thank V. J. Roden, Darmstadt, for checking the English spelling of an first draft, as well as T. R. Stegemann and A. Gehler (both Göttingen) for technical assistance.

\section{References}

Antunes, M. T. \& Mateus, O. (2003): Dinosaurs of Portugal. Comptes Rendus Palevol 2 (1): 77-95.

Canudo, J. I.; Barco, J. L.; Cuenca-Bescós, G. \& Ruiz-Omeñaca, J. I. (2005): Presence of two different theropod footprints in the Valanginian - Hauterivian (Lower Cretaceous) of Villanueva de Huerva (Zaragoza, Aragón, Spain). In International Symposium on Dinosaur and other Vertebrates Palaeoichnology (2005), Fumanya, Barcelona - Abstract book: 38-39.

Diedrich, C. (2004): New important iguanodontid and theropod trackways of the tracksite Obernkrichen in the Berriasian of NW Germany and megatracksite concept of Central Europe. Ichnos 11 (3): 215-228. 
Dietrich, O. W. (1927): Über Fährten ornithopodider Saurier im Oberkirchner Sandstein. Zeitschrift der Deutschen Geologischen Gesellschaft 78 [for 1926] (4): 614-621.

Falkingham, P. L.; Bates, K. T.; Margetts, L. \& Manning, P. L. (2011): The 'Goldilocks' effect: preservation bias in vertebrate track assemblages. Journal of the Royal Society Interface 8 (61): 1142-1154.

Fischer, R. (1998): Die Saurierfährten im Naturdenkmal Münchehagen. In Fischer, R. (ed.): Das Naturdenkmal „Saurierfährten Münchehagen“. Mitteilungen aus dem Institut für Geologie und Paläontologie der Universität Hannover 37: 3-59.

Gierliński, G. D.; Niedźwiedzki, G. \& Nowacki, P. (2009): Small theropod and ornithopod footprints in the Late Jurassic of Poland. Acta Geologica Polonica 59 (2): 221-234.

Hendricks, A. (1981): Die Saurierfährte von Münchehagen bei Rehburg-Loccum (NW-Deutschland). Abhandlungen aus dem Landesmuseum für Naturkunde zu Münster in Westfalen 43: 1-22.

Hornung, J. J.; Böhme, A., Lubbe, T. van der; Reich, M. \& Richter, A. (2012): Vertebrate tracksites in the Obernkirchen Sandstone (late Berriasian, Early Cretaceous) of northwest Germany - their stratigraphical, palaeogeographical, palaeoecological, and historical context. Paläontologische Zeitschrift 86 (3): 231-267.

Hornung, J. J.; Böhme, A. \& Reich, M. (2012a): The type material of the theropod ichnotaxon "Bueckeburgichnus" maximus Kuhn, 1958 - reconsidered. In Richter, A. \& Reich, M. (eds.): Dinosaur Tracks 2011. An International Symposium, Obernkirchen, April 14-17, 2011. Abstract Volume and Field Guide to Excursions, p. 27; Göttingen (Universitäts-Verlag).

Hornung, J. J.; Böhme, A. \& Reich, M. (2012b): Excursion Guide B2: Wölpinghausen. In Richter, A. \& Reich, M. (eds.): Dinosaur Tracks 2011. An International Symposium, Obernkirchen, April 14-17, 2011. Abstract Volume and Field Guide to Excursions, 143-149; Göttingen (Universitäts-Verlag).

Hulke, J. W. (1880): Iguanodon prestwichii, a new species from the Kimmeridge Clay, distinguished from I. mantelli of the Wealden Formation in the S.E. of England and the Isle of Wight by differences in the shape of the vertebral centra, by fewer than five sacral vertebrae, by the simpler character of its tooth-serrature, etc., founded on numerous fossil remains lately discovered at Cumnor, near Oxford. Quarterly Journal of the Geological Society of London 36: 433-456.

Kaufmann, R.; Oppermann, H.-U. \& Petsch, K. (1980): Zur Entwicklung der tiefen Unterkreide (Berrias/Valangin) im Süden des Rehburger Sattels unter besonderer Berücksichtigung der Tongrube Sachsenhagen. Ballerstedtiana 3: 5-27.

Kuhn, O. (1958): Die Fährten der vorzeitlichen Amphibien und Reptilien. 64 pp.; Bamberg (Meisenbach).

Lehmann, U. (1978): Eine Platte mit Fährten von Iguanodon aus dem Obernkirchener Sandstein (Wealden). Mitteilungen aus dem Geologisch-Paläontologischen Institut der Universität Hamburg 48: 101-114.

Leonardi, G. (1984): Le impronte fossili di dinosauri. In Bonaparte, J. F. (ed.): Sulle orme dei dinosaur. Esplorazioni ricerche IX: 161-186; Venezia (Erizzo).

Lockley, M. G. (2000): An amended description of the theropod footprint Bueckeburgichnus maximus Kuhn 1958, and its bearing on the megalosaur tracks debate. Ichnos 7 (3): 217-225.

Lockley, M. G.; dos Santos, V. F.; Meyer, C. A. \& Hunt, A. P. (1998a): A new dinosaur tracksite in the Morrison Formation, Boundary Butte, Southeastern Utah. In Carpenter, K.; Chure, D. J. \& Kirkland, J. I. (eds.): The Upper Jurassic Morrison 
Formation - an interdisciplinary study. Modern Geology 23 (1): 317-330.

Lockley, M. G.; Meyer, C. A. \& dos Santos, V. F. (1998b): Megalosauripus and the problematic concept of megalosaur footprints. In Pélaez-Moreno, B. P.; Holtz, T. jr.; Sanz, J. L. \& Moratalla, J. (eds.): Aspects of Theropod Paleobiology. Gaia 15: 313-337.

Lockley, M. G. \& Wright, J. L. (2001): Trackways of large quadrupedal ornithopods from the Cretaceous: a review. In Tanke, D. H. \& Carpenter, K. (eds.): Mesozoic Vertebrate Life: 428-442; Bloomington (Indiana University Press).

Lockley, M. G.; Wright, J. L. \& Thies, D. (2004): Some Observations on the Dinosaur Tracks at Münchehagen (Lower Cretaceous), Germany. Ichnos 11 (3-4): 261-274.

Lubbe, T. van der; Richter, A. \& Böhme, A. (2009): Velociraptor's sisters: First report of troodontid tracks from the Lower Cretaceous of northern Germany. Journal of Vertebrate Paleontology 29 (3) [suppl.]: p. 194A.

Manning, P. L. (2004): A new approach to the analysis and interpretation of tracks: examples from the dinosaurian. In McIlroy, D. (ed.): The Application of Ichnology to Palaeoenvironmental and stratigraphic analysis. Geological Society of London, Special Publication 228: 93-123.

Marsh, O. C. (1881): Principal characters of American Jurassic dinosaurs. Part V. The American Journal of Science and Arts (series 3) 21: 417-423.

McDonald, A. T.; Kirkland, J. I.; DeBlieux, D. D.; Madsen, S. K.; Cavin, J.; Milner, R. C. \& Panzarin, L. (2010): New Basal Iguanodonts from the Cedar Mountain Formation of Utah and the Evolution of Thumb-Spiked Dinosaurs. PLoS ONE 5 (11): [e14075]

Meyer, C. A. \& Thüring, B. (2003): The First Iguanodontid Dinosaur Tracks from the Swiss Alps (Schrattenkalk Formation, Aptian). Ichnos 10 (2-4): 221-228.

Owen, R. (1842): Report on British Fossil Reptiles, Part II. Report of the Annual Meeting of the British Association for the Advancement of Science 11 [1841]: 60-204.

Pascual-Arribas, C.; Hernández-Medrano, N.; Latorre-Macarrón, P. \& Sanz-Pérez, E. (2009): El icnogénero Iguanodontipus en el yacimento de "las Cuestas I" (Santa Cruz de Yanguas, Soria, España). Studia geológica Salmanticensia 45: 105128.

Pollard, J. E. \& Radley, J. D. (2011): Trace Fossils. In Batten, D. J. (ed.): English Wealden Fossils. Palaeontological Association Field Guide to Fossils 14: 653-676.

Reich, M. (2012): Zur frühen Geschichte der Göttinger Universitätssammlungen. In Georg-August-Universität Göttingen (ed.): Dinge des Wissens. Die Sammlungen, Museen und Gärten der Universität Göttingen: 79-88; Göttingen (WallsteinVerlag).

Reich, M.; Reitner, J.; Roden, V. J. \& Stegemann, T. (2009): The Geoscientific Collections oft he Göttingen University: 24 pp.; Göttingen (Geowiss. Museum).

Richter, A.; Böhme, A. \& Lubbe, T. van der (2009): “Chicken Run”: A new unusual, heavily dinoturbated tracksite from the Lower Cretaceous sandstones of Obernkirchen, northern Germany. In $69^{\text {th }}$ Annual Meeting Society of Vertebrate Paleontology and the $57^{\text {th }}$ Symposium of Vertebrate Palaeontology and Comparative Anatomy (SVPCA), University of Bristol, Bristol, United Kingdom, September 23-26, 2009. Journal of Vertebrate Paleontology 29 (3) [suppl.]: p. 171A. 
Richter, A.; Lubbe, T. van der; Böhme, A. \& Stratmann, U. (2012): Obernkirchen - an old becomes a new dinotrack locality. In Richter, A. \& Reich, M. (eds.): Dinosaur Tracks 2011. An International Symposium, Obernkirchen, April 14-17, 2011. Abstract Volume and Field Guide to Excursions, p. 52; Göttingen (Universitäts-Verlag).

Sarjeant, W. A. S.; Delair, J. B. \& Lockley, M. G. (1998): The footprints of Iguanodon: a History and Taxonomic Study. Ichnos 6 (3): 183-202.

Schmidt, H. (1959): Die Cornberger Fährten im Rahmen der Vierfüßler-Entwicklung. Abhandlungen des Hessischen Landesamtes für Bodenforschung 28: 137 pp.

Seeley, H. G. (1887): On the classification of the fossil animals commonly called Dinosauria. Proceedings of the Royal Society of London 43: 165-171.

Sereno, P. C. (1986): Phylogeny of the bird-hipped dinosaurs (Order Ornithischia). National Geographic Research 2: 234256.

Sternberg, C. M. (1932): Dinosaur tracks from Peace River, British Columbia. Annals and Reports of the National Museum of Canada [1930]: 59-85.

Struckmann, C. (1880a): Die Wealden-Bildungen der Umgebung von Hannover. Eine geognostisch-paläontologischstatistische Darstellung. viii + 122 pp.; Hannover (Hahn).

Struckmann, C. (1880b): Vorläufige Nachricht über das Vorkommen großer, vogelähnlicher Thierfährten (Ornithoidichnites) im Hastingssandsteine von Bad Rehburg bei Hannover. Neues Jahrbuch für Mineralogie, Geologie und Paläontologie [1880] (1): 125-128.

Thulborn, R. A. (2001): History and nomenclature of the theropod dinosaur tracks Bueckeburgichnus and Megalosauripus. Ichnos 8 (3-4): 207-222.

Wright, J. L. (1999): Ichnological evidence for the use of the forelimb in iguanodontians. In Unwin, D. M. (ed.): Cretaceous Fossil Vertebrates. Special Papers in Palaeontology 60: 209-219. 
Chapter VI

Metatetrapous valdensis Nopcsa, 1923 and the presence of ankylosaur tracks (Dinosauria: Thyreophora) in the Berriasian (Early Cretaceous) of northwestern Germany 


\title{
Metatetrapous valdensis Nopcsa, 1923 and the presence of ankylosaur tracks (Dinosauria: Thyreophora) in the Berriasian (Early Cretaceous) of northwestern Germany
}

\author{
JAHN J. HORNUNG ${ }^{1}$ and MIKE REICH ${ }^{1,2}$ \\ ${ }^{1}$ Department of Geobiology, Geoscience Centre, Georg-August University of Göttingen, Germany \\ ${ }^{2}$ Museum, Collections \& Geopark, Geoscience Centre, Georg-August University of Göttingen, Germany
}

\begin{abstract}
Metatetrapous valdensis Nopcsa, 1923 from the late Berriasian of northwestern Germany was the first dinosaur ichnotaxon ever attributed to a thyreophoran trackmaker. However, the subsequent lost of the original material made this identification and the status of the ichnotaxon questionable for many subsequent authors. This situation was aggravated by the fact that there are only very brief original descriptions accompanied by a single drawing. A reconsideration of the original description recognizes $M$. valdensis as a valid ichnotaxon, which, albeit showing great resemblance in pes morphology to similar ichnotaxa, stands out from them by a tetradactyl manus. It not only still holds its original systematic attribution, but also has sparked early hypotheses on the phylogeny of dinosaurs already in 1922, possibly for the first time based upon tracks. Two surviving natural hypichnial casts of ankylosaurian pes imprints from the same stratum cannot be straightforwardly identified with the type material due to a lack of documentation. However, comprehensive circumstantial evidence, including complete accordance in size and morphology among others, strongly supports such an association. The tracks confirm the presence of ankylosaurs in this lacustrine-deltaic setting as a very rare element of the local dinosaur fauna.
\end{abstract}

Keywords: Metatetrapous, Ankylosauria, ichnotaxonomy, Early Cretaceous, Germany

\section{Introduction}

The Ankylosauria Osborn, 1923 are heavily armoured, obligatory quadrupedal, ornithischian dinosaurs, which appeared during the Jurassic and underwent considerable radiation during the Early Cretaceous (Coombs and Maryanska, 1990; Vickaryous et al., 2004). Ankylosauria is the sistergroup of Stegosauria Marsh, 1877, within the monophyletic Thyreophora Nopcsa, 1915 (Norman et al., 2004; Butler et al., 2008). Except for Africa, ankylosaurs have been found on every continent, including Antarctica (Salgado and Gasparini, 2006). 
The ichnological record of the Ankylosauria is relatively sparse, until now about 20 localities with purported ankylosaur trackways have been reported worldwide (Currie, 1989; McCrea, 2000, 2003; McCrea et al., 2001; Gangloff et al., 2004; Weems, 2004; Gierliński et al., 2005; Goldring et al., 2005; Lockley et al., 2006; Stanford et al., 2007; Tanke and Newman, 2007; Xing et al., 2007; McCrea and Buckley, 2008; Sacchi et al., 2009; Petti et al., 2010; Apesteguía and Gallina, 2011). Although the oldest tracks tentatively referred to a thyreophoran trackmaker originate from the uppermost Triassic of Sweden (Milàn and Gierliński, 2004), the record of purported ankylosaur tracks does not increase reasonably before the beginning of the Cretaceous (McCrea et al., 2001).

Historically, the first tracks identified as those of an armoured ornithischian dinosaur were found in 1921 by the amateur palaeontologist Max Ballerstedt (1857-1945) in the Berriasian of northwestern Germany. Nopcsa (1923), recognizing its importance, was the first to identify it as the track of an armoured dinosaur (including stegosaurs, ankylosaurs, and ceratopsians in contemporary taxonomic concepts) and rejected a sauropod identification, based on comparison with their ichnological record, which at the time was sparse. Unfortunately the rather obscure original publications and the subsequent loss of the type material resulted in problems surrounding the verification of these ideas, and the discovery was later overshadowed by the discovery of abundant well-preserved ankylosaurian track material especially from the Late Cretaceous of North America (e.g. Sternberg, 1932; Currie, 1989; McCrea et al., 2001).

Surprisingly, two natural hypichnial casts of dinosaurian tetradactyl pes tracks have been recognized recently among material from Ballerstedt's collection which show clear affinities ichnites assigned to ankylosaurs. Due to a gap in documentation, they cannot be identified unequivocally as part of the original material found in the 1920s; nonetheless they deserve attention as the only preserved ichnological evidence for the presence of ankylosaurs in the Berriasian of Germany. This is especially of interest, as ornithopod- and theropod-dominated dinosaur ichnofaunas are very abundant in the same strata (e.g., Struckmann, 1880; Lockley et al. 2004; Hornung et al., 2012a, and references therein).

It is the aim of this work to reconsider Ballerstedt's (1922) original figure and Nopcsa's (1923) diagnosis and descriptions in the light of modern concepts, to assess the status of the resulting ichnotaxonomy, and to describe the rediscovered specimens and their possible relationships with the historical material.

\section{Methods}

The stereo images were created with a Fujifilm Finepix True 3D W1 digital stereo camera.

\section{Institutional Abbreviations}

GZG: Geoscience Centre, University of Göttingen, Göttingen, Germany; GZG.BA.: Max Ballerstedt collection at GZG; ZPAL: Institute of Palaeobiology of the Polish Academy of Sciences, Warsaw, Poland. 


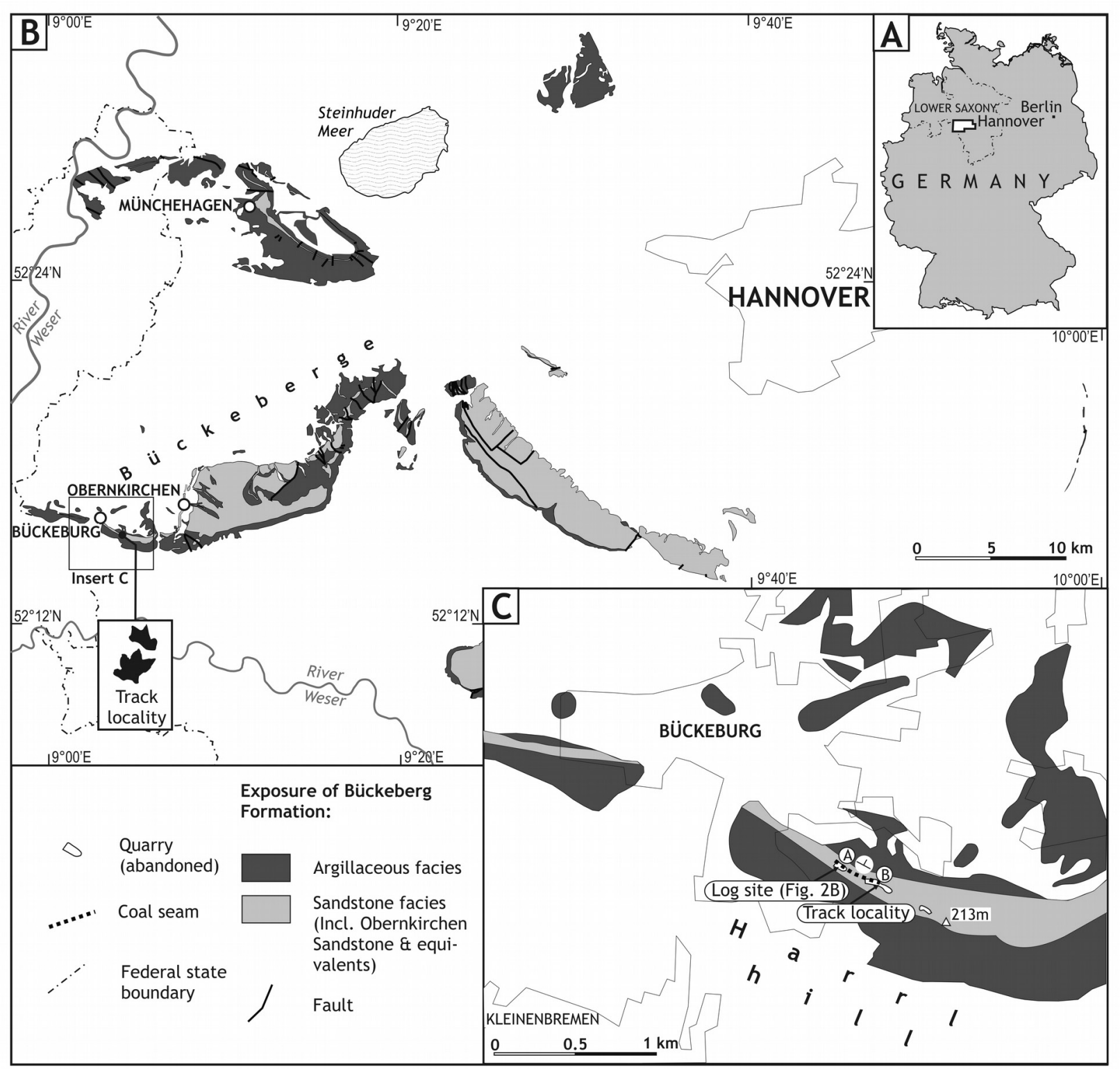

Fig. VI.1 Locality map, showing the outcrop of the Bückeberg Formation and the ankylosaur track localities. (A) Overview. (B) Outcrop of the Bückeberg Formation. (C) Detail map of the Harrl hill east of Bückeburg showing the outcrop exposing the log in Fig. VI.2B $(A)$ and the old, partly inaccessible quarry which yielded $M$. valdensis $(B)$. Note strike and dip of the Bückeberg Formation and the continuous coal seam, allowing for a correlation between both outcrops. Geological data after LBEG (2013) and own observations.

\section{The status of Metatetrapous valdensis Nopcsa, 1923}

Original description and validity. The trackway in discussion was excavated during the summer of 1921 at the Harrl hill near Bückeburg, Lower Saxony (Figs. VI.1-VI.2), by Max Ballerstedt (18571945). Still in the same year, this passionate local vertebrate fossil collector and amateur palaeontologist published a short notice on a newly discovered trackway of a "quadrupedal, humble 
dinosaur" (Ballerstedt, 1921). In the following year, he figured this trackway along with other tracks from the Late Jurassic and Early Cretaceous of northwestern Germany in a short overview (Ballerstedt, 1922, here: Fig. VI.3).

In March 1923, Franz Baron Nopcsa visited Max Ballerstedt at Bückeburg and probably had the opportunity to study the trackway. In the same year he gave a short description of the tracks and published the name Metatetrapous valdense (Nopcsa, 1923: p. 147, 199). His definition of the taxon and discussion of its relationships consisted of a very short passage, which is - due to its historical importance - repeated and translated here (Nopcsa, 1923: p. 147):

"Merkwürdig wenig ist bisher über die Fährten vierfüßiger Dinosaurier bekannt geworden. Ballerstedt hat eine solch Fährte aus dem Wealden erwähnt und abgebildet. Eine der von Ballerstedt abgebildeten Fährten, für die er den Namen Metatetrapous valdense vorschlägt [reference in footnote: Ballerstedt, Über Schreckensaurier und ihre Fußspuren. Kosmos. Berlin 1922. S. 78, Fig. 1, Nr. 3 (der Name in einem im Drucke befindl. Manuskript)], zeigt eine vierzehige Hand ohne Ballen und einen etwas größeren vierzehigen mit Ballen versehenen Fuß, der beim Niederstellen geschleift wurde. Da alle Zehen gleich lang sind und nur schwache Krallen haben, weist dies nicht auf Sauropoda sondern auf Thyreophora."

"Curiously, little has become known about the tracks of quadrupedal dinosaurs. Ballerstedt noticed and figured such a track from the Wealden. One of the figured tracks, for which he proposes the name Metatetrapous valdense [reference in footnote: Ballerstedt, Über Schreckensaurier und ihre Fußspuren. Kosmos. Berlin 1922 [=Ballerstedt, 1922 herein]. P. 78, Fig. 1, No. 3 (the name in a manuscript in press)], shows a tetradactyle hand without heel and a somewhat larger, tetradactyle, heeled foot, which slipped during stepping down. The equal length of the digits, bearing only weak claws, indicate a referral to Thyreophora instead of Sauropoda".

[Translated from German].

Further back in this volume he gave an addendum which he intended to be inserted behind the above statement (Nopcsa, 1923: p. 199):

"S. 147. In Textzeile 9 (von unten) ist nach dem Worte "Thyreophora" folgendes einzuschalten:

'An den Metatetrapous des Wealden erinnert eine isolierte, vierzehige Spur der Trias, die Beasley (Rep. Brit. Ass. Adv. Sc., 1909, S. 152) als "Typus P" beschrieb. Von Chirotherium unterscheidet sich dieser Fußabdruck, wie eine Untersuchung des Originals zeigte, durch den völligen Mangel des bei Chirotherium immer gut sichtbaren fünften Fingers und durch die sehr kurzen und zur Basis schnell dicker werdenden Zehen. Von Metatetrapous ist der Abdruck nur durch seine geringere Größe und den Mangel einer Grenze zwischen dem vorderen breiten Ballen und dem schmäleren rückwärtigen Teile unterscheidbar. Diese Spur 


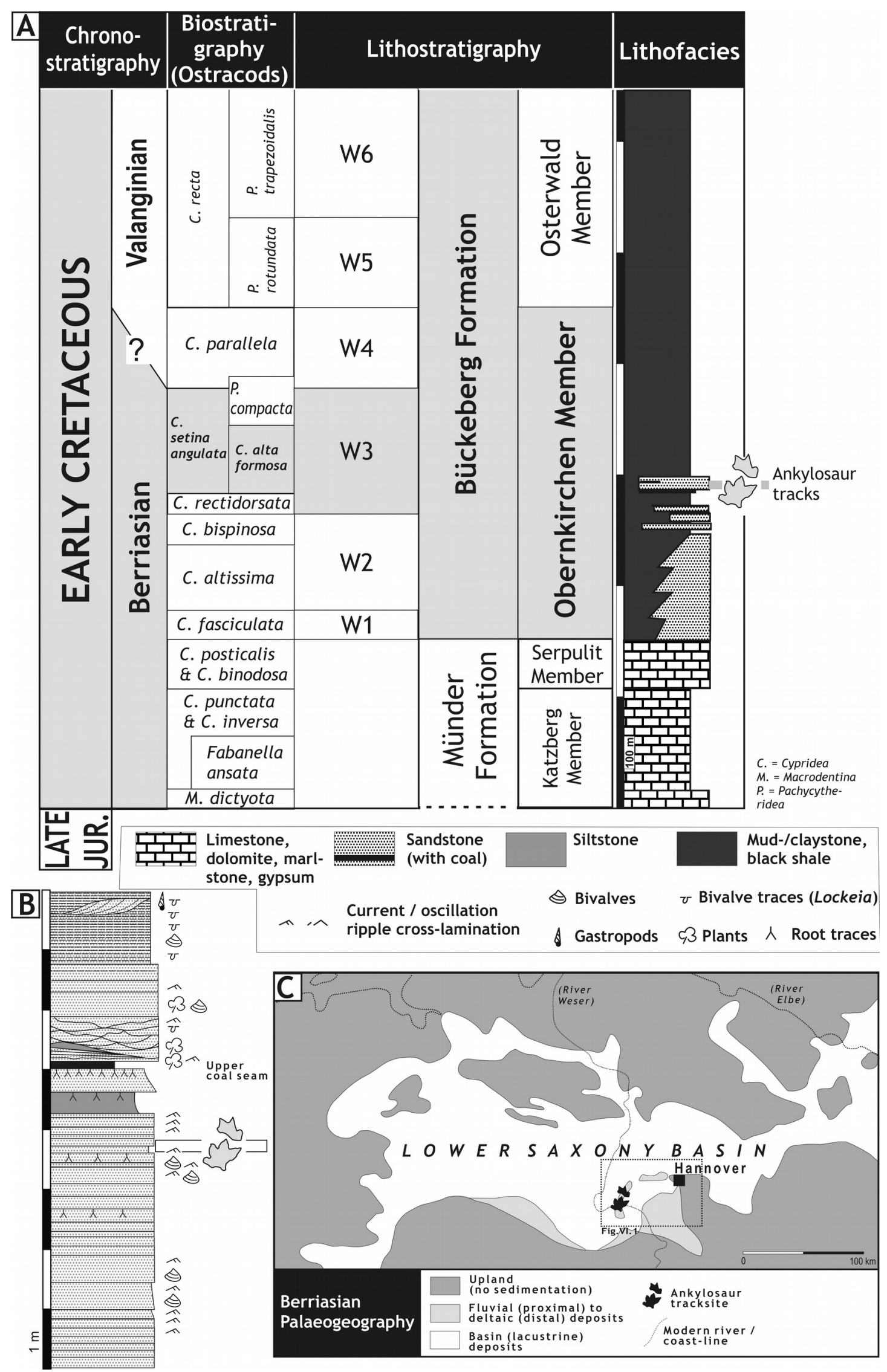


spricht für die Existenz kurzzehiger, vierfüßiger Dinosaurier während der oberen Trias, dies ist aber, da so eine Form (Scelidosaurus) schon aus dem Lias bekannt ist, nicht unwahrscheinlich. Im Anklange an Metatetrapous will ich Beasleys Fährte "P" Deuterotetrapous triassicus nennen."”

"[Addendum to] p. 147. Following the word "Thyreophora", insert the following in text-line 9 (from the bottom [of the page]):

'An isolated, tetradactyl track from the Triassic, which was described by Beasley (Rep [ort of the] Brit[ish] Ass[ociation for the] $A d v$ [ancement of] Sc[ience], 1909 [=Beasley, 1910 herein], p. 152) as "type P", is reminiscent of Metatetrapous from the Wealden. This footprint differs from Chirotherium, as the investigation of the original specimen showed, by the complete lack of a fifth digit, which is well observable in any Chirotherium, and by the very short toes, thickening rapidly towards their base. This impression is only distinguishable from Metatetrapous by its smaller size and the lack of a defined boundary between the anteriorly wide part of the heel and the more narrow posterior part of it. This track gives support to the existence of short-toed, quadrupedal dinosaurs during the Upper Triassic, which is, since one form (Scelidosaurus) is already known from the Liassic, not improbable. In allusion to Metatetrapous, I will name Beasley's track "P" Deuterotetrapous triassicus."”

[Translated from German].

Technically, by giving the trackway from the Harrl hill a short but sufficiently precise description and referring to a published figure, which unambiguously shows the specimen in question, Nopcsa satisfied the requirements for establishing an (ichno)taxon before 1931 (ICZN 1999: Articles 11, 12). The referral to the figure also unequivocally implies that the whole trackway has to be considered the ichnoholotype (by monotypy, see also Sarjeant, 1989). The explicit note that Ballerstedt has proposed the name may raise the question whether the ichnotaxon has to be attributed to his authorship in some way. Kuhn (1963) assigned it to Ballerstedt (1922) which is unquestionably wrong, because Ballerstedt never used this name, neither in this paper nor in any other published work. As to judge from the footnote by Nopcsa it appears that Ballerstedt was preparing a more comprehensive work on this trackway. Nopcsa even assumed it to be "in press" when his paper was published. This also explains to some degree the very abbreviated nature of the description Nopcsa presented. Sadly this work - if it ever existed - was never printed. There is also no manuscript or fragments of a manuscript known from Ballerstedt's personal notes, though the

Fig. VI.2 Stratigraphy and paleogeography of the Bückeberg Formation. (A) Chrono-, bio- and lithostratigraphical overview of the Bückeberg Formation. The track occurrence including the stratum typicum of Metatetrapous valdensis is indicated. (B) Detail log of the outcrop at the western side of Harrl hill (compare Fig. VI.1C) with the track horizon correlated tentatively by Pelzer (1998) to the track horizon discovered by Ballerstedt (1905) C. $350 \mathrm{~m}$ to the east. From Pelzer (1998), modified and own data (Hornung et al., 2012b). (C) Paleogeography of the Lower Saxony Basin during the Berriasian (after Schott et al., 1967, 1969; Kemper, 1973; modified). W1 to W6: Wealden 1 to Wealden 6 (Wolburg 1949). 
lost pictures may have been part of its preparation. Due to these facts, and that Ballerstedt never used this name in conjunction of even the shortest description or his figure, he does not qualify for recognitions like "Ballerstedt in Nopcsa, 1923" or "Nopcsa ex Ballerstedt, 1922". A similar conclusion was already stated by Haubold (1971: p. 89) who noted the ichnotaxon's author to be "Nopcsa 1923 (alleged Ballerstedt 1922)". For the same reason a referral of the authorship to Haubold (1971), as for example implied by Avanzini et al. (2001) and McCrea et al. (2001), has to be corrected.

Though short, Nopcsa's description mentions some key features, which could otherwise only be ambiguously interpreted from Ballerstedt's sketch drawing. These include tetradactyl manus impressions which lack a "heel" (indicating a fully digitigrade stance of the forelimbs). Also of importance is the explicit notion of slipping of the foot. The latter is also obvious from the figure of the complete track, where only the footprints in the middle part of the trackway show a posterior elongation. It can therefore be assumed that the tracks especially near both ends of the trackway represent better the true shape of the foot with a broad, rounded "heel" (i.e. the metapodiophalangeal pad). The presence of slip-faces in parts of the ichnoholotype of $M$. valdensis assumes particular importance as it has been proposed to group Metatetrapous together with some other ichnogenera in a "heel-dominated" morphological group, in contrast to a "toe-dominated" group, which included the ichnogenus Tetrapodosaurus Sternberg, 1932 (Gierliński et al., 2005). However, for reasons discussed above, the "heel" was probably much shorter and the footprint not very different from that in Tetrapodosaurus. However such a misinterpretation - which may also result in an over-estimation of the true foot-length - can possibly result from the re-illustration of the type trackway in Haubold (1971, 1974, 1984, here Fig. 4). In these publications, which are far more easily available and widespread than that by Ballerstedt (1922), only the central part of the trackway is depicted in which the slip-faces are most prominent.

The reference of Nopcsa (1923: p. 199) to his Deuterotetrapous triassicus provides further interesting insights. Nopcsa claims a close morphological similarity between Deuterotetrapous and Metatetrapous. Beasley (1910: pl. III, the text-fig. on p. 152 appears to be idealized and too symmetrical) provides a good photographic illustration of two isolated pes impressions of the former. They show a clear posterior off-set of a medially directed digit I, as was also indicated in the figure of Ballerstedt (1922) for Metatetrapous, but not mentioned by Nopcsa. This character is also important to note when considering Nopcsa's statement on M. valdensis that all digits are of equal length - considering Ballerstedt's figure, this is obviously only true for digits II to IV. Digit I is smaller (it is indiscernible in some footprint sketches), has a posterior off-set, and apparently a variable divarication angle with digit II. Somewhat dubious is the "lack of a defined boundary between the anteriorly wide part of the heel and the more narrow posterior part of it", Nopcsa (1923) claimed as a difference between Deuterotetrapous and Metatetrapous. From the two specimens Beasley figured, only one (Beasley, 1910: pl. III, fig. 1) has an elongated "heel", which appears to represent the impression of a relatively elongate metapodium. The medial and lateral margins of this "heel" in fact slightly converge posteriorly. It is not clear in how far this compares to Metatetrapous, especially if one takes into consideration that the posterior elongation in this ichnotaxon was caused by slipping and the true "heel" seems to be short and squared-off 
(coinciding with the other specimen of D. triassicus figured in Beasley, 1910: pl. III, fig. 2).

Based upon stratigraphic grounds (being Middle Triassic in age), size, and the missing manus that makes its referral to a quadruped completely conjectural, Nopcsa's assertion of a thyreophoran dinosaur trackmaker is highly questionable for D. triassicus. Haubold $(1971,1974,1984)$ reasonably referred it to a therapsid.

Historical reception and interpretations. The phylogenetic concepts of dinosaurs that were adopted by Ballerstedt can only be glimpsed in small bits from his scattered works mostly on fossil tracks. As an academically somewhat reclusive amateur (Probst and Windolf, 1993), he was very reluctant in publicizing his scientific ideas broadly. Nevertheless, from the few papers, as well as private notes and letters, the picture of an avid observer with a wide range of knowledge emerges. When he found the trackway of Metatetrapous valdensis, he did not assign it to a distinct orthotaxonomic group. Instead he noted that it was made by a dinosaur that has "re-transformed from a biped to a quadruped" (Ballerstedt, 1922: p. 79). This interpretation was probably fueled by the observation that the pes imprints were basically similar to those of some ornithopods Ballerstedt had studied first-hand, and which were conceived as strictly bipedal at this time. Among the first tracks found in the same locality were not only the common tridactyl ornithopod tracks but also tetradactyl footprints (with a small hallux impression), which Ballerstedt (1905) related to Camptosaurus. These, later named Bueckeburgichnus maximus (Kuhn, 1958), were subsequently referred to a theropod trackmaker (Nopcsa, 1923; Abel, 1935). The observation of free digits with claw-marks on the new trackway, in contrast to the sauropod tracks from the Late Jurassic of Barkhausen he studied at the same time (Ballerstedt, 1922), probably made him hesitate to assign it more definitely. It is interesting however, that he anticipated the phylogenetic origin of a nonsauropod, quadrupedal dinosaur from a bipedal ancestor, based upon ichnological data. Proof of this idea in the form of skeletal remains only came to light before several decades later (e.g. Colbert, 1981). It was also one of the first times that an evolutionary process was explicitly postulated based upon observations of a vertebrate track.

Nopcsa (1923), who had a more practical experience with quadrupedal ornithischians, elaborated further on Ballerstedt's ideas. In Nopcsa's concept of dinosaur systematics there were only two groups of quadrupedal dinosaurs, the sauropods and the thyreophorans, the latter of which including all "heavily armed" ornithischians (ankylosaurs, stegosaurs, and ceratopsians, Nopcsa, 1915). When describing M. valdensis, Nopcsa (1923: p. 147) pointed out the differences to a track he identified to have been left by a sauropod (following Hatcher, 1903), as follows: (1) all toes are of equal length and (2) weak, anteriorly directed claws. The first is somewhat misleading as only the toes II-IV in M. valdensis are subequal in length but nevertheless the pes has a clearly mesaxonic structure contrary to the entaxonic condition in sauropods.

All studies after 1923 referred only to the data from Ballerstedt (1922) and Nopcsa (1923). In later years some authors even doubted about the existence of a distinct ichnotaxon, partly inferring a misidentification of an ornithopod trackway, which are very abundant in the same region and strata (Schmidt, 1969). Others, more or less accepting the validity of the ichnotaxon, supported the ankylosaurian origin of the trackway but emphasized upon the lack of original material and scarceness of the descriptions to testify this hypothesis (Haubold, 1971, 1974, 1984; Thulborn, 


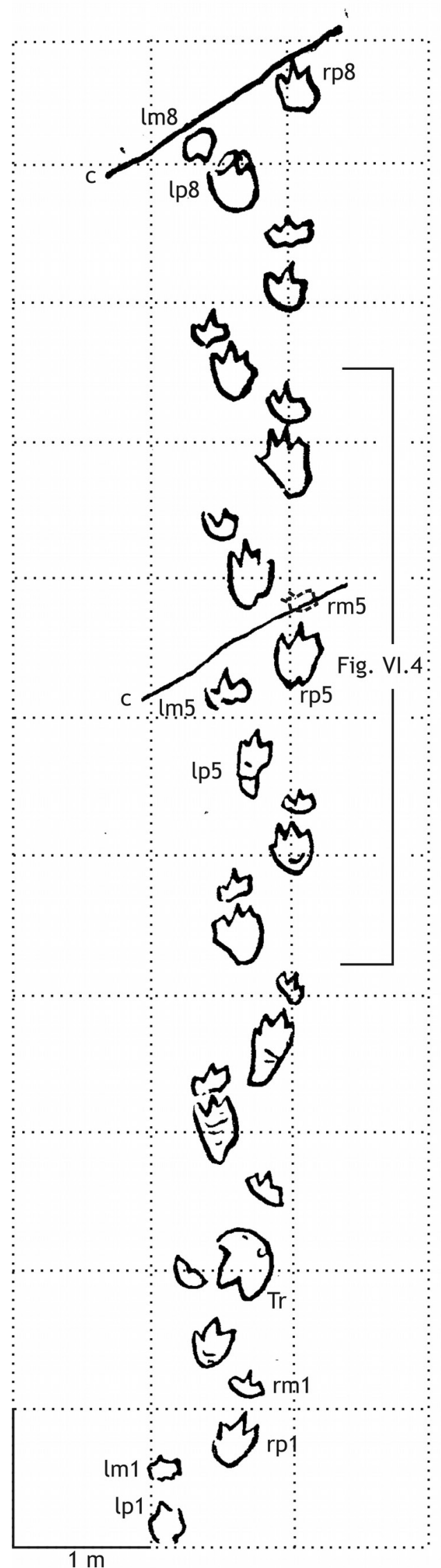

1990; Probst and Windolf, 1993; McCrea et al., 2001; Gierliński et al., 2005; Gierliński and Sabath, 2008). Due to these circumstances, Metatetrapous valdensis became an ichnotaxon enclosed in mystery despite its archetypical importance for thyreophoran ichnotaxonomy.

Trackmaker identification. Contrary to Nopcsa's definition, modern concepts of the Thyreophora exclude the marginocephalians (Norman et al., 2004). As a consequence, a more detailed identification of the trackmaker will not only require a comparison between thyreophorans and sauropods but also between various quadrupedal ornithischian groups. The latter problem has a rather long history considering tracks of similar morphology. Sternberg (1932) described the very similar Tetrapodosaurus borealis and referred it to a ceratopsian trackmaker. Carpenter (1984) instead proposed the nodosaurid Sauropelta edwardsi Ostrom, 1970 to be the producer of T. borealis, based upon close similarity of the manus and pes osteology to the track morphology. Following this approach, McCrea et al. (2001) demonstrated the potential criteria to distinguish ankylosaurian trackways from those of other quadrupedal dinosaurs. The analysis of these authors is the only one to include comparative osteological studies of the ankylosaur manus and pes and their fit to alleged ankylosaurian tracks. In summary the combination of the following

4Fig. VI.3 Metatetrapous valdensis Nopcsa, 1923. Type trackway as mapped by Ballerstedt (1922). Obernkirchen Sandstone equivalent, Bückeberg Formation, Harrl near Bückeburg. The $1 \mathrm{~m}$-grid was added here for better scale, the section depicted in Fig. VI.4 is indicated. Abbreviations: $c$ : crack or cleft, Im: left manus impression, Ip: left pes impression, rm: right manus impression, $r p$ : right pes impression, Tr. pes track of crossing tridactyle biped. 


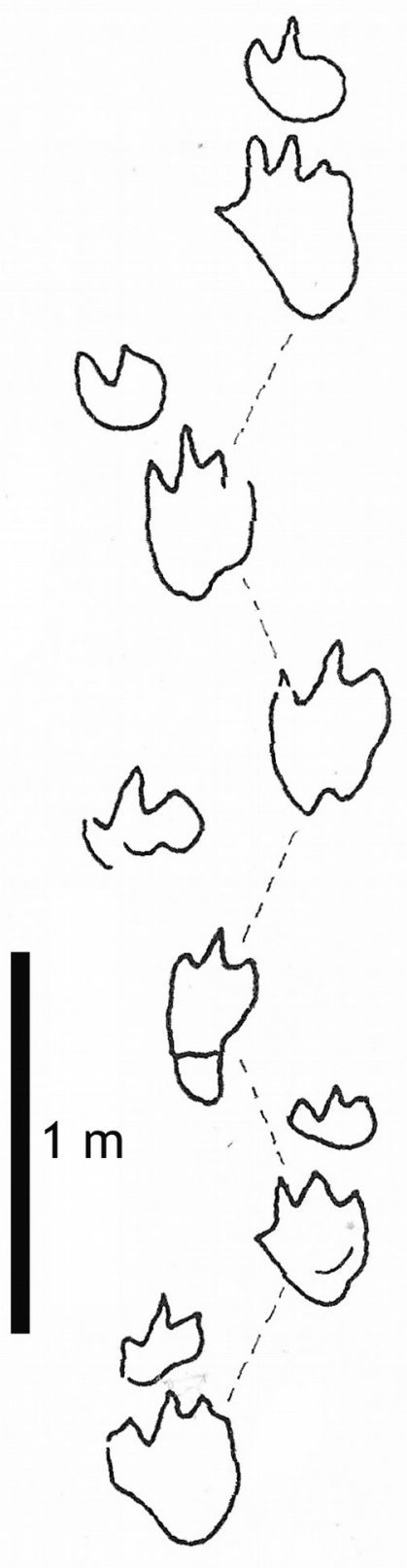

Fig. VI.4 Metatetrapous valdensis Nopcsa, 1923. Section of type trackway as figured by Haubold (1971, 1974, 1984). This figure, a slightly modified copy of Ballerstedt (1922, compare Fig. VI.3) formed the principal base of more recent discussions of this ichnotaxon. characters have been proposed to diagnose ankylo-saur tracks: (1) moderate to large size, (2) quadru-pedal gait, (3) tetradactyl pes, (4) metapodial and metacarpal regions relatively short compared to free digit length, (5) digits on manus and pes well separated and not webbed, (6) pes digit I distinctly shorter than than digit II, (7) pes asymmetric, with digit IV located distinctly anterior to digit I, (8) pentadactyl manus, (9) manus imprint width reaching 60-80 $\%$ of pes imprint width, (10) trail of manus imprints slightly medial to or in front of pes imprints, (11) manus strongly arcuate with an angle of $180^{\circ}$ to $250^{\circ}$ between digit I and IV or V, respectively.

Of the above listed characters all except (8) are in concordance with previous descriptions and figures (Ballerstedt, 1922; Nopcsa, 1923). Nopcsa (1923) explicitly noted a tetradactyl manus in Metatetrapous, which is in accordance with the figure by Ballerstedt. This in facts holds as the most important difference of this ichnotaxon to Tetrapodosaurus and similar tracks. In the absence of original material it cannot be decided whether the tetradactyl manus impres-sions are artefacts of preservation or reflect a true anatomical trait of the trackmaker.

Gierliński and Sabath (2008) have doubted on the diagnostic value of some of the above mentioned characters, pointing out that the tracks (especially of the pes) of ankylosaurs and basal ceratopsians are predicted to be essentially similar. This would be of special significance in stratigraphic intervals when ankylosaurs and basal ceratopsians co-occured (Late JurassicEarly Cretaceous). A close similarity in morphology was recently confirmed by the direct association of a skeleton of the basal ceratopsian (Protoceratops sp.; ZPAL Mg D-II/3) with the hypichnial cast of a pedal footprint which was suggested to have been left by the same 
individual (Niedźwiedzki et al., 2012). However, basal ceratopsians of Late Jurassic and Early Cretaceous age were small, cursorial animals. Species like Yinlong downsi Xu, Forster, Clark, and Mo, 2006 or Stenopelix valdensis von Meyer, 1857 (Butler and Sullivan 2009, Butler et al. 2011) hardly reached one meter in length, while animals the size of the $M$. valdensis trackmaker were restricted to the ankylosaurian clade during this time interval. An interpretation of the latter as to have been produced by an ankylosaurian is therefore reasonable in the light of current paradigms.

Systematic Ichnology

\section{Ichnogenus Metatetrapous Nopcsa, 1923}

Type ichnospecies. Metatetrapous valdensis Nopcsa, 1923, by monotypy.

Metatetrapous : Nopcsa, 1923, p. 147, 199; McCrea et al., 2001, p. 422.

Metatetrapous $\dagger$ Ballerstedt : Kuhn, 1958, p. 27; Kuhn, 1963, p. 105.

Metatetrapous Ballesterdt [sic!] : Romero Molina et al., 2003, p. 18, 26.

Metatetrapous Nopcsa 1923 (angeblich Ballerstedt 1922) : Haubold, 1971, p. 89; Haubold, 1974, p. 46; Haubold, 1984, p. 52; Gierliński and Sabath, 2008, p. 41, 42.

Diagnosis. As for the type and only ichnospecies.

Differential diagnosis. At least three ichnogenera which currently considered valid, are very similar

to Metatetrapous: (1) Tetrapodosaurus (type ichnospecies: T. borealis Sternberg, 1932), (2) Apulosauripus Nicosia, Marino, Mariotti, Muraro, Panigutti, Petti and Sacchi, 1999 (type ichnospecies A. federicianus Nicosia, Marino, Mariotti, Muraro, Panigutti, Petti and Sacchi, 1999), and (3) Qijiangpus Xing, Wang, Pan and Chen, 2007 (type ichnospecies Q. sinensis Xing, Wang, Pan and Chen, 2007).

As noted before, the main difference between Metatetrapous and Tetrapodosaurus relates to the tetradactyl manus impressions of the former. Additionally, the trackway gauge is narrower in Metatetrapous than in Tetrapodosaurus (Sternberg, 1932; McCrea, 2000; McCrea et al. 2001; Harington et al., 2005). However, the meaning and potential variation in trackway gauge in this type of tracks is not well understood, making its use for ichnotaxonomy questionable at the present state of knowledge.

Metatetrapous differs from Apulosauripus in having four digits on the pes instead of three (Gierliński and Sabath, 2008).

Qijiangpus has very large, pentadactyl manus impressions (larger than the pes) and a squared outline of the manus. The pes is relatively similar to that of Metatetrapous, however, digit I appears to be very short and broad. The trackway patterns of Qijiangpus are not sufficiently enough known for comparison (Xing et al., 2007). 


\section{Metatetrapous valdensis Nopcsa, 1923}

Figs. VI.3-VI.4

“fortlaufende Spur eines ..., vierfüßigen' Dinosauriers“: Ballerstedt, 1921, p. 233.

"Fährte eines [...] Vierfüßlers": Ballerstedt, 1922, p. 78, fig. 1, no. 3.

Metatetrapous valdense Nopcsa, 1923, p. 147, 199.

Metatetrapous valdense Ballerstedt 1922 : Kuhn, 1958, p. 27; Kuhn, 1963, p. 105, pl. 5, no. 14 [copy of Ballerstedt, 1922, fig. 1, no. 3].

Metatetrapous valdense Nopcsa 1923: Haubold, 1971, p. 89.

Metatetrapous valdensis: Haubold, 1971, p. 88, fig. 55, no. 3 [pro parte copy of Ballerstedt, 1922, fig. 1, no. 3]; Haubold, 1974, p. 141, fig. 89, no. 5 [pro parte copy of Ballerstedt, 1922, fig. 1, no. 3]; Haubold, 1984, p. 190, fig. 130, no. 5 [pro parte copy of Ballerstedt, 1922, fig. 1, no. 3]; Müller, 1985, p. 387, fig. 455i [copy of Haubold, 1971, fig. 55, no. 3]; Thulborn, 1990, p. 206, fig. 6.41c, 6.42c [pro parte copy of Haubold, 1971, fig. 55, no. 3]; Lockley and Meyer, 2000, p. 217, fig. 8.15a [pro parte copy of Haubold, 1971, fig. 55, no. 3]; McCrea et al., 2001, p. 420, fig. 20.3d [pro parte copy of Haubold, 1971, fig. 55, no. 3]; Avanzini and Petti, 2008, p. 294.

Metatetrapous valdensis Haubold, 1971: Avanzini et al., 2001, p. 174; McCrea et al., 2001, p. 421.

Note. The correct species epithet has to be valdensis instead of valdense, due to the masculine gender of the genus epithet (ICZN 1999: Articles 30, 31.2). The correct name was applied (without explanation) for the first time by Haubold (1971: caption of fig. 55, no. 3; but not in the text of the volume), and many later references (see synonymy list).

Ichnoholotype. The ichnoholotype was a $10.70 \mathrm{~m}$ long, epichnial trackway consisting of 15 manus and 16 pes imprints (by monotypy; Ballerstedt, 1921, 1922: fig. 1, no. 3, here Fig. 3), preserved in situ. It was exposed in the summer of 1921 and has been destroyed subsequently to its discovery. Written records by M. Ballerstedt (GZG archive) indicate the presence of a plaster cast at least from a manus impression in his collection but this is missing. According to the label on a - regrettably empty - box there were also photographs of the ichnoholotype, but they could not be traced, leaving the sketch drawing from Ballerstedt (1922: loc. cit.) the only figure of the trackway currently known.

Original diagnosis (excerpted from Nopcsa 1923: p. 147). "Fährte [eines] vierfüßige[n] Dinosaurier[s], [Ballerstedt [...] 1922. S. 78, Fig. 1, Nr. 3] [...] zeigt eine vierzehige Hand ohne Ballen und einen etwas größeren vierzehigen mit Ballen versehenen Fuß [...] [A]lle Zehen sind gleich lang sind und [haben] nur schwache Krallen [...]".

"Trackway of a quadrupedal dinosaur [...] [Ballerstedt, 1922: p. 78, fig. 1 no. 3] [...] [that] shows a tetradactyl hand without heel and a somewhat larger, tetradactyl, heeled foot [...]. The digits [of the pes] are of equal length , bearing only weak claws [...]." (Translated from German).

Emended diagnosis (based on Ballerstedt, 1922: fig. 1, no. 3; Nopcsa, 1923: p. 147, 199). Including the information from the figure by Ballerstedt (1922: fig. 1, no. 3), and the addendum by Nopcsa (1923: p. 199), an emended diagnosis of the ichnotaxon is proposed. However, this must be considered preliminary, owing to the loss of original material. Characters marked with $\left(^{*}\right)$ are conceived or interpreted from Ballerstedt's figure:

Moderately sized, quadrupedal, dinosaur (probably ankylosaurian) trackway, manus tetradactyl, pes tetradactyl. Manus imprints short*, arcuate*, digitigrade*, mesaxonic* or slightly entaxonic*, 
transversely wide $(\sim 80 \%$ of pes width)*. Manus digits short and triangular*; digit I directed posteromedially*. Manus imprints separated from pes imprints* and situated slightly anterolaterally to the latter*. Pes imprints semiplantigrade*, mesaxonic*, with well developed and separated digits I to IV. While digits II to IV point into craniad direction* and converge proximally nearly symmetrical relative to the base of digit III*, digit I shows a distinct posterior offset*, is smaller*, and divaricates medially from digit II in a wide angle*. No distinct phalangeal pads present*. Digits with short, slender, pointed claw-marks. Longitudinal axis of manus and pes imprints point slightly outward from the trackway midline*.

Type locality. Ballerstedt $(1921,1922)$ reported the trackway from "the large quarry at the Harrl hill", some $2 \mathrm{~km}$ southeast of Bückeburg, Lower Saxony, northwestern Germany (Fig. 1). At the same locality he had found an extensive track horizon before (Ballerstedt 1905, 1921), yielding abundant tracks of large ornithopods and theropods. Among this material preserved at the GZG also a turtle footprint was identified recently (Hornung and Reich, in press). As Ballerstedt (1921) noted, the quarry which produced the tracks was largely inactive since the 1860s and discoveries were made by active research excavation. He also stated that all of his material (including the M. valdensis type track) came from this single horizon.

The quarry from which Ballerstedt recovered the tracks is only partly accessible today (JJH, pers. obs. 2009, 2011). A second quarry is situated along strike, approximately $350 \mathrm{~m}$ to the west. It exposes c. 8 m of sand-, silt-, claystone and coal (Pelzer, 1998; Hornung et al., 2012a, 2012b; Fig. 2B). Its succession is laterally continuous with the upper part of the large quarry.

Type horizon. Sandstone interval within the middle Obernkirchen Member, Bückeberg Formation, late Berriasian, Early Cretaceous (Fig. 2).

The Bückeberg Formation (traditionally referred to as the northwestern "German Wealden", Elstner and Mutterlose, 1996) comprises predominantly limnic to brachyhaline deposits from the early Berriasian through the early Valanginian in the Lower Saxony Basin (Mutterlose 2000). The Obernkirchen Member is the lower part of the Bückeberg Formation. It is composed of a marginal, sandy facies complex and a fine-grainded silty-clayey basin facies with subordinate carbonates (Pelzer, 1998). The marginal facies is currently interpreted to represent a SE-NW facies succession from fluvial/alluvial plain to shallow-water deltaic environments. The lithology is dominated by interbedded sandstones, mudstones, and local coal seams (Pelzer, 1998).

At the Harrl hill locality, two cm-thick coal seams were separated by a ca. $8 \mathrm{~m}$ thick sandstone interval (Grupe, 1933). The lower coal seam was located at the base of the quarry and is today covered by debris. The upper seam is easily recognizable in the upper part of the succession and can be readily used to correlate the strata between adjacent quarries (Hornung et al., 2012b). Ballerstedt (in Grupe, 1933) noted that all dinosaur tracks were found below the upper coal seam. Pelzer (1998) recognized sedimentary structures in the small quarry which he tentatively related to a dinosaur track horizon, c. 1.2 m below the upper coal seam. He also speculated that this horizon may be Ballerstedt's track level. Recently the presence of this horizon was confirmed by the observation of in situ, tridactyl footprint casts (Hornung et al., 2012b). The tracks were left in (and partly penetrated) a c. $10 \mathrm{~cm}$ thick, dark-gray, silty, flasery, current-ripple cross-laminated, finegrained sandstone and were cast by a slightly coarser, yellow, massive, fine-grained sandstone. The 

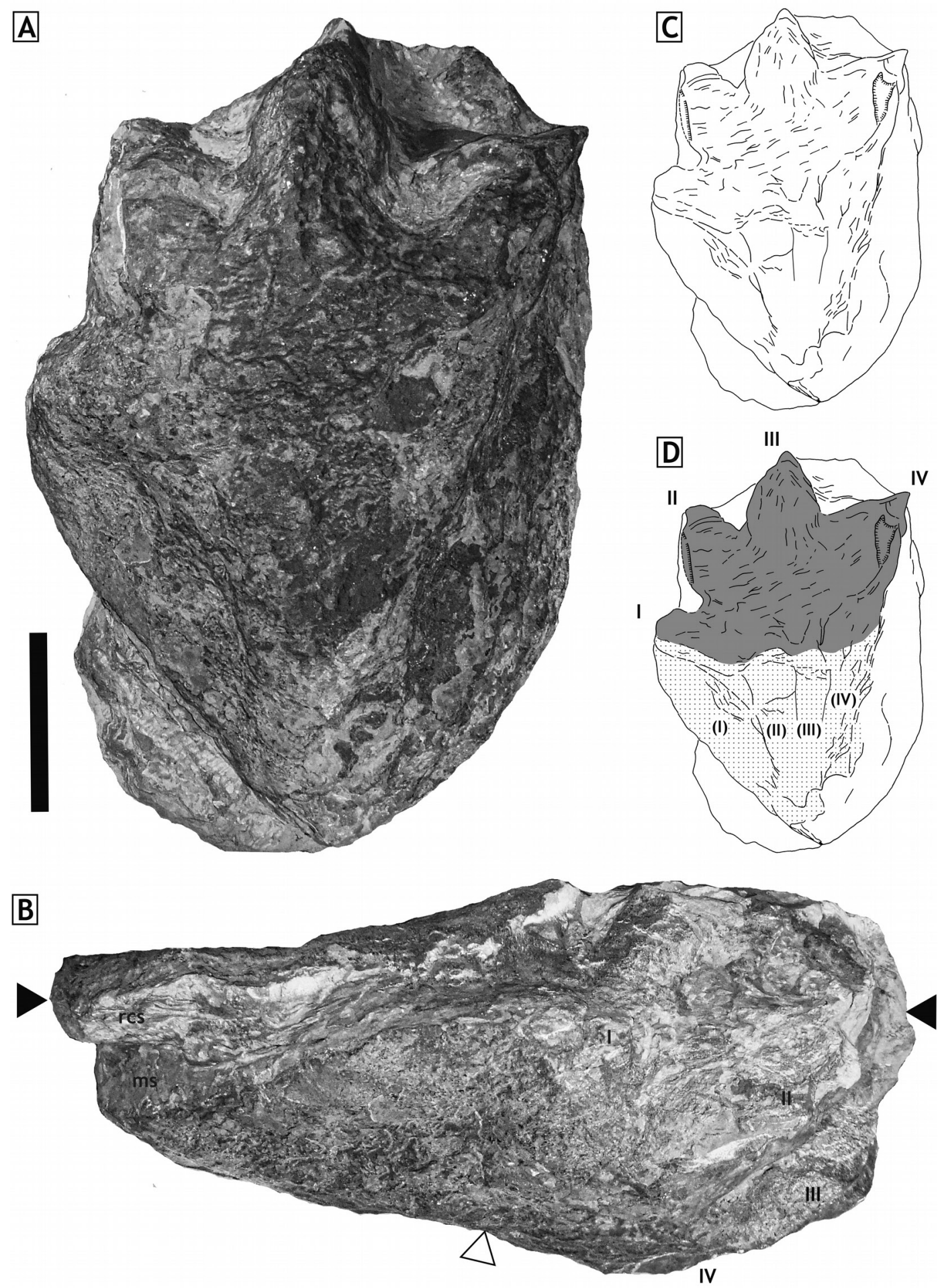

Fig. VI.5 GZG.BA.0050, ankylosaur left footprint natural cast, Obernkirchen Sandstone equivalent, Bückeberg Formation, Harrl near Bückeburg. A. ventral view, B. medial view, C. interpretative sketch, D. annotated interpretative sketch. I to IV: digits I to IV, (I) to (IV): scratch marks of digits I to IV on the slip-face, ms: massive casting sandstone, rcs: ripple cross-laminated, track hosting sandstone, grey shading: approximate outline of palmar surface impression, dotted shading: slip-face, black triangles: approximate level of sediment surface during track formation, white triangle: position of posterior end of palmar surface impression. Scale bar: $10 \mathrm{~cm}$. 

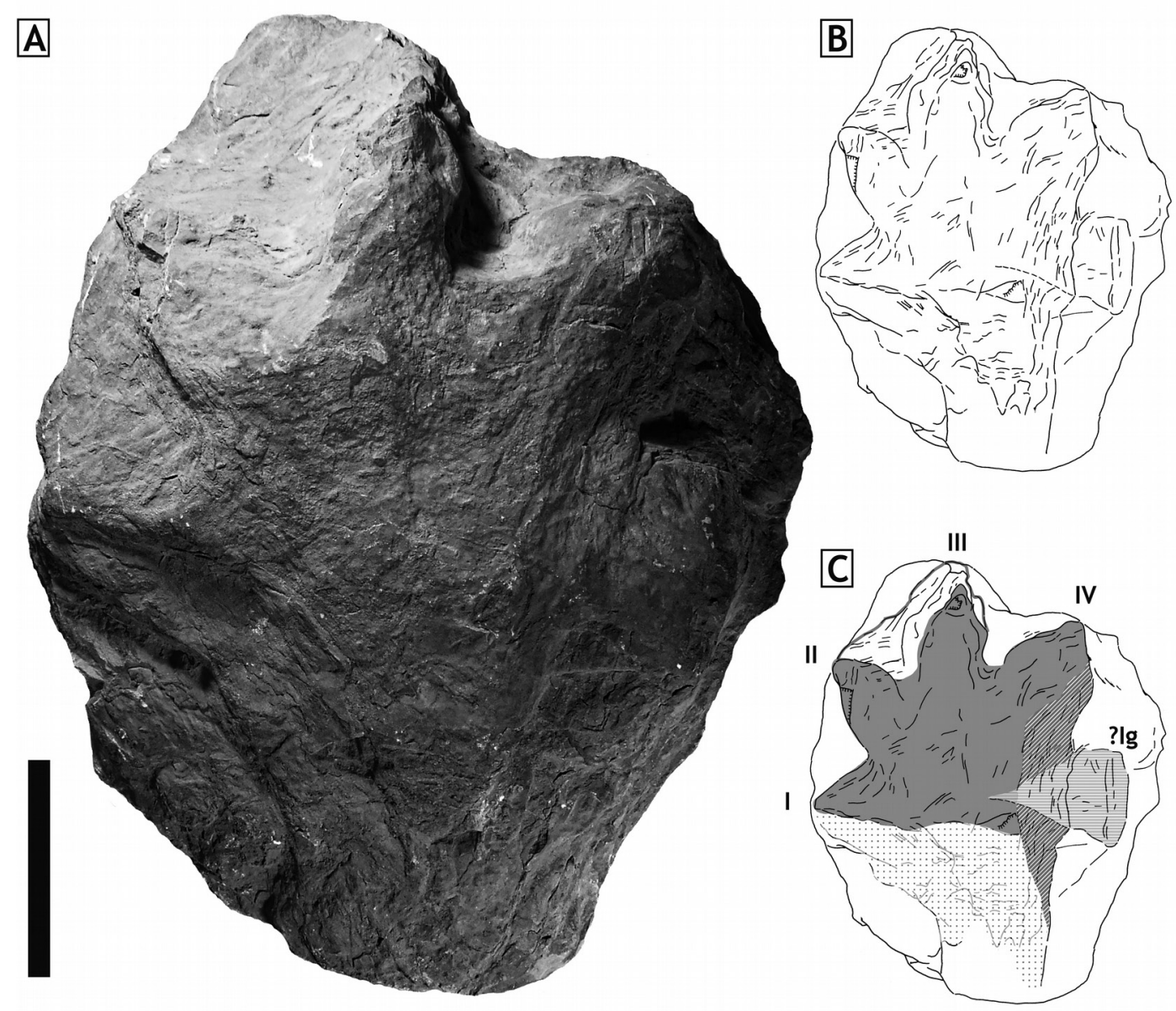

Fig. VI.6 GZG.BA.0049, ankylosaur left footprint natural cast, Obernkirchen Sandstone equivalent, Bückeberg Formation, Harrl near Bückeburg. A. ventral view, B. interpretative sketch, C. annotated interpretative sketch. Oblique hatching: collapsed regions of the footprint margin, horizontal hatching marked ?lg: Overstepping feature, possibly a iguanodontian ornithopod manus impression. For other abbreviations see Fig. VI.5. Scale bar: $10 \mathrm{~cm}$.

lithology of hypichnial casts and the host rock of the tracks from the Ballerstedt collection (see also below) clearly support the assumption that the track horizon is identical to that excavated by Ballerstedt, though the existence of further track horizons deeper in the succession cannot be excluded.

\section{Preserved ankylosaurian track material from the Ballerstedt collection}

The larger part of the fossil collection and private archive of M. Ballerstedt, resides today at the Geoscience Centre, University of Göttingen (GZG, for a short history and inventory of the collection see Probst and Windolf, 1993; Reich et al., 2009, in press; Probst 2010a, $2010 \mathrm{~b}$ ). In the course of a reinvestigation project of the whole Ballerstedt collection (Hornung and Reich, 2006, 2007) two isolated ichnites were found (Hornung et al., 2007), which can be attributed to an ankylosaurian trackmaker. Their inclusion in this collection, 

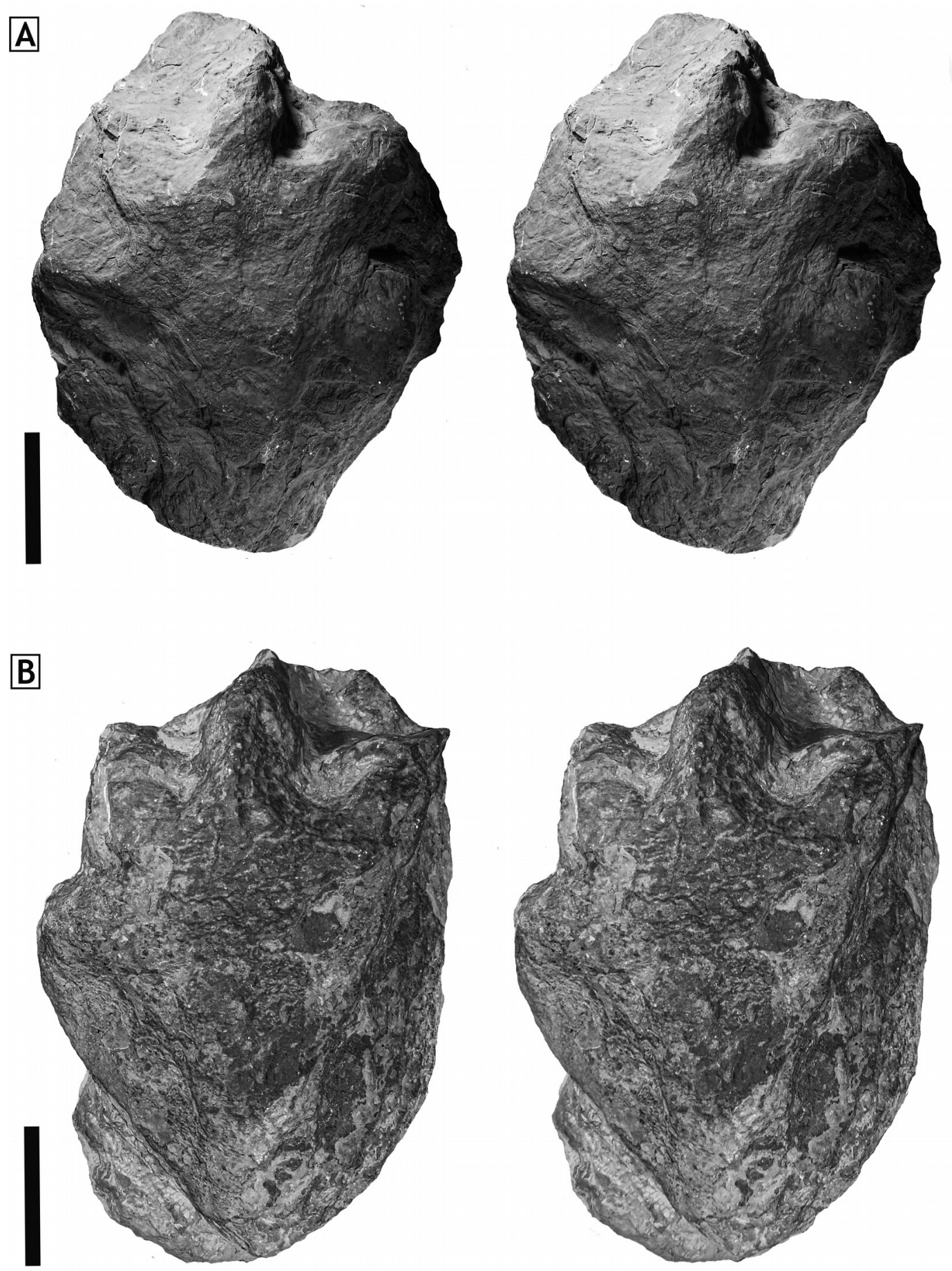

Fig. VI.7 Ankylosaur footprint natural casts, Obernkirchen Sandstone equivalent, Bückeberg Formation, Harrl near Bückeburg. Stereo views. A. GZG.BA.0049, B. GZG.BA.0050. Scale bars: $10 \mathrm{~cm}$.

morphology and other properties suggest an association with the type trackway of Metatetrapous valdensis, though - unfortunately - there are no primary data available to confirm this at the moment. 
Tab. VI.1 Measurements from the ichnoholotype of Metatetrapous valdensis Nopcsa, 1923 and preserved ankylosaur footprint casts.

\begin{tabular}{|c|c|c|c|}
\hline \multicolumn{4}{|l|}{ Trackway measurements* } \\
\hline & $\max$ & $\min$ & mean \\
\hline Stride length $\left(S_{m}\right)[c m](n=12)$ & 160 & 121 & 135 \\
\hline Pace angulation $(\rho)\left[^{\circ}\right](n=7)$ & 122 & 114.5 & 119.4 \\
\hline \multicolumn{4}{|l|}{ Pes imprint measurements ${ }^{* *}$} \\
\hline & \multicolumn{2}{|l|}{ GZG.BA.0049 } & GZG.BA.0050 \\
\hline Pes length $(\mathrm{FL})[\mathrm{cm}]$ & \multicolumn{2}{|l|}{25.0} & 25.0 \\
\hline Pes width (FW) [cm] & \multicolumn{2}{|l|}{28.0} & 27.5 \\
\hline Digit I length $\left(L_{1}\right)[\mathrm{cm}]$ & \multicolumn{2}{|l|}{14.0} & 16.0 \\
\hline Digit I free toe length $\left(T_{1}\right)[\mathrm{cm}]$ & \multicolumn{2}{|l|}{6.5} & 7.0 \\
\hline Digit II length $\left(\mathrm{L}_{\|}\right)[\mathrm{cm}]$ & \multicolumn{2}{|l|}{22.0} & 23.0 \\
\hline Digit II free toe length $\left(T_{\|}\right)[\mathrm{cm}]$ & \multicolumn{2}{|l|}{9.0} & $\sim 9.5$ \\
\hline Digit III length $\left(\mathrm{L}_{\mathrm{III}}\right)[\mathrm{cm}]$ & \multicolumn{2}{|l|}{25.0} & 25.0 \\
\hline Digit III free toe length $\left(T_{I I I}\right)[\mathrm{cm}]$ & \multicolumn{2}{|l|}{11.0} & 11.0 \\
\hline Digit IV length $\left(\mathrm{L}_{\mathrm{IV}}\right)[\mathrm{cm}]$ & \multicolumn{2}{|l|}{24.0} & 25.0 \\
\hline Digit IV free toe length $\left(\mathrm{T}_{\mathrm{IV}}\right)[\mathrm{cm}]$ & \multicolumn{2}{|l|}{12.0} & 11.0 \\
\hline Toe divarication $\mathrm{I-I}\left(\Theta_{\mathrm{I-II}}\right)\left[^{\circ}\right]$ & \multicolumn{2}{|l|}{40.0} & 38.5 \\
\hline Toe divarication II-III $\left(\Theta_{\mathrm{II-III}}\right)\left[^{\circ}\right]$ & \multicolumn{2}{|l|}{30.0} & 38.5 \\
\hline Toe divarication III-IV $\left(\Theta_{\mathrm{III-IV}}\right)\left[^{\circ}\right]$ & \multicolumn{2}{|l|}{30.0} & 37.0 \\
\hline
\end{tabular}

${ }^{*}$ Measurements obtained from Ballerstedt (1922: Fig. 1/3).

** Measurements obtained from original specimens.

Material Two hypichnial natural casts of left pes impressions (GZG.BA.0049, GZG.BA.0050, Figs. 5-7).

Locality Bückeberge, most probably the type locality of Metatetrapous valdensis, as specified above. All track material in the Ballerstedt collection comes from the Bückeberge, and by far the most of it from the single Harrl locality. The assumption that the preserved material also derives from the latter is further supported by the lithology of the host and casting strata present in the material. The tracks have been left in a grey to dark-grey, cross-laminated, muddy, fine-grained sandstone, which is preserved in places on the casts, 
and were cast by a massive, yellow-greyish, fine-grained sandstone. The contact between both is marked by a intensively rust-colored coating. This lithology is identical to that at the track horizon at the Harrl hill (see above and Hornung et al., 2012b). The cross-laminated, dark grey sandstone is also identical to a slab (without tracks) of the same material in the Ballerstedt collection (GZG.BA.0861) which is labelled "Fährtenboden Harrl" (Harrl track surface) in Ballerstedt's handwriting. A rust-colored coating is also present on many other natural track casts from this locality.

Description. Measurements are given in Tab. 1. Both hypichnia are approximately the same size and exhibit gross morphology, though their preservation is slightly different. The contact and contrast between the host rock and the casting material is sharp and clear and the casting sandstone is massive and thicker than the depth of the track. This and the preservation of distinct features like the nearly freely protruding claw-cast on digit IV in GZG.BA.0050 indicate that the casts show the true tracks and not transmitted "ghost tracks". The foot was deeper impressed into the substrate in GZG.BA.0050 than in GZG.BA.0049. In both specimens, the long axis of the foot is slightly inclined antero-ventrally with respect to the former sediment surface and the anterior margin of the track (area of digits II to IV) is sharply defined and cast as a full relief. In the posterior region (digit I and metapodial area) of both the tracks are less well defined and shallow, the casts more resembling a bas-relief.

Both ichnites show the impression of a tetradactyl pes. Digits II to IV are proportionally short compared to the foot-length and triangular to spindle-shaped in outline with no discernible interphalangeal pads. All bear short, conical claw-marks, the best preserved is on digit IV of GZG.BA.0050. These digits are subequal in size, though digit IV is slightly broader than II and III. Digit I is smaller, narrower, and less deeply impressed than II to IV. It is triangular and located with a distinct posterior off-set to the base of digits II to IV. There is no clear claw-mark on digit I, in both specimens it terminates in a rounded, knob-like structure. A flat plantar surface is present between the base of the digits. Anteriorly and medially it is defined by the base of the digits. Posteriorly it is confined by a distinct transverse, anteriorly arched line, beginning behind the base of digit I. The lateral border of the plantar surface is formed in the cast by a step-like, rugged area, located between the base of digit IV and the posterior margin of the plantar surface. In GZG.BA.0049 the posterior area of the plantar surface is slightly raised on the cast, suggesting the presence of a distinct metapodial ("heel") pad. Posterior to the line forming the posterior border of the plantar surface both ichnites show additional structures which are, however, better preserved in GZG.BA.0050. It consists of a broadly triangular, bulge (on the cast, groove on the original track), which tapers posteriorly. The long-axis of this bulge is more steeply inclined (c. $20^{\circ}$ ) with respect to the sediment surface than the anterior part of the footprint, and it intersects smoothly with the former at its posterior end. Anteriorly the bulge widens and contacts not only the plantar surface but also the posterior edge of digit I. Although less distinct in GZG.BA.0049 a similar feature, especially posterior to digit I is also present. The bulge is broadly rounded in cross-section though especially in GZG.BA.0050 its surface is further differentiated by three indistinct longitudinal ridges, the middle of which is the longest and points to the posterior apex of the bulge. 
The posterior elongation of the tracks can either be interpreted as an impression of the metapodium (thus inferring a crouching trackmaker), or to represent traces left by a slipping foot (slip-faces). It can be problematic to clearly differentiate between the two, however, in the present case an interpretation as slip-faces is preferred in both specimens. This is foremost based upon the extension of the bulges to and along the posterior margin of digit I. This would leave open only the possibilities of the digit I being either extremely broad and paddle-like, attached to the metapodium in a narrow angle for most of its length, or that it has been dragged into the sediment for some distance. However, as the impression of digit I clearly shows a narrow triangular shape, consistent with the other digits in both specimens and other tracks of similar morphology, and an orientation of its main axis is clearly almost perpendicular to the axis of the foot, the latter explanation is considered much more feasible. Therefore the posterior section of the tracks are interpreted to be slip-faces and the longitudinal ridges on the bulge in GZG.BA.0050 are probably the faint traces of the individual digits II to IV left during insertion of the foot into the sediment. The part of the track anterior to the posterior border of the plantar surface represents the part of the track which was formed when the foot came to rest. When the foot entered the substrate at an angle of about $20^{\circ}$, it pushed and compacted the sediment in front and between the digits by its forward thrust which explains the excellent track preservation in this area. In GZG.BA.0050 at least the tip to digits II to IV were completely submerged below the sediment surface Along the less compacted lateral margin of the track, a steep margin was initially also formed, which subsequently collapsed inward, leaving the rugged, stepped and somewhat indistinct confinement of the track in this part.

In GZG.BA.0049 a triangular structure is present opposite to digit I on the lateral side of the track which is reminiscent of a fifth digit. However, there is reason to dismiss such an interpretation. The plantar surface of the track is impressed deeper than this structure and is separated from it by a continuous (though slightly disturbed) fringe of the rugged, stepped margin, extending from the base of digit IV to the posterior margin of the footprint. Furthermore the structure widens laterally while it could be expected for a true digit to taper laterally. As the remainder of the footprint is nearly identical in morphology, proportions and dimensions to GZG.BA.0050, which unquestionably lacks a digit $\mathrm{V}$, both are considered to have been left by a limb of identical morphology and this feature is interpreted to not belong to the tetradactyl track. A plausible explanation of this structure is that it is the hypichnial cast of an iguanodontian ornithopod manus impression. Ballerstedt (1905) collected ornithopod tracks from the Harrl locality and Ballerstedt's (1922) figure shows a tridactyl pes track overstepping the type track of Metatetrapous valdensis. However the typical manus tracks of these ornithopods were unknown by this time and overlooked. They were only reported much later (Lockley et al. 2004) from the Obernkirchen Sandstone, but have been frequently encountered in excavations since then. These tracks are normally transversely ovate, peanut- or eight-shaped though formation of this specimen may has involved some dragging or slipping causing the triangular shape and slight disturbance of the tetradactyl footprint. It has to be noted that, if correctly interpreted, the orientation and sequence of creation of this imprint relative to the tetradactyl pes imprint is in agreement with the orientation of the tridactyl track crossing the type track of M. valdensis in Ballerstedt (1922). 


\section{Discussion}

As it has been shown above, several misconceptions surrounded the subsequent interpretation of the original Metratetrapous valdensis trackway as it was figured and described by Ballerstedt and Nopcsa. Most of them root in the interpretation of later figures which show only parts of the trackway but were published in more widely distributed publications than the original figure. The most important of these misconceptions relate to the foot-length and morphology, which was apparently over-estimated by later workers, as they referred mostly to the middle part of the trackway, where the footprints where longitudinally elongated by slipping. Such an extramorphological modification was also explicitly mentioned by Nopcsa (1923). In fact, considering these modifications, the morphology of the footprint appear to have been quite similar to typical ankylosaur footprints, with a relatively short "heel" region, as represented by Tetrapodosaurus borealis. Unfortunately, the original figure is too sketchy to provide further details beyond rough comparison.

Nevertheless, the original figures and description allow M. valdensis to be defined as a valid ichnotaxon, which has the outstanding importance to be the first ever referred to an thyreophoran trackmaker. The most diagnostic feature is a tetradactyl instead of pentadactyl manus, which is unique among formally described ankylosaurian ichnotaxa. This character was depicted by Ballerstedt (1922) and explicitly noted by Nopcsa (1923). It is considered herein to be valid, although it is possibility that a fifth digit - which is commonly faintly impressed in ankylosaur tracks - was overlooked on the original track cannot be ruled out without the original material.

Material preserved from the Ballerstedt collection, and described herein for the first time, can unequivocally be identified as to have been produced by an ankylosaurian trackmaker. The inclusion of these tetradactyl footprint casts into this collection and lithological evidence clearly support an origin from the M. valdensis type locality and stratum. Dimensions, morphology and presence of features reasonably interpreted as slip-faces are further very similar to those on the $M$. valdensis type track. This may support a close relationship of this material with the type trackway, a hypothesis which is given even more credibility by the fact, that this ichnomorphotype was never reported again from this or other sites (Hornung et al., 2012a), neither in Ballerstedt's nor other publications, unpublished records nor in any material excavated in recent years (JJH, pers. obs. 2005-2012). However, lacking direct evidence or records, this assumption must be considered plausible, but yet unproven. It would have be a logical action for Ballerstedt to store hypichnia from the original track in his collection as they were generally much easier to recover and transport than the original track relief and he had no machinery or means of transportation except a hand-drawn cart at his disposal (Probst and Windolf, 1993). His (unpublished) records clearly state, that he made (hypichnial) plaster casts of manus impressions of $M$. valdensis, though unfortunately these are not traceable among the collection material at present. If the footprint casts are referrable to Metatetrapous, they further support a great similarity in pedal morphology to other ankylosaur ichnotaxa, especially Tetrapodosaurus and Qijiangpus.

The presence of ankylosaurs in the Bückeberg Formation is, however, not only documented by M. valdensis and the newly described track material. Osteological evidence of their presence is given 
by a fragmentary humerus from the earlies Valanginian of Gronau in Westphalia (Sachs, 1997). From the same locality originates a lateral spine, and both elements have been referred to as ? Hylaeosaurus sp. (Sachs and Hornung, 2013). Koken (1887) reported two caudal vertebrae from the Bückeberg Formation at Duingen south of Hannover and identified them as Hylaeosaurus sp. Considered lost for a long time, one of them has recently been rediscovered at the Niedersächsisches Landesmuseum, Hannover. A brief examination showed that this specimen suffered from substantial crushing and deformation in all three dimensions, and identification to a level below an inderminate dinosaur might be problematical (Sachs and Hornung, 2013). A quadrupedal trackway with pentadactyl manus and pes imprints (Ensom, 1987), from the Purbeck Limestone Group of Dorset, England, close to the Jurassic/Cretaceous boundary, was previously identified to have been produced by an ankylosaur (Lockley, 1991; Lockley and Meyer, 2000). Scattered bone remains of ankylosaurs are known from the Late Jurassic or Earliest Cretaceous of southern England (Galton, 1980) and the English Wealden has yielded at least three valid taxa of ankylosaurs: Hylaeosaurus armatus Mantell, 1833 (Valanginian), Polacanthus foxii Owen in Anonymous, 1865, and P. rudgwickensis Blows, 1996 (Barremian; see Pereda-Suberbiola, 1993; Blows, 2001; Barrett and Maidment, 2011).

The uniqueness of ankylosaurs in the known material of dinosaur footprints from the Bückeberg Formation indicates that its producer was a rare and possibly exotic element of the coastal low-land and shoreline dinosaur fauna in the Lower Saxony Basin. This picture is especially contrasted by the virtually thousands of ornithopod and theropod footprints from the same strata. It seems that ankylosaurs were as rare as sauropods, which are only represented by one locality but multiple individuals (Fischer, 1998; Lockley et al., 2004; Hornung et al., 2012a).

\section{Conclusions}

A detailed reconsideration of the original publications of Metatetrapous valdensis Nopcsa, 1923 by Ballerstedt (1922) and Nopcsa (1923) show, that this enigmatic dinosaurian ichnotaxon can be considered valid and was reasonably referred to a thyreophoran (ankylosaurian) trackmaker. According to the single existing original depiction and explicit statements by Nopcsa (1923), the manus impressions of $M$. valdensis are tetradactyl, which would differentiate them from all other ankylosaurian ichnotaxa, while the pes impressions are similar to those of other ichnogenera such as Tetrapodosaurus and Qijiangpus. Another interesting observation noted by Nopcsa was the presence of slip-faces stretching posteriorly from the footprints. These, together with an only partial reproduction of the original figure in later, but more widespread publications, may easily result in an over-estimation of the true footlength.

From a historical point of view, M. valdensis represents the first ichnotaxon ever referred to a thyreophoran dinosaur, an identification first proposed by Nopcsa (1923) and still considered correct. It is further interesting that its discovery led to the expressis verbis formulation of the hypothesis that quadrupedal dinosaurs evolved from bipedal ancestors by M. Ballerstedt (1922) possibly the first time that this idea was based on the ichnological record and a very early example 
of ichnological interpretation beyond morphology and trackmaker identification.

Unfortunately, none of the unambiguous original material is known to have survived. However, the Ballerstedt collection at the GZG includes two natural hypichnial casts of ankylosaurian footprints. Though lacking a proper documentation, there are several strong indications that they originate from the type locality of M. valdensis and may even be part of its ichnoholotype. Aside of lithological criteria supporting their geographical origin, they share very similar size, morphology and proportions, as well as the presence of distinct slip-faces as noted by Nopcsa from M. valdensis. Associated with one of the tracks is a structure which may be interpreted as a iguanodontian ornithopod manus impression, and a crossing ornithopod trackway was also sketched by Ballerstedt (1922). Finally this track morphotype is extremely rare in the Bückeberg Formation. Following increasing excavation activity that has taken place in recent years, and the discovery of thousands of dinosaur footprints, the lost trackway and the two specimens described here remain the only known examples of purported ankylosaur tracks.

Sadly, the gap in documentation hinders a sound referral of the surviving material to the ichnoholotype of $M$. valdensis. Nevertheless, a close relationship to this ichnotaxon must be considered. Furthermore it gives direct physical evidence to the presence of this morphotype of tracks in the Bückeberg Formation, which have been previously doubted or even dismissed (Schmidt, 1969). Its referral to an ankylosaur trackmaker gives further evidence for the presence of this clade in the Berriasian of Germany, which is otherwise only recorded by scanty skeletal remains from a slightly younger horizon (early Valanginian). The lithofacies of the host rocks indicate a deltaic mouthbar setting as environment, where ankylosaurs, together with sauropods, apparently comprised a rare faunal element compared to abundant ornithopods and theropods.

\section{Acknowledgments}

We wish to thank Jerry D. Harris, Richard T. McCrea, and an anonymous reviewer for numerous comments, suggestions, and constructive critique of the manuscript. We further gratefully acknowledge the support by Annina Böhme and Tanja R. Stegemann (both Göttingen) as well as Julia König (formerly Göttingen) during fieldwork at the type locality of M. valdensis. Vanessa Julie Roden (Darmstadt, formerly Göttingen) read an early draft of our paper and her comments greatly improved this draft linguistically.

\section{References}

Abel, 0. 1935. Vorzeitliche Lebensspuren. Fischer Verlag, Jena, XV+664 pp.

Anonymous, 1865. A new Wealden dragon. Order, Sauria; Family, Dinosauria; Genus, Polacanthus; Species, foxii. Illustrated London News, 47 [10 ${ }^{\text {th }}$ September 1865]: p. 270. 
Apesteguía, S., and Gallina, P. A. 2011. Tunasniyoj, a dinosaur tracksite from the Jurassic Cretaceous boundary of Bolivia. In Proceedings of the Third Gondwanan Dinosaur Symposium. Anais da Academia Brasileira de Ciências, 83 (1): 267-277.

Avanzini, M., and Petti, F. M. 2008. Updating the dinosaur tracksite from the Lower Jurassic Calcari Grigi Group (Southern Alps, Northern Italy). Acta Geologica [Studi trentini di scienze naturali], 83: 289-301.

Avanzini, M., Leonardi, G., Tomasoni, R., and Campolongo, M. 2001. Enigmatic dinosaur trackways from the Lower Jurassic (Pliensbachian) of the Sarca valley, northeast Italy. Ichnos, 8 (3-4): 235-242.

Ballerstedt, M. 1905. Über Saurierfährten der Wealdenformation Bückeburgs. Naturwissenschaftliche Wochenschrift (Neue Folge), 4 (31): 481-485.

Ballerstedt, M. 1921. Dinosaurierfährten im Wealdensandstein des Harrl bei Bückeburg und eine zurzeit freiliegende Spur eines „vierfüssigen“ plumpen Dinosauriers. Zeitschrift der Deutschen Geologischen Gesellschaft, 72: 231-233.

Ballerstedt, M. 1922. Über Schreckensaurier und ihre Fußspuren. Kosmos. Handweiser für Naturfreunde, 19 (3): 77-80.

Barrett, P. M., and Maidment, S. C. R. 2011. Armoured dinosaurs. In Batten, D. J. (ed.), English Wealden fossils. Palaeontological Association Field Guide to Fossils, 14: 391-406.

Beasley, H. C., 1910. Report on Footprints from the Trias. Part VI. In Herdman, W. A., Beasley, H. C., Newton, E. T., Seward, A. T., Ussher, W. A. E., Watts, W. W., and Smith Woodward, A. (eds.) Investigation of the Fauna and Flora of the Trias of the British Isles. Seventh Report of the Committee. Report of the Seventy-Ninth Meeting of the British Association for the Advancement of Science. John Murray, London, pp. 151-155.

Blows, W. T. 1996. A new species of Polacanthus (Ornithischia: Ankylosauria) from the Lower Cretaceous of Sussex, England. Geological Magazine, 133 (6): 671-682.

Blows, W.T. 2001. Dermal armor of the polacanthine dinosaurs. In Carpenter, K. (ed.), The Armored Dinosaurs. Indiana University Press, Bloomington, pp. 363-387.

Butler, R. J., Liyong, J., Jun, C., and Godefroit, P. 2011.The postcranial osteology and and phylogenetic position of the small ornithischian dinosaur Changchunsaurus parvus from the Quantou Formation (Cretaceous: Aptian-Cenomanian) of Jilin Province, north-eastern China. Palaeontology, 54 (3): 667-683.

Butler, R. J., and Sullivan, R. M. 2009. The phylogenetic position of the ornithischian dinosaur Stenopelix valdensis from the Lower Cretaceous of Germany and the early fossil record of Pachycephalosauria. Acta Palaeontologica Polonica, 54 (1): 
21-34.

Butler, R. J., Upchurch, P., and Norman, D. B. 2008. The phylogeny of the ornithischian dinosaurs. Journal of Systematic Palaeontology, 6 (1): 1-40.

Carpenter, K. 1984. Skeletal reconstruction and life restoration of Sauropelta (Ankylosauria: Nodosauridae) from the Cretaceous of North America. Canadian Journal of Earth Sciences, 21 (12): 1491-1498.

Colbert, E. H. 1981. A primitive ornithischian dinosaur from the Kayenta Formation of Arizona. Bulletin of the Museum of Northern Arizona, 53: 1-61.

Coombs, W. P. jr., and Maryanska, T. 1990. Ankylosauria. In Weishampel, D. B., Dodson, P., and Osmólska, H. (eds.), The Dinosauria. University of California Press, Berkeley, pp. 456-483.

Currie, P. J. 1989. Dinosaur footprints of western Canada. In Gillette, D. D., and Lockley, M. G. (eds.), Dinosaur Tracks and Traces. Cambridge University Press, Cambridge, pp. 293-300.

Elstner, F. and Mutterlose, J. 1996. The Lower Cretaceous (Berriasian and Valanginian) in NW Germany. Cretaceous Research, 17(1):119-133.

Ensom, P. 1987. Dinosaur tracks in dorset. Geology Today, 3(6): 182-183.

Fischer, R. 1998. Die Saurierfährten im Naturdenkmal Münchehagen. Mitteilungen des geologischen Instituts der Universität Hannover, 37: 3-59.

Galton, P. M. 1980. Priodontognathus phillipsii (Seeley), an ankylosaurian dinosaur from the Upper Jurassic (or probably Lower Cretaceous) of England. Neues Jahrbuch für Geologie und Paläontologie, Monatshefte, [1980] (8): 477-489.

Gangloff, R. A., May, K. C., and Storer, J. E. 2004. An early Late Cretaceous dinosaur tracksite in central Yukon Territory, Canada. Ichnos, 11 (3/4): 299-309.

Gierliński, G., Mossbrucker, M. T., and Sabath, K. 2005. Stegosaurian footprints from the Morrison Formation of western United States and their implications for other finds. In LeLoeuff, J., Vila, B., Marmi, J., Galobart, Á., and Oms, O. (eds.), International Symposium on Dinosaurs and other Vertebrates Palaeoichnology (October 4-8 ${ }^{\text {th }}$ 2005), FumanyaSant Corneli, Catalunya. Abstract Book. Cercs \& Barcelona, pp. 28-29.

Gierliński, G., and Sabath, K. 2008. Stegosaurian footprints from the Morrison Formation of Utah and their implications for interpreting other ornithischian tracks. Oryctos, 8: 29-46. 
Goldring, R., Pollard, J. E. and Radley, J. D. 2005. Trace fossils and pseudofossils from the Wealden strata (non-marine Lower Cretaceous) of southern England. Cretaceous Research, 26(4): 665-685.

Grupe, 0. 1933. Blatt Bückeburg, Nr. 2017. Erläuterungen zur geologischen Karte von Preußen und benachbarter deutscher Länder. Lieferung 330, Berlin, 69 pp.

Harington, C. R., Foster, H., Holmes, R. and Currie, P. J. 2005. Photographic Catalogue of Trackways in the Canadian Museum of Nature. Syllogeus, 74:1-151.

Hatcher, J. B. 1903. Osteology of Haplocanthosaurus, with description of a new species, and remarks on the probable habits of the Sauropoda and the age and origin of the Atlantosaurus beds. Memoires of the Carnegie Museum, 2: 1-72.

Haubold, H. 1971. Ichnia Amphibiorum et Reptiliorum fossilum. Handbuch der Paläoherpetologie, 18. G. Fischer, Stuttgart / Jena, $124 \mathrm{p}$.

Haubold, H. 1974. Die fossilen Saurierfährten. Die neue Brehm-Bücherei, 479. A. Ziemsen, Wittenberg, 168 pp.

Haubold, H. 1984. Saurierfährten. Die neue Brehm-Bücherei, 479. A. Ziemsen, Wittenberg Lutherstadt, 231 pp.

Hornung, J. J., and Reich, M. 2006. The "Wealden" collection of Max Ballerstedt (1857-1945) - undisclosed treasures from the Early Cretaceous of northwestern Germany. In 76. Jahrestagung der Paläontologischen Gesellschaft. Kiel, 28.-30. August 2006. Beitragskurzfassungen. Berichte-Reports des Instituts für Geowissenschaften, Christian-AlbrechtsUniversität Kiel, 22: 40-41.

Hornung, J. J., and Reich, M. 2007. Krokodile, Schildkröten \& Dinosaurier. Die „Wealden“-Sammlung der Universität Göttingen. Fossilien, 24 (1): 32-36.

Hornung, J. J. and Reich, M. in press. Derived appendicular morphology in Early Cretaceous aquatic turtles evidenced by the track record. Lethaia, doi: 10.1111/let.12024.

Hornung, J. J., König, J. and Reich, M. 2007. Rediscovered type material of the ankylosaurian ichnospecies Metatetrapous valdensis Nopcsa, 1923 (Early Cretaceous, NW Germany). In Elicki, O. and Schneider, J. W. (eds.), Fossile Ökosysteme. 77. Jahrestagung der Paläontologischen Gesellschaft. Kurzfassungen der Vorträge und Poster. Wissenschaftliche Mitteilungen des Instituts für Geologie der TU Bergakademie Freiberg, 36: 59-60.

Hornung, J. J., Böhme, A., Lubbe, T. van der, Reich, M., and Richter, A. 2012a. Vertebrate tracksites in the Obernkirchen 
Sandstone (late Berriasian, Early Cretaceous) of northwest Germany - their stratigraphical, palaeogeographical, and historical context. Paläontologische Zeitschrift, 86(3): 231-267.

Hornung, J. J., Böhme, A. and Reich, M. 2012b: Excursion Guide A2: Harrl hill near Bückeburg. In Richter, A., and Reich, M. (eds.), Dinosaur Tracks 2011. An International Symposium, Obernkirchen, April 14-17, 2011, Abstract Volume and Field Guide to Excursions, Universitätsverlag Göttingen, Göttingen, pp. 101-112.

ICZN [International Committee for Zoological Nomenclature] 1999. International Code for Zoological Nomenclature. Fourth Edition. The International Trust for Zoological Nomenclature, Natural History Museum, London, xxix + 306 p.

Kemper, E. 1973. Das Berrias (tiefe Unterkreide) in NW-Deutschland. Geologisches Jahrbuch, Reihe A: Allgemeine und regionale Geologie BR Deutschland und Nachbargebiete, Tektonik, Statigraphie, Paläontologie, 9: 47-67.

Koken, E. 1887. Die Dinosaurier, Crocodiliden und Sauropterygier des Norddeutschen Wealden. - Palaeontologische Abhandlungen, 3: 1-111.

Kuhn, 0. 1958. Die Fährten der vorzeitlichen Amphibien und Reptilien. Verlagshaus Meisenbach, Bamberg, 64 p.

Kuhn, O. 1963. Ichnia Tetrapodorum. Fossilium Catalogus (I: Animalia), 101: 176 p.

LBEG [Landesamt für Bergbau, Energie und Geologie Niedersachsen] 2013. NIBIS Kartenserver, http://nibis.lbeg.de/cardomap3/ [last accessed June 19, 2013].

Lockley, M. G. 1991. Tracking dinosaurs: a new look at an ancient world. Cambridge University Press, New York, 238 p.

Lockley, M. G., and Meyer, C. A. 2000. Dinosaur tracks and other fossil footprints of Europe. Columbia University Press, Columbia, $323 \mathrm{pp}$.

Lockley, M. G., Wright, J. L. and Thies, D. 2004. Some observations on the Dinosaur tracks at Münchehagen (Lower Cretaceous), Germany. Ichnos, 11 (3/4): 261-274.

Lockley, M., Holbrook, J., Kukihara, R., and Matsukawa M. 2006. An ankylosaur-dominated dinosaur tracksite in the Cretaceous Dakota Group of Colorado: paleoenvironmental and sequence stratigraphic context. New Mexico Museum of Natural History and Science Bulletin, 35: 95-104.

Mantell, G. A. 1833. Geology of the South East of England. Longman, Rees, Orme, Brown, Green, and Longman, London, $415 \mathrm{p}$. 
Marsh, 0. C. 1877. New order of extinct Reptilia (Stegosauria) from the Jurassic of Rocky Mountains. American Journal of Science (series 3), 14: 513-514.

McCrea, R. T. 2000. Vertebrate Palaeoichnology of the Lower Cretaceous (lower Albian) Gates Formation of Alberta. Unpublished Ph.D. thesis, University of Saskatchewan, Saskatoon, $\mathrm{xx}+184 \mathrm{p}$.

McCrea, R. T. 2003. Fossil tracks from Tumbler Ridge: a brief history of collaboration between amateurs and academics. In Anonymous (ed.), Alberta Palaeontological Society, Seventh Annual Symposium. Mount Royal College, Calgary, pp. 4148.

McCrea, R. T., and Buckley, L. G. 2008. Fossil vertebrate tracks from the Gorman Creek Formation, northeastern B.C. In Anonymus (ed.), Alberta Palaeontological Society, Twelfth Annual Symposium. Mount Royal College, Calgary, pp. 3743.

McCrea, R. T., Lockley, M. G. and Meyer, C. A. 2001. Global Distribution of Purported Ankylosaur Track Occurrences. In Carpenter, K. (ed.), The Armored Dinosaurs. Indiana University Press, Bloomington, pp. 413-454.

Meyer, H. von 1857. Beiträge zur näheren Kenntnis fossiler Reptilien. Neues Jahrbuch für Mineralogie, Geologie und Paläontologie, for 1857: 532-543.

Milàn, J. and Gierliński, G. 2004. A probable thyreophoran (Dinosauria, Ornithischia) footprint from the Upper Triassic of southern Sweden. Bulletin of the Geological Society of Denmark, 51: 71-75.

Müller, A. H. 1985. Lehrbuch der Paläozoologie. Band III. Vertebraten, Teil 2. Reptilien und Vögel, 2. Auflage. G. Fischer, Jena, $665 \mathrm{pp}$.

Mutterlose, J. 2000. Unterkreide im Niedersächsischen Becken. In Stratigraphische Kommission Deutschlands (ed.), Die Kreide der Bundesrepublik Deutschland. Courier Forschungsinstitut Senckenberg, 226: 79-101.

Nicosia, U., Marino, M., Mariotti, N., Muraro, C., Panigutti, S., Petti, F. M. and Sacchi, E. 1999. The late Cretaceous dinosaur tracksite near Altamura (Bari, southern Italy). Geologica Romana, 35: 231-236.

Niedźwiedzki, G., Singer, T., Gierliński, G., and Lockley, M. G. 2012. A protoceratopsid skeleton with an associated track from the Upper Cretaceous of Mongolia. Cretaceous Research, 33 (1): 7-10.

Nopcsa, F. 1915. Die Dinosaurier des siebenbürgischen Landesteile Ungarns. Mitteilungen und Jahresberichte der Königlich Ungarischen Geologischen Reichsanstalt, 23: 1-26. 
Nopcsa, F. 1923. Die Familien der Reptilien. Fortschritte der Geologie und Palaeontologie, 2: 1-210.

Norman, D. B., Witmer, L. M., and Weishampel, D. B. 2004. Basal Thyreophora. In Weishampel, D. B., Dodson, P., and Osmólska, H. (eds.), The Dinosauria, $2^{\text {nd }}$ ed. University of California Press, Berkeley, pp. 335-342.

Osborn, H. F. 1923. Two Lower Cretaceous dinosaurs from Mongolia. American Museum Novitates, 95: 1-10.

Ostrom, J. H. 1970. Stratigraphy and paleontology of the Cloverly Formation (Lower Cretaceous) of the Bighorn Basin area, Wyoming and Montana. Peabody Museum of Natural History, Yale University, Bulletin, 35: 1-234.

Pelzer, G. 1998. Sedimentologie und Palynologie der Wealden-Fazies im Hannoverschen Bergland. Courier Forschungsinstitut Senckenberg, 207: 1-211.

Pereda-Suberbiola, X. 1993. Hylaeosaurus, Polacanthus, and the systematics and stratigraphy of Wealden armoured dinosaurs. Geological Magazine, 130 (6): 767-781.

Petti, F. M., D’Orazi Porchetti, S., Sacchi, E., and Nicosia, U. 2010. A new purported ankylosaur trackway in the Lower Cretaceous (lower Aptian) shallow-marine carbonate deposits of Pugli, southern Italy. Cretaceous Research, 31 (6): 546-552.

Probst, E. 2010a. Dinosaurier in Niedersachsen. Von Elephantopoides bis zu Stenopelix. GRIN Verlag, München, 80 p.

Probst, E. 2010b. Dinosaurier in Deutschland. Von Compsognathus bis zu Stenopelix. GRIN Verlag, München, 112 p.

Probst, E., and Windolf, R. 1993. Dinosaurier in Deutschland. C. Bertelsmann Verlag, München, 316 p.

Reich, M., Reitner, J., Roden, V. J., and Stegemann, T. 2009. The Geoscientific Collections of the Göttingen University. GZG, Göttingen, $24 \mathrm{p}$.

Reich, M., Hornung, J. J., and Stegemann, T. R. in press. Geologische Sammlung des Adolfinums Bückeburg. In Reich, M. (coord.), Ein "kleiner Führer" durch die Sammlungen, Museen und Gärten der Universität Göttingen. Universitätsverlag Göttingen, Göttingen.

Romero Molina, M. M., Pérez-Lorente, F., and Rivas Carrera, P. 2003. Análisis de la parataxonomía utilizada con las huellas de dinosaurio. In Pérez-Lorente, F., Romero, M., and Rivas Carrera, P. (coord.), Dinosaurios y otros reptiles mesozoicos en España. Ciencias de la Tierra, 26: 13-32. 
Sacchi, E., Conti, M. A., D’Orazi Porchetti, S., Logoluso, A., Nicosia, U., Perugini, G., and Petti, F. M. 2009. Aptian dinosaur footprints from the Apulian platform (Bisceglie, Southern Italy) in the framework of periadriatic ichnosites. Palaeogeography, Palaeoclimatology, Palaeoecology, 271 (1-2): 104-116.

Sachs, S. 1997. First record of an armored dinosaur (Reptilia, Ornithischia, Thyreophora) from the Lower Cretaceous (Berriasian) of Gronau in Westfalen, Germany. Neues Jahrbuch für Geologie und Paläontologie, Monatshefte, [1997] (1): $56-64$.

Sachs, S. and Hornung, J.J. 2013. Ankylosaur remains from the Early Cretaceous (Valanginian) of northwestern Germany PLoS One, 8(4): e60571. doi:10.1371/journal.pone.0060571

Salgado, L. and Gasparini, Z. 2006. Reappraisal of an ankylosaurian dinosaur from the Upper Cretaceous of James Ross Island (Antarctica). Geodiversitas, 28: 119-135.

Sarjeant, W. A. S. 1989. 'Ten Paleoichnological Commandments'. A standardized procedure for the description of fossil vertebrate footprints. In Gillette, D. D., and Lockley, M. G. (eds.), Dinosaur Tracks and Traces. Cambridge University Press, Cambridge, pp. 369-370.

Schmidt, H. 1969. Stenopelix valdensis H. v. Meyer, der kleine Dinosaurier des norddeutschen Wealden. Paläontologische Zeitschrift, 43 (3/4): 194-198.

Schott, W., Jaritz, W., Kockel, F., Sames, C. W., Stackelberg, U. von, Stets, J., Stoppel, D., Baldschuhn, R. and Krampe, K.-D. 1967. Paläogeographische Karten von Nordwestdeutschland im Maßstab 1:200 000. In Bundesanstalt für Bodenforschung (ed.), Paläogeographischer Atlas der Unterkreide von Nordwest-Deutschland mit einer Übersichtsdarstellung des nördlichen Mitteleuropa. Bundesanstalt für Bodenforschung, Hannover, 289 pp.

Schott, W., Jaritz, W., Kockel, F., Sames, C. W., Stackelberg, U. von, Stets, J., Stoppel, D., Baldschuhn, R. and Krampe, K.-D. 1969. Erläuterungen. In Bundesanstalt für Bodenforschung (ed.), Paläogeographischer Atlas der Unterkreide von Nordwest-Deutschland mit einer Übersichtsdarstellung des nördlichen Mitteleuropa. Bundesanstalt für Bodenforschung, Hannover, 315 p.

Seeley, H. G. 1887. On the classification of the fossil animals commonly called Dinosauria. Proceedings of the Royal Society of London, 43: 165-171.

Stanford, R., Lockley, M. G., and Weems, R. 2007. Diverse dinosaur-dominated ichnofaunas from the Potomac Group (Lower Cretaceous) Maryland. Ichnos, 14 (3/4): 155-173. 
Sternberg, C. M. 1932. Dinosaur tracks from Peace River, British Columbia. Annals and Reports of the National Museum of Canada, [1930]: 59-85.

Struckmann, C. 1880. Vorläufige Nachricht über das Vorkommen großer, vogelähnlicher Thierfährten (Ornithoidichnites) im Hastingssandsteine von Bad Rehburg bei Hannover. Neues Jahrbuch für Mineralogie, Geologie und Paläontologie, [1880] (I): 125-128.

Tanke, D., and Neuman, A. 2007. Results of 2006 Royal Tyrell Museum exploration in the Two Lakes and Kakwa Wildland Provincial Park regions, western Alberta. In Anonymus (ed.), Alberta Palaeontological Society, Eleventh Annual Symposium. Mount Royal College, Calgary, pp. 55-67.

Thulborn, R. A. 1990. Dinosaur Tracks. Chapman and Hall, London, 424 p.

Vickaryous, M. K., Maryanska, T., and Weishampel, D. B. 2004. Ankylosauria. In Weishampel, D. B., Dodson, P., and Osmólska, H. (eds.), The Dinosauria, $2^{\text {nd }}$ ed. University of California Press, Berkeley: pp. 363-392.

Weems, R. E. 2004. A dinosaur-dominated ichnofauna from the Lower Cretaceous Patuxent Formation of Virginia. Geological Society of America, Abstracts with Programs, 36: 116.

Wolburg, J. 1949. Ergebnisse der biostratigraphie nach Ostracoden im nordwestdeutschen Wealden. In Bentz, A. (ed.), Erdöl und Tektonik in Nordwestdeutschland. Amt für Bodenforschung, Hannover, pp. 349-360.

Xing, L., Wang, F., Pan, S., and Chen, W. 2007. The Discovery of Dinosaur Footprints from the Middle Cretaceous Jiaguan Formation of Qijiang County, Chongqing City. Acta Geologica Sinica, 81 (11): 1591-1602.

Xu, Xing, Forster, C. A., Clark, J. M., and Mo, J. 2006. A basal ceratopsian with transitional features from the Late Jurassic of northwestern China. Proceedings of the Royal Society of London (B: Biological Sciences), 273 (1598): 2135-2140. 


\section{Chapter VII}

Ankylosaur remains from the Early Cretaceous (Valanginian) of Westphalia (northwestern Germany) 


\title{
Ankylosaur remains from the Early Cretaceous (Valanginian) of Westphalia (northwestern Germany)
}

\author{
SVEN SACHS ${ }^{1}$ and JAHN J. HORNUNG ${ }^{2}$ \\ ${ }^{1}$ Im Hof 9, Engelskirchen, Germany, Sachs.Pal@gmx.de \\ ${ }^{2}$ Department of Geobiology, Geoscience Centre, Georg-August University of Göttingen, Germany
}

\begin{abstract}
A fragmentary cervico-pectoral lateral spine and partial humerus of an ankylosaur from the Early Cretaceous (early Valanginian) of Gronau in Westfalen, northwestern Germany, are described. The spine shows closest morphological similarities to the characteristic cervical and pectoral spines of Hylaeosaurus armatus from the late Valanginian of England. An extensive comparison of distal humeri among thyreophoran dinosaurs supports systematic differences in the morphology of the distal condyli between Ankylosauria and Stegosauria and a referral of the Gronau specimen to the former. The humerus fragment indicates a rather small individual, probably in the size range of $H$. armatus, and both specimens are determined herein as ?Hylaeosaurus sp.. A short overview of other purported ankylosaur material from the Berriasian-Valanginian of northwest Germany shows that, aside from the material described herein, only tracks can be attributed to this clade with confidence at present.
\end{abstract}

\section{Introduction}

The Gerdemann clay-pit in Gronau in Westfalen (northwestern Germany, Fig. VII.1a) has yielded a considerable amount of vertebrate fossils, including remains of fishes, turtles, plesiosaurs, crocodilians and dinosaurs $[1,2,3,4,5]$. The fossils were collected mainly during the first decades of the 20th century and sold or donated by the clay-pit owner to various museums and collections in northern Germany and the Netherlands. Most specimens are kept in the Geomuseum of the University of Münster and in the Museum TwentseWelle in Enschede.

The exposed strata in Gronau belong to the argillaceous facies of the upper Bückeberg Formation (Osterwald Member, Fig. VII.1b). Mostly deposited under limnic conditions in the Early Cretaceous Lower Saxony Basin., the western part of the basin, including the Gronau region, occasionally came under brackish to marine influence via passages to the Boreal Sea ([6]; Fig. VII.2). These brackish and marine intervals increase in number and prominence in the youngest part of the succession and 


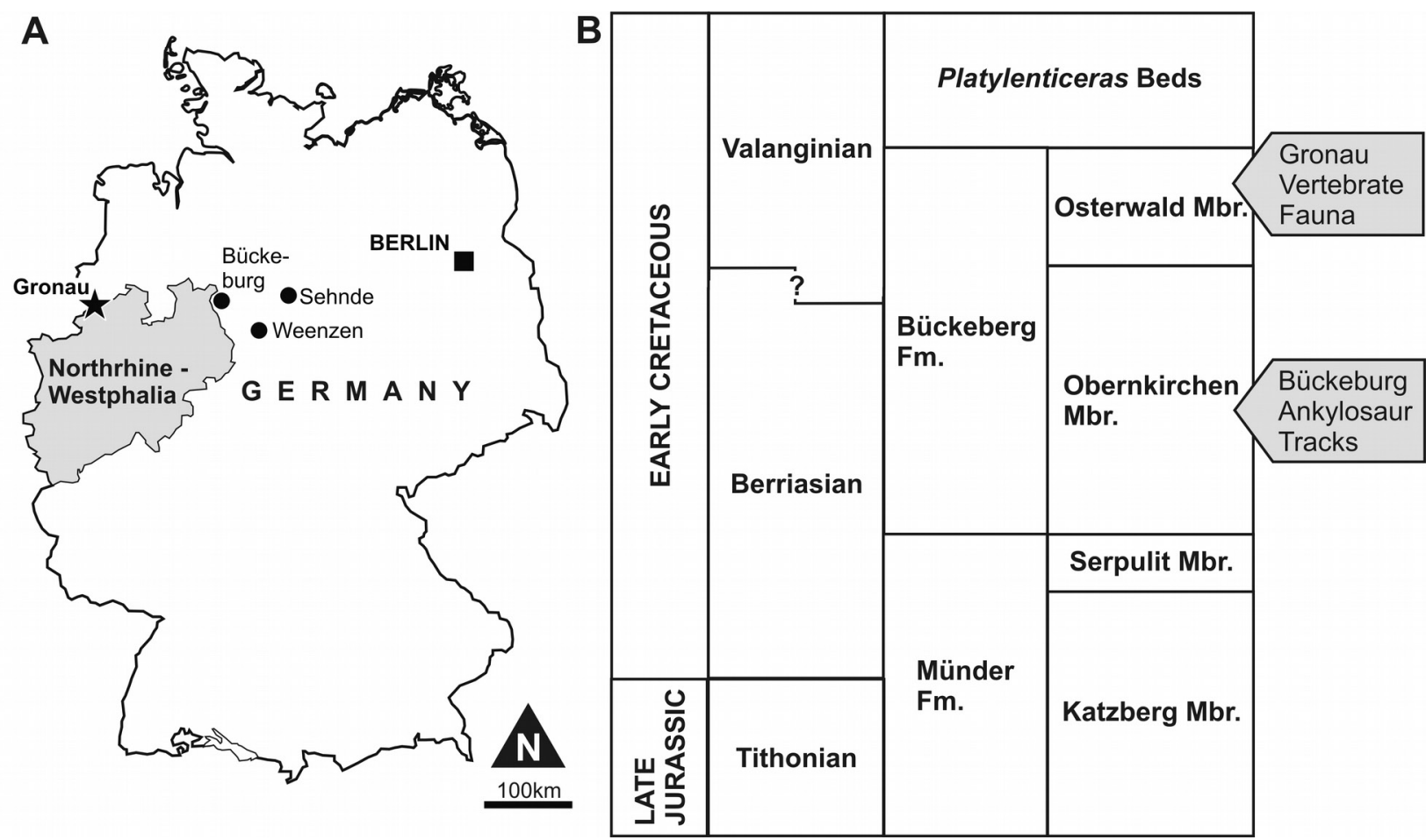

Fig. VII.1 Geographic and stratigraphic information. (A) Location map. (B) Lithostratigraphy of the basal Cretaceous in northwestern Germany (after [15, 17, 41]; simplified). The stratigraphic positions of the Gronau vertebrate site and the ankylosaur tracks from Bückeburg are indicated.

may correlate with diversity peaks in the aquatic fossil faunas. However, according to paleogeographical reconstructions, the Gronau area was not in immediate proximity to shorelines (distance ca. 5-10 km [7]) and the mixture of aquatic (fishes, plesiosaurs, some turtles), semiaquatic (crocodilians) and terrestrial (dinosaurs) vertebrates in the rather monotonous pelitic succession is remarkable. Possibly subaqueous density flows have played a role in the formation of this taphocoenosis by transporting carcasses from the littoral zone deeper into the basin [5].

Here we describe ankylosaur remains from the Gerdemann clay-pit. The material includes a humerus fragment [4] and a cervico-pectoral spine that was recently discovered by the authors in the collection of the Drilandmuseum in Gronau. A short overview of the thyreophoran record of the Early Cretaceous of Germany is also provided.

\section{Materials and Methods}

In the context of this paper, "spines" refer to slender, pointed osteoderms of ankylosaurs, whereas "spike" is used for the similarly shaped parascapular/parasacral and caudal elements in stegosaurs. Positional terminology for osteoderms used herein follows Scheyer and Sander [8]. Surfaces and features of elements closer to the epidermis are referred to as "external". Surfaces and features closer to the body wall (towards the body axis) are referred to as "basal". Pointed structures terminate externally in an "apex". We refer to the most ventrolateral line of osteoderms, 


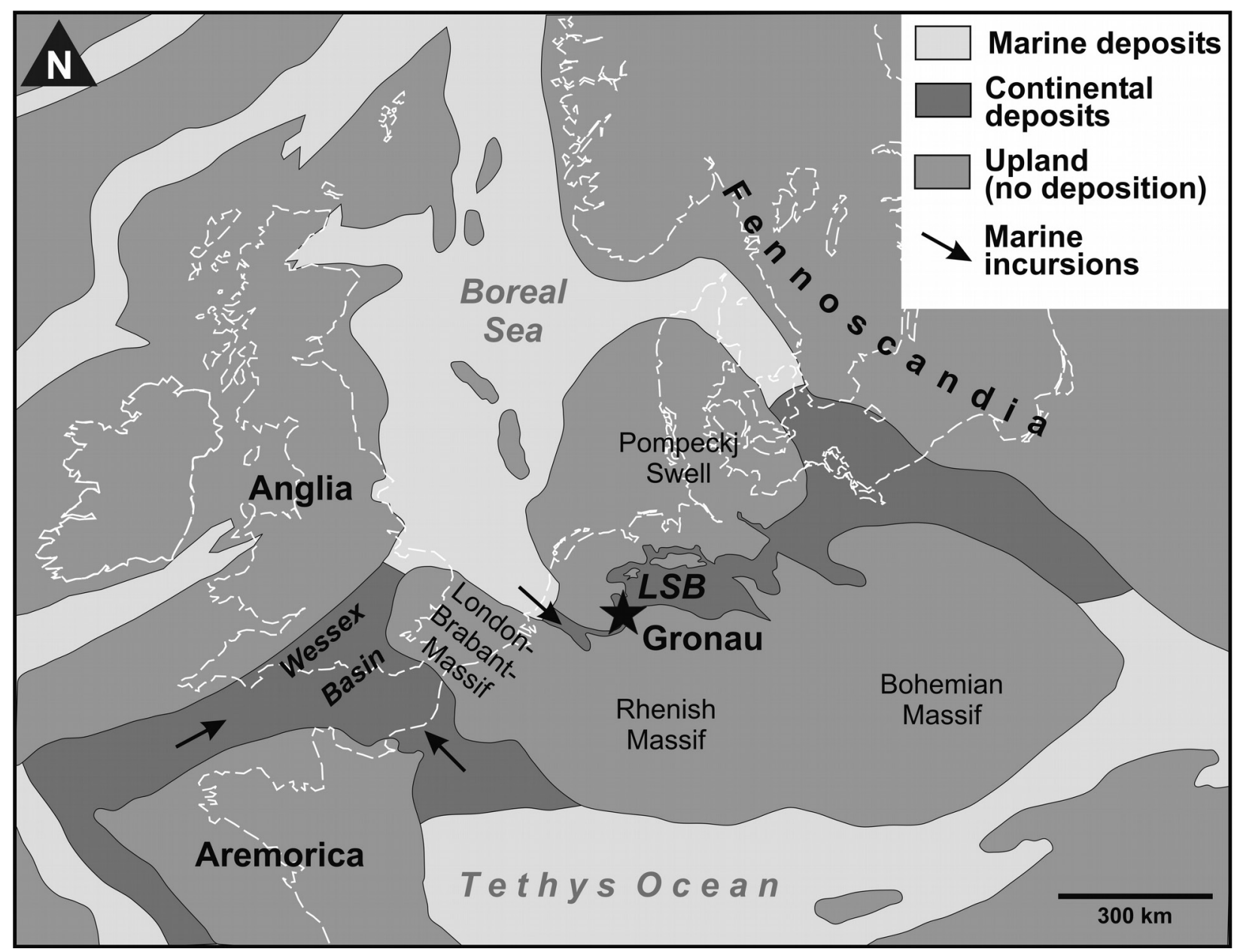

Fig. VII.2 Paleogeography of the Berriasian/early Valanginian of central Europe (after [41]; modified). The location of the Gronau vertebrate site is indicated.

which often point more or less laterally to the body axis, as "lateral osteoderms", whereas elements dorsal and medial to this row are considered as "dorsal osteoderms". The lateral dermal armor may be organized in subsections according to anteroposterior changes in osteoderm morphology. For the purpose of this work we use "cervical lateral spines" for the those occurring between the skull and the pectoral girdle, "pectoral lateral spines" for those located adjacent to the pectoral girdle, and "thoracal lateral spines" for those situated between the pectoral girdle and the pelvic region (following Ford [9]). Because of the morphological similarity of the Gronau osteoderm with the pectoral spines of Hylaeosaurus armatus Mantell, 1833 [10] (see discussion), we decided to apply the anatomical orientation of these elements [11].

The comparison to other Early Cretaceous thyreophorans are based on references as specified in the discussion section as well as on detailed photographies of the holotype specimen (NHM R3775) of H. armatus. In order to assess the relationships of the humerus fragment discussed herein, an extensive survey of the references on thyreophoran humerus morphology was undertaken, which shows a systematic and informative distribution of characters with respect to the distal condyli (method, results and references in supplementary information S1).

Measurements were taken with a caliper. 
Institutional Abbreviations

DLM, Drilandmuseum, Gronau in Westfalen, Germany, GPMM, Geomuseum of the Westfälische Wilhelms University, Münster in Westfalen, Germany, NHM, Natural History Museum, London, United Kingdom.

\section{Results}

Systematic paleontology

Ornithischia Seeley, 1888 [12].

Thyreophora Nopcsa, 1915 [13].

Ankylosauria Osborn, 1923 [14].

Hylaeosaurus Mantell, 1833 [10].

?Hylaeosaurus sp.

(Figs. VII.3-VII.4, Table VII.1)

Material. DLM 537, right cervico-pectoral lateral spine (Fig. VII.3; Table 1); GPMM A3D.3, distal portion of a right humerus (Fig. VII.4; Table VII.1).

Stratigraphic Provenance. 'Wealden 6' (Pachycytheridea trapezoidalis ostracod subzone), upper Osterwald Member, Bückeberg Formation, early Valanginian, Early Cretaceous [7, 15, 16, 17].

Locality. Gerdemann clay-pit (abandoned), NW of Gronau in Westfalen, Borken district, North Rhine-Westphalia, northwestern Germany.

Table VII.1 Measurements of the cervico-pectoral lateral spine (DLM 537) and the humerus (GPMM A3D.3) from the early Valanginian of Gronau in Westfalen, northwestern Germany. All measurements in millimeters ( ${ }^{*}$ marks preserved length of incomplete elements).

\begin{tabular}{llc}
\hline Element & \multicolumn{1}{c}{ Dimensions } & Measurements \\
\hline Lateral spine & Length apicobasal & $199^{*}$ \\
& Mid-diameter anteroposteriorly & 49 \\
& Anteroposterior diameter at lateral end & 28 \\
& Maximum anteroposterior diameter & 51 \\
& Dorsoventral diameter at preserved apical end & 35 \\
& Dorsoventral diameter at preserved basal end & 29 \\
& Length of ventral groove & 68 \\
Humerus & Proximodistal length & $145^{*}$ \\
& Mediolateral width of distal end & 103 \\
& Anteroposterior diameter of condylus radialis & 35 \\
& Anteroposterior diameter of condylus ulnaris & 26 \\
\hline
\end{tabular}




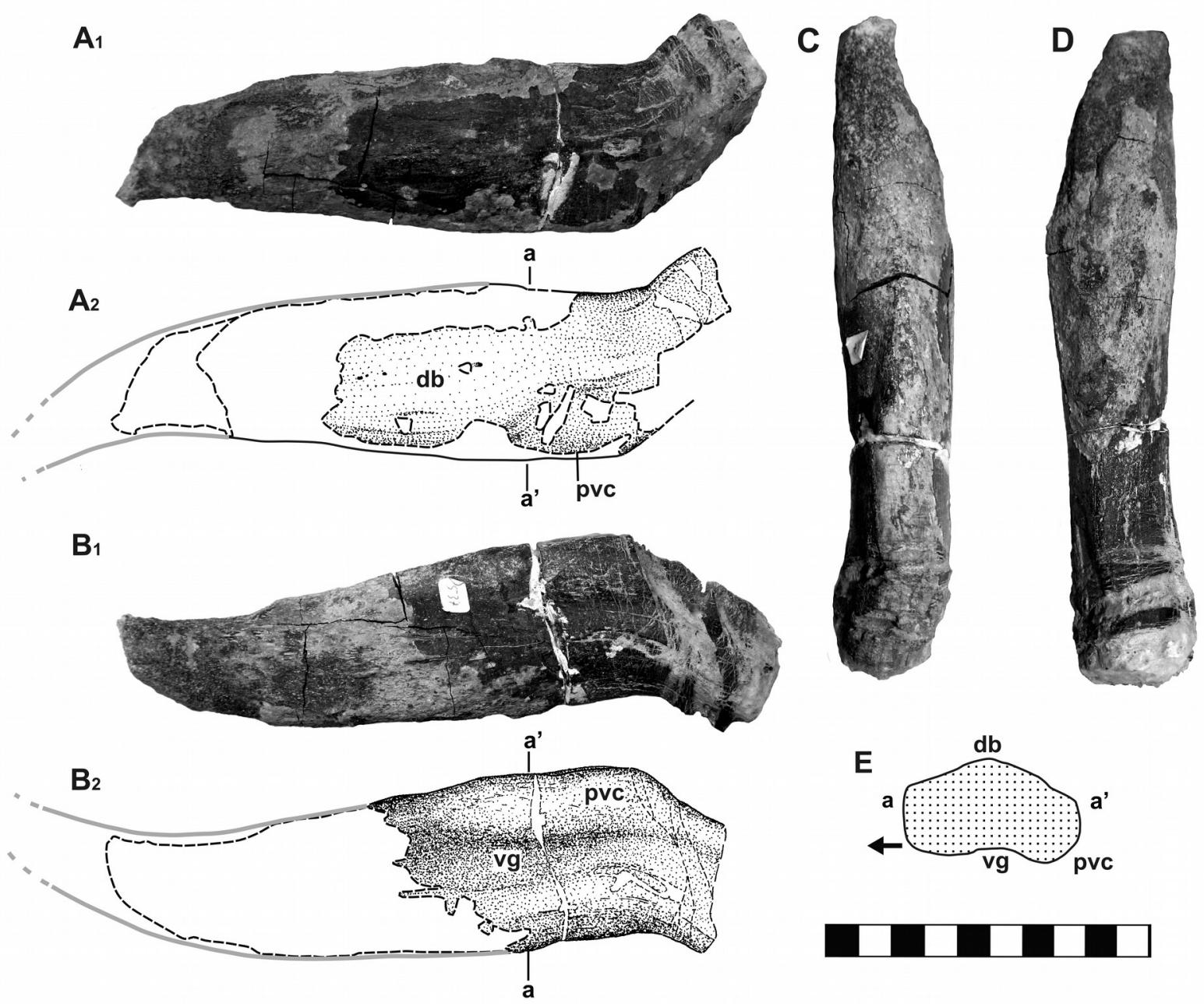

Fig. VII.3 Cervico-pectoral lateral spine of ?Hylaeosaurus sp. (DLM 537) from the Bückeberg Formation (early Valanginian) of Gronau in Westfalen, northwestern Germany. (A) dorsal view; (B) ventral view; (C) posterior view; (D) anterior view. (E) cross-section at a-a'; arrow points anteriorly. White areas in dashed lines: areas with missing substantia compacta; gray line: reconstructed outline. Note that the drawings have been slightly reconstructed to compensate for distortion of the basal part. Abbreviations: $\mathrm{db}$, dorsal bulge; pvc, posteroventral crest; vg, ventral groove. Scale-bar units equal $1 \mathrm{~cm}$.

\section{Osteological description}

Cervico-pectoral lateral spine (DLM 537). The cervico-pectoral spine (Fig. VII.3) represents most of a slender and pointed osteoderm. Basally it has a subrectangular cross-section, becoming more elliptical apically. The long axis of the cross-section is oriented anteroposteriorly. Its apex and base are missing and the preserved basal-most section is broken and displaced by shearing. Despite this distortion, it is evident that the base tapers basally in an anteroposterior, as well as, in a dorsoventral direction and is anteriorly and weakly ventrally deflected at its base. The preserved section of the osteoderm is curved posteriorly and the sides converge to form the apex. In the basal 
half of the posterior edge, a blunt, bulging crest (posteroventral crest in Fig. VII.3 E-G) is formed that thins out apically. Towards the dorsal side, the crest is confluent with the smoothly curved surface. On the ventral surface, the crest is delimited anteriorly by a groove that shallows and widens apically. The dorsal surface inflates dorsally in the mid-section of the osteoderm, forming a broad bulge pierced by a few vascular foramina. Towards the base of the osteoderm this bulge tapers to a narrow ridge. Most of the apical part of the spine is missing the thin substantia compacta, but a partial, $5 \mathrm{~cm}$ long core formed by substantia spongiosa is preserved, showing a posterior and slightly ventral curvature of its apex.

Humerus (GPMM A3D.3). The distal portion of a right humerus (Fig. VII.4) is preserved. The diaphysis and the distal epiphysis are anteroposteriorly compressed, and the maximal constriction of the diaphysis is situated immediately proximal to the epiphysis. The angle formed between the long axis of the diaphysis and a baseline defined by the distal condyli is about $90^{\circ}$. The condylus radialis is larger than the condylus ulnaris, and is distinctly protruding anteriorly in a right angle from the diaphysis in lateral view (Fig. VII.4F), whereas both protrude distally to the same distance. The condylus ulnaris is accompanied proximomedially by a distinct entepicondylus. The presence of an ectepicondylus cannot be ascertained due to erosion of the bone surface proximolaterally to the condylus radialis. The fossa intercondylaris is shallow and well defined. On the posterior side, above the condyli, a rhomboidal fossa olecrani, is present that reaches proximally to about the middle of the humerus fragment. Anteriorly, a fossa is present that extends from medially, above the condylus ulnaris, to the proximal break.

\section{Discussion}

Comparisons

The shape and size of the osteoderm is similar to dermal elements known in thyreophoran dinosaurs. Barrett and Maidment [18] note that distinguishing between stegosaurian and ankylosaurian isolated dermal elements must be done with caution, because there is some morphological overlap between these groups. Both are known from the Valanginian through Barremian of Western Europe $([18,19]$ for overview). The osteoderm from Gronau differs from typical stegosaur spikes by its longitudinal groove on the ventral side of the basal section, the posteroventral bulging crest and the posteriorly-curved apical section. The elliptical to subrectangular cross-section, which is basally asymmetrical, is also different from the symmetrically ovate to circular cross-section in stegosaur caudal spikes [20, 21, 22]. The spineshaped plates ('splates' sensu Blows [23]) of Kentrosaurus aethiopicus Hennig, 1915 [24] from the posterior thoracic region are superficially similar in outline, but the anterior and posterior edges are sharp and blade-like [25] instead of rounded. Additionally, the base of stegosaurian spikes often acutely expands parallel to the body wall to varying degrees. Due to the damage of the base of the Gronau osteoderm, the absence of such an expansion cannot be verified with certainty. However, the basal-most part of the osteoderm is tapering proximally, a condition unknown in spines and 


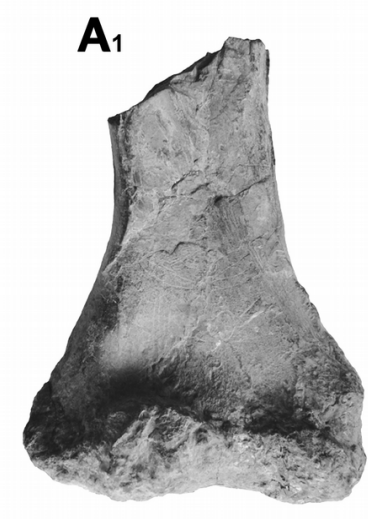

$\mathbf{B}_{1}$

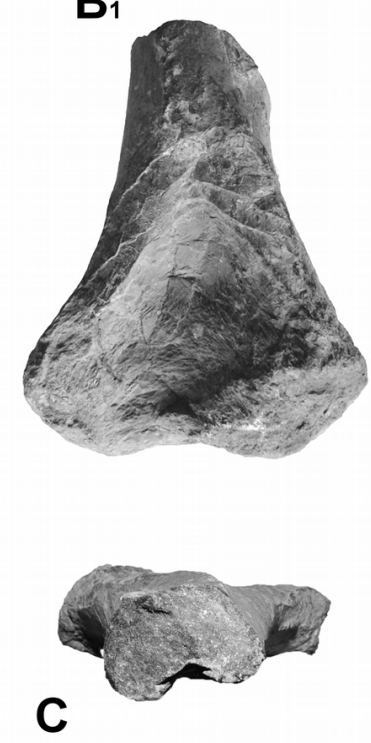

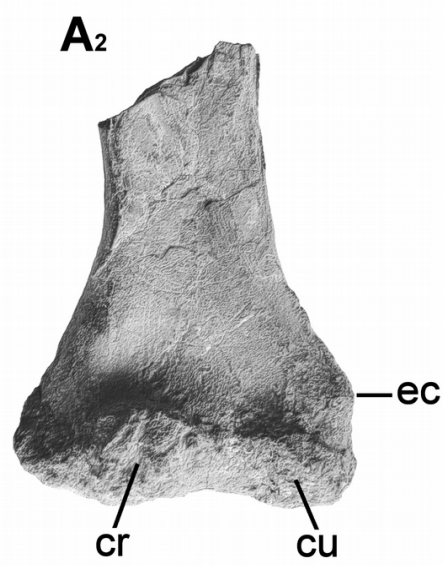

$\mathrm{B}_{2}$

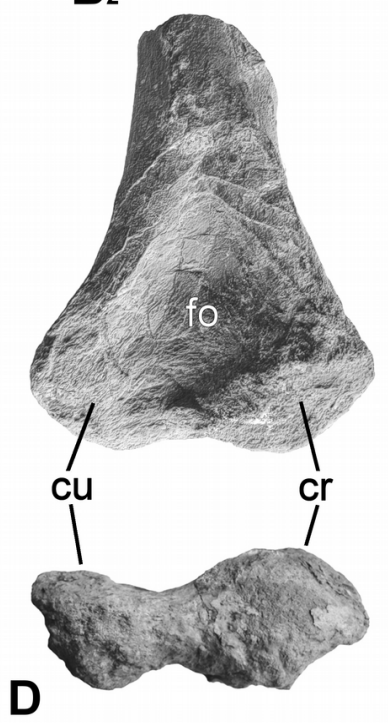

E

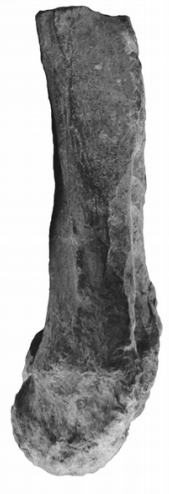

$\mathbf{F}$

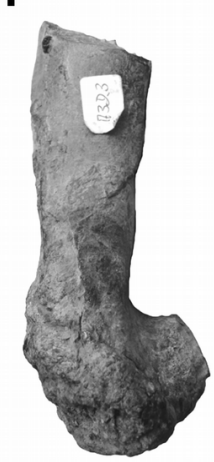

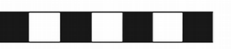

Fig. VII.4 Distal portion of a right humerus of ?Hylaeosaurus sp. (GPMM A3D.3) from the Bückeberg Formation (early Valanginian) of Gronau in Westfalen, northwestern Germany. (A) anterior view; (B) posterior view; (C) proximal view; (D) distal view; $(\mathbf{E})$ medial view; $(\mathbf{F})$ lateral view. Figures $\left(\mathbf{A}_{2}\right)$ and $\left(\mathbf{B}_{2}\right)$ have been digitally enhanced. Abbreviations: cr, condylus radialis; cu, condylus ulnaris; ec, entepicondylus; fo, fossa olecrani. Scale-bar units equal $1 \mathrm{~cm}$.

spikes with broad basal sections in which the base is normally gently expanded (e.g. [23]).

More similarities are present between the Gronau osteoderm and ankylosaur spines. However, in most taxa lateral and dorsal spines have broad, hollow bases [23, 26, 27, 28, 29] or are basally expanded. Lateral spines may have sharp, longitudinal keels and exhibit a distinct triangular crosssection in some taxa [9]. However, the Gronau spine shows close similarities to the cervical and pectoral spines of at least one taxon, Hylaeosaurus armatus Mantell, 1833 [10] from the late Valanginian of southern England. Among the preserved dermal elements [11] of the holotype specimen (NHM R3775 [30], Fig. VII.5, 6), four spines could be related to the cervical, pectoral, and anterior thoracal lateral series. These include the first spine immediately behind the skull and a 
series of three spines located near the thoracal vertebral series of the semi-articulated holotype (the latter marked "s'" in [11]: fig. 1b); the posterior of which is incomplete. A fourth spine marked "s'" in [11]: fig. 1b, situated anterior to the others of the thoracal series, does not seem to belong to the lateral row. A picture (courtesy M. Triebold) of this element on a cast of NHM R3775, made with the base of the posteriorly located spine removed, shows a more symmetrical, cone-shaped base of this osteoderm, suggesting its relation to the dorsal series of spines.

The lateral spines show morphological differences between the cervical one and the pectoral and thoracal series. The cervical lateral spine has an inflated, apparently subovate, crosssection and tapers rapidly to a gently posteriorly recurved apex. The shaft of the spine probably extruded in a right angle to the long axis of the animal's body, whereas its most basal part is deflected anteriorly similar to the basal part in DLM 537. It also has a rounded posterobasal crest and a rather steep, flat anterior face. The spines in the pectoral and anterior thoracal lateral series differ mostly from the cervical lateral spine by their dorsoventral flatness which becomes more prominent posteriorly along the series. The two most posterior spines are more similar to triangular plates than to true spines, whereas the anterior thoracal spine has a thicker crosssection. Due to damage, the presence of an anteriorly curved base is not recognizable in the pectoral and anterior thoracal lateral spines. In the pectoral and anterior thoracal series the spines are slanted posteriorly at an angle of about $30^{\circ}-40^{\circ}$ with respect to the transverse axis of the body. However all lateral spines of $H$. armatus as well as DLM 537 share the presence of a ventral longitudinal groove, which is most prominent on the anterior pectoral spine and becomes an increasingly shallow and broad depression on the posterior pectoral and anterior thoracal spines. All lateral spines of $H$. armatus show a posterobasal expansion of the shaft, which has the shape of a bulge-like crest in the anterior cervical spine but flattens to a more wing-like structure in the posterior pectoral and anterior thoracal spines. In addition to this groove, DLM 537 shares with the anterior cervical lateral spine of $H$. armatus an anteroposterior constriction of the posterobasal part of the shaft and a posteroventral bulge-like crest, whereas the shaft is anteroposteriorly wider (dorsoventrally flatter) than in the former. In its overall morphology, DLM 537 would fit well into a transitional series between the anterior cervical and the anterior pectoral spine in H. armatus (Fig. VII.6). This supports a posterior cervical or anterior pectoral position of the element in an animal with similar lateral spines. In order to express the slight uncertainties on the position of the osteoderm we designate it as a cervico-pectoral lateral spine. At present, there is no other ankylosaur known with these distinctive characters of the lateral spines. The genus Polacanthus Owen, in Anonymous 1865 [31] from the Hauterivian-Barremian of southern England differs from Hylaeosaurus in possessing triangular pectoral spines with expanded bases and sharp anterior and posterior keels $[23,32,33]$ and the difference in the morphology between the pectoral spines is considered useful to distinguish between the genera by Barrett and Maidment [18].

Due to the morphological similarity and the close stratigraphical proximity to the English material, the spine from Gronau is therefore tentatively referred to as ?Hylaeosaurus sp..

As noted previously [4], the humerus likely belongs to an ankylosaurian as well. This assignment is supported by the morphology of the distal condyli, which protrude distally to the same plane, a condition commonly present in ankylosaurs, but unknown in stegosaurs (see supplementary 

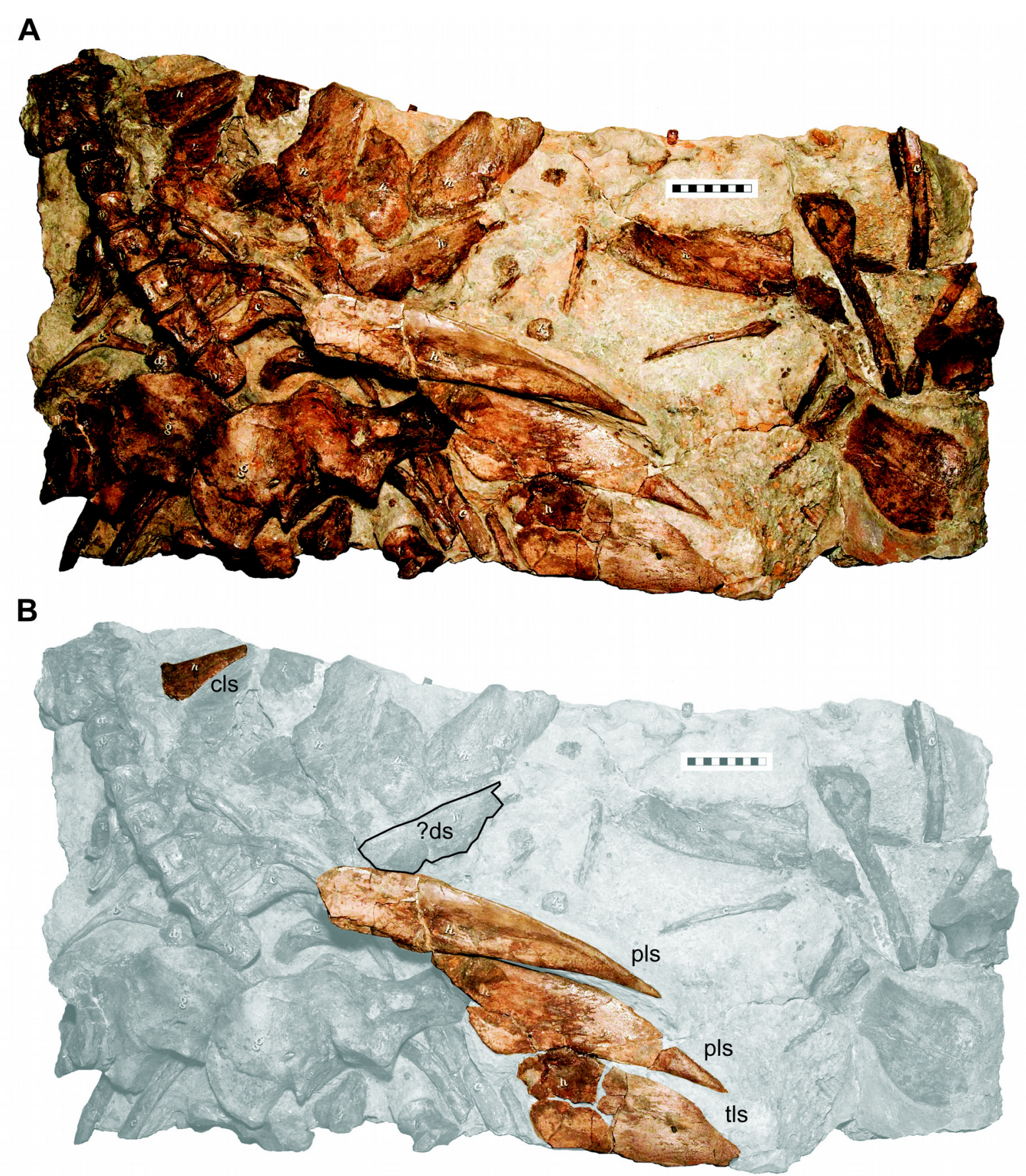

Fig. VII.5 Holotype specimen of Hylaeosaurus armatus Mantell, 1833 (NMH R3775) from the Grinstead Clay Formation (late Valanginian) of Tilgate Forest, Sussex, southern England. (A) skeleton as preserved; (B) purported elements of lateral row of osteoderms highlighted. Abbreviations: cls, cervical lateral spine; ?ds, supposed dorsal spine, considered a pectoral lateral spine by [11] (see text); pls, pectoral lateral spine; tls, thoracal lateral spine. Scale-bar units equal $1 \mathrm{~cm}$. Photo courtesy M. Triebold. 


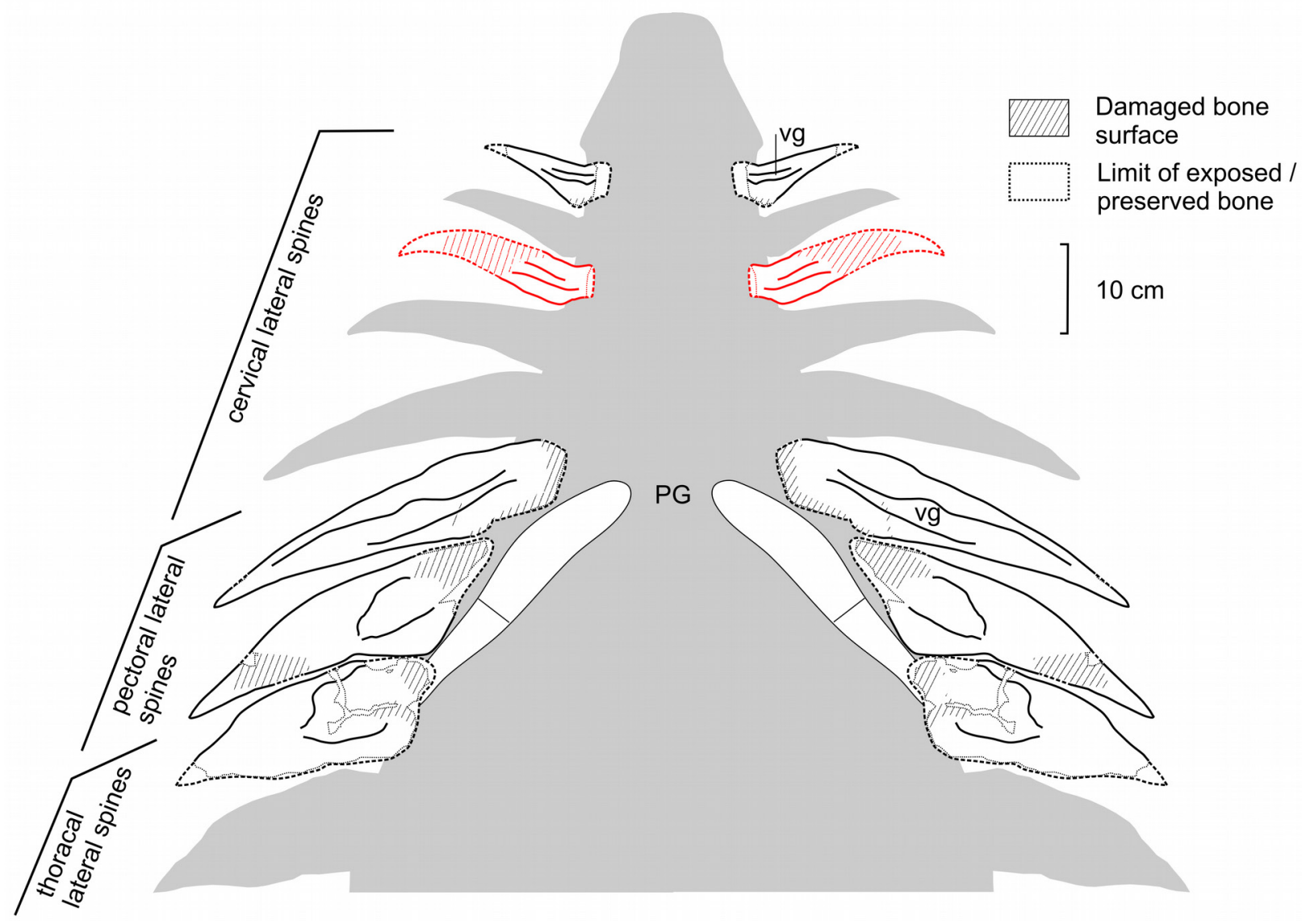

Fig. VII.6 Tentative reconstruction of the lateral cervico-thoracal armor in Hylaeosaurus armatus. The reconstruction is shown in ventral aspect, based upon NMH R3775 (holotype, white elements) and added by DLM 537 (red element). Abbreviations: PG, pectoral girdle (approx. position, schematic); vg, ventral groove.

information [S1, Fig. VII.S1, Table S1] for detailed evaluation of this character).

Unfortunately, the humerus is not described in Hylaeosaurus, although a fragment may be included with the holotype (see Fig.1b in [11]). The Gronau humerus is similar but not identical to the humerus of Polacanthus foxii Owen, in Anonymous 1865 [31] ([4]). Its size, compared to corresponding elements of other ankylosaurs [34], indicates that it originates from a small individual, probably in the size range of H. armatus, which may be estimated to a total length of 3 to $4 \mathrm{~m}$ [35]. The rarity of terrestrial elements in the Gronau reptile fauna and the presence of two ankylosaurian skeletal elements indicative of similar body size give the idea that the material might belong to the same individual some credence; however, this remains conjectural. Given the tentative nature of open nomenclature we nonetheless feel it justified to refer the humerus also to ? Hylaeosaurus sp., although a direct comparison of this element with $H$. armatus is not possible at present. 
Record of Thyreophoran Dinosaurs from the Early Cretaceous of Germany

Koken [36] first described two fragmentary caudal vertebral centra from the BerriasianValanginian of Duingerwald near Weenzen (Lower Saxony, Northern Germany) that he referred to Hylaeosaurus sp.. They were considered lost, but one of them has recently been relocated in the collection of the Niedersächsisches Landesmuseum in Hannover. It is poorly preserved, affected by severe crushing (J. Hornung pers obs.), and its assignment to a thyreophoran is tentative (its referral to Hylaeosaurus was already dismissed by [11]). From the lowermost Valanginian (Osterwald Member) of Gretenberg near Sehnde (Lower Saxony) Windolf [37] reported a tooth, a long-bone fragment, a calcaneum and a hoof-like ungual, as belonging to an ankylosaur. This material was not figured and has not been formally described to date, but a recent review of most of the material (the tooth could not be found) from the Roemer-Pelizaeus Museum, Hildesheim and the Geoscience Centre, University of Göttingen, did not reveal any thyreophoran affinities (J. Hornung, unpubl. data).

An ichnological record of ankylosaurs is represented by the ichnospecies Metatetrapous valdensis Nopcsa, 1923 [38], known from a single trackway found in 1921 in the Berriasian Obernkirchen Member of the Bückeberg Formation near Bückeburg (Lower Saxony [39]). The trackway is considered lost, but two hypichnial casts of ankylosaurian pedal imprints from the same stratum and area of origin have been identified recently [40]. In conclusion, the osteological material from Gronau and the tracks from Bückeburg represent the only material from Germany unequivocally referable to the Ankylosauria at present.

\section{Acknowledgments}

We thank G. Lippert (archivist, Gronau town administration) for access to DLM 537 on display at the Drilandmuseum in Gronau. M. Bertling (GPMM) kindly provided us photos of the humerus specimen. J. Vespermann (Roemer-Pelizaeus Museum, Hildesheim) kindly granted access to material under his care. S. Chapman (NHM) is thanked for information about the holotype of $H$. armatus and the permission to use the photo of NHM R3775 provided by M. Triebold (Triebold Paleontology). The later is also thanked for sending us detailed photos of a cast of NHM R3775. Finally we wish to thank Michael Burns (University of Alberta, Edmonton) and an anonymous reviewer for their helpful comments, which improved this publication.

\section{References}

1. Wegner T (1911) Desmemys Bertelsmanni n. g. n. sp. Ein Beitrag zur Kenntnis der Thalassemydidae Rütimeyer. Palaeontographica 58: 105-132.

2. Wegner T (1914) Brancasaurus Brancai n. g. n. sp. ein Elasmosauride aus dem Wealden $\quad$ Westfalens. In: Wilhelm Branca zum siebzigsten Geburtstage, 9. Sept. 1914. Eine Festschrift seiner Schüler, F. Schöndorf, editor. Branca-Festschrift. 
Verlag der Gebrüder Bornträger, Leipzig. pp. 235-305.

3. Sachs S (1996) Dinosaurier-Funde aus Westfalen. Bericht des Naturwissenschaftlichen Verein Bielefeld und Umgebung 37: 237-253.

4. Sachs S (1997) Erster Nachweis eines gepanzerten Dinosauriers (Reptilia, Ornithischia, Thyreophora) aus der Unterkreide (Berrias) von Gronau in Westfalen. Neues Jahrb Geol Palaontol Mh 1: 56-64.

5. Nyhuis C, Herbig HG (2009) Ichthyolithe aus dem Berriasium von Gronau/Westfalen (westliches Niedersächsisches Kreidebecken) - Rekonstruktion einer trophischen Kette aus sturmkondensierten Bonebeds. In: Martin T, Kaiser SI, editors. Paläontologie - Schlüssel zur Evolution. 79. Jahrestagung der Paläontologischen Gesellschaft. Kurzfassungen der Tagungsbeiträge. Terra Nostra. Schriften der Alfred-Wegener-Stiftung ～2009/3. p. 85.

6. Mutterlose J, Bornemann A (2000) Distribution and facies patterns of Lower Cretaceous sediments in northern Germany: a review. Cretaceous Res 21: 733-759.

7. Kemper E (1976) Geologischer Führer durch die Grafschaft Bentheim und die angrenzenden Gebiete mit einem Abriß der emsländischen Unterkreide. Das Bentheimer Land 64: 1-206.

8. Scheyer T, Sander PM (2004) Histology of ankylosaur osteoderms: implications for systematics and function. Journal of Vertebrate Paleontology 24: 874-893.

9. Ford TL (2000) A review of ankylosaur osteoderms from New Mexico and a preliminary review of ankylosaur armor. New Mexico Museum of Natural History and Science Bulletin 17: 157-176.

10. Mantell GA (1833) Observations on the remains of the Iguanodon, and other reptiles, of the strata of Tilgate Forest in Sussex. Proceedings of the Geological Society of London 1: 410-411.

11. Pereda-Suberbiola J (1993) Hylaeosaurus, Polacanthus, and the systematic and stratigraphy of Wealden armoured dinosaurs. Geological Magazine 130: 767-781.

12. Seeley HG (1888) The classification of the Dinosauria. Adv Sci 1887: 698-699.

13. Nopcsa F (1915) Die Dinosaurier der Siebenbürgischen Landesteile Ungarns. Mittheilungen aus dem Jahrbuche der königlich ungarischen Geologischen Reichsanstalt 23: 1-26.

14. Osborn HF (1923) Two Lower Cretaceous dinosaurs from Mongolia. Bull Am Mus Nat Hist 95: 1-10.

15. Kemper E (1973) Das Berrias (tiefe Unterkreide) in NW-Deutschland. Geologisches Jahrbuch A9: 47-67.

16. Mutterlose J, Kaplan U, Hiss M (1995) Die Kreide im nördlichen Münsterland und im Westteil des Niedersächsischen Beckens, Exkursionsführer zur Geländetagung der Subkommission für Kreide-Stratigraphie. Bochumer geologische und geotechnische Arbeiten 45. pp. 1-72.

17. Mutterlose J (2000) Unterkreide im Niedersächsischen Becken. In: Stratigraphische Kommission Deutschlands, editor. Die Kreide der Bundesrepublik Deutschland. Courier Forschungsinstitut Senckenberg 226. pp.79-101.

18. Barrett PM, Maidment SCR (2011) Armoured dinosaurs. In: Batten DJ, editor. English Wealden fossils. Palaeontological Association Field Guides to Fossils Number 14. pp. 391-406.

19. Pereda-Suberbiola X, Galton PM, Ruiz-Omeñaca JI, Canudo JI (2005) Dermal spines of stegosaurian dinosaurs from the Lower Cretaceous (Hauterivian-Barremian) of Galve (Teruel, Aragón, Spain). Geogaceta 38: 35-38.

20. Company J, Pereda Suberbiola X, Ruiz-Omeñaca, JI (2010) New stegosaurian (Ornithischia, Thyreophora) remains from Jurassic-Cretaceous transition beds of Valencia province, (Southwestern Iberian Range, Spain). Journal of Iberian Geology 36: 243-252. 
21. Hayashi S, Carpenter K, Watabe M, McWhinney LA (2012) Ontogenetic histology of Stegosaurus plates and spikes. Palaeontology 55: 145-161.

22. Mallison H (2011) Defense capabilities of Kentrosaurus aethiopicus Hennig, 1915. Palaeontologica Electronica 14: 125.

23. Blows WT (2001) Dermal armor of the polacanthine dinosaurs. In: Carpenter K, editor. The armored dinosaurs. Bloomington: Indiana University Press. pp. 363-385.

24. Hennig E (1915) Kentrosaurus aethiopicus der Stegosauride des Tendaguru. Sitzungsberichte der Gesellschaft naturforschender Freunde Berlin 6: 219-247.

25. Hennig E (1925) Kentrurosaurus aethiopicus - Die Stegosaurier-Funde vom Tendaguru. Palaeontographica, Supplement Band 7: 103-253.

26. Eaton TH (1960) A new armored dinosaur from the Cretaceous of Kansas. The University of Kansas Paleontological Contributions, Vertebrata, Art. 8: 1-24.

27. Carpenter K (1984) Skeletal reconstruction and life restoration of Sauropelta (Ankylosauria: Nodosauridae) from the Cretaceous of North America. Can J Earth Sci 21: 1491-1498.

28. Carpenter K, Kirkland JI (1998) Review of Lower and Middle Cretaceous Ankylosaurs from North America. New Mexico Museum of Natural History and Science Bulletin 14: 249-270.

29. Kilbourne B, Carpenter K (2005) Redescription of Gargoyleosaurus parkpinorum, a polacanthid ankylosaur from the Upper Jurassic of Albany County, Wyoming. Neues Jahrb Geol Palaontol Abh 237: 111-160.

30. Owen R (1858) Monograph on the Reptilia of the Wealden and Purbeck Formations. Part IV. Dinosauria (Hylaeosaurus), (Wealden). Palaontographical Society of London (Monographs) 10: 8-26.

31. Anonymus (1865) A new Wealden dragon. Order, Sauria; Family, Dinosaurian; Genus, Polacanthus; Species, foxii. Illustrated London News 47: 270.

32. Blows WT (1987) The armoured dinosaur Polacanthus foxi from the Lower Cretaceous of the Isle of Wight. Palaeontology 30: 557-580.

33. Naish D, Martill DM (2001) Armoured dinosaurs. In: Martill DM, Naish D, editors. Dinosaurs on the Isle of Wight. Palaeontological Association Field Guides to Fossils Number 10. pp. 147-184.

34. Vickaryous MK, Maryańska T, Weishampel DB (2004) Ankylosauria. In: Weishampel DB, Dodson P, Osmólska H, editors. The Dinosauria, Second Edition. Los Angeles: University of California Press. pp. 363-392.

35. Naish D, Martill DM (2001) Armoured Dinosaurs: Thyreophorans. In: Martill DM, Naish D, editors. Dinosaurs of the Isle of Wight. Palaeontological Association Field Guides to Fossils 10. pp. 147-184

36. Koken E (1887) Die Dinosaurier, Crocodiliden und Sauropterygier des norddeutschen Wealden. Geologische und Palaeontologische Abhandlungen 3: 311-420.

37. Windolf R (1998) Dinosaurierfunde in Niedersachsen. Arbeitskreis Paläontologie Hannover 26: 1-7.

38. Nopcsa F (1923) Die Familien der Reptilien. Fortschritte der Geologie und Paläontologie 2: 1-210.

39. Ballerstedt M (1922) Über Schreckensaurier und ihre Fußspuren. Kosmos 19: 77-80.

40. Hornung JJ, König J, Reich M (2007) Rediscovered type material of the ankylosaurian ichnospecies Metatetrapous valdensis Nopcsa, 1923 (Early Cretaceous, NW Germany). In: Elicki O, Schneider JW, editors. Fossile Ökosysteme: 77. Jahrestagung der Paläontologischen Gesellschaft. Kurzfassungen der Vorträge und Poster. Technische Universität 
Bergakademie Freiberg, Institut für Geologie, Wissenschaftliche Mitteilungen 36. pp. 59-60.

41. Mutterlose J (1997) Lower Cretaceous. In: Mutterlose J, Wippich WGE, Geisen M, editors. Cretaceous Depositional Environments of NW Germany. Bochumer Geologische und Geotechnische Arbeiten 46. pp.7-12. 


\title{
Supplementary Information
}

\section{S1 Distal humerus morphology in Thyreophora}

\author{
Methods
}

As in most dinosaurs, the morphology of the distal part of the humerus is variable among taxa (and, to a lesser degree between individuals, e.g. Penkalski [S1]), especially with respect to the relative size and morphology of the distal condyli. However, the systematic distribution of these differences has not been considered yet for the purpose of assigning distal humeri of thyreophorans to distinct subclades of the group.

Data mining across a wide range of thyreophorans shows that the relative proximodistal position of the distal condyli is promising for a systematic distribution. We used references for humeri of all available stegosaurian and ankylosaurian taxa from the literature. To establish and qualify the position of the distal condyli, we compared (in anterior aspect of the humerus) the distance between the points, where a horizontal line, tangential to the distalmost point of each condylus intersect a line parallel to the diaphysis in a right angle (Fig. VII.S1). If these lines meet in the same location, the condyli are considered equal in proximodistal expansion (Fig. VII.S1 A); if the line tangentially to the condylus ulnaris intersects above that one tangentially to the condylus radialis, the latter is considered to protrude (antero)distally (Fig. VII.S1 B) and vice versa (Fig. VII.S1 C). In fact, the protrusion of the condyli has also an anterior component, which is obscured when seen from the posterior side of the humerus, which then results in an underestimation of the condylar inequality. Due to the variability of source quality we choose to present the results in a qualitative form (Table VII.S1).

\section{Results}

A comparison of the distal humerus morphology shows clear differences between stegosaurs and ankylosaurs. In stegosaurs uniformly the condylus ulnaris is anterodistally protruding. The protrusion is generally well marked, at least in adult specimens.

Contrary, most ankylosaurian taxa share a condition where both condyli are located at the same plane, only in Cedarpelta bilbeyhallorum, "Crichtonsaurus" benxiensis, and Peloroplites cedrimontanus the condylus radialis is protruding anterodistally. Among the surveyed taxa only two exceptions were recognized: In Hungarosaurus tormai the condylus ulnaris is more protruding distally than the condylus radialis, though the latter is larger in overall size (Ösi \& Makádi [S2]). In Saichania chulsanensis the condylus ulnaris is more massive and protruding distally than the condylus radialis (Maryanska [S3]: pl. 35, fig. 1b). In the latter taxon, as well as in an indetermined ankylosaurine humerus (possibly belonging to Scolosaurus cutleri Nopcsa, 1928 [S4], see Penkalski \& Blows [S5]: fig. 6a), the condylus radialis is reduced in size and prominence but the laterodistal 


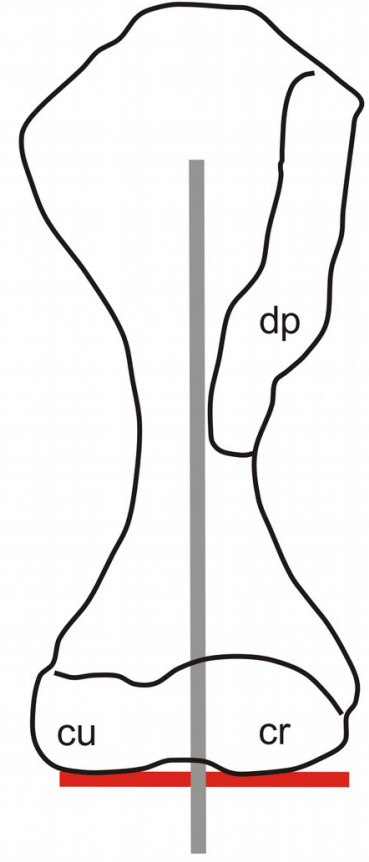

A

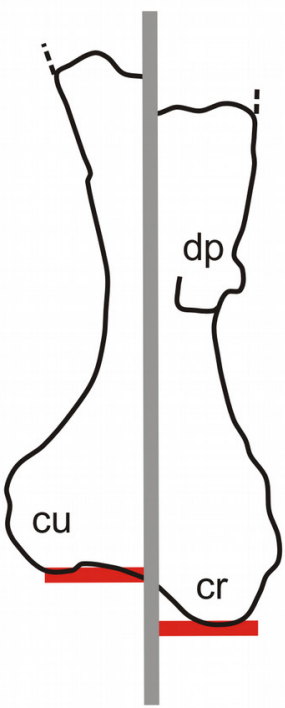

$B$

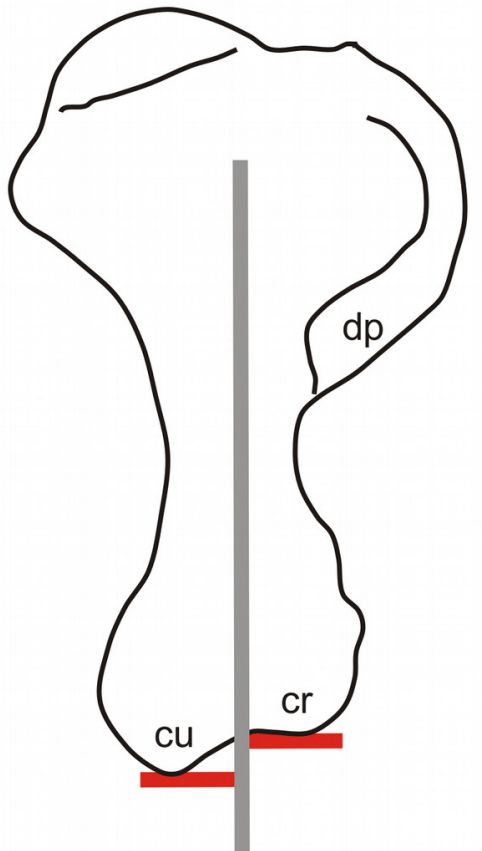

C

Fig. VII.S1 Assessment of anterodistal protrusion of distal condyli in thyreophoran humeri. Examples partially reversed to show the same aspect, no scale intended. (A) Condylus radialis and condylus ulnaris protrude to the same plane, (Ankylosauria: Niobrarasaurus coleii, after Carpenter et al. [S51], modified). (B) Condylus radialis protrudes farther anterodistally than condylus ulnaris (Ankylosauria: Peloroplites cedrimontanus, after Carpenter et al. [S33], modified). (C) Condylus ulnaris protrudes farther anterodistally than condylus radialis (Stegosauria: Loricatosaurus priscus, after Galton [S15] [as Lexovisaurus durobrivensis], modified). Abbreviations: cu, condylus ulnaris; $\mathbf{c r}$, condylus radialis; $\mathbf{d p}$, crista deltopectoralis.

margin of the humerus is formed by a flange-like, large ectepicondylus.

In the few instances where a series of individuals of the same species is described (Euoplocephalus tutus: Penkalski [S1]; Ankylosaurus magniventris: Carpenter [S6]; Stegosaurus armatus: Gilmore [S7], Galton [S8]), the inequality in condylar protrusion can vary between individuals. However, the current record indicates that if a protrusion is recognizable, within the same species, always the same condylus protrudes. The morphology of the distal condyles may be strongly influenced by the ontogenetic stage of the individual due to increasing ossification of the epiphyseal cartilage with increasing individual age (e. g. Holliday et al. [S9]).

According to this dataset, an anterodistally protruding condylus ulnaris is the common condition in Stegosauria and occurs very rarely in Ankylosauria. An equality of distal protrusion of both condyli is the common condition in Ankylosauria with some taxa showing an anterodistal protrusion of the condylus radialis. The latter conditions are entirely unknown in Stegosauria, though the inequality in distal condylar protrusion is less pronounced in some juvenile individuals of Stegosaurus armatus (see Galton [S8]).

Based upon these results, we feel it justified to use the orientation of the distal condyli in thyreophorans to assign distal humeri to either of the subclades, further supporting a referral of GPMM A3D.3 to the Ankylosauria. 
Table VII.S1 Character distribution for distal condyli morphology in thyreophoran dinosaurs. Taxonomy follows Maidment et al. [S10], Carpenter [S11] (Stegosauria), and Thompson et al. [S12] (Ankylosauria), respectively. Only taxa where the humerus is known are included.

\begin{tabular}{|c|c|c|c|c|c|c|}
\hline Taxon & $\begin{array}{l}\text { Condylus } \\
\text { ulnaris } \\
\text { protruding }\end{array}$ & $\begin{array}{l}\text { Condylus } \\
\text { radialis } \\
\text { protruding }\end{array}$ & $\begin{array}{l}\text { Condyli at the } \\
\text { same plane }\end{array}$ & $\begin{array}{l}\text { Insufficient } \\
\text { data }\end{array}$ & Remarks & Data sources \\
\hline "Chialingosaurus kuani" Young, 1959 [S13] & $\mathrm{x}$ & & & & $=$ Stegosauridae indet. & [S14] \\
\hline Chungkingosaurus sp. & $\mathrm{x}$ & & & & & [S15] \\
\hline Dacentrurus armatus (Owen, 1875) [S16] & $\mathrm{x}$ & & & & & [S17] \\
\hline Gigantspinosaurus sichuanensis Ouyang, 1992 [S18] & & & & $\mathrm{x}$ & Information not provided & [S18] \\
\hline Hesperosaurus mjosi Carpenter, Miles \& Cloward, 2001 [S19] & & & & $x$ & Information not provided & [S11], [S19] \\
\hline Huayangosaurus taibaii Dong, Tang \& Zhou, 1982 [S20] & $\mathrm{x}$ & & & & & [S21] \\
\hline Kentrosaurus aethiopicus Hennig, 1915 [S22] & $\mathrm{x}$ & & & & & [S23] \\
\hline Loricatosaurus priscus (Nopcsa, 1911) [S24] & $\mathrm{x}$ & & & & & [S17] \\
\hline Miragaia Iongicollum Mateus, Maidment \& Christiansen, 2009 [S25] & $\mathrm{x}$ & & & & & [S25] \\
\hline Stegosaurus homheni (Dong, 1973) [S26] & & & & $x$ & Information not provided & [S26], [S27] \\
\hline Stegosaurus armatus Marsh, 1877 [S28] & $x$ & & & & & [S7] \\
\hline Tuojiangosaurus multispinus Dong, Li, Zhou \& Zhang, 1977 [S29] & $\mathrm{x}$ & & & & & [S15] \\
\hline Ahshislepelta minor Burns \& Sullivan, 2011 [S30] & & & & $\mathrm{x}$ & Humerus incomplete & [S30] \\
\hline Aletopelta coombsi Ford \& Kirkland, 2001 [S31] & & & & $\mathrm{x}$ & Humerus damaged & [S31] \\
\hline Animantarx ramaljonesi Carpenter, Kirkland, Burge \& Bird, 1999 [S32] & & & & $\mathrm{x}$ & Humerus crushed & [S32] \\
\hline Ankylosaurus magniventris Brown, 1908 [S33] & & & $\mathrm{x}$ & & & [S6] \\
\hline Anoplosaurus curtonotus Seeley, 1879 [S34] & & & & $\mathrm{x}$ & Humerus incomplete & [S34] \\
\hline Cedarpelta bilbeyhallorum Carpenter, Kirkland, Burge \& Bird, 2001 [S35] & & $\mathrm{x}$ & & & & [S36] \\
\hline Crichtonsaurus bohlini Dong, 2002 [S37] & & & & $\mathrm{x}$ & Information not provided & [S37] \\
\hline "Crichtonsaurus" benxiensis Lü, Ji, Gao \& Li, 2007 [S38] & & $\mathrm{x}$ & & & & [S38] \\
\hline Edmontonia rugosidens (Gilmore, 1930) [S39] & & & $?$ & & Information not provided & [S40] \\
\hline Euoplocephalus tutus Lambe, 1902 [S41] & & & $\mathrm{x}$ & & & [S1] \\
\hline Gargoyleosaurus parkpinorum Carpenter, Miles \& Cloward, 1998 [S42] & & & & $\mathrm{x}$ & Humerus crushed & [S43] \\
\hline Gastonia burgei Kirkland, 1998 [S44] & & & $\mathrm{x}$ & & & [S45] \\
\hline Gobisaurus domoculus Vickaryous, Russell, Currie \& Zhao, 2001 [S46] & & & & $\mathrm{x}$ & Information not provided & [S46] \\
\hline Hoplitosaurus marshi (Lucas, 1901) [S47] & & & $\mathrm{x}$ & & & [S48] \\
\hline Hungarosaurus tormai Ösi, 2005 [S49] & $\mathrm{x}$ & & & & & [S2] \\
\hline Liaoningosaurus paradoxus Xu, Wang \& You, 2001 [S50] & & & & $\mathrm{x}$ & Early ontogenetic stage & [S50] \\
\hline Minmi paravertebra Molnar, 1980 [S51] & & & $x$ & & & [S52] \\
\hline Niobrarasaurus coleii (Mehl, 1936) [S53] & & & $\mathrm{x}$ & & & [S54] \\
\hline Panoplosaurus mirus Lambe, 1919 [S55] & & & $\mathrm{x}$ & & & [S54] \\
\hline Peloroplites cedrimontanus Carpenter, Bartlett, Bird \& Barrick, 2008 [S36] & & $\mathrm{x}$ & & & & [S36] \\
\hline Pinacosaurus grangeri Gilmore, 1933 [S56] & & & $\mathrm{x}$ & & & [S3] \\
\hline Pinacosaurus mephistocephalus Godefroit, Pereda-Suberbiola, Li \& Dong, 1999 [S57] & & & & $\mathrm{x}$ & Information not provided & [S57] \\
\hline Polacanthus foxii Owen, in Anonymous 1865 [S58] & & & $\mathrm{x}$ & & Referred isolated humerus & [S48] \\
\hline Polacanthus rudgwickensis Blows, 1996 [S59] & & & & $\mathrm{x}$ & Humerus fragmentary & [S59] \\
\hline Saichania chulsanensis Maryanska, 1977 [S3] & $\mathrm{x}$ & & & & & [S3] \\
\hline Sauropelta edwardsorum Ostrom, 1970 [S60] & & & $\mathrm{x}$ & & & [S60] \\
\hline Scolosaurus cutleri Nopcsa, 1928 [S4] & & & & $\mathrm{x}$ & Humerus incomplete & [S5] \\
\hline Shamosaurus scutatus Tumanova, 1983 [S61] & & & & $\mathrm{x}$ & Information not provided & [S61] \\
\hline Shanxia tianzhenensis Barrett, You, Upchurch \& Burton, 1998 [S62] & & & $\mathrm{x}$ & & & [S62] \\
\hline Struthiosaurus austriacus Bunzel, 1871 [S63] & & & & $x$ & Humerus incomplete & [S64] \\
\hline Talarurus plicatospineus Maleev, 1952 [S65] & & & $\mathrm{x}$ & & & [S65] \\
\hline Texasetes pleurohalio Coombs, 1995 [S66] & & & $?$ & & Humeri incomplete & [S67] \\
\hline Tianzhenosaurus youngi Pang \& Cheng, 1998 [S68] & & & $\mathrm{x}$ & & & [S68] \\
\hline Zhongyuansaurus luoyangensis Li, Lü, Zhang, Jia, H & & & & $\mathrm{x}$ & Information not provided & [S69] \\
\hline
\end{tabular}




\section{References for Supporting Information Text and Table S1}

[S1] Penkalski PG (2001) Variation in specimens referred to Euoplocephalus tutus. In: Carpenter K, editor. The armored dinosaurs. Bloomington: Indiana University Press. pp. 261-298.

[S2] Ösi A, Makádi L (2009) New remains of Hungarosaurus tormai (Ankylosauria, Dinosauria) from the Upper Cretaceous of Hungary: skeletal reconstruction and body mass estimation. Paläontologische Zeitschrift 83: 227-245.

[S3] Maryanska T (1977) Ankylosauridae (Dinosauria) from Mongolia. Palaeontologia Polonica 37: 85-151.

[S4] Nopcsa F (1928) Paleontological notes on reptiles. Geologica Hungarica, Series $\quad$ Palaeontologica 1: 51-74.

[S5] Penkalski PG, Blows WT (2013) Scolosaurus cutleri (Ornithischia: Ankylosauria) from the Upper CretaceousDinosaur Park Formation of Alberta, Canada. Can J Earth Sci 38 (advance online publication) doi: 10.1139/cjes-2012-0098.

[S6] Carpenter K (2004) Redescription of Ankylosaurus magniventris Brown 1908 (Ankylosauridae) from the Upper Cretaceous of the Western Interior of North America. Can J Earth Sci 41: 961-986.

[S7] Gilmore CW (1914) Osteology of the armored Dinosauria in the United States National $\quad$ Museum, with special reference to the genus Stegosaurus. United States National Museum Bulletin 89: 1-136.

[S8] Galton P (1982) Juveniles of the stegosaurian dinosaur Stegosaurus from the Upper Jurassic of North America. Journal of Vertebrate Paleontology 2: 47-62.

[S9] Holliday CM, Ridgely RC, Sedlmayr JC, Witmer LM (2010) Cartilaginous Epiphyses in Extant Archosaurs and Their Implications for Reconstructing Limb Function in Dinosaurs. PLoS ONE 5(9): e13120. doi:10.1371/journal. pone.0013120

[S10] Maidment SCR, Norman DB, Barrett PM, Upchurch P (2008) Systematics and phylogeny of Stegosauria (Dinosauria: Ornithischia). Journal of Systematic Palaeontology 6: 364-407.

[S11] Christiansen NA, Tschopp E (2010) Exceptional stegosaur integument impressions from the Upper Jurassic Morrison Formation of Wyoming. Swiss Journal of Geosciences 103:163-171.

[S12] Thompson RS, Parish JC, Maidment SCR, Barrett PM (2012) Phylogeny of the ankylosaurian dinosaurs (Ornithischia: Thyreophora). Journal of Systematic Palaeontology 10: 301-312.

[S13] Young CC (1959) On a new Stegosauria from Szechuan, China. Vertebrata PalAsiatica 3: 1-8.

[S14] Maidment SC, Wei G (2006) A review of the Late Jurassic stegosaurs (Dinosauria, Stegosauria) from the People's Republic of China. Geol Mag 143: 621-634.

[S15] Dong Z, Zhou SW, Zhang YH (1983) The dinosaurian remains from Sichuan Basin, Chinas (in Chinese). Palaeontologica Sinica, New Series C 162: 1-136.

[S16] Owen R (1875) Monographs on the fossil Reptilia of the Mesozoic formations. Part II. (Genera Bothriospondylus, Cetiosaurus, Omosaurus). The Palaeontographical Society, London 1875: 15-93.

[S17] Galton P (1985) British plated dinosaurs (Ornithischia, Stegosauridae). Journal of Vertebrate Paleontology 5: 211254

[S18] Ouyang H (1992) Discovery of Gigantspinosaurus sichanensis and its scapular spine orientation (in Chinese). Abstracts and Summaries for Youth Academic Symposium on New Discoveries and Ideas in Stratigraphic Paleontology null: 47-49. 
[S19] Carpenter K, Miles C, Cloward K (2001) New primitive stegosaur from the Morrison Formation, Wyoming. In: Carpenter K, editor. The armored dinosaurs. Bloomington: Indiana University Press. pp. 55-75.

[S20] Dong Z, Tang Z, Zhou SW (1982) Note on the new Mid-Jurassic stegosaur from Sichuan Basin, China (in Chinese). Vertebrata PalAsiatica 20: 83-87.

[S21] Zhou S (1984) The Middle Jurassic Dinosaur Fauna from Dashanpu, Zigong, Sichuan. Vol. II: Stegosaurs (in Chinese). Sichuan: Sichuan Scientific and Technological Publishing House, 52 pp..

[S22] Hennig E (1915) Kentrosaurus aethiopicus der Stegosauride des Tendaguru. Sitzungsberichte der Gesellschaft naturforschender Freunde zu Berlin 1915: 219-247.

[S23] Hennig E (1925) Kentrurosaurus aethiopicus - Die Stegosaurier-Funde vom Tendaguru, Deutsch-Ostafrika. Palaeontographica Suppl 7:101-254.

[S24] Nopcsa F (1911) Notes on British dinosaurs. Part IV: Stegosaurus priscus, sp. nov.. Geol Mag 5: 109-115.

[S25] Mateus O, Maidment SCR, Christiansen NA (2009) A new long-necked 'sauropod-mimic' stegosaur and the evolution of the plated dinosaurs. Proc Biol Sci 276: 1815-1821.

[S26] Dong Z (1973) Dinosaurs from Wuerho (in Chinese). Reports of Paleontological Expedition to Sinkiang (II): Pterosaurian Fauna from Wuerho, Sinkiang. Memoirs of the Institute of Vertebrate Paleontology and Paleoanthropology, Academia Sinica 11:45-52.

[S27] Dong Z (1990) Stegosaurs of Asia. Carpenter K, Currie PJ, editors. Dinosaur Systematics: Cambridge University Press: $255-268$.

[S28] Marsh OC (1877) A new order of extinct Reptilia (Stegosauria) from the Jurassic of the Rocky Mountains. Am J Sci 14: 513-514.

[S29] Dong Z, Li X, Zhou S, Zhang Y (1977) On the stegosaurian remains from Zigong (Tzekung), Szechuan province (in Chinese). Vertebrata PalAsiatica 15:307-312.

[S30] Burns ME, Sullivan RM (2011) A new ankylosaurid from the Upper Cretaceous Kirtland Formation, San Juan Basin, with comments on the diversity of ankylosaurids in New Mexico. In: Sullivan RM, Lucas SG, Spielmann JA. Fossil Record 3. New Mexico Museum of Natural History and Science Bulletin 53: 169-178.

[S31] Ford T, Kirkland JI (2001) Carlsbad ankylosaur (Ornithischia, Ankylosauria): An ankylosaurid and not a nodosaurid. In: Carpenter K, editor. The armored dinosaurs. Bloomington: Indiana University Press. pp. 239-260.

[S32] Carpenter K, Kirkland JI, Burge D, Bird J (1999) Ankylosaurs (Dinosauria: Ornithischia) of the Cedar Mountain Formation, Utah, and their stratigraphic distribution. In: Gillette D, editor. Vertebrate Paleontology in Utah. Utah Geological Survey Miscellaneous Publication 99-1: 243-251.

[S33] Brown B (1908) The Ankylosauridae, a new family of armored dinosaurs from the Upper Cretaceous. Bull Am Mus Nat Hist 24: 187-201.

[S34] Seeley HG (1879) On the Dinosauria of the Cambridge Greensand. Quart J Geol Soc London 35: 591-636.

[S35] Carpenter K, Kirkland JI, Burge D, Bird J (2001) Disarticulated skull of a new primitive ankylosaurid from the Lower Cretaceous of Eastern Utah. In: Carpenter K, editor. The armored dinosaurs. Bloomington: Indiana University Press. pp. 211-238.

[S36] Carpenter K, Bartlett J, Bird J, Barrick R (2008) Ankylosaurs from the Price River Quarries, Cedar Mountain Formation, (Lower Cretaceous), East-Central Utah. Journal of Vertebrate Paleontology 28: 1089-1101. 
[S37] Dong Z (2002) A new armored dinosaur (Ankylosauria) from Beipiao Basin, Liaoning Province, northeastern China (in Chinese). Vertebrata PalAsiatica 40: 276-285.

[S38] Lü J, Ji Q, Gao Y, Li Z (2007) A new species of the ankylosaurid dinosaur Crichtonsaurus (Ankylosauridae: Ankylosauria) from the Cretaceous of Liaoning Province, China. Acta Geologica Sinica 81: 883-897.

[S39] Gilmore CW (1930) On dinosaurian reptiles from the Two Medicine Formation of Montana. Proceedings of the United States National Museum 77: 1-39.

[S40] Russell LS (1940) Edmontonia rugosidens (Gilmore), an armored dinosaur from the Belly River Series of Alberta. University of Toronto Studies. Geology Series 43: 3-27.

[S41] Lambe LM (1902) New genera and species from the Belly River Series (mid-Cretaceous). Geological Survey of Canada Contributions to Canadian Palaeontology 3: 25-81.

[S42] Carpenter K, Miles C, Cloward K (1998) Skull of a Jurassic ankylosaur (Dinosauria). Nature 393: 782-783.

[S43] Kilbourne B, Carpenter K (2005) Redescription of Gargoyleosaurus parkpinorum, a polacanthid ankylosaur from the Upper Jurassic of Albany County, Wyoming. Neues Jahrb Geol Palaontol Abh 237: 111-160.

[S44] Kirkland JI (1998) A polacanthine ankylosaur (Ornithischia: Dinosauria) from the Early Cretaceous (Barremian) of Eastern Utah. In: Lucas SG, Kirkland JI, Estep JW, editors. Lower and Middle Cretaceous Terrestrial Ecosystems. New Mexico Museum of Natural History and Science Bulletin 14: 271-282.

[S45] Gaston RW, Schellenbach J, Kirkland JI (2001) Mounted skeleton of the polacanthine ankylosaur Gastonia burgei. In: Carpenter K, editor. The armored dinosaurs. Bloomington: Indiana University Press. pp. 386-398.

[S46] Vickaryous M, Russell AP, Currie PJ, Zhao X (2001) A new ankylosaurid (Dinosauria: Ankylosauria) from the Lower Cretaceous of China, with comments on ankylosaurian relationships. Can J Earth Sci 38: 1767-1780.

[S47] Lucas FA (1901) A new dinosaur, Stegosaurus marshi, from the Lower Cretaceous of South Dakota. Proceedings of the United States National Museum 23: 591-592.

[S48] Pereda-Suberbiola J (1994) Polacanthus (Ornithischia, Ankylosauria), a transatlantic armoured dinosaur from the Early Cretaceous of Europe and North America. Palaeontographica A 232: 133-159.

[S49] Ösi A (2005) Hungarosaurus tormai, a new ankylosaur (Dinosauria) from the Upper Cretaceous of Hungary. Journal of Vertebrate Paleontology 25: 370-383.

[S50] Xu X, Wang XL, You HL (2001) A juvenile ankylosaur from China. Naturwissenschaften 88: 297-300.

[S51] Molnar RW (1980) An ankylosaur (Ornithischia, Reptilia) from the Lower Cretaceous of southern Queensland. Mem Queensl Mus 20: 77-87.

[S52] Molnar RW (1996) Preliminary report of a new ankylosaur from the Early Cretaceous of Queensland, Australia. Mem Queensl Mus 45: 653-668.

[S53] Mehl MC (1936) Hierosaurus coleii: a new aquatic dinosaur from the Niobrara Cretaceous of Kansas. Denison University Bulletin 31: 1-20.

[S54] Carpenter K, Dikes D, Weishampel DB (1995) The dinosaurs of the Niobrara Chalk Formation (Upper Cretaceous, Kansas). Journal of Vertebrate Paleontology 15: 275-297.

[S55] Lambe LM (1919) Description of a new genus and species (Panoplosaurus mirus) of an armoured dinosaur from the Belly River Beds of Alberta. Trans R Soc Can, series 3 13: 39-50.

[S56] Gilmore CW (1933) Two new dinosaurian reptiles from Mongolia with notes on some fragmentary specimens. Am 
Mus Novit 679: 1-20.

[S57] Godefroit P, Pereda-Suberbiola X, Li H, Dong Z (1999) A new species of the ankylosaurid dinosaur Pinacosaurus from the Late Cretaceous of Inner Mongolia (P. R. China). Bulletin de l'Institut Royal des Sciences Naturelles de Belgique, Sciences de la Terre 69 (suppl): 17- 36

[S58] Anonymus (1865) A new Wealden dragon. Order, Sauria; Family, Dinosaurian; Genus, Polacanthus; Species, foxii. Illustrated London News 47: 270.

[S59] Blows WT (1996) A new species of Polacanthus (Ornithischia; Ankylosauria) from the Lower Cretaceous of Sussex, England. Geol Mag 133: 671-682.

[S60] Ostrom JH (1970) Stratigraphy and Paleontology of the Cloverly Formation (Lower Cretaceous) of the Bighorn Basin Area, Wyoming and Montana. Bull Peabody Mus Nat Hist 35: 1-355.

[S61] Tumanova TA (1983) The first ankylosaurs from the Lower Cretaceous of Mongolia (in Russian). In: Tatarinov LP, Barsbold R, Vorobyeva E, Luvsandanzan B, Trofimov BA, Reshetov YA, Shishkin MA, editors. Fossil Reptiles of Mongolia. Trudy Sovmestnaya Sovetsko-Mongol'skaya Paleontologicheskaya Ekspeditsiya 24:110-118.

[S62] Barrett PM, You H, Upchurch P, Burton AC (1998) A new ankylosaurian dinosaur (Ornithischia: Ankylosauria) from the Upper Cretaceous of Shanxi Province, People's Republic of China. Journal of Vertebrate Paleontology 18: 376-384.

[S63] Bunzel E (1871) Die Reptilfauna der Gosau-Formation in der Neuen Welt bei Wiener-Neustadt. Abhandlungen der Kaiserlich-Königlichen Geologischen Reichsanstalt 5: 1-19.

[S64] Pereda-Suberiola X, Galton P (2001) Reappraisal of the nodosaurid ankylosaur Struthiosaurus austriacus Bunzel from the Upper Cretaceous Gosau Beds of Austria. In: Carpenter K, editor. The armored dinosaurs. Bloomington: Indiana University Press. pp. 173-210.

[S65] Maleev EA (1952) A new ankylosaur from the Upper Cretaceous of Mongolia (in Russian). Doklady Akademii Nauk SSSR 87: 273-276.

[S66] Coombs WP (1995) A nodosaurid ankylosaur (Dinosauria: Ornithischia) from the Lower Cretaceous of Texas. Journal of Vertebrate Paleontology 15: 298-312.

[S67] Carpenter K, Kirkland JI (1998) Review of Lower and Middle Cretaceous ankylosaurs from North America. In: Lucas SG, Kirkland JI, Estep JW, editors. Lower and Middle Cretaceous Terrestrial Ecosystems. New Mexico Museum of Natural History and Science Bulletin 14: 249-270.

[S68] Pang Q Cheng Z (1998) A new ankylosaur of Late Cretaceous from Tianzhen, Shanxi. Progress in Natural Science 8:326-334.

[S69] Li X, Lü J, Zhang X, Jia S, Hu W, Zhang J, Wu Y, Ji Q (2007) A new nodosaurid dinosaur fossil from the Cretaceous Period of Ruyang, Henan (in Chinese). Acta Geologica Sinica 81: 433-438. 


\section{Chapter VIII}

A new look into the periorbital morphology of Goniopholis

(Mesoeucrocodylia: Neosuchia) and related forms 
Published in:

Journal of Vertebrate Paleontology, 31(2): 352-368 [2011]. DOI: 10.1080/02724634.2011.550353

\title{
A new look into the periorbital morphology of Goniopholis (Mesoeucrocodylia: Neosuchia) and related forms
}

\author{
MARCO BRANDALISE DE ANDRADE ${ }^{1,2}$ and JAHN JOCHEN HORNUNG ${ }^{3}$
} ${ }^{1}$ Department of Earth Sciences, Faculty of Sciences, University of Bristol, Wills Memorial Building, Queens Road, BS8
1RJ, Bristol, Avon, England, United Kingdom, marcobranda@yahoo.com.br;
${ }^{2}$ Current address: Departamento de Paleontologia e Estratigrafia, Universidade Federal do Rio Grande do Sul (UFRGS),
Avenida Bento Gonçalves 9500, 91501-970 Porto Alegre, RS, Brazil, C.P. 15001.
${ }^{3}$ Department of Geobiology, Geoscience Centre, Georg-August-University Göttingen, Goldschmidtstrasse 3-5, D-37077
Göttingen, Germany, jhornun@gwdg.de

\begin{abstract}
The periorbital morphology of goniopholidids is discussed, exploring the diversity of patterns and the relevance of the data for phylogenetic studies. Revision of material is focused on Goniopholis spp. and aff. Goniopholis spp., from England, Germany, and Belgium, providing a comparative description of their interorbital morphology. Traditional interpretation of the interorbital elements in species of Goniopholis (G. simus, G. baryglyphaeus), where the frontal is interpreted as excluded from the orbit by a prefrontal-postorbital contact in the skull roof, is contested and clarified through the analysis of new specimens, including a morphometric analysis. In Goniopholis, failure to identify the palpebral and its subtle contact with the prefrontal has lead to misinterpretation of elements and structures near the orbit, and the differential preservation/loss of palpebrals explains variability of the orbit in shape and orientation. In all European goniopholidids the frontal reaches the primary orbital border and there is no prefrontal-postorbital contact on the dorsal surface of the skull. Extensive contact of the palpebral with the primary orbital border creates a secondary (functional) orbital border, from which the frontal is excluded in most taxa. The condition is not exclusive of European goniopholidids and is paralleled by protosuchids, peirosaurids, and baurusuchids. At least four main morphological patterns are recognized, revealing a high diversity of European goniopholidids.
\end{abstract}

\section{Introduction}

Goniopholis Owen, 1842, is a genus of semi-aquatic non-eusuchian crocodilian, closely resembling modern forms in gross cranial morphology, although retaining a 'mesosuchian' type of choana (i.e., bounded by palatines and pterygoid; see Clark, 1986, 1994; Benton and Clark, 1988; Turner and Buckley, 2008). Of all members of its family, Goniophois simus Owen, 1878, is among the best known species, mainly thanks to extensive and detailed review by Salisbury et al. (1999). Even though the 
genus has been known from England for over a century (Owen, 1842, 1878, 1879), several aspects remain to be explored in the genus and the family Goniopholididae, including phylogenetic relationships. The periorbital morphology has been considered taxonomically important in the group (e.g., Salisbury et al., 1999; Schwarz, 2002; Lauprasert et al., 2007), and is here explored to understand elements of diversity and evolution.

Here we analyze a wide range of goniopholidids from Europe to describe and compare the morphology of periorbital elements in Goniopholis and related taxa, based on a wide sample of specimens, including new specimens and three unnamed goniopholidids (also previously referred to Goniopholis; see Salisbury, 2002; Andrade et al., 2008), and on morphometric analysis. The patterns of periorbital morphology found are then used to evidence the high diversity of European goniopholidids, while making new information available for systematic studies.

Special attention is directed to the periorbital morphology of Goniopholis, to understand the relation of prefrontal, frontal, and postorbital with the orbit. The traditional interpretation of periorbital morphology in G. simus is based on the type (BMNH 41098) and referred (IPB R359) specimens, respectively, from England and Germany. In this interpretation, the frontal is excluded from the orbit by a prefrontal-postorbital contact, posteromedial to the orbit (Fig. VIII.1A), a character then considered diagnostic of the species and unique among crocodyliformes (Salisbury et al., 1999). The exclusion of the frontal from the orbit was also attributed to Goniopholis baryglyphaeus Schwarz, 2002 (Guimarota Formation; Upper Jurassic, Portugal), suggesting that the character would be a common element of the genus. However, this interpretation has been contradicted by new information. Reconstruction of a new specimen of $G$. simus from Germany, by Karl et al. (2006), shows the frontal broadly participating in the posteromedial border of the orbit. It seems then that there is non-taphonomic variability in the orbital shape in several specimens referred to Goniopholis (compare Owen, 1878; Salisbury et al., 1999; Schwarz, 2002; Karl et al., 2006), including differences in interorbital distance, evidencing problems in the interpretation of periorbital morphology. It is of key importance to resolve the relations of frontal, palpebrals, and orbit in G. simus and G. baryglyphaeus, in order to provide accurate comparisons in Goniopholididae.

Institutional Abbreviations-AMNH, American Museum of Natural History, New York, U.S.A.; BMNHB, Booth Museum of Natural History, Brighton, England, United Kingdom; BMNH, Natural History Museum, London, England, United Kingdom; BRSUG, Department of Earth Sciences, University of Bristol, Bristol, England, United Kingdom; DORCM, Dorset County Museum, Dorchester, England, United Kingdom; GZG.BA., Geowissenschaftliches Zentrum der Universität Göttingen, Abteilung Museum, Sammlungen und Geopark, Ballerstedt collection, Göttingen, Germany; IPB, Steinmann-Institut für Geologie, Mineralogie und Palaontologie, Goldfuß-Museum, Universität Bonn, Bonn, Germany; IRSNB, Institut Royal des Sciences Naturelles de Belgique, Brussels, Belgium; MG, Museu Geologico, Lisbon, Portugal; MB, Museum für Naturkunde, Humboldt-Universität zu Berlin, Berlin, Germany. 

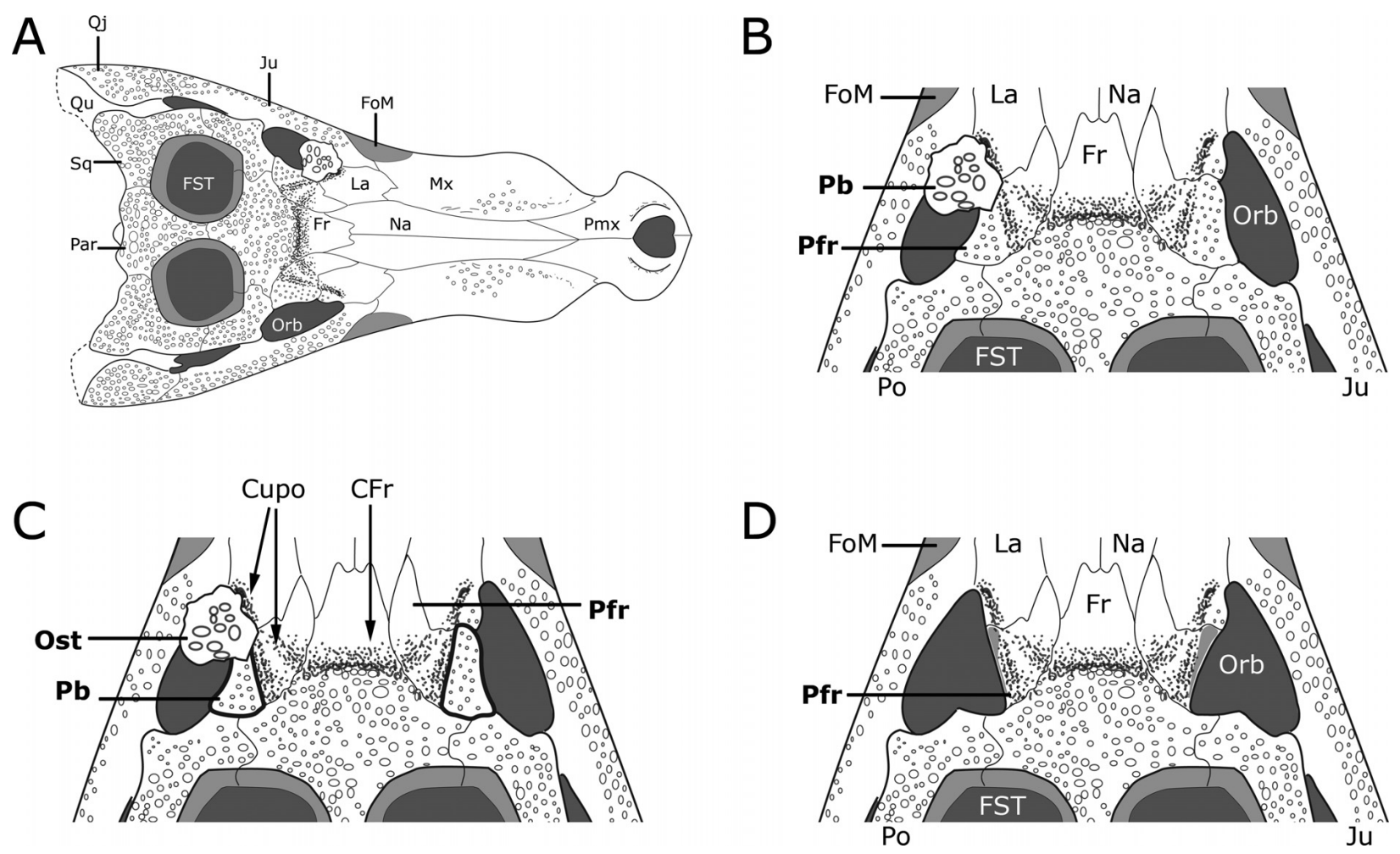

Fig. VIII.1 Summary view of the reinterpretation of Goniopholis IPB R359. The skull of this specimen (A) was originally interpreted as having the frontal excluded from the orbit by a prefrontal-postorbital contact (B) and round orbits, but lacking facets for the attachment of palpebrals (Salisbury et al., 1999). In A-B, the upper periorbital crests are far too medial to the dorsal orbital margin, and the interorbital distance is greater (IOF $\approx 59 \%$ ) than in all other specimens of Goniopholis (see Tables 2-3). After the study of IPB R359 and identification of the prefrontal-palpebral contact (C), the presence of the true palpebrals became evident on both sides, as well as the participation of the frontal in the primary orbit. Following this reinterpretation, the orbit of IPB R359 has a triangular outline and a proportionally shorter interorbital distance (D) than previously conceived, but as in other specimens of G. simus (IOF $<50 \%$ of width of skull table). The reinterpretation (C) also explains the apparent absence of attachment scars at the medial border of the orbit, which can only be evident in the absence of palpebrals (D). Note that the associated dermal element on top of the left lacrimal of IPB R359, previously identified as a possible palpebral in A-B by Salisbury et al. (1999), is here interpreted as a possible dermal scute (C) from its morphology, and was removed from D. Redrawn (A-B) and modified (C-D) from Salisbury et al. (1999); drawings not to scale.

Anatomical Abbreviations-Clpo, lower periorbital crest; Cupo, upper periorbital crest; CFr, transverse interorbital (trans-frontal) crest; FIT, laterotemporal fenestra; FoM, fossa maxillaris; FST, supratemporal fenestra; Fr, frontal; Jug, jugal; La, lacrimal; Mx, maxilla; Na, nasal; Orb, orbit; Ost, osteoderm; Par, parietal; Pb, palpebral; PbS, surface (facet) for attachment of palpebral; Pfr, prefrontal; Pmx, premaxilla; Po, postorbital; $\mathbf{Q j}$, quadrate-jugal; Qu, quadrate; Sq, squamosal.

\section{Materials and Methods}

Specimens used for this study include Goniopholis and closely related taxa (Table VIII.1) from the 
Lower Cretaceous of England, Germany, Portugal, and Belgium (see Supplementary Data 1; available online at www.vertpaleo.org/jvp/JVPcontents.html), including information on geology and preservation (Clements, 1993; Salisbury et al., 1999; Salisbury, 2002; Schwarz, 2002; Hornung and Reich, 2006; Yans et al., 2006; Andrade et al., 2008), comments on Nannosuchus (Kälin, 1933; Joffe, 1967; Clark, 1986), G. crassidens (Salisbury et al., 1999; Salisbury, 2002; Hornung et al., 2009), and comparative data on goniopholidids (Mook, 1942, 1964, 1967; Cope, 1878; Young, 1948; Wu et al., 1996; Tykoski et al., 2002; Lucas and Sullivan, 2003; Salisbury et al., 2006; Lauprasert et al., 2007, Smith et al., 2010), pholidosaurids (Meyer, 1841; Dunker, 1843-1844; Koken, 1887; MansellPleydell, 1888; Andrews, 1913), protosuchids (Bonaparte, 1971), peirosaurids (Gasparini et al., 1991), and baurusuchids (Riff, 2003; Pinheiro et al., 2008). A conservative taxonomic approach to the specimens of Pholidosaurus is preferred here, in order to provide a better identification of different materials, although it should be noticed that most species assigned to the genus are currently considered as P. purbeckensis (see Salisbury, 2002). A summary of characters studied is in Table VIII.2.

Measurements taken from a number of specimens belonging to several taxa (Table VIII.3) and a range of morphometric procedures (Grubbs, 1969; Hammer et al., 2001; Hammer and Harper, 2006) were used to test whether the interorbital distance provided for IPB R359 (106.1 mm) by Salisbury et al. (1999:132) is consistent with the interorbital distance taken from other goniopholidids. Morphometric data provided four sets of relative values of interorbital distance (see Table VIII.3), organized into two main groups. 'Group 1' include nine specimens and uses the interorbital distance in its traditional sense (i.e., not considering palpebrals). 'Group 2' comprises doubled measurements for five specimens in 'Group 1,' but with interorbital distance including the palpebrals. The specimen IPB R359, as interpreted by Salisbury et al. (1999), was either compared to these two groups, or was a priori assumed to be part of 'Group 1' (without palpebrals). Further information on procedures, as well as data files to replicate analysis, are available in the supplementary files (Supplementary Data 1-3, www.vertpaleo.org/jvp/JVPcontents.html).

\section{Description of Periorbital Elements}

Ornamentation and Crests

The skull ornamentation of most goniopholidids is characterized by well-defined pits that cover much of the dorsal surface of the skull (Fig. VIII.1). In Goniopholis, ornamentation is best developed on most periorbital elements, but is absent from the postorbital bar. Goniopholis simus has a smoother ornamentation on the surface of the rostrum (Salisbury et al., 1999), including the prefrontals, as exemplified by BMNH 41098 (Fig. VIII.2), IPB R359 (Fig. VIII.3), and GZG.BA.0067 (Fig. VIII.4). By comparison, Goniopholis aff. simus DORCM 12154 (Fig. VIII.5), G. baryglyphaeus (Fig. VIII.6), and all other taxa analyzed have heavier and more extensive sculpturing of skull elements, regardless of preservation bias. In goniopholidids, the pits are mostly circular and hardly ever 
Table VIII.1 Age and provenance of specimens included in this study.

\begin{tabular}{|c|c|c|c|c|c|}
\hline Age & Provenance & Specimen & Taxonomy & Material & References \\
\hline $\begin{array}{l}\text { Early } \\
\text { Cretaceous }\end{array}$ & $\begin{array}{l}\text { Southern England } \\
\text { (?) }\end{array}$ & BMNHB 001876 & $\begin{array}{l}\text { aff. Goniopholis sp. } \\
\text { (= G. simus in } \\
\text { Hulke, 1878) }\end{array}$ & Skull without mandible & Hulke, 1878; Salisbury, 1998 \\
\hline $\begin{array}{l}\text { Barremian/ early } \\
\text { Aptian }\end{array}$ & $\begin{array}{l}\text { Saint-Barbe Clays } \\
\text { Fm.; Bernissart, } \\
\text { Belgium } \\
\text { Vectis Fm.; Isle of } \\
\text { Wight, Southern } \\
\text { England }\end{array}$ & BMNH R.3876 & $\begin{array}{l}\text { aff. Goniopholis sp. ( } \\
=\text { G. simus in Dollo, } \\
\text { 1883) } \\
\text { aff. Goniopholis sp. ( } \\
=\text { G. crassidens in } \\
\text { Hooley, 1907) }\end{array}$ & $\begin{array}{l}\text { Skull and postcranium } \\
\text { (almost complete) } \\
\text { Skull and postcranium } \\
\text { (partial) }\end{array}$ & $\begin{array}{l}\text { Dollo, 1883; Salisbury et al., } \\
1999 \\
\text { Hooley, 1907; Salisbury et al., } \\
1999\end{array}$ \\
\hline \multirow[t]{10}{*}{ Berriasian } & \multirow[t]{3}{*}{$\begin{array}{l}\text { Durlstone Fm., } \\
\text { PLG;Dorset, } \\
\text { Southern } \\
\text { England }\end{array}$} & $\begin{array}{l}\text { BMNH } 41098 \\
\text { DORCM } 12154\end{array}$ & $\begin{array}{l}\text { Goniopholis aff. } \\
\text { simus }\end{array}$ & $\begin{array}{l}\text { Skull without mandible } \\
\text { Skull without mandible }\end{array}$ & $\begin{array}{l}\text { Owen, 1878; Salisbury et al., } \\
1999 \\
\text { Andrade et al. (in press) }\end{array}$ \\
\hline & & BMNH 28432 & $\begin{array}{l}\text { Pholidosaurus } \\
\text { purbeckensis }\end{array}$ & Skull without mandible & $\begin{array}{l}\text { Mansell-Pleydell, 1888; } \\
\text { Salisbury } 2002\end{array}$ \\
\hline & & BMNH R.3414 & $\begin{array}{l}\text { Pholidosaurus } \\
\text { laevis }\end{array}$ & Skull without mandible & $\begin{array}{l}\text { Andrews, 1913; Salisbury, } \\
2002\end{array}$ \\
\hline & \multirow[t]{7}{*}{$\begin{array}{l}\text { Bückeberg Fm.; } \\
\text { Lower Saxony, } \\
\text { Northwestern } \\
\text { Germany }\end{array}$} & BMNH R.5259 & Goniopholis simus & \multicolumn{2}{|l|}{$\begin{array}{l}\text { Skull without mandible (cast- } \\
\text { of GZG.BA.0061, } \\
\text { produced prior to } \\
\text { damage; does not } \\
\text { include postcranium) }\end{array}$} \\
\hline & & $\begin{array}{l}\text { BMNH } \\
R .5260 / B M N H \\
R .5261\end{array}$ & Goniopholis simus & $\begin{array}{l}\text { Set of casts (medial/lateral } \\
\text { faces) of a single } \\
\text { hemimandible }\end{array}$ & - \\
\hline & & BMNH R.5262 & Goniopholis simus & Skull without mandible & - \\
\hline & & IPB R359 & Goniopholis simus & Skull & Salisbury et al., 1999 \\
\hline & & GZG.BA.0061 & Goniopholis simus & $\begin{array}{l}\text { Damaged skull, mandible } \\
\text { and partial postcranium } \\
\text { (original of BMNH } \\
\text { R.5259, damaged after } \\
\text { casting) }\end{array}$ & Hornung et al., 2009 \\
\hline & & GZG.BA.0065 & Goniopholis simus & $\begin{array}{l}\text { Single hemimandible } \\
\text { (possibly associated with } \\
\text { GZG.BA.0067) }\end{array}$ & - \\
\hline & & GZG.BA.0067 & Goniopholis simus & $\begin{array}{l}\text { Skull without mandible } \\
\text { (possibly associated with } \\
\text { mandible GZG.BA.0065) }\end{array}$ & Hornung et al., 2009 \\
\hline
\end{tabular}

\begin{tabular}{|c|c|c|c|c|}
\hline $\begin{array}{l}\text { Lulworth Fm., PLG; } \\
\text { Dorset, Southern } \\
\text { England }\end{array}$ & BMNH 48217 & $\begin{array}{l}\text { Nannosuchus } \\
\text { gracilidens }\end{array}$ & Skull without mandible & Owen, 1879; Salisbury, 2002 \\
\hline
\end{tabular}

\begin{tabular}{cclll}
\hline Kimmeridgian & "Guimarota Strata", & "Gui Croc 1" & Goniopholis & Fragmentary skull, \\
Alcobaça Fm.; & (MG 26014 and & baryglyphaeus & Schwarz, 2002 \\
& Leiria, Portugal & associated material) & postcranium & \\
\hline
\end{tabular}

Type specimens are in bold; casts from original specimens in italics. Abbreviations: PLG, Purbeck Limestone Group. 
elongated, in comparison with any living eusuchian (see Buffrénil, 1982). At least in G. simus and DORCM 12154, the rostrolateral region of the lacrimal is ornamented with sharp ridges, radiating rostrolat-erally from the central area towards the suture with the maxilla. This is especially pronounced in large, presumably adult individuals (e.g., GZG.BA.0067, DORCM 12154) where this type of ornamentation can also be present on the rostral-most tip of the jugal. Palpebral ornamentation in most crocodylomorphs is not as distinct as in the skull (M.B.A., pers. observ.). In other goniopholidids such as Nannosuchus the palpebral surface is mostly smooth, and in BMNHB 001876 there are well-defined pits, small and shallow. We have no knowledge of a taxon where the palpebral ornamentation is more pronounced than the one seen on the frontal and skull table.

Wu et al. (1996) recognized groove-dominated ornamentation in younger individuals of Sunosuchus junggarensis, whereas older specimens show almost only pits. This suggests an ontogenetic change from grooves to pits, opposing the pattern shown by eusuchians. In the latter, pits evolve to grooves, particularly on the frontal, parietal, jugal, and rostrum (see Buffrénil, 1982). Conversely, larger specimens of Goniopholis have a proportionally low number of grooves, always poorly elongated (e.g., DORCM 12154).

Crests on the dorsal surface of skull roof are evident in all European Goniopholis and Nannosuchus (Fig. VIII.7), and known also at least in "Goniopholis" stovalli. A sagittal crest is absent in most goniopholidids, and is only known in Siamosuchus (see Lauprasert et al., 2007).

The lower periorbital crest is actually the dorsal border of the jugal, and bounds most of the anteroventral to posteroventral orbit. The upper periorbital crest extends from the lacrimal surface, anterodorsally to the orbit, to the dorsal/medial border of the orbit, at the postorbital. In Nannosuchus (BMNH 48217) this crest is single and continuous. In Goniopholis simus and G. baryglyphaeus the crest is divided by a notch into anterior (lacrimal) and posterior (prefrontal) sections. The notch is particularly evident in larger specimens (see Table VIII.2). The anterior section of the crest is much longer than wide, whereas the second is as long as wide, tuberous, and knob-like. Goniopholis (DORCM 12154) also has a deeply notched crest, but the prefrontal section of the crest is longer than wider, tapering posteriorly. The DORCM specimen also differs from $G$. simus and $G$. baryglyphaeus by having proportionally robust periorbital, transfrontal, and nasal crests. However, it is possible that some of the differences observed in G. simus, G. baryglyphaeus, DORCM 12154, and Nannosuchus are related to an ontogenetic component.

The upper periorbital crest is in the immediate vicinity of the orbit itself, and typically bears a lateral scar for palpebral attachment (Goniopholis simus: BMNH 41098, BMNH R.5814, BMNH 48217, GZG.BA.0061 [and cast BMNH R.5259]; Goniopholis aff. simus: DORCM 12154; G. baryglyphaeus: MG 26014; Nannosuchus: BMNH 48217). As a consequence of this scar, the lacrimal section of the crest becomes narrower posteriorly as it approaches the prefrontal. The scar surface is smoother in Nannosuchus and G. baryglyphaeus, and deeply marked in DORCM 12154. Other taxa (aff. Goniopholis spp.: BMNH R.3876, IRSNB R47, BMNHB 001876) lack dorsally projected crests, but the lacrimal edge projects laterally, creating more common type of crest-like edge, which is also 
Table VIII.2 Periorbital morphology in Goniopholis and closely related forms.

Goniopholis simus

\begin{tabular}{|c|c|c|c|c|}
\hline \multicolumn{5}{|c|}{ Goniopholis simus } \\
\hline IPB R359 & BMNH 41098 & GZG.BA.0061 & $B M N H$ & GZG.BA.0067 \\
\hline & & (BMNH & R.5262 & \\
\hline & & $R .5259)$ & & \\
\hline
\end{tabular}

Goniopholis

DORCM

12154

Goniopholis

baryglyphaeus

"Gui Croc 1"

aff. Goniopholis spp.

(MG-26014)

Characteristic

1

\begin{tabular}{llllll}
\hline Rostrum heavily sculpted & 0 & 0 & 0 & 0 & 0 \\
\hline Transverse frontal crest & 1 & 1 & 1 & - & 1 \\
\hline
\end{tabular}

Buttressed area at transverse Projection Projection Projection ? Projection and

frontal crest

1

$1 \quad 1$

IRSNB R47

BMNHB 001876

(Hooley's

(Dollo's

(Willet's

specimen)

Nannosuchus

specimen)

specimen)

\begin{tabular}{|c|c|c|c|c|c|c|c|c|c|c|c|}
\hline Upper periorbital crest & 1 & 1 & 1 & 1 & 1 & 1 & 1 & 0 & 0 & 0 & 1 \\
\hline Notch at upper periorbital crest & $?$ & $?$ & 1 & 0 & 1 & 1 & 1 & - & - & - & 0 \\
\hline Shape of 'orbit' & Circular & Triangular & Triangular & Triangular & $\begin{array}{l}\text { Subcircular/ } \\
\text { triangular }\end{array}$ & Triangular & Triangular & Circular & $\begin{array}{l}\text { Circular/ } \\
\text { triangular }\end{array}$ & Circular & Circular \\
\hline Palpebral preserved & 1 & 0 & 0 & 0 & Partial/0 & 0 & 0 & 1 & $1 / 0$ & 1 & 1 \\
\hline $\begin{array}{l}\text { Palpebral extensively sutured } \\
\text { to primary orbital border }\end{array}$ & 1 & 1 & 1 & 1 & 1 & 1 & 1 & 1 & 1 & 1 & 1 \\
\hline Palpebral shape & Triangular & - & - & - & $?$ & Triangular & - & Rectangular & Rectangular & Triangular & Triangular \\
\hline Elongated lacrimal (AP/ML 3) & 0 & 0 & 0 & 0 & 0 & 1 & 0 & 0 & $?$ & 1 & 0 \\
\hline Frontal in 'two levels' & 1 & 1 & 1 & 1 & 1 & 1 & 1 & 0 & 0 & 0 & 1 \\
\hline Anterior process of frontal & Narrow & Narrow & Narrow & Narrow & Narrow & Narrow & Narrow & Narrow & Narrow & Triangular & Narrow \\
\hline Anterior-most tip of frontal & Truncated & Triangular & Truncated & Truncated & Truncated & Truncated & Truncated & Triangular & $?$ & Triangular & Triangular \\
\hline $\begin{array}{l}\text { Prefrontal, extreme elongation } \\
\text { of posterior end }\end{array}$ & 0 & 0 & 0 & 0 & 0 & 0 & 0 & 1 & 1 & 0 & 0 \\
\hline $\begin{array}{l}\text { Postorbital with anterolaterally } \\
\text { facing edge }\end{array}$ & 1 & 1 & 1 & 1 & 1 & 1 & $?$ & 0 & 0 & 0 & 1 \\
\hline Postorbital bar & Inclined & Inclined & Inclined & Inclined & $?$ & Inclined & Inclined & Vertical & Vertical & Inclined & Vertical \\
\hline $\begin{array}{l}\text { Anterolateral postorbital } \\
\text { process elongated, shielding } \\
\text { the orbit laterally }\end{array}$ & 0 & 0 & 0 & 0 & 0 & 0 & 0 & 1 & 1 & 0 & 0 \\
\hline $\begin{array}{l}\text { Anterior end of jugal expanded } \\
\text { rostrally to the orbit }\end{array}$ & 1 & $?$ & 1 & $?$ & 1 & 1 & 1 & 1 & 1 & 1 & $?$ \\
\hline
\end{tabular}

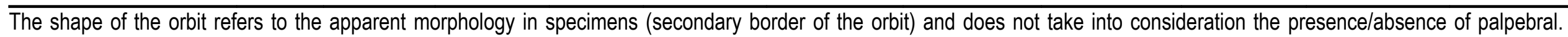

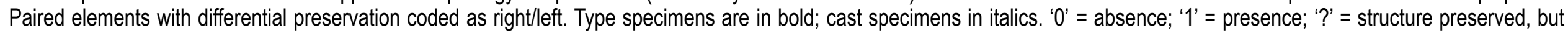
morphology unclear/unknown; '-' = structure not preserved/character inapplicable; 'AP/ML' = anteroposterior/medial-lateral. 
Table VIII.3 Measurements (mm) taken from specimens of Goniopholis, Nannosuchus, and the Hulke specimen (BMNHB 001876).

\begin{tabular}{|c|c|c|c|c|c|c|c|c|c|c|}
\hline \multirow[b]{2}{*}{ Measurements } & \multicolumn{6}{|c|}{ Goniopholis simus } & \multirow{2}{*}{$\begin{array}{l}\text { Goniopholis } \\
\text { baryglyphaeus } \\
\text { "Gui Croc 1" }\end{array}$} & \multirow{2}{*}{$\begin{array}{c}\text { Goniopholis } \\
\text { aff. simus } \\
\text { DORCM } \\
12154\end{array}$} & \multirow{2}{*}{$\begin{array}{l}\text { Nannosuchus } \\
\text { gracilis } \\
\text { BMNH } 48217\end{array}$} & \multirow{2}{*}{$\begin{array}{c}\text { aff. } \\
\text { Goniopholis } \\
\text { BMNHB } \\
001876\end{array}$} \\
\hline & $\begin{array}{l}\text { IPB R359 } \\
\text { (original) }\end{array}$ & $\begin{array}{l}\text { IPB R359 } \\
\text { (direct) }\end{array}$ & BMNH 41098 & GZG.BA.0061 & GZG.BA.0067 & $\begin{array}{l}\text { BMNH } \\
\text { R.5262 }\end{array}$ & & & & \\
\hline $\begin{array}{l}\text { Interorbital distance, } \\
\text { excluding palpebrals } \\
\text { (IOF) }\end{array}$ & 106.1 & 72.5 & 65.0 & 84.0 & 84.0 & 40.5 & 43.3 & 87.7 & 14.8 & 71.5 \\
\hline $\begin{array}{l}\text { Interorbital distance with } \\
\text { palpebrals (IOP) }\end{array}$ & - & 106.1 & - & - & $113.0^{*}$ & - & - & $122.0^{*}$ & 25.0 & 125.0 \\
\hline Skull length (SL) & 471.0 & 478.0 & 367.0 & 472.0 & 518.0 & 274.0 & 293.0 & 475.6 & 104.3 & 569.8 \\
\hline $\begin{array}{l}\text { Skull width at postorbital } \\
\text { bars (SWPo) }\end{array}$ & 186.0 & 186.0 & 130.0 & $186.5^{*}$ & 196.0 & 105.0 & 100.0 & 185.0 & 45.6 & 189.0 \\
\hline Rostrum length (RL) & 300.0 & 300.0 & 240.0 & 293.0 & 325.0 & 175.0 & 200.0 & 326.0 & 51.3 & 400.0 \\
\hline Narial opening, width (NW) & 39.1 & 39.1 & 32.5 & $48.0^{*}$ & 51.0 & 24.3 & $26.3^{*}$ & 41.98 & 7.0 & 35.2 \\
\hline $\begin{array}{l}\text { Fenestra supratemporal, } \\
\text { distance to occipital } \\
\text { surface (FDO) }\end{array}$ & 29.0 & 29.0 & 27.8 & 32.0 & 35.0 & 22.3 & 29.4 & 34.55 & 9.2 & 34.8 \\
\hline IOF/SWPo (IOP/SWPo) & 0.57 & $0.39(0.57)$ & 0.50 & 0.45 & $0.43(0.58)$ & 0.39 & 0.43 & $0.47(0.66)$ & $0.32(0.55)$ & $0.38(0.66)$ \\
\hline IOF/RL (IOP/RL) & 0.35 & $0.24(0.35)$ & 0.27 & 0.29 & $0.26(0.35)$ & 0.23 & 0.22 & $0.27(0.37)$ & $0.29(0.49)$ & $0.18(0.31)$ \\
\hline IOF/NW (IOP/NW) & 2.71 & $1.85(2.71)$ & 2.00 & 1.75 & $1.65(2.22)$ & 1.67 & 1.65 & $2.09(2.91)$ & $2.11(3.57)$ & $2.03(3.55)$ \\
\hline IOF/FDO (IOP/FDO) & 3.66 & $2.50(3.66)$ & 2.34 & 2.63 & $2.40(3.23)$ & 1.82 & 1.47 & $2.54(3.53)$ & $1.61(2.72)$ & $2.06(3.60)$ \\
\hline
\end{tabular}

Note that interorbital distance (without palpebrals) for G. simus IPB R359, after Salisbury et al. (1999), diverge from other specimens, even of similar size. Dissimilar values are retained even when interorbital distance is considered in proportion to other element of the skull, as shown by the indices used. Type specimens are in bold; cast specimens in italics:

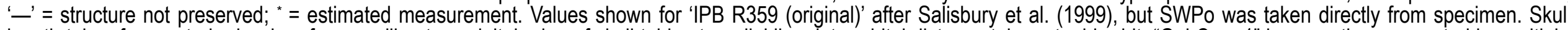

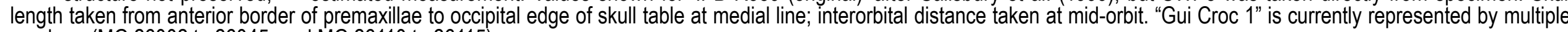
numbers (MG 26002 to 26045, and MG 26110 to 26115). 

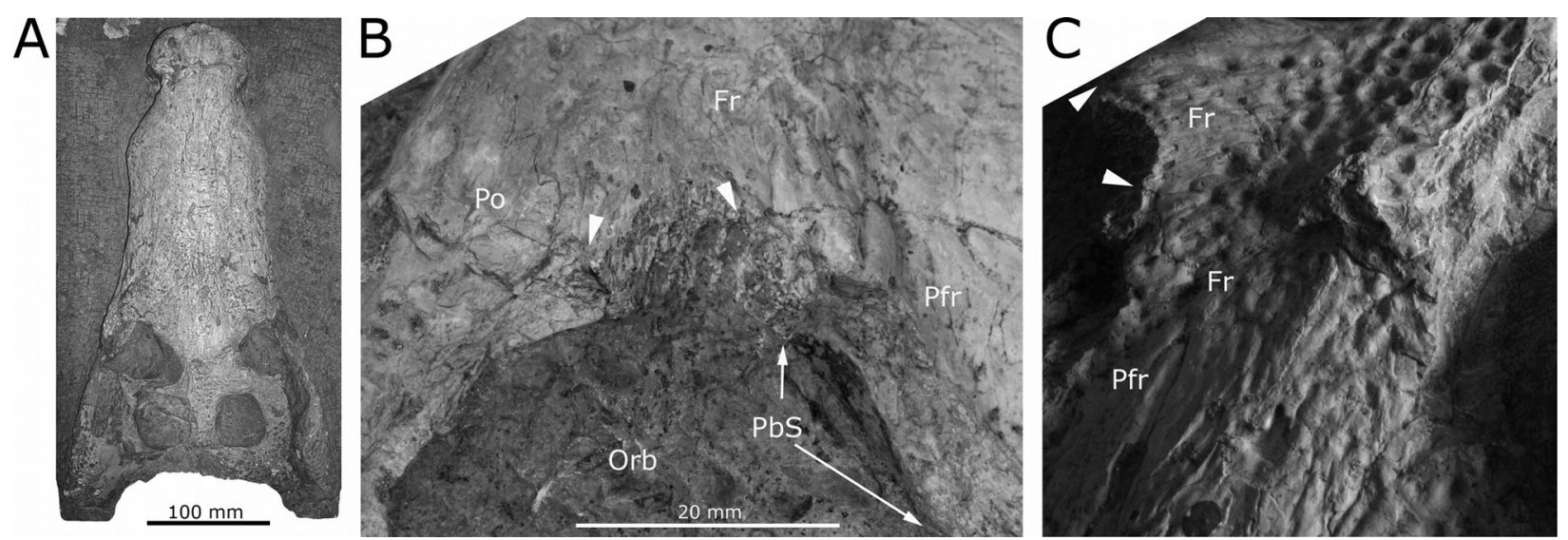

Fig 2 Periorbital morphology of Goniopholis simus BMNH 41098, type specimen. (A) Dorsal view of the skull. (B) Laterodorsal view of the right and best preserved orbit; (C) oblique view of the skull roof, where angled light accentuates the topographic features of the skull. White pointers indicate where sutural contacts with the frontal approach the orbit. Note that the orbit is mostly preserved, because the scar for the palpebral is visible (B). The frontal edge at the orbit, apparently damaged in (B), is indicated by the presence of a shallow trench along its dorsal margin, as seen in $(\mathbf{C})$ between the white pointers. Indeed, the damaged area affects only the internal lateral surface of the orbit. Therefore, no prefrontal-postorbital contact occurs at the dorsal surface of skull roof.

present in thalattosuchians, notosuchians, and other mesoeucrocodylian clades (Fig. VIII.7). The absence of crests in these specimens is interpreted as a true taxonomic signal, rather than ontogenetic bias. Considering the range of materials of Goniopholis, IPB R359 is the single specimen where the upper periorbital crests were reconstructed medial to the orbital border (see Salisbury et al., 1999: fig. 6). Particularly evident is the distance between the prefrontal section of the crest, which in all other specimens is located immediately next to the border of the orbit. These crests and their position on the skull, as well as the presence of palpebrals, are potentially one of the reasons that the sutures in the Bonn specimen were misinterpreted.

A crescent-shaped crest crosses the interorbital surface transversely, forming the transfrontal crest (=transverse frontal crest), connecting both ends of the upper periorbital crests in Goniopholis simus, G. baryglyphaeus, and G. aff. simus (DORCM 12154). This crest is absent from BMNH R.3876, and the same occurring with BMNHB 001876 and IRSNB R47 (Hulke, 1878; Dollo, 1883; Hooley, 1907; Salisbury et al., 1999). In G. simus and DORCM 12154, the medial area of this crest is more robust and seems to create an intumescent tuberous structure, flattened anteriorly and projecting dorsally (Fig. VIII.5). A similar condition is present in G. baryglyphaeus, where the transfrontal crest is tuberous and robust along most of its width, but does not project dorsally or posteriorly. In the Hulke specimen (BMNHB 001876), the structure is incipient and hump-like. This projection is evident only in European Goniopholis. With the exception of the Hulke specimen, all other taxa lack this medial tuberous structure (Figs. VIII.2, VIII.5, VIII.6), including Nannosuchus BMNH 48217. The fact that smaller specimens of G. simus (e.g., BMNH R.5262) and the type of G. baryglyphaeus also have the same structure suggests that ontogeny does not affect its presence. 
Orbital Shape and Orientation

In several well-preserved specimens of Goniopholis simus the shape of the orbits varies from subcircular and dorsolaterally directed to rounded-triangular and more laterally directed (compare Salisbury et al., 1999; Karl et al., 2006), the same occurring in all closely related taxa. Although postburial deformation (either gravitationally or tectonically induced) is a common factor in the morphological variability of vertebrate remains, in this case the diagenetic effects can be considered insignificant (see Supplementary Data 1). Many of the affected specimens (e.g., IPB R359, GZG.BA.0061, GZG.BA.0067) originate from the same stratum (Obernkirchen Sandstone) with closely comparable taphonomic and diagenetic conditions, excluding deformation as the cause of variability in orbital shape. On the other hand, damage or loss of the palpebrals is common (due to their more delicate structure), and can better explain orbital shape variability.

The articulated palpebrals contribute significantly to the orbital shape in G. simus and all closely related forms, as exemplified by the Hulke specimen and IPB R359. The absence of palpebrals reveals the triangular profile of the primary orbital border, which is quite evident in $G$. simus (BMNH 41098, BMNH R.5259, BMNH R.5262), G. baryglyphaeus (MG 26014), and DORCM 12154. Removal of palpebrals of the Hulke specimen (BMNHB 001876) would reveal the primary triangular orbital border. Differential preservation of the palpebral in Goniopholis simus GZG.BA.0067, and Dollo's goniopholidid (IRSNB R47), where each specimen preserves only one palpebral, leads to the evident asymmetry of the orbits (Fig. VIII.4).

\section{Palpebrals}

The fragment of a palpebral, reported in IPB R359 by Salisbury et al. (1999:fig. 6) cannot be considered as such because

(1) the ornamentation is far coarser than the ornamentation seen in the skull roof of the same specimen; (2) the fragment is by far too large and robust to fit the orbit, and if set in place would obliterate most of its area; (3) there is no attachment surface for a palpebral in the orbital border of IPB R359 (as interpreted by Salisbury et al., 1999; i.e., secondary border of the orbit, this paper) or in the dermal fragment, as seen in other specimens of G. simus, and most other goniopholidids; (4) the morphology seen in this element is neither consistent with the palpebral morphology of any other goniopholidid, including BMNHB 001876 and Nannosuchus, nor with other crocodylomorphs. Instead, this element is here interpreted as a partially damaged osteoderm. The association of this dermal fragment with the dorsal part of the skull roof of IPB R359 is considered as accidental, facilitated by the way the specimen is positioned in the sediment (palatal side upwards, as inferred by Salisbury et al., 1999:127).

True palpebrals are rarely preserved in goniopholidids, and thus not always known for each taxon. Palpebrals are absent from both sides of most Goniopholis specimens studied (G. simus BMNH 41098, BMNH R.5262, and GZG.BA.0061, Goniopholis DORCM 12154, and G. baryglyphaeus MG 26014), but their occurrence and general profile is attested by a long, groove-shaped contact area at 
A
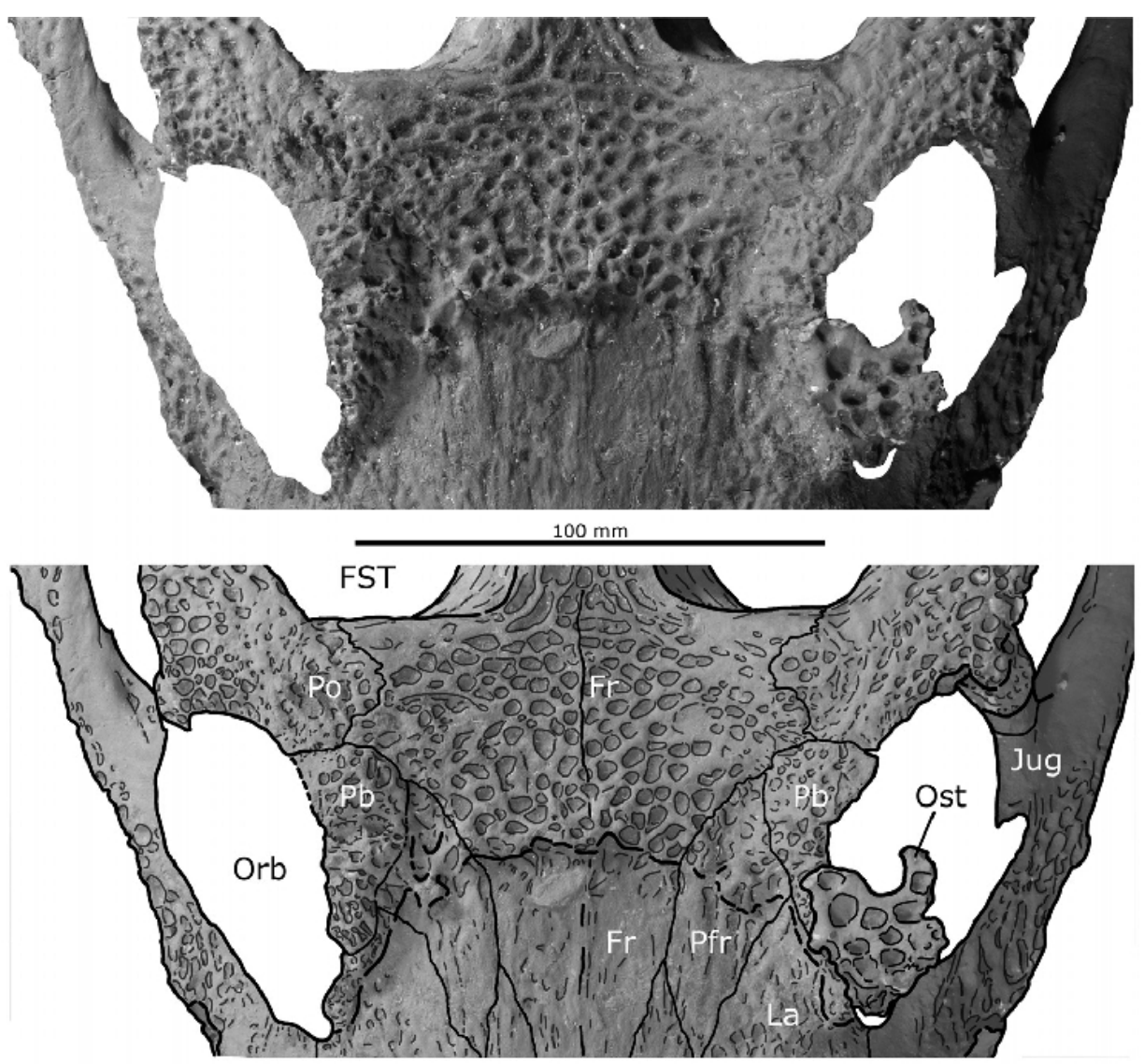

B
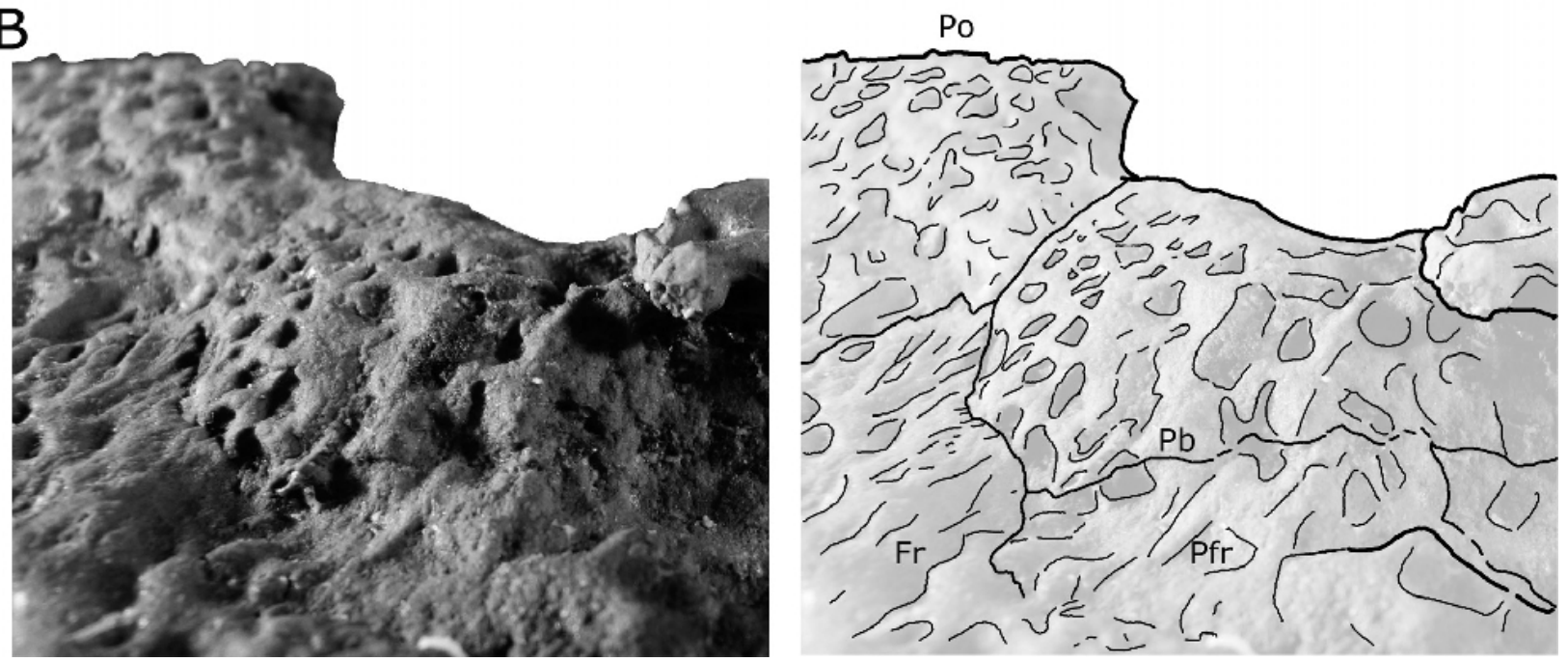

Fig. VIII.3 Detailed periorbital morphology in the German specimen of G. simus IPB R359, in dorsal view, and including a schematic view of sutural contacts. (A) Skull roof at orbits; (B) detail of the skull roof near the left orbit, where the prefrontal-palpebral suture is preserved, evidencing the presence of palpebrals in the specimen (contra Salisbury et al., 1999). 


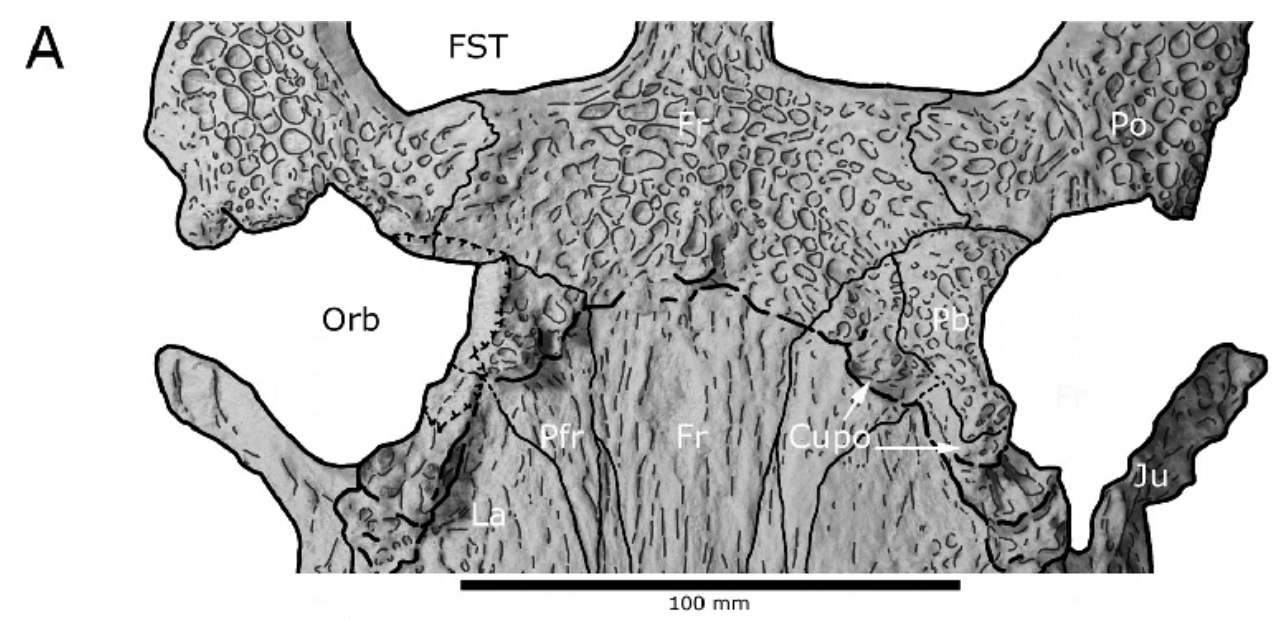

B
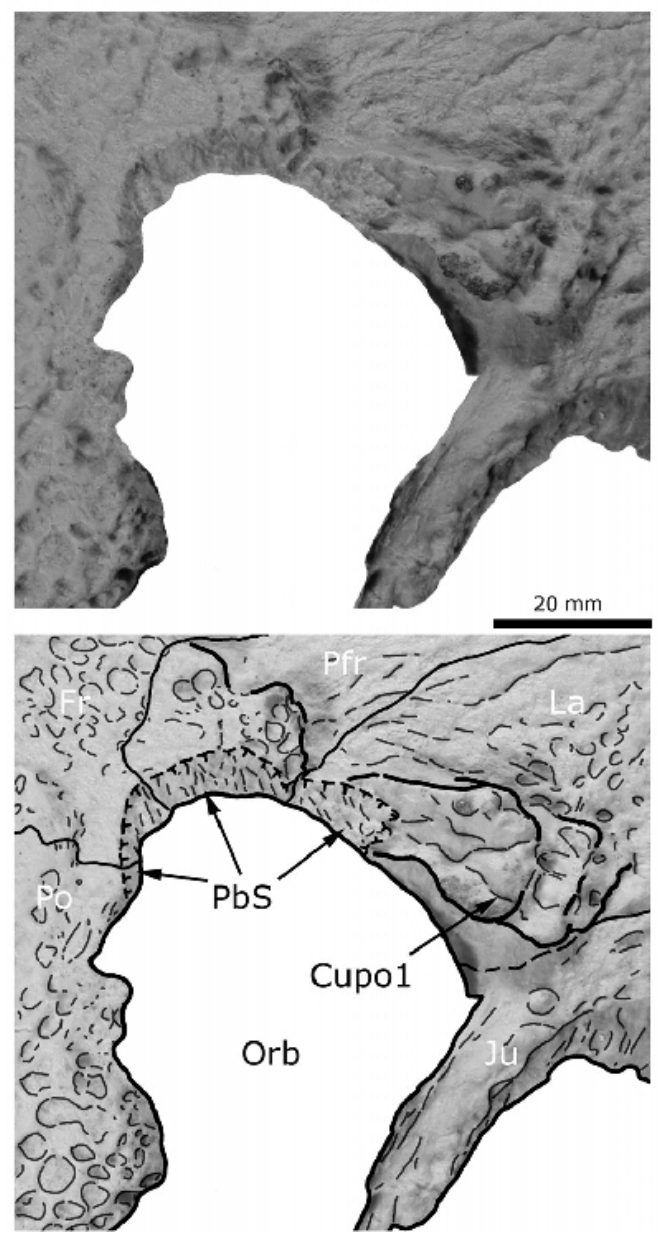

C
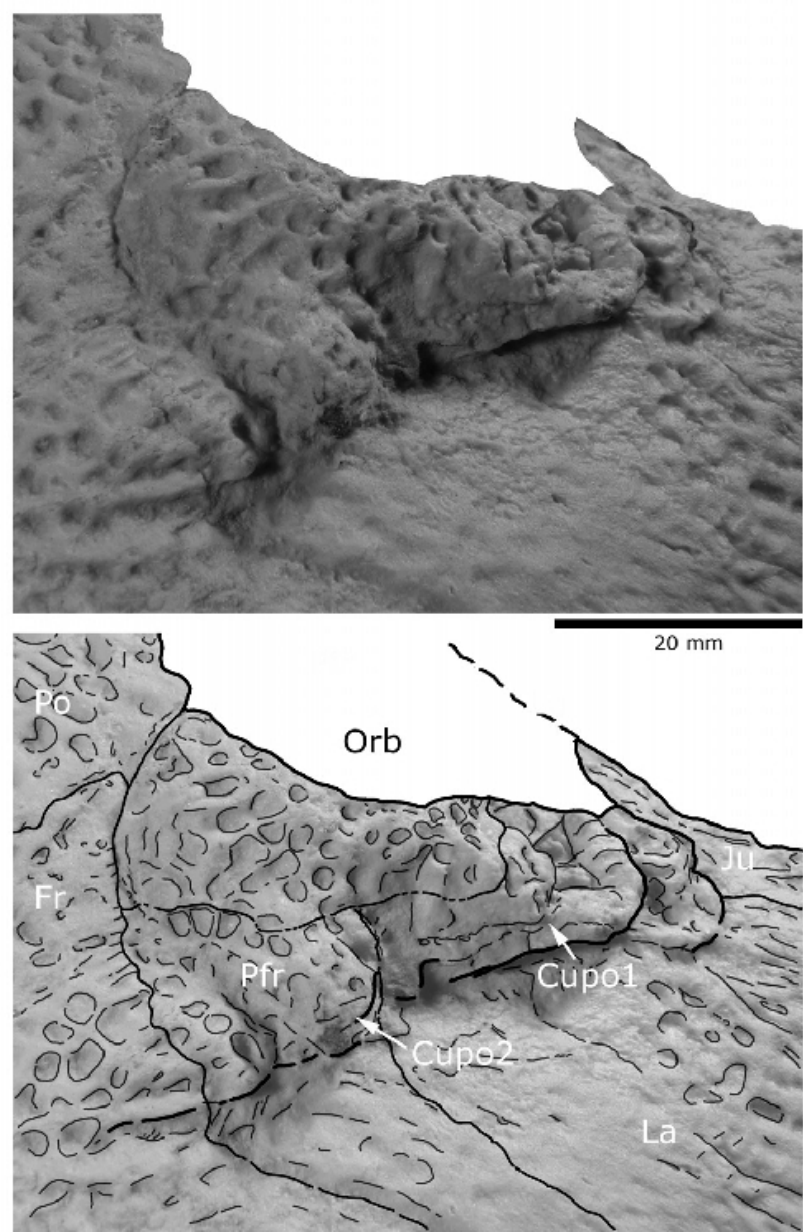

Fig. VIII.4 Periorbital morphology in the German specimen of G. simus GZG.BA.0067 (cast), in dorsal view, and including a schematic view of sutural contacts. (A) Skull roof at orbits, where the asymmetry between orbits is evident, owing to the preservation of only the left palpebral; (B) detail of right orbit, where the surface for palpebral attachment is evident, and where the upper periorbital crest margins the orbit; (C) detail of the left orbit, where the attachment facet is covered by the palpebral and the upper periorbital crest is distant from the secondary (functional) dorsal border of the orbit. Note that the upper periorbital crest is divided in anterior (Cupo1) and posterior (Cupo2) sections, respectively, set at the lacrimal and prefrontal, and are separated by a notch. 
the medial border of the orbit. This contact surface can be clearly seen in the right side of the $G$. simus type BMNH 41098 (Fig. VIII.2). It is particularly well developed in the anteromedial to medial borders of the orbit, scarring the lateral edges of lacrimal and prefrontal, but also ranging over the frontal and postorbital in the orbit. In the lacrimal, the groove also reaches dorsally, to the posterolateral face of the upper periorbital crest. This facet for the attachment of the palpebral is exposed laterodorsally along most of its length, and is therefore visible in dorsal view. It is easily recognizable in Goniopholis (DORCM 12154), where the ridged contact is stronger and also extends to the lateral edge of frontal, but the contact area is smoother in G. baryglyphaeus (MG 26014) and Nannosuchus (BMNH 48217). Whenever the palpebral is preserved in situ, the attachment facet is not exposed.

In Goniopholis, true palpebrals were only identified in IPB R359 and GZG.BA.0067. In the latter, just a fragment of the left palpebral is preserved (Fig. VIII.4), whereas its right counterpart is missing, resulting in an asymmetric profile. The remaining section of the palpebral is subrectangular, but the lateral edge is worn and missing. A prefrontal-palpebral contact is visible and readily identifiable at least in the left orbit of the Bonn specimen (IPB R359), contrasting with the interpretation proposed by Salisbury et al. (1999), and revealing the presence of both palpebrals (Figs. VIII.1, VIII.3, VIII.7). The contact runs medial to the orbital border, next to the upper periorbital crest, although a small area is damaged near the prefrontal section of the upper periorbital crest. Both palpebrals are extensively attached to the orbits, very similar to BMNHB 001876. The left palpebral is broken near the lacrimal-prefrontal contact. The large osteoderm fragment (identified as a palpebral, by Salisbury et al., 1999) partially covers the lacrimal border of the orbit, preventing the identification of any remains of the anterior end of the true palpebral. However, the posterior and lateral edges are well preserved. The posterolateral corner of the palpebral is a thin and smooth lamina, contrasting with the overall robust and heavily sculpted surface of the remaining palpebral. The smooth area is bounded medially by a very faint, straight ridge. The right palpebral of IPB R359 is preserved along its length, although its sutural contact with prefrontal and lacrimal is not as evident. The element is transversely broken in two places, but the three resulting sections remain in situ. Its posterolateral edge is not as well preserved as on the left side, but a smooth posterolateral corner can also be recognized. Palpebrals are also preserved on Nannosuchus, the Hulke, Dollo, and Hooley specimens. Of all specimens studied, palpebrals can be best recognized in Nannosuchus BMNH 48217 and the Hulke specimen. In these taxa, the palpebral is slightly longer than wide, narrow anteriorly, and broadening considerably towards its posterior end, assuming a general triangular outline. From the study of GZG.BA.0067 and IPB R359, the palpebral of $G$. simus, when preserved in articulation, is intimately attached to the border of the orbit. The palpebral contacts the prefrontal medially, the frontal posteromedially, and the postorbital posterolaterally (Figs. VIII.7C, D). The anterior-most edge of the palpebral ends anterior relative to the knob-like projection (i.e., prefrontal section of the upper periorbital crest), meaning that the contact with the lacrimal is extensive. The posterolateral edge of the palpebral contacts the small anteromedial corner of the postorbital, where both elements are smooth (only preserved in IPB R359). This smooth palpebral corner is so far observed in G. simus (unknown in $G$. baryglyphaeus and DORCM 12154). The primary orbit of Goniopholis simus is therefore dorso- 
A

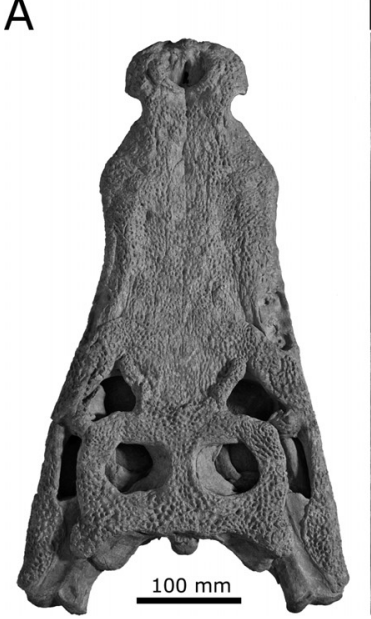

B

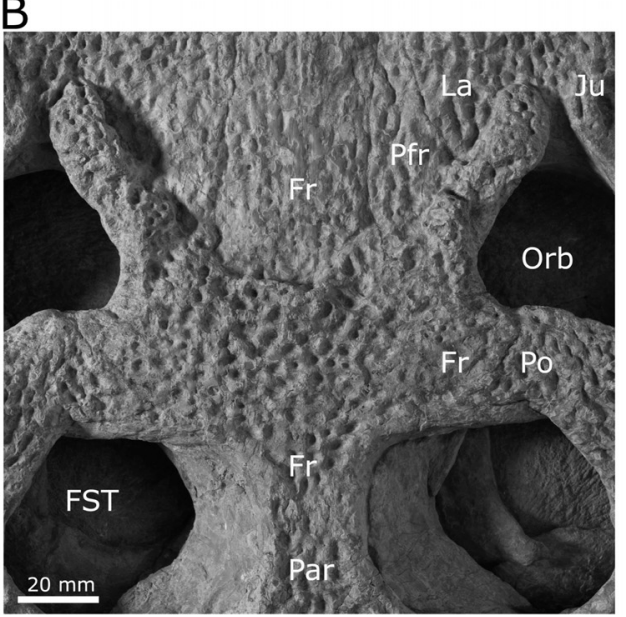

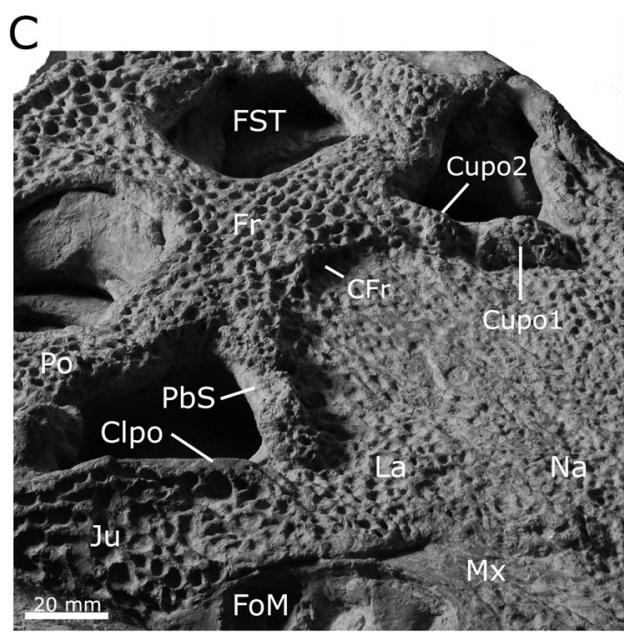

Fig. VIII.5 Periorbital morphology of Goniopholis aff. simus DORCM 12154. (A) Dorsal view of the skull; (B) detail of the skull roof, in dorsal view; $(C)$ oblique view of the skull roof, where topographic elements are recognizable. Note that overall morphology is similar to all other specimens of Goniopholis.

medially bounded by the supraorbital crest in all specimens, including IPB R359. The secondary border of the orbit is delimited by the triangular palpebral. When the palpebral is present, the orbit assumes a subcircular profile, the functional border of the orbit is displaced to a position far lateral to the upper periorbital crest (as seen in the original interpretation of IPB R359), and the frontal becomes excluded from the functional border of the orbit. The same arrangement also occurs in Nannosuchus and the Hulke specimen, and can also be inferred for G. baryglyphaeus (MG 26014) and DORCM 12154, based on the presence of the area for the attachment of the palpebral.

Only BMNH R.3876 and IRSNB R47 clearly differ from Goniopholis and most other crocodylomorphs. In these specimens, the palpebral does not project laterally at all, being intimately inserted in the skull roof and hardly identifiable. Due to its particular morphology, they are highly cryptic elements, and no reference for them can be recognized in the original descriptions (Dollo,

A

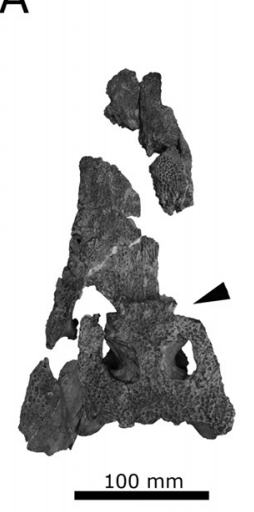

B

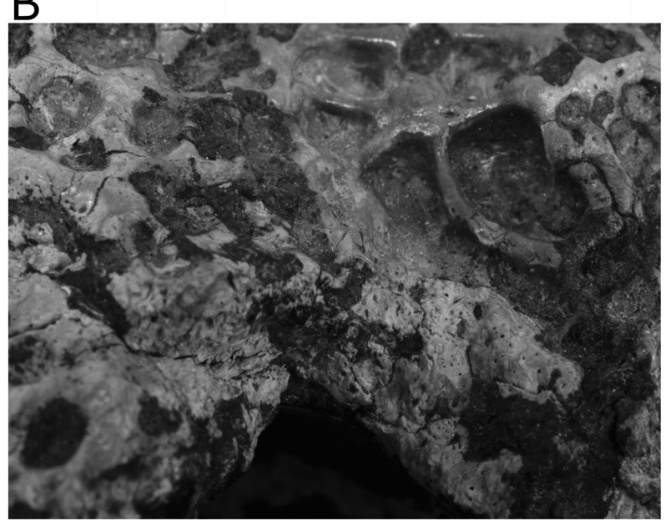

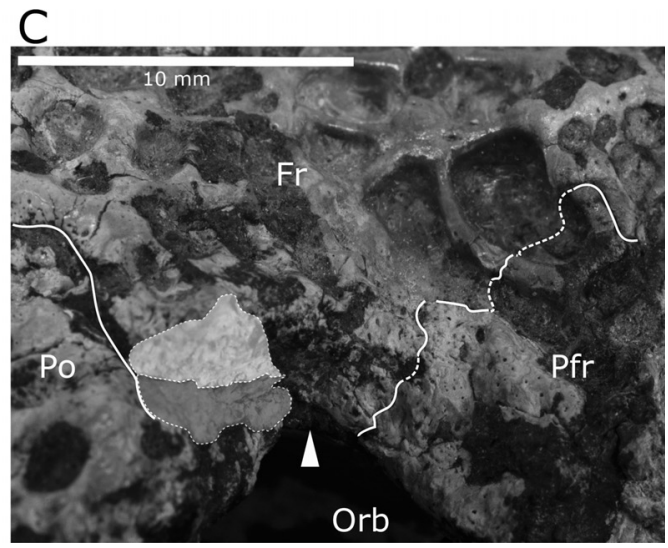

Fig. VIII.6 Periorbital morphology of Goniopholis baryglyphaeus Schwarz, 2002, as preserved on the right orbit of the type specimen. (A) Dorsal view of the skull; (B) anterolateral view of the medial corner of the orbit, showing preservation; (C) right orbit with sutures and other features indicated. The light grey area in $\mathbf{C}$ represents a broken edge of frontal, which originally extended over the small and unornamented surface of postorbital (dark grey area). Black pointer indicates view in B-C; white pointer indicates where frontal reaches the orbit.. 

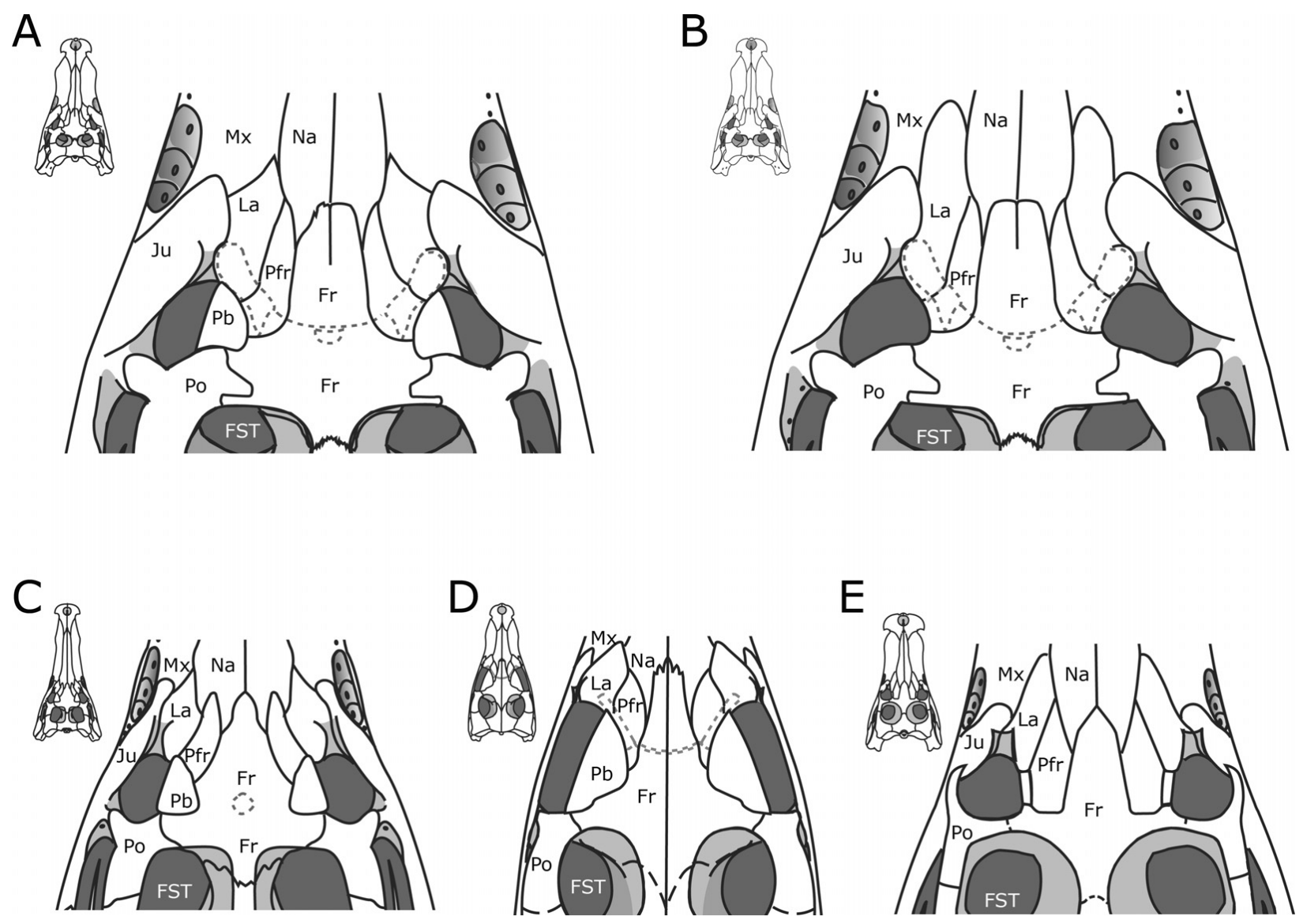

Fig. VIII.7 Diversity in the periorbital morphology of European goniopholidids reconstructed from specimens used in the study (see Table VIII.1). (A) Goniopholis simus, (B) Goniopholis aff. simus DORCM 12154, (C) Hulke specimen BMNHB 001876, (D) Nannosuchus BMNH 48217, and (E) Hooley specimen BMNH R.3876. Despite differences in morphology, in all cases the palpebral extensively contacts the true (primary) dorsal border of the orbit, creating a secondary functional border. Drawings not to scale.

1883; Hooley, 1907). Nonetheless, Dollo's specimen (IRSNB R47) has the left palpebral preserved, whereas the medial section of the right orbit is damaged. The Hooley specimen (BMNH R.3876) has both palpebrals present, but extensively damaged, because the skull was severed at the level of the orbits. In both specimens, where the palpebral is present, the orbit assumes a circular profile, as in IPB R359 and BMNHB 001876, but does not change orientation.

In all cases above, including Goniopholis, the primary border of the orbit creates a 'notch' for the intimate attachment of the palpebral. This feature is also evident in Calsoyasuchus and Pholidosaurus. In all cases, the palpebral seems to be in continuity with the prefrontal. Considering the difficulty of identifying the periorbital sutures in most specimens, the palpebral can be easily mistaken as the distal end of the prefrontal, as in IPB R359 (Figs. VIII.1, VIII.3), BMNH R.3876 and IRSNB R47 (see Dollo, 1883; Hooley, 1907). Among goniopholidids, only Eutretauranosuchus seems to lack any type of facet for the palpebral attachment (Smith et al., 2010).

In most taxa examined, as well as in pholidosaurids, thalatto-suchians, dyrosaurids, and elosuchids, there seems to be no evidence of a posterior palpebral. Only in Nannosuchus BMNH 48217 is a small bony element preserved in the orbit, which was interpreted by Clark (1986) as possibly the 
posterior palpebral. However, the position and the morphology indicate that the bony element may also be the broken posterolateral tip of the anterior palpebral. Based on the morphology of the posterior orbital border of the specimens studied, the presence of a posterior palpebral in goniopholidids and related forms is considered unlikely until new specimens can provide better evidence of this structure.

\section{Lacrimals}

In Goniopholis lacrimals are relatively wide elements that extend alongside the rostrum, separating completely the maxilla from the prefrontals, and broadly contacting the nasals. Only in Eutretauranosuchus this contact is absent, prevented by long prefrontals (Smith et al., 2010). In most crocodilians the lacrimal constitutes the anteroventral to anterodorsal orbital borders. In this respect, the lacrimal of Goniopholis is different, because it only takes part in the anterior to anterodorsal borders of the orbit (Fig. VIII.7). In this genus, the jugal constitutes the anteroventral border of the orbit, preventing the lacrimal from reaching this position. At least in DORCM 12154 the lacrimal-jugal suture can be clearly identified, placed immediately anterior to the orbit. In Goniopholis simus, G. baryglyphaeus, and BMNH R.3876, the lacrimals are only slightly longer than wide $(\mathrm{AP} / \mathrm{ML} \cong 1.5-2.0$ ), being subquadratic in Nannosuchus (AP/ML $=1.35$ ). Lacrimals are particularly elongated in BMNHB $001876(\mathrm{AP} / \mathrm{ML}=2.85)$ and DORCM $12154(\mathrm{AP} / \mathrm{ML}=3.15)$.

\section{Prefrontals}

The prefrontals in goniopholidids are usually thin elements, projecting from the anterodorsal (or anteromedial) border of the orbit, and reaching the nasals anteriorly in a broad contact, as in most mesoeucrocodylians. In G. simus, the contact of prefrontal with surrounding elements (palpebral, lacrimal, frontal) becomes inconspicuous next to the periorbital crest. However, the heavier sculpture of these bones (including the palpebral) allows their distinction from the proportionally smoother prefrontal (Figs. VIII.2-VIII.4). In contrast, the prefrontal is well ornamented in all other taxa, e.g., DORCM 12154, G. baryglyphaeus MG 26014, and BMNHB 001876 (Figs. VIII.5-VIII.7).

In all Goniopholis spp., the upper periorbital crest facilitates the location of sutural contacts, which run very close to medially (prefrontal) and laterally (lacrimal). However, the distal end of the prefrontals extends posteriorly, with the suture moving away from the crest and reaching the medial corner of the orbit. The long distal process of prefrontal prevents the frontal from reaching the medial border of the orbit (although this element still takes part at least in the posteromedial border). The arrangement found in Goniopholis is also present in Nannosuchus and BMNHB 001876, but BMNH R.3876 and IRSNB R47 share an extreme condition. In these specimens, the prefrontals project posteriorly almost to the same relative position as the posterior-most border of the orbit. The long distal process of prefrontal of Goniopholis and related taxa contrasts with the shorter distal 
process of prefrontal found in many mesoeucrocodylians, including all extant taxa.

Despite the posterior projection of the prefrontal, this element does not contact the postorbital on the dorsal skull roof in any taxa, including Goniopholis (contra Salisbury et al., 1999; Salisbury, 2002; Schwarz, 2002; Lauprasert et al., 2007). On the other hand, this arrangement does not prevent a prefrontal-postorbital contact on the ventral surface of the skull roof, a condition identified by Salisbury et al. (1999:fig. 12) in the left orbit of G. simus BMNH 41098 as an impression on the sediment. In IPB R359 and GZG.BA.0067 it is not possible to verify the ventral prefrontal-postorbital contact, but the contact is absent at least on the dorsal skull roof. This indicates that the frontal may overlap the ventral prefrontal-postorbital contact in the ventral skull roof. The arrangement is consistent with the morphology seen in the right orbit of BMNH 41098 and GZG specimens, but is still not possible to state that this contact reaches the dorsal orbital margin and is exposed in lateral view, or only occurs ventral to the frontal. In G. baryglyphaeus MG 26014, the frontal-postorbital contact is clearly inclined medioventrally to dorsolaterally (Fig. VIII.6) and, as a consequence, the ventral edge of the postorbital reaches the medial corner of the orbit ventrally, but not dorsally. The suture with the prefrontal approaches-but never reachesthe medial corner of the orbit or the postorbital, even in lateral view (contra Schwarz, 2002).

\section{Frontal}

The frontal is a central element among other periorbital bones. It comprises paired elements fused medially during ontogeny. However, in goniopholidids this fusion is often incomplete and a suture is retained even in mature specimens (e.g., DORCM 12154), at the anterior process (Fig. VIII.7). In all specimens examined, the frontal is a wide and flat element, usually representing at least $35-40 \%$ of the width of the skull roof.

The frontal is laterally limited by the prefrontals and anteriorly by the nasals, as in other crocodilians. Variation in the shape of the medial border of prefrontal determines the shape of the anterior process of frontal, and the extent of participation of frontal in the medial border of the orbit. In Goniopholis the anterior process of frontal is a somewhat narrow blade, constricted between prefrontals, which becomes even more evident in BMNH R.3876 and IRSNB R47. In contrast, BMNHB 001876 and Nannosuchus have a wide triangular process that tapers anteriorly, as seen in pholidosaurids, dyrosaurids, and thalattosuchians.

The main body of the frontal extends posteriorly in Gonio-pholis and aff. Goniopholis, entering the intertemporal bar and the wide supratemporal fossa. Only Amphicotylus and Denazinosuchus have a different arrangement, because the frontal-parietal medial contact occurs in a rather anterior position, almost between the orbits (see Mook, 1942; Lucas and Sulli-van, 2003). In all taxa studied -including Goniopholis - the lateral processes of the main body extend towards the postorbital and take part in the posteromedial (primary) border of the orbit (contra Salisbury et al., 1999; Schwarz, 
2002). These processes are particularly long in BMNH R.3876 and IRSNB R47 (Hooley, 1907; Salisbury et al., 1999; Salisbury, 2002).

The type of $G$. simus has the left orbit highly damaged, but the right orbit is mostly preserved, and the dorsal surface of the frontal can be followed up to its lateral edge. The edge of the dorsal surface of the frontal is shaped into a smooth curve, consistent with the medial border of the orbit, and has no signs of damage (contra Salisbury et al., 1999). At the very edge, an elongated trench or groove is present along the entire margin of the frontal, from its contact with the prefrontal to the suture with the postorbital (Fig. VIII.2C). The orbital border of the frontal slopes ventrally from the skull roof to the inner margin of the orbit at a strong angle, and it is only at this lateral surface that bony texture is exposed, indicating actual damage. Despite the limited signs of wear and damage, it is possible to identify the prefrontal-frontal and the frontal-postorbital sutures, and follow the first as it reaches the dorsal border of the orbit. The frontal-postorbital suture reaches the dorsal rim of the orbit at a rather separate position, posteriorly. Neither the prefrontal nor the postorbital interfere or relate to the lateral edge of frontal, and the frontal clearly takes part in the orbit. However, differences in bone texture at the medial edge of the orbit are consistent with the idea that the frontal overlies the prefrontal-postorbital contact, which only occurs ventral to the interorbital bar.

In the type of $G$. baryglyphaeus the frontal has a long and deep break that extends from midfrontal to the medial edge of the orbit, complicating overall interpretation of contacts between elements. This break also continues to the posterior edge, damaging the lateral process of the frontal. Furthermore, the (left) lateral edge of the skull roof is displaced anteriorly, towards the orbit. As a result, proper identification of sutures near the medial corner of the orbit is prevented. However, the right side of the specimen is well preserved and provides better evidence of true sutural contacts. The morphology agrees with G. simus and Goniopholis DORCM 12154, apart from small differences in the crests. The frontal reaches the right orbit at its posteromedial corner and evidently separates the prefrontal and postorbital, particularly on the dorsal skull table (Fig. VIII.6).

\section{Postorbital}

In most mesoeucrocodylians the postorbital is a complex element divided into two main sections, namely a dorsal section that composes the skull roof, and a ventral process that projects ventrally towards the jugal and constitutes part of the postorbital bar.

In Goniopholis the dorsal section of the postorbital takes part in the skull roof and delimits the posterior border of the orbit, in dorsal view. The postorbital shows a two-edged border (see Salisbury et al., 1999:fig. 6), the rostral one facing anterolaterally, and the caudal edge facing laterally. This interpretation is reasonably consistent with the phylogenetic coding by Clark (1994:91, 95; character 29) as character state (0) "dorsal part of postorbital with anterior and lateral edges only," although the rostral edge actually faces anterolaterally. The character is used in several phylogenetic studies, following the original coding (e.g., Pol and Apesteguia, 2005, Jouve et 
Fig. VIII.8 Proportional interorbital distance

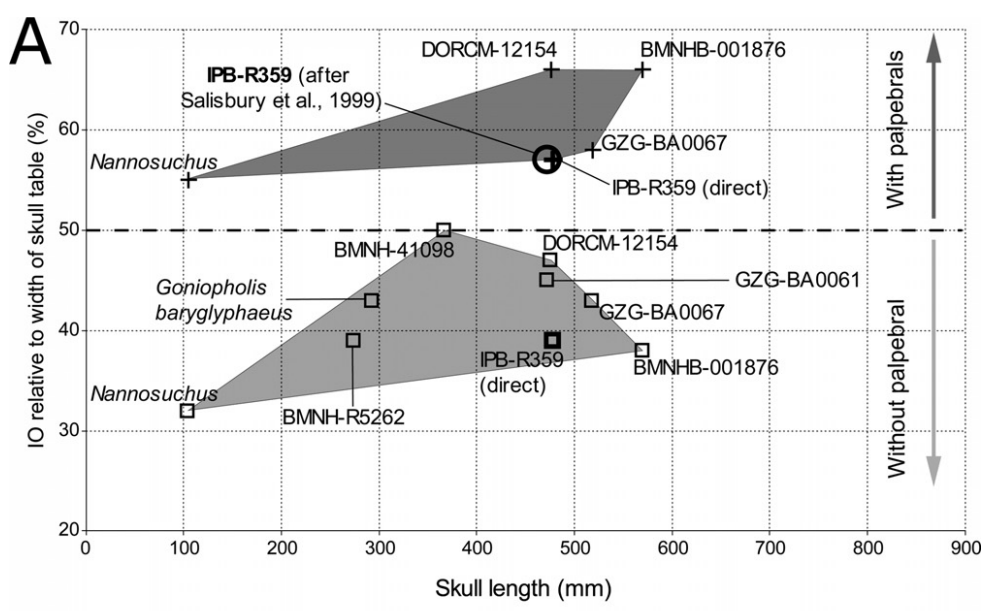
(IO) in goniopholidids. (A), relative values plotted against skull length; (B), discriminant analysis; (C), principal component analysis (PCA). In the plots, two key groups can be identified: goniopholidids without palpebrals (light grey $=$ 'Group 1') and with palpebrals (dark grey = 'Group 2'). The specimen IPB R359, based on the interorbital distance provided by Salisbury et al. (1999) (circle), plots closer to the group with papebrals rather than to the group excluding these elements (true interorbital distance). The discriminant analysis sets this specimen in the group with palpebrals, even though it was considered a priori as part of the group without palpebrals. The sample includes Goniopholis, Nannosuchus and the Hulke specimen (BMNHB 001876); IPB R359 is indicated by larger symbols; in $\mathbf{A}$ and $\mathbf{C}$, each cross identifies 10 values including palpebrals; squares identify 10 values without palpebrals.
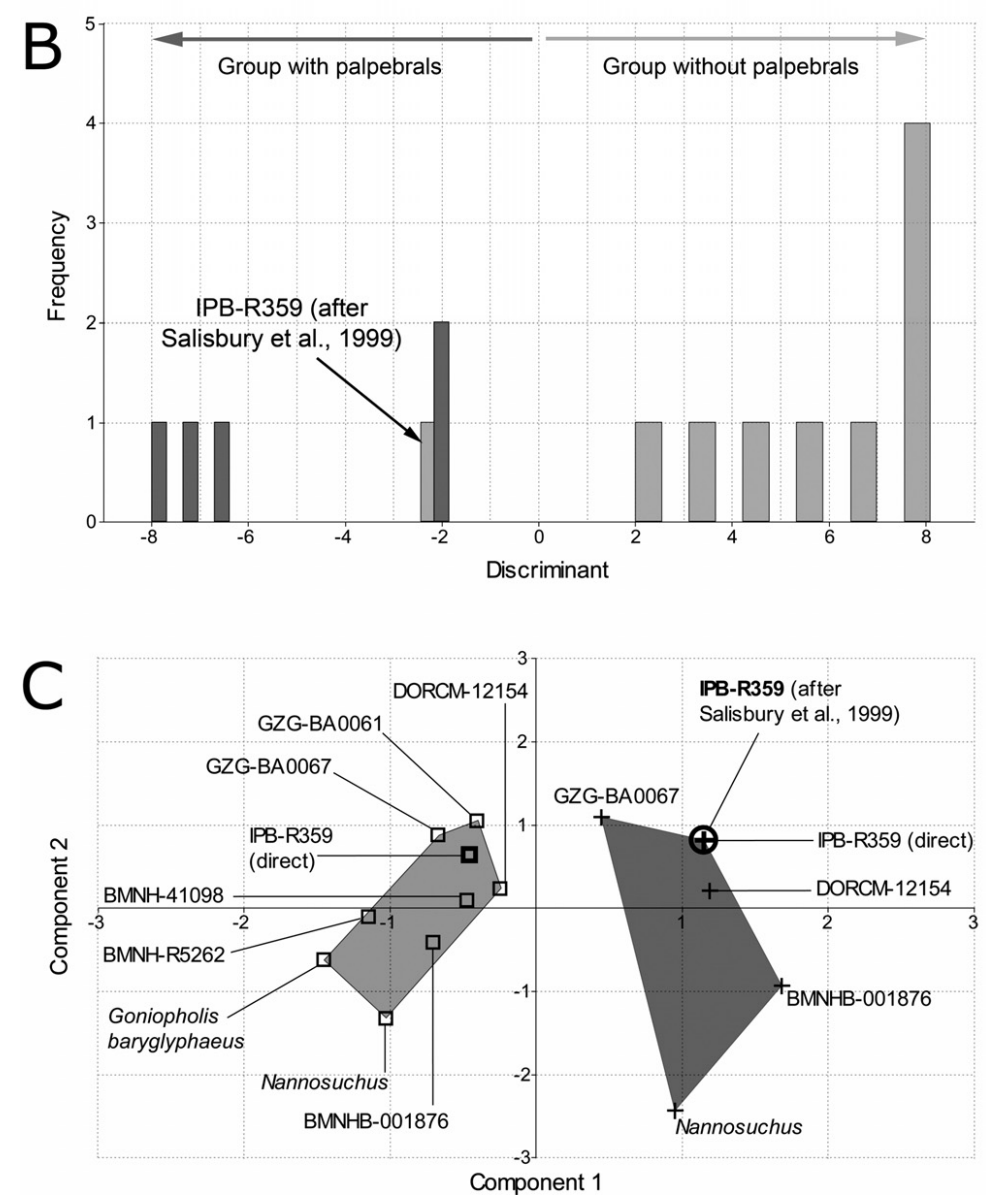

al., 2006; Turner and Buckley, 2008) and considered equally as state (0) in all Neosuchia. According to our observations, Goniopholis has a small additional edge facing anteriorly, but masked by the palpebral. This makes the postor-bital a three-edged structure, where the anterior edge faces rostrally (contacting the palpebral), the middle edge faces rostrolat-erally, and the posterior edge faces laterally. This morphology, as described here, is consistent with Clark's (1994) state (1) "(dorsal part of postorbital) with an anterolaterally facing edge." The only other neosuchians where this condition was identified during this study are Nannosuchus and Pholidosaurus, although it may occur in Amphicotylus and other goniopholidid taxa. Other specimens (BMNH R.3876, IRSNB R47, 
and BMNHB 001876) certainly correspond to Clark's (1994) state (0), lacking the 'an-terolaterally oriented edge.'

In Goniopholis and BMNHB 001876 a robust anterolateral process originates from the main body of the postorbital, at the posterior anterolateral corner of the dorsal surface, between the anterolateral and the lateral faces (see Hulke, 1878; Salisbury, 2002). This process is very similar to the structure found in Pholidosaurus, being approximately twice as long as wide, and rounded dorsally. The process found in BMNH R.3876 and IRSNB R47 is also robust, but contrasts with all other taxa by its extreme elongation (Fig. VIII.7; = spine-like processus rostralis of postorbital, Salisbury et al., 1999:143). As the process projects anteriorly, it shields the orbit laterally and introduces a strong dorsal component to the orientation of the orbit, preventing lateral vision, while protecting the eyes. A somewhat similar condition is found in Sarcosuchus, where the process is also long, but not to the same extent. Elosuchus and dyrosaurids (Broin and Taquet, 1966; Sereno et al., 2001; Broin, 2002; Jouve et al., 2006) have a much shorter process (as in Goniopholis), but projecting anteroventrally and almost reaching the dorsal edge of the jugal, therefore also partially shielding the orbit (unlike Goniopholis).

Among the taxa examined, Nannosuchus seems to have the shortest process, hardly projecting anteriorly. In fact, it is the only species of those studied where the process is gracile, laminar in structure, differing from all other goniopholidids, pholidosaurids, and dyrosaurids. It is not clear whether this condition arises from an immature stage, or if this truly represents a consistent morphological character of the species. A very short and laminar process is apparently present also in Amphicotylus, Denazinosuchus, Sunosuchus, and Eutretauranosuchus.

Postorbital Bar

The postorbital bar is a composite structure, with contributions also from the jugal and ectopterygoid. Regarding the orbital limits, the bar constitutes the posterior border in lateral aspect. In Goniopholis the bar is similar to other basal mesoeucrocodylian groups (including Amphicotylus, Eutretauranosuchus, Sunosuchus), inclined dorsomedially, unornamented, subdermal, and cylindrical (subcircular cross-section).

Specimens BMNH R.3876, IRSNB R47, and BMNHB 001876 have a mostly vertical bar (although the structure is fairly damaged in the latter), as in Pholidosaurus, Vectisuchus, Sarcosuchus, and dyrosaurids (e.g., Buffetaut and Hutt, 1980; Sereno et al., 2001, Jouve et al., 2006). In Nannosuchus the postorbital region is damaged, and dorsoventral compression seems to have produced some degree of lateral deformation. Therefore, the left bar is exposed, but the bar at the right side is hidden under the dorsal body of the postorbital. Nonetheless, there is no inclination in the anteroposterior axis, and Nannosuchus most likely had a fully vertical postorbital bar, as in BMNH R.3876 and IRSNB R47.

Identification of sutures is difficult in the bar, and the ectopterygoid-postorbital contact is unknown (bar damaged, or not visible) in all specimens of G. simus, DORCM 12154, BMNH R.3876, 
and IRSNB R47. In BMNHB 001876 it is possible to locate the ectopterygoid-postorbital contact on the medial face of the bar. In contrast, the ectopterygoids of G. baryglyphaeus (MG 26019, left jugal; MG 26020, right jugal, ectopterygoid, and maxilla) feebly contribute to the bar, and never reach the postorbital.

Jugal Anterior Ramus

In Crocodylomorpha the jugal is a triradiate element where the anterior process usually defines the ventral border of the orbit, whereas the ascending process contributes to the postorbital bar, bounding the orbit posteriorly. The anterior jugal ramus of Goniopholis simus has a flattened lateral surface, expanding dorsally and ventrally. It also extends anteriorly, dorsal to the maxillary depressions. The dorsal margin projects dorsally and progresses to an area anterior to the orbit, below the anterior end of the upper periorbital crest. At this point, the dorsal edge of the jugal flares laterally and ends (Fig. VIII.7).

In DORCM 12154 (G. aff. simus) the area of the lacrimal-jugal suture is extremely well preserved on both sides, with the lacrimal-jugal suture running diagonally from the anteroventral corner of the orbit (medial to the dorsal margin of the jugal) to the anterior-most tip of the upper periorbital crest. Because the dorsal margin of the jugal extends anterior to the orbit and flares laterally to this suture, it actually ends on the laterodorsal surface of the jugal, forming a crest (i.e., lower periorbital crest). The lacrimal-jugal suture seems to be fused in many specimens of Goniopholis simus (BMNH R.5814, BMNH 5262, GZG.BA.0061), but this problem may be the result of poor preservation (see Supplementary Data 1). In GZG.BA.0067 the rostral part of the lacrimal-jugal contact is clearly visible but becomes indistinct immediately in front of the anteroventral corner of the orbit. From close examination, it can be inferred, however, that the configuration is similar to that in DORCM 12154. Salisbury et al. (1999:fig. 6) reconstruct the same suture of the left side of BMNH 41098 in a slightly more lateral position, although still medial to the lower periorbital crest. Unfortunately, the anterior corner of the orbit of the type of $G$. baryglyphaeus is heavily damaged (Schwarz, 2002). The interpretation of sutures in aff. Go-niopholis spp. (BMNH R.3876, IRSNB R47, BMNHB 001876) and Pholidosaurus is consistent with Goniopholis. Furthermore, this configuration is also found in basal crocodylomorphs, e.g., Hemiprotosuchus (Bonaparte, 1971) and is plesiomorphic within the group. The opposing morphology (i.e., jugal dorsal margin receded; ventral extension of lacrimal; prefrontal projecting ventrally to the anterior border of the orbit) can be found in dy-rosaurids and thalattosuchians.

The lower margin of the jugal smoothly continues to the alveolar margin. Neurovascular foramina may be present on the ju-gal surface, near the alveolar margin of the maxilla, but in most specimens of Goniopholis and related taxa preservation hinders the identification. At least two foramina (typically three to five) are present in basal neosuchians (Pholidosaurus, dyrosaurids, Bernissartia, Hylaeochampsa) and all extant taxa, facing ventrally to lateroventrally (Andrade and Bertini, 2008; 
but see also Brochu, 1999). At least G. baryglyphaeus (MG 26019, MG 26020) has a depressed area near the ventral edge of each jugal, below the orbit, where at least two putative foramina can be identified. This depressed area may be a unique characteristic of $G$. baryglyphaeus, and is present on both sides of the type, consistently in the same relative position.

\section{Results of Morphometric Analysis}

The relative interorbital distance of IPB R359, as conceived by Salisbury et al. (1999), is wider than any other goniopholidid included in the study, regardless of skull length or taxonomic affinity. The specimen plots near 'Group 1' in all cases analyzed (Supplement Data 1), which is more intuitively understood when interorbital distance is evaluated relative to the width of the skull table (Fig. VIII.8A). The interorbital distance of this specimen represents $57 \%$ of the skull table, whereas other goniopholidids have a substantially narrower interorbital distance (32\%-50\%). The value for IPB R359 (Salisbury et al., 1999) was identified as the furthest when sampled in 'Group 1' (Grubbs, 1969), and also as statistically different from 'Group 1' (or from a combined sample of Groups 1 and 2) by parametric and non-parametric tests (see Hammer and Harper, 2006). Multivariate analysis provides further support for this difference between IPB 359 (Salisbury et al., 1999) and 'Group 1.' Discriminant analysis (Fig. VIII.8B) rejects IPB R359 (Salisbury et al., 1999) as part of 'Group 1,' and resets it into 'Group 2' (Supplement Data 2). A PCA scatter plot summarizes the results from all relative measurements evaluated (Fig. VIII.8C).

On the other hand, direct measurements of IPB R359 (after identification of palpebrals) provides a much narrower interorbital distance $(72.5 \mathrm{~mm} ; 39 \%$ of skull table width) that fits well within 'Group 1' (statistical analysis, scatter plots, PCA), and is not reclassified into 'Group 2' by the discriminant analysis. Goniopholis baryglyphaeus, with a relative interorbital distance of $43 \%$ of skull table width, also fits well within 'Group 1'.

Based on this analysis, the value for interorbital distance provided by Salisbury et al. (1999) deviates from the expected values for our sample of goniopholidids. Although the sample is restricted, it is clear that the interorbital distance provided by Salisbury et al. (1999) approaches closely the values where palpebrals were considered as part of the interorbital width ('Group 2'), whereas it deviates from values where the palpebrals are not considered ('Group 1').

\section{Discussion}

The Problematic Identification of Palpebrals in Goniopholis

The interpretation of Goniopholis simus IPB R359 is the key in resolving discrepancies in the periorbital morphology of go-niopholidids. The reconstruction by Salisbury et al. (1999) considered a dorsal prefrontal-postorbital contact that fully isolated the frontal from the orbit, and identified 
an isolated fragmentary element set over the lacrimal border of the orbit as a palpebral. Four main problems occur with this interpretation: (1) the orbits are subcircular, and have a different orientation than the triangular profile of orbits found in other specimens of $G$. simus, including the holotype (right orbit); (2) there is no visible facet for the attachment of a palpebral, although such facet is present and evident in other specimens of G. simus; (3) periorbital crests do not form the margin the orbit in IPB R359 and are located medially to it, contrasting to all other specimens of $G$. simus; and (4) the interorbital distance presented by Salisbury et al. (1999) is far too wide when compared with other goniopholidids. Furthermore, the putative palpebral of IPB R359 (Salisbury et al., 1999) is not consistent with the palpebral found in GZG.BA.0067 (Fig. VIII.4). The study of the IPB R359 cast provided evidence for the presence of a palpebral by means of a suture with the prefrontal (Fig. VIII.3).

A reanalysis of the morphology of the right orbit of the holotype (BMNH 41098) further demonstrates that the prefrontal does not meet the postorbital. Although the medial corner of the orbit is partially worn, the damage does not affect the frontal on its dorsal surface and the border is preserved as it reaches the orbit (Fig. VIII.2). The prefrontal-postorbital contact shown by Salisbury et al. (1999) on the badly damaged left orbit only reflects the morphology on the ventral surface of the interorbital bar, and does not clarify how the frontal relates to these elements dorsally or laterally. Nonetheless, the prefrontal-postorbital contact is present in G. simus (Salisbury et al., 1999). Currently, this condition is autapomorphic for this species, but needs to be clar-ified in other taxa, particularly in goniopholidids.

The study of IPB R359 and BMNH 41098 are congruent, in dismissing the presence of a prefrontal-postorbital contact on the skull roof and the exclusion of the frontal from the orbit. The asymmetry of the orbits of GZG.BA.0067 evidences the presence of the left palpebral and of a prefrontal-palpebral suture. Other specimens (GZG.BA.0061 and the cast BMNH R.5262), where palpebrals are not preserved, have the primary medial and posterior orbital borders set at an acute angle (giving the orbit its triangular profile), the upper periorbital crest margining the orbit, and facets for palpebral attachment exposed. The hypothetical exclusion of the palpebrals from IPB R359 immediately solves most problems with the original interpretation of the specimen: the orbit assumes a triangular profile, and the proximity between the upper periorbital crests and the primary border of the orbit becomes evident (Fig. VIII.1D). It also explains the 'absence' of palpebral attachment facets (covered by the palpebrals) and provides an interorbital distance (39\% of skull table width) well within the range expected for Goniopholis (39\%-50\%) and Goniopholididae (32\%-50\%).

The original description of G. baryglyphaeus by Schwarz (2002) poses a different problem, because the palpebral facets are visible, upper periorbital crests are set next to the orbital margin, the triangular profile of the orbit is evident, and the interorbital distance ( $43 \%$ of skull table) is well within the range expected in the genus (39\%-50\%). A combination of very smooth and inconspicuous sutures, and a damaged bony surface complicates the observation of the specimen, as previously described. It was only possible to recognize the participation of the frontal in the orbit on the right side of the specimen, where the true morphology is not obscured by preservation 
problems.

The new observations on periorbital morphology imply in a revised diagnosis at least for G. simus and G. baryglyphaeus, which is made available in the supplementary file (Supplementary Data 1). Furthermore, the presence of the same morphology in G. simus, G. baryglyphaeus, and Goniopholis DORCM 12154 points towards a common pattern in the genus. In this pattern, the true (primary) dorsal border of the orbit, subtriangular and dorsolaterally oriented, becomes evident when the palpebral is absent. The palpebral is triangular in shape and well ornamented with shallow pits. When present, it creates a new functional border of the orbit, which assumes a subcircular profile and more lateral orientation, and the frontal becomes completely isolated from the functional border, as in IPB R359, but also in Nannosuchus BMNH 48217 and the Hulke specimen (BMNHB 001876).

Diversity and Homology in European Goniopholidids

The diversity of forms among European goniopholidids is clearly demonstrated by periorbital morphology. Considering only the taxa analyzed in this study, periorbital morphology allows distinction of at least four main patterns, providing information to characterize individual taxa (e.g., Goniopholis baryglyphaeus) and supraspecific groups.

The extensive palpebral contact with the medial orbit border, the presence of scars for palpebral attachment, as well as periorbital and transfrontal crests, the restricted participation of the frontal in the orbit, and orbits with a primary triangular profile are among the features that clearly differentiate G. simus, G. baryglyphaeus, and Gonipholis DORCM 12154 from all other taxa. Nonetheless, some of these features are not unique to Goniopholis, and closely approach Nannosuchus and the other undescribed goniopholidids.

The Hulke specimen (BMNHB 001876) stands alone among goniopholidids in combining a more common distribution of periorbital elements, unique topographical features of the frontal (tuberous hump, no crests, anterior process of frontal unleveled with main body) and its distinguishable longer rostrum (see Hulke, 1878; Fig. VIII.7C). Not only does this material constitute a new taxon (contra Hulke, 1878; as in Salisbury, 1998, 2002; Salisbury et al., 1999), but it also represents a peculiar pattern in Goniopholididae.

Despite great similarities with other Goniopholis and related forms, Nannosuchus has an unusual combination of periorbital characteristics (Fig. VIII.7D) that allows its differentiation, such as the vertical postorbital bar (inclined in Goniopholis and other taxa), and triangular palpebral and anterior process of frontal (different from aff. Goniopholis BMNH R.3876 and IRSNB R47). Although the key specimen (BMNH 48217) is possibly not an adult (e.g., Joffe, 1967), such differences cannot be explained by ontogeny alone (as in Salisbury, 2002), and assignment to any other goniopholidid taxon, either from the PLG or elsewhere, is not supported by our observations. A new full revision of the material, including undescribed BMNH specimens, is therefore needed. 
A fourth distinctive type of morphology (Fig. VIII.7E) is shared by BMNH R.3876 and IRSNB R47, allowing immediate differentiation from other forms (as in Salisbury, 2002). This includes the highly constricted anterior frontal process, small palpebrals deeply inserted in the medial border of the orbit, vertical postor-bital bar (shared with Nannosuchus), and elongate anterolateral process of postorbital. The presence of this postorbital process is often taken as a distinctive characteristic of Goniopholididae, but it is in fact present in several other taxa (pholidosaurids and dyrosaurids), where it seems to reinforce the structure of the orbit at its posterolateral edge. This process is usually short and robust, but it is gracile in Nannosuchus, and extraordinarily elongate in BMNH R.3876 and IRSNB R47. At least in BMNH R.3876 and IRSNB R47 this process broadly shields the orbit laterally, a condition paralleled by Sarcosuchus.

Similar aspects of periorbital morphology can also be found in Sunosuchus, Pholidosaurus, Sarcosuchus, Elosuchus, and Vectisuchus. However, at least dyrosaurids, thalattosuchians, and part of the Goniopholididae (Eutretauranosuchus, Calsoyasuchus) seem to lack a prefrontal-postorbital 'notch' at the medial border of the orbit, and the entire anterior border of the postorbital is obliquely oriented, facing anterolaterally. Unfortunately, most aspects of the periorbital morphology (particularly those involving the the palpebral-orbit association) have been mostly ignored in pholidosaurids, dyrosaurids, (North American and Asian) goniopholidids, and other related groups, and it is unclear which of these taxa share the same morphology.

Convergence in the Palpebral Attachment in Crocodylomorpha

The extensive suturing of palpebrals to the orbital border is characteristic of Goniopholis and related forms, but not exclusive to them. Among all crocodylomorphs, a similar condition is present in protosuchids (e.g., Protosuchus, Hemiprotosuchus; see Bonaparte, 1971), peirosaurids (e.g., Lomasuchus; see Gasparini et al., 1991), and baurusuchids (e.g., Stratiotosuchus; see Riff, 2003; Pinheiro et al., 2008), constituting good examples of convergent evolution. In these groups, palpebrals are extensively sutured to the primary medial border of the orbit and at least in peirosaurids the outline of the palpebral can be remarkably similar. Evidently, there is a different arrangement of elements in both groups (e.g., in Lomasuchus the posterior palpebral is present and contacts the anterior palpebral extensively at its posterior end, whereas the anterior palpebral barely contacts the postorbital). This condition implies that the palpebral is fully integrated with other skull elements, and therefore originally had very limited mobility, if any at all.

The arrangement contrasts with most other crocodylomorphs, including all extant taxa, where the palpebral is a highly movable element imbedded in the eyelid and feebly connected to the anteromedial margin of the orbit, or only present as a free-floating element. In eusuchians, the upper lid and the retractor bulbi muscle are responsible for closing the eye, as it retracts into the orbit (see Underwood, 1970), and palpebral mobility is necessary to close the eye. The reduced palpebral mobility found in peirosaurids, baurusuchids, protosuchids, and at least part of the goniopholidids implies limited projection/retraction of the eyeball itself. Furthermore, the closure of the eyelid and its relation with associated muscles were also probably different in these forms 
than in extant taxa.

The convergence among goniopholidids, peirosaurids, bau-rusuchids, and protosuchids in the configuration of periorbital elements on the skull roof is remarkable, because they diverged in many aspects of their morphology and paleoecology. Goniopholidids are widely recognized as semiaquatic platyrostral taxa (e.g., Cope, 1878; Dollo, 1883; Hooley, 1907; Salisbury, 2002; Schwarz, 2002), whereas baurusuchids, peirosaurids, and protosuchids are oreinrostral forms, often associated with a fully terrestrial lifestyle from the morphology of limbs, orientation of external naris, and orbits (e.g., Bonaparte, 1971; Gasparini et al., 1991). Furthermore, baurusuchids and peirosaurids are recognized as highly predaceous taxa, and are often considered as part of the Sebecosuchia (see Gasparini et al., 1991; Ortega et al., 2000; Riff, 2003; Pinheiro et al., 2008). It is therefore surprising that groups that diverged in many aspects of their morphology (and possibly also other aspects of their biology) converged in this particular aspect. It is possible that the extensive connection of the palpebral to the skull provided mechanical advantage for these taxa, contributing to reduce stress during food acquisition and ingestion (proper biomechanical studies are necessary to test such hypotheses). Conversely, most of these crocodylomorphs are also characterized by robust teeth, well fit to endure high biomechanical stress. Finally, these palpebrals could provide extra protection to the orbit, avoiding injuries during food acquisition or intraspecific interactions.

\section{Conclusions}

In crocodylomorphs, periorbital morphology is a rich source of data, which is particularly true for goniopholidids (see Salisbury et al., 1999; Salisbury, 2002). The present study discusses and clarifies the periorbital morphology in Goniopholididae, exploring the diversity of patterns and the relevance of the data for phylogenetic studies.

The relations of frontal, prefrontal, and postorbital with the orbit are re-evaluated in G. simus and G. baryglyphaeus. The reconstruction of periorbital elements in Goniopholis simus IPB R359 (Salisbury et al., 1999) is incongruent in several aspects to the morphology seen in other specimens of this taxon. The apparently unique morphology of IPB R359 is the result of the presence of in situ palpebrals in IPB R359, confirmed by abundant evidence, including the identification of the palpebral-prefrontal suture in the specimen. Morphometric analysis was used to further demonstrate that the interorbital width previously attributed to the specimen is far broader than expected for European gonio-pholidids, but can be explained by the presence of in situ palpebrals. The original interpretation G. baryglyphaeus (see Schwarz, 2002) is also not confirmed, and direct evidence is presented that the frontal takes part in the orbit. In this specimen, palpebrals are absent and the relative interorbital width is within a consistent range of values for goniopholidids, and it is the preservation that complicates the identification of the actual periorbital morphology.

This leads to two main consequences in the interpretation of Goniopholis: (1) the prefrontal does not contact the postorbital on the dorsal skull roof (although this does not preclude a contact ventral to the frontal), and (2) the frontal takes part in the orbit in all European Goniopholis. In 
European Goniopholis (G. simus, G. baryglyphaeus, Goniopholis DORCM 12154), sutures are arranged in such a way that if the prefrontal-palpebral contact is not identified or preserved, the palpebral can easily be mistaken for the posterolateral end of the prefrontal (Fig. VIII.1). Provided the medial border of the orbit is not damaged or worn, the absence' of the scar for the attachment of palpebral is a practical indicator that this element is preserved in situ. The posterior (i.e., prefrontal) section of the upper periorbital crest can be used as a reliable landmark to help locate and identify the primary border of the orbit, and the end of the sutures of prefrontal with frontal and lacrimal. This new interpretation is consistent with a previous reconstruction of $G$. simus by Karl et al. (2006). Nonetheless, the participation of the frontal in the dorsal margin of the orbit is indeed narrow in European Goniopholis (but not in Nannosuchus and other taxa).

The broad comparative study of three specimens (BMNHB 001876, BMNH R.3876, IRSNB R47) supports previous observations that these specimens are new unnamed taxa (Salisbury, 1998, 2002; Salisbury et al., 1999; Schwarz, 2002) that can be differentiated from Goniopholis and should not be included in this genus. Furthermore, the Bernissart specimen (IRSNB R47; = G. simus in Dollo, 1883) is remarkably similar to BMNH R.3876 (see Salisbury et al., 1999). Other crocodylomorphs (i.e., pro-tosuchids, peirosaurids, baurusuchids) share a similar morphology with European goniopholidids, where the anterior palpebral is extensively sutured and integrated into the primary orbital border, creating a secondary functional orbital border that does not include the frontal. However, this morphology is not shared by non-European goniopholidids, supporting the idea that these were not closely related to the European taxa (see Allen, 2007).

This revision also provides information to support the description of new taxa (aff. Goniopholis spp. and Goniopholis aff. simus) and Nannosuchus. Regardless of a plethora of previous studies (e.g., Salisbury, 2002; Schwarz, 2002; Tykoski et al., 2002; Lauprasert et al., 2007), goniopholidids have long been overlooked on both sides of the Atlantic. The existence of several specimens of Goniopholis simus provides elements for an extended revision of this taxon. Important problems remain to be explored in Nannosuchus and the non-European goniopholidids (Amphicotylus, Denazinosuchus, Eutretauranosuchus). Conversely, the very definition of the genus Goniopholis needs to be re-evaluated. This work is part of a broader series of studies, focused on European taxa, with the objective of revising the poorly explored Goniopholididae.

\section{Acknowledgments}

The authors are indebted to A. C. Milner, L. Steel, H. Ketchum, S. Chapman, and P. Barrett (BMNH), J. Cooper (BMNHB), M. Reich (GZG), S. Kaiser (IPB), E. Sterbaut, A. Folie, and T. Smith (IRSBN), D. Schwarz-Wings (MB), M. Ramalho and J. Sequeira (MG), and B. Battail and V. Bouetel (MNHN) for access to specimens used in this study. Michael J. Benton (BRSUG) kindly revised an early version of the text, and S. W. Salisbury (University of Queensland) and D. Schwarz-Wings (MB) provided detailed critiques of the original manuscript. M.B.A. extends further gratitude to R. Edmonds (Jurassic Coast Heritage Team) and P. Ensom (DORCM) for access to DORCM 12154; D. SchwarzWings for the generous exchange of ideas; P. Gill, M. Ruta, and M. Sakamoto (BRSUG) for their 
critique and advice on the use of morphometric data; R. Schouten (BRSUG) for advice on preparation of DORCM 12154; S. Powell (BRSUG) for valuable directions on macrophotography. J.J.H. acknowledges J. Kimmig for providing especially valuable support and information; and M. Reich and T. Stegemann (GZG) for logistical support with the loan of IPB R359.

Goniopholis DORCM 12154 was recovered with the kind permission of the Swanage Town Council and Natural England, and prepared with financial support from the Jurassic Coast Trust (England). M.B.A. receives a scholarship from Conselho Nacional de Desenvolvimento Científico e Tecnológico (CNPq Proc. $n^{\circ}$ 200381/2006-7), Brazil; and also benefited from the following small awards: (a) the Bob Savage Memorial Fund (BRSUG), at the BMNH and MG; (b) Synthesys project FR-TAF-4858, at MNHN; (c) Synthesys project BE-TAF-5357, at RBINS-IRSNB/RMCA/NBG. J.J.H. benefited from grants from Synthesys project GB-TAF-4204, at BMNH. Synthesys (http://www.synthesys.info/) is financed by the European Community Research Infrastructure Action under the FP6 "Structuring the European Research Area Programme."

\section{Literature Cited}

Allen, E. 2007. Re-description and systematic reanalysis of the goniopholidid crocodile Goniopholis stovalli from the Morrison Formation of Oklahoma. Journal of Vertebrate Paleontology 27(3, Supplement):40A.

Andrade, M. B., and R. J. Bertini. 2008. A new Sphagesaurus (Mesoeucrocodylia: Notosuchia) from the Upper Cretaceous of Monte Alto City (Bauru Group, Brazil), and a revision of the Sphagesauridae. Historical Biology 20:101-136.

Andrade, M. B., R. Edmonds, M. J. Benton, and R. Schouten. In press. A new Berriasian species of Goniopholis (Mesoeucrocodylia, Neosuchia) from England, and a review of the genus. Zoological Journal of the Linnean Society.

Andrade, M. B., R. Edmonds, M. J. Benton, and R. Schouten. 2008. A Goniopholis skull from the Intermarine Member (Berriasian, Lower Cretaceous), Swanage (England); pp. 13-14 in Symposium of Vertebrate Palaeontology and Comparative Anatomy, 56, Abstracts; Dublin, University College Dublin/National Museum of Ireland, Dublin, 2-6 September 2008.

Andrews, C. W. 1913. On the skull and part of the skeleton of a crocodile from the Middle Purbeck of Swanage, with the description of a species (Pholidosaurus laevis), and a note on the skull of Hylaeochampsa. Annals and Magazine of Natural History 8:485- 494.

Benton, M. J., and J. M. Clark. 1988. Archosaur phylogeny and the relationships of Crocodylia; pp. 295-338 in M. J. Benton (ed.), The Phylogeny and Classification of the Tetrapods, Volume 1. Clarendon Press, Oxford, U.K.

Bonaparte, J. F. 1971. Los tetrapodos del sector superior de la Formacion Los Colorados, La Rioja, Argentina. (Triásico Superior). Opera Lilloana, San Miguel de Tucumán 22, 184 pp.

Brochu, C. A. 1999. Phylogenetics, taxonomy, and historical biogeography of Alligatoroidea. Journal of Vertebrate Paleontology 19(2, Supplement):9-100.

Broin, F. L. 2002. Elosuchus, a new genus of crocodile from the Lower Cretaceous of the North of Africa. Comptes Rendus Palevol 2002:275-285. 
Broin, F. L., and P. Taquet. 1966. Découverte d'un crocodilien nouveau dans le Crétacé inférieur du Sahara. Comptes Rendus de l'Académie des Sciences de Paris, Ser. D 262:2326-2329.

Buffetaut, E., and S. Hutt. 1980. Vectisuchus leptognathus, n.g. n.sp., a slender-snouted goniopholidid crocodilian from the Wealden of the Isle of Wight. Neues Jahrbuch für Geologie und Paläontologie, Monatshefte 1980:385-390.

Buffrénil, V. 1982. Morphogenesis and bone ornamentation in extant and extinct crocodilians. Zoomorphology 99:155166.

Clark, J. M. 1986. Phylogenetic relationships of the crocodylomorph ar-chosaurs. Unpublished Ph.D. Dissertation. University of Chicago, Chicago, Illinois, $556 \mathrm{pp}$.

Clark, J. M. 1994. Patterns of evolution in Mesozoic Crocodyliformes; pp. 84-97 in N. C. Fraser and H.-D. Sues (eds.), In the Shadows of Dinosaurs: Early Mesozoic Tetrapods. Cambridge University Press, London.

Clements, R. G. 1993. Type-section of the Purbeck Limestone Group, Durlston Bay, Swanage, Dorset. Proceedings of the Dorset Natural History and Archaeological Society 114:181-206.

Cope, E. D. 1878. Descriptions of new extinct Vertebrata from the Upper Tertiary and Dakota Formations. Bulletin of the United States Geological and Geographical Survey of the Territories 4:379- 396.

Dollo, L. 1883. Première note sur les crocodilians de Bernissart. Bulletin du Musée Royal d'Histoire Naturelle de Belgique 2:309-338.

Dunker, W. 1843-1844. Über den norddeutschen sogenannten Wälderthon und dessen Versteinerungen. Programm der höheren Gewerbeschule in Cassel, 46 pp.

Gasparini, Z., L. M. Chiappe, and M. Fernandez. 1991. A new Senonian peirosaurid (Crocodylomorpha) from Argentina and a synopsis of the South American Cretaceous crocodilians. Journal of Vertebrate Paleontology 11:316-333.

Grubbs, F. 1969. Procedures for detecting outlying observations in samples. Technometrics 11:1-21.

Hammer, Ø., and D. A. T. Harper. 2006. Paleontological Data Analysis. Blackwell Publishing, Oxford, U.K., 351 pp.

Hammer, Ø., D. A. T. Harper, and P. D. Ryan. 2001. PAST: Paleontological statistics software package for education and data analysis. Palaeontologia Electronica 4:1-9.

Hooley, R. W. 1907. On the skull and greater portions of the skeleton of Goniopholis crassidens from the Wealden shales of Atherfield (Isle of Wight). Quarterly Journal of the Geological Society 63:50-63.

Hornung, J. J., and M. Reich. 2006. The "Wealden" collection of Max Ballerstedt (1857-1945)—undisclosed treasures from the Early Cretaceous of northwestern Germany. Berichte des Instituts für Geowissenschaften, Christian-AlbrechtsUniversität Kiel 22:40-41.

Hornung, J., M. Andrade, and M. Reich. 2009. Are Goniopholis crassidens and G. simus different species of crocodilians? New postcranial evidence solving a taxonomic riddle. Journal of Vertebrate Paleontology 29(3, Supplement):117A.

Hulke, J. W. 1878. Note on the two skulls from the Wealden and Purbeck formations indicating a new subgroup of Crocodilia. Quarterly Journal of the Geological Society 34:377-382. 
Joffe, J. 1967. The dwarf crocodiles of the Purbeck Formation, Dorset: a reappraisal. Palaeontology 10:629-639.

Jouve, S., M. Iarochene, B. Bouya, and M. Amaghzaz. 2006. A new species of Dyrosaurus (Crocodylomorpha, Dyrosauridae) from the early Eocene of Morocco: phylogenetic implications. Zoological Journal of the Linnean Society 148:603-656.

Kälin, J. A. 1933. Beiträge zur vergleichenden Osteologie des Crocodilidenschädels. Zoologisches Jahrbuch, Anatomie 57:535-714.

Karl, H.-V., E. Gröning, C. Brauckmann, D. Schwarz, and N. Knötschke. 2006. The Late Jurassic crocodiles of the Langenberg near Oker, Lower Saxony (Germany), and description of related materials (with remarks on the history of quarrying the "Langenberg Limestone" and “Obernkirchen Sandstone"). Clausthaler Geowissenschaften 5:59-77.

Koken, E. 1887. Die Dinosaurier, Crocodiliden und Sauropterygier des norddeutschen Wealden. Palaeontologische Abhandlungen 3:309-419.

Lauprasert, K., G. Cuny, E. Buffetaut, V. Suteethorn, and K. Thirakhupt. 2007. Siamosuchus phuphokensis, a new goniopholidid from the Early Cretaceous (ante-Aptian) of northeastern Thailand. Bulletin de la Société Geológique de France 178:201-216.

Lucas, S. G., and R. M. Sullivan. 2003. A new crocodilian from the Upper Cretaceous of the San Juan Basin, New Mexico. Neues Jarbuch für Geologie und Paläontologie, Monatshefte 2003:109-119.

Mansell-Pleydell, J. C. 1888. Fossil reptiles of Dorset. Proceedings of the Dorset Natural History and Antiquarian Field Club 9:1-40.

Meyer, H. von. 1841. Pholidosaurus schaumburgensis, ein Saurus aus dem Sandstein der Wald-Formation NordDeutschlands. Neues Jahrbuch für Mineralogie, Geologie und Petrefakten-Kunde 1841:443-445.

Mook, C. C. 1942. Skull characters of Amphicotylus lucasii Cope. American Museum Novitates 1165:1-5.

Mook, C. C. 1964. New species of Goniopholis from the Morrison of Oklahoma. Oklahoma Geology Notes 24:283-287.

Mook, C. C. 1967. Preliminary description of a new goniopholid crocodilian. Kirtlandia 2:1-5.

Ortega, F., Z. Gasparini, A. D. Buscalioni, and J. O. Calvo. 2000. A new species of Araripesuchus (Crocodylomorpha, Mesoeucrocodylia) from the Lower Cretaceous of Patagonia (Argentina). Journal of Vertebrate Paleontology 20:5776.

Owen, R. 1842. On British fossil reptiles. Reports of the British Association for the Advancement of Science 11:60-204.

Owen, R. 1878. Monograph on the fossil Reptilia of the Wealden and Purbeck formations-Crocodilia (Goniopholis, Pterosuchus, and Suchosaurus). Palaeontographical Society Monograph 7:1-15.

Owen, R. 1879. Monograph of the fossil Reptilia of the Wealden and Purbeck formations-Crocodilia (Goniopholis, Brachydectes, Nan-nosuchus, Theriosuchus, and Nuthetes). Palaeontographical Society Monograph 9:1-19.

Pinheiro, A. E. P., R. J. Bertini, M. B. Andrade, and R. G. Martins Neto. 2008. New specimen of Stratiotosuchus maxhechti (Baurusuchidae, Crocodyliformes) from the Adamantina Formation (Upper Cretaceous), Southeastern Brazil. Revista Brasileira de Paleontologia 11:37-50. 
Pol, D., and S. Apesteguia. 2005. New Araripesuchus remains from the early Late Cretaceous (Cenomanian-Turonian) of Patagonia. American Museum Novitates 3490:1-38.

Riff, D. 2003. Descrição morfológica do crânio e mandíbula de Stratiotosuchus maxhechti (Crocodylomorpha, Cretáceo Superior do Brasil) e seu posicionamento filogenético. M.Sc. thesis. Universidade Federal do Rio de Janeiro, Rio de Janeiro, $173 \mathrm{pp}$

Salisbury, S. W. 1998. The long-lost crocodilian of Mr Willett; in Symposium of Vertebrate Palaeontology and Comparative Anatomy, 46; Abstracts; Bournemouth University, Bournemouth.

Salisbury, S. W. 2002. Crocodilians from the Lower Cretaceous (Berriasian) Purbeck Limestone Group of Dorset, Southern England; 121-144 in A. R. Milner and D. J. Batten (eds.), Life and En-viroments in Purbeck Times. Special Papers in Palaeontology 68.

Salisbury, S. W., P. M. A. Willis, S. Peitz, and P. M. Sander. 1999. The crocodilian Goniopholis simus from the Lower Cretaceous of NorthWestern Germany; pp. 121-148 in D. M. Unwin (ed.), Cretaceous Fossil Vertebrates. Special Papers in Palaeontology 60.

Salisbury, S. W., R. E. Molnar, E. Frey, and P. M. A. Willis. 2006. The origin of modern crocodyliforms: new evidence from the Cretaceous of Australia. Proceedings of the Royal Society of London B 273:2439-2448.

Schwarz, D. 2002. A new species of Goniopholis from the Upper Jurassic of Portugal. Palaeontology 45:185-208.

Sereno, P. C., H. C. E. Larsson, C. A. Sidor, and B. Gado. 2001. The giant crocodyliform Sarcosuchus from the Cretaceous of Africa. Science 294:1516-1519.

Smith, D. K., E. R. Allen, R. K., Sanders, and K. L. Stadtman. 2010. A new specimen of Eutretauranosuchus (Crocodyliformes, Goniopho-lididae) from the Dry Mesa, Colorado. Journal of Vertebrate Paleontology 30:1466-1477.

Turner, A. H., and G. A. Buckley. 2008. Mahajangasuchus insignis (Crocodyliformes: Mesoeucrocodylia) cranial anatomy and new data on the origin of the eusuchian-style palate. Journal of Vertebrate Paleontology 28:382-408.

Tykoski, R. S., T. B. Rowe, R. A. Ketcham, and M. W. Colbert. 2002. Calsoyasuchus valliceps, a new crocodyliform from the Early Jurassic of Kayenta Formation of Arizona. Journal of Vertebrate Paleontology 22:593-611.

Underwood, G. 1970. The eye; pp. 73-97 in C. Gans and T. S. Parsons (eds.), Biology of Reptilia: Morphology B, Volume 2. Academic Press, London.

Wu, X.-C., D. B. Brinkman, and A. P. Russel. 1996. Sunosuchus junggarensis sp. nov. (Archosauria: Crocodyliformes) from the Upper Jurassic of Xinjiang, People's Republic of China. Canadian Journal of Earth Sciences 33:606-630.

Yans, J., J. Dejax, D. Pons, L. Taverne, and P. Bultynck. 2006. The Iguanodons of Bernissart (Belgium) are middle Barremian to earliest Aptian in age. Bulletin de l'Institut Royale des Sciences Naturelles de Belgique. Sciences de la Terre 76:9195.

Young, C. C. 1948. Fossil crocodiles in China, with notes on dinosaurian remains associated with the crocodiles. Bulletin of the Geological Society of China 28:225-288.

Submitted October 24, 2009; accepted November 13, 2010.

Handling editor: Johannes Müller. 


\section{Supplementary Data 1}

\section{Materials}

Materials used for this study includes specimens of Goniopholis and closely related taxa from the Early Cretaceous of England, Germany and Belgium (Table VIII.1).

Goniopholis simus (Fig. VIII.1) is seen as the hallmark of the genus, and is frequently included in phylogenetic analysis as the key representative of the Goniopholididae (e.g. Benton and Clark, 1988; Clark, 1986, 1994; Ortega et al., 2000; Sereno et al., 2001; Pol and Apesteguia, 2005; Jouve et al., 2006; Turner and Buckley, 2008). A wide range of specimens comes from England and Germany, as do the specimens included here, but the historical nature of the British specimens often prevents a precise identification of stratigraphic origin, to a specific layer/bed. The type BMNH 41098, along with its complementary slab, BMNH 41098a comes from the Purbeck Limestone Group (PLG; 'Intermarine Beds', Stair Hole Member, Durlston Formation, Berriasian), southern coast of England (Salisbury, 2002). Material of G. simus from Germany (Obernkirchen Sandstone, Bückeberg Formation, mid- to late Berriasian; Lower Saxony) includes a range of specimens from the historical Ballerstedt collection. The "Bonn specimen" (IPB R359) was used by Salisbury et al. (1999) in the redescription of $G$, simus, and its examination is critical, because the specimen was used to provide evidence for the exclusion of frontal from the orbit. Nonetheless, study of the type of G. simus (BMNH 41098) is even more important, since this is the reference material to define the species. Other skulls include two adult specimens (GZG.BA.0061, associated with a partial postcranium; and GZG.BA.0067), mostly preserved. Four casts represent Ballerstedt material, including skulls (BMNH R.5259, R.5262) and a mandible (complementary casts BMNH R.5260 and BMNH R.5261). Of these, BMNH R.5259 corresponds to the cast of GZG.BA.0061, which shows that the specimen was originally more complete, but is approximately $10 \%$ smaller than the original. It is possible that the mandible casts mandible casts (BMNH R.5260, BMNH R.5261) were originated from GZG.BA.0065, an isolated mandible. Unfortunately, the whereabouts of the original of BMNH R.5262 is presently unknown. Although no relation is documented between GZG.BA.0061 and GZG.BA.0065, their casts have the appropriate size to fit each other.

The genus Goniopholis was originally introduced for G. crassidens Owen, 1842, based upon a disarticulated but associated postcranial skeleton with partial mandible and a questionably referred fragmentary skull roof (BMNH 3798, 3799; Salisbury, 2002) from the PLG. Although various specimens from England and Belgium (Barremian-Aptian) have been referred to G. crassidens

(Dollo, 1883; Hooley, 1907), there is no support for these hypotheses (see below). G. crassidens is limited to its type specimen. Conversely, there is growing evidence that $G$. simus is conspecific with G. crassidens, the latter therefore becoming a senior synonym of the former (see Salisbury et al., 1999; Salisbury, 2002; Hornung et al., 2009). However, for practical purposes, here we prefer to retain the use of $G$. simus until this matter can be properly resolved. Currently, we consider that the only unequivocal record of G. crassidens is limited to its type specimen, BMNH 3798. 
Material of Goniopholis baryglyphaeus comes from the coal layer (part of the 'Guimarota Strata') within the Alcobaça Formation (Schwarz, 2002), Portugal. Originally, this material was deposited in Germany, but was recently returned to Portugal and is currently housed by the Museu Geológico in Lisbon (M. M. Ramalho, pers. comm. 2010). Most specimens are fragmentary, and several of the remains are part of a single individual (IPFUB Gui Croc 1; parts numbered from 1/1 to 1/48). These remains received new catalogue numbers (MG 26002 to MG 26045, and MG 26110 to MG 26115) and, therefore, the type of $G$. baryglyphaeus became represented by a range of numbers, instead of a single one. The skull of the type is composed of the main section of the cranium (MG 26014; previously IPFUB Gui Croc 1/1), left jugal (MG 26019; Gui Croc 1/7), and anterior section of the rostrum (MG 26015, MG 26016 and MG 26017; respectively, Gui Croc 1/2, 1/3 and 1/4). This specimen is important because the reconstruction in the original description (Schwarz, 2002: Fig. VIII.3) also depicts a frontal excluded from the orbit. However, the area is damaged and it is difficult to reconstruct the relationships between bones (D. Schwarz-Wings, pers. comm. to MBA, 2009).

A new specimen, DORCM 12154 (Fig. VIII.5), is a skull from an undescribed taxon from southern coast of England. Although its similarities with G. simus are evident, autapomorphic characteristics allow its placement in a new taxon (M. B. Andrade, R. Edmonds, M. J. Benton; unpubl. data, submitted), and the specimen is currently classified as Goniopholis aff. simus. This is the single British Goniopholis that is traceable to a precise bed (129b sensu Clements, 1993; 'Intermarine Beds', Durlston Formation; see Andrade et al., 2008). Although affinities with Goniopholis simus are evident, specific morphologic characteristics allow its placement in a new taxon (M. B. Andrade, R. Edmonds, M. J. Benton; unpubl. data, submitted). The DORCM 12154 specimen is explicitly included in this study because its exceptional preservation provides a valuable element of comparison with G. simus and G. baryglyphaeus.

The specimen BMNHB 001876 (Fig. VIII.7C) was initially considered as Goniopholis simus by Hulke (1878), a position later refuted by Salisbury (1998; ="Mr Willett's crocodilian skull") and Salisbury et al. (1999), with further support by Schwarz (2002) and this study. The provenance of the specimen is actually unknown, but other crocodilian material from that collection always comes from the southern coast of England, making the PLG or the Wealden Group the most likely sources. Therefore, it can be putatively assigned to the Berriasian-Aptian (Lower Cretaceous). Presently, BMNHB 001876 can be classified as aff. Goniopholis sp., as at least two other unnamed materials included in this study. To avoid confusion among these different taxa, BMNHB 001876 will be referred to as the 'Hulke specimen'.

The specimen BMNH R.3876 (Fig. VIII.7E) was initially identified by Hooley (1907) as Goniopholis crassidens Owen, 1842. It comes from the Vectis Formation (Wealden Group, Barremian to early Aptian; Isle of Wight), but actually represents an unnamed taxon (see Salisbury et al., 1999; Salisbury, 2002; Schwarz, 2002; and below), therefore currently classified as aff. Goniopholis sp. To avoid confusion with other materials, this specimen is referred herein as the 'Hooley specimen', or simply BMNH R.3876. The Belgian IRSNB R47 includes a well preserved skull and skeleton. It was identified by Dollo (1883) as Gonopholis simus, but Salisbury et al. (1999) considered it to be a different taxon. In fact, as discussed below, IRSNB R47 shows more affinities with BMNH R.3876 than with any Goniopholis. It comes from the Sainte-Barbe Clays Formation at Bernissart (Dollo, 
1883), mid-Barremian to Early Aptian in age (Yans et al., 2006). In this study, IRSNB R47 is classified as aff. Goniopholis sp., like other undescribed taxa. To avoid confusion with these materials, this specimen is referred herein as the 'Dollo specimen', or simply IRSNB R47.

The "Goniopholis" specimens of Hulke (1878), Dollo (1883) and Hooley (1907) have never been fully included in a published phylogenetic analysis. Only Salisbury et al. (2006) included the information provided by the 'Dollo' and 'Hooley' specimen in a phylogenetic analysis, but the data was used to built a single composite terminal summarizing 'Goniopholis spp.' (along with specimens referred to G. crassidens and G. simus). This study, however, provides no clue on the relationships of these taxa. Preliminary phylogenetic results show that these undescribed taxa constitute a clade of closely related species, not distant from Goniopholis, and that the 'Hooley' and 'Dollo' specimens are sister taxa (M. B. Andrade, R. Edmonds, M. J. Benton; unpubl. data, submitted). The same analysis firmly places Goniopholis DORCM 12154 in a clade with G. simus and G. baryglyphaeus. All specimens here feferred to as aff. Goniopholis can be readily distinguished from any Goniopholis, or even from Nannosuchus and other goniopholidids (see 'Discussion').

Observations on Nannosuchus gracilidens Owen, 1879 (Fig. VIII.3D) are here based on the type skull BMNH 48217). The history of this material is confusing, as it was previously interpreted as a juvenile Goniopholis simus (see Kälin, 1933; Joffe, 1967; Clark, 1986). The taxon was considered a different species by Salisbury et al. (1999) and Salisbury (2002), although still a Goniopholis. In this study, we agree with its status as an independent species, but prefer to refer to this taxon in its original form since there is currently no phylogenetic support for its placement in Goniopholis.

Nannosuchus comes from the 'Beccles Residuary Marls' (untraced beds, either bed 108 sensu

Clements, 1993, or below; see Salisbury, 2002), and is the only goniopholidid from the Worbarrow Member (Lulworth Formation, Southern England). The geological provenance of Nannosuchus contrasts with Goniopholis simus and related forms (Durlston Formation, or overlying layers), supporting the idea that these are indeed not the same species.

Pholidosaurid reference material was also examined and compared whith goniopholidid material. This genus share several characters with Goniopholis simus (e.g., large supratemporal fenestrae/fossae, morphology of teeth, quadrates, paroccipital processes), which makes comparison of periorbital structures relevant. Material from England includes the type specimens of "Petrosuchus laevidens" Owen, 1878 [BMNH 28432; =Pholidosaurus purbeckensis (Mansell-Pleydell, 1888) of Salisbury (2002)] and of Pholidosaurus laevis Andrews, 1913 (BMNH R3414), referred to the Intermarine beds (Durlston Formation). Pholidosaurid material from Germany consists of cast of skull of Pholidosaurus meyeri (Dunker, 1843-44) MB R1966 and comes from the Obernkirchen Sandstone, Bückeberg Formation.

Whenever possible, comparisons are made with other taxa present in the literature. Unfortunately, most other goniopholidids (e.g. Amphicotylus, Denazinosuchus, Eutretauranosuchus, "Goniopholis" stovalli, Siamosuchus, Sunosuchus) do not have well described sutures, or have poorly preserved sutures, and comparisons are introduced only where data is available (e.g., Cope, 1878; Mook, 1942, 1964, 1967; Young, 1948; Wu et al., 1996; Tykoski et al., 2002; Lucas and Sullivan, 2003; Lauprasert et al., 2007; Smith et al., 2010). 


\section{Preservation of the Obernkirchen specimens}

Vertebrate material from the Obernkirchen Sandstone, here represented by G. simus and Pholidosaurus, is characterized by a peculiar preservation in which the original remains are substituted by a soft, argillaceous material, commonly lost during preparation. The remaining cavities within the mature, fine-grained, often silicified sandstone provide an excellent grade of detail, which can be interpreted by the means of artificial casts. The quality of this process allows the use of casts for study, as previously mentioned by Salisbury et al. (1999). However, these casts will document solely the superficial morphology of the specimens. Sutures are only visible if they formed a microrelief on the original bone surface. Tight and inconspicuous periorbital sutures provide very little space for sediment to settle in between bones, a problem which increases with progressive suture obliteration in late ontogenesis. Furthermore, the superficial relief is easily lost (e.g., pre-burial erosion of the bone surface), resulting in an endocast that may not completely reflect the sutural contacts of the original specimens. Since any given cast can only represent as much as the natural mold preserves, and there is no guarantee that any particular structure not seen in the mold is really absent in the original specimen, identification of sutures and structures in such casts is limited. Therefore, it is not surprising that the recognition of contacts in Obernkirchen specimens is debatable, As a general rule, specimens such as G. simus BMNH R.41098, DORCM 12154 , and the type of $G$. baryglyphaeus allow a more accurate identification of sutures, when compared to the Obernkirchen specimens, and their study is favored over the examination of casts.

Vertebrates from the Obernkirchen Sandstone occasionally show damage by tiny cracks, either formed during pre-burial exsiccation of the bones, or brittle deformation due to the collapse of unfilled cavities in the course of early burial and diagenetic stages. However, ductile deformation (i.e., asymmetries, bending) in later diagenetic stages is not known. Many specimens hardly exhibit any damage to individual elements. On the other hand, articulated or partly articulated specimens (e.g. the holotype of Pholidosaurus schaumburgensis von Meyer, 1841, GZG.BA.0049) are very rare and skeletal assemblages often consist of associated, yet but disarrayed remains (e.g. GZG.BA.0061, G. simus; GZG.BA.0102, Pholidosaurus sp.). Crocodilian crania in the Obernkirchen Sandstone normally do not disintegrate, but show transport-related damage in peripheral areas (e.g., disarticulated right premaxilla and mandibular rami in GZG.BA.0061).

The lack of documentation, storage in isolated blocks and homogeneity of the sediment prevents an evaluation of original spatial orientation of most specimens from the Obernkirchen Sandstone. Nonetheless, sedimentological evidence indeed confirms the orientation of IPB R359, embedded with the palatal side upwards (as inferred by Salisbury et al., 1999: 127). In cross-section of the block it is evident that the specimen was deposited at the base of a coarsening-upward, yellowish fine-grained sandstone, exhibiting an irregular-erosive base. Numerous bivalve shell fragments and bone debris forms a basal lag, in which the skull was deposited upside-down. 


\section{Morphometric Analysis}

The presence of in situ palpebrals implies an interorbital distance (IOP) that is proportionally wider than the interorbital distance (in its traditional sense) without palpebrals (IOF). We measured a number of specimens of Goniopholis to demonstrate that the interorbital distance of $106.1 \mathrm{~mm}$, given for IPB R359 by Salisbury et al. (1999), is greater than expected for the group.

The sample was composed of five specimens of G. simus, including the type and IPB R359, and other European taxa (G. baryglyphaeus, Goniopholis DORCM 12154, Nannosuchus, and BMNHB 001876), totaling nine specimens ('Group 1') in which values for interorbital distance excluded palpebrals (IOF). Measurements for five of these specimens were doubled, but with the interorbital distance including the palpebrals (IOP). For practical purposes, these were treated as "new" additional specimens ('Group 2'). In both cases, IPB R359 was measured directly. The final addition is represented once again by IPB R359, but following the measurements provided by Salisbury et al. (1999), only adding the width of the skull table at the postorbitals. The final sample (Table VIII.3; Supplementary Data 2, http://www.vertpaleo.org/publications/JVPContent.cfm) therefore includes three data points for IPB R359, shown in the scatter data and PCA plots: (1) according to the interpretation presented in this paper, and excluding palpebrals; (2) according to the interpretation presented in this paper, but including palpebrals; (3) according to the traditional interpretation, and assuming the palpebrals do not contribute to the interorbital distance.

Overall, only non-significant disagreement was found in a few values previously provided for specimens (Salisbury et al., 1999; Schwarz, 2002). However, assembly of the fragmented type of $G$. baryglyphaeus included for the first time the right maxilla, allowing alignment of dentition on both sides of the skull and repositioning of the two main sections of the skull (see Fig. VIII.6). The new estimate of total skull length $(293.0 \mathrm{~mm})$ is greater than the original value $(281.0 \mathrm{~mm})$.

Raw measurements of interorbital distance (IO) were combined with four other measurements (narial width, rostrum length, skull width at skull table, and span between supratemporal fenestra to occiput) to produce values of relative values (Table VIII.3). These were scored against skull length with the use of PAST software (Hammer et al., 2001; Hammer and Harper, 2006), providing plots of relative interorbital width (Fig. VIII.8; Fig. VIII.1S) in goniopholidids, with and without palpebrals. These show that the interorbital width for IPB R359, given by Salisbury et al. (1999), is set outside the polygon formed by all other specimens (without palpebrals).

Values for relative interorbital width (palpebrals excluded) were tested for normal distribution (Shapiro-Wilk, Jarque-Bera, and Monte Carlo; see Hammer and Harper, 2006) in a sample including Goniopholis, Nannosuchus and the Hulke specimen $(\mathrm{n}=10)$, where p-values only reject normality for values relative to narial width (Supplementary Data 2-3, http://www.vertpaleo.org/ publications/JVPContent.cfm). Overall, it is understood that normality cannot be rejected but, as the small sample size reduces confidence, non-parametric tests are considered the safest approach to analyze this particular dataset. Parametric tests thus constituted a complementary approach, but were not applied to values relative to narial width.

Measurements of all specimens for interorbital width (without palpebrals) were tested for outliers with the use of the (parametric) extreme studentized deviate method (= ESD; Grubb, 1969). 

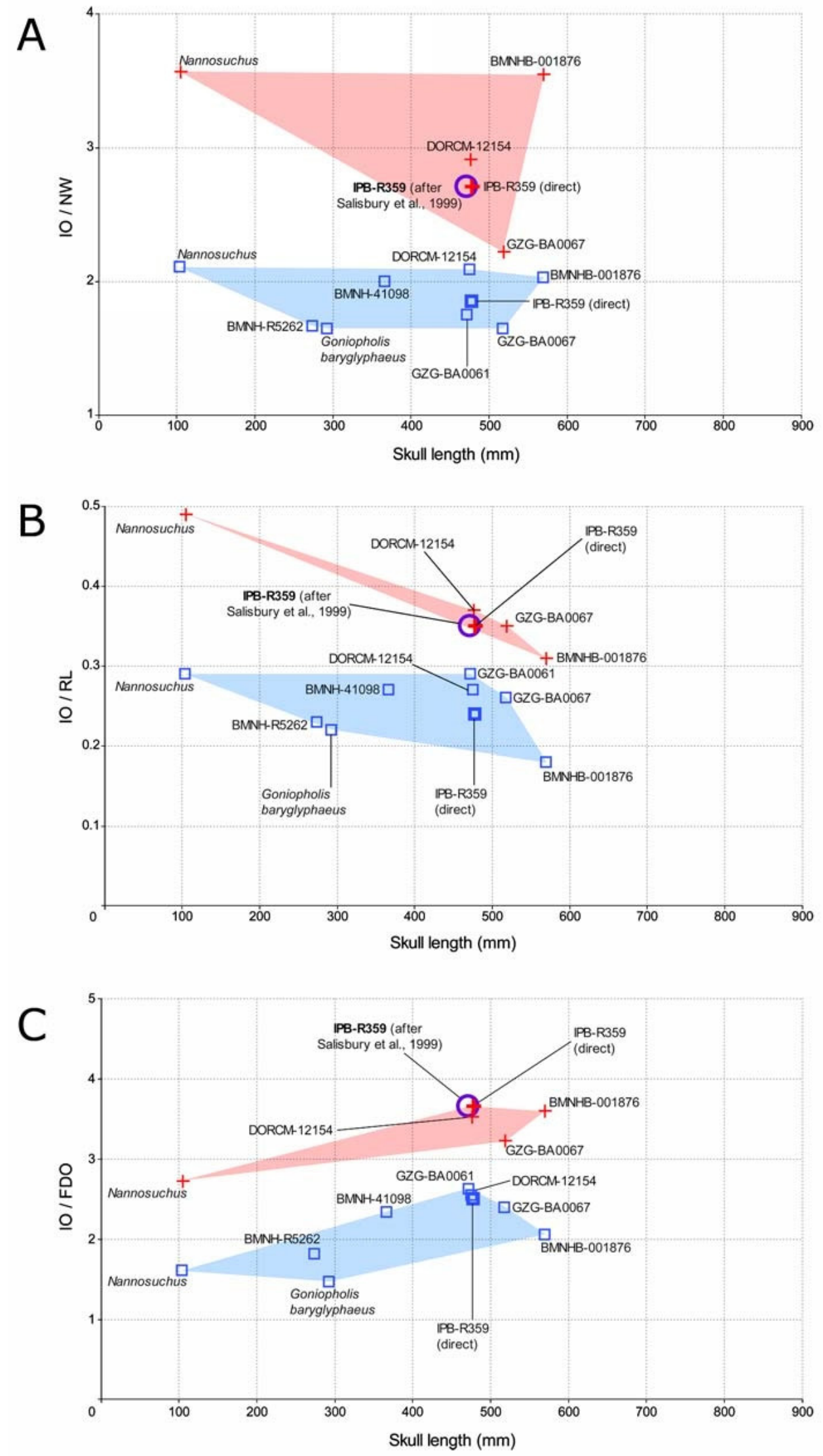
4 Fig. VIII.1S Proportional interorbital distance (IO) in goniopholidids, ploted agains skull length. (A) interorbital distance relative to narial width (NW); (B) interorbital distance relative to rostrum length (RL); (C) interorbital distance relative to distance from supratemporal fenestra to occipital surface (FDO). In the plots, two key groups can be identified: goniopholidids without palpebrals (blue) and with palpebrals (red). The specimen IPB R359, based on the interorbital distance provided by Salisbury et al. (1999) (purple circle), plots closer to the group with papebrals rather than to the group excluding these elements (true interorbital distance). The sample includes Goniopholis, Nannosuchus and the Hulke specimen (BMNHB 001876); IPB R359 is indicated by larger symbols; each cross identifies 10 values including palpebrals; squares identify 10 values without palpebrals.

Values for relative interorbital width (generated with data given by Salisbury et al., 1999) cannot be formally considered as outliers, but results $(\mathrm{IO} / \mathrm{SWPo}=1.9547, / \mathrm{RL}=1.9385$, $/$ FDO $=2.1697$; critical z-value $=2.29$ ) indeed demonstrate that they are always the furthest value of the sample.

Measurements of all specimens for interorbital width (without palpebrals) were tested for statistical significance. The Mann-Whitney (non-parametric) verified the relation between the interorbital distance (without palpebrals) of our sample $(n=9)$ against the measurement provided by Salisbury et al. (1999), which was used as the given mean. In all cases, the null hypothesis was rejected and the interorbital distance of Salisbury et al. (1999) was considered as different from our sample of measurements (without the palpebral). The null hypothesis is rejected even if values including the palpebrals are added to the sample $(n=14)$. The one-tailed $t$ test (parametric) also rejected normality in all cases. The interorbital distance provided by Salisbury et al. (1999) diverges from the sample of European goniopholidids, even though the variance of this sample is higher.

The sample has also undergone a multivariate study through discriminant analysis and PCA (Fig. VIII.H), following Hammer and Harper (2006). Discriminant analysis assumed that the interorbital distance for IPB R359 given by Salisbury et al. (1999) was part of 'Group 1' (i. e., without papebrals. The data sample separates neatly in the morphospace, forming groups with and without palpebrals, and placing IPB R359 (as by Salisbury et al., 1999) in 'Group 2' (i.e., with palpebrals). The discriminant analysis also reclassified into 'Group 2'.

\section{Systematic Palaeontology}

Crocodylomorpha Walker, 1970

Crocodyliformes Benton and Clark, 1988

Neosuchia Benton \& Clark, 1988

Goniopholididae Cope, 1875

Goniopholis Owen, 1842 
Type species. G. crassidens Owen, 1842.

Referred species. G. simus Owen, 1878; G. baryglyphaeus Schwarz, 2002

Geographic and stratigraphic range. Upper Jurassic (Alcobaça Formation, Kimmeridgian) to Lower Cretaceous (Durlston and Bückeberg formations, late Berriasian) of Western and Central Europe (Portugal, England, and Germany).

Remarks on diagnosis. Previous works providing diagnoses of Goniopholis simus and G. baryglyphaeus.(see Salisbury et al., 1999; Schwarz, 2002) emphasized the presence of a prefrontalpostorbital contact along the medial border of the orbit as an important characteristic of this genus. This cannot be confirmed in the present work. The apparent exclusion of the frontal from the orbital margin is induced by the presence of the palpebral, which creates a secondary (functional) orbital margin as the element tightly articulates with the lacrimal, prefrontal, frontal and postorbital. This configuration is not exclusive to Goniopholis and occurs independently also in distant crocodilian clades.

\section{Goniopholis simus Owen, 1878}

Type-material. BMNH 41098 and complementary counter slab BMNH 41098a: skull minus the mandibles (Fig. VIII.2), and two paravertebral osteoderms.

Referred-material. IPB R359, skull and associated mandible (Salisbury et al., 1999); GZG.BA.0061, skull and postcranium; GZG.BA.0067, skull. Cast specimens includes BMNH R.5259 (cast from GZG.BA.0061), BMNH R.5260 (and complementary cast BMNH R.5261), and BMNH R.5262, which in most cases cannot be related to its original mold. Further material is mentioned by Salisbury et al. (1999).

Locality and Horizon. United Kingdom: unknown specific location at Swanage, southern coast of England, from Stair Hole Member, Durlston Formation, Purbeck Limestone Group, Wessex-Weald Basin. Germany: unknown specific location(s) at Bückeberge area, northwestern Germany, from Obernkirchen Sandstone, Bückeberg Formation, Lower Saxony Basin. Sediments are firmly correlated to the late Berriasian (see Salisbury et al., 1999).

Amended Diagnosis. Differs from all other crocodylomorph taxa in possessing the following combination of features: paroccipital process and ventrolateral lamina of squamosal do not contact the quadrate; cranioquadrate canal exposed laterally, continuing caudally at the quadrate as a shallow sulcus; naso-oral (=incisive) foramen absent, with diamond-shaped fossa on the rostral floor of the nasal vestibulum; transversely elongated squamoso-exoccipital foramen; skull sculpture present and evident, with smoother ornamented surfaces at nasal, maxilla, prefrontals (modified from Salisbury et al., 1999); frontal reaching primary border of the orbit at posteromedial angle; prefronto-postorbital contact present ventral to interorbital bar; main body and anterior process of frontal not leveled; upper periorbital crests contiguous with the anteromedial border of the orbit; anterolateral process of postorbital short, robust, and rhomboid; postorbital bars inclined laterally and anteriorly from the skull table; palpebrals integrated to medial border of the orbit (this paper). 
Type-material. Single fragmented specimen, numbered from MG 26002 to 26045 , and MG 26110 to 26115 , previously referred to as 'Gui Croc 1', composing an articulated partial skeleton, including a nearly complete dorso-ventrally flattened skull with major portions of the lower jaw; four cervical vertebrae, six thoracic vertebrae, one sacral vertebra and three caudal vertebrae; the right and left coracoids, the left ischium and portions of the right femur, tibia and fibula, a metacarpal, and several dorsal and ventral osteoderms (updated from Schwarz, 2002).

Locality and Horizon. Guimarota coal mine at Leiria, Portugal, from Lower lignite coal layer ('Fundschichten') of the Guimarota Strata, Alcobaça Formation, Lusitanian Basin; Kimmeridgian, Upper Jurassic (after Schwarz, 2002).

Amended Diagnosis. Differs from all other European Goniopholis taxa in possessing the following combination of features: a retroarticular process oriented caudodorsally; an articular with a facet placed ventral to the retroarticular process, and directed slightly medioventrally; a caudal margin of the mandible vertical and forming nearly a right angle at its caudoventral corner; nearly square rostrolateral corners of the cranial table; a straight frontoparietal suture with a small rostral process, and a rostrally tapering wedge-shaped lacrimal, skull sculpture present and evident, including heavy ornamentation at nasal, maxilla, premaxillae, and prefrontals (modified from Schwarz, 2002); frontal reaching the primary border of the orbit at its posteromedial angle; main body and anterior process of frontal not leveled; upper periorbital crests present, margining the anteromedial border of the orbit; anterolateral process of postorbital short, robust, and rhomboid; postorbital bars inclined laterally and anteriorly from the skull table; postorbital-ectopterygoid contact absent at postorbital bar; palpebrals integrated to medial border of the orbit (this paper).

\section{Additional References}

Andrade, M.B., R. Edmonds, M. J. Benton, and R. Schouten. 2008. A Goniopholis skull from the Intermarine Member (Berriasian, Lower Cretaceous), Swanage (England). In: Symposium of Vertebrate Palaeontology and Comparative Anatomy, 56. Abstracts, Dublin. University College Dublin / National Museum of Ireland, p.13-14.

Andrews, C.W. 1913. On the skull and part of the skeleton of a crocodile from the Middle Purbeck of Swanage, with the description of a species (Pholidosaurus laevis), and a note on the skull of Hylaeochampsa. Annals and Magazine of Natural History 8: 485-494.

Benton, M. J., and J. M. Clark. 1988. Archosaur phylogeny and the relationships of Crocodylia. In: Benton, M. J. (ed.). 1988. The phylogeny and classification of the tetrapods. Oxford: Clarendon Press. v.1, p.295-338.

Clark. J. M. 1986. Phylogenetic relationships of the crocodylomorph archosaurs. Unpublished Ph.D. Dissertation. University of Chicago, Chicago, 1986.

Clark, J. M. 1994. Patterns of evolution in Mesozoic Crocodyliformes. In: Fraser, N. C. and H-D. Sues (eds.). In the shadows 
of dinosaurs: early Mesozoic tetrapods. London: Cambridge University Press. p.84-97.

Clements, R. G. 1993. Type-section of the Purbeck Limestone Group, Durlston Bay, Swanage, Dorset. Proceedings of the Dorset Natural History and Archaeological Society 114:181-206.

Cope, E. D. 1878. Descriptions of new extinct Vertebrata from the Upper Tertiary and Dakota Formations. Bulletin of the United States Geological and Geographical Survey of the Territories 4:379-396.

Dollo, L. 1883. Première note sur les crocodilians de Bernissart. Bulletin du Musée Royal d'Histoire Naturelle de Belgique 2:309-338.

Dunker, W. 1843-44. Über den norddeutschen sogenannten Wälderthon und dessen Versteinerungen. Programm der höheren Gewerbeschule in Cassel, 1843-44: 46 pp.

Grubbs, F. 1969. Procedures for detecting outlying observations in samples. Technometrics 11(1):1-21.

Hammer, Ø., and D. A. T. Harper. 2006. Paleontological data analysis. Oxford: Blackwell Publishing. 351pp.

Hammer, Ø., Harper, D.A.T., and Ryan, P.D. 2001. PAST: Paleontological statistics software package for education and data analysis. Palaeontologia Electronica 4(1): 1-9.

Hooley, R. W. 1907. On the skull and greater portions of the skeleton of Goniopholis crassidens from the Wealden shales of Atherfield (Isle of Wight). Quarterly Journal of the Geological Society 63:50-63.

Hornung, J. J., and M. Reich. 2006. The “Wealden” collection of Max Ballerstedt (1857-1945) - Undisclosed treasures from the Early Cretaceous of northwestern Germany. Berichte des Instituts für Geowissenschaften, Christian-AlbrechtsUniversität Kiel 22:40-41.

Hornung, J., M. Andrade, and M. Reich. Are Goniopholis crassidens and G. simus different species of crocodilians? New postcranial evidence solving a taxonomic riddle. Journal of Vertebrate Paleontology, 29: 117A.

Hulke, J. W. 1878. Note on the two skulls from the Wealden and Purbeck formations indicating a new subgroup of Crocodilia. Quarterly Journal of the Geological Society 34:377-382.

Joffe, J. 1967. The dwarf crocodiles of the Purbeck Formation, Dorset: a reappraisal. Palaeontology 10:629-639.

Jouve, S., M. Iarochene, B. Bouya and M. Amaghzaz. 2006. A new species of Dyrosaurus (Crocodylomorpha, Dyrosauridae) from the early Eocene of Morocco: phylogenetic implications. Zoological Journal of the Linnean Society 148:603-656.

Kalin, J. A. 1933. Beiträge zur vergleichenden osteologie des crocodilidenschädels. Zoologisches Jahrbuch, Anatomie 57:535-714.

Lauprasert, K., G. Cuny, E. Buffetaut, V. Suteethorn. and K. Thirakhupt. 2007. Siamosuchus phuphokensis, a new goniopholidid from the Early Cretaceous (ante-Aptian) of northeastern Thailand. Bulletin de la Société Géologique de France 178:201-216.

Lucas, S. G., and R. M. Sullivan. 2003. A new crocodilian from the Upper Cretaceous of the San Juan Basin, New Mexico. 
Neues Jarbuch für Geologie und Paläontologie, Montashefte 2003:109-119.

Mansell-Pleydell, J. C. 1888. Fossil reptiles of Dorset. Proceedings of the Dorset Natural History and Antiquarian Field Club 9: $1-40$.

Meyer, H. von. 1841. Pholidosaurus schaumburgensis, ein Saurus aus dem Sandstein der Wald-Formation NordDeutschlands. Neues Jahrbuch für Mineralogie, Geologie und Petrefakten-Kunde, 1841: 443-445.

Mook, C. C. 1942. Skull characters of Amphicotylus lucasii Cope. American Museum Novitates 1165:1-5.

Mook, C. C. 1964. New species of Goniopholis from the Morrison of Oklahoma. Oklahoma Geology Notes 24:283-287.

Mook, C. C. 1967. Preliminary description of a new goniopholid crocodilian. Kirtlandia 2:1-5 Ortega, F., Z. Gasparini, A. D. Buscalioni, J. O. Calvo. 2000. A new species of Araripesuchus (Crocodylomorpha, Mesoeucrocodylia) from the Lower Cretaceous of Patagonia (Argentina). Journal of Vertebrate Paleontology 20:57-76.

Owen, R. 1842. On British fossil reptiles. Reports of the British Association for the Advancement of Science 11:60-204.

Owen, R. 1878. Monograph on the fossil Reptilia of the Wealden and Purbeck formations - Crocodilia (Goniopholis, Pterosuchus, and Suchosaurus). Palaeontographical Society Monograph 7:1-15.

Owen, R. 1879. Monograph of the fossil Reptilia of the Wealden and Purbeck Formations - Crocodilia (Goniopholis, Brachydectes, Nannosuchus, Theriosuchus, and Nuthetes). Palaeontographical Society Monograph 9:1-19.

Pol, D., and S. Apesteguia. 2005. New Araripesuchus remains from the early Late Cretaceous (Cenomanian-Turonian) of Patagonia. American Museum Novitates 3490:1-38.

Salisbury, S. W. 1998. The long-lost crocodilian of Mr Willett. Symposium of Vertebrate Palaeontology and Comparative Anatomy, 46. Abstracts, Bournemouth University, Bournemouth.

Salisbury, S. W. 2002. Crocodilians from the Lower Cretaceous (Berriasian) Purbeck Limestone Group of Dorset, Southern England. In: Milner and Batten (eds.) Life and Enviroments in Purbeck times. Special Papers in Palaeontology 68:121-144.

Salisbury, S. W., P. M. A. Willis, S. Peitz and P. M. Sander. 1999. The crocodilian Goniopholis simus from the Lower Cretaceous of North-Western Germany. In: Unwin, R. L. (ed.). Cretaceous Fossil Vertebrates. Special Papers in Palaeontology 60:121-148.

Salisbury, S. W., R. E. Molnar, E. Frey, and P. M. A. Willis. 2006. The origin of modern crocodyliforms: new evidence from the Cretaceous of Australia. Proceedings of the RoyalSociety of London B 273:2439-2448.

Schwarz, D. 2002. A new species of Goniopholis from the Upper Jurassic of Portugal. Palaeontology 45:185-208.

Sereno, P. C., H. C. E. Larsson, C. A. Sidor and B. Gado. 2001. The giant crocodyliform Sarcosuchus from the Cretaceous of Africa. Science 294:1516-1519.

Smith, D. K., E. R. Allen, R. K., Sanders, and K. L. Stadtman. 2010. A new specimen of Eutretauranosuchus (Crocodyliformes, 
Goniopholididae) from the Dry Mesa, Colorado. Journal of Vertebrate Paleontology 30:1466-1477.

Tykoski, R. S., T. B. Rowe, R. A. Ketcham, and M. W. Colbert. 2002. Calsoyasuchus valliceps, a new crocodyliform from the Early Jurassic of Kayenta Formation of Arizona. Journal of Vertebrate Paleontology 22:593-611.

Turner, A. H. and G. A. Buckley. 2008. Mahajangasuchus insignis (Crocodyliformes: Mesoeucrocodylia) cranial anatomy and new data on the origin of the eusuchian-style palate. Journal of Vertebrate Paleontology 28:382-408.

Wu, X-C., D. B. Brinkman, and A. P. Russel. 1996. Sunosuchus junggarensis sp.nov. (Archosauria: Crocodyliformes) from the Upper Jurassic of Xinjiang, People's Republic of China. Canadian Journal of Earth Sciences 33:606-630.

Yans, J., J. Dejax, D. Pons, L. Taverne and P. Bultynck. 2006. The Iguanodons of Bernissart (Belgium) are middle Barremian to earliest Aptian in age. Bulletin de l'Institut Royale des Sciences Naturelles de Belgique. Sciences de la Terre 76:9195.

Young, C. C. 1948. Fossil crocodiles in China, with notes on dinosaurian remains associated with the crocodiles. Bulletin of the Geological Society of China 28:225-288. 


\section{Chapter IX}

Derived appendicular morphology in Early Cretaceous aquatic turtles evidenced by the track record 
Published in:

Lethaia, 46: 470-479 [2013].

\title{
Derived appendicular morphology in Early Cretaceous aquatic turtles evidenced by the track record
}

\author{
JAHN J. HORNUNG ${ }^{1}$ and MIKE REICH ${ }^{1,2}$ \\ ${ }^{1}$ Department of Geobiology, Geoscience Centre, Georg-August University of Göttingen, Germany \\ ${ }^{2}$ Museum, Collections \& Geopark, Geoscience Centre, Georg-August University of Göttingen, Germany
}

Hornung, J.J. \& Reich, M. 2013 Derived appendicular morphology in Early Cretaceous turtles evidenced by the track record. Lethaia, DOI: 10.1111/let.12024.

A well preserved isolated manus impession evidences the presence of derived aquatic adaptations in the forelimb morphology of Berriasian turtles. Size and the abundant co-occurring turtle fauna indicate that the track was left by a large-sized, bottom-walking basal pancryptodiran. The footprint shows an interesting mosaic of primitive and derived features. The basic turtle pattern is reflected by a short and broad autopodium but thin phalanges, claw reduction and extensive webbing enclosing the digits and lateral and medial margins of the distal metapodium are clearly specialized features related to the aquatic environment. Some characters including the proportional elongation of the first digit which reached as far distally as the other digits and was probably highly mobile at the metacarpal-phalangeal joint, indicate an even higher degree of specialization.

The specimen gives evidence on a hitherto unknown range of appendicular modification in Early Cretaceous turtles and redundantly proves the aquatic habitat and locomotion of large-sized turtles from the Berriasian of northwestern Germany.

Keywords. Testudines, Cryptodira, aquatic habitat, appendicular morphology, track, Early Cretaceous

Among amniotes turtles are one of the most controversial groups regarding their phylogenetic origin and taxonomic relationships. From an ecological point of view, evidence for habitat preferences of ancestral turtles are controversial, suggesting either a terrestrial (Joyce \& Gauthier 2004, Reisz \& Head 2008) or an aquatic (Li et al. 2008) origin of the clade. Most stem-group turtles (sensu Joyce 2007) were terrestrial (Joyce \& Gauthier 2004), though there is growing evidence that some taxa may have been aquatic as well (Anquetin et al. 2009, Anquetin 2011). As it has been shown by Joyce \& Gauthier (2004) the common ancestor of crown-group turtles (Testudines, sensu Joyce 2007) was aquatic, and all extant terrestrial turtles have acquired this habitat secondarily.

During turtle evolution, the change in habit and habitat was connected to some important modifications in the plesiomorphic turtle bauplan. Various key features and phylogenetic trends have been proposed to be indicative for an aquatic life-style: (1) increasing reduction and fenestration of the carapace in adults, (2) increasing reduction of the keratinous epidermal shields, (3) relatively "flat" carapaces in aquatic turtles, (4) the presence of a ligamenteous bridge between 
carapace and plastron, (5) different patterns in bone histology in aquatic and terrestrial turtles (Scheyer \& Sander 2007), and (6) a shift of appendicular proportions (Joyce \& Gautier 2004), culminating in the development of "flipper-like organs" in all autopodia. Unfortunately, criteria 1 to 5 have been proven to be problematic because they might either be present in certain ontogenetic stages ( 1 and 2), or show an ambiguous dispersion among extant aquatic and terrestrial turtles (3 to 5, Joyce \& Gauthier 2004; Anquetin et al. 2009). Criterion 6 is unambiguous in its derived state be-cause the presence of "flippers" is linked to a swimming mode of locomotion, while an unspecialized appendicular morphology is otherwise present in terrestrial as well as in aquatic turtles.

Unfortunately, the transformation of hands and feet with free digits to elongated flippers or paddles (Joyce 2007), enveloped in skin, is harder to trace, since appendicular skeletons of turtles are far rarer in the fossil record than shells.

The limited fossil record so far indicates that the evolution of specialized limb morpho-logies related to an aquatic habitat occurred only in the Eucryptodira. Most Late Jurassic basal pancryptodiran and panpleurodiran taxa known from complete, articulated speci-mens (e. g. Joyce 2000, 2003; Karl \& Tichy 2006) do not show any hint of modified appen-dicular morphology. The short autopodia exhibit moderately elongated phalanges (not as short as in some terrestrial taxa) and well-developed claws. Some very well preserved specimens show the presence of webbing between the digits (e. g. Karl \& Tichy 2006: fig. 2). Considering the basal position of these taxa within the Testudines and their doubtlessly aquatic habitat, this morphotype may be considered plesiomorphic within the frame of Testudines. However, diversification of limb morphology in basal eucryptodirans apparently started as early as Late Jurassic: Well-preserved specimens of the Late Jurassic marine eucryptodiran Neusticemys neuquina (Fernández \& de la Fuente, 1988) indicate that this species may have had already small forelimb flippers and a modified pes with enlarged digit $\mathrm{V}$ (de la Fuente \& Fernández 2011). Specialized aquatic locomotion patterns (bilateral-synchronous, parasagittal limb movement, preceding the chelonioid "underwater flight") apparently had already evolved as early as the Late Jurassic (Gaillard et al. 2003).

Here we present an exceptionally well-preserved turtle manus trace fossil from the Early Cretaceous of northwestern Germany. The specimen shows a high level of morphological detail and originates from a stratum with an abundant and diverse fauna of turtles (e. g. Peitz 1998; Karl et al. 2007a, 2007b). The new ichnological evidence is not only the first turtle track from this stratum and corroborates the inferred aquatic habitat of these turtles but provides some information on the autopodial soft tissue morphology and the degree of functional adaptation to this environment.

\section{Geological setting}

The turtle track originates from the late Berriasian Obernkirchen Sandstone (Cypridea alta formosa ostracod subzone (Mutterlose 1997), Obernkirchen Member, Bückeberg Formation, late Berriasian). This lithological unit is very rich in vertebrate tracks. The material described here was among dinosaur track material collected by M. Ballerstedt in the early $20^{\text {th }}$ century from the Harrl 
hill (Fig. IX.1A-C), close to the town of Bückeburg, c. $55 \mathrm{~km} \mathrm{SE}$ of Hannover, Lower Saxony (Ballerstedt 1905).

The Obernkirchen Sandstone (Fig. IX.1D) is a predominantly fine-grained, pure, quartzose sandstone, interbedded by subordinate beds of silt- and mudstones, which is generally interpreted as to represent a limnic, distal deltaic environment (Pelzer 1998). Local facies variations indicate deposition as retrograding barrier and shoal sands or deltaic mouthbars, fringing perideltaic shallow lagoons (Pelzer 1998; Hornung et al. 2012a; Fig. IX.1E). The lagoons and shoals were frequently crossed by dinosaurs which left abundant trackways (e. g. Ballerstedt 1905, 1921, Hornung et al. 2012a).

The turtle track was left in thinly bedded, current-ripple cross-laminated, fine-grained, silty sandstone. Although no label was associated with the specimen, it can be deduced from the lithology that it derived most probably from the region of a prominent track horizon described by Ballerstedt $(1905,1921)$, which yielded many well preserved footprints of ornithopod, theropod and ankylosaur dinosaurs. Ballerstedt (in Grupe 1933) indicated this horizon to occur below the upper one of two coal seams and it is can probably be identified with a single track horizon in the same stratigraphic position in a small outcrop c. $350 \mathrm{~m}$ to the $\mathrm{W}$ of the large quarry (Pelzer 1998, Hornung et al. 2012b, Fig. IX.1D). This horizon, which, is embedded in a 1-2 m thick succession of thinly bedded, ripple cross-laminated, root-bearing sand-, silt- and mudstones, overlying a scoured, cross-stratified sandstone complex terminating with the cm-thick, upper coal-seam. This succession is tentatively interpreted to represent a largely abandoned, but at least partly submerged mouthbar system. It became subsequently vegetated, stabilized and finally covered by a lagoonal peat-bog swamp (Hornung et al. 2012a, b).

Turtle shells and shell fragments are very abundant in the Obernkirchen Sandstone (Peitz 1998; Karl et al. 2007a, 2007b). However, cranial remains of turtles have not yet been found and appendicular skeletal elements are extremely rare. This indicates short-range transport of dismembering carcasses which may have led to strong segregation of turtle shells from the remaining skeleton due to high mass ratios between these components. In opposition to the abundance of turtle remains and vertebrate (dinosaur) tracks, no turtle track has been reported yet from this stratum. Hitherto palaeoecological hypotheses regarding turtles from the Obernkirchen Sandstone were entirely based upon shell morphology (e.g. Karl et al. 2007a).

\section{Material and description}

The specimen (GZG.BA.0116a, Figs. IX.2-IX.3) consist of a slab of sandstone containing a single hypichnium impressed by a left manus (plus an epichnial artificial silicone cast GZG.BA.0116z).

Fig. IX.1 (A-C), Exposure of the Bückeberg Formation and locality map. Geology after Landesamt für Bergbau, Energie und Geologie Niedersachsen (2013); (D) Simplified stratigraphy of the Bückeberg Formation (after Mutterlose 1997) and lithological log near the track locality (after Pelzer 1998, Hornung et al. 2012b); E, Palaeogeographical context of the track locality, after Schott et al. (1967). 


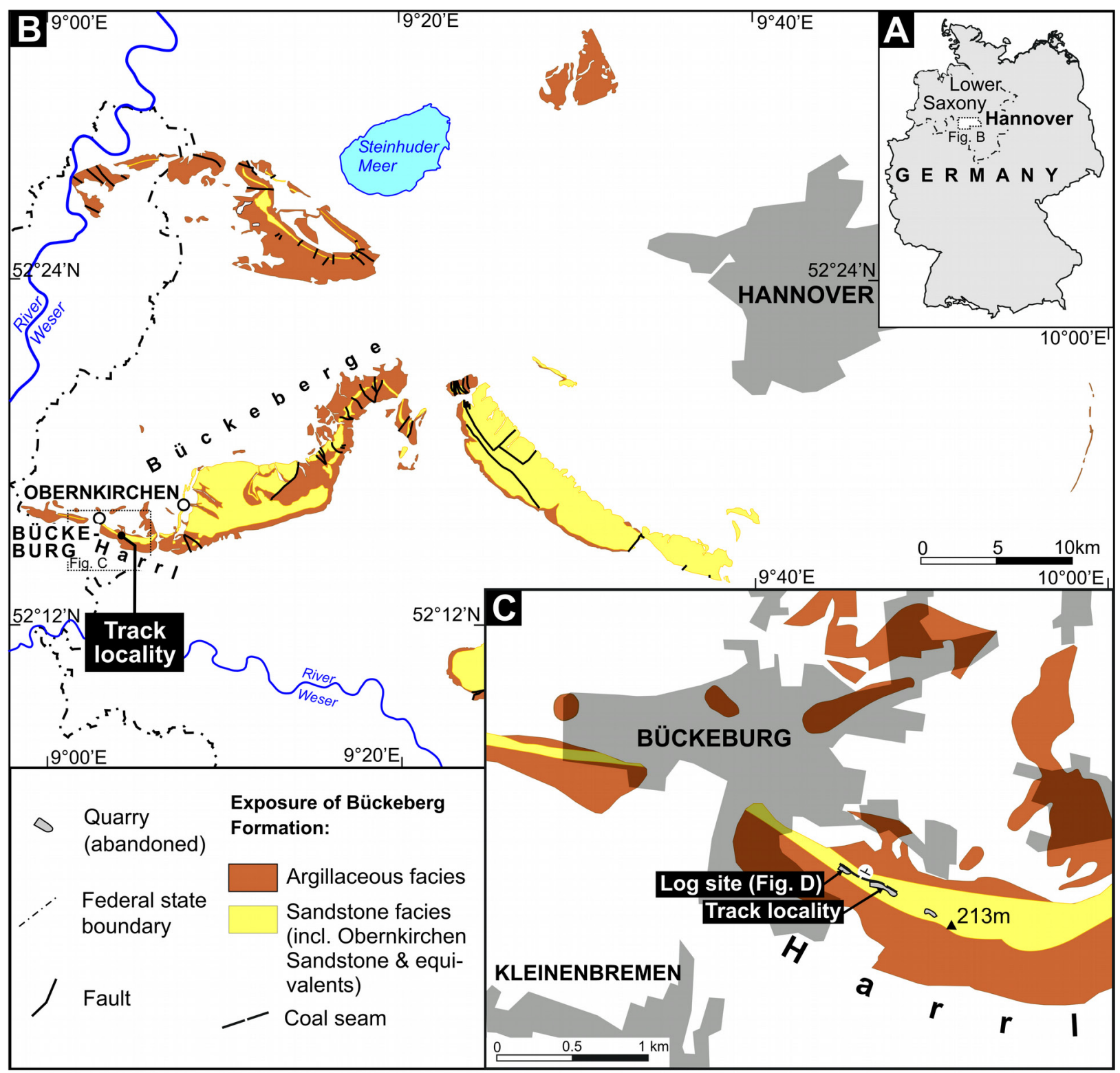

D
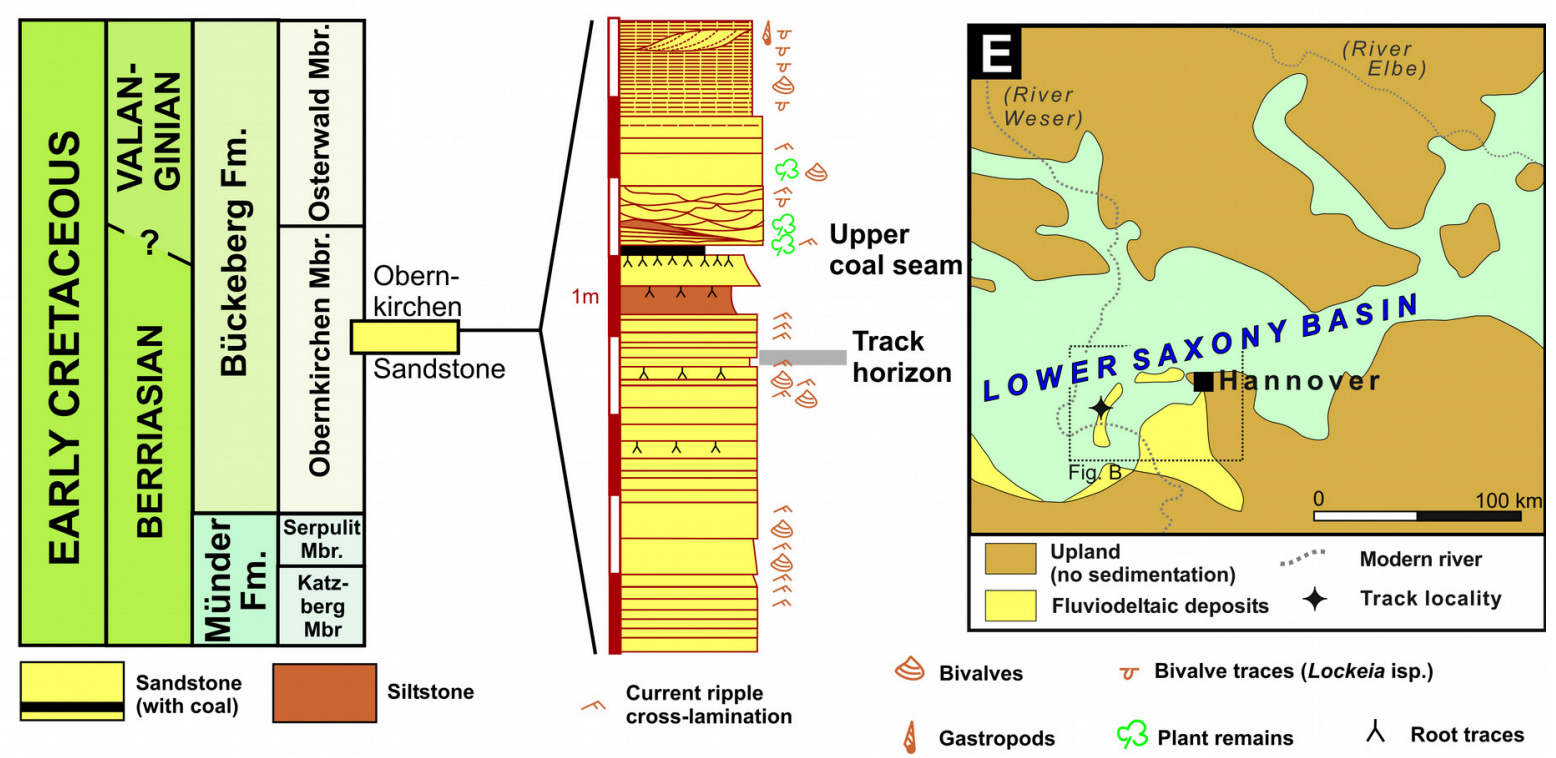
The $\sim 38$ x $20 \mathrm{~cm}$ large slab contains a single, $\sim 16 \mathrm{~cm}$ wide hypichnial cast of a tetradactyle tetrapod track. Due to the relatively small size of the slab, compared to the track size and inferred track gauge and stride, no other tracks are preserved. The absence of other tracks and morphological indicators complicates the referral of the track to a body side, but since in similar tracks the digits are deflected laterally (e. g. Gaillard et al. 2003), it is assumed that it originated from the left side.

The track shows the impression of four digits which are strongly laterally deflected. The largest digit diverges slightly medially from the direction of the other digits and its metapodial-phalangial joint shows a slight proximal off-set relative to the homologous joints of the other digits. It is therefore identified as digit I (see below for discussion). All digits show extension at their metapodial-phalangeal and interphalangeal joints, which is weakest in digit I, strongest in digit II and intermediate in digits III and IV. Digit II was hyperextended to a degree that only the base of the proximal phalanx was impressed in the sediment. Digit I was oriented subparallel to the sediment surface distally, while digits III and IV pointed upward.

Digits III and IV were subequal in size, while digit I was slightly more robust and longer than the others. As only the base of digit II was impressed, it is not possible to assess whether it was intermediate in size between III and I or subequal to III. The digits are connected proximally in a broad metapodial ridge, which is oriented transversally to the base of the digits. The metapodialphalangeal joint of digit I shows a slight off-set from this ridge and is demarcated by an oval thickening.

The individual digits are proportionally gracile and taper slowly towards their tip. At least two interphalangeal joints can be traced on digit I by weak thickenings. The digits were enclosed by a connective skin-web which was thin and flexible, enveloping the whole digits up to their tips. Aside of folds, no skin-surface textures are visible. There are no claws discernible.

The track is bounded posteriorly by a shallow, broad displacement rim. Minor sedimenr displacement also occured anteriorlaterally and -medially along some parts of the digits, especially digit I (Fig. IX.3). The ventrolateral part of the metapodium is impressed to the posterior displacement rim. It is bounded laterally by a convex margin, which is confluent with the lateral margin of digit IV, than curves laterally and terminates in a medial curvature. This shape suggests a short and broad metapodium. Loose folds at the lateral base of digit IV suggest that the interdigital web originates at the distal lateral margin of the metapodium, possibly enveloping a short and indiscernible digit $\mathrm{V}$ (see below). The margin medially to the base of digit I is incompletely preserved, caused by the microrelief of the substrate which formed a slight depression in this area. Therefore not all parts of the autopodium inserted fully into the sediment.

Fig. IX.2 GZG.BA.0116a, left manus impression (hypichnium) of a turtle, Obernkirchen Sandstone, Obernkirchen Member, Bückeberg Formation, late Berriasian, Harrl hill near Bückeburg, Lower Saxony, northwestern Germany. (A) Photography; (B) interpretative sketch. I to IV: digits I to IV, ipj: interphalangeal joints, mpj: metacarpal-phalangeal joint. 


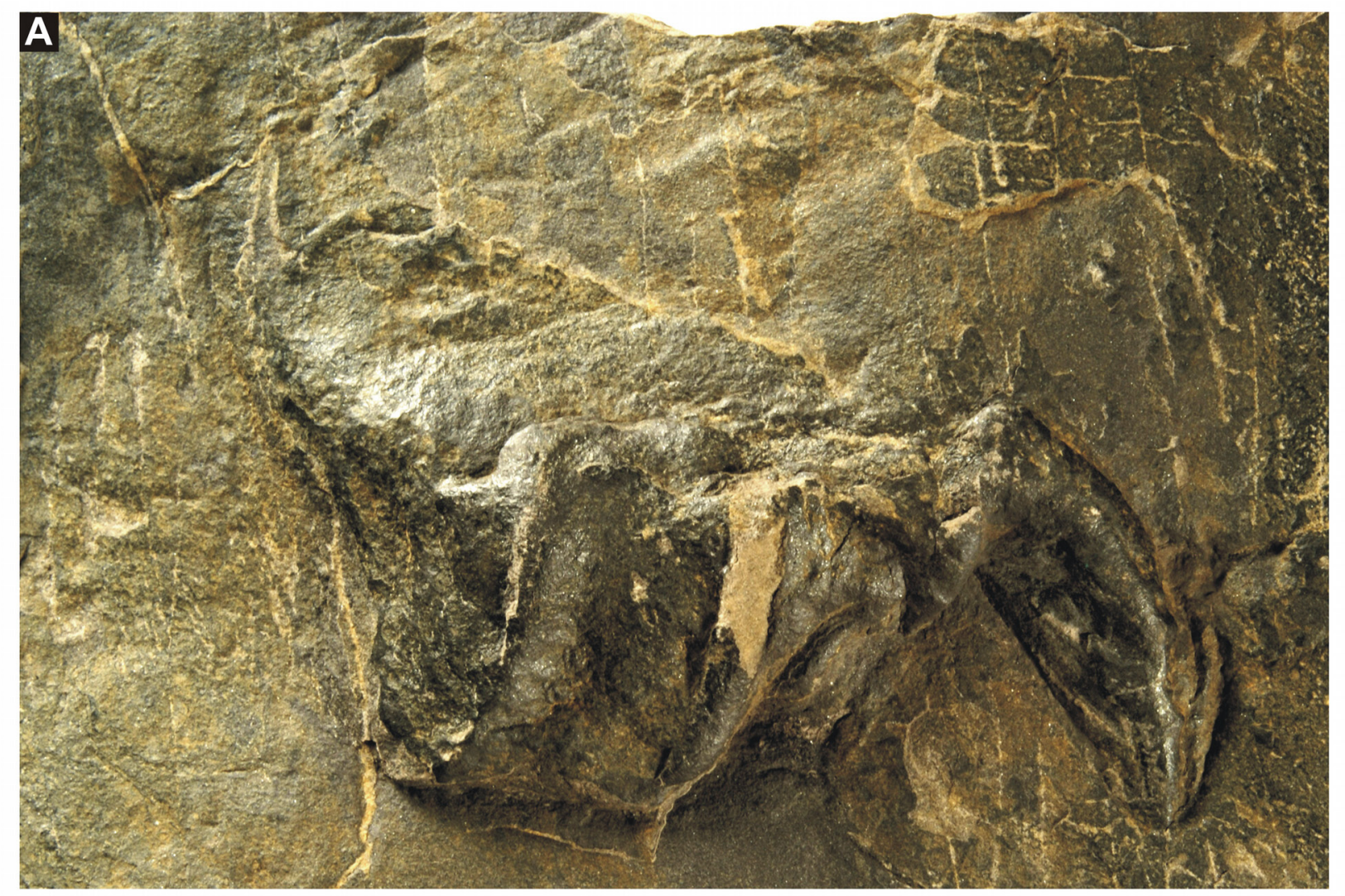

\section{B}
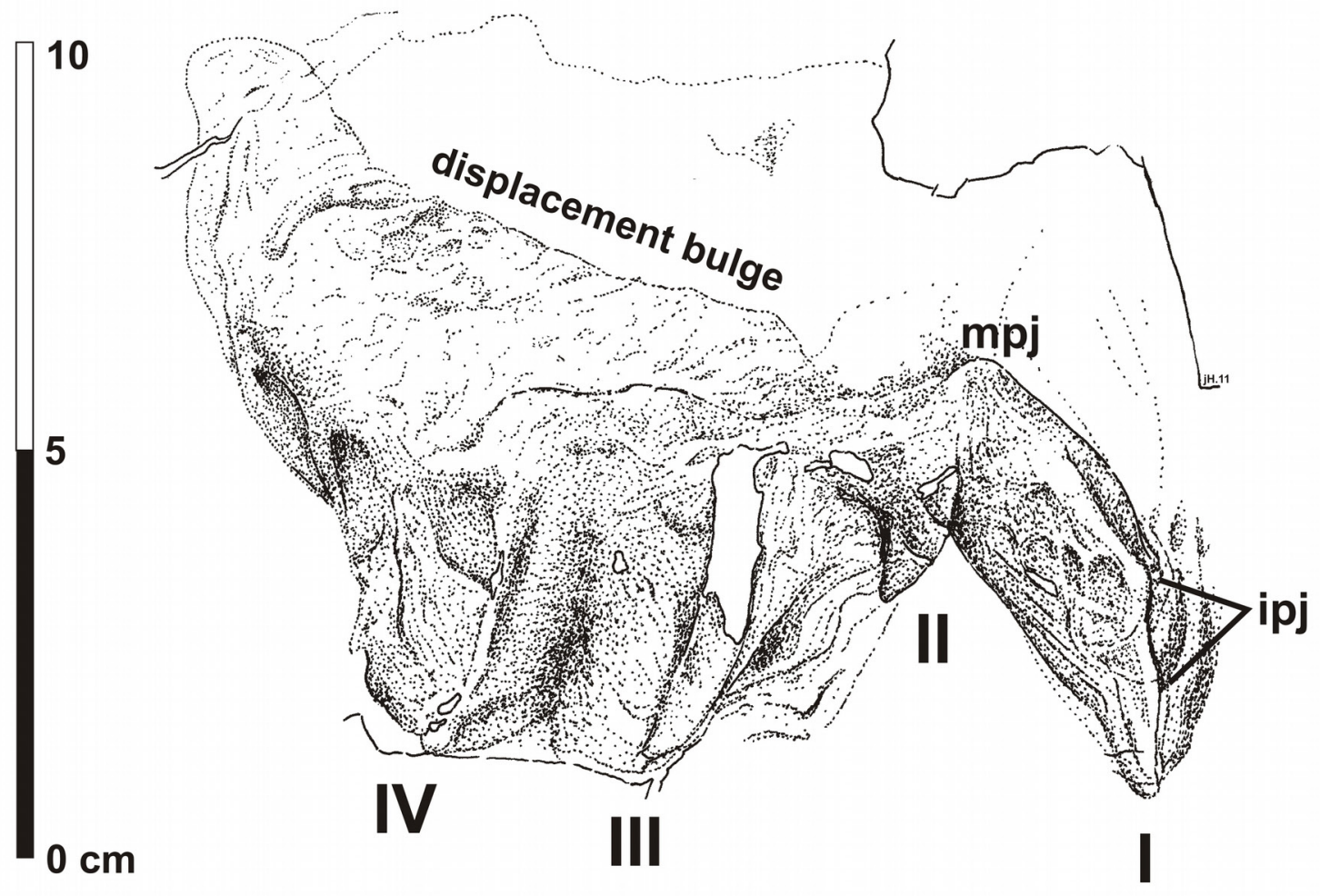

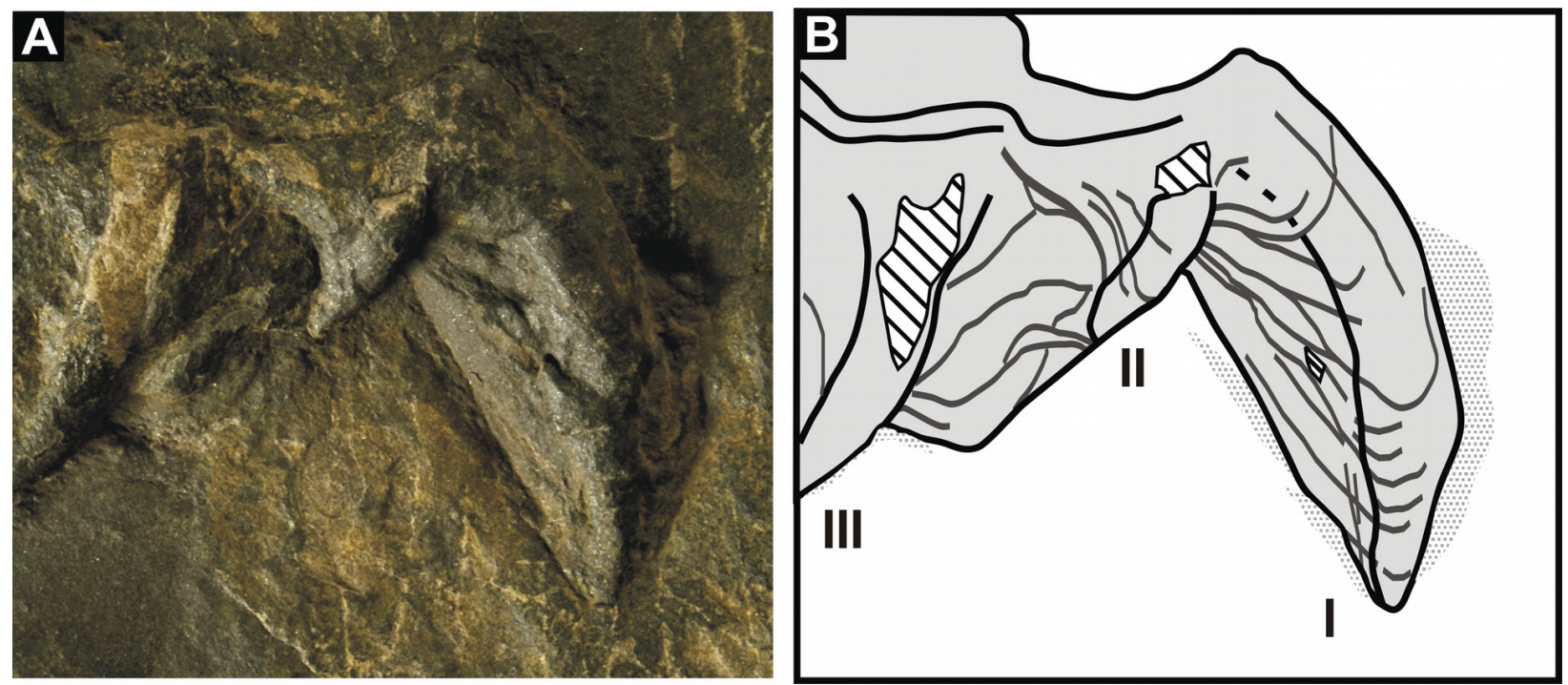

Fig. IX.3 GZG.BA.0116a, left manus impression (hypichnium) of a turtle. (A) Details of digits I to III; (B) interpretative sketch to show folds and orientation of the interdigital skin between digits I and II and II and III. I to III: digits I to III, light grey: track, dark grey lines: skin folds, diagonally hatched areas: damage, stippled areas: areas of displaced sediment.

\section{Discussion}

Track producer

The general morphology of the track is in congruence with a number of similar tracks which have been identified alternatively as crocodile or turtle tracks. A distinction between both trackmakers is often not straightforward, especially in case when no consecutive trackways are preserved. However, the autopodial morphology of most non-marine, semi-aquatic crocodylomorphs remained relatively conservative since the Triassic (Steel 1973), while turtles showed a broad diversity of modifications (e. g. Joyce 2007).Therefore a number of key features relate GZG.BA.0116 to a turtle rather than a crocodile as trackmaker:

(1) The proportions of the autopodium. Though not completely preserved, GZG.BA.0116 clearly shows that the trackmaker possessed a short, transversally broad autopodium. This is especially evident in the free digits. While crocodiles may have relatively short digits in the manus, they converge proximally towards the metacarpals. In the pes the digits are proportionally elongate (e. g. Farlow \& Elsey 2010). Both autopodia in crocodiles quickly taper posteriorly, and even in crocodylomorph tracks with parallel digits (e. g. ichnogenus Batrachopus, see Olsen \& Padian 1986) the metapodial area is transversally narrower than the aligned digits. Contrarily in turtles broad metapodial areas and short digits are common, especially in the manus (e. g. Joyce \& Gauthier 2004). In tracks this criterion may be applicable to varying degree, as the proximal part of the digits and the metapodial area might not be preserved, e. g. in swim tracks. However, in GZG.BA.0116 the base of the digits and their 
articulation with the metacarpals are clearly observable.

(2) The relative length of the digits: all four digits are subequal in length. The sizerelation between the inner- and outermost digits is most relevant. The manus of crocodiles is pentadactyle though the manus tracks often preserves only the impression of digits II to IV (e. g. Avanzini et al. 2010). If preserved, digits I and V of the crocodile manus are often shorter than digits II to IV (which are also slightly different in length in most taxa) and at least digit V is positioned distinctly more proximally with respect to the others. This is even observable in tracks left by basal crocodylomorphs of the Triassic (Olsen \& Padian 1986). In the crocodilian pes digit I is generally shorter than the others, while digits II to IV are also unequal (though to a lesser degree) in length. The difference between digit III and IV is generally the slightest with III being the longest. At least in some crown-group crocodilians digit IV is often modified by being more slender and lacking a claw (Farlow \& Elsey 2010). In turtles there is a broad range of ratios in digital length, including the presence of three or four subequal digits. This is even true for basal taxa as Proganochelys quenstedti Baur, 1887 (see Gaffney 1990) and is observable in the track record also (Avanzini et al. 2005).

(3) The width of the digits. In crocodilians the digits of manus and pes show welldeveloped interphalangeal pads and a slender conical shape, gently tapering towards the ungual. In GZG.BA.0116 the digits are very slender and not distinctly "fleshy" - instead of interphalangeal pads they show what is interpreted as thickened interphalangeal joints (Fig. IX.2). The margins of the digits are parallel-sided for most of their length. Similar morphologies can be observed in aquatic turtles especially in taxa with soft flippers (Trionychia, Joyce 2007) though GZG.BA.0116 lacks the elongation of phalanges common to the latter.

(4) The presence of an extensive interdigital web, enveloping at least four (?five) digits to their distal extremity, and the absence of claws on these digits. There is no non-marine crocodile known to date with this autopodial morphology though it is also uncommon with short-toed turtles.

Characters (1) and (2) seem to be suited to distinguish between isolated turtle and crocodile tracks in general, while (3) and (4) support the affinity to turtles based upon features not generally present in the appendicular morphology of turtles. GZG.BA.0116 is therefore considered to have been left by the left manus of a turtle (see also e. g. Gaillard et al. 2003; Avanzini et al. 2005).

As all known turtles have pentadactyle hands, this raises the question whether the homologization of the largest digit in GZG.BA.0116 with the pollux is correct. Two scenarios seem possible: either the largest digit preserved is in fact digit II. In this case digit I would have been located more proximally and did not leave a trace due to the incompleteness in the medial part of the track. Or the largest digit is indeed the pollux and a short digit $V$ may be concealed in the folded web skin laterally to digit IV. Given the extension of webbing in this area the second alternative appear to be more probable.

The track indicates a considerable body size of the trackmaker. Similar tracks described by Gaillard et al. (2003) have a manus width of 20-30 cm and an external trackway width of 1.5-1.6 m. Therefore a trackway width of 1.0-1.2 $\mathrm{m}$ can be assumed for the producer of GZG.BA.0116 and an 
anterior carapax width of 0.5-0.8 $\mathrm{m}$ appears to be a realistic estimate. Only two of the Berriasian turtle species from north-western Germany are known to reach such a size: the basal pancryptodirans Pleurosternon bullockii (Owen, 1842) and "Emys" menkei Roemer, 1836. Both are abundant in the Obernkirchen Sandstone (Karl et al. 2007a). The appendicular skeleton of "E." menkei is entirely unknown, while a partial right pes of P. bullockii is preserved (Karl et al. 2007b). The latter show the presence of five digits ( $V$ is reduced in size) and a slightly elongated metatarsal III. Due to the imperfect knowledge of the appendicular anatomy of "E." menkei and P. bullockii, the track producer can only be identified to the level of a large turtle, but most probably a basal pancryptodiran.

During the revision phase of this manuscript we became aware of a publication by Karl et al. (2012) on the same specimen. While most of the descriptive part and some of the conclusions in the work of these authors were heavily based upon an early and preliminary conference abstract (Hornung et al. 2008), they proceeded in an ichnotaxonomic referral of the specimen to Emydhipus cameroi Fuentes Vidarte, Meijede Calvo, Meijede Fuentes \& Meijede Fuentes, 2003. This referral, which was repeated in Karl (2012), was based apparently rather on stratigraphic and geographic considerations than upon qualitative or quantitative morphological characters. The ichnoholotype of E. cameroi consists of a trackway in which the manus impressions are represented by morphologically undifferentiated scratch marks, which, in addition, are much smaller than GZG.BA.0116 (Fuentes Vidarte et al. 2003). Furthermore Avanzini et al. (2005) reasonably proposed to base valid turtle ichnotaxa on trackway patterns rather than on the often morphologically indistinct autopodial impressions. Therefore we reject a referral of GZG.BA.0116 to E. cameroi and, at present, to any other described turtle ichnotaxon.

Track formation and quality of preservation

GZG.BA.0116 shows a quality of preservation which is superior to that commonly provided by aquatic turtle tracks (e. g. Bernier et al. 1982, Foster et al. 1999, Wright \& Lockley 2001, Fuentes Vidarte et al. 2003, Avanzini et al. 2005, Lockley \& Foster 2006, Moratalla \& Hernán 2009).

The characters preserved in GZG.BA.0116 suggest that it resulted from "bottom-walking" (Zug 1971), or at least a single but firm contact (bounce) of the manus with the substrate during slow swimming. Apparently the appendage entered the sediment surface subvertically close to the middle phase of limb retraction. The palmar surface was directed ventrally rather than laterally. Feathering of the manus (Rivera \& Blob 2010) during this phase probably resulted in a relatively low-angle contact of the anterior palmar surface with the ground (Fig. IX.4A). This led to a hyperextension of the digits and formation of the slight displacement bulge after contact with the sediment surface (Fig. IX.4B). The rather steep orientation of the metapodium to the ground (high angle of action) resulted in a termination of backward sweeping movement of the manus after it intruded into the sediment. The persistent limb retraction in conjunction with the ground reaction force produced an increased forward (and probably upward) impulse on the animal's body until the end of the retraction phase of the forelimb. The resulting movement led to a rotation at the shoulder 

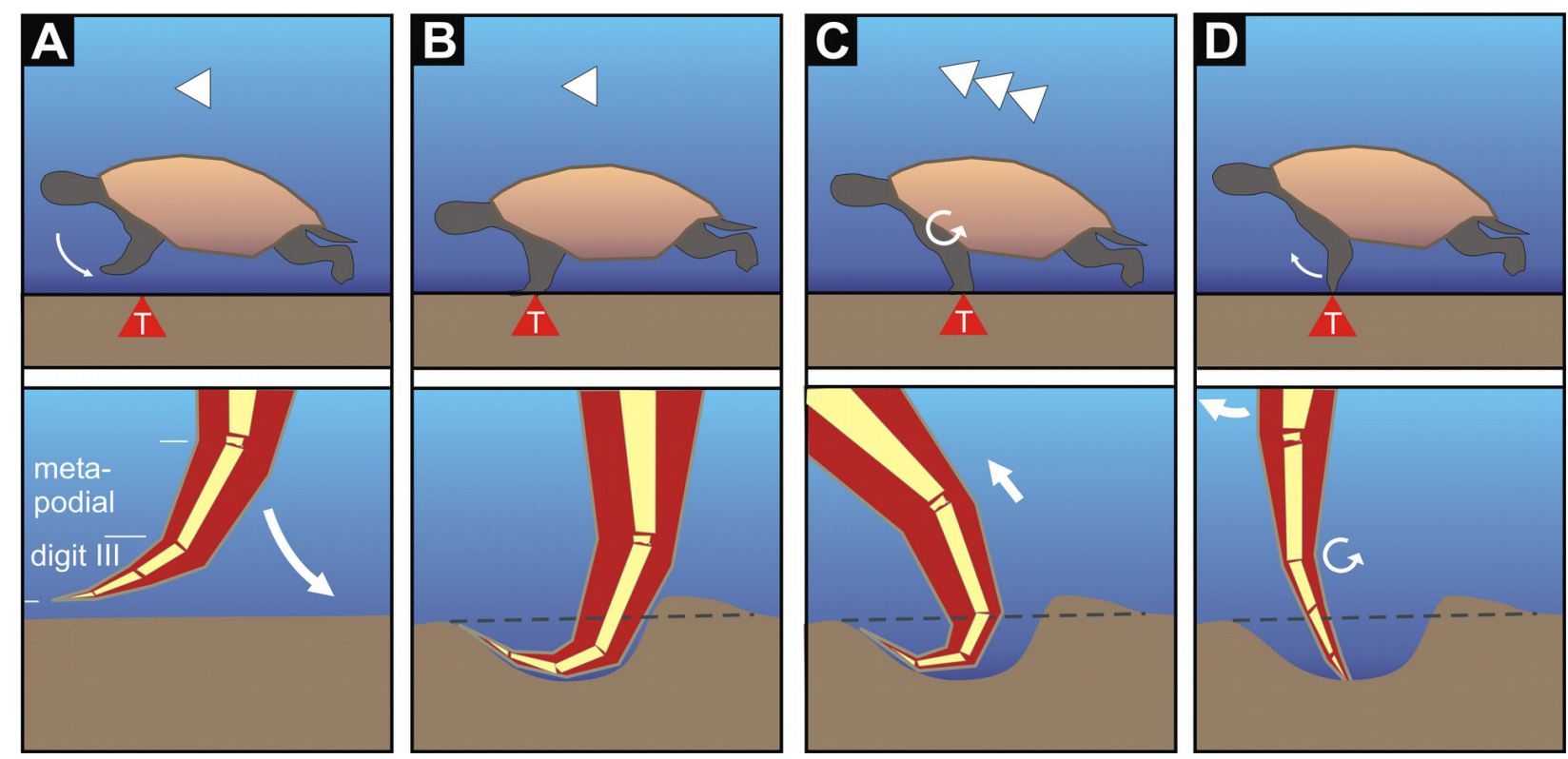

Fig. IX.4 Supposed sequence of subaquatic track formation in GZG.BA.0116. The upper row of figures shows the complete animal, the lower row details a schematic sagittal section through digit III. The white triangles indicates the approximate intensity and direction of impulse to the buoyant turtle's body, the red triangles with " $T$ " the location of the footprint in relation to the turtle. (A) retraction of forelimb with feathered manus; (B) maximum depth of insertion, the backward movement of the manus relatively to the ground is terminated by relatively low-angle palmar contact with the surface. A shallow displacement bulge is formed posterior to the manus and the digits underwent hyperextension; $(C)$ after the ground reaction force has added to the impulse generated from limb retraction the turtle's body moved forward and upward, detaching the manus from the ground surface during latest stage of retraction phase; (D) feathering of the manus during initial protraction phase may have produced faint scratches in the track by the digit tips.

joint rather than a parallel displacement of the manus relatively to the ground. The upward component of the impulse initiated a detachment of the palmar surface from the ground, aided by resistance force from the digits reaching their maximum angle of extension (Fig. IX.4C). The preserved footprint represents the moment during late retraction when the contact surface with the substrate reaches its maximum extent. There may have been some secondary scratching by the distalmost tips of the most deeply impressed digits (Fig. IX.4D) during their subsequent flexion, resulting from the release of weight load and feathering of the manus at initial protraction (Rivera \& Blob 2010): the trace of digit IV shows a faint longitudinal groove (preserved as ridge) which may result from this event. The surface of the trace of digit III is slightly damaged and the presence of such a ridge/groove cannot be assessed. Of digit II only the base was impressed and digit I does not show any trace of scratching. There is no evidence that plane-parallel movement of the autopodium through the substrate formed a prominent directional component during track formation, as it could be expected in a true swim track. The dominantly subvertical movement of the appendage into and out of the substrate greatly enhanced the quality of preservation. On the other hand the incomplete outline of the track indicates that it was not impressed fully, constrained by the microrelief of the substrate. This is in accordance with a buoyant trackmaker, which did not impose 
the full weight on its autopodium.

Evidence of webbing between digits in vertebrate tracks may be compromised by a number of extramorphological processes and effects. Load-induced failure and microfaulting in the surrounding sediment during creation of the track may be pronounced during diagenesis and result in webbing-like structures in tracks (Manning 2004, Falkingham et al. 2009). In low-viscosity substrates (e. g. mud with high water-content) the margins of steeply entrenched tracks may fail rapidly, resulting in an an epigenetic shallowing and "blurring" of the track outline and in the illusion of laterally confluent digits. These factors can only be excluded, and true webbing positively evidenced, if anatomical or morphological structures related to the interdigital tissue are preserved.

A very few fossil turtle tracks show web-like structures between the digits. Potential candidates are manus and pes imprints from the Late Jurassic of Spain (Avanzini et al. 2005: figs. 3i-j, 5a-b), however they do not seem to show any trace of interdigital skin morphology and must be considered ambiguous in this respect. In contrast, GZG.BA.0116 shows the presence of what can be reasonably be interpreted as skin-folds in the webbed area. Quasi three-dimensional preservation, e. g. between digits I and II, and II and III supports the interpretation that these structures are true folds and not microfaults (Fig. IX.3). In these areas, the morphology is consistent with the impression of a deformed, flexible membrane spanning between the digits while digit II is hyperextended. The proximal part of digit II is laterally bend, subparallel to digit III but slightly diverging with digit I. The interdigital structures on the track suggest a tautly streched, inclined membrane between digits I and II. In contrary, between digits II and III, the impressions indicate the presence of folds, proceeding between the tip of digit III and the base of digit II. This is consistent with the presence of an inclined membrane, which was not streched to its maximum possible extent, resulting in some drape. The interpretation as interdigital membrane traces is further strengthened by the largely undistorted preservation of lineaments across the palmar surface along the digits (especially in digit I), which are in continuity of the interdigital skin-folds. These features are contrasting to those which would be expected from compressional (microfolding) as well as extensional (microfaulting) deformation of the track margins, as in both the strike of resulting structures would mostly follow the outline of the impression.

In conclusion GZG.BA.0116 represents an exceptional quality of preservation including evidence of true webbing, and a largely accurate representation of the autopodial morphology which is yet unparalleled in the record of fossil turtle tracks.

Diversity of appendicular morphology in Early Cretaceous turtles

GZG.BA.0116 shows a mosaic of primitive and specialized, as well as unique key features, mostly related to aquatic adaptations. The trackmaker retained a plesiomorphic, broad and rather short autopodium. Advanced features include the proportionally slim phalanges, indicating that their function was not primarily focused upon weight-bearing, reduction of the unguals, and comprehensive webbing enclosing all digits, and protruding to the medial and lateral metapodium. The total absence of visible claws is unusual and unlike the condition in any extant turtle except for 
marine species with fully developed, elongate paddles. Another unusual feature is the relative elongation and robustness of the first digit, which reached the length of the other digits. Its angle of divarication and pronounced metacarpal-phalangeal joint further suggests a high degree of movability. In the basic turtle pattern the first digit is often build stoutly, although it normally not reached the length of the other digits. The morphology of digit I in GZG.BA.0116 therefore may be related to some additional specialization.

Its unique characters hint to an unknown diversity of appendicular morphology in Berriasian turtles with yet unknown appendicular osteology. The association of the track with basal pancryptodiran species suggests that this diversity may be nested deeply in the phylogeny of Testudines and characterize an early radiation of the cryptodiran stem-group.

Palaeoecological significance

Aside from the relative abundance in the deltaic and lacustrine deposits of the Obernkirchen Member no unambiguous, direct morphological or redundant ichnological evidence for the semiaquatic to aquatic habit of the Berriasian stem-group cryptodirans was yet present. GZG.BA.0116 clearly shows morphological character optimization of the producer for an aquatic habitat and lifestyle and supports previous palaeoecological models for these turtles (Karl et al. 2007a).

The sedimentary and palaeontological context, in which the turtle track was embedded, indicates that the habitat of the turtle included interdistributary bays or calm water bodies inundating inactive mouth-bars.

\section{Conclusions}

A well preserved isolated manus impression evidences the presence of advanced aquatic adaptations in the forelimb morphology of a Berriasian turtle. The size of the track and the associated turtle fauna strongly suggests that it was left by a stem-group cryptodiran.

The footprint shows an interesting mosaic of primitive, specialized, and potentially autapomorphic features. The basic turtle pattern is reflected by a short and broad autopodium. However, thin phalanges, claw reduction, and extensive interdigital webbing enclosing the digits and lateral and medial margins of the distal metapodium are clearly specialized features related to the aquatic environment. The proportional elongation of the first digit, that reached as far distally as the other digits and was probably highly mobile at the metacarpal-phalangeal joint, might represent an even higher level of specialisation.

The specimen gives redundant evidence on the aquatic habitat and locomotion of Berriasian turtles from the Obernkirchen Sandstone, otherwise only inferred by shell morphology. 


\section{Acknowledgments}

We thank M. Avanzini, P. Falkingham, W. Joyce, and M. Lockley for their reviews, and helpful as well as constructive comments on an earlier version of this article. We also thank H.-V. Karl for discussions and comments during early stages of this work and A. Böhme for technical assisstance and support during fieldwork.

\section{References}

Anquetin, J. 2011: Evolution and palaeoecology of early turtles: a review based on recent discoveries in the Middle Jurassic. Bulletin de la Societé géologique de France 182(3), 231-240.

Anquetin, J., Barrett, P.M., Jones, M.E.H., Moore-Fay, S. \& Evans, S.E. 2009: A new stem turtle from the Middle Jurassic of Scotland: new insights into the evolution and palaeoecology of basal turtles. Proceedings of the Royal Society of London (B: Biological Sciences) 276, 879-886.

Avanzini, M., García-Ramos, J.C., Lires, J., Menegon, M., Piñuela, L. \& Fernández, L.A. 2005: Turtle tracks from the Late Jurassic of Asturias, Spain. Acta Palaeontologica Polonica 50, 743-755.

Avanzini, M., Piñuela, L. \& García-Ramos, J.C. 2010: Preservational morphotypes of Crocodylopodus from the Late Jurassic of Asturias (Spain). In Milàn, J., Lucas, S.G., Lockley, M.G. \& Spielmann, J.A. (eds.): Crocodyle tracks and traces. New Mexico Museum of Natural History and Science Bulletin 51, 239-244.

Ballerstedt, M. 1905: Über Saurierfährten der Wealdenformation Bückeburgs. Naturwissenschaftliche Wochenschrift (Neue Folge) 4(31), 481-485.

Ballerstedt, M. 1921: Dinosaurier im Wealdensandstein des Harrl bei Bückeburg und eine zur Zeit freiliegende Spur eines “vierfüßigen” plumpen Dinosauriers. Zeitschrift der Deutschen Geologischen Gesellschaft 72, 231-233.

Baur, G. 1887: On the phylogenetic arrangement of the Sauropsida. Journal of Morphology 1(1), 93-104.

Bernier, P., Barale, G., Bourseau, J.P., Buffetaut, E., Demathieu, G., Gaillard, C. \& Gall, J.C. 1982: Trace nouvelle de locomotion de chélonien et figures d'émersion associées dans les calcaires lithographiques de Cerin (Kimméridgien supérieur, Ain, France). Geobios 15, 447-467.

Falkingham, P.L., Margetts, L., Smith, I. M. \& Manning, P. L., 2009: A Reinterpretation of Palmate and Semi-Palmate (Webbed) Fossil Tracks; Insights from Finite Element Modelling. Palaeogeography, Palaeoclimatology, Palaeoecology 271(1-2), 69-76.

Farlow, J.O. \& Elsey, R.M. 2010: Footprints and trackways of the American alligator, Rockefeller Wildlife Refuge, Louisiana. In Milàn, J., Lucas, S.G., Lockley, M.G. \& Spielmann, J.A. (eds.): Crocodyle tracks and traces. New Mexico Museum of Natural History and Science Bulletin 51, 31-39.

Fernández, M.S. \& de la Fuente, M.S. 1988: Una nueva tortuga (Cryptodira: Thalassemydidae) de la Formación Vaca Muerta (Jurásico: Titoniano) de la provincia del Neuquén, Argentina. Ameghiniana 25, 129-138.

Foster, J.R., Lockley, M.G. \& Brockett, J. 1999: Possible turtle tracks from the Morrison Formation of southern Utah. In 
Gillette, D.D. (ed): Vertebrate Paleontology in Utah, Utah Geological Survey, Miscellaneous Publication 99-1, 185-191.

de la Fuente, M.S. \& Fernández, M.S. 2011: An unusual pattern of limb morphology in the Tithonian marine turtle Neusticemys neuquina from the Vaca Muerta Formation, Neuquén Basin, Argentina. Lethaia 44, 15-25.

Fuentes Vidarte, C., Meijede Calvo, M., Meijede Fuentes Calvo, F. \& Meijede Fuentes Calvo, M. 2003: Rastro de un tetrapodo de pequeño tamaño en el Weald de Cameros (Sierra de Oncala, Soria, España) nov. icnogen. nov. icnosp.: Emydhipus cameroi. In Perez Lorente, F. (ed.): Dinosaurios e otros reptiles mesozoicos en España. Instituto de Estudios Riojanos (Logroño) - Ciencias de la Terra 26, 119-128.

Gaffney, E.S. 1990: The comparative osteology of the Triassic turtle Proganochelys. Bulletin of the American Museum of Natural History 194, 1-263.

Gaillard, C., Bernier, B., Barale, G., Bourseau, J.-P., Buffetaut, E., Ezquerra, R., Gall, J.-C., de Lapparent de Broin, F., Renous, S. \& Wenz, S. 2003: A giant Upper Jurassic turtle revealed by its trackways. Lethaia 36, 315-322.

Grupe, 0. 1933: Erläuterungen zur geologischen Karte von Preußen und benachbarter deutscher Länder. Blatt Bückeburg (Lfg. 330/2017), 69 pp. Berlin, Preußische Geologische Landesanstalt.

Hornung, J. J., Karl, H.-V. \& Reich, M. 2008: An exquisitely preserved turtle footprint from the Berriasian (lowermost Cretaceous) of northwestern Germany. In Löffler, S.B. \& Freiwald, A (eds.): Jahrestagung der Paläontologischen Gesellschaft. 8.-10. September 2008, Erlangen. Erlanger geologische Abhandlungen, Sonderband 6, 91-92.

Hornung, J.J., Böhme, A., van der Lubbe, T., Reich, M. \& Richter, A. 2012a: Vertebrate tracksites in the Obernkirchen Sandstone (Bückeberg Formation, late Berriasian, Early Cretaceous) of northwest Germany - their stratigraphical, palaeogeographical, palaeoecological, and historical context. Paläontologische Zeitschrift 86, 231-267.

Hornung, J.J., Böhme, A. \& Reich, M. 2012b: Excursion Guide A2: Harrl hill near Bückeburg. In Richter, A. \& Reich, M. (eds.): Dinosaur Tracks 2011. An International Symposium, Obernkirchen, April 14-17, 2011, Abstract Volume and Field Guide to Excursions., 101-112 pp., Universitätsverlag Göttingen, Göttingen.

Joyce, W.G. 2000: The first complete skeleton of Solnhofia parsonsi (Cryptodira, Eurysternidae) from the Upper Jurassic of Germany. Journal of Paleontology 74, 684-700.

Joyce, W.G. 2003: A new Late Jurassic turtle specimen and the taxonomy of Palaeomedusa testa and Eurysternum wagleri. PaleoBios 23(3), 1-8.

Joyce, W.G. 2007: Phylogenetic Relationships of Mesozoic Turtles. Bulletin of the Peabody Museum of Natural History 48, 3-102.

Joyce, W.G. \& Gauthier, J.A. 2004: Palaeoecology of Triassic stem turtles sheds new light on turtle origins. Proceedings of the Royal Society of London (Biological Sciences) 271, 1-5.

Karl, H.-V. 2012: Testudimorpha I. Index Ichnia et Ova Testudinarum fossilium, Testudinata permotriadica. Fossilium Catalogus. I: Animalia. Pars 149, 1-20.

Karl, H.-V. \& Tichy, G. 2006: Altmühltal: neue Schildkrötenfunde im Plattenkalk. Biologie in unserer Zeit 36, 214-215.

Karl, H.-V., Gehler, A., Roden, V.J. \& Reich, M. 2007a: Die Schildkröten des nordwestdeutschen “Wealden” (Unter-Kreide: Berriasium) und ihre Palökologie. In Elicki, 0. \& Schneider, J.W. (eds): Fossile Ökosysteme. 77. Jahrestagung der Paläontologischen Gesellschaft. Kurzfassungen der Vorträge und Poster. Technische Universität Bergakademie 
Freiberg, Institut für Geologie, Wissenschaftliche Mitteilungen 36, 64-65.

Karl, H.-V., Staesche, U., Tichy, G., Lehmann, J. \& Peitz, S. 2007b: Systematik der Schildkröten (Anapsida: Chelonii) aus Oberjura und Unterkreide von Nordwestdeutschland. Geologisches Jahrbuch (B: Regionale Geologie Ausland) 9, 5-89.

Karl, H.-V., Valdiserri, D. \& Tichy, G. 2012: New material of the chelonian ichnotaxon Emydhipus cameroi Fuentes Vidarte et al., 2003 from the Berriasian (Lowermost Cretaceous) of Northern Germany. Studia Palaeocheloniologica 4, 103-113.

Landesamt für Bergbau, Energie und Geologie Niedersachsen, 2013: Geodatenzentrum Hannover, NIBIS Kartenserver. http://nibis.lbeg.de/cardomap3/

Li, C., Wu, X.-C., Rieppel, O., Wang, L.-T. \& Zhao, L.-J. 2008: An ancestral turtle from the Late Triassic of southwestern China. Nature 456, 497-501.

Lockley, M.G. \& Foster, J.R. 2006: Dinosaur and turtle tracks from the Morrison Formation (Upper Jurassic) of Colorado National Monument, with observations on the taxonomy of vertebrate swim tracks. In Foster, J.R. \& Lucas, S.G. (eds.): Paleontology and Geology of the Upper Jurassic Morrison Formation. New Mexico Museum of Natural History and Science Bulletin 36, 193-198.

Manning, P. L. 2004. A new approach to the analysis and interpretation of tracks: examples from the dinosauria. In McIlroy, D. (ed): The Application of Ichnology to Palaeoenvironmental and Stratigraphic Analysis. Geological Society, London, Special Publications 228, 93-123.

Moratalla, J. \& Hernán, J. 2009: Turtle and pterosaur tracks from the Los Cayos dinosaur tracksite, Cameros Basin (Cornago, La Rioja, Spain): tracking the Lower Cretaceous biodiversity. Revista Española de Paleontología, 24(1), 5977.

Mutterlose, J. 1997: Lower Cretaceous. In Mutterlose, J., Wippich, M.G.E. \& Geisen, M. (eds): Cretaceous Depositional Environments of NW Germany. Bochumer Geologische und Geotechnische Arbeiten 46, 123-128.

Olsen, P.E. \& Padian, K. 1986: Earliest records of Batrachopus from the soutwestern United States, and a revision of some Early Mesozoic crocodylomorph genera. In Padian, K. (ed.): The Beginning of the Age of Dinosaurs, Faunal Change Across the Triassic-Jurassic Boundary, 259-273. New York, Cambridge University Press.

Owen, R. 1842: Report on British fossil reptiles, part II. Report for the British Association for the Advancement of Science, Plymouth 11 [1841], 60-204.

Peitz, S. 1998: Schildkröten der deutschen Wealden-Fazies - Ein Einblick in die Ballerstedtsche Sammlung. In Maisch, M.W. \& Matzke, A.T. (eds): 2. Treffen der deutschsprachigen Paläoherpetologen, Tübingen 27.02.-01.03.1998. Extended Abstracts, 12-18. Tübingen.

Pelzer, G. 1998: Sedimentologie und Palynologie der Wealden-Fazies im Hannoverschen Bergland. Courier Forschungsinstitut Senckenberg 207, 1-211.

Reisz, R.R. \& Head, J.J. 2008: Palaeontology: Turtle origins out to sea. Nature 456, 450-451.

Rivera, A.RV \& Blob, R.W. 2010: Forelimb kinematics and motor patterns of the slider turtle (Trachemys scripta) during swimming and walking: shared and novel strategies for meeting locomotor demands of water and land. Journal of Experimental Biology 213(20), 3515-3526. 
Roemer, F.A. 1836. Die Versteinerungen des nord-deutschen Oolithen-Gebirges. 59 pp. Hannover, Hahn.

Scheyer, T.M. \& Sander, P.M. 2007: Shell bone histology indicates terrestrial palaeoecology of basal turtles. Proceedings of the Royal Society (B: Biological Sciences) 274, 1885-1893.

Schott, W., Jaritz, W., Kockel, F., Sames, C.W., von Stackelberg, U., Stets, J., Stoppel, D., Baldschuhn, R. \& Krampe, K.-D. 1967: Paläogeographischer Atlas. In Bundesanstalt für Bodenforschung (ed): Paläogeographischer Atlas der Unterkreide von Nordwest-Deutschland mit einer Übersichtsdarstellung des nördlichen Mitteleuropa, 289 pp. Hannover, Bundesanstalt für Bodenforschung.

Steel, R. 1973: Crocodylia. Handbuch der Paläoherpetologie, Teil 16 [Encyclopedia of Paleoherpetology, Part 16], VIII+116 pp. Stuttgart, Gustav Fischer Verlag.

Wright, J.L. \& Lockley, M.G. 2001: Dinosaur and turtle tracks from the Laramie/Arapahoe formations (Upper Cretaceous), near Denver, Colorado, U.S.A. Cretaceous Research 22, 365-376.

Zug, G.R. 1971: Buoyancy, locomotion, morphology of the pelvic girdle and hindlimb, and systematics of cryptodiran turtles. Miscellaneous Publications, Museum of Zoology, University of Michigan 142, 1-98. 
IX. Appendicular morphology in Early Cretaceous turtles

$-240-$ 
Chapter X

The first record of the pterosaur ichnogenus Purbeckopus in the late Berriasian (Early Cretaceous) of northwest Germany 
Published in:

Ichnos, 20: 193-201 [2013, in press].

\title{
The first record of the pterosaur ichnogenus Purbeckopus in the late Berriasian (Early Cretaceous) of northwest Germany
}

\author{
JAHN J. HORNUNG ${ }^{1}$ and MIKE REICH ${ }^{1,2}$ \\ ${ }^{1}$ Department of Geobiology, Geoscience Centre, Georg-August University of Göttingen, Germany \\ ${ }^{2}$ Museum, Collections \& Geopark, Geoscience Centre, Georg-August University of Göttingen, Germany
}

\begin{abstract}
A hypichnium of a manus imprint (preserved as plaster cast) indicates for the first time the presence of the large pterosaur ichnotaxon Purbeckopus cf. pentadactylus Delair, 1963 in the late Berriasian of northwest Germany. It is only the second record of Purbeckopus globally and the first pterosaur track from Germany. It provides evidence of a very large pterosaur (wingspan c. $6 \mathrm{~m}$ ) in this area and from this time period, which are not yet represented by skeletal remains. When compared to the English type material, the specimen exhibits some differences that are related mostly to different properties of the substrate on which both were left. These include, in the German track, an impression of the metacarpo-phalangeal joint of the wing finger, normally not present in pterosaur tracks. Also interesting is the rather blunt termination of the deeply impressed digits I-III, indicating rather short and blunt claws, which seem more suitable for walking than for grasping or climbing.

The specimens of Purbeckopus in England and Germany occur in different environments: the English locality was situated close to a brackish lagoon, while the German site belongs to a limnicdeltaic system at the margin of a large, freshwater lake.
\end{abstract}

Keywords Pterosaur track, Purbeckopus pentadactylus, Early Cretaceous, Bückeburg, northwest Germany

\section{Introduction}

Although they have been disputed for a long time, tracks made by pterosaurs during terrestrial locomotion have been well established in vertebrate ichnology in recent years (e. g., Unwin, 1997; Mazin et al., 2003) and are known from many Jurassic and Cretaceous localities around the world (see Lockley et al., [2008] for an overview). Most Late Jurassic-earliest Cretaceous examples were created by small individuals, which accords to the majority of the osteological record from this timespan (maximum wingspan 2.5 m; e.g., Wellnhofer, 1991; Meyer and Hunt, 1999; Barrett et al., 2008). Extremely rare skeletal remains suggest that pterosaurs with a 
wingspan up to 3.5-5.0 m already existed in the Late Jurassic (Meyer and Hunt 1999), and the ichnogenus Purbeckopus Delair, 1963, so far known only from the Berriasian of southern England, indicates that very large pterosaurs occurred as early as in the basal Cretaceous (Wright et al., 1997).

Here we report a second occurrence of this ichnogenus from the Berriasian of Germany (Figs. X.1-X.2). This record is based on historical material kept at the Geoscience Centre, University of Göttingen (GZG). The specimen consists of a plaster cast (hypichnial relief) of a well-preserved manus impression (Figs. X.3-X.4). Two notes on its back side (Fig. X.4b) elucidate the history of the specimen: it was presented, in May 1935, by collector Max Ballerstedt to Othenio Abel, then professor of paleontology at Göttingen, which is confirmed in the latter's own handwriting:

"Geschenk von Professor Ballerstedt an Abel, Mai 1935"

"[Presented to Abel by Professor Ballerstedt, May 1935]"

(Translated from German)

According to a second note (translated below), in the handwriting of Ballerstedt, he found it at Harrl hill, a locality close to his hometown of Bückeburg at which he had collected dinosaur tracks since the early $20^{\text {th }}$ century. Aside from this note and the cast, there is no trace of the original specimen. If it was ever collected, and not merely cast in situ in the field, it might be lost, as happened with some other specimens from the Ballerstedt collection after 1945. Though there is an incomplete, unpublished, written record of the Ballerstedt collection (Hornung and Reich, 2007) there is no hint of this specimen in the archive. When Abel returned to his homeland, Austria, for retirement in 1940, he left behind some specimens from his private collection, including the one here under consideration.

A third note on the back of the specimen identifies it as "Iguanodon", as many other tracks from this stratum. According to F. Langenstrassen (GZG, pers. com. 2012), this note dates from the 1960s. However, a close examination of this specimen showed that it is not congruent with any known morphotype of dinosaur track, but closely resembles the pterosaurian ichnogenus Purbeckopus. Here we provide a detailed description and interpretation of this specimen.

\section{Methods}

The stereo images were created with a Fujifilm Finepix True 3D W1 digital stereo camera.

Institutional Abbreviations

DORCM: Dorset County Museum, Dorchester, Dorset, UK; GZG.IF.: Ichnofossil collection, Geoscience Centre, University of Göttingen, Göttingen, Germany; NHM: Natural History Museum, London, UK, SMC: Sedgwick Museum, University of Cambridge, Cambridge, UK. 


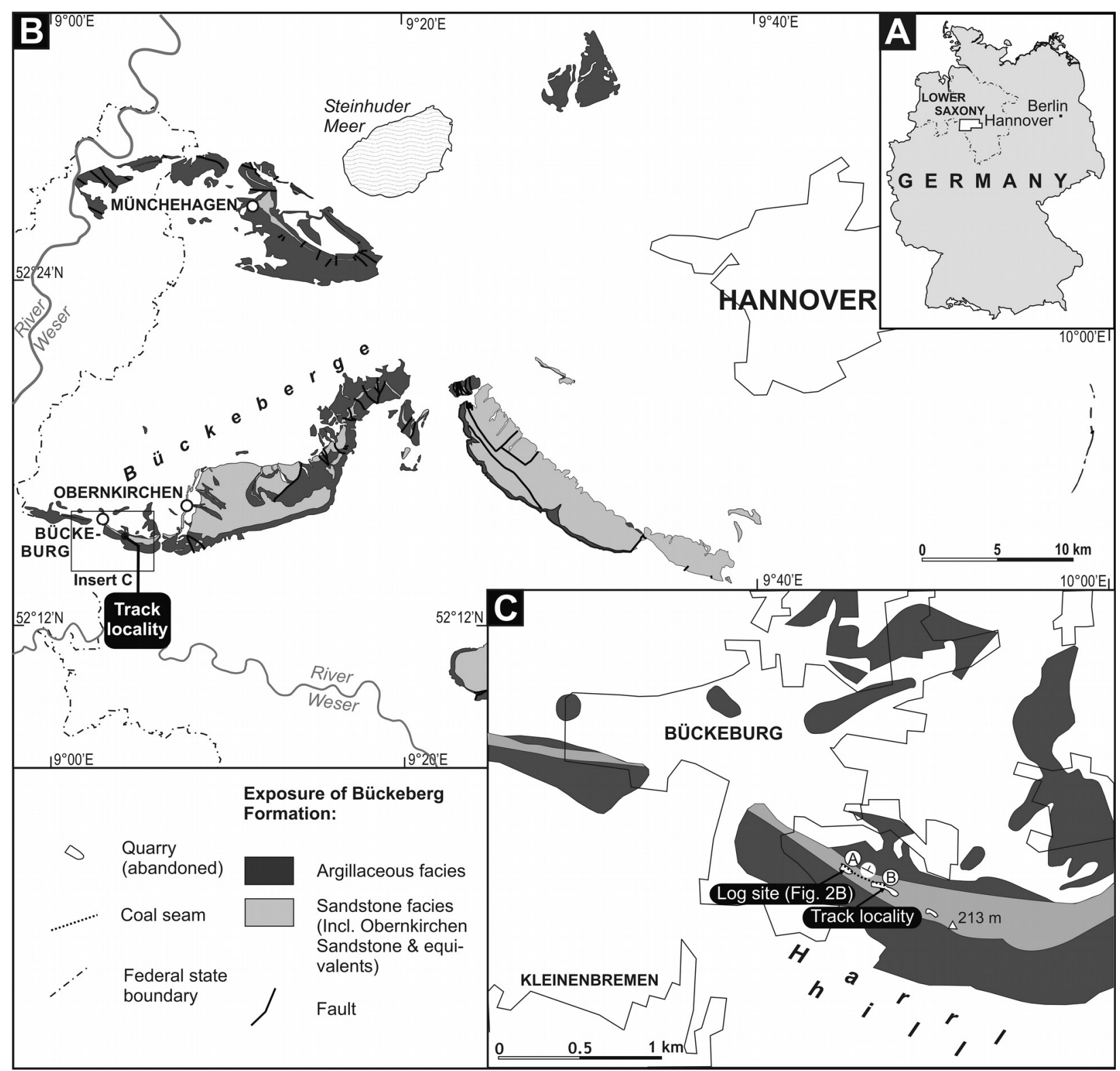

Fig. X.1 (A-C) Exposure of the Bückeberg Formation and locality map. Geology after Landesamt für Bergbau, Energie und Geologie Niedersachsen (2012).

\section{Geological Setting}

Ballerstedt's note on the back side (Fig. 4b) of the cast details the locality and stratum as:

"Harrl-Steinbruch[.] Aus den Schichten zwischen dem ersten u[nd]. zweiten Kohlenflöz (von oben nach unten gerechnet)."

[Harrl quarry[.] From the strata between the first a[nd] the second coal seam (as counted from top to base).].

(Translated from German) 
The (main) quarry on Harrl hill (Figs. X.1-X.2) is located c. $2 \mathrm{~km}$ east of the town of Bückeburg, about $50 \mathrm{~km}$ southwest of Hannover, Lower Saxony (locality 6 in Hornung et al., 2012a). During the $19^{\text {th }}$ century, the outcrop produced a number of important vertebrate fossils including, among others, the enigmatic small dinosaur Stenopelix valdensis von Meyer, 1857 and the crocodylian Pholidosaurus schaumburgensis von Meyer, 1841. The skeletal remains are augmented by a rich vertebrate ichnofauna, including theropod, ornithopod, ankylosaur, and turtle tracks (Ballerstedt, 1905, 1921, 1922; Nopcsa, 1923; Hornung et al., 2012a, 2012b). Lithofacies and palaeontology of the succession indicates a distal deltaic mouth-bar setting (Pelzer, 1998; Hornung et al., 2012b).

At present, the old quarry is only partly accessible and a lithological log is only available from a smaller outcrop c. $350 \mathrm{~m}$ to the west, which shows the upper part of the succession mentioned on the specimen (Fig. X.2c). The lower coal seam is not exposed at present, but is located a short distance below the base of the exposure. The upper coal seam forms a readily recognizable horizon in the upper part of the quarry wall. In conformity with the note on the cast, Ballerstedt (in Grupe, 1933) reported that track occurrences were confined to the sand- to siltstone interval between the coal-seams. A track horizon with ornithopod tracks and local dinoturbation exists c. $1.3 \mathrm{~m}$ below the upper (first) coal-seam, which is probably the same horizon that was exploited by Max Ballerstedt in the early $20^{\text {th }}$ century (Pelzer, 1998; Hornung et al., 2012b). It is reasonable that the track from which Abel's cast was made originated from this horizon.

The exposed succession pertains to the local stratigraphic equivalent of the Obernkirchen Sandstone, a sandy, deltaic succession, deposited at the southeastern margin of the Lower Saxony Basin (LSB, Figs. X.2a-b). It forms part of the Obernkirchen Member the of lower Bückeberg Formation. The Bückeberg Formation is a predominantly limnic deposit, ranging from midBerriasian to early Valanginian (Kemper, 1973; Casey et al., 1975). The relatively thin tongue of the Obernkirchen Sandstone and its lateral equivalents date to the late Berriasian (Cypridea alta formosa ostracod subzone; Mutterlose, 2000). Its lithology is dominated by fine-grained, mature, quartzose sandstones with intercalated, thin mudstones and local coal seams.

\section{Systematic Ichnology}

Pterosauria Kaup, 1834

Ichnogenus Purbeckopus Delair, 1963

Type ichnospecies: Purbeckopus pentadactylus Delair, 1963.

\section{Ichnospecies Purbeckopus cf. pentadactylus Delair, 1963}

Material GZG.IF.00102, plaster cast of the impression of a right manus, preserved as hypichnium (Figs X.3a-b, X.4).

Locality and Horizon Old quarry on Harrl hill, c. 2 km east of Bückeburg, Lower Saxony, NW 


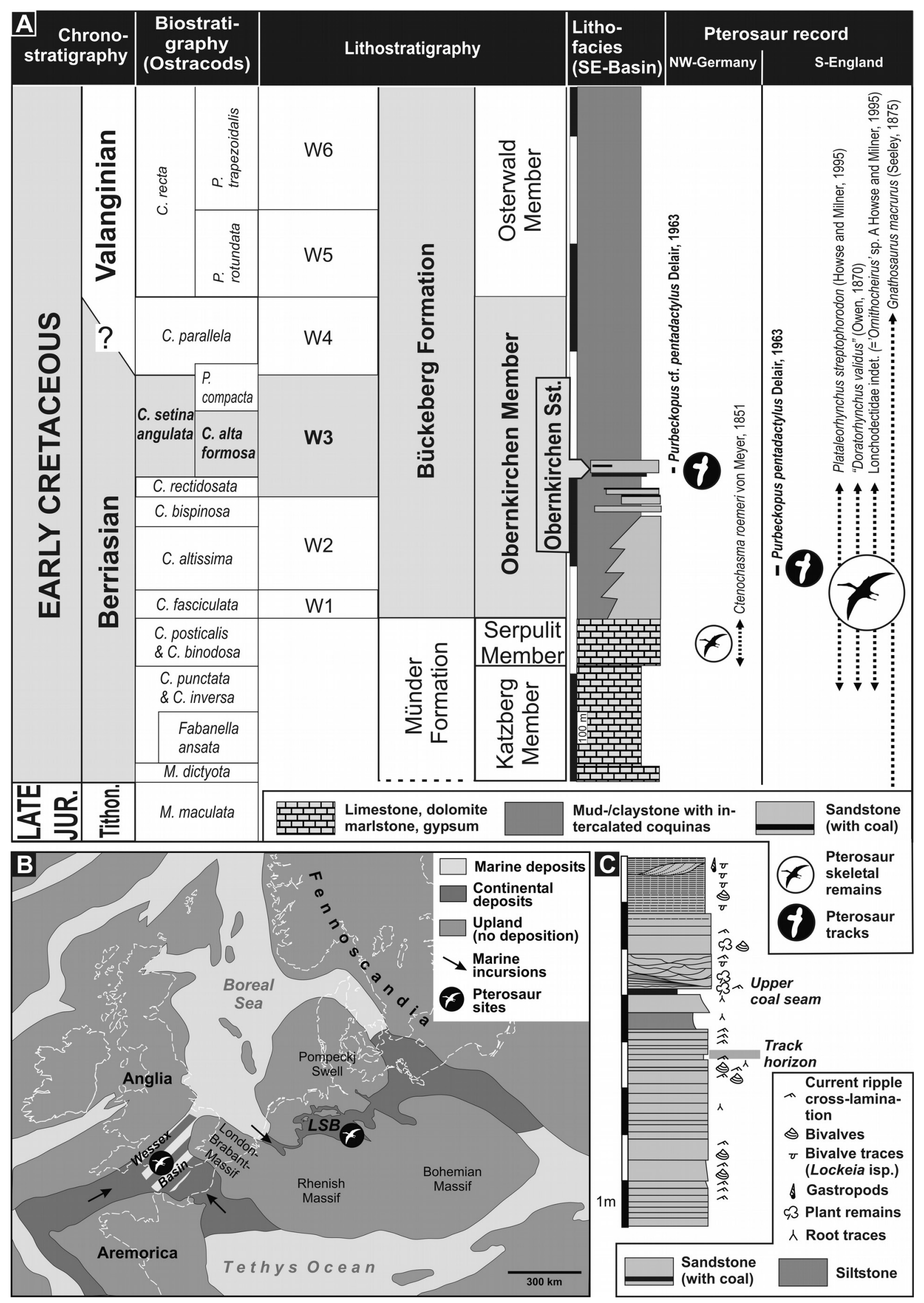


Fig. X.2 (A) Stratigraphy of the Bückeberg Formation (redrawn after Kemper, 1973; Elstner and Mutterlose, 1996; Mutterlose, 2000, and others, modified) and distribution of pterosaur tracks and taxa in the Berriasian of Germany and southern England (Purbeck Limestone Group, after Howse and Milner, 1995). Note that the stratigraphic occurrence of the skeletal remains is uncertain in the range of the dashed arrows. Correlation of the English occurrences to the German stratigraphic scale is based upon Hoedemaker and Herngreen (2003). (B) Paleogeo-graphy of central Europe during the Berriasian, redrawn after Mutterlose (1997), modified. The diagonally hatched area in the Wessex Basin indicates brackish conditions during deposition of the upper Intermarine Beds, Durlston Formation (Batten, 2002), which are the stratum typicum of Purbeckopus pentadactylus. White, broken lines represent presentday coastlines. (C) Lithological log of the upper part of the sandstone succession near the upper coal seam, c. $350 \mathrm{~m}$ W of the main outcrop that yielded the bulk of vertebrate tracks (see text for details). GZG.IF.00102 came from the interval below the upper coal seam, possibly from the indicated (dinosaur) track horizon. Based on Pelzer (1998) and own observations (Hornung et al., 2012b).

W1 to W6: "Wealden 1" to "Wealden 6" (Wolburg 1949); C.: Cypridea; M.: Macrodentina; P.: Pachycytheridea.

Germany; Obernkirchen Sandstone equivalent, Obernkirchen Member, Bückeberg Formation, upper Berriasian, Lower Cretaceous.

Description The hypichnial relief consists of the casts of three digits splayed over an angle of $150^{\circ}$ between digits I and III. The interdigital angle between digits II and III is $\sim 100^{\circ}$; that between digits I and II $\sim 50^{\circ}$. Digits I and II are subequal in length (6.5 and $6.2 \mathrm{~cm}$, respectively) while digit III is longer $(8.0 \mathrm{~cm}$ ). The latter is, however, more slender (max width $3.5 \mathrm{~cm}$ ) than the the other digits (digit I: $4.0 \mathrm{~cm}$, digit II: $4.4 \mathrm{~cm}$ ). Digits II and III are more solidly connected at their shared base than are digits II and I. The shape of digits I and II reflects the presence of a single, "fleshy" phalangeal pad, while such a structure is not so distinct in digit III. The posterior margin of the impression of digit I shows a "duplication" or "emargination" which that might have resulted from movement of the digit during track formation, or a collapse of the over-steepened margin of the impression. Proximal to the bases of the digits is a subovate impression, which is slightly less conspicuous and deeply impressed than those of the digits. Though the tips of all digits taper distally, and are delimited distally, no distinct, pointed claw-marks can be recognized. However, the impression of digit II terminates in an equilateral-triangular area covered by proximo-distally oriented striations. This feature might represent the impression of a rather blunt, short claw.

Remarks The morphology and dimensions of GZG.IF.00102 accord well with to those described and figured for the manus in the type material of $P$. pentadactylus from the Berriasian Durlston Formation (Purbeck Limestone Group) of the Wessex Basin, southern England (DORCM G6664, Wright et al., 1997: figs. 3 and 5, here Fig. X.3c). Diagnostic characters include the short, stubby, and "fleshy" digits I and II and the lack of pointed claw marks. The only significant difference, the presence of a subovate impression proximal to the digital convergence in the German material, can be unambiguously referred to differences in preservation. In DORCM G6664, the tracks are preserved as very shallow, epichnial reliefs (depth $\sim 0.5 \mathrm{~cm}$ ). The preservation of the subovate structure would have required a deeper substrate impression (as in the up to $3.9 \mathrm{~cm}$ depth in GZG.IF.00102) than clearly was available to the track maker of the English material. Considering 

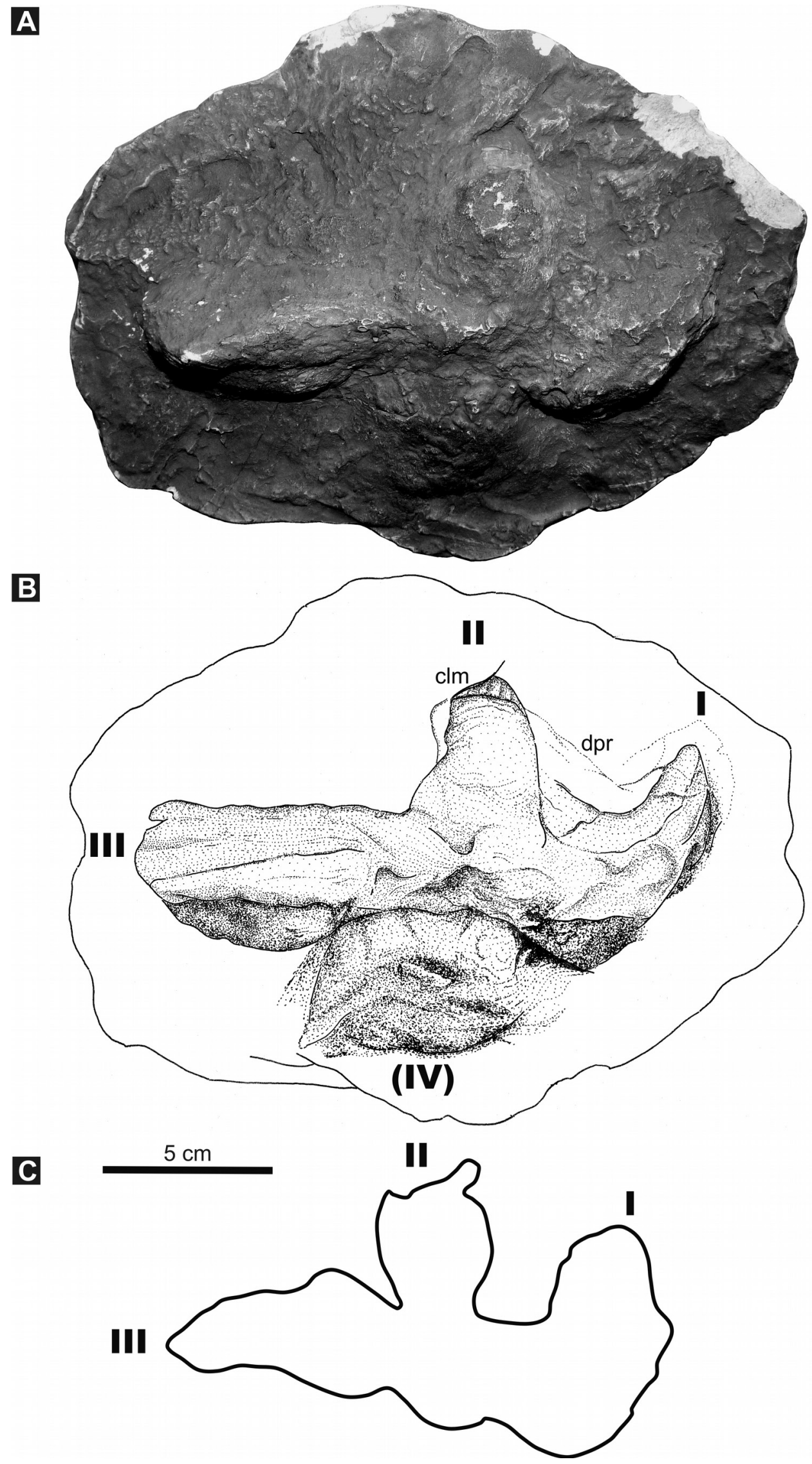

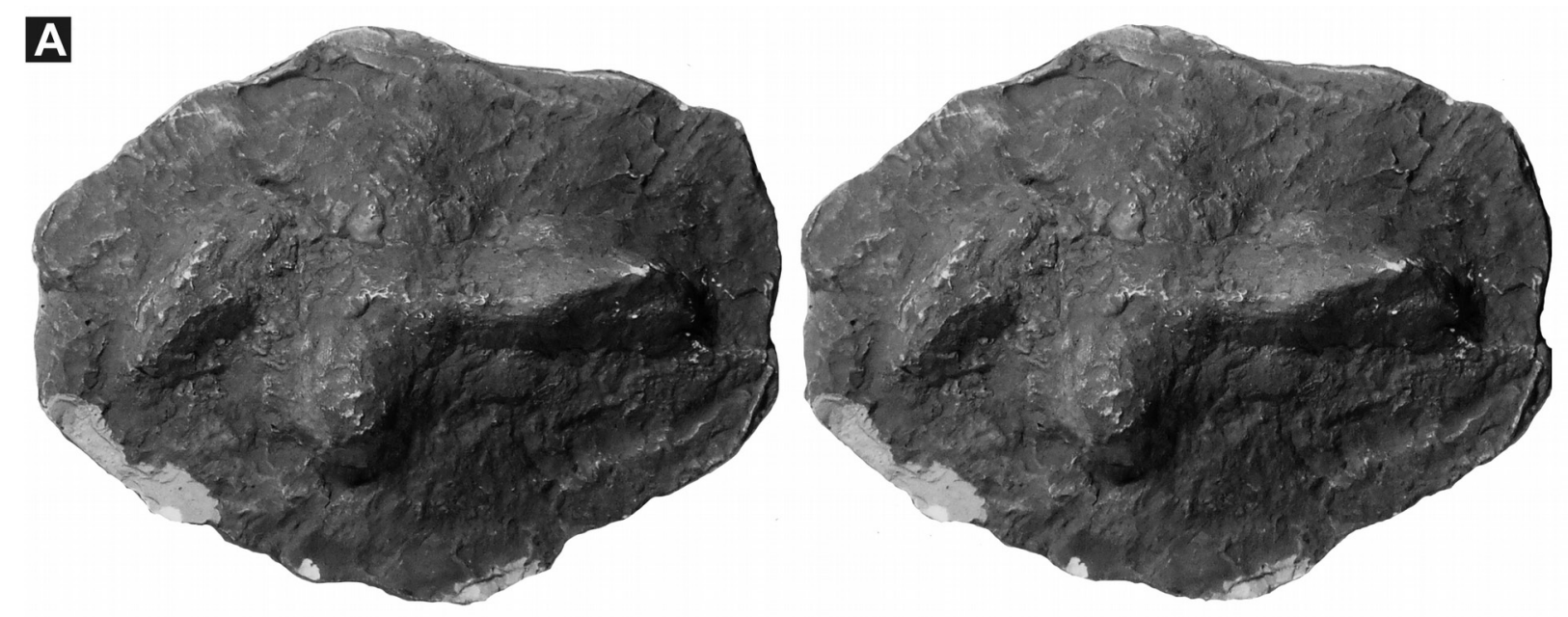

$5 \mathrm{~cm}$
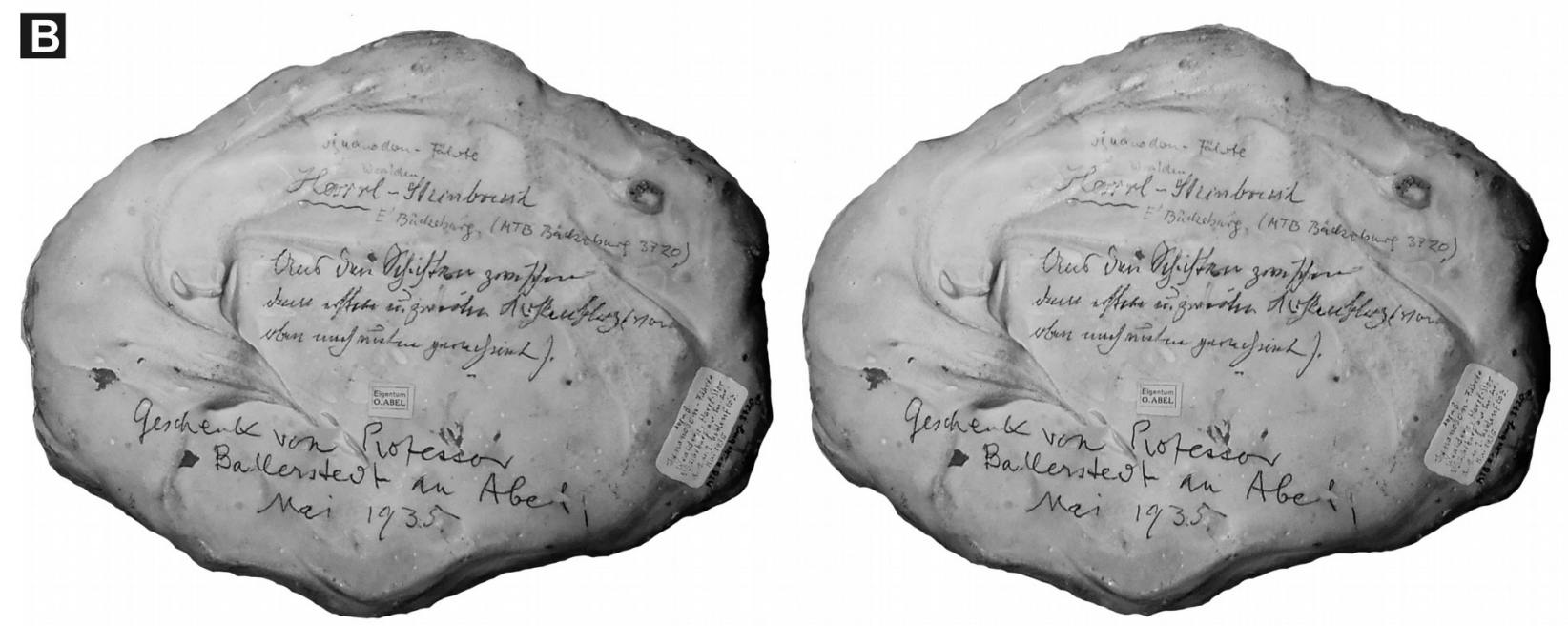

Fig. X.3 (A-B) Purbeckopus cf. pentadactylus Delair, 1963, GZG.IF.00102 (leg. M. Ballerstedt, ex coll. O. Abel), manus track, plaster cast of hypichnium; from the Obernkirchen Sandstone equivalent, Obernkirchen Member, Bückeberg Formation, late Berriasian of Harrl hill near Bückeburg, Lower Saxony. (A) photography and (B) interpretative drawing. (C) Purbeckopus pentadactylus Delair, 1963, DORCM G6664, ichnoholotype, outline of manus track, epichnial relief (M2 of Wright et al., 1997); from the 'roach stone', Intermarine Beds, Stair Hole Member, Durlston Formation, upper Middle Purbeck Limestone Group, late Berriasian, of Chinchen's Quarry near Langton Matravers, Dorset, England. Redrawn after Wright et al. (1997: fig. 5d), modified.

I to III: digits I to III; (IV): impression of the metacarpo-phalangeal joint of digit IV (wing finger); clm: claw-mark; dpr: displacement rim. Drawn to the same scale.

A Fig. X.4 Purbeckopus cf. pentadactylus Delair, 1963, GZG.IF.00102, stereo images. (A) front side, note different lighting compared to Fig. X.3. (B) Back side with various labels. The text in the center is in the handwriting of M. Ballerstedt, that one near the bottom is in that of $\mathrm{O}$. Abel (see text for transcriptions and translation). 
these similarities, the only reason not to unequivocally refer the German specimen to the ichnospecies P. pentadactylus properly is the current unavailability of pes tracks.

\section{Discussion}

Though it was considered a rather enigmatic vertebrate ichnotaxon for decades (Delair, 1963; Walkden and Oppé, 1969; MacFayden, 1970; Haubold, 1971; Delair and Lander, 1973; Sarjeant, 1974; Ensom 1984, 1986), Purbeckopus was finally identified as pterosaur track by M. G. Lockley in Wright et al. (1997; see also Ensom, 2002a; Lockley et al., 2008; Witton, 2010). BillonBruyat and Mazin (2003) questioned the affiliation of the tracks with pterosaurs, arguing that there is no clear manus-pes association identifiable in the available material. They also criticized the alleged presence of elongate penultimate phalanges - a diagnostic feature of pterosaur feet (Unwin, 1997) - as ambiguous on the ichnoholotype and referred material. However, other features also support a pterosaur origin of Purbeckopus, including the subequal lengths of pedal digits (Wright et al., 1997) and the proximal offset of the metapodial-phalangeal joint in pedal digit IV. The proportions and arrangement of the manual digits are also known exclusively in pterosaur tracks. Therefore, the closely associated manus and pes morphotypes individually exhibit characters typical of pterosaurs. Additionally, pterosaur appendicular anatomy allowed for a wide range of relative positions of the manus with respect to the pes if the animal was not walking in a straight direction. We therefore agree with Lockley et al. (2008) in confirming an assignment of Purbeckopus to a pterosaurian track maker. Currently, it represents one of only three or four diagnosable pterosaur ichnogenera and contains only its type ichnospecies (Lockley et al., 2008; Sánchez-Hernández et al., 2009).

GZG.IF.00102 is the first fossil track from Germany that can be related to a pterosaur with reasonable confidence. Historically, the first ichnofossils ever assigned to this clade was an enigmatic trackway from the Late Jurassic of Bavaria (Kouphichnium lithographicum (Oppel, 1862); see Figuier, 1866: fig. 116), but this was later identified as the trace of a limulid (Caster, 1940). Despite the abundance of pterosaur body fossils in the Jurassic of southern Germany, no tracks from the region have since been published (Lockley et al., 2008).

The size of P. pentadactylus clearly indicates a large pterosaurian track maker, with an estimated wingspan of about $6 \mathrm{~m}$ (Wright et al., 1997). The dimensions of GZG.IF.00102 corroborates this size for the German occurrence. Unfortunately the osteological record of very large pterosaurs from the basal Cretaceous is very scanty (e.g., Barrett et al. 2008).

Howse and Milner (1995) reviewed skeletal material from the Purbeck Limestone Group. The precise stratigraphic origins are unknown for this material, though most is labelled as from the "Middle Purbeck Limestone", which corresponds to the upper Worbarrow Tout Member (Lulworth Formation) and the Stair Hole Member (Durlston Formation) and spans a stratigraphic range from the base of the Cretaceous to the lower German "Wealden 3" (top of the Cypridea rectidorsata ostracod zone, Ensom, 2002b; Hoedemaker and Herngreen, 2003; Fig. 2a).

Plataleorhynchus streptophorodon Howse and Milner, 1995, a gnathosaurine ctenochasmatid 
known from a partial upper jaw (NHM R.11957), has an estimated skull length of $40 \mathrm{~cm}$ (Howse and Milner, 1995). Compared to the proportions in other, more completely known ctenochasmatids (e.g., Bennett, 2007) this allows an estimate of its wingspan as about 2-3 m.

Gnathosaurus macrurus (Seeley, 1875) was redescribed by Howse and Milner (1995) from its rostrum (SMC J5339); however, Andres and Ji (2008) argued that a a $10.9 \mathrm{~cm}$-long mid-cervical vertebra (SMC J5340, Howse, 1986), associated with the holotype according to Seeley $(1869,1875)$, can be referred to the same species. Compared to the size of the more completely known ctenochasmatid Elanodactylus prolatus Andres and Ji, 2008, which has similarly elongate cervical vertebrae, the wingspan of $G$. macrurus may have been approximately $2.8 \mathrm{~m}$.

The lower jaw of an unnamed lonchodectid (NHM R.11958, "Ornithocheirus sp. A" of Howse and Milner, 1995) is too incomplete to assess skull length with any confidence but the wingspan of this pterosaur was probably much smaller than $5 \mathrm{~m}$.

A large wing phalanx (NHM 40653, holotype of Doratorhynchus validus [Owen, 1870], Seeley, 1875) from the Purbeck Group indicates a pterosaur with a wingspan of about $5 \mathrm{~m}$, close in size to the producer of $P$. pentadactylus. However, the phalanx is not sufficient for identification beyond Pterodactyloidea incertae sedis (Howse and Milner, 1995).

The size of Coloborhynchus clavirostris Owen, 1874, an ornithocheirid from the Valanginian Wadhurst Clay Formation of East Sussex, England (Rodrigues and Kellner, 2008; Martill et al., 2011), is difficult to estimate because the type and only specimen consists of the rostral tip of the fused premaxillae. Its general size, in comparison to similar genera, suggests that it's skull measured around $50 \mathrm{~cm}$ and the wingspan may have been in the range of 3-5 $\mathrm{m}$.

The Berriasian record of pterosaurs from Germany is even more scarce, consisting so far only of the holotype mandibular fragment of Ctenochasma roemeri von Meyer, 1851, from the upper Münder Formation of the Deister mountains, Lower Saxony, which underlies the Bückeberg Formation (Bennett, 2007; Barrett et al., 2008). This animal was however small-sized, with a wingspan less than $1 \mathrm{~m}$. Therefore, the track record provides an important documentation of very large to giant pterosaurs, albeit of yet unknown affinities, in the basalmost Cretaceous.

The most important difference between GZG.IF.00102 and the English type material of Purbeckopus is the depth of substrate intrusion of the manus, which was enabled by softer sediment in the German material. This reveals a feature not known from the type specimen: a mediolaterally ovate depression posterior to the bases of digits I to III. This depression was formed by the metacarpo-phalangeal joint of digit IV, which was normally kept aloft from the substrate during quadrupedal locomotion in pterosaurs (e.g., Unwin, 1997). However, when the forelimb sank deeply into a soft substrate, the joint also left an impression.

The rather blunt, but clearly delimited, deeply impressed terminations of digits I-III also indicate that the claws on these fingers were apparently short and not very sharp. A more distinct delimitation of the claw in digit II may be related to preservational reasons. The bluntness of claws contrasts the condition in most small pterosaurs in which the claws are sharp, narrow, pointed, and recurved. In these small pterosaurs, the claws potentially functioned in grasping and clinging to steep surfaces, but this habit seems to be unsuitable for large species. The short, possibly worn, keratineous claws support the hypotheses that the forelimbs were regularly used for quadrupedal 
locomotion, possibly during foraging, at least in some species of large pterosaurs (e.g., in azhdarchids; Witton and Naish, 2008).

The paleoenvironment of the type locality and stratum of Purbeckopus pentadactylus was considered to be supratidal, storm-accumulated shell lags, fringing a shallow, brackish lagoon (ElShahat and West, 1983; Wright et al., 1997). Though the exact location of the coast is not clear, marine incursions apparently affected repeatedly the entire Wessex Basin during deposition of the lower Durlston Formation (Batten, 2002). In contrast, the deposits of the Harrl locality were deposited in a liminic-deltaic environment, dominated by sandy mouthbar complexes (Pelzer, 1998; Hornung et al., 2012b). Though the western part of the Lower Saxony Basin had brief connections with the open sea via narrow straits (Mutterlose and Bornemann, 2000), most of the basin was separated from the ocean by the Pompeckj Swell to the north and the Rhenish-Bohemian Massif to the south (Mutterlose, 1997). In the eastern part (including the Obernkirchen Sandstone and its equivalents), its character was entirely limnic, with distances of more than $300 \mathrm{~km}$ to the nearest marine coast (Fig. 2b). These differences indicate a certain ecological diversity or tolerance of the Purbeckopus trackmaker(s).

The peculiarities of its morphology - which are supported by the new material to be related to the anatomy of the track maker rather than preservational factors -, its occurrence across various paleoenvironments, and the narrow stratigraphic interval from which it is known yet, may indicate a promising ichnostratigraphic potential for Purbeckopus, depending on a future increase of records.

\section{Conclusions}

A hypichnial cast (preserved only as plaster cast) of a well-preserved manus impression from the late Berriasian Bückeberg Formation of northwest Germany constitutes the first occurrence of the pterosaur ichnogenus Purbeckopus outside the type area and stratum (Durlston Formation, southern England). It documents the occurrence of very large (wingspan $\sim 6 \mathrm{~m}$ ) pterosaurs in the basal Cretaceous of Germany, which are not yet recorded by skeletal remains. The specimen, referred to $P$. cf. pentadactylus, exhibits some interesting features, mostly due to different preservation from registration in a more plastic substrate, that let the manus sink deeper below the surface, than that in the English material. The resulting trace has an ovate depression proximal to the convergence of these digits I-III, which we interpret as the impression of the metacarpophalangeal joint of the wing finger, that was held free from the substrate during terrestrial locomotion in pterosaurs. The track, despite its depth, lacks substantial claw impressions, suggesting that the track maker had short claws. These may be related to frequent quadrupedal progression feeding, rather than use as grasping or climbing organs.

The occurrences of Purbeckopus in England and Germany, though nearly coeval, were made in different environments: the English locality was situated close to a brackish lagoon, while the German site was placed in a limnic-deltaic system at the margin of a large freshwater lake. 


\section{Acknowledgments}

The authors thank J. D. Harris, D. Hone, and M. G. Lockley for their thoughtful and constructive reviews of the manuscript. F. Langenstrassen is thanked for some specimen information.

\section{References}

Andres, B. and Ji, Q. 2008. A new pterosaur from the Liaoning Province of China, the phylogeny of Pterodactyloidea, and convergence in their cervical vertebrae. Palaeontology, 51: 435-469.

Ballerstedt, M. 1905. Über Saurierfährten der Wealdenformation Bückeburgs. Naturwissenschaftliche Wochenschrift, Neue Folge, 4: 481.

Ballerstedt, M. 1921b. Dinosaurierfährten im Wealdensandstein des Harrl bei Bückeburg und eine zur Zeit freiliegenden Spur eines „vierfüßigen“ plumpen Dinosauriers. Zeitschrift der Deutschen Geologischen Gesellschaft, 72: 231233.

Ballerstedt, M. 1922. Über Schreckensaurier und ihre Fußspuren. Kosmos, 19: 77-80.

Barrett, P.M., Butler, R.J., Edwards, N.P., and Milner, A.R. 2008. Pterosaur distribution in time and space: an atlas. Zitteliana, B28: 61-107.

Batten, D.J. 2002. Palaeoenvironmental setting of the Purbeck Limestone Group of Dorset, southern England. In Milner, A.R. and Batten D.J. (eds.), Life and Environments in Purbeck Times, Special Papers in Palaeontology, 68: 13-20.

Bennett, S.C. 2007. A review of the pterosaur Ctenochasma: taxonomy and ontogeny. Neues Jahrbuch für Geologie und Paläontologie, Abhandlungen, 245: 23-31.

Billon-Bruyat, J.-P. and Mazin, J.-M. 2003. The systematic problem of tetrapod ichnotaxa: the case study of Pteraichnus Stokes, 1957 (Pterosauria, Pterodactyloidea). In Buffetaut, E. and Mazin, J.-M (eds.). Evolution and Palaeobiology of Pterosaurs. Geological Society, London, Special Publications, 217: 315-324.

Casey, R., Allen, P., Dörhöfer, G., Gramann, F., Hughes, N.F., Kemper, E., Rawson, P.F., and Surlyk, F. 1975. Stratigraphical subdivision of the Jurassic-Cretaceous boundary beds in NW Germany. Newsletters on Stratigraphy, 4: 4-5.

Caster, K.E. 1940. Die sogenannten „Wirbeltierspuren“ und die Limulus-Fährten der Solnhofener Plattenkalke. Paläontologische Zeitschrift, 22: 12-29.

Delair, J.B. 1963. Notes on Purbeck fossil footprints, with descriptions of two hitherto unknown forms from Dorset. Proceedings of the Dorset Natural History and Archaeological Society, 84: 92-100. 
Delair, J.B. and Lander, A.B. 1973. A short history of the discovery of reptilian footprints in the Purbeck Beds of Dorset, with notes on their stratigraphical distribution. Proceedings of the Dorset Natural History and Archaeological Society, 94: 17-20.

El-Shahat, A. and West, I.M. 1983. Early and late lithification of aragonitic bivalve beds in the Purbeck Formation (Upper Jurassic - Lower Cretaceous) of Southern England. Sedimentary Geology, 35: 15-41.

Elstner, F., and Mutterlose, J. 1996. The Lower Cretaceous (Berriasian and Valanginian) in NW Germany. Cretaceous Research, 17: 119-133.

Ensom, P.C. 1984. Purbeckopus pentadactylus Delair. Proceedings of the Dorset Natural History and Archaeological Society, 105: 166.

Ensom, P.C. 1986. Purbeckopus pentadactylus Delair: a figured specimen rediscovered. Proceedings of the Dorset Natural History and Archaeological Society, 107: 183.

Ensom, P.C. 2002a. Vertebrate trace fossils in the Purbeck Limestone Group of southern England. In Milner, A.R. and Batten D.J. (eds.), Life and Environments in Purbeck Times, Special Papers in Palaeontology, 68: 203-220.

Ensom, P.C. 2002b. The Purbeck Limestone Group of Dorset, Southern England: a guide to lithostratigraphic terms. In Milner, A.R. and Batten D.J. (eds.), Life and Environments in Purbeck Times, Special Papers in Palaeontology, 68: 7-11.

Figuier, L. 1866. The World before the Deluge. D. Appleton\& Co., New York, 448 p.

Grupe, O. 1933. Erläuterungen zur geologischen Karte von Preußen und benachbarter deutscher Länder. Blatt Bückeburg (Lfg. 330/2017). Berlin, 69 p.

Haubold, H. 1971. Ichnia Amphibiorum et Reptiliorum fossilium. Handbuch der Paläoherpetologie, Part 18: 1-124.

Hoedemaeker, P.J. and Herngreen, G.F.W. 2003. Correlation of Tethyan and Boreal Berriasian - Barremian strata with emphasis on strata in the subsurface of the Netherlands. Cretaceous Research, 24: 253-275.

Hornung, J.J. and Reich, M. 2007. Krokodile, Schildkröten \& Dinosaurier. Die "Wealden"-Sammlung der Universität Göttingen. Fossilien, 24(1): 32-36.

Hornung, J.J., Böhme, A., van der Lubbe, T., Reich, M. and Richter, A. 2012a. Vertebrate tracksites in the Obernkirchen Sandstone (late Berriasian, Early Cretaceous of northwest Germany - their stratigraphical, palaeogeographical, palaeoecological, and historical context. Paläontologische Zeitschrift, 86: 231-267.

Hornung, J.J., Böhme, A. \& Reich, M. 2012b. Excursion Guide A2: Harrl hill near Bückeburg. In Richter, A. and Reich, M. (eds.): Dinosaur Tracks 2011. An International Symposium, Obernkirchen, April 14-17, 2011, Abstract Volume 
and Field Guide to Excursions. Universitätsverlag Göttingen, Göttingen, pp. 101-112.

Howse, S.C.B. and Milner, A.R. 1995. The pterodactyloids from the Purbeck Limestone Formation of Dorset. Bulletin of the Natural History Museum, London (Geology), 51: 73-88.

Kaup, J.J. 1834. Versuch einer Eintheilung der Säugethiere in 6 Stämme und der Amphibien in 6 Ordnungen. Isis, [1834]: 311-324.

Kemper, E. 1973. Das Berrias (tiefe Unterkreide) in NW-Deutschland. Geologisches Jahrbuch, Reihe A: Allgemeine und regionale Geologie BR Deutschland und Nachbargebiete, Tektonik, Stratigraphie, Paläontologie, 9: 47-67.

LBEG [Landesamt für Bergbau, Energie und Geologie Niedersachsen] 2013. NIBIS Kartenserver. http://nibis.lbeg.de/cardomap3/ [last accessed 19 June 2012]

Lockley, M., Harris, G.D., and Mitchell, L. 2008. A global overview of pterosaur ichnology: tracksite distribution in time and space. Zitteliana, B28: 185-198.

MacFayden, W.A. 1970. Geological Highlights of the West Country: a nature conservancy handbook. Butterworths, London, $296 \mathrm{p}$.

Martill, D.M., Sweetman, S.C., and Witton, M.P. 2011. Pterosaurs. In Batten, D.J (ed.). English Wealden Fossils. Palaeontological Society Field Guide to Fossils: Number 14. The Palaeontological Association, London, pp. 370390.

Mazin, J.-M., Billon-Bruyat, J.-P., Hantzpergue, P., and Lafaurie, J.-P. 2003. Ichnological evidence for quadrupedal locomotion in pterodactyloid pterosaurs: trackways from the Late Jurassic of Crayssac (south western France). In Buffetaut, E. and Mazin, J.-M (eds.). Evolution and Palaeobiology of Pterosaurs. Geological Society, London, Special Publications, 217: 283-296.

Meyer, C.A. and Hunt, A.P. 1999. The first pterosaur from the Late Jurassic of Switzerland: evidence for the largest Jurassic flying animal. Oryctos, 2: 111-116.

von Meyer, H. 1841. Pholidosaurus schaumburgensis, ein Saurus aus dem Sandstein der Wald-Formation NordDeutschlands. Neues Jahrbuch für Mineralogie, Geologie, Geognosie und Petrefakten-Kunde, 4: 443-445.

von Meyer, H. 1851. Ctenochasma Roemeri. Palaeontographica, 2: 82.

von Meyer, H. 1857. Beiträge zur näheren Kenntnis fossiler Reptilien. Neues Jahrbuch für Mineralogie, Geologie und Paläontologie, 1857: 532-543.

Mutterlose, J. 1997. Lower Cretaceous. In Mutterlose, J., Wippich, M.G.E., and Geisen, M. (eds.), Cretaceous Depositional Environments of NW Germany. Bochumer Geologische und Geotechnische Arbeiten, 46: 7-12. 
Mutterlose, J. 2000. Unterkreide im Niedersächsischen Becken. In Stratigraphische Kommission Deutschlands (ed.), Die Kreide der Bundesrepublik Deutschland. Courier Forschungsinstitut Senckenberg, 226: 79-101.

Mutterlose, J. and Bornemann, A. 2000. Distribution and facies patterns of Lower Cretaceous sediments in northern Germany: a review. Cretaceous Research, 21: 733-759.

Nopcsa, F. 1923. Die Familien der Reptilien. Fortschritte der Geologie und Paläontologie, 2: 1-210.

Oppel, A. 1862. Über Fährten im lithographischen Schiefer (Ichnites lithographicus). Palaeontologische Mittheilungen aus dem Museum des koeniglich-bayerischen Staates, 2: 120-125.

Owen, R. 1870. A monograph of the fossil Reptilia of the Liassic formations. ii. Order Pterosauria. Palaeontographical Society Monograph, 23: 41-56.

Owen, R. 1874. The fossil Reptilia of the Mesozoic Formations. I. Pterosauria. Palaeontographical Society Monograph, 27: $1-14$.

Pelzer, G. 1998. Sedimentologie und Palynologie der Wealden-Fazies im Hannoverschen Bergland. Courier Forschungsinstitut Senckenberg, 207: 1-211.

Rodrigues, T. and Kellner, A.W.A. 2008. Review of the pterodactyloid pterosaur Coloborhynchus. Zitteliana, B28: 219-228.

Sánchez-Hernández, B., Przewieslik, A.G., and Benton, M.J. 2009. A reassessment of the Pteraichnus ichnospecies from the Early Cretaceous of Soria Province, Spain. Journal of Vertebrate Paleontology, 29: 487-497

Sarjeant, W.A.S. 1974. A history and bibliography of the study of fossil vertebrate footprints in the British Isles. Palaeogeography, Palaeoecology, Palaeoclimatology, 16: 265-378.

Seeley, H.G. 1869. Index to the fossil remains of Aves, Ornithosauria and Reptilia, from the Secondary system of strata arranged in the Woodwardian Museum in the University of Cambridge. Deighton Bell and Co., Cambridge, $143 p$.

Seeley, H.G. 1875. On an Ornithosaurian (Doratorhynchus validus) from the Purbeck Limestone of Langton near Swanage. Quaterly Journal of the Geological Society, London, 31: 465-468.

Unwin, D.M. 1997. Pterosaur tracks and the terrestrial ability of pterosaurs. Lethaia, 29: 373-386.

Walkden, G. and Oppé, E. 1969. In the footsteps of dinosaurs. Amateur Geologist, 3: 19-35.

Wellnhofer, P. 1991. The Illustrated Encyclopedia of Pterosaurs. Crescent Books, New York, 192 p.

Witton, M.P. 2010. Pteranodon and beyond: the history of giant pterosaurs from 1870 onwards. In Moody, R.T.J., Buffetaut, E., Naish, D., and Martill, D.M. (eds.), Dinosaurs and Other Extinct Saurians: A Historical Perspective. Geological 
Society, London, Special Publication, 343: 313-323.

Witton, M.P. and Naish, D. 2008. A Reappraisal of Azhdarchid Pterosaur Functional Morphology and Paleoecology. PLoS ONE, 3(5): e2271. doi:10.1371/journal.pone.0002271.

Wolburg, J. 1949. Ergebnisse der Biostratigraphie nach Ostracoden im nordwestdeutschen Wealden. In Bentz, A. (ed.), Erdöl und Tektonik in Nordwestdeutschland. Amt für Bodenforschung, Hannover, pp. 349-360.

Wright, J.L., Unwin, D.M., Lockley, M.G., and Rainforth, E.C. 1997. Pterosaur tracks from the Purbeck Limestone Formation of Dorset, England. Proceedings of the Geologists' Association, 108: 39-48. 
Synopsis: Archosaurs during the dawn of the Cretaceous in Europe - the temporal and palaeobiogeographical context of the archosaur fauna from the Bückeberg Formation 


\section{Synopsis: Archosaurs during the dawn of the Cretaceous in Europe - the temporal and palaeobiogeographical context of the archosaur fauna from the Bückeberg Formation}

The record of earliest Cretaceous (Berriasian-Valanginian) archosaur faunas is quite scarce in quantity as well as in quality, when compared to those of the Late Jurassic and late Early Cretaceous. However, this scarcity of data unfortunately coincides with a crucial phase in the commencing differentiation of palaeobiogeographical patterns of terrestrial faunas following the Jurassic break up of Pangea (Lillegraven et al. 1979).

As a result of the break apart of Pangea, which roots back into the Triassic, most of Europe, located in a focus-point of divergence between North America and Asia, as well as Africa, was palaeotopographically structured by a complex system of graben and basins from the Late Triassic into the Cretaceous (e.g. Ziegler 1990, Cope et al. 1999, Golonka 2007, Pieńkowski et al. 2008, Voigt et al. 2008). A consequence of this palaeotopography was a rapid change of environmental conditions in depositional areas in accordance with the global sea-level. Phases of highstand resulted in flooding of epicontinental basins and rifts, effectively creating island archipelagos. This fractionation of environments favoured an increase of vicariance in palaeogeographical patterns of terrestrial vertebrates and may have resulted in an increased ecological pressure due to resource partitioning (e.g. Sander et al. 2006). During lowstand, basins and rifts were occupied by limnic depositional systems, while terrestrial topographic barriers were of low relief (Abbink et al. 2001) and probably did not pose a significant obstruction to faunal dispersal.

The beginning of the Cretaceous saw a major drop in global sea-level (e.g. Miller et al. 2011) which resulted in drastic changes in the palaeotopography of Central and Western Europe, accompanied by climatic trends towards increased aridity (evaporation of residual peri-marine water bodies, latest Jurassic, earliest Berriasian, e.g. West 1975, Pelzer \& Wilde 1987, Gramann et al. 1997, Allen 1998, Rawson \& West 1999, Abbink et al. 2001, Schnyder et al. 2006). This obviously had important consequences for terrestrial faunas which are assumed to have been at least partly strongly regionalised during Late Jurassic highstand (Sander et al. 2006): an increase in regional faunal interchange can be assumed, which may, in turn have resulted in the extinction in local faunas due to increased competition. Aside of the - poorly recorded - regional and small-scale trends, the earliest Cretaceous sea-level lowstand may have been pivotal in a commencing faunal interchange between Africa (Gondwana) and southern and western Europe (e.g. Ezcurra \& Agnolín 2012). From well documented interchanges of previously separated vertebrate faunas, which developed in relative phylogenetic isolation at a continental scale, severe feedback effects on local faunal compositions are known. These effects are largely driven by a rapidly changing topography of competition (e.g. Marshall 1981, 1988). Such effects may also be postulated for earliest Cretaceous faunal interchanges in Europe at regional and continental scales. 


\section{Berriasian-Valanginian archosaur faunas of Europe}

The Berriasian-Valanginian archosaur fauna of the Bückeberg Formation (summarized in Tab. XI.1, Fig. XI.1) can be compared to an assortment of other archosaur faunas from this time interval across Central and Western Europe (Fig. XI.2) within their palaeoenvironmental context. The assumed phylogenetic relationships between the taxa mentioned in this chapter follow those outlined in Fig. XI.3. The results are graphically summarized in Fig. XI.4.

Purbeck Limestone Group (late Tithonian - late Berriasian) of southern England

The Purbeck Limestone Group comprises a series of carbonate and clastic deposits in an array of small basins (Wessex Basin, Wealden Basin, Channel Basin) stretching across southern England (Rawson \& West 1999) during the latest Tithonian through the end of the Berriasian (Hoedemaeker \& Herngreen 2003). The depositional history includes a highly restrictive marine to peri-marine environment with hypersaline lagoons under an arid climate during deposition of the lower Purbeck Limestone Group (West 1975, West \& Clayton [in Taylor \& Ruffell 1993], Underhill 2002), which is in agreement to the contemporaneous environment in the Lower Saxony Basin (Münder Formation Pieńkowski et al. 2008, Arp \& Mennerich 2008). During deposition of the middle and upper Purbeck Limestone Group, the precipitation increased, leading to a shallow lacustrine to lagoonal environment, which was, however, often still brachy- to mesohaline, due to evaporation from the enclosed basin and rare marine incursions from the northeast (El-Shahat \& West 1983, West \& Clayton [in Taylor \& Ruffell 1993], Batten 2002, Schnyder et al. 2009).

The Purbeck Limestone Group contains a diverse archosaur (and other reptile and mammal) fauna which has been described intensively by Richard Owen in a series of monographs during the second half of the $19^{\text {th }}$ century. However, the great majority of the fossils come from a narrow stratigraphic interval between the Mammal Bed (Worbarrow Tout Member, upper Lulworth Formation) and the Intermarine Beds (Stair Hole Member, lower Durlston Formation, Ensom 2002a-c, 2010, Milner 2002, Norman \& Barrett 2002, Salisbury 2002). This interval correlates with the Serpulit Member (upper Münder Formation) to the "Wealden 2" (lower Obernkirchen Member, lower Bückeberg Formation) in Germany (Hoedemaeker \& Herngreen 2003) and is therefore slightly older than the German vertebrate abundance maximum in the Obernkirchen Sandstone.

Pterosauria. A significant similarity between the Bückeberg Formation and the Purbeck Limestone Group is the occurrence of the large-sized pterosaur ichnogenus Purbeckopus (see Chapter $\mathrm{X}$ for discussion). A number of pterosaur skeletal elements are known belonging to ctenochasmatids and lonchodectids, as well as indeterminable taxa (Howse \& Milner 1995 and Chapter X) are known from Southern England. The diagnostic skeletal record from Germany is restricted to the lost holotype mandible of the small ctenochasmatid Ctenochasma roemeri von Meyer, 1851, which most probably came from the Serpulit Member, underlying the Bückeberg Formation. Other fragments from the upper Bückeberg Formation (Appendix A) cannot be compared sufficiently to the Purbeck taxa. 
Tab. XI.1 Overview of archosaur (ichno-)taxa from the Bückeberg Formation and their distribution across facies regions (as defined in Fig. XI.1). Material which can only be referred to higher clades is generally omitted.

\begin{tabular}{|c|c|c|c|c|c|c|c|}
\hline & & Taxa & $\operatorname{Rec}$ & & & ies regi & \\
\hline & & & $\begin{array}{l}\text { Skeletal } \\
\text { material }\end{array}$ & Tracks & $\begin{array}{c}\text { proxi- } \\
\text { mal }\end{array}$ & central & distal \\
\hline DINOSAURIA & & & & & & & \\
\hline Ornithischia & & & & & & & \\
\hline & Ankylosauria & & & & & & \\
\hline & & ?Hylaeosaurus sp. & & & & & \\
\hline & & Metatetrapous valdensis & & & & & \\
\hline & & ?M. valdensis & & & & & \\
\hline & Ornithopoda & & & & & & \\
\hline & ?Dryosauridae & & & & & & \\
\hline & & Ichnogen. \& sp. indet. & & & & & \\
\hline & Ankylopollexia & & & & & & \\
\hline & & Gen. \& sp. indet. & & & & & \\
\hline & Styracosterna & & & & & & \\
\hline & & Gen. \& sp. indet. & & & & & \\
\hline & & Ichnogen. \& sp. indet.* & & & & & \\
\hline & Ceratopsia & & & & & & \\
\hline & Stenopelixidae & & & & & & \\
\hline & & Stenopelix valdensis & & & & & \\
\hline Saurischia & & & & & & & \\
\hline & Theropoda & & & & & & \\
\hline & & Altispinax dunkeri & & & & & \\
\hline & & Gen. \& sp. indet. & & & & & \\
\hline & & Ichnogen. \& sp. indet. ${ }^{*}$ & & & & & \\
\hline & Troodontidae & & & & & & \\
\hline & & Ichnogen. \& sp. indet. & & & & & \\
\hline & Sauropoda & & & & & & \\
\hline & & Brontopodus isp. & & & & & \\
\hline & Macronaria & & & & & & \\
\hline & & Gen. \& sp. indet. & & & & & \\
\hline & Brachiosauridae & & & & & & \\
\hline & & Gen. \& sp. indet. & & & & & \\
\hline PTEROSAURIA & & & & & & & \\
\hline & & Gen. \& sp. indet. & & & & & \\
\hline & & Purbeckopus cf. pentadactylus & & & & & \\
\hline
\end{tabular}


Tab. XI.1 (continued)

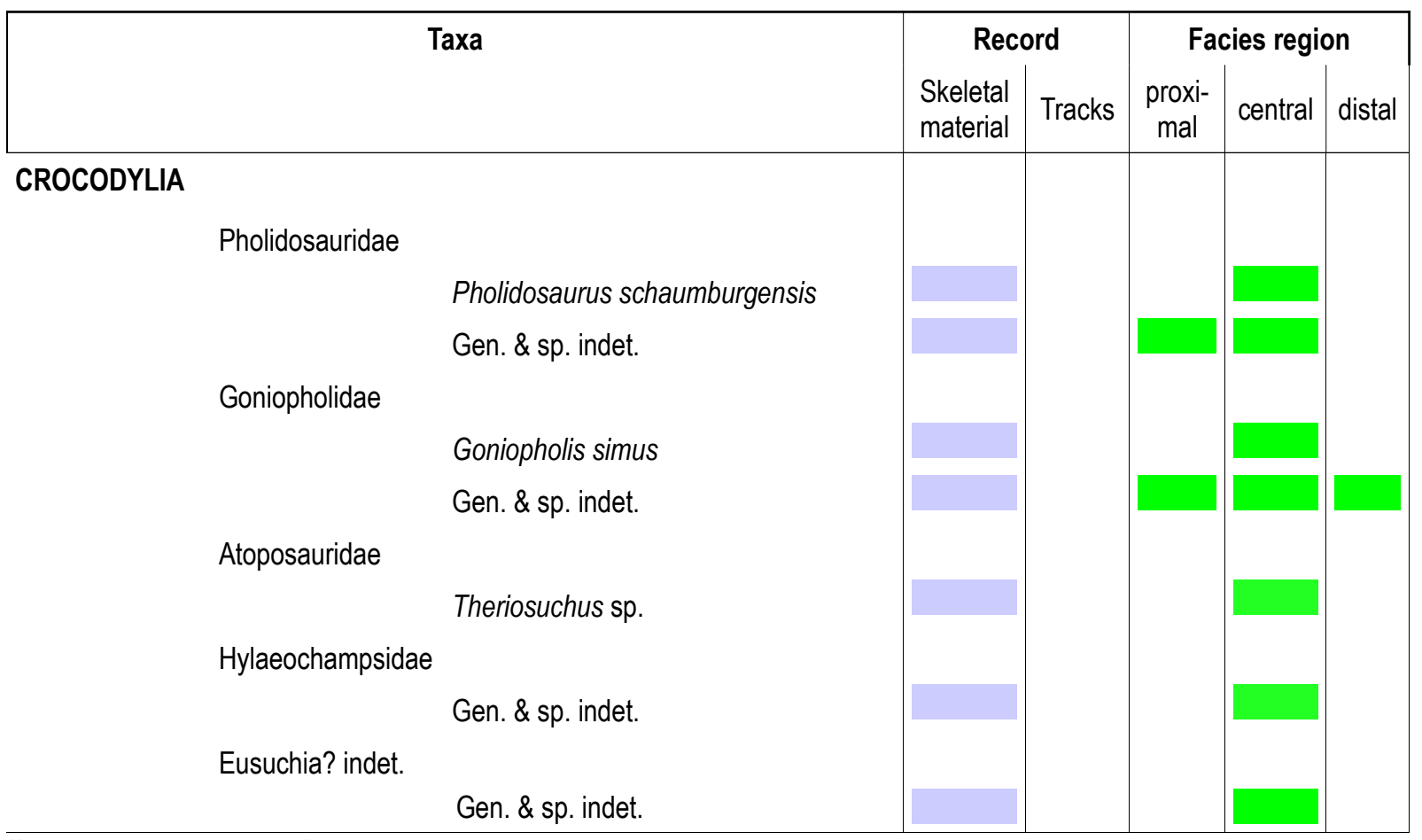

*) several morphotypes / ichnotaxa present.

Fig. XI.1 Schematic characterisation of facies regions applied in Tab. XI.1.

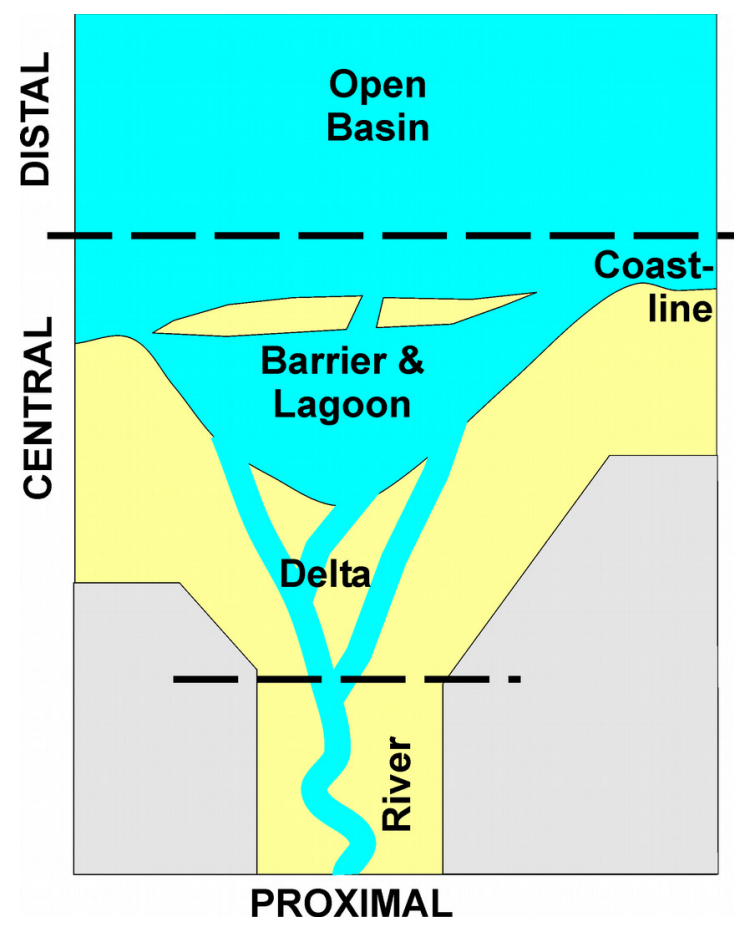


Fig. XI.2 Location of Berriasian archosaur localities used for comparison in Chapter XI. 1 Bückeberg Fm., northern Germany; 2 - Nyker Group, Bornholm, Denmark; 3 - Purbeck Limestone Group, England 4 - Hastings Group, England; 5 - Cherves-de-Cognac, France; 6 Iberian Range, Spain; 7 - Cornet, Romania.

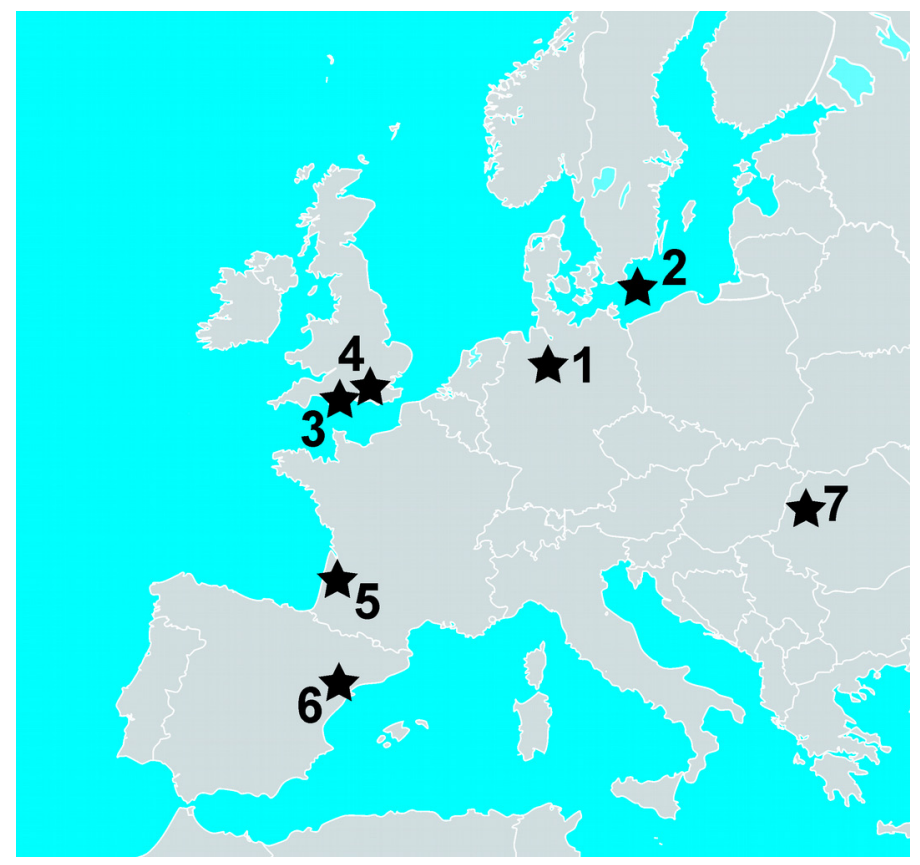

Crocodylia. The crocodilian fauna of the Purbeck Limestone Group is very closely comparable to that of the Bückeberg Formation. At least one taxon, Goniopholis simus, occurs in both deposits (Salisbury et al. 1999, Salisbury 2002, Chapter VIII), and the difference in members of Pholidosaurus are also minor (Salisbury et al. 1999, Salisbury 2002), suggesting a conspecifity of the material (pending further revision). The genus Theriosuchus is relatively abundant in the Purbeck Limestone Group, however, very rare in the Bückeberg Formation. The referred angular (Appendix A) is distinctly different from T. pusillus, the species from southern England.

Otherwise, the crocodilian fauna of the Purbeck Limestone Group is slightly more diverse, with the additional occurrence of another species of Goniopholis (G. kiplingi, Andrade et al. 2011), Nannosuchus gracilidens Owen, 1879, Bernissartia sp. and fragmentary remains (e.g. “Goniopholis tenuidens" Owen, 1879) that cannot be further determined (Salisbury 2002). It should be noted however, that the lack of overlap concerns small (often considered "dwarfed") taxa, which may be a potential target of microvertebrate screening, which could reveal that the diversity is much higher than anticipated (compare Ensom 2002c, Sweetman 2011).

Dinosauria. The dinosaur fauna of the Purbeck Limestone Group includes - based upon skeletal material - indetermined ankylosaur remains, a basal styracosternan ornithopod (Owenodon hoggii), indetermined ornithopod remains, the heterodontosaurid Echinodon becklesii Owen, 1861, the small theropod Nuthetes destructor, a large non-avian theropod (based upon a single, $6.4 \mathrm{~cm}$ high tooth, NHMUK 44806, Milner 2002), an enantiornithine bird, and indetermined sauropods (Galton 1980a, b, 1983, Milner 2002, Norman \& Barrett 2002, Ensom \& Delair 2007, Benson \& Barrett 2009, Galton et al. 2009, Barrett et al. 2010, Barrett \& Maidment 2011). All of the material is very fragmentary. The track record includes sauropods (some quadrupedal tracks may be ankylosaurian), ornithopods, and most probably also theropods (e.g. Norman 1980, Wright et al.. 
1998, Wright 1999, Ensom 1995a, b, 2002b, Ensom \& Delair 2007). The track quality is often mediocre, making an orthotaxonomic assignment of tridactyl (theropod/ornithopod) and quadrupedal tracks (sauropod/thyreophoran) difficult (Ensom 2002b, Ensom \& Delair 2007, Barrett \& Maidment 2011). Poor track quality is often caused by the substrate which consists of relatively coarse grained, early cemented shell beds (West \& El-Shahat 1985, Wright et al. 1997, Ensom 2002b). The tracks occur in the entire Tithonian-Berriasian succession though with a clear abundance peak in the Intermarine Beds. Ensom (2002b) discussed various potential reasons for this pattern, including a palaeoecological signal, the occurrence of lithologies suitable for track preservation, or a sampling bias due to intensive quarrying of the Intermarine Beds.

Norman \& Barrett (2002) considered the scarce dinosaur fauna of the Purbeck Limestone Group as "impoverished" compared to the comparatively rich diversity in smaller tetrapods and to the overlying Wealden Group. They proposed as possible reason adverse climatic events as extreme heat and droughts, perceptible from the sedimentary record, in opposition to the more humid and lush climate of the Wealden Group. Due to evaporation and increasing salinities there may have been seasonal shortages of potable water in the region for large animals.

In contrast to the crocodilian and pterosaur (track-)record, the dinosaur record from the Bückeberg Formation hardly shows any overlap beyond the generalized joint presence of ornithopods, sauropods, and probably theropods in the track record. The potential intra-clade diversity of trackmakers cannot be assessed for the Purbeck Limestone Group dinosaur tracks because of the poor preservation. The best comparable material, the ornithopod teeth from the earliest Valanginian of Sehnde are distinct from Owenodon (referred material, Galton 2009). Other material does not have an anatomical overlap. A taxonomic link between Altispinax dunkeri and Nuthetes destructor is hypothetical, given the juvenile status of the latter and the plesiomorphic and potentially homoplastic characters they share. The better definable taxa Echinodon becklesii and Stenopelix valdensis both do not have a taxonomic equivalent outside their type area. The relationships of the few ankylosaur fragments from southern England (the only specimen with detailed stratigraphic record, a caudal vertebra, comes from the Tithonian section of the Purbeck Limestone Group, Galton 1980a, Norman \& Barrett 2002) can neither be compared to the early Valanginian material considered here (?Hylaeosaurus sp., Chapter VII), nor is it similar to the specimen described by Koken (1887) as Hylaeosaurus sp. (considered ?Ornithischia indet. herein, Appendix A).

Given the otherwise good overlap in the crocodilian fauna (as well as in e.g. turtles Milner 2004, Karl et al. 2007), and a lack of potential palaeogeographical barriers between both regions, a potential paleoecological signal in the dinosaur distribution between the Purbeck Limestone Group and the Bückeberg Formation has to be taken into consideration. This is supported by the palaeoenvironmental and palaeoclimatic interpretations which see for the slightly younger vertebrate abundance maximum in the Obernkirchen Sandstone much more favourable conditions (abundance of freshwater, vegetation etc., Pelzer \& Wilde 1987, Abbink et al. 2001). However, the bias given by the fossil record may not be underestimated: the relatively high diversity assumed for the Bückeberg Formation is mostly based upon the track record, which is potentially underrepresented in the Purbeck Limestone Group given the poor preservational quality of tracks. 
The assessment from the skeletal remains is hampered in both cases by the small statistical sample; against a relatively rich sample in crocodilians.

Nyker Group (Berriasian—Valanginian) of Bornholm, Denmark

The Nyker Group consists of Berriasian through Valanginian, continental to lagoonal / marginal marine deposits exposed on the island of Bornholm, Denmark (Gravesen et al. 1982). It was formed as a predominantly clastic infill of chain of basins, following the Sorgenfrei-Tornquist Zone and connecting the North Sea Basin to the Polish Trough. The succession begins with the dominantly limnic Tithonian-Berriasian Rabekke Formation, which is succeded by the shallow marine to littoral, Robbedale Formation and finally overlain by the brackish to limnic Jydegård Formation.

Archosaur remains have been described from the uppermost Rabekke Formation and the basal part of the Jydegård Formation, while the Robbedale Formation seems to be at present devoid of them.

The uppermost Rabekke Formation (Skyttegård Member) correlates with the Runctoni boreal ammonite zone (Lindgren et al. 2008) which in turn correlates with the "Wealden 1" to basal "Wealden 2" of the Bückeberg Formation (Hoedemaeker \& Herngreen 2003, Harding et al. 2011). It was mainly deposited within a liminic system dominated by rivers, lakes and swamps (Petersen et al. 1996, Surlyk et al. 2008). Mass occurrences of the freshwater alga Botryococcus braunii Kützing, 1849 indicate an annual palaeotemperature range of $14-22{ }^{\circ} \mathrm{C}$, while an abundance of zynematacean zygospores indicate the occurrence of seasonal environmental stress, e.g. droughts (Lindgren et al. 2008). The palynomorph spectrum suggests a dense and lush vegetation in the vicinity of the water bodies, dominated by taxodiaceans, araucariaceans, pteridosperms and ferns (Lindgren et al. 2008). Dinoflagellate cysts indicate a proximity to marine environments (Lindgren et al. 2008). Surlyk et al. (2008) interpreted vertical burrows as aestivation cubichnia of dipnoans, which would further indicate the presence of dry seasons. However, Bonde (2012) questioned this interpretation, referring to the lack of osteological evidence for the presence of dipnoans in the Early Cretaceous of Europe. Aside from other archosaurs, a moderately diverse vertebrate microfauna (actinopterygians, frogs, salamanders, lizards, mammals) has been found in the upper Rabbeke Formation (Rees et al. 2005).

The lower part of the Jydegård Formation was palynostratigraphically correlated to the middle Bückeberg Formation ("Wealden 3-4", Piasecki 1984) and is therefore nearly age-equivalent to the Obernkirchen Sandstone. The upper part comprises most of the Valanginian (Allen \& Wimbledon 1991). The environment of the Jydegård Formation has been reconstructed as a lagoonal setting in close proximity to the sea and probably separated from it by sandy barriers. The back-barrier zone has been influenced by freshwater discharges from rivers and was a seasonally or episodically

Fig. XI.3 Phylogenetic relationships of archosaur groups here unter discussion. Crocodylia (1) after Andrade et al. (2011) and Martin \& Buffetaut (2012); Ornithischia (2) after Butler et al. (2008, 2011a), McDonald et al. (2010a), and McDonald (2011, 2012); Saurischia (3) after Carrano et al. (2012, Theropoda), and d'Emic (2012, Sauropoda), modified. 

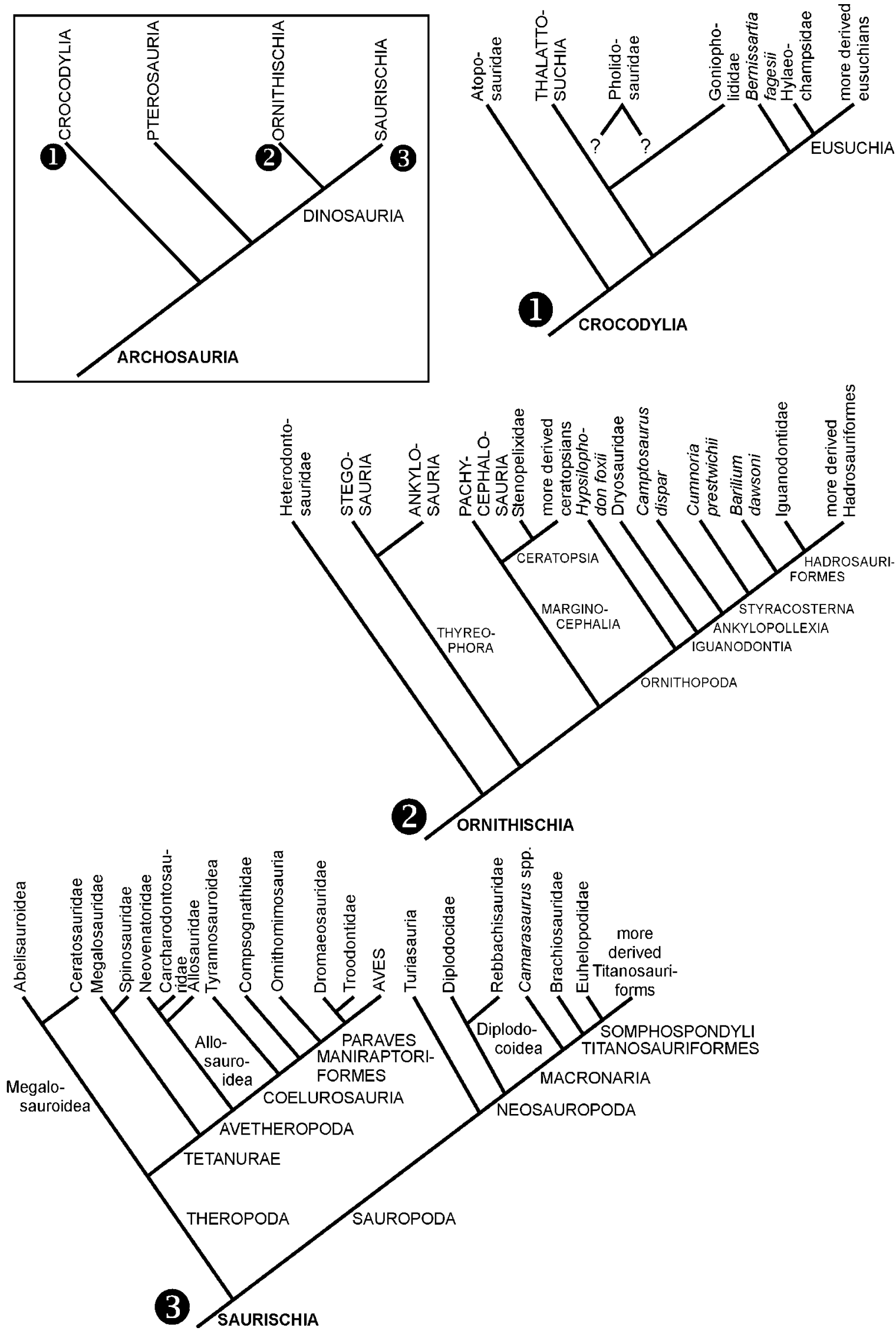
stressed aquatic environment as indicated by mollusc mass-mortality layers (Noe-Nygaard et al. 1987, Noe-Nygaard \& Surlyk 1988).

Crocodylia. Schwarz-Wings et al. (2009) reported an abundant crocodilian fauna from the uppermost Rabekke Formation. The record, mostly based on teeth, includes Bernissartia sp., Theriosuchus sp., and Goniopholis sp.

In the lowermost Jydegård Formation basal crocodilian remains are restricted to slender, elongate teeth, probably of Pholidosaurus sp., and indeterminate bone fragments (Bonde 2004, Schwarz-Wings et al. 2009).

The apparent stratigraphic separation of Goniopholis and Pholidosaurus in the Danish crocodilian fauna is noteworthy, as the co-occurrence of both taxa is well-documented in the middle Bückeberg Formation. Bernissartia is common in the Rabekke Formation, as in other Berriasian localities, but lacks in the Bückeberg Formation.

Dinosauria. Lindgren et al. (2008) reported a set of small to tiny theropod tooth-crowns from the lower Rabekke Formation. Dental characters indicate a referral to the Dromaeosauridae Matthew \& Brown, 1922 for most of them. A single specimen was found to be similar to a (referred) premaxillary tooth of Nuthetes destructor. However, Lindgren et al. (2008) considered the uneven denticle size of this tooth to be unusual for non-avian theropods and compared it to those of hesperornithiform birds. Bonde (2012) found a considerable diversity in this sample and proposed the presence of up to three different dromaeosaurid taxa, some of which may belong to Microraptoria Senter, Barsbold, Britt \& Burnham, 2004, an unranked sub-clade of Dromaeosauridae. Surlyk et al. (2008) reported the presence of sauropod tracks in the Rabekke Formation. They were mostly exposed in a vertical cross-section along a cliff.

The basal part of the Jydegård Formation has yielded two dromaeosaurid teeth (described as Dromaeosauroides bornholmensis Christiansen \& Bonde, 2003) and a small tooth of a basal titanosauriform sauropod (Christiansen \& Bonde 2003, Bonde \& Christiansen 2003, Bonde 2012). The sauropod tooth shows a slight longitudinal twist of the crown's long axis, according to d'Emic (2012) an apomorphic character of brachiosaurids.

The dinosaur faunas are different from that of the Bückeberg Formation in their lack of ornithopods and abundance of dromaeosaurid theropods. However the material is limited, and, as stated before there may be a sampling bias due to the lack of microvertebrate analyses to the Bückeberg Formation. Furthermore, the upper Rabekke Formation represents a time interval which is slightly older than the Obernkirchen Sandstone vertebrate abundance maximum. The basal Bückeberg Formation ("Wealden 1-2") is poorly sampled for vertebrates.

\section{Berriasian of Cherves-de-Cognac, Charentes, southwestern France}

The Champblanc gypsum quarry near Cherves-de-Cognac has yielded an abundant vertebrate fauna, including articulated cranial and skeletal material (e.g. Buffetaut et al. 1989, Mazin et al. 
2006, 2008, Pouech et al. 2006). While microvertebrate remains are abundant throughout the section, articulated material is restricted to a narrow stratigraphical interval, dubbed the Highly Fossiliferous Zone (HFZ, El Albani et al. 2004).

The succession was dated to the Berriasian, more precisely correlating the HFZ to the Cypridea granulosa zone of southern England, by the occurrence of ostracods and charophytes (Colin et al. 2004). It therefore corresponds to the upper Münder Formation (upper Katzberg Member, lower Serpulit Member, uppermost C. punctata to lower C. posticalis/C. binodosa zones) in Germany, and to the Marly Freshwater Beds and Cherty Freshwater Beds (upper Lulworth Formation) in England (Ensom 2002a, Hoedemaeker \& Herngreen 2003).

The environment of the Cherves-de-Cognac succession is reconstructed mainly as a evaporiticcarbonate succession of hyperhaline lagoons and coastal sabkha systems whith short intercalations of shoreface and fore-shore deposits during sea-level highstands (El Albani et al. 2004). During the $\mathrm{HFZ}$, a limnic influence is recorded and the salinity dropped to brachyhaline conditions. El Albani et al. (2004) interpreted the HFZ as storm-related fore-shore deposits, including a seaward transport of a mixed terrestrial to semiaquatic vertebrate fauna. The occurrence of articulated skeletons of small reptiles (e.g. sphenodontian Homoeosaurus sp., Buffetaut et al. 1989, crocodilian Theriosuchus sp., Mazin et al. 2006) suggests, however, that this transport was not far and burial occured rapidly in these instances. Other material is disarticulated and partly worn, indicating a broad range of taphonomic history (El Albani et al. 2004). The climate is considered to be dominantly arid, with a slight increase in humidity towards the top (e. g. the HFZ, El Albani et al. 2004). However, recurrence of hyperhaline conditions in the beds overlying the HFZ interval (Colin et al. 2004, El Albani et al. 2004) suggest prevalence of arid conditions again. Aside from the archosaurs discussed below, the vertebrate fauna includes chondrichthyes, actinopterygians, albanerpetontid amphibians, turtles, sphenodontians, lizards, and four families of mammals (Pouech et al. 2006, Mazin et al. 2008, Vullo et al. 2008).

Crocodylia. Goniopholis spp., Pholidosaurus purbeckensis, Theriosuchus pusillus, ?T. sp., and Bernissartia fagesii, and Bernissartiidae indet. have been reported from Cherves-de-Cognac (Mazin et al. 2005, 2006, 2008, Pouech et al. 2006, Vullo et al. 2008, Martin \& Buffetaut 2012). Some specimen consist of fairly complete skulls and complete atoposaurid skeletons are preserved. However, detailed descriptions have not yet published. Mazin et al. (2005) noted two species of Goniopholis, which they refer to G. simus and G. crassidens, without providing details. However, the distinction of these two species is problematic due to insufficient type material in G. crassidens (Salisbury 2002, Hornung et al. 2009). A skull of Goniopholis sp. figured by Mazin \& Billon-Bruyat (2002) differs in details (e.g. ornamentation, rostral shape) slightly from G. simus and is therefore probably not conspecific with the German and English species. Bernissartia fagesii was originally described from the late Barremian of Bernissart, Belgium (Dollo 1883), and its referral from Cherves-de-Cognac is based upon isolated teeth only. A conspecifity may be doubtful based upon the large time interval from the early Berriasian to the late Barremian. 
Dinosauria. The dinosaur fauna from Cherves-de-Cognac includes a sauropod, theropods (including dromaeosaurids and archaeopterygids), an iguanodontian ornithopod, a heterodontosaurid, and a stegosaur (Le Loeuff et al. 1996, Mazin et al. 2006, 2008, Pouech et al. 2006, BillonBruyat et al. 2010, Vullo et al. 2008). The material consists of isolated bones and teeth. The fauna shows similarities to that from the Purbeck Limestone Group, including theropod teeth partially referred to Nuthetes sp., and the presence of a heterodontosaurid. The dental record of a stegosaur is unique to the basal Early Cretaceous in Europe (Billon-Bruyat et al. 2010), though being supported by ichnological evidence from Spain (Pascual et al. 2012, see below). A caudal centrum indicates a basal neosauropod, probably a basal camarasauromorph (Le Loeuff et al. 1996), and therefore different to the slightly younger material from the Bückeberg Formation, which has titanosauriform affinities (Appendix A).

Basal Cretaceous of the Iberian Range and adjacent regions, north-eastern Spain

In north-eastern Spain (Valencia, Teruel, and Soria Provinces) marginalmarine to continental Late Jurassic to Early Cretaceous deposits are widespread. They were deposited in several basins stretching in northwest to southeast direction. Archosaur remains and tracks are abundant in various levels.

In the Cameros Basin, a relatively complete succession from the Tithonian into the early Berriasian is preserved (Tera Group, Oncala Group; Clemente 2010). A broad diversity of facies were deposited in a continental basin (Meléndez \& Gómez-Fernández 2000, Clemente 2010, and references therein), including alluvial piedmont, fluvial braid-plain deposits of Tithonian age, transiting

$\rightarrow$ Fig. XI.4 Temporal correlation and palaeoclimatological conditions of Tithonian to Hauterivian archosaur faunas in Europe. For details and references see text. BER - Berriasian; HAU - Hauterivian; TIT - Tithonian; VAL - $\mathbf{O}$ Valanginian.

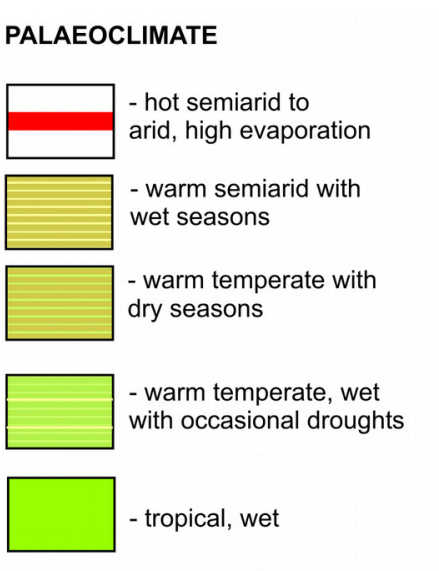

\section{SELECTED ARCHOSAUR FAUNAL} ELEMENTS

\begin{tabular}{lll}
\hline P & SKELETAL REMAINS \\
S & & Pterosaurs \\
A & A & Ankylosaurs \\
O & (O) & Ornithopods \\
H & & Heterodontosaurids \\
C & & Ceratopsians \\
T & (T) & Theropods \\
S & (S) & Sauropods \\
& D & Dinosaurs (unspecified)
\end{tabular}

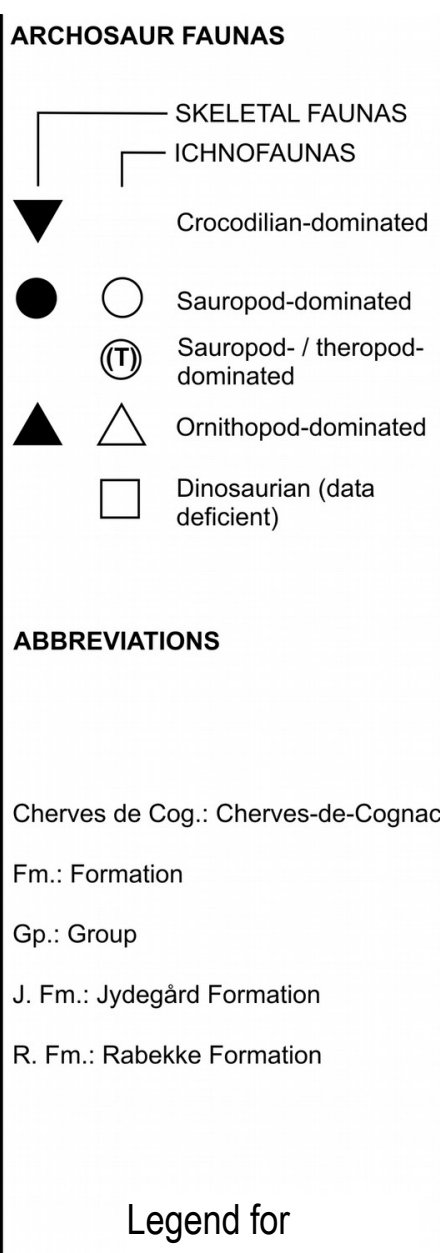

Fig. XI.4

(opposite page) 


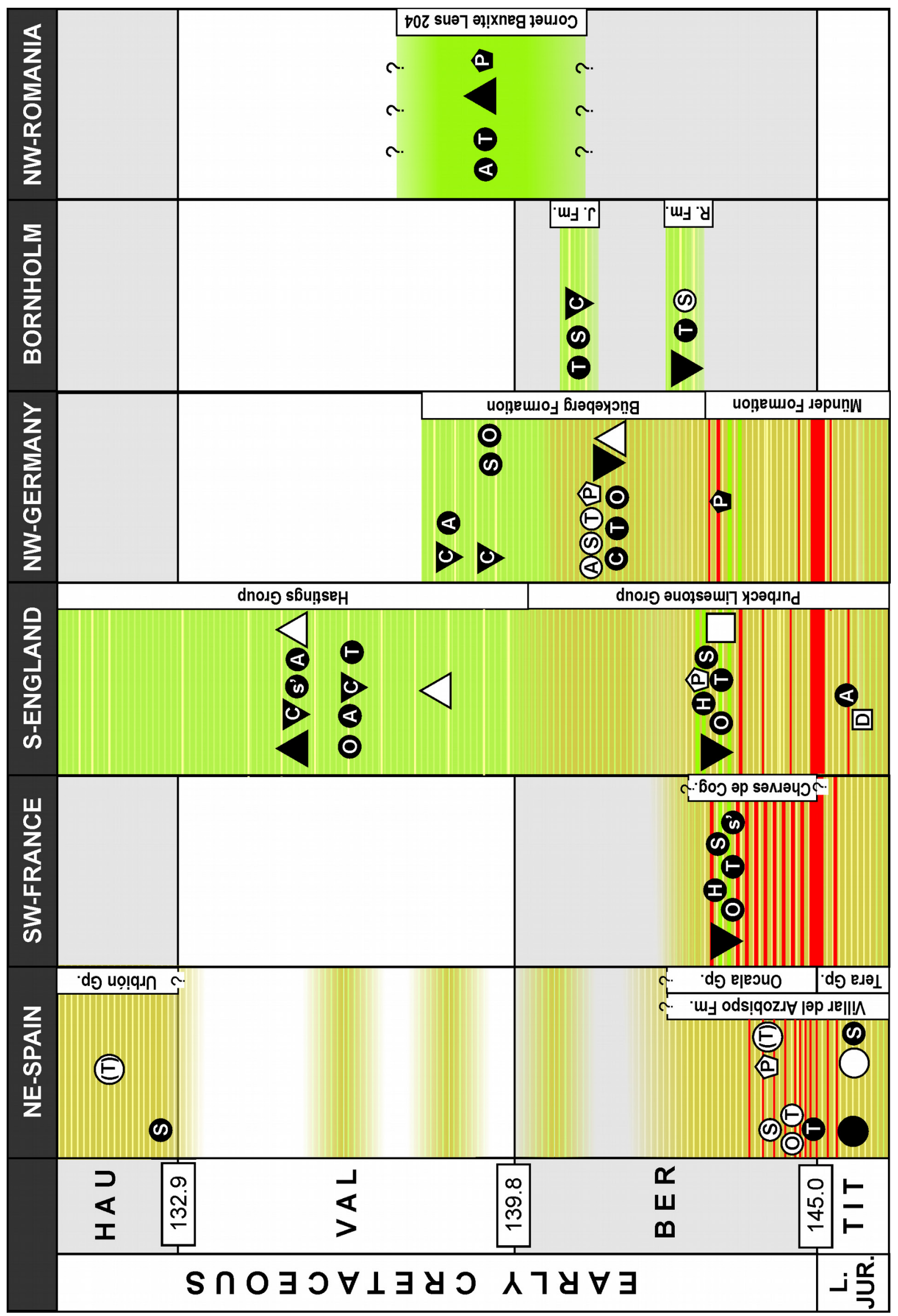


upwards into ephemeral river and partly evaporitic, carbonate lacustrine beds (lower Berriasian).

The osteological record of archosaurs from the Tithonian-Valanginian of the Cameros Basin is scarce in contrast to the extemely rich ichnofauna, the most abundant in Europe (e.g. Moratalla 1993, Moratalla \& Sanz 1997, Wright et al. 1998, Perez-Lorente 2003, Hernández Medrano et al. 2006). The tracks occur in the Tera, Oncala, and the overlying (Valanginian - Hauterivian) Urbión Groups, whith an abundance maximum in the Huérteles Formation (Oncala Group, lowermost Berriasian, Clemente 2010). This formation consists mainly of shallow lacustrine carbonates, grading laterally in basinal lacustrine shales, evaporitic carbonates and fluvial clastics (Clemente 2010). The environment consisted of a mudflat with ephemeral, hyperhaline pools within a hydrologically closed basin transiting laterally into a larger, hyperhaline lake (Meléndez \& GómezFernández 2000, Clemente 2010). The climate was arid, though ephemeral stream deposits and the abundant vertebrate ichnofauna indicate humid seasons or periods.

Towards southeast, the Villar del Arzobispo Formation represents a shallow-marine to continental succession exposed in the Teruel and Valencia Provinces (e.g. Aurell \& Meléndez 1993). The formation spans the Tithonian through early (or even mid-) Berriasian, however, the intraformational stratigraphic resolution is rather poor and the exact position of the Jurassic/Cretaceous boundary not fixed. The upper part of the formation was deposited in a tidal flat and coastal plain setting opening towards the Tethys Ocean in the southeast (Aurell \& Meléndez 1993).

The lower to middle part of the Villar de Arzobispo Formation has produced a rather rich archosaur fauna, however, due to the problem locating the Tithonian/Berriasian boundary this fauna is mostly referred to as "Tithonian-Berriasian" in age. The more confidently Berriasian (see below) record is much sparser.

Pterosauria. Fuentes Vidarte \& Meijide Calvo (1996) reported a few phalanges of a indeterminate pterosaur from the Huérteles Formation (lowermost Berriasian) of the Cameros Basin. Pterosaur tracks are extremely abundant in the Cameros Basin (Hernández Medrano et al. 2006 estimate about 2000 imprints to be known from 33 localities) A total of 6 ichnospecies of Pteraichnus Stokes, 1957 have been described from the Huérteles Formation, however, a review by Sánchez-Hernández et al. (2009) found only two, P. parvus Meijide Calvo, Meijide Fuentes, Fuentes Vidarte \& Meijide Fuentes, 2001, and P. longipodus Fuentes Vidarte, Meijide Calvo, Meijide Fuentes \& Meijide Fuentes, 2004, to be valid. The track size ranges from 1.5 to $14.7 \mathrm{~cm}$ (pes length, Hernández Medrano et al. 2006).

Though the largest ichnospecies from the Cameros Basin approaches Purbeckopus pentadactylus in size, its morphology is clearly different from the track described as Purbeckopus cf. pentadactylus from the roughly contemporaneous Bückeberg Formation (Chapter X). The wide range of track morphologies in the former probably reflects a considerable taxonomic diversity of Pterosaurs in Spain, which is not yet recovered from other European Berriasian sites.

Crocodylia. Crocodilians are represented by much rarer tracks. Two morphotypes have been described from 5 localities within the Oncala Group (Cameros Basin, Hernández Medrano et al. 
2006), one of them named as an ichnotaxon, Crocodylopodus meijidei Fuentes Vidarte \& Meijide Calvo, 2001. The track record from Spain does not allow for a taxonomic comparison to crocodile faunas from other European Berriasian sites, mostly based upon skeletal remains.

Dinosauria. From the Cameros Basin Pascual et al. (2012) reported the presence of a stegosaur footprint (Deltapodus isp.) in the Huérteles Formation. Ornithopod tracks are of comparatively low diversity, two morphotypes can be distinguished (Hernández Medrano et al. 2006). While the moderately sized morphotype OR-1 sensu Hernández Medrano et al. (2006) approaches the ichnogenus Iguanodontipus Sarjeant, Delair \& Lockley, 1998 in morphology, the larger morphotype OR-2 is distinct by broad feet and broad and short digits, similar to Caririchnium Leonardi, 1984. Among dinosaurs, theropod (including avian) tracks are most abundant and diverse. Hernández Medrano et al. (2006) catalogued a total of 12 theropod track morphotypes (including two avian). A number of ichnotaxa have been established or recognized, including Kalohipus bretunensis Fuentes Vidarte \& Meijide Calvo, 1998, Therangospodus oncalensis Moratalla, 1993, "Filichnites gracilis" Moratalla, 1993, Yanguanosaurus luzoni Fuentes Vidarte, Meijide Calvo, Meijide Fuentes \& Meijide Fuentes, 2005a, Archaeornithipus meijidei Fuentes Vidarte, 1996, "Bueckeburgichnus" maximus Kuhn, 1958 (Hernández Medrano et al. 2006), and “Megalosauripus” isp. (Barco et al. 2004, 2006).

Sauropod tracks are also common and occur in at least 4 morphotypes, two of "narrow gauge" and two "wide gauge" (Hernández Medrano et al. 2006, Castanera \& Canudo 2011). Two sauropod ichnotaxa have been named, Parabrontopodus distercii Meijide Fuentes, Fuentes Vidarte \& Meijide Calvo, 2001, and Brontopodus oncalensis Meijide Fuentes, Fuentes Vidarte, Meijide Calvo \& Meijide Fuentes, 2001. These morphotypes have been variously related to turiasaurs, diplodocoideans, basal macronarians, basal titanosauriforms and titanosaurs, respectively (Pascual-Arribas et al. 2008, Moratalla 2009, dos Santos et al. 2009, Pascual-Arribas \& Hernández-Medrano 2010, Castanero \& Canudo 2011). Sanz et al. (1992) reported an indeterminate sauropod femur from the Tera Group (basal Berriasian, Cameros Basin). Royo-Torres \& Canudo (2003) listed additional indeterminate sauropod fragments.

Skeletal remains from the Berriasian part of the Villar de Arzobispo Formation (Ruiz-Omeñaca et al. 2004, Canudo et al. 2005a) are restricted to a an indeterminate theropod caudal vertebra and a fragment of a theropod tooth, a sauropod metapodial and a tooth referred to the dryosaurid Valdosaurus sp. from the Galve area (Barco \& Ruiz-Omeñaca 2001a, b, Sánchez-Hernández et al. 2007). The ichnological record is more productive, including tracks from iguanodontian ornithopods (Pérez-Lorente et al. 1997, Castanera et al. 2013), theropods (Gascón \& Pérez-Lorente 2012), and sauropods (Castanera et al. 2011, Gascón \& Pérez-Lorente 2012). The titanosauriform sauropod tracks of the Las Cerradicas site are interpreted to have been left by a herd of subadult individuals (Castanera et al. 2011).

From the early Berriasian of the Sierra de la Pozo (Province of Jéan, southeastern Spain) GarcíaHernández et al. (2003) described a few medium-sized theropod tracks.

From the late Berriasian Arcera Formation in the adjacent Vasco-Cantabrican Basin, Pereda Suberbiola et al. (2006) described fragmentary remains (dorsal and caudal vertebrae) of a basal iguanodontian ornithopod.

Aragosaurus ischiaticus Sanz, Buscalioni, Casanovas \& Santafé, 1987, a basal titanosauriform of 
uncertain affinities (d'Emic 2012), was collected from the lower El Castellar Formation, dating from the ?Valanginian to the Hauterivian (Canudo et al. 2012). Canudo et al. (2005b) reported Bueckeburgichnus isp. and an unnamed theropod ichnotaxon from the Valanginian-Hauterivian Villanueva de Huerva Formation (Aguilón Basin).

Due to the marked decrease in the skeletal record of dinosaurs in the stratigraphical units which can be more safely regard to be of Berriasian age, the comparison to other dinosaur faunas can be better achieved by the extensive ichnological record in this time-slice. As noted above, the Villar del Arzobispo Formation has a poor stratigraphic correlation, while the age of the Huérteles Formation can be constrained to earliest Berriasian (ostracod biostratigraphy, Clemente 2010). It is therefore coeval to the Katzberg Member of the Münder Formation in northern Germany and somewhat older than the archosaur diversity peak in the lower Purbeck Limestone Group.

The ornithopod tracks from the Las Cerradices site (Galve, Teruel Province) have been found to be among the oldest ornithopod tracks with manus imprints, indicating at least facultative quadrupedalism of their producers (Pérez-Lorente et al. 1997, Castanera et al. 2013), though their exact stratigraphic placement in relationship to other near contemporaneous occurrences (Purbeck Limestone Group, Bückeberg Formation) is not well constrained. Interestingly, the manus impressions are small, ovate and do not show indications of separate digits. Therefore the trackmakers probably had the modified, closely, adpressed manual digits II-IV diagnostic to styracosternans (Sereno 1986). In contrast, the pedes were rather slender with low divarication angles of the digits (Castanera et al. 2013), which is a primitive trait in Iguanodontia. The pes impressions are similar in morphology and size to a rare ornithopod morphotype from the Bückeberg Formation of Wölpinghausen described as large Dinheichnus isp. in Chapter V. This observation is in accordance to the recent referral of relatively lightly build basal, iguanodontians as Cumnoria prestwichii and Uteodon aphanoecetes to the Styracosterna (McDonald 2011), which can give a model for the trackmakers of La Cerradices and Wölpinghausen. This idea is also supported by the scarce skeletal record from Spain (Pereda Suberbiola et al. 2006). The Spanish and German Berriasian Dinosaur faunas may also share the presence of dryosaurids, as indicated by a tooth from Spain (SánchezHernández et al. 2007) and the German track record (Appendix B, Chapter IV). On the other hand, a marked contrast exists between the abundance of massive, broad-footed ornithopod tracks in the Bückeberg Formation were they form the majority of tracks, and the relative rareness of this track type in the Oncala Group. As discussed below, this is probably the result of palaeoecological and stratigraphical settings of both occurrences.

Concurrent in the Bückeberg and Huérteles Formations is a high diversity of theropod tracks. At least two ichnotaxa, "Bueckeburgichnus" maximus and "Megalosauripus" isp. occur in both units. The latter represents a rather generalized and widely distributed type of Late Jurassic - Early Cretaceous theropod track (Lockley et al. 1998). "B." maximus is more distinct and possibly was made by a more restricted group of large-bodied theropod. Its very early occurrence in Spain supports the view, that it may have been produced by a member of the Late Jurassic theropod community that persisted into the Cretaceous but is not yet known by skeletal remains. Differences in the theropod ichnofauna include the presence of paravian (troodontid) tracks in Germany and the presence of avian tracks in Spain, both yet missing in the respective occurrences. 
Berriasian-Valanginian bauxitic palaeocarst fillings of Cornet, Romania.

A bauxitic deposit ('lens 204'), filling a palaeocarst system at Cornet near Oradea, northwestern Romania has been found to contain a large number of archosaur remains since the late 1970s (Benton et al. 1997 and references therein, Grigorescu 2003, Benton et al. 2006). Unfortunately, the age of the deposit could only be constrained to late Berriasian through end of Valanginian (Patrulius et al. 1983, Grigorescu 1993), however Dragastan et al. (1988) proposed a restriction to late Berriasian to early Valanginian). Posmoşanu (2003a) considered a late Berriasian to Valanginian age based upon dinosaur biostratigraphy, but this concept probably relies upon a too concise identification of taxa, based on isolated bones (see below). Deposition of the bauxite, as a result of tropical soil formation, and associated sediments took place in large sinkholes beneath small lakes on an island. The climate was hot-humid (Patrulius et al. 1983, Grigorescu 1993, Benton et al. 1997, 2006).

The Romanian deposits have yielded thousands of archosaur bones. The abundance distribution of the bones clearly show a strong taphonomic control, resulting in an overrepresentation of vertebral centra and autopodial elements (Posmoşanu \& Cook 2000, Posmoşanu 2003b). Benton et al. (2006) proposed dwarfing to be present in the dinosaur fauna induced by its insular setting.

Pterosauria. The only non-dinosaurian group of archosaurs present are pterosaurs (Jurcsák \& Popa 1983a, b, 1984), which include a dsungaripterid and an azhdarchid, aside of undiagnostic material (Dyke et al. 2011). Agnolin \& Varricchio (2012) questioned the referral of several specimens to birds by previous authors, and re-identified the holotype of Palaeolimnornis corneti (Kessler \& Jurcsák, 1984) (=P. biharicus Kessler \& Jurcsák, 1986, see Bock \& Bühler 1996 for clarification of nomenclature) as distal humerus of an azhdarchid pterosaur. They do not make any remarks on the nomenclatorial status of $P$. corneti, but do not list any potential autapomorphies. Additionally they identify the holotype of Eurolimnornis corneti Jurcsák \& Kessler, 1986 to repredent an inde-terminable genus of pterosaur, inferring a nomen dubium status for the taxon.

The record from the Bückeberg Formation does not allow for a direct comparison with the Cornet pterosaur fauna, due to the scarce record of both and the lack of overlap between the elements preserved.

Dinosauria. The presence of thyreophorans in Cornet is evidenced by a slender, elongate, spineshaped osteoderm which was referred to an ankylosaur (Jurcsák \& Kessler 1991, Benton et al. 1997). It should be noted, that the slender form of the osteoderm and its cross-section is also similar to that of stegosaur tail-spikes (e.g. Mallison 2011), while it does not show considerable similarity to spines of Hylaeosaurus armatus (see e.g. Chapter VII). Further examinations should be done to the assignment of this element (Galton 2009). Posmoşanu (2003a) mentioned an ankylosaurian scapula with similarities to Hylaeosaurus armatus as cf. Hylaeosaurus sp., but this material is not yet figured. Metapodials referred by Jurcsák \& Kessler (1991) to an ankylosaur were reidentified as belonging to an ornithopod by Galton (2009).

By number of elements, ornithopods are by far the most abundant dinosaurs at Cornet (e.g. 
Benton et al. 1997). Several attempts have been made to clarify the taxonomy of the Cornet ornithopods, basically resulting in the identification of a dryosaurid and probably two or more taxa of more derived ankylopollexians (e.g. Jurcsák \& Popa 1979, Patrulius et al. 1983, Marinescu 1989, Jurcsák \& Kessler 1991, Tallodi-Posmoşanu \& Popa 1997, Benton et al. 1997, Posmoşanu 2003c). A smaller, more basal form was repeatedly identified as Camptosaurus sp. (Tallodi-Posmoşanu \& Popa 1997, Posmoşanu 2002, Posmoşanu 2003c), while an apparently larger and more derived taxon was related to Iguanodon (e.g. Petrulius et al. 1983, Jurcsák \& Kessler 1991, Posmoşanu 2003b). The smaller Early Cretaceous genera Hypsilophodon Huxley, 1869, Dryosaurus Marsh, 1894, and Valdosaurus Galton, 1977 were also repeatedly identified (e.g. Jurcsák \& Popa 1979, Jurcsák 1982, Jurcsák \& Kessler 1991, Benton et al. 1997, 2006). However, in the most recent reviews, Galton $(2009,2012)$ identifies most ornithopod material as indeterminable at genus level. An exception were some teeth which he referred to Owenodon sp.. Additionally Galton (2009) argued to include various cranial and postcranial elements in Owenodon sp. based upon their phylogenetic which is considered more advanced than Camptosaurus but less then Styracosterna. However, the referral of these has to be contested by future material overlapping with 0 . hoggii, the type species. Galton $(2009,2012)$ further confirmed the presence of a more advanced styracosternan (Iguanodontea sensu Galton 2009).

Non-avian theropods are rare, two vertebrae and a two manual unguals of undertermined systematic affinities have been identified (the vertebrae have previously been referred to the genus Aristosuchus Seeley, 1887b, see Jurcsák 1982, Jurcsák \& Popa 1984b, Benton et al. 1997, Galton 2009). Various elements of avian theropods have been identified and the presence of archaeopterygids, as well as neognathan birds postulated (e.g. Kessler 1984, Jurcsák \& Kessler 1984, 1986, Kessler \& Gall 1995). However, a review by Dyke et al. (2011) showed, that the avian material is largely undiagnostic and the only taxon identifyable is a basal hesperornithine.

The record of theropods and thyreophorans from Cornet allows no direct comparison to that of the Bückeberg Formation. However, if confirmed, the presence of an ankylosaur similar to Hylaeosaurus armatus may be significant. The contemporaneous presence of several taxa of iguanodontian ornithopods mirrors that documented by the track record of the Bückeberg Formation. A basal styracosternan comparable to the phylogenetic stage of Owenodon hoggii is probably also present in the earliest Valanginian of Germany, though its dental morphology excludes it from a referral to this genus (see Appendix A). Although the age of the Cornet fauna is relatively loosely constrained, much evidence supports a late Berriasian - early Valanginian age (e.g. Dragastan et al. 1988) which is contemporaneous to the upper vertebrate abundance maximum in the Bueckeberg Formation (see Appendix C). It is further younger than the mid-Berriasian type stratum of $O$. hoggii, and it may be therefore possible that $O$. hoggii shares an ancestor with $O$. sp. from Cornet during the Late Jurassic lowstand which allowed it to immigrate to the Romanian island archipelago. There the genus may have survived in isolation into Valanginian times while it was succeeded by new taxa in western Europe mainland. 
Hastings Group (Berriasian-Valanginian) of southern England

The Hastings Group of southern England forms the lower stratigraphic unit of the Wealden Supergroup (Batten 2011). Stratigraphically it spans a range from the late Berriasian to the end of the Valanginian, with most of the section belonging to the Valanginian, though the exact position of the Berriasian/Valanginian boundary is not fixed (Batten \& Austen 2011). The depositional setting was in an extensive lacustrine basin with occasional intercalations of deltaic and perifluvial deposits. The climate was apparently humid supporting a highly diverse and abundant flora (Austen \& Batten 2011), invertebrate and vertebrate faunas (Batten \& Austen 2011). According to Kemper (1987) the annual temperatures had probably somewhat cooled since the Berriasian with more abundant short-term fluctuations.

Pterosauria. Only few fragmentary remains are known, with two potentially valid taxa, the ornithocheirid Coloborhynchus clavirostris Owen, 1874, and the ?lonchodectid Lonchodectes? sagittirostris (Owen, 1874) (see Martill et al. 2011).

Crocodylia. Crocodilian remains are abundant, though only a single species is yet formally described from the upper Valanginian Grinstead Clay Formation, Goniopholis willetti Salisbury \& Naish, 2011 (see also Chapter VIII as aff. Goniopholis sp.). Isolated material from this formation further includes Goniopholis sp., Goniopholididae indet., cf. Eusuchia, and Mesoeucrocodylia indet. The late Berriasian to mid-Valanginian Ashdown and Wadhurst Clay Formations contain Theriosuchus sp., Bernissartia sp., Goniopholididae indet., cf. Eusuchia indet., and Mesoeucrocodylia indet. (Salisbury \& Naish 2011).

The crocodilian fauna is congruent with the pattern from other Berriasian-Valanginian occurrences. However, the absence of pholidosaurids is conspicuous which occur most lately in the earliest Valanginian of Germany (Appendix A).

Dinosauria. The Hastings Group has yielded the problematic thyreophoran "Regnosaurus northamptoni" Mantell, 1848, which may represent a stegosaur, and the ankylosaurs Hylaeosaurus armatus Mantell, 1833 and Polacanthus sp. (Austen et al. 2010, Barrett \& Maidment 2011). The presence of stegosaurs is further supported by the holotype specimen of Craterosaurus pottonensis Seeley, 1874, a partial vertebra from the Lower Greensand Group, which was probably reworked from Valanginian strata (Galton 1981a).

An unnamed dryosaurid was reported by Norman (2011a) from several occurrences. Largebodied, styracosternan ornithopods are known to occur in at least two taxa since the $19^{\text {th }}$ century. Originally considered to belong to Iguanodon by Lydekker (1888a, 1889a, see also Blows 1989), they were subjugated to a convolute taxonomic chaos during the late $2000 \mathrm{~s}$, which finally resulted in Barilium dawsoni (Lydekker, 1888a) and Hypselospinus fittoni (Lydekker, 1889a) being the valid taxon names (Norman 2010, 2011a, b 2012). A third taxon, Kukufeldia tilgatensis McDonald, Barrett \& Chapman, 2010a may be present, but its based only on a single dentary and its distinction from $B$. dawsoni is disputed (McDonald et al. 2010a, Norman 2011a, b). The styracosternans occur in the 
mid-Valanginian Wadhurst Clay and Lower Turnbridge Wells Sand Formations. Therefore they are the iguanodontians stratigraphically most closely located to the German ornithopod ichnofaunas which are known from reasonable comprehensive material. They can therefore be considered model taxa for (some of) the trackmakers. The size of the more massive B. dawsoni (body length up to $>10 \mathrm{~m}$, Norman 2011a) would fit the larger tracks. Ornithopod tracks from the Hastings Group occur throughout the succession (e.g. Woodhams \& Hines 1989, Pollard \& Radley 2011), and belong to the first dinosaur tracks scientifically described from Europe (e.g. Tagert 1846, Beckles 1851, 1852, Owen 1858). They are morphologically very similar to those from Germany.

The theropod fauna is rich, though mostly fragmentary. Scattered material from the Hastings Group include dromaeosaurids, an unidentified, tiny maniraptoran, baryonychine spinosaurids, an allosauroid, the diagnostic Valdoraptor oweni of uncertain systematic position, and the similarly enigmatic Becklespinax altispinax (Naish 2003, 2011, Naish \& Sweetman 2011). Theropod tracks are also known (Pollard \& Radley 2011).

The sauropod fauna, though also known only from isolated element exhibits a unexpected diversity of palaeobiostratigraphically very interesting taxa. Two taxa, Pelorosaurus conybeari (Melville, 1849) (mid-Valanginian) and Xenoposeidon proneneukos Taylor \& Naish 2007 (probably late Berriasian or early Valanginian) were referred by Upchurch et al. (2011) to basal somphospondylian titanosauriforms, which would mean that they represent the oldest well dated occurrences of this group. However, d'Emic (2012) considered X. proneneukos, - based upon a partial dorsal vertebra - a nomen dubium with uncertain affinities. He did not further mention $P$. conybeari which was based upon a humerus, four anterior caudal vertebrae and haemapophyses, most probably from a single animal (Taylor \& Naish 2007). Upchurch et al. (2012) based their referral to basal somphospondylians mostly on absence of a hyposphenal ridge between the postzygapohyses, a derived trait. Additionally, d'Emic (2012) defined the presence of tubercles or ridges on the dorsal margin of the prezygapophyses in proximal caudal vertebrae a synapomorphy of a clade formed by the euhelopodids Phuwiangosaurus sirindhornae Martin, Buffetaut \& Suteethorn, 1994 and Tangvayosaurus hoffeti Allain, Taquet, Battail, Dejax, Richir, Véran, LimonDuparcmeur, Vacant, Mateus, Sayarat, Khenthavong \& Phouyavong, 1999 from the Early Cretaceous of Thailand. Similar tubercles or emarginations seem to be present in Pelorosaurus conybeari (Upchurch et al. 2011: text-fig. 28.7b, e), further supporting a referral of P. conybeari to the euhelopodids. Phuwiangosaurus sirindhornae is from the Sao Khua Formation of BerriasianBarremian age (Racey \& Goodall 2009) and therefore temporally close to P. conybeari. "Pelorosaurus" becklesii Mantell, 1852, based upon a partial forelimb with associated patches of skin-impressions from an unknown horizon within the Hastings Group, was proposed by Upchurch et al. (2011) to belong to a titanosaur, which would make it the most advanced sauropod known from the Early Cretaceous of Europe. However, d'Emic (2012) disputed this and suggested "P." becklesii to be a titanosauriform of uncertain affinities. The same is true for "Pleurocoelus valdensis" Lydekker, 1889b, a nomen dubium based upon teeth (Upchurch et al. 2011).

The probable occurrence of an euhelopodid in the Valanginian of Europe is very remarkable and supports a faunal exchange with Asia, where the focus region of euhelopodids was located. Euhelopodids are possibly also present in the Barremian of Spain (Canudo et al. 2002). The 
presence of basal titanosauriforms is shared with the Bückeberg Formation and with the Berriasian-Hauterivian of Spain.

Conclusions

A comparison of Berriasian-Valanginian archosaur faunas from Europe show a complex pattern of diversity (see also Fig. XI.9). The assessment of the meanings of this diversity is hampered by the poor quality of preservation and completeness, as well as by biases due to different sampling methods employed yet. However, some preliminary conclusions may be drawn:

The pterosaur record is to ambivalent for a wide-ranging interpretation. However the record from the early to mid Berriasian of England (Howse \& Milner 1995) and Germany (von Meyer 1851) seem to indicate a prevalence of ctenochasmatids in arid environments with extensive playa lakes and lagoons of changing salinities. This is in accordance to their trophological interpretation as filter feeders which probably foraged of small invertebrates (Bennett 2007). The taxonomically and palaeoecologically more diverse record from Cornet probably reflect the more humid, tropical environment of this deposit. The track maker of Purbeckopus pentadactylus cannot be referred to a certain clade but the presence of very large pterosaurs with apparently a broad palaeoecological spectrum is evident (Chapter X).

The crocodilian fauna is remarkably uniform across the localities. However, it should be noted, that, with the exception of England and Germany, the diversity is either not yet studied at species level (Cherves-de-Cognac), or the crocodilian fauna is nearly exclusively represented by teeth and tracks (Denmark, Spain), which do not allow for an assessment at low taxonomic levels. The high number of isolated but distinct elements (Owen 1878, 1879, Salisbury 2002) and recent indication of at least two sympatric species of Goniopholis in England (Andrade et al. 2011) is a hint to a higher diversity than documented by complete and well-described specimens. A marked deviation from the pattern elsewhere in Europe is the stratigraphic separation of the occurrence of goniopholidids from pholidosaurids in Denmark (Schwarz-Wings et al. 2009). This separation may be due to palaeoecological reasons, which however cannot be assessed yet.

The thyreophoran fauna is apparently of low diversity. Definitive stegosaurs are restricted to the early Berriasian of southwestern Europe, however their presence in the Valanginian of England is probable. Ankylosaurs are known from two taxa, Hylaeosaurus armatus and Polacanthus sp., mostly from the mid-Valanginian of England. Hylaeosaurus sp. is probably also present in northern Germany (earliest Valanginian, see Chapter VII). The distribution of this taxon as well as that of ankylosaurian tracks (Chapter VI) suggest a preference for seasonal but not arid climate. Its rareness in the ichnological record may otherwise mean that they were solitary animals and did not frequently occur in the immediate vicinity of lakeshores. It may also be a hint that the often problematic quadrupedal tracks from the Purbeck Limestone Group (e.g. Ensom 2002b) may be rather left by sauropods, which are evidently more common in dry environments (see below). The thyreophoran record from Romania requires a reassessment.

The abundant but patchy record of ornithopods suggests a high diversity and a sympatric 
coexistence of representatives of different phylogenetic levels. Dryosaurids occur in the ?lower Berriasian of Spain (Sánchez Hernández et al. 2007), and the Valanginian of England (Norman 2011a), tracks of relatively small, bipedal ornithischians from the late Berriasian of Germany (Chapter IV) may also be attributed to them. Based upon their distribution, dryosaurids may have been palaeoecologically linked to the presence of abundant freshwater. Basal ankylopollexians ("camptosaurids") may still be present in the Obernkirchen Member of the Bückeberg Formation (Chapter V, Appendix A) but the bulk of trackway evidence suggest a basal styracosternan grade of the trackmakers (Appendix B). The latter are present with at least four taxa in the BerriasianValanginian of England and Romania (Galton 2009, 2012, Norman 2011a) and the early Valanginian of Germany (Appendix A). According to their relative abundance (see below) ankylopollexians seem to have preferred more humid habitats than sauropods though were more tolerant to aridity than dryosaurids. The only local fauna without any record of ornithopods is from Bornholm Island, another indication of potentitially different faunal composition and history in northeastern Europe.

Heterodontosaurids are rare and known only from Cherves-de-Cognac and the Purbeck Limestone Group. Their distribution may suggest that they preferred dry climates.

The ceratopsian Stenopelix valdensis is not only unique by its taxonomic assignment but also by its taphonomy. In contrast to all other dinosaur remains from the Obernkirchen Sandstone (and other Berriasian-Valanginian deposits) it is represented by a fully articulated, nearly complete postcranium. While this may be interpreted as evidence for environmental authochthony, circumstantial evidence contradicts such an assumption. Despite the abundance of dinosaur tracks, none have been found so far in the Obernkirchen Sandstone which match the pedal osteology of $S$. valdensis. The perfect articulation and posture of the specimen (crouching with flexed hindlimbs and posteriorly extended forelimbs) suggests that the corpse was mummified by dehydration prior to burial and not drifting in water as a fresh carcass. Fixed by the shrunken skin, the lightweight carcass could have been fluvially transported with few damage, as it is evidenced e.g. by fully articulated hadrosaurid specimens with preserved integument from fluvial channel deposits (Murphy et al. 2007) and actualistic observations (Weigelt 1927). It is therefore concluded that $S$. valdensis probably inhabited a seasonally dry hinterland and the mummified specimen was washed during the rainy season towards the lake basin. This interpretation is in line with the interpretation of the Harrl type locality as distal shallow deltaic deposits with seasonally high sediment input (Chapter III) and a characterization of the climate as strongly seasonally wet/dry (Pelzer \& Wilde 1987). If the missing head was lost during transport or by excavation is unknown, however, Gottmann (1999) recognized a structure similar to a cluster of scales near the cervical series which she proposed to be the impression of osteoderms from the squamosal-parietal region. This interpretation would also be concurrent with the recognition of such tubercular osteoderms on the squamosal arc in Yinlong downsi (see Xu et al. 2006), the sister taxon of S. valdensis. However, it shows also some resemblance to a twig with scaly needles of the conifer Brachyphyllum sp. (see Austen \& Batten 2011).

Among theropods, dromaeosaurids seem to be ubiquitious - they are present in nearly all faunas which have been screened with adequate methods, lacking only in Germany and Spain so far (the record from the Purbeck Limestone Group is disputed). The intra-clade diversity may be high 
(Bonde 2012). The ichnological record of troodontids from Germany (van der Lubbe et al. 2009) is unique in the basal Cretaceous of Europe. The absence of similar tracks in the coeval rich ichnocoenoses of Spain may suggest a palaeoecological and/or palaeobiogeographical signal. Equally, there is no osteological record of this group known from this time-span in Europe. Baryonychine spinosaurids appear in the late Berriasian of England and occur there throughout the Early Cretaceous at least to the Aptian (Naish 2011). Otherwise the interpretation of the very scarce theropod record is impossible beyond an apparently very high diversity suggested by the track record (e.g. Hernández Medrano et al. 2006, Richter et al. 2009, Chapter IV).

Sauropod diversity and abundance across Europe was apparently also not uniform. Based upon the ichnological record, the highest diversity of sauropods occurred in Iberia (e.g. Pascual Arribas \& Hernández-Medrano 2010, Castanera \& Canudo 2011), however the skeletal record is mostly not identifyable beyond Sauropoda indet. A basal titanosauriform probably occurred in the ?Valanginian-Hauterivian. Basal macronarians apparently occured in the early Berriasian of southwestern France and Spain (tracks). Otherwise the tracks and rare skeletal evidence supports a taxonomic dominance of basal titanosauriforms (brachiosaurids) during the Berriasian-Valanginian of central and northeastern Europe. This reflects a general reduction of sauropod diversity in the earliest Cretaceous (Mannion et al. 2011). Skeletal evidence for the presence of diplodocideans have not yet been found in the basal Cretaceous of Europe (Upchurch et al. 2011, Mannion et al. 2012), though tracks from the earliest Berriasian of Spain have been interpreted to have been left by diplodocoideans (Pascual-Arribas \& Hernández-Medrano 2010). However, the Valanginian probably saw the advent of euhelopodids in England. They are associated with indicators of humid climate, suggesting different ecological preferences than in more basal titanosauriforms (see below). The appearance of euhelopodids is probably the most important faunal change in large herbivores in Europe prior to the late Hauterivian/Barremian major faunal substitution. A complex pattern of sauropod distribution and interaction with ornithopods as the other major clade of large terrestrial herbivores is also supported by the different patterns of local biome dominance as outlined below.

European faunal trends at the Jurassic/Cretaceous boundary

(Fig. XI.5)

The Late Jurassic archosaur fauna of Iberia is abundant and well known (e.g. Lapparent \& Zbyszewski 1957, Galton 1980b, Rauhut 2000b, Schwarz 2002, Santisteban et al. 2003, Antunes \& Mateus 2003, Rauhut 2003, Ruiz-Omeñaca et al. 2004 and references therein, Schwarz \& Salisbury 2005, Sánchez-Hernández 2005, Barco et al. 2005, Canudo et al. 2005a, 2006, Mateus et al. 2006, 2009, Royo-Torres et al. 2006, 2009, Escaso et al. 2007, Lockley et al. 2008, Mateus \& Milán 2008, 2009, Canudo 2009, Avanzini et al. 2010, Company et al. 2010, Cobos et al. 2010, Malafaia et al. 2010, Mateus et al. 2011, Pereda Suberbiola et al. 2011, Alcalá et al. 2012, Gascó et al. 2012, Mannion et al. 2012, Royo-Torres \& Upchurch 2012). It contains goniopholidids, atoposaurids, crocodile tracks, stegosaurs, stegosaur tracks, ankylosaurs (a ?nodosaurid), basal euornithopods, basal ankylopollexians, ornithopod tracks, theropods (ceratosaurids, megalosaurids, allosaurids, 
basal ?coelurosaurians, ?compsognathids, tyrannosauroids, dromaeosaurids, ?troodontids, ? archaeopterygids, aff. Paronychodon sp., and cf. Richardoestesia sp.), theropod tracks, sauropods (diplodocids, brachiosaurids, and turiasaurians), and sauropod tracks.

The record from central parts of Europe is less abundant and well preserved for the most parts. The Tithonian Plattenkalk deposits of Cerin, France and the Altmühl Valley, Germany are an exception and produced rich pterosaur faunas, including rhamphorhynchids, anugnathids, ctenochasma-toideans, and dsungaripteroideans (e.g. Wellnhofer 1970, 1975, 1978, Bennett 2007, 2013). Well preserved specimens are also found in increasing numbers in the Kimmeridgian of Oker, northern Germany, and less complete material of these groups occur also elsewhere in the Kimmeridgian-Tithonian of Europe (see Martill \& Etches [in press] for a summary).

Atoposaurids are known predominantly from the Plattenkalk deposits (e.g. Wellnhofer 1971) but also from the Kimmeridgian of Oker, Lower Saxony, from isolated teeth as well as some splendid skulls and a nearly complete skeleton (Thies et al. 1997, Thies \& Broschinski 2001, Karl et al. 2006, Raddatz 2011). Otherwise crocodilian faunas nearly entirely consist of marine thalattosuchians (e.g. Selenka 1867, Steel 1973, Benton \& Spencer, 1995, Grange \& Benton 1996, Hua 1999, Karl et al. 2006, 2008, Young \& Andrade 2009). Karl et al. (2006) reported Goniopholis simus from the Kimmeridgian of Oker, however the material is very scarce (teeth, osteoderms) and can only be identified as Goniopholididae indet. at best. Buffetaut (1986) reported Goniopholis sp. from the Upper Jurassic of France.

In England dacentrurine stegosaurs, fragmentary ankylosaur remains, a basal styracosternan (Cumnoria prestwichii), a metriacanthid theropod (Metriacanthus parkeri [von Huene, 1923]), various indeterminate theropod remains, a basal titanosauriform sauropod (Duriatitan humerocristatus [Hulke, 1874]) and other fragmentary sauropod remains are known (e.g. Galton \& Powell 1980, Galton 1980a, 1985, Taylor et al. 1993, Benton \& Spencer 1995, Naish \& Martill 2007, 2008, Barrett et al. 2010).

In France Kimmeridgian-Tithonian strata have produced dacentrurine stegosaurs, ankylosaurs, ornithopods (including iguanodontians), ornithopod tracks, indetermined theropods and a nearly complete compsognathid, theropod tracks, sauropods (including probably turiasaurians, see RoyoTorres et al. 2006), and sauropod tracks (Allain \& Pereda Suberbiola 2003 and references therein,

Fig. XI.5 Temporal distribution of non-avian dinosaur clades and archosaur faunal succession in the Kimmeridgian throughout the Albian in Europe. For details and references see text. Black arrows indicate possible dispersal events. Af - Africa; ALB - Albian; APT - Aptian; As - Asia; BAR - Barremian; BER - Berriasian; CRISIS Tithonian/Berriasian aridity crisis; HAU - Hauterivian; KIM - Kimmeridgian; PAG - Opening of Periadriatic gateway to Gondwana (Africa); TIT - Tithonian; VAL - Valanginian.

$\left.{ }^{*}\right)$ excluding Spinosauridae.

$\left.{ }^{* *}\right)$ excluding Rebbachisauridae.

${ }^{* * *}$ ) excluding Titanosauriformes.

${ }^{* * * *}$ ) excluding Euhelopodidae, including Brachiosauridae.

Colour coding (palaeozoogeographical provenance) according to Fig. XI.9. 


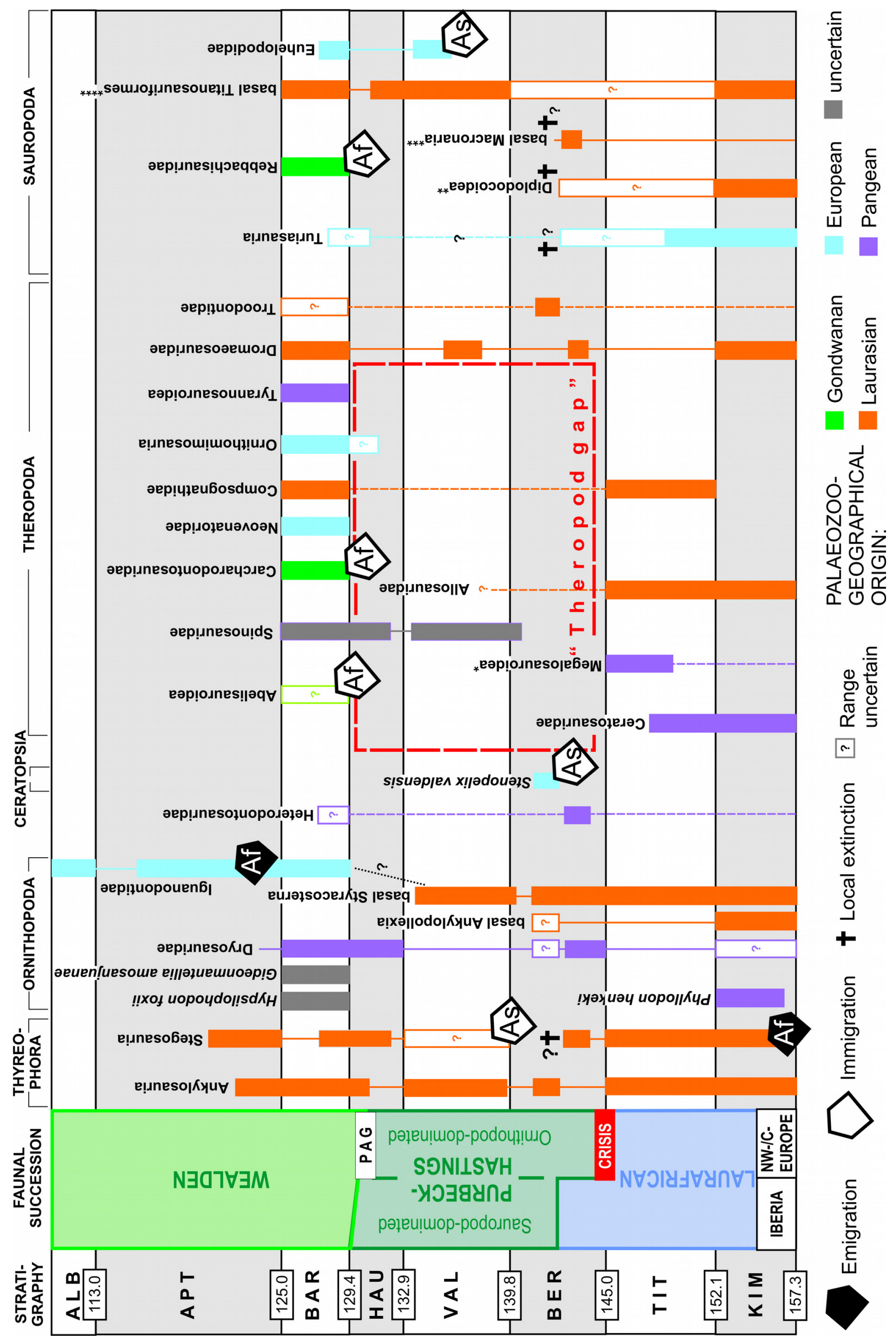


Le Loeuff et al. 2006, Weishampel et al. 2004).

Kimmeridgian-Tithonian dinosaurs of Switzerland include a stegosaur, theropods (ceratosaurs, ? dromaeosaurids), a sauropod of uncertain affinities ("Cetiosauriscus" greppini [von Huene, 1922]), and numerous and extensive tracksites with sauropod and rarer theropod tracks (e.g. Meyer \& Thüring 2003, Marty 2008, Marty \& Meyer 2012).

Kimmeridgian-Tithonian dinosaur faunas of Germany include ?ankylosaurs, ornithopods (? dryosaurids), ornithopod tracks, theropods (megalosauroids, ?allosauroids, compsognathids, dromaeosaurids, and archaeopterygids), theropod tracks, sauropods (diplodocids, basal brachiosaurids), and sauropod tracks (e.g. Ballerstedt 1922, Kaever \& Lapparent 1974, Ostrom 1978, Probst \& Windolf 1993, Windolf 1997, Göhlich \& Chiappe 2006, Sander et al. 2006, Diedrich 2011, van der Lubbe et al. 2009b, Wellnhofer 2009, Rauhut et al. 2012, Wings 2012, and undescribed GZG material [pers. obs.]).

Comparing these faunas to those listed above from the basal Cretaceous, there seem to be some major changes in habitat dominance and potentially diversity over this time-span. This mostly concerns the stegosaurs, which were quite ubiquitious in the terminal Late Jurassic of western Europe, though apparently of low taxic diversity (e.g. Mateus et al. 2009). Stegosaur footprints are known from Iberia, some in pristine preservation. A high diversity was enjoyed by sauropods and theropods in the Late Jurassic, though most occurrences of diagnostic skeletal material contain only one or two taxa. Exceptions are the rich dinosaur biocoenoses of Portugal and the taphocoenoses of the Plattenkalk deposits of southern Germany which preserve a diversity of small theropods. The sauropod skeletal record shows the presence of turiasaurs, diplodocids, and basal titanosauriforms (as well as several taxa incertae sedis), and such a diversity is also mirrored by the track record. The latter are more often dominated by narrow-gauge tracks, mostly associated with diplodocoideans. Sauropod tracks are generally more abundant than theropod tracks (though the latter may also be abundant locally, Marty 2008).

The remains of ankylosaurs and ornithopods are generally too scarce to assess their diversity, though a partial skeleton of the ankylosaur Dracopelta zbyszewskii Galton, 1980b, and a relatively complete skeleton of the basal styracosternan Cumnoria prestwichii are known (Galton \& Powell 1980). Ornithopod footprints are rarities, however single specimens from Portugal (Mateus \& Milàn 2008) and Germany (Diedrich 2011) indicate the presence of moderately to large-bodied iguanodontian ornithopods in the Late Jurassic of Europe. Diedrich (2011) also referred a small tridactyl footprint from northwestern Germany to Grallator isp., and considered it to have been left by a dryosaurid. However, the proportions of the digits and asymmetry, as well as the very narrow claw-marks clearly suggest that it is a small theropod footprint, which shows similarity to the Cretaceous ichnogenus Columbosauripus Sternberg, 1932.

However, despite these differences between Late Jurassic and earliest Cretaceous archosaur faunas, at a second glance a sudden, clear-cut general faunal turnover can hardly be evidenced. The basal Cretaceous pterosaurs are too poorly known for a reasonable comparison, with the exception that ctenochasmatids may have flourished in some faunas, which they did already in the Tithonian (Bennett 2007). The change in the crocodilian fauna shows clearly an ecological signal thalattosuchians where typically marine and are replaced in terrestrial beds by goniopholids, 
pholidosaurids, and atoposaurids, the first and the last obtaining the same ecological niches across the Jurassic/Cretaceous boundary. Pholidosaurids may have originated from goniopholidids by attaining a more specialized trophic niche (Martin \& Buffetaut 2012), or may be a more land-bound sister-group of thalattosuchians (e.g. Andrade et al. 2011). A small set of steneosaurid teeth from the Münder Formation at Thüste (Lower Saxony, Roemer-Pelizaeus-Museum, Hildesheim collection, uncatalogued) show that thalattosuchians persisted rarely into the earliest Berriasian in northern Germany,. These occurrences were related to the shrinking perimarine lagoons and vanished with the onset of the limnic deposition of the Bückeberg Formation. The survival of thalattosuchians across the Jurassic/Cretaceous boundary in marine realms elsewhere is evidenced by their recurrence in Early Cretaceous marine deposits (e.g. Koken 1883, Debelmas \& Strannoloubsky 1957, Hua et al. 2000, Young et al. 2010).

A survival of stegosaurs across the Jurassic/Cretaceous boundary is evident in southern Europe (Billon-Bruyat et al. 2010, Pascual et al. 2012), and this may be also true for diplodocid and turiasaurian sauropods, though the evidence is based upon the track record (Pascual-Arribas \& Hernández-Medrano 2010, Castanera \& Canudo 2011). In central Europe, the last known diplodocoideans are represented by Late Kimmeridgian narrow-gauge trackways (Ballerstedt 1922, Lockley \& Meyer 2000) and probably by skeletal remains (Wings 2012). In Spain, the trackway evidence suggests their survival at least into the earliest Berriasian. This, together with the discrepancies in biotope dominance of sauropods vs. ornithopods in Germany and Spain, respectively (see below), suggest a complex and mosaic-like pattern of decimation across the European sauropod fauna. Several clades of large-bodied theropods also have their last occurrence in Europe in the Late Jurassic, including ceratosaurids, megalosauroids, metriacanthids, and allosaurid allosauroids. However, as noted before, the ichnological record is in incongruence with the osteological record, suggesting that one or several of these clades still occurred in Europe after the Jurassic/Cretaceous boundary. All other dinosaurian groups apparently continued to exist across the boundary.

\section{Interpreting the fossil record of Late Jurassic / Early Cretaceous archosaur faunas in Europe}

The effect of taphonomic and sampling biases

In the light of the above described distribution patterns, it must be brought into consideration which extrinsic factors may be intrumental in shaping our dataset on Late Jurassic / Early Cretaceous archosaur faunas. The most obvious is a drastic change in the environment that enshrined the fossil record. With exception of the Iberian occurrences, all archosaurian-bearing European localities of Late Jurassic age are located in shallow-marine to intertidal deposits. In general terms, these sedimentary environments may be characterized as to be represented by marine sub- to intertidal, with very subordinate supratidal facies associations as evidenced by palaeosol horizons in some localities (e.g. Waite 2010, Diedrich 2011). Regarding the preservation potential of terrestrial or terrestrial-limnic vertebrates, the transport of their skeletal remains to 
these environments employs a taphonomical filter, which is complicate to assess in its effectivity. For example, a shallow-marine environment which bounds a large fluvial system (i. e. marine delta or estuary) with high and potentially fluctuating sediment transport and aggradation rates will have a higher potential to contain terrestrial vertebrates then another which is located near a landmass with small drainage systems and low-volume run-off. This may be exemplified by the Plattenkalk deposits of Bavaria, which were deposited in a lagoonal setting with very low terrigenous influx, bounding an island system with low local run-off (Barthel et al. 1990): The dinosaur record is restricted to very small theropods, some of which are apparently juvenile (Rauhut et al. 2012). The latter indicate that the insular landmasses were inhabited by larger individuals, which had, due to the lack of a transport medium, hardly a chance to become fossilized in the lagoonal sediments. Therefore the fossil record of this lagerstaette, though superior in quality, is clearly biased taphonomically in terms of taxic sampling, a factor which should be put in consideration when dealing with the "lagerstaetten problem" in overall palaeodiversity estimations (e.g. as in Benson et al. 2010a, Benson \& Butler 2011).

In other localities, exceptional preservation may be event-based (and therefore a nonrepresentative sampling method), as the concentration of well preserved tetrapods to very confined lithological subunits or horizons implies (e.g. Oker locality, Sander et al. 2006, Swiss Cetiosauriscus greppini occurrence, Meyer \& Thüring 2003). A similar variant of such a potential biased sampling may be provided by condensation bonebeds (e.g. Rogers \& Kidwell 2007), which bear the risk of time-averaging and faunal mixture, which is examplified by the occurrence of reworked Jurassic belemnites in a Berriasian bonebed in the Bückeberg Formation (see Appendix B).

The situation is different when regarding the track record. The non-Iberian Late Jurassic dinosaur track record is bound to intertidal depositional systems which may have formed permanent passages between islands during sea-level lowstands (e.g. Meyer 1993, Meyer \& Thüring 2003, Marty 2008, Diedrich 2011). In fact these deposits were formed as a result of short-term sea-level fluctuations which changed the regime of the low-relief mudflats from shallow subtidal via truly intertidal to supratidal (Waite 2010). It can be anticipated that using the passages was easier for genuinely terrestrial animals like dinosaurs during the supratidal phases, however the preservational potential of these intervals (represented by paleosols, carstified hardgrounds, or hiatuses) for vertebrate tracks is comparatively low (e.g. Marty et al. 2009). The intertidal intervals were more favourable for track preservation, though only suboptimal for passage of the trackmakers. The resulting fossil record may therefore represent an intersecting set of both factors. Furthermore, the intertidal flats were most probably not a suitable permanent habitat for the large herbivores, and in consequence also not for the large carnivores. They may therefore be seen as representing episodic migrational routes, and as a sampling subset of these taxa which employed such a migrational habit. Smaller carnivores may have specialized in feeding upon marine biota from the intertidal zone, and therefore be seen at least as more permanent inhabitants of this biotope. These considerations may also affect the statistical assessment by Mannion \& Upchurch (2010) that non-titanosauriforms preferred marine coastal habitats, which was obtained by integrating narrow-gauge sauropod track occurrences in their dataset. However, these may represent a taphonomically favoured extract of total sauropod distribution which is further biased 
by the palaeogeographical situation during the Late Jurassic. The abundance and diversity of nontitanosauriforms in inland habitats, as e.g. represented by the Morrison and Lourinhã Formations, suggest, that intertidal flat crossing may have been a strategy of local sauropod populations to cope with habitat limitations imposed by the Late Jurassic sea-level highstand. Though non-titanosauriforms probably had a wider habitat range than derived titanosaurs, a habitat preference for coastal environments must be considered with caution.

In contrast to the other European Late Jurassic localities, those from the Iberian Peninsula show a very different setting, as they represent clearly terrestrial, alluvial to perilimnic habitats with only occasional, minor marine incursions (e.g. Aurell \& Meléndez 1993, Martin \& Krebs 2000, Gutierrez \& Sheldon 2012, Myers et al. 2012). This is clearly reflected by the abundance and diversity of terrestrial vertebrates, especially those of dinosaurs, as summarized above. The skeletal and ichnological record preserves a broad range of autochthonous or parauthochthonous taxa which were subjugated to the process of taphonomical filtering by transport much less than in marine deposits. This appears to be an important factor in explaining the differences in quality and quantity to other contemporaneous localities and emphasizes their potential undersampling in terms of diversity. In fact, in terms of diversity completeness and comparability deposits as the Portuguese Lourinhã Formation or the North American Morrison Formation may represent an optimum, though being inferior in quality of morphological information to lagerstaetten deposits. However, the preservational chances may considerably vary within this overall setting. For example, the Villar del Arzobispo Formation in Spain represents a continuous deposition of shallowmarine/coastal to fluvial deposits across the Jurassic-Cretaceous boundary (Aurell \& Meléndez 1993), reflecting a relative drop in sea-level over this time-span. The record of vertebrates in this formation is highly discontinuous, with most of the skeletal remains concentrated in the stratigraphically lower, coastal-deltaic deposits (Ruiz-Omeñaca et al. 2004). This may reflect a habitat preference, however, the record of dinosaur tracks increases proportionally towards the top of the formation (Peréz-Lorente et al. 1997, Castanera et al. 2013), suggesting rather a taphonomic control of fossil distribution than a true diversity signal. Proximal fluvial environments may be less susceptible for fossil preservation as the limited accomodation space of the sediments has a higher chance of remobilization and reworking by thalweg migration when compared to the dominantly aggradational regime of distal fluvial systems in coastal plains.

Some of the concepts outlined above for the relationship between habitat, migration and track preservation and distribution in marine intertidal settings are also applicable to the Obernkirchen Sandstone track associations. Though they clearly represent an inland dinosaur fauna, these thrived along the margin of a large lake and left their tracks in sedimentary system which may be comparable to those known from marine littoral settings. As it is outlined in Chapters II to IV, vertebrate localities in the Obernkirchen Sandstone are spread across a variety of clastic facies assemblages, representing different subenvironments. In a first-level approach these may be distinguished in a most distal facies assemblage as represented by the lower beds exposed in the Rehburg Mountains (Jürgens 1972, Pelzer 1998, Fischer 1998), a central facies as found in the Bückeberge (Grupe 1931, Jürgens 1972, Chapter IV), and a proximal facies exposed south of Hannover (Jürgens 1972, Pelzer 1998, Fig. XI.1). As outlined in Chapters I to IV and in accordance to 


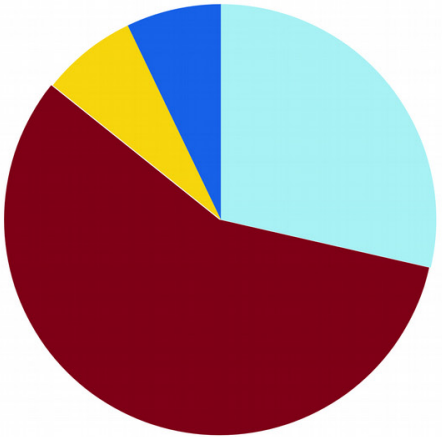

Huérteles Fm.

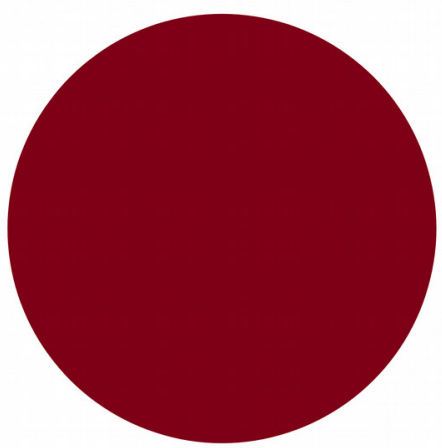

Bavaria
- Stegosauria

- Ceratopsia

- Ankylosauria

- Theropoda

- Ornithopoda

Sauropoda

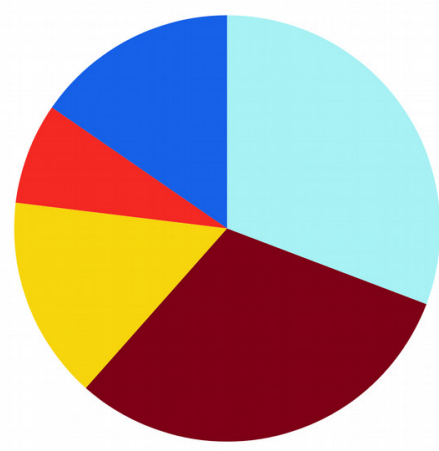

Lourinhã Fm.

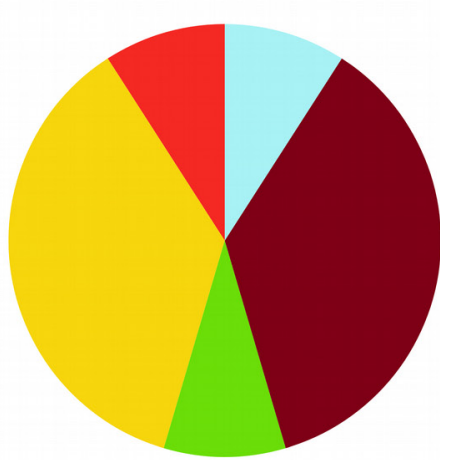

Bückeberg Fm.

曾

A Fig. XI.6 Relative diversity (percentage of taxa, Tab. XI.2) of selected Late Jurassic to Early Cretaceous dinosaur faunas, showing effects of sampling and taphonomic biases. See text for details.

Tab. XI.2 Database for Fig. XI.7. Taxon numbers are minimum estimates, based on ichnological and skeletal record, for references see text.

\begin{tabular}{|c|c|c|c|c|c|c|c|c|c|c|}
\hline \multirow{3}{*}{ Stegosauria } & \multicolumn{2}{|c|}{ Guimarota Fm. } & \multicolumn{2}{|c|}{ Lourinha Fm. } & \multicolumn{2}{|c|}{ Bavaria } & \multicolumn{2}{|c|}{ Huérteles Fm. } & \multicolumn{2}{|c|}{ Bückeberg Fm. } \\
\hline & $\begin{array}{l}\text { \# of } \\
\text { taxa }\end{array}$ & {$[\%]$} & $\begin{array}{l}\text { \# of } \\
\text { taxa }\end{array}$ & [\%] & $\begin{array}{l}\text { \# of } \\
\text { taxa }\end{array}$ & {$[\%]$} & $\begin{array}{l}\text { \# of } \\
\text { taxa }\end{array}$ & {$[\%]$} & $\begin{array}{l}\text { \# of } \\
\text { taxa }\end{array}$ & {$[\%]$} \\
\hline & 0 & 0,0 & 2 & 15,4 & 0 & 0,0 & 1 & 7,7 & 0 & 0,0 \\
\hline Ankylosauria & 0 & 0,0 & 1 & 7,7 & 0 & 0,0 & 0 & 0,0 & 1 & 9,1 \\
\hline Ornithopoda & 2 & 15,4 & 2 & 15,4 & 0 & 0,0 & 1 & 7,7 & 4 & 36,4 \\
\hline Ceratopsia & 0 & 0,0 & 0 & 0,0 & 0 & 0,0 & 0 & 0,0 & 1 & 9,1 \\
\hline Theropoda & 10 & 76,9 & 4 & 30,8 & 5 & 100,0 & 8 & 61,5 & 4 & 36,4 \\
\hline Sauropoda & 1 & 7,7 & 4 & 30,8 & 0 & 0,0 & 4 & 30,8 & 1 & 9,1 \\
\hline Total & 13 & 100,0 & 13 & 100,0 & 5 & 100 & 13 & 100,0 & 11 & 100,0 \\
\hline
\end{tabular}


Pelzer (1998) these are interpreted as barrier sand, distal delta plain, and perifluvial deposits, respectively. The barrier environment preserved tracks of high quality, however, the barrier and barrier shoals were highly mobile and did not support any significant vegetation, but they may have provided a pathway to bypass the back-barrier lagoon in shore-parallel migrations. In this respect they had a similar function as the Jurassic marine tidal flats. As it can be seen in Table XI.1, the highest diversity (skeletal remains and tracks) and abundance is found in the central facies, though the dinosaur skeletal record is still poor in contrast to that of crocodilians. This is in accordance to an interpretation as distal delta plain forming the landward shore of the lagoon and supporting some vegetation on emerged and stabilized mouthbars and in swamps. The rarity of skeletal material of dinosaurs is puzzling, even the intense collection activity of M. Ballerstedt over decades in a few outcrops has produced only a handful of isolated dinosaur elements compared to a wealth of crocodile specimens (see Appendix A). The density of dinosaur tracks may represent a seasonal gathering of these animals in the area, rather than a dominant permanent presence. Further upstream, the fossil record again becomes rarer, however, the very strong signal may partly be caused by smaller outcrops and undersampling.

To illustrate these aspects, a set of European Jurassic-Cretaceous dinosaur localities is compared in Fig. XI.6 and Tab. XI.2. The diversity has been estimated by blending ichnological and skeletal data using a minimum approach, i.e. the minimum of recognizable morphotypes is considered to represent distinct orthotaxa, regardless of its preservation. For example, if a formation contains three ichnomorphotypes and two skeletal morphotypes of theropods, which cannot be differentiated otherwise (e.g. by pes morphology), the number of theropod orthotaxa is estimated to three, as an overlap of record cannot be ruled out. In conclusion, two observations can be stated:

(1) The differences in diversity and diversity distribution (dominance of taxa) is strongly dependant of (a) taphonomical filtering and (b) the sampling method employed. The strong overrepresentation of theropods in the Bavarian Plattenkalk deposits are most probably a taphonomic effect (as outlined above). Otherwise the differences between the Guimarota and Lourinhã faunas are dependent of the sampling method: The dinosaurs of Guimarota are represented by microvertebrate remains which were obtained by screening (Rauhut 2000b), which may easily lead to an overrepresentation of small-sized theropods and ornithischians, while the Lourinhã fauna is dominated by large skeletal remains of sauropods. Underlying this distinction is of course also a taphonomical signal, as deposits in which large skeletal remains are rare, may be promising for microvertebrate remains (e.g. Sweetman 2011). However, a lack of applying screening techniques to many macrofossil bearing deposits will potentially result in an over-emphasizing of diversity vicariance between local faunas.

(2) Integrating a conservative estimation of dinosaur diversity based upon the track record from the earliest Cretaceous of Spain and Germany, there appears to be at best a slight decrease of overall dinosaur diversity, though a shift of dominance in the record of some groups can be recognized. Notwithstanding that the principles of taphonomic filtering and sampling biases outlined above must be imposed to this result, too, there seem to be a lack 
of evidence for a massive, general "pauperisation" of the dinosaur fauna across the Jurassic/Cretaceous boundary in Europe. Potential faunal changes and successions must be evaluated at a regional scale.

These observations are supportive to the conclusion by Benton et al. (2011), that estimations and predictions of fossil vertebrate diversity are fraught with difficulty when attempted at a global scale (see also Lloyd 2012) and are most promising on regional scales. With respect to the multiple constraints on habitat segregation of extant terrestrial animals, stronger palaeoecological and palaeoclimatological effects should be expected than those expected from general sampling proxy correlation with the fossil record (as e.g. in Barrett et al. 2009, Butler et al. 2011b, Mannion et al. 2011, Upchurch et al. 2011, but see Benson \& Mannion 2012). It has also to be taken in consideration that higher-level diversity may not be an accurate proxy of species-level diversity (Lloyd et al. 2012), a factor that gains importance with respect to the low taxonomic resolution of the Berriasian-Valanginian archosaur faunas compared to older and younger ones.

\section{Palaeoenvironmental factors}

(Fig. XI.4)

Palaeoclimatological data indicate that Kimmeridgian dinosaur-rich biomes of the Morrison Formation, the Iberian Peninsula and East Africa share a semi-arid, hot seasonal climate with wetter winter seasons, with a slightly lower temperatures and higher humidity in southern Europe (Rees et al. 2004, Gutierrez \& Sheldon 2012, Myers et al. 2012). In contrast, the slightly higher palaeolatitudes of central and western Europe were more temperate, though still warm, and more humid during the Kimmeridgian (Abbink et al. 2001, Hesselbo et al. 2009). During the Tithonian the climate became markedly more arid, and, after several fluctuations in the course of the Tithonian reached an extreme peak in the latest Tithonian in central and western Europe (Abbink et al. 2001, Hesselbo et al. 2009). This is recorded by widespread occurrences of evaporites and other signs of hypersalinity, e.g. in England (e.g. Underhill 2002) and Germany (e.g. Gramann et al. 1997, Dragastan \& Richter 2011). In both regions a drop in sea-level and hot-arid climate resulted in the formation of hyperhaline perimarine lagoons and saline supratidal flats. In Germany this phase is characterized by an extreme rareness of vertebrate remains. The local biotopes were probably not able to sustain large herbivores and an ecologically induced absence of dinosaurs may be inferred. However, a group that may have benefited from the extreme environment were probably ctenochasmatine pterosaurs: These trophically specialized filter-feeders (Bennett 2007) may have foraged on small invertebrates that were able to cope with the extreme conditions of the lagoons. Ctenochasmatines are also abundant in Tithonian restricted environments of the Plattenkalk deposits (Bennett 2007) and in deposits of partly ecologically stressed lagoons / playa lakes of the Purbeck Limestone Group (Howse \& Milner 1995). The first ever found ctenochasmatid specimen, the (presently lost) holotype jaw of Ctenochasma roemeri, originated from the middle or upper part of the Münder Formation of the Deister mountains (though its exact stratigraphic position is 
unknown, von Meyer 1851).

In conclusion, extreme climatic conditions may have rendered parts of central Europe inhospitable for many archosaur clades near the Jurassic/Cretaceous boundary, though some specialized taxa were obviously present. However, the ecological stress period seems to have been of short duration, probably due to a minor local transgression during earliest Berriasian, which again changed hydraulic conditions in the Lower Saxony Basin. Arp \& Mennerich (2008) described a stratified water-body, with low-salinity to freshwater overlying brackish-marine waters in the uppermost Münder Formation of the marginal Hils Embayment, suggesting considerable inflow of freshwater and hence a more humid climate. The same shift to more precipitations may have led to deposition of the "intermarine beds" in the Purbeck Limestone Group, which preserve a vertebrate abundance peak. Within the overlying Bückeberg Formation, no signs of aridity are preserved, and the climate is reconstructed to be warm-temperate, seasonally-humid with occasional dryness.

Although the Tithonian-Berriasian palaeoclimatic history of southwestern Europe seems to be similar, its impact for the local archosaur fauna is different. In the Cameros Basin, the Tera Group, and the Matute Formation (which either belong to the upper Tera or lower Oncala Group, depending on reviewer, Meléndez \& Gómez-Fernández 2000, Clemente 2010), exhibit sedimentary features which correspond to other Iberian continental deposits from the Tithonian (Gutierrez \& Sheldon 2012, Myers et al. 2012): they consist of fluvial deposits from meandering and anastomosing rivers, laterally intercalating with lacustrine deposits (Meléndez \& Gómez-Fernández 2000). Though caliche horizons suggest seasonality of precipitation, signs of aridity are absent and the drainage system supported a palaeoflora (Meléndez \& Gómez-Fernández 2000).

The overlying Huérteles Formation (Oncala Group, earliest Berriasian), which contains the peak abundance in Tithonian-Hauterivian dinosaur tracksites in the Cameros Basin (HernándezMedrano et al. 2006), shows a strong change in palaeoclimatic regime, when compared to the earlier deposits (Meléndez \& Gómez-Fernández 2000): It consists of deposits of an extensive, lowrelief mudflat with occasional ephemeral stream channels and hyperhaline ponds, passing laterally into a large lake basin formed in a rapidly subsiding subbasin. High salinity and evaporation rates and low sedimentary input resulted in microbially induced carbonate formation in the lake, interbedded with evaporites. Sedimentary data suggest a repeated cyclicity in salinity suggesting episodical changes in precipitation to evaporation ratios. Plant and animal fossils are extremely sparse in the formation, though the vertebrate ichnofauna is abundant and diverse. In summary the Huérteles Formation, shows a clear shift to semiarid or arid conditions. The climate can be characterized as dry with only seasonal or even only episodic precipitations, though the severity of aridity probably oscillated on some scale. The stratigraphic position of the formation strongly suggests a correlation with the Tithonian-Berriasian "aridity peak" recorded in central Europe. However, the tracksites clearly indicate that in constrast to the barren sabkhas and hyperhaline lagoons of Germany and England, the Spanish environment evidently supported a rich archosaur fauna. However, this fauna may have been forced to acquire behaviours which are favourable for a preservation of their footprints, e.g. gathering around freshwater sources. Ichnotaphonomically, the low rate of erosion and deposition on the mudflats were also useful in preserving the footprints.

As it was the case in central Europe, the crisis probably lasted not long - the upper horizons of 
the Huérteles Formation already show indications of increased humidity, and in the overlying Peñacoba Formation (late Berriasian-early Valanginian) oligohaline lakes are present (Clemente 2010). On the other hand, it is noteworthy that arid conditions prevailed in southwestern France slightly later, as evidenced by the Cherves-de-Cognac site (El Albani et al. 2004).

Another palaeoclimatic change occurred during the early Valanginian, when the climate turned slightly colder and wetter in central Europe (Kemper 1987). This episode is represented by the deposits of the Hastings Group in England, while most of the Valanginian in northern Germany is represented by marine deposits. This change, associated to extensive limnic systems and a rich flora probably triggered the immigration of basal somphospondylian (euhelopodid) sauropods from Asia. It may also be instrumental in a re-immigration of stegosaurs, which, once being widespread and abundant in western and central Europe ,have not been evidenced there since the Late Jurassic. and since the Berriasian in southwestern Europe. They also probably entered from Asia, where they persisted since the Jurassic. As a whole, the increase in plant biomass in the supportive climatic conditions during deposition of the Hastings Group may have opened new trophic niches for herbivores (e.g. an increased number of canopylevels), fostering the sympatric diversification of herbivorous dinosaur species and relieved these communities from competitive pressures.

\section{Palaeoecological factors}

(Fig. XI.7-XI.8)

It was proposed that the beginning of the Cretaceous was characterized by a palaeoecological "takeover" of ornithopods (e.g. Bakker 1978). At a first glance, the fossil record seems to support such an assumption for Europe. A key role in investigation of this question plays the ichnological evidence: For example Moratalla \& Sanz (1997) found sauropod tracks to make up only $4 \%$ of the ichnofauna in the Cameros Basin (Berriasian-Aptian), while ornithopods are represented by $16 \%$ and theropods by $80 \%$ of the tracks. Moratalla (2009) even reduced the sauropod share to $2 \%$.

However, these ratios are based upon summing up absolute counts of single footprints. This method has some caveats, when ratios of abundance of certain clades (and an inference of their habitat dominance) should be based on them. They are strongly dependent upon trackmaker behaviour (e.g. gregarious vs. solitary, or the repeated use of fixed routes by some animals vs. random routing etc.) and outcrop conditions (relative size of outcrops preserving different track types - resulting in an underrepresentation of ichnotaxa preserved only on smaller exposures). In more general terms, the probability of adverse statistical effects is rather high using absolute ratios based on single tracks. This may be exemplified by the Obernkirchen Sandstone track association: Up until very recently, theropod tracks have been considered extremely rare in this unit, especially when compared to ornithopods. Though this has never quantified absolutely, the only described theropod tracks up to 2003 was the limited set of theropod tracks found by Ballerstedt (1905) at a single locality and correctly identified by Abel (1935, see also Lockley 2000). As it has been shown by additional finds (Haderer \& Neef 2004, Diedrich 2004, Chapters IV, V), the fraction of theropod tracks was underestimated by previous investigators, however, in absolute terms ornithopod tracks 
are generally still much more abundant than theropods. The single exception within the whole unit so far is one special track horizon from a single locality, dubbed the "chicken yard" (Richter et al. 2009, van der Lubbe et al. 2009a, Chapter IV). This laterally extensive level contains thousands of footprints, c. $66 \%$ of which were left by theropods (A. Richter, pers. com.). In a total census of absolute footprint numbers, this single occurrence - apparently bound to very special conditions of formation and preservation - would radically shift the proportions between theropods and ornithopods. However, with a view on the total stratigraphic unit this shift does not realistically represent the relative abundances of theropods vs. ornithopods, creating the ichnological equivalent of the "lagerstaetten effect" (sensu Benson et al. 2010b, Benson \& Butler 2011).

To overcome these problems, a novel approach to abundance estimation of dinosaur clades based upon tracks is proposed here. In a locality-based abundance index (LBAX, $\boldsymbol{a}_{L[\%]}$ ) the abundance of a clade is expressed as the ratio between the number of localities $\left(n_{x}\right)$ in which a certain clade $(x)$ is present, to the total number of localities $(n)$ assigned to the stratigraphic and regional context (SRC) that is investigated:

$$
a_{L[\%]}=n_{x} / n
$$

The locality based abundance (LBA), expressed as percentages values, may sum up to more than $100 \%$; this results from double-counting at multi-taxon localities and may be taken as a firstlevel approach of sympatricity in the investigated ichnofauna. However true sympatricity analyses should be based only upon horizon-by-horizon in-vestigation (especially when dealing with reference data from the literature), as co-occurrence at a single locality means not necessarily cooccurrence in the same track level, the only reliable proxy for sympatricity as two track horizons at the same locality may be separated by an unknown amount of time.

Relying on the relative number of localities instead of single footprints has the advantage to dampen adverse statistical effects by setting discrete extreme peaks of abundance into relation to a wider SRC. In other words: binary recording of the presence or absence of a certain clade at discrete localities is probably a more representative sampling method than recording of absolute footprint numbers of this clade across the whole set (i.e. the SRC), because it more broadly reflects the potential range of specific conditions which led to the taxon representation in discrete localities. It gives a rough prediction of the probability to encounter a certain clade on the basis of the already known record. Another advantage of this method is its usability if the absolute number of footprints from the chosen SRC is unknown (as it is presently the case in the Obernkirchen Sandstone). The reliability and comparability of this method depends on the number of samples (localities) which can be used for each set. Choosing the SRC, it is pivotal to use intervals that are characterized by stratigraphic, palaeoecological and taxonomical continuity, i.e. that it is inferred to represent a natural ichnofauna.

Applying this principle to evaluate the LBA of sauropods, ornithopods, and theropods in Early Cretaceous ichnofaunas of Germany and Spain (Fig. XI.7, Tab. XI.3) reveals a picture different from a general massive outnumbering of sauropods by theropods and ornithopods. In fact in three SRCs 


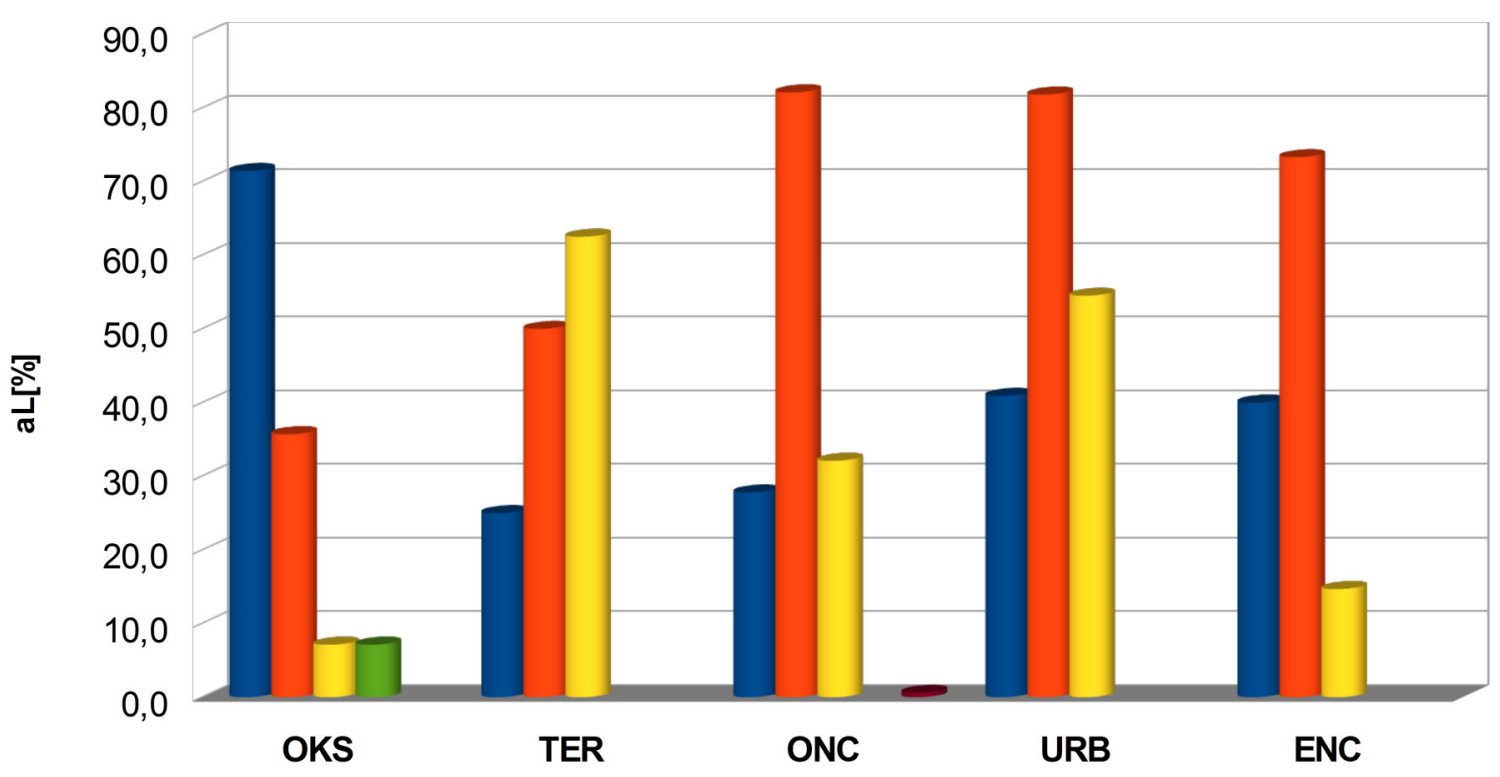

- Ornithopoda $\square$ Theropoda $\square$ Sauropoda $\square$ Ankylosauria $\square$ Stegosauria

\begin{tabular}{lrr}
\hline & & Total \# of tracksites \\
\hline & \# of tracksites with taxon & LBA [\%] \\
\hline OBERNKIRCHEN SANDSTONE (OKS) & 10 & 14 \\
\hline Ornithopoda & 5 & 71,4 \\
Theropoda & 1 & 35,7 \\
Sauropoda & 1 & 7,1 \\
Ankylosauria & & 7,1 \\
\hline TERA GROUP (TER) & 2 & $\mathbf{8}$ \\
\hline Ornithopoda & 4 & 25,0 \\
Theropoda & 5 & 50,0 \\
Sauropoda & & 62,5 \\
\hline ONCALA GROUP (ONC) & 45 & $\mathbf{1 6 2}$ \\
\hline Ornithopoda & 133 & 27,8 \\
Theropoda & 52 & 82,1 \\
Sauropoda & 1 & 32,1 \\
Stegosauria & & 0,6 \\
\hline URBIÓN GROUP (URB) & 9 & $\mathbf{2 2}$ \\
\hline Ornithopoda & 18 & 40,9 \\
Theropoda & 12 & 81,8 \\
Sauropoda & & 54,5 \\
\hline ENCISO GROUP (ENC) & 30 & $\mathbf{7 5}$ \\
\hline Ornithopoda & 55 & 40,0 \\
Theropoda & 11 & 73,3 \\
Sauropoda & & 14,7 \\
\hline
\end{tabular}


Fig. XI.7 Dominance of dinosaur clades based upon relative tracksite abundance for the Obernkirchen Sandstone and four track-bearing units in the Upper Jurassic to Lower Cretaceous of Spain. Note relative sauropod dominance in the Tera, Oncala, and Urbión Groups. See text for details. ENC - Enciso Group; OKS - Obernkirchen Sandstone; ONC - Oncala Group; URB - Urbión Group; TER - Tera Group.

$4 \nabla$ Tab. XI.3 Database for Fig. XI.8. Data for the Spanish sites compiled from Perez-Lorente (2003) and Hernández Medrano et al. (2006).

from Spain, the Tera (Tithonian), Oncala (Berriasian), and Urbión Groups (Hauterivian) sauropods are relatively more abundant than ornithopods, with the Oncala Group having the best database $(n=162)$. The sauropod dominance is even more pronounced in the Tera and Urbión Groups, but the statistical base is much poorer ( $n=8$ and $n=22$, respectively), but it decreases distinctly towards the Enciso Group (Barremian-Aptian, $\mathrm{n}=75$ ). The absolute abundance of theropod tracks is also mirrored by their relative abundance in all Spanish SRCs. These characters are in a strong contrast to the mid-Berriasian Obernkirchen Sandstone $(n=14)$, where ornithopods are not only absolutely but also relatively the most dominant group, followed by theropods, and sauropods.

These observations confirm earlier studies (e.g. Barrett \& Upchurch 2005), where a simple process of ornithopod vs. sauropod substitution at the Jurassic/Cretaceous boundary was questioned. They support the idea of a complex regional abundance pattern of both groups in Europe at this time, apparently controled by climatic and ecological constraints.

When comparing the environments of the Spanish and the German ichnofaunas, it can be stated, that probably the most important difference is their palaeoclimatic setting. The Spanish as well as the German sauropod ichnofauna are clearly present in an inland habitat, though the latter is associated to the marginal deposits of a large, permanent freshwater body. The early Berriasian Spanish ichnofaunas occur in a closed basin with generally hot and dry climate with only episodical or strictly seasonal precipitation and high evaporation rates. The access to freshwater was probably limited at least seasonally. Though this situation later improved, the relatively sauropod-dominated ichnofauna of the Hauterivian Urbión Group still occurs in fluvial deposits with clear signs of semiaridity (e.g. Ansorena et al. 2008, Clemente 2010). Ornithopod dominance in the mid-/late Berriasian of Germany may have been triggered by local sauropod extinction during the TithonianBerriasian aridity peak and supported by locally wetter climate and low-land topography. Diplodocid and basal titanosauriforms, especially brachiosaurids, according to their cervical and forelimb anatomy, occupied different browsing niches, with the former occupying the low medium canopy browsing heights, while the latter fed on the upper canopy (e.g. Stevens \& Parrish 1999, 2005, Tütken 2011, Whitlock 2011). An extinction of diplodocids in the earliest Cretaceous would have opened up opportunities for iguanodontian ornithopods to expand into these trophic niches, while basal titanosauriforms remained unaffected.

An even more complex pattern of ecological preference for sauropods and ornithopods is further indicated by the Danish Berriasian and English Valanginian record: In the temperate lowland to coastal Bornholm Island dinosaur fauna ornithopods are missing completely but sauropods are evidenced by tracks and a tooth. The reason for this is unknown, though the very small sample in tracks as well as in skeletal material has to be accounted for. 
In the Valanginian of England iguanodontian ornithopods lived sympatrically to sauropods in a humid, perilimnic environment. However the latter represent a clade (basal somphospondylians) unknown from older deposits, which may explain their different habitat preferences: Christian (2010) reconstructed high browsing for the basal somphospondylian Euhelopus zdanskyi, which would suggest that the new faunal element became a competitor for basal titanosauriforms, but not for the sympatric iguanodontians. However, according to the palaeoenvironment of the Hastings Group, they inhabited wet lowlands and may have been therefore separated from basal titanosauriforms, more common in drier uplands.

The absence of sauropods from the Cornet local fauna may be a primary signal due to the insular setting, however, a considerable taphonomic bias must be considered due to deposition in a carstic sinkhole system (compare Posmoşanu \& Cook 2000).

It should be further noted, that the enormous abundance of theropod tracks in Iberia (in absolute as well as in relative numbers) eludes from an interpretation at present. Evidence from Spain, as well as from Germany ("chicken yard") suggests that conditions must have been present which resulted in a high frequency of trackmaking by theropods in locations favourable for further preservation. These "mass occurrences" are most probably partly time-avaraged and do not represent a realistic ratio of theropods to non-theropods, as the resulting abundance patterns would be contradictory to any reasonable predator/prey-ratio (e.g. Bakker 1986), though the range of taxa represented by the tracks suggests a location on a span of trophic levels for the trackmakers.

\section{Faunal successions in the Early Cretaceous of Europe}

In an integrative cluster analysis of dinosaur biogeography, Holtz et al. (2004b) found nearly all of the above mentioned local faunas to form a cluster with the late Early Cretaceous faunas from the Wealden of England and Wealden facies deposits of Spain, as well as the Aptian-Albian El Rhaz Formation of Niger. They characterised this cluster as "Greater Wealden" Fauna. From the Berriasian strata, they found only the Purbeck Limestone Group not to be included in this cluster, but linked instead to a number of Early Cretaceous (Aptian-Albian) faunas from North America and the Late Cretaceous (Maastrichtian) of France, as well as to the Barremian El Castellar Formation from Spain. However, the dataset on which the cluster analysis was based (Weishampel et al. 2004) summarized an extremely broad range of data with a high variability of data quality due to completeness of fossil record and state of faunal revision. For example, Weishampel et al. (2004) lists Iguanodon sp. to occur in the Obernkirchen Sandstone and recognized Stenopelix valdensis as a pachycephalosaur. Both identifications - which are not longer upheld - doubtlessly affected the outcome of the Holtz et al. (2004b) analysis.

As it can be deduced from the above summary, an inclusion of most of the European Berriasian

Fig. XI.8 Synoptic reconstruction of Early Cretaceous local herbivorous dinosaur communities of the PurbeckHastings Fauna and their palaeoenvironmental settings. For details see text. 


\section{EARLY HAUTERIVIAN (URBIÓN GROUP) NE-SPAIN}

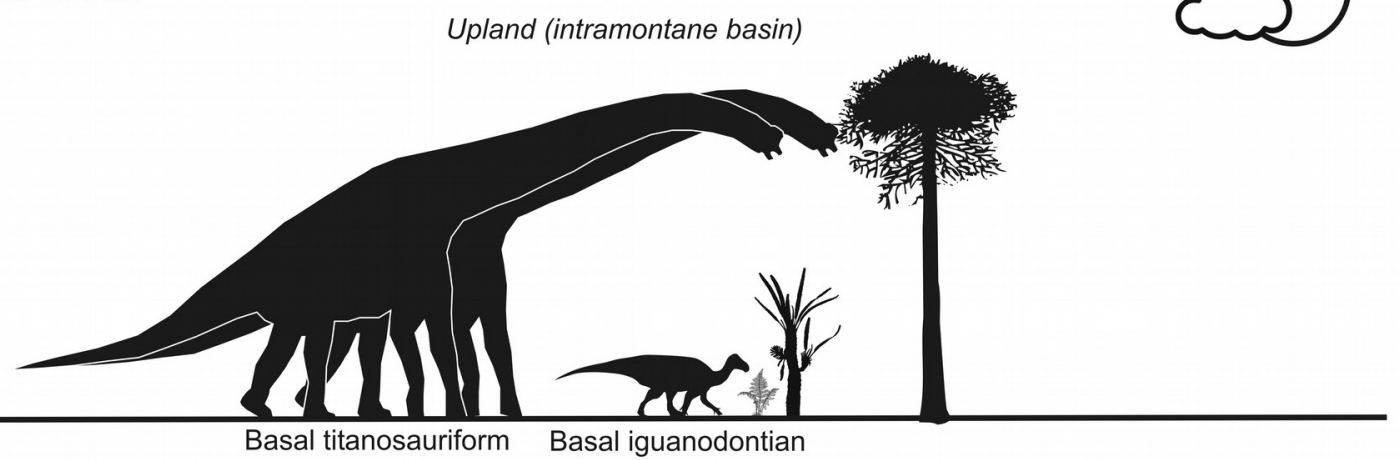

MID-LATE VALANGINIAN (HASTINGS GROUP) S-ENGLAND

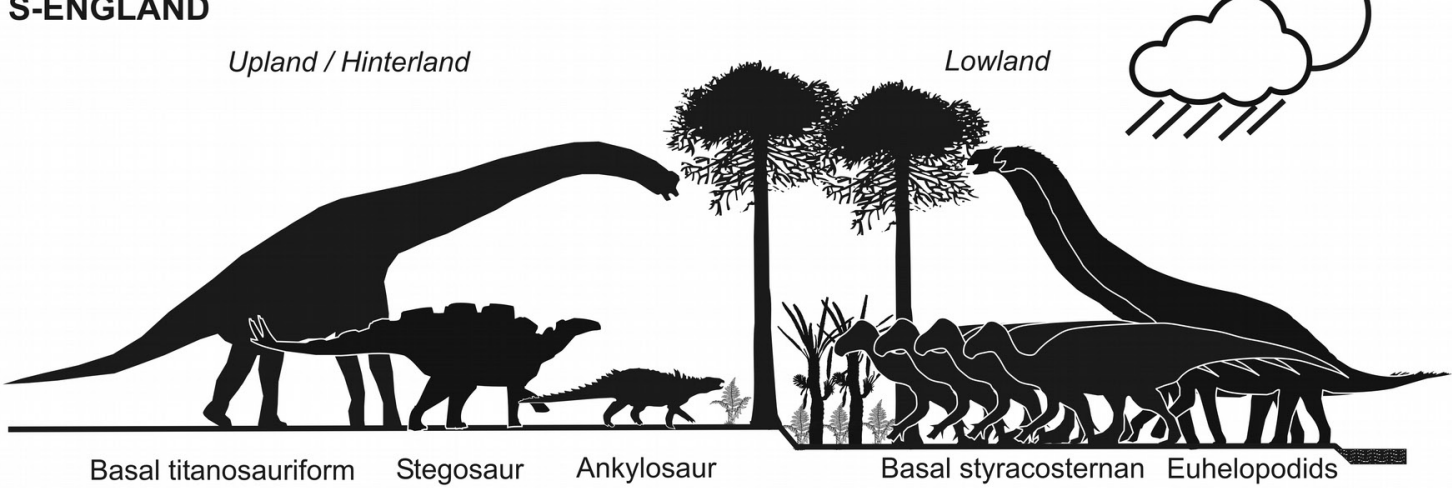

LATE BERRIASIAN (BÜCKEBERG FORMATION) NW-GERMANY

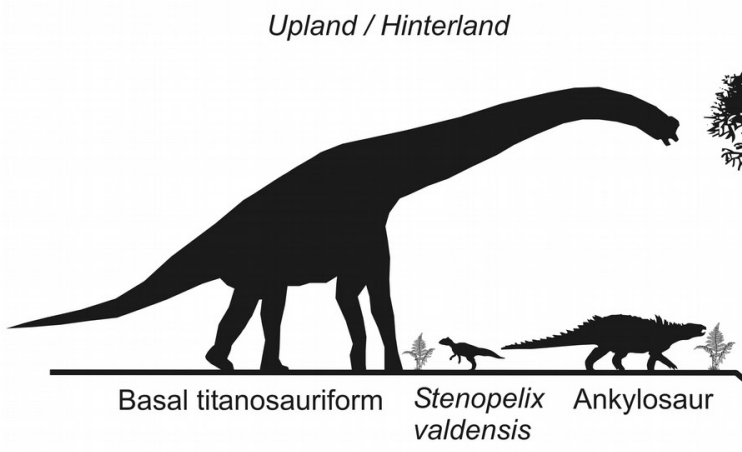

Lowland

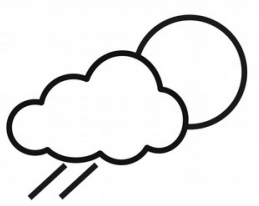

\section{EARLIEST BERRIASIAN (HUÉRTELES FM.)} NE-SPAIN

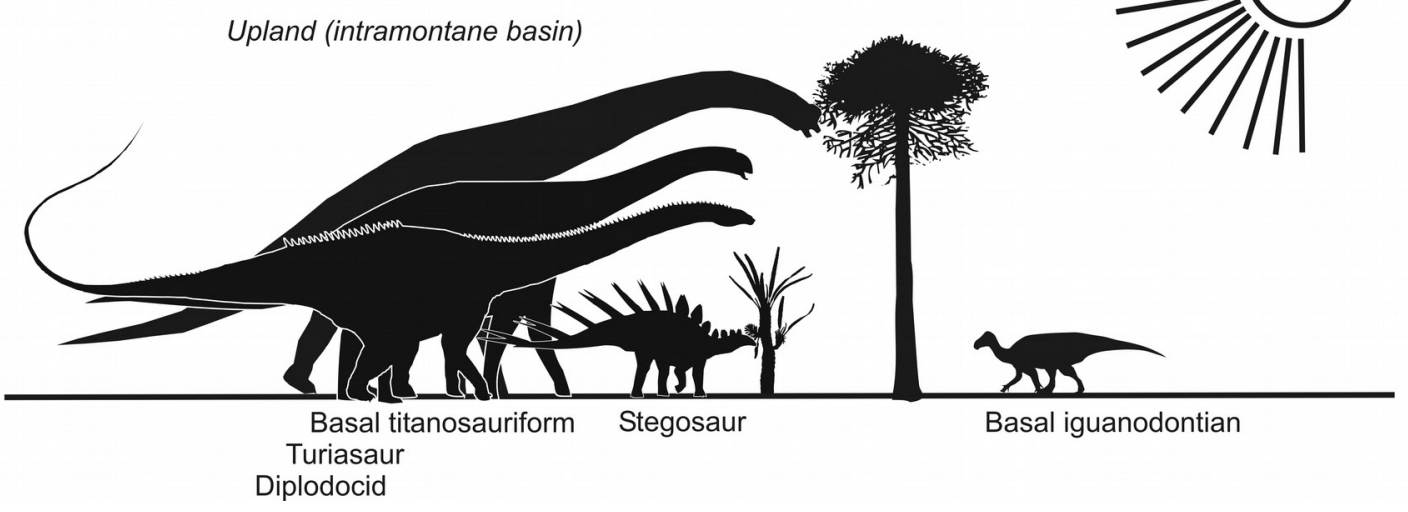


through Albian faunas in a "Greater Wealden" Fauna is problematic. The Wealden Fauna sensu stricto (Hauterivian/Barremian to Aptian of England, Belgium, Germany and Spain) contains a number of novel elements when compared to pre-late Hauterivian European faunas, either by potential local evolution and diversification, or by Gondwanan immigration. Others are conservative elements present since the Late Jurassic.

The pre-Hauterivian faunas are characterized by a prevalence of inherited Late Jurassic elements. Immigration of Laurasian clades may have occurred during this time (ceratopsians, euhelopodid sauropods, ?microraptors) but these are mostly uncertain in exact dating and extend. In fact, in terms of higher-level clades, the pre-Hauterivian faunas blend very well with the Late Jurassic North American-Iberian-African faunas (the Laurafrican Fauna). The pattern of changes in biotope dominance between sauropods and ornithopods appear to be complex - a trend for an ornithopod faunal dominance is most evident in southern England and Germany, areas which were most severely affected by the Tithonian-Berriasian aridity crisis and may have lost temporarily their large herbivore faunas completely. In these regions, large-bodied ornithopods may have spread into trophic niches which were previously occupied by mid-level browsing sauropods, especially diplodocids, in more humid lowlands after climate recovery. In other areas, e.g. in Spain and probably also in Denmark, sauropods remained to form a quantitatively important, if not exclusive faunal constituent deeply into the Early Cretaceous. In Spain relative sauropod dominance can be traced up to the Hauterivian and may have been supported by relatively dry conditions (semi-arid fluvial deposits of the Urbión Group). Reasons for the apparently early Berriasian extinctions of diplodocids and turiasaurs are unclear - as documented by the Huérteles Formation ichnofauna, they were able to cope with dry to arid inland settings and an immediate relationship of their total demise with the Tithonian-Berriasian aridity crisis cannot be found. However, their absence may be one of the most distinctive criteria to distinguish the genuinely earliest Cretaceous archosaur faunas from the typical Late Jurassic faunas, and the latter can therefore be considered to have persisted into the early Berriasian in Iberia (see also Canudo et al. 2005a, Canudo 2006, 2009).

Basal Early Cretaceous and late Early Cretaceous faunas show major differences in composition which reflect the demise of several groups from Europe before the Barremian. However, unfortunately these important changes are most complicate to pin down. This is most true for the large-bodied theropods, the role of which in the basal Cretaceous of Europe cannot be outlined more precisely beyond simply acknowledging their presence. The "theropod gap" prevents to elucidate the history of the marked differences between Late Jurassic and late Early Cretaceous theropod faunas. Sauropod faunas are dominated by a flourishing of immigrant rebbachisaurid, though basal titanosauriforms and somphospondylians still occurred to the end of widespread terrestrial faunal record in central Europe during the Albian. This diversity may be a hint that the dominance of ornithopods in late Early Cretaceous faunas as in the English, Belgian, French and German Wealden facies sensu stricto may be a result of selective habitat representation in the facies. This may be true especially with reference to the taphonomically restricted preservation of reptile faunas in the carstic sinkholes of Bernissart and Brilon-Nehden (Norman 1987b, Baele et al. 2012, Quinif \& Licour 2012, Spagna et al. 2012).

According to these differences it seems suitable to characterize the Berriasian-Hauterivian 
archosaur faunas as a distinct Purbeck-Hastings Fauna in contrast to the late Hauterivian-Albian Wealden Fauna. The former term alludes to the close relationship of Berriasian-early Valanginian (typical "Purbeckian") to mid-Valanginian-Hauterivian faunas, which are best represented in the Hastings Group (late Berriasian-Hauterivian) of England. A typical "Hastingian" element is the appearance of euhelopodid sauropods in this interval. The Valanginian faunal composition corresponds to the Lower Biostratigraphic Zone regionally established for southern England based upon ankylosaurs and iguanodontians (Norman 1987a, Blows 1998) and expanded to an European scope by Pereda Suberbiola (1993). Blows (1998) proposed an extinction event in the Hauterivian, based upon the rareness of dinosaurs from the English Hauterivian Lower Weald Clay Formation. However, this stratigraphic interval is proportionally less outcropping than older and younger strata and at least one genus, the ankylosaur Polacanthus, occurs below and above the Lower Weald Clay Formation (Austen et al. 2010). This supports more faunal continuity across this interval and the perseverance of some taxa even after the major faunal change in the late Hauterivian. European-Asian interchange during within the Purbeck-Hastings Fauna is evident by several clades, however, exact dating and directions of this interchange is mostly unclear. Assessing the relationships to North America is hampered by the stratigraphic hiatus there between the Tithonian and Barremian (Kirkland et al. 1998).

The Wealden Fauna equals the Upper Biostratigraphic Zone of Norman (1987a) and Blows (1998). It shows some relationships to Asia and northern Africa, but is less comparable to North American faunas of that time.

Faunal change across Europe was probably not isochronous as a typical Late Jurassic fauna probably survived in Iberia at least into the earliest Berriasian while in central Europe a faunal hiatus is probably located at the Tithonian/Berriasian boundary. The stratigraphic ranges of these faunas do not coincide with those of the homonymous lithostratigraphic units, as the Hastings Group is traditionally included in the Wealden succession (e.g. Batten 2011). However, distinction between Purbeck and Wealden faunas is established in Europe since the early $19^{\text {th }}$ century, and the term "Hastings Sandstone" has once been used to correlate basal Cretaceous strata of Germany to those from England (e.g. Hoffmann 1830). It seems therefore prudent to redefine these long established termini.

Other groups of archosaurs are less informative than dinosaurs, though goniopholidid crocodilians show some evolution during this time (Andrade et al. 2011), and limnic pholidosaurids may be restricted to Purbeckian-Hastingian faunas. The record of pterosaurs is too scarce for an assessment, though filter-feeding ctenochasmatids may have had an abundance maximum in late Laurafrican and early Purbeck-Hastingian faunas due to ecological circumstances.

In the following the three successive faunas are defined:

\section{Laurafrican Fauna}

Geographic distribution: North America, Europe, Africa.

Temporal distribution: Late Jurassic (Kimmeridgian-Tithonian) of North America, central Europe and Africa, Late Jurassic - Earliest Cretaceous (Kimmeridgian - early Berriasian) of Iberia and southwestern France. Note: In North America and Africa a stratigraphic hiatus caps the faunal 
succession, the precise age of its upper termination is unknown.

Important (ichno-)taxa (key taxa marked with an asterisk): D i n o s a u r i a: Stegosauria*, Deltapodus ispp.*, basal Ankylosauria* (only in North America and Europe), Dryosauridae, basal Ankylopollexia* (only in North America and Iberia), basal Styracosterna (only in North America and northwestern Europe), Dinehichnus ispp., Dromaeosauridae (known only from Europe), Troodontidae (known only from North America), Archaeopterygidae (known only from Europe), Megalosauridae, Spinosauridae (known only from Africa), Allosauridae*, basal Carcharodontosauria (known only from Africa), Ceratosauria*, Abelisauroidea (known only from Africa), "Megalosauripus" teutonicus*, Diplodocidae*, Dicraeosauridae (known only from Africa), basal Macronaria, Brachiosauridae*, Turiasauria* (only in Europe), Haplocanthosaurus spp., Pachyonyx isp.*, Brontopodus ispp.*, Parabrontopodus ispp.

C r o c o d y l i a: Atoposauridae, Goniopholididae.

P t e r o s a u r i a: Rhamphorhynchoidea, Pterodactylidae, Ctenochasmatidae, Dsungaripteridae.

General characterisation: Terrestrial herbivore communities dominated by sauropods, ornithopods rare, high diversity of theropods, low diversity of limnic crocodilians, high diversity of pterosaurs.

Habitats: Mostly warm, semi-arid coastal and inland basins with seasonal precipitation, perilimnic environments and coastal-plains. Specialized subfauna on islands.

Local subfaunas: Kimmeridgian-Tithonian Central European Archipelago fauna, characterised by dwarfed sauropods and various dinosaur taxa using inter-island tidal flats as migration routes, exploiting limited resources in warm to hot, semi-arid to arid island environments.

\section{Purbeck-Hastings Fauna}

Geographic distribution: Europe.

Temporal distribution: early Berriasian to late Hauterivian/early Barremian. A basal faunal hiatus may be present across most of western and central Europe during latest Tithonian and earliest Berriasian.

Important taxa (key taxa marked with an asterisk, Hastingian taxa with a cross): D i n o s a u r i a : Heterodontosauridae, Stegosauria+ (known only from England), Ankylosauria+ (Hylaeosaurus spp.*, Polacanthus spp.+), Stenopelix valdensis* (known only from Germany), basal Ankylopollexia, basal Styracosterna*, Iguanodontipus isp.*, aff. Iguanodontipus isp.*, Dromaeosauridae, Troodontidae (known only from Germany), Spinosauridae*+, Becklespinax altispinax, "Bueckeburgichnus" maximus*, "Megalosauripus" isp.*, basal Titanosauriformes* (incl. Brachiosauridae), Somphospondyli*+ (known only from England).

C r o c o d y l i a: Goniopholis spp.*, Nannosuchus gracilidens, Pholidosaurus spp.*, Theriosuchus spp.*, Bernissartia sp.

P t e r o s a u r i a : Ctenochasmatidae, Ornithocheirids+, Purbeckopus pentadactylus*.

General characterisation: Locally and temporally differentiated, herbivore communities may be dominated by ornithopods (western and central Europe) or by sauropods (Iberia), theropods apparently abundant and diverse, though insufficently preserved. Crocodilians moderately diverse, pholidosaurids form important part of the fauna. Pterosaurs with wing-spans up to $6 \mathrm{~m}$. 
Habitats: During the Berriasian warm to temperate semi-arid inland basins with seasonal precipitation, sabkha (early Berriasian) to perilimnic environments, during the Valanginian to Hauterivian more temperate temperatures and increased precipitation, extensive lacustrine environments. Specialized subfauna on island in tropical climate.

Local subfaunas: Iberia: Poorly documented, theropod-sauropod dominated fauna, probably of reduced diversity. Exchange with northwestern and central Europe was probably of low degree until late Hauterivian. Western and central Europe: Berriasian (Purbeckian) communities with ornithopod dominated lowland faunas, sauropod-dominated(?) upland faunas, rich theropod (ichno-)faunas, locally and temporally reduced diversity. Valanginian (Hastingian) herbivore communities ornithopod-dominated, but with increased non-ornithopod diversity (stegosaurs, ankylosaurs, euhelopodid sauropods), exchange with Asian faunas.

Cornet island fauna: ornithopod-dominated tropical island fauna, characterised by dwarfing and possible preservation of anachronistic taxa (delayed evolution).

The Berriasian-Hauterivian archosaur local faunas are characterized by a high amount of higher taxa inherited from Late Jurassic Laurasian or cosmopolitic faunas. Some elements probably immigrated from adjacent Laurasian areas but there is no indication of an Gondwanan influence during this time-span. The rather diverse sauropod record during the Early Cretaceous as well as the regionally variable sauropod/ornithopod abundance pattern proposed above indicate that a simple replacement scenario for ornithopods vs. sauropods at the Jurassic/Cretaceous boundary most probably falls short of the complex reality. In fact, the sauropod fauna shows a highly dynamic history and several input phases by immigration of clades which had developed elsewhere, though the most plesiomorphic surviving clade (basal titanosauriforms) persisted parallel at least to the Aptian. As outlined before, local abundance of ornithopods versus sauropods may reflect a palaeoecological rather than a stratigraphical signal and may be biased by habitat representation in the geological record. In the case of ornithopods, ankylopollexians made a rapid phylogenetic advance during the Early Cretaceous in Europe, possibly triggered by local sauropod extinction. Influences by immigration from outside the continent cannot be evidenced but also not excluded but a scenario of endemic evolution into hadrosauriforms is also plausible. Apparently in most habitats suitable for basal iguanodontians at least two or more taxa occurred sympatrically. A tentative reconstruction of non-avian dinosaur communities across various Purbeck-Hastingian local subfaunas, based upon the skeletal and ichnological record and summarizing the above conclusions is given in Fig. XI.8.

\section{Wealden Fauna}

Geographic distribution: Europe.

Temporal distribution: Late Hauterivian/early Barremian to Albian. The record of terrestrial vertebrate faunas in Europe is largely terminated after the Albian due to widespread marine transgression, though only a minimum upper range can be given.

Important taxa (key taxa marked with an asterisk): D i n o s a u r i a : Heterodontosauridae(?), Stegosauria, Ankylosauria, Hypsilophodon foxii* (known only from S-England), Gideonmantellia 
amosanjuanae (known only from Spain), Dryosauridae (Valdosaurus spp..*), basal Styracosterna, Iguanodontidae*, Abelisauroidea(?), Spinosauridae, Carcharodontosauridae*, Neovenatoridae*, Compsognathidae, Ornithomimosauria*, Tyrannosauroidea* Dromaeosauridae, Rebbachisauridae*, basal Titanosauriformes, Somphospondyli.

C r o c o d y l i a: Anteophthalmosuchus hooleyi* (known only from England, related taxon also in Belgium), Leiokarinosuchus brookensis* (known only from England), Vectisuchus leptognathus*, Theriosuchus sp., Bernissartia fagesii*, basal eusuchians (Hylaeochampsidae*).

P t e r o s a u ri a : Istiodactylidae*, Ornithocheiridae*.

General characterisation: Diverse and abundant dinosaur faunas, relatively widespread but with apparently endemic local elements (e.g. Hypsilophodon foxii Huxley, 1869). Herbivore communities dominated by iguanodontian ornithopods, thyreophorans are less abundant though regular faunal components. Sauropods are less dominant with rebbachisaurids forming important faunal elements especially in western Europe, though titanosauriforms persisted. Theropods very diverse, including the definitive appearance of several major clades (Neovenatoridae, Ornithomimosauria, Tyrannosauroidea) in Europe (though earlier occurrence may be obscured by the "theropod gap"). Crocodilian communities are dominated by advanced goniopholidids, including long-snouted taxa, replacing pholidosaurids. Early eusuchian radiation.

Habitats: Generally temperate to warm, humid inland basins with rich fluvial and lacustrine environments.

The Wealden (s. str.) archosaur fauna is characterized by a broad diversity, including the appearence of several new clades in Europe. Partly these appearances are related to immigration from Gondwana after establishment of the Periadriatic gateway, (e.g. rebbachisaurids) while in other cases the origins are unclear. Purbeck-Hastingian faunal elements are mostly inherited, though evolutionary advances are recognizable in several clades (e.g. styracosternans and crocodilians), which may possibly related to increased competition from immigrant taxa.

An overall domination of ornithopods has been established in Europe, probably linked to the wet climate and richness in available water-bodies. Though reduced in ecological dominance, sauropods remained diverse and, similar to euhelopodids in the Valanginian, rebbachisaurids seem to have been occupied also wet lowland environments while basal titanosauriforms preferred drier hinterlands explaining their rare occurrence in the fossil record.

\section{European archosaur faunas in the framework of Tithonian-Valanginian global faunal exchange patterns}

The palaeobiogeographic context of Berriasian-Valanginian European archosaur clades

(Fig. XI.9)

Pterosaurs are not considered here, because they probably had a high mobility, and potential dispersal constraints for them are unknown. 
To a certain degree this is true also for the crocodilian fauna, in which the dispersal potential of limnic taxa is often underestimated due to their tolerance for saltwater (Taplin \& Grigg 1989). A stronger palaeobiogeographical signal may be expected from small-bodied crocodilian clades with more terrestrial affinities - at least in some genera - as the Atoposauridae. However, the goniopholidids are a clade with deeply rooted Laurasian distribution since the Early Jurassic in North America (Tykowski et al. 2002) and the Middle Jurassic in Asia (Averianov 2000, Fu et al. 2005), and Goniopholis was present in the Late Jurassic of southern Europe (Schwarz 2002). The species found by Andrade et al. (2011) to unequivocally belong to this genus are all restricted to Europe, with sistergenera in East Asia and North America. Nannosuchus gracilidens is only known from Europe so far. Goniopholidids are therefore considered a Laurasian faunal element (e.g. Buffetaut \& Ingavat 1980). They are present and dominant throughout the Early Cretaceous, however, they underwent considerable evolution and diversification within this timespan. The genus Goniopholis has its last occurrence in the mid-Valanginian (Salisbury \& Naish 2011) and is superseded in the BarremianAptian by Vectisuchus leptognathus Buffetaut \& Hutt, 1980 and species of Anteophthalmosuchus Salisbury \& Naish, 2011 (A. hooleyi Salisbury \& Naish, 2011 and most probably a second species from Bernissart, see Dollo 1883, = aff. Goniopholis sp. in Chapter VIII).

The oldest pholidosaurids are known from the Upper Jurassic of South America and probably from the Middle and Upper Jurassic of England and France (Fortier et al. 2011). They occur broadly in a wide range of habitat, marine and limnic and acquired the top-predator niche in the late Early Cretaceous of western Africa and Brazil (de Broin \& Taquet 1966, Buffetaut \& Taquet 1977, Sereno et al. 2001). They are clearly of Pangaean origin and their dispersal was probably facilitated by the marine affinities of several taxa (e.g. Hua et al. 2007).

Atoposaurids also probably have an Jurassic European origin with the best record from the Upper Jurassic (Kimmeridgian) of France and Germany (Wellnhofer 1971, Buscalioni \& Sanz 1988, Schwarz \& Salisbury 2005, Karl et al. 2006, Raddatz 2011). Occurrences from a ?Late Jurassic/Berriasian to Barremian interval (Phu Kradung Formation, Thailand; Racey \& Goodall 2009) are known from East Asia (Lauprasert et al. 2011), though better dated and preserved specimens are from Asia date to the later Early Cretaceous (Wu et al. 1996, Lauprasert et al. 2011). Possible occurrences of the family in North America are solely based upon teeth and do not predate the Aptian-Albian (Winkler et al. 1990, Fiorillo 1999). Therefore atoposaurids are also considered a Laurasian, possibly indigenous taxon. They occured in Europe until the Maastrichtian (Martin et al. 2010).

Well-preserved material of Bernissartia is known only from the type species B. fagesii, occuring at the type locality, Bernissart, Belgium and near Galve, Spain (Dollo 1883, Buffetaut 1975, Buscalioni et al. 1984, Buscalioni \& Sanz 1990). These localities are dated to Barremian to earliest Aptian, or Barremian, respectively (Yans et al. 2005, Buscalioni et al. 1984). The otherwise geographically and temporally widespread record is based largely upon isolated teeth which exhibit a characteristic morphology (Buffetaut 1975, Buffetaut \& Ford 1979). Bernissartia-like teeth range from the Kimmeridgian (Brinkmann 1989, Cuny et al. 1991) to the Barremian (?Albian, Fiorillo 1999), and is very common in Berriasian-Valanginian vertebrate communities (see above). The geographical range covers most of Europe from Denmark to Iberia (Salisbury \& Naish 2011), and 
similar teeth have been reported from the Aptian-Albian of North America (Winkler et al. 1990, Fiorillo 1999). Therefore, Bernissartia is considered to be indigenous to Europe, with a possible partial Laurasian spread during the late Early Cretaceous.

The late Early Cretaceous (Barremian) saw the appearence of Leiokarinosuchus brookensis Salisbury \& Naish, 2011, a mesoeucrocodylian of uncertain affinities, and of the hylaeochampsids, a basal eusuchian clade (Buscalioni et al. 2011). The phylogenetic position of the latter suggest that they may have immigrated from Gondwana, as their successive outgroups are Gondwanan taxa which probably had a last common ancestor with European neosuchians during Late Jurassic times (Salisbury et al. 2006, Buscalioni et al. 2011). However, questionable remains of eusuchians also occur in the Valanginian of the Hastings Group (Salisbury \& Naish 2011).

Thyreophorans have a long Jurassic history in Europe. Stegosaurs are abundant with Dacentrurus armatus (Owen, 1875) in western Europe. The Portuguese fauna also include Stegosaurus cf. ungulatus Marsh, 1879, and Miragaia longicollum Mateus, Maidment \& Christiansen, 2009 (Escaso et al. 2007, Mateus et al. 2009). They are present in Africa from the Kimmeridgian to the ?Early Cretaceous and from South America during the Barremian-Aptian (Pereda Suberbiola et al. 2013), however, they are not known from other southern continents (given the referral of the dubious Dravidosaurus blanfordi Yadagiri \& Ayyasami, 1979 from India to a non-dinosaurian clade, Chatterjee \& Rudra 1996, but see Pereda Suberbiola et al. 2003). It is therefore possible that a Gondwanan immigration of stegosaurs took place lately via the Late Jurassic North AmericanIberian-African land bridge. Ichnological and osteological evidence so far restrict them to southwestern Europe (Iberia, Aremorica) during the early Berriasian. A questionable record is "Regnosaurus northamptoni" Mantell, 1848 from the upper Valanginian of England (Barrett \& Maidment 2011). A single stegosaurian spine was reported by Pereda Suberbiola \& Galton (2001) from the Hauterivian of Burgos, Spain.

During the earliest Cretaceous, European stegosaurs were apparently restricted in distribution to Iberia and southwestern France, where their record terminates in the Berriasian. Their reappearence in the mid-late Valanginian of England under very different climatic conditions, and in associations with other Asian immigrant taxa (euhelopodid sauropods and possibly spinosaurids, see below), may suggest a (re-)immigration, too. In eastern Asia, their persistence well into the Early Cretaceous is documented (e.g. Dong 1990).

Pereda Suberbiola et al. (2003) described a stegosaurian vertebra and plate from the Piedrahita de Muñó Formation of Burgos and indicated a ?Valanginian-Barremian age. However, the Piedrahita de Muñó Formation overlies the Hortigüele Formation and is therefore Aptian in age (Clemente 2010). This may be the youngest unquestionable stegosaurian record from Europe. Otherwise the potential record in the late Early Cretaceous of Europe is extremely scarce, consisting only of Craterosaurus pottonensis, almost certainly reworked from the Wealden Supergroup (?Valanginian, Galton 1981a) in the Lower Greensand Group (Aptian-Albian) of England.

Fig. XI.9 Summary of archosaur palaeozoogeography (excl. pterosaurs) from the Kimmeridgian through the Aptien in Europe. See text for details and references. Palaeogeography by R. Blakey (Colorado Plateau Geosystems, Inc., http://cpgeosystems.com), Cherves-de-C - Cherves de Cognac. 

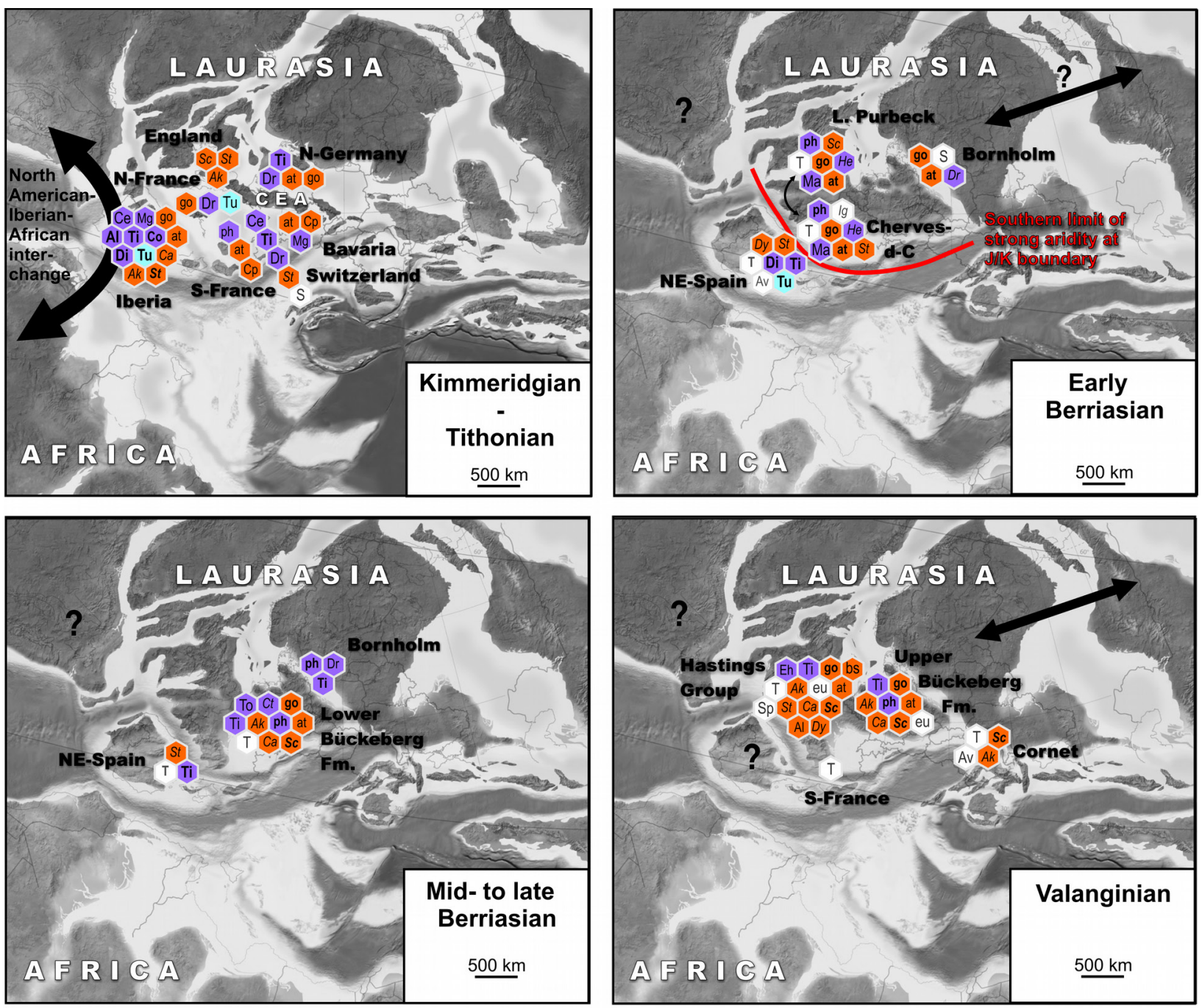

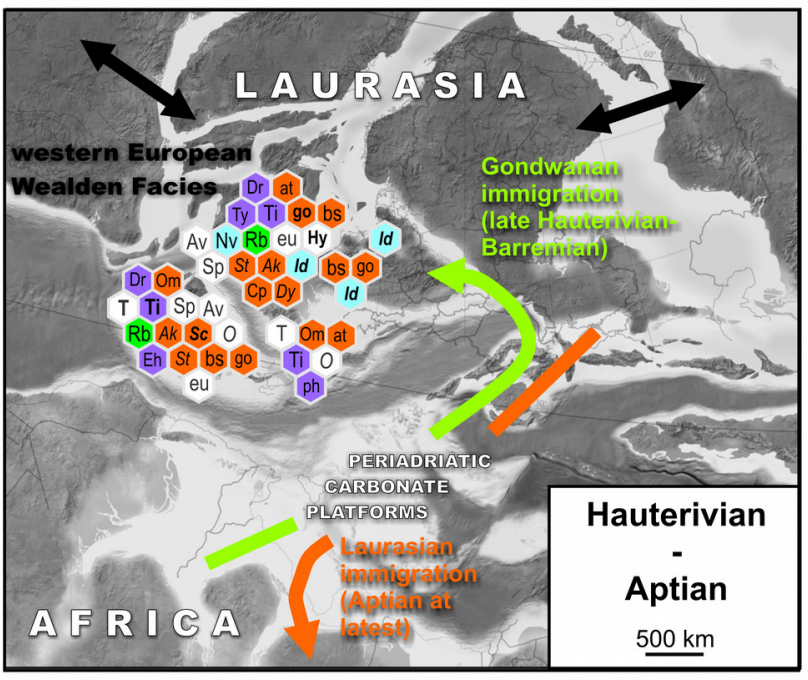

\section{PALAEOZOOGEOGRAPHICAL ORIGIN}
Pangean
Gondwanan
Laurasian
uncertain
European
Faunal exchange

\section{TAXON ABBREVIATIONS}

Ak: Ankylosauria

Al. Allosauroidea at: Atoposauridae Av: Aves

bs: Bernissartiidae

Ca: Basal Ankylopollexia („Camptosauridae“)

Ce: Ceratosauria

Co: basal Coelurosauria $\mathrm{Cp}$ : Compsognathidae Ct: Ceratopsia

Di: Diplodocoidea

Dr: Dromaeosauridae

$D y$ : Dryosauridae

Eh: Euhelopodidae

eu: Eusuchia (incl. Hylaeochampsidae)

go: Goniopholididae

He: Heterodontosauridae

Hy: "Hypsilophodontidae" Id: Iguanodontidae

Ig: basal Iguanodontia Ma: basal Macronaria

Mg: Megalosauroidea (excl. Spinosauridae)
O: Ornithopoda indet. Om: Ornithomimosauria ph: Pholidosauridae Nv: Neovenatoridae Rb: Rebbachisauridae $S$ : Sauropoda indet. Sc: Styracosterna St: Stegosauria

Sp: Spinosauridae

$\mathrm{T}$ : Theropoda indet.

Ti: basal Titanosauriformes

To: Troodontidae

Tu: Turiasauria

Ty: Tyrannosauroidea 
Late Jurassic ankylosaurs are present in Portugal and England (Galton 1980a, b), and possibly of Germany (GZG unpublished material), as well as in the Kimmeridgian-Tithonian of North America (Kirkland \& Carpenter 1994, Carpenter et al. 1998). They are therefore a Laurasian faunal element but unterwent dispersal to Gondwana at latest as early as the late Early Cretaceous (Molnar 1980), though the apparently basal position of Minmi paravertebra Molnar, 1980 (Thompson et al. 2011) may indicate a long Gondwanan ghost lineage of ankylosaurs. Another puzzling phenomenon is the absence of ankylosaurs from Africa, though, given their generally patchy record previous to the Upper Cretaceous, this may be a sampling bias. The basal Early Cretaceous record of ankylosaurs is of low diversity with most material grouped in close taxonomic proximity to a single genus, Hylaeosaurus (Pereda-Suberbiola 1993, Posmoşanu 2003a, Chapter VII), which seems not to be present in southern Europe. Its stratigraphic separation from the genus Polacanthus, which was first described from the late Hauterivian/Barremian, was emphasized to mark a biostratigraphic separation of a Lower from an Upper Biostratigraphic Zone in English Wealden dinosaur faunas (Pereda Suberbiola 1993, Blows 1998). However, recently Polacanthus has been found in the mid-/late Valanginian Lower Tunbridge Wells Formation of Sussex (Batten \& Austen 2011), which is older than the stratum typicum of Hylaeosaurus armatus, suggesting a co-occurrence of both in the upper Valanginian. Polacanthus remains the single ankylosaur genus known from diagnostic remains in the upper Wealden faunas of England and Spain (Pereda-Suberbiola 1993, PeredaSuberbiola et al. 1999, Canudo et al. 2004, Barrett \& Maidment 2011).

Among ornithopods, dryosaurids occur in western Laurasia as well as in Africa in the Late Jurassic (Galton 1981b, 1983). Whether Elrhazosaurus nigeriensis (Galton \& Taquet, 1982) from the Aptian-Albian of Niger is a descendent of an Early Cretaceous emigration or of intra-African evolution depends on its relationship to the European Valdosaurus canaliculatus, which was considered close (even congeneric, Galton \& Taquet 1982), or the African taxa (Dysalotosaurus lettowvorbecki Virchow, 1919, Kangnasaurus coetzeei Haughton, 1915) respectively. However, the resolution within dryosaurids is chronically poor (McDonald et al. 2010a, McDonald 2012). Other more basal forms like Hypsilophodon foxii and Gideonmantellia amosanjuanae Ruiz-Omeñaca, Canudo, Cuenca-Bescós, Cruzado-Caballero, Gasca \& Moreno-Azanza, 2012 are even more unclear in their origins but probably had a Pangean origin, regarding the distribution of a diversity of basal ornithopods ("hypsilophodontids") across Laurasia and Gondwana during the Cretaceous.

Basal ankylopollexians and styracosternans are present in the Kimmeridgian-Tithonian of North America and Europe (Mateus \& Antunes 2001, McDonald 2011). The more massive morphotype of styracosternan documented by the track record was possibly also present as early as the Late Jurassic (Mateus \& Milan 2008). Ankylopollexians, as well as styracosternans are probably of Jurassic (pre-Kimmeridgian) Laurasian origin (McDonald 2012). In Africa they appeared first during the Aptian (Taquet 1976). There is a considerable phylogenetic progress between the better known basal styracosternans Hypselospinus fittoni (Lydekker, 1889a) and Barilium dawsoni (Lydekker, 1888a) (?=Kukufeldia tilgatensis McDonald, Barrett \& Chapman 2010b) from the middle Valanginian and the iguanodontids (sensu Wu \& Godefroit 2012) Mantellisaurus atherfieldensis and Iguanodon bernissartensis from the Barremian (Norman 2011a), though it is not clear whether a local evolution took place, or more advanced immigrants replaced the more basal taxa. 
Heterodontosaurids have a Gondwanan origin (e.g. Norman et al. 2004) but were distributed throughout North America and East Asia by Late Jurassic (Zheng et al. 2009, Butler et al. 2010). The European record from the Berriasian of England and France and possibly the Barremian of Spain (Ruiz-Omeñaca \& Canudo 2003) is the youngest of the group.

The recent identification of Stenopelix valdensis as a very basal ceratopsian (Butler et al. 2011a) gives another interesting perspective. Its sister taxon Yinlong downsi from the Late Jurassic of China is the stratigraphically oldest ceratopsian. An early radiation of this group into Europe during the Late Jurassic/Early Cretaceous supports the idea of an influx of Asian taxa to the basal Cretaceous dinosaur fauna as proposed e.g. by Bonde (2012).

An evaluation of the theropod record is hampered by the extreme scarceness of this group in terms of diagnostic remains in the Berriasian-Valanginian of Europe. Dromaeosauridae, which ist the most safely identified subclade, occur as early as the Bathonian and are more abundant in the Kimmeridgian in Europe (Metcalf et al. 1992, Zinke 1998, van der Lubbe et al. 2009b), and the somewhat disputed species Xiaotingia zhengi Xu, You, Du \& Han, 2011 (Senter et al. 2012) occurs in the Oxfordian of China. If a microraptorian relationship of the teeth from the Berriasian of Denmark (Bonde 2012) can be confirmed, these would not only be the oldest representatives of this clade, but also support Early Cretaceous faunal interchange with Asia. The oldest record of dromaeosaurids from Gondwana date from the Cenomanian of Sudan (Rauhut \& Werner 1995). These data suggest a Laurasian origin and subsequent spread of dromaeosaurids to Gondwana. However, the ichnological record indicates the possible presence of a paravian theropod in the ?Middle Jurassic of Niger (Mudroch et al. 2010), implying the presence of deinonychosaurian precursors also in Gondwana. Their fate and connection with basal Upper Cretaceous dromaeosaurids remains unknown, however this may due to poor sampling in Early Cretaceous Gondwanan localities.

Troodontids, exclusively documented by the track record in the Berriasian of Europe (van der Lubbe et al. 2009a) are known as early as the Late Jurassic (Kimmeridgian) in North America, Europe, and East Asia (Chure 1994, Zinke 1998, Hartman et al. 2005, Hu et al. 2009). This clade is a typical Laurasian faunal element, which has no known Gondwanan member (e.g. Makovicky \& Norell 2004).

Among avian theropods, two groups, hesperornithines and enantiornithines, may have their earliest representatives in Europe (Lindgren et al. 2008, Galton et al. 2009, Dyke et al. 2011), though the record is sparse and/or not yet fully described. The track record supports the presence of an avifauna in the earliest Berriasian of Spain (e.g. Hernández Medrano et al. 2006). However, enantiornithine birds began to flourish in southern Europe at least since the Barremian (e.g. Sanz \& Ortega 2004).

Other theropods are too incompletely known from the Berriasian-Valanginian of Europe to make further assessments of their relationships. This is especially problematical as the differences between the rich Portuguese Late Jurassic theropod fauna with typical western Laurasian elements (megalosaurids, allosaurids, ceratosaurids, tyrannosauroids, Rauhut 2003, Mateus et al. 2006, Carrano et al. 2012) was apparently completely superseded by a new one in the late Hauterivian/Barremian. The latter is composed of neovenatorids (which may have evolved in Europe), carcharodontosaurids (whose basalmost members are from Africa and may have a Gondwanan 
origin), tyrannosauroids (a Laurasian clade), and possibly ?abelisauroids (a Gondwanan clade, e.g. Charig \& Milner 1986, Hutt et al. 1996, 2001, Naish et al. 2001, Canudo \& Ruiz-Omeñaca 2003, Sereno \& Brusatte 2008, Benson et al. 2010a, Ortega et al. 2010, Naish 2011, Rauhut 2011). However, the timing and modus operandi of the faunal change is totally obscure. The osteological (e.g. Milner 2002, Benson \& Barrett 2009, Appendix A) as well as the ichnological record (e.g. Ballerstedt 1905, Abel 1935, Lockley 2000, Fuentes Vidarte et al. 2005, Hernández Medarte et al. 2006) suggests the presence of medium- to large-sized theropods during the Berriasian-Valanginian in Europe. At least taxa with possible allosauroid affinities were present in the Early Valanginian of southern France (Pérez-Moreno et al. 1993) and in the Valanginian of England (Naish 2003), but otherwise the remains do not permit an assessment of their phylogenetic relationships. This circumstance may be characterized as a "theropod gap". Another member of the new theropod fauna were ornithomimosaurs which are known from the Hauterivian-Barremian of southwestern France and the Barremian of Spain (Pérez-Moreno et al. 1994, Néraudeau et al. 2012). A basal ornithomimosaurian was also present in the early Valanginian to early Barremian of China (Jin et al. 2012), supporting an Eurasian origin of the group. In contrast, the presence of compsognathids during the basal Cretaceous in Europe may be inferred, considering the compsognathid affinities of the Barremian Aristosuchus pusillus (see Naish et al. 2001), though they are not verified by material. Another clade which can be recognized easily by isolated teeth are spinosaurids. The oldest members have been recently recognized from the Late Jurassic of Tanzania (Fowler 2007, Buffetaut 2011) and baryonychine spinosaurids occur in the Wealden Supergroup of England from the late Berriasian to the Aptian, as well as in the Barremian of Spain and Portugal (Charig \& Milner 1986, 1997, Ruiz-Omeñaca et al. 1998, 2005, Naish 2011, Mateus et al. 2011). The palaeobiogeographic history of this clade is problematic (e.g. Buffetaut et al. 2008), though an increasing body of evidence supports a Jurassic Pangaean origin (Allain et al. 2012). However, among theropods, the distribution of spinosaurids (at least derived, specialized taxa) may be especially influenced by local palaeoclimates and palaeohydrology, as they where found to be ichthyophagous and semiaquatic in habit (Amiot et al. 2010) and therefore required suitable water-bodies. The lack of such environments in the Late Jurassic island topography of Central Europe and the following aridity of the early Berriasian strongly restricted the availability of such habitats and spinosaurids have been absent from most of Europe during this time. Their earliest European appearance during in the uppermost Berriasian Ashdown Formation (Naish 2011) coincides with the beginning emergence of a humidity peak and large lake systems. As some sauropod taxa and possibly some stegosaurs, the spinosaurids may have immigrated from Asia at this time.

It should be noted, that the typical Gondwanan lineage of abelisauroids has been reported to be present in Africa as early as the Late Jurassic (Rauhut 2011), and even in the Middle Jurassic of South America (Pol \& Rauhut 2012). This raises the question whether this group would have been able to immigrate to Laurasia before the Jurassic/Cretaceous boundary. However, even the possible presence of abelisauroids in the Barremian of England (Naish 2011) is highly tenable. Pol \& Rauhut (2012) proposed climatic or palaeoecological reasons for the restriction of the distribution and this seems to be plausible for similar reasons than in spinosaurids, though the palaeoecological and palaeoclimatological constraints of abelisauroid distribution are unknown. 
The Berriasian-early Valanginian sauropod fauna consists initially of basal macronarians, basal titanosauriforms (including brachiosaurids) which are inherited from the Late Jurassic cosmopolitic sauropod fauna. Diplodocids and possibly turiasaurs probably persisted into the basal Berriasian at least in Iberia. The Valanginian of England (Hastings Group) has produced, aside of titanosauriforms of uncertain affinities, at least one taxon probably related to euhelopodids. Canudo et al. (2002) proposed the presence of euhelopodids in the Barremian of Spain. Wilson \& Upchurch (2009) discussed a Jurassic Laurasian origin of somphospondylians, which is supported by the taxa from the Valanginian of England. However the purported Jurassic-Valanginian range of the group remains hypothetical, a Berriasian-Albian range for Euhelopus zdanskyi Wiman, 1929 as given by Zaher et al. (2011: fig. 7, referring to Wilson \& Upchurch 2009) is most probably erroneous, as Upchurch \& Wilson (2009) gave a Barremian-Aptian age for E. zdanskyi, though the deposit is not welldated. Other records of euhelopodids from eastern Asia, which apparently formed a diversity plexus in this region, are poorly dated, hampering an exact assessment of their temporal relationship to European occurrences. Therefore it must stay open in which direction the European-Asian faunal exchange took place in the Valanginian.

The role of turiasaurs remains somewhat mysterious. They seem to be present in western Europe (England) during the Bathonian and in central and southern Europe (London-Brabant Massif and Iberia) during the Latest Jurassic (Royo-Torres et al. 2006). Their stratigraphic range as well as their phylogenetic position as most basal neosauropods (Royo-Torres et al. 2009) indicate an early emergence from the Jurassic cosmopolitic dinosaur fauna, though apparently with a distribution restricted to Europe. The latter may be related to island character of western and central Europe during the Jurassic. It is unknown whether they form a part of the BerriasianValanginian sauropod fauna. Néraudeau et al. (2012) described some teeth of typical turiasaurian morphology from the Hauterivian-Barremian of southern France. However these authors found those associated to postcranial elements similar in morphology to the basal titanosauriform Tastavinsaurus sanzi Canudo, Royo-Torres \& Cuenca-Bescós, 2008, and raised the question, whether this morphology may not be unique to turiasaurs. Turiasaurian survival more deeply into the Early Cretaceous is therefore uncertain. They may have fallen victim - together with diplodocids - to the invasion of more advanced sauropods (euhelopodids, rebbachisaurids, e.g. Pereda Suberbiola et al. 2003, Upchurch et al. 2011, Torcida Fernández-Baldor et al. 2011) to Europe.

Did an "Eurogondwanan Fauna" exist?

Two major global events paved the way for faunal exchange during the Late Jurassic and earliest Cretaceous. The first, on a longterm scale, is the progressive upbreak of Pangaea, resulting in a segregation of Laurasian and Gondwanan faunas. The second are global and local changes in sealevel which greatly changed the European palaeogeography during short times, opening or closing potential migration routes.

The palaeogeographic situation at the Jurassic/Cretaceous boundary saw a northern Laurasian megacontinent that consists of North America, most of Europe and Asia and a southern 
megacontinent Gondwana, composed of South America, Africa, Madagascar, India, Australia and Antarctica. Eurasia and Africa were separated by the Tethys Ocean, even during the coalescence of all continents into Pangaea. After the pangaean breakup, and especially with incipient spreading of the central and southern Atlantic during the Jurassic, Africa began to drift northwards, narrowing the Tethys Ocean and approaching the southern fringes of the European parts of Laurasia. During this approach, several smaller terranes wedged between Africa and Europe received a crucial role as "stepstones" in early faunal exchanges between Laurasia and Gondwana. These include Iberia at the "hinge" of rotation between Africa and Laurasia, and the Apulian, Adria-Dinaric and Apennine Platforms (summarily the Periadriatic Platforms) in the central Tethys. The latter was however mostly a submerged sytem of carbonate platforms until the Hauterivian, when dinosaur ichnofaunas became abundant on emergent parts of the platforms (Dalla Vecchia 2008). Iberia in contrast, was found an important pathway for faunal exchange as early as the Late Jurassic. Kimmeridgian-Tithonian Portuguese Late Jurassic dinosaur faunas have shown a close relationship to contemporaneous assemblages from North America - sharing several genera - and also to Africa (Mateus 2006). The Late Jurassic global dinosaur fauna is generally considered cosmopolitic (Ezcurra \& Agnolín 2012), however Laurasian-Gondwanan interchange was palaeogeographically confined to the Mesoamerican land bridge and the North American - Iberian - African pathway. The faunal data from Africa, Iberia, and North America supports an intensive use of the latter (Mateus 2006). For the Early Cretaceous Ezcurra \& Agnolín (2012) poposed an "eurogondwanan" modell of dispersion, arguing that most of Europe became disjunct from Laurasian faunas but received an input from Gondwana via an emergent Periadriatic Platform system. During the later Early Cretaceous these authors proposed a reconnection of European with Asiamerican faunas resulting in the mixing of Gondwanan and Laurasian faunas as observed during the Barremian through Aptian (the time-span of typical "Wealden faunas" in Europe). In the meantime, ocean spreading has begun south of the Periadriatic Platforms, hindering Laurasian faunas from an immigration to Africa. This model was introduced to solve the problem of an "one way" dispersal of Gondwanan faunas to Europe but not vice versa during the Early Cretaceous. In this concept, the Periadriatic Platforms served as a "Noah's Ark" (sensu McKenna 1973, see Jacobs et al. 2011), a part of a landmass that becomes isolated and contacted another landmass after some period of isolation, acting as an unidirectional "raft" for biota from the realm of origin.

Immigration from Gondwana began during the late Hauterivian (Canudo et al. 2009), which coincides with the onset of dinosaur ichnocoenoses on the Periadriatic Platforms (Dalla Vecchia 2008). During the Barremian these immigrant taxa mixed up with strongly modified local faunas, which have superseded the Berriasian-Hauterivian faunas. The origin of these new faunal elements are not clear, some may have evolved locally (ornithopods), other result from interchange with adjacent Laurasian areas (sauropods), or the database is too insufficient for any reasoned hypothesis (e. g. many theropods). An emigration of European taxa towards Africa probably occured from the Aptian onwards (El Rhaz Fauna, Niger).

Ezcurra \& Agnolín (2012) performed a heuristic analysis of Jurassic and Cretaceous vertebrate faunas resulting in a stratistically closer relationship of European with African faunas during the Early Cretaceous. However, this conclusion emerges from an averaging of data across a time-slice 
spanning from the Berriasian to the end of the Barremian. The time-slice contains at least two successive, different archosaur assemblages, which cannot be separated by the method employed by Ezcurra \& Agnolín (2012), and the stratistical weight of data may have been biased by the much better record from the Barremian than from the Berriasian-Hauterivian. As stated before, Berriasian - early Hauterivian faunas in Europe do not show evidence for the presence of distinctly Gondwanan clades. In consequence, a general "Eurogondwanan" character of the archosaur fauna during the Early Cretaceous as proposed by Ezcurra \& Agnolín (2012) is only constituted for the late Hauterivian - early Aptian interval. Furthermore, this interval may have been even shorter given the scarce pre-Aptian fossil record in Africa. In fact, the timing of the onset of Laurasian faunal immigration into Africa is very poorly constrained and may have coincided with that in the contrary direction (see also Canudo et al. 2009). The postulated isolation of Europe from Laurasia during the Early Cretaceous is also problematic, as there are indications of intra-Laurasian faunal exchange during this time (e.g. sauropods, stegosaurs). The Periadriatic Platforms may therefore well have functioned as a true landbridge rather than a "Noah's Ark".

References on p. 364. 
Outlook 


\section{Outlook}

This work summarizes a number of threads of research into the archosaur fauna of the Bückeberg Formation, trying to disentangle a part of the wealth of data provided by the geological and palaeontological record of this interesting and revealing time-span in Earth's history. It was also tried to provide an overview and clarification on information given by pioneering works on this subject, dating back as far as into the $19^{\text {th }}$ century. However, as one of the most evident results, it may become clear, that in nearly every instance, more research is strongly desirable for the future. A number of prospective issues for this research may include:

- Screening for microvertebrate remains: This is one of the most important data source which has not yet been used for the Bückeberg Formation. In many other Early Cretaceous localities (Chapter XI) microvertebrate screening has been applied with great success, often multiplying the known diversity (e.g. Sweetman 2011). The lack of such data hampers an objective comparison of the local faunas to some degree. Regarding promising sampling sites and facies, perifluvial deposits of the proximal facies region (south of Hannover) seem to be most interesting, as in the very clean and mature sandstones of the deltaic facies region previous micropalaeontological screening efforts yielded no results (Mutterlose 1997, M. Schudack, pers. com. 2011). However, certain horizons in the latter may be in contrary especially promising, including the Dachplatte bed (immediately underlying the Obernkirchen Sandstone), known for its richness in vertebrate remains since the 1830s or bonebeds in the Osterwald Member of the Sehnde area, when material of these become available. The basinal (distal) facies region is also less promising as, with the exception of density flow deposits (Nyhuis \& Herbig 2009), there is only sporadical chance of embedding of terrestrial vertebrates compared to the volume of available hostrock. This facies has also often tested in the past for invertebrate microfossils, with only rare records of vertebrates if any.

- Development of statistical approaches to ichnological data: The abundance of dinosaur tracks and the increasing access to well-documented in situ data (which almost universally lack in old descriptions and collection specimens) open up the possibility to gain an indepth knowledge on dinosaur diversity, palaeobiology, and behaviours by the application of statistical methods. For example the application of principal components analyses (PCA) to a set of iguanodontian tracks reveals the presence of at least two morphotypes among the material and potential ontogenetic trends, encrypted in the relatively uniform track morphology (Hornung et al. subm.).

- Refinement of palaeoenvironmental reconstructions: Though several attempts have been undertaken during the last decades and a wealth of data has been compiled, many details of the palaeoenvironments are unknown or subject of models and speculation. This considers the geological as well as the palaeontological record. Regarding geology, only a part of available outcrops has been studied in detail and the depth and detail of analysis 
varies strongly in those recorded. Similarly, though general overviews on flora and fauna have been published for more than 150 years, only a very few groups ever received up-todate revisions.

Other issues, some of which are already in the process of preparation, include detailed reviews of specific archosaur groups, including dinosaurs, crocodilians, and controversal ichnotaxonomies.

Finally, I hope that the recently renewed interest on Early Cretaceous world in northern Germany will continue, not only amongst the scientific community but also to the interest, fascination, and enjoyment of the general public, to ever see further scenes of what Richard Dawkins called The Greatest Show on Earth.

References on p. 364. 
Outlook 
Appendix A

Archosaur skeletal material from the Bückeberg Formation 


\section{Appendix A: Archosaur skeletal material from the Bückeberg Formation}

\section{Introduction}

The following catalogue lists all material referrable to archosaurian reptiles known at present from the Berriasian-Valanginian Bückeberg Formation of northwestern Germany. Annotations, short descriptions and justifications are given regarding the assumed phylogenetic position of the specimens and the systematic framework applied. However, this appendix is not meant as a formal, in-depth analysis or revision, which will be undertaken elsewhere. Specimens mentioned in previous works (e.g. ornithopod tooth in Dunker [1843/44, 1849], ornithopod humerus in Dames [1884a]) but not traceable in any collection were not regarded. Lost specimens were only considered in exception when referenced by an accession number or unequivocal statement of public, still existing repository in earlier works. References provided are weighted for specimenspecific works, while references dealing with problems of wider-frame questions (e.g. comprehensive phylogenetic analyses) are only quoted if they are based significantly on discrete, relevant specimens or for the sake of establishing the systematic framework used herein.

A short summary section discussing the compilation and possible conclusions are located at the end of Appendix A, the references for Appendices A and B are listed at the end of Appendix B. The locality numbers refer to the locality map is provided in Appendix B (Fig. B.1), where also a stratigraphical scheme is given (Fig. B.2).

\section{Institutional Abbreviations}

DFMMh - Freilichtmuseum und Dinopark Münchehagen, Münchehagen, Germany, DLM - DrilandMuseum, Gronau/Westfalen, Germany, GAB - Gymnasium Adolfinum, Bückeburg, Germany, GPMM - Geomuseum of the Westfälische Wilhelms University, Münster in Westfalen, Germany, MB Museum für Naturkunde der Humboldt-Universität, Berlin, Germany, GZG (formerly GPIGö) Geowissenschaftliches Museum, Georg-August-Universität, Göttingen, Germany, including GZG.BA. Max Ballerstedt collection and GZG.STR. stratigraphic collection, IGPM - Geologisch-Paläontologisches Institut der Phillips-Universität Marburg, Marburg, Germany IPB - Steinmann-Institut für Geologie, Paläontologie und Mineralogie, Universität Bonn, Bonn, Germany, IVPP - Institute of Vertebrate Paleontology and Paleoanthropology, Chinese Academy of Sciences, Beijing, P. R. China, NHMUK - Natural History Museum, London, UK, NLMH - Niedersächsisches Landesmuseum Hannover, Germany, pcWA - private collection Willi Adam, RPMH - Roemer- und PelizaeusMuseum, Hildesheim, Germany, SLMB - Schaumburg-Lippisches Landesmuseum und Stadtmuseum Bückeburg, Bückeburg, Germany.

Other Abbreviations

ded. - dedit, det. - determined by, fragm. - fragmentary, impr. - impression, refers to preservation as natural impression typically left in the Obernkirchen Sandstone vertebrate fossils after removal of 
the soft, re-mineralised, unsavable skeletal material (see Chapters I and VIII: Supplementary Material for preservational issues).

Specimens preserved only as casts are marked in italics. A dagger $(\dagger)$ indicates lost material.

\author{
REPTILIA Laurenti, 1768 \\ ARCHOSAUROMORPHA von Huene, 1946 \\ ARCHOSAURIA Cope, 1869
}

CROCODYLOMORPHA Hay, 1930

CROCODYLIA Gmelin, 1789 (sensu Martin \& Benton 2008)

\author{
Mesoeucrocodylia Whetstone \& Whybrow, 1983 \\ Neosuchia Clark, 1988
}

Goniopholididae Cope, 1875

\title{
Goniopholis Owen, 1842
}

Remarks. The type species of Goniopholis is G. crassidens Owen, 1842, which is based upon NHMUK 3798/3799 (Owen 1842, Salisbury 2002), a specimen missing most of the cranium from the Purbeck Group, southern England. The diagnostic value of this specimen is problematical as most of the relevant, cranial characters are unobservable or ambiguous (Hooley 1907, Salisbury et al. 1999, Salisbury 2002). Due to this situation, G. simus Owen, 1878, which is based upon a wellpreserved cranium from the Purbeck Group, is commonly used as reference for Goniopholis, despite the possibility that it is conspecific with G. crassidens (Salisbury et al. 1999). The latter assertion was supported by a preliminary study of postcranial characters, which shows potential diagnostic features in the pelvis present in NHMUK 3798/3799 and referred postcranial material of G. simus (GZG.BA.0061, Hornung et al. 2009). However, the recent description of a new species, Goniopholis kiplingi Andrade, Edmonds, Benton \& Schouten, 2011, which is also based upon an isolated cranium (DORCM 12154) from the Purbeck Group, leaves open the possibility that the pelvic morphology recognized in $G$. crassidens and $G$. simus was also present in the latter, rather representing an synapomorphy at genus level.

In the light of these problems, $G$. simus is currently used as a reference base for the genus. A future formal resolution of this dilemma for this important genus may relie on an official redesignation of $G$. simus as type species of the genus, following the example of e.g. Iguanodon (Charig \& Chapman 1998, ICZN 2000).

At the present state of knowledge, all material of Goniopholis from the Bückeberg Formation that is sufficiently preserved seem to belong to a single species, which is indistinguishable from $G$. simus (Salisbury et al. 1999, Hornung et al. 2009, Andrade \& Hornung 2011, Hornung \& Reich 2012). The 
well preserved and abundant material from the Bückeburg Formation helped significantly in a detailed re-analysis of important cranial characters in this and related species (Andrade \& Hornung 2011, Chapter VIII).

A wide range of more fragmentary material can only be referred to as Goniopholis sp. or Goniopholididae indet. This applies also to Goniopholis minor Koken, 1887 and G. pugnax Koken, 1887, both based mostly upon isolated postcranial elements (Koken 1887), which were also previously regarded as nomina dubia (Salisbury et al. 1999).

\section{Goniopholis simus Owen, 1878}

(?=G. crassidens Owen, 1842)

Holotype. NHMUK 41098: Cranium and two paravertebral osteoderms (Owen 1878, Salisbury et al. 1999, Salisbury 2002, Andrade \& Hornung 2011).

Locus typicus. Swanage, Dorset, southern England, UK (Owen 1878).

Stratum typicum. Lulworth or Durlstone Formation, "middle" Purbeck Group, Berriasian, Early Cretaceous (Owen 1878, Salisbury et al. 1999).

Temporal and geographical range. Berriasian, Early Cretaceous; Dorset, southern England and Lower Saxony, northwestern Germany (Andrade \& Hornung 2011, Andrade et al. 2011). Karl et al. (2006) reported G. simus from the Upper Jurassic (Kimmeridgian) of Langenberg/Oker, Lower Saxony. However, the material on which this record is based - a ventral osteoderm and several teeth - are not sufficient for determination at species level.

(1) Obernkirchen Sandstone, Obernkirchen Member.

(1.1) Bückeberg, old sandstone quarries, c. 5 km ESE Obernkirchen, Lower Saxony [Loc. C-8b].

SLMB unnumbered - rostral part of cranium, [impr.] (Koken 1896 [referred to G. pugnax], Salisbury et al. 1999).

SLMB unnumbered - anterior fragment of dentary, associated to previous specimen, [impr.] (Koken 1896 [referred to G. pugnax], Salisbury et al. 1999).

pcWA unnumbered - most of cranium, [impr. in private collection] (Karl et al. 2006: fig. 6).

(1.2) Old comital quarry, Harrl hill, c. 1.7 km SE of Bückeburg, Lower Saxony [Loc. C-6].

GZG.BA.0061 - cranium, mandible, large part of postcranial skeleton, [impr., leg. M. Ballerstedt, in or before 1925] (Hornung et al. 2009, Hornung \& Reich 2012).

MB.R.2006.1 - Right ilium [cast from GZG.BA.0061, ded. M. Ballerstedt 11/1925].

NHMUK R.5259 - cranium [cast from GZG.BA.0061].

Fig. A.1 Goniopholis simus Owen, 1878, GZG.BA.0067z, cast of skull roof and rostrum, dorsal view. Obernkirchen Sandstone, Obernkirchen Member: Harrl hill or Bückeberg, leg. M. Ballerstedt. Skull length $60 \mathrm{~cm}$. 


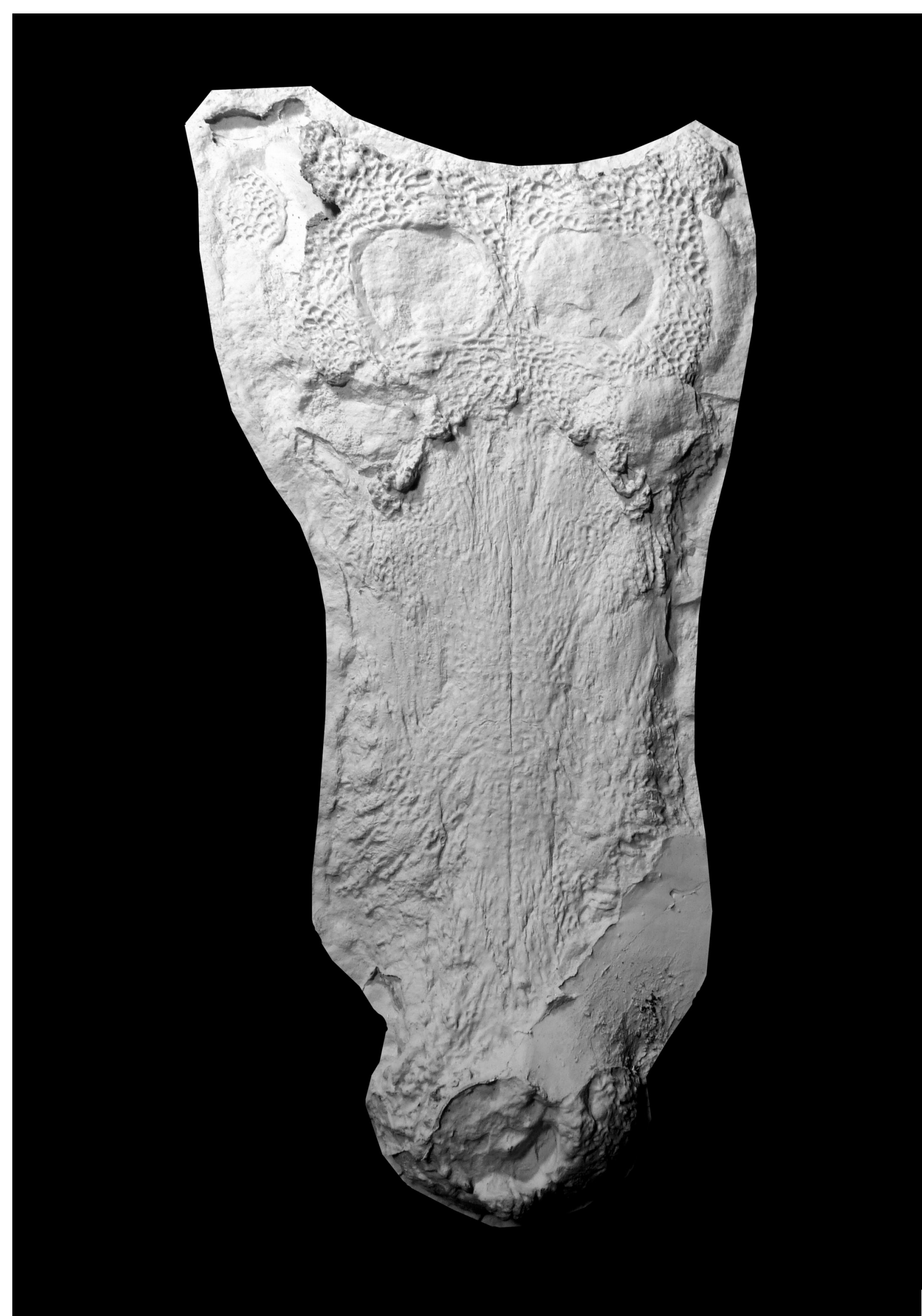


(1.3) Bückeberg or Harrl hill, unknown specific locality, Lower Saxony.

GZG.BA.0064b - fragmentary small cranium [impr. of ventral surface, leg. M. Ballerstedt].

GZG.BA.0065 - right mandible [impr., leg. M. Ballerstedt], possibly associated to GZG.BA.0067 (Andrade \& Hornung 2011).

GZG.BA.0067 - cranium [impr., leg. M. Ballerstedt, ex DFMMh Sch. 1a in Salisbury et al. (1999: 123); Figs. A.1, VIII.4; counter-slab with impr. of ventral surface, GZG.BA.0067b (ex GAB Sch. 1 in Salisbury et al. 1999: 123), on display at Gymnasium Adolfinum school, Bückeburg] (Andrade \& Hornung 2011).

GZG.BA.0127 - right maxilla [impr., leg. M. Ballerstedt].

GZG.BA.0129a - partial cranium (skull table) [impr., leg. M. Ballerstedt].

NLMH 103.176 - rostral part of small cranium [impr. of dorsal surface].

NHMUK R.5262 - small cranium [impr. of dorsal surface, original specimen lost, possibly counter-slab to GZG.BA.0064b] (Salisbury et al. 1999, Andrade \& Hornung 2011).

†GPIM Pr. 280 - cranium [impr., lost, leg. M. Ballerstedt, fide Salisbury et al. 1999]. Salisbury et al. (1999: 123) mentions fotos of the specimen at the GZG, the whereabouts of these images are unknown.

(1.4) Unknown locality, Lower Saxony.

IPB R359 - Skull [impr., Fig. VIII.3] (Salisbury et al. 1999, Andrade \& Hornung 2011).

\section{Goniopholis cf. simus Owen, 1878}

Remarks. The following elements are morphological congruent to specimens associated to diagnostic cranial material of G. simus and stratigraphically and geographically very close to the latter. However, as diagnostic characters in the postcranium of Goniopholis at species level are poorly constrained at present, they are regarded here as $G$. cf. simus.

(1) Obernkirchen Sandstone, Obernkirchen Member.

(1.1) Bückeberg or Harrl hill, unknown specific locality, Lower Saxony.

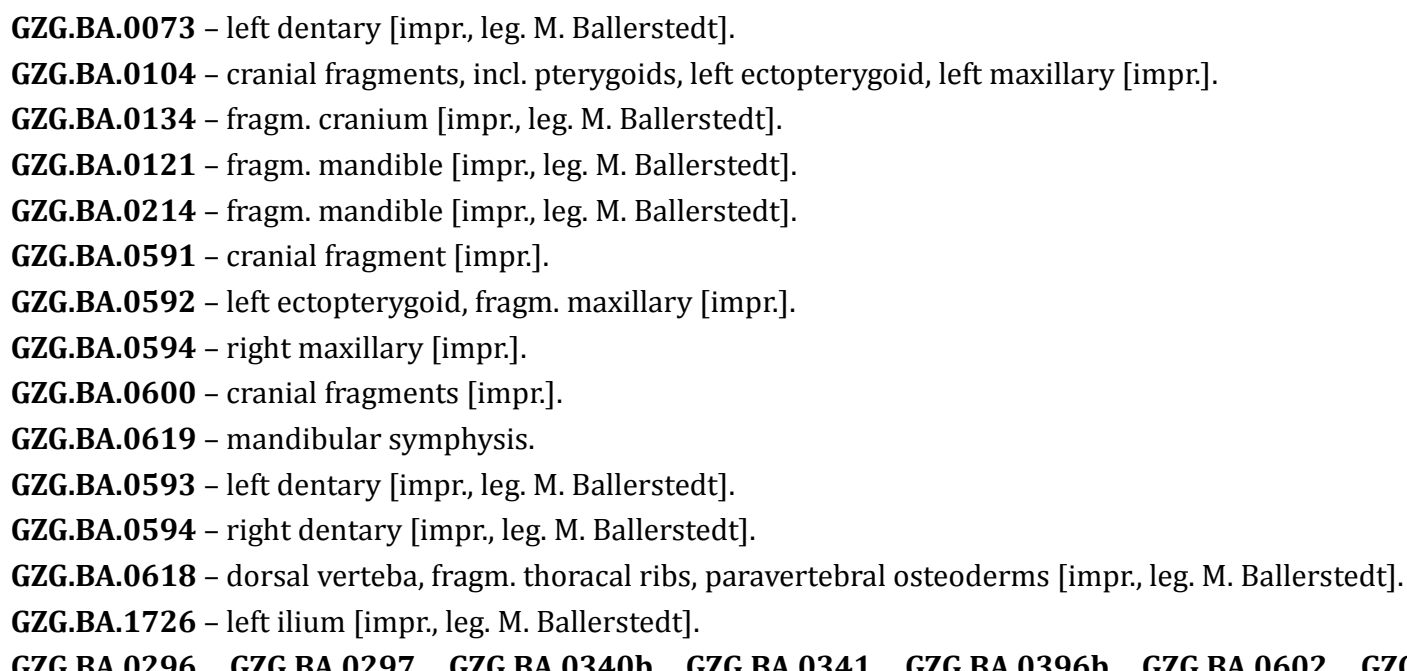

GZG.BA.0296, GZG.BA.0297, GZG.BA.0340b, GZG.BA.0341, GZG.BA.0396b, GZG.BA.0602, GZG.BA.0603, 
GZG.BA.0604, GZG.BA.0605a, GZG.BA.0606a, GZG.BA.0607, GZG.BA.0608, GZG.BA.0609, GZG.BA.0610, GZG.BA.0611, GZG.BA.0612, GZG.BA.0614, GZG.BA.0616, GZG.BA.1730 - paravertebral osteoderm(s) [impr., leg. M. Ballerstedt].

GZG.BA.0133 - ventral osteoderms, partly articulated armour [impr.].

GZG.BA.0233, GZG.BA.0613, GZG.BA.0615 - vental osteoderms [impr., leg. M. Ballerstedt].

NLMH unnumbered - both dentaries in articulation, dorsal vertebra [impr.].

\section{Goniopholis sp.}

(1) Obernkirchen Member, unspecified sublevel ("Middle Wealden"), "coal seam no. 4".

(1.1) Unspecified coal mine, Minden/Westfalen [Loc. C-14]

MB.R.4088.1-7 - cranial fragments, incl. fragm. left quadrate, tooth [leg. W. Musching].

MB.R.4089 - fragm. left jugal and quadratojugal, 2 fused ventral ?osteoderms [leg. W. Musching].

\section{Goniopholididae indet.}

(1) “Mittlerer Wealden”, Obernkirchen Member.

(1.1) Obernkirchen, Lower Saxony [Loc. C-8b?].

NLMH 101.733 - 3 teeth [leg. 1884].

(2) "Coal seam no. 4", Wealden 3-4, Obernkirchen Member.

(2.1) [Unspecified] coal mine, [SE of] Minden/Westfalen, Lower Saxony [C-14].

MB.R.4087 - (partim) 3 teeth [leg. W. Musching].

(3) Wealden 3-4, Obernkirchen Member.

(3.1) Abandoned mine shaft, Wackerfeld, Lower Saxony [C-22a].

GZG.STR.50002 - 2 teeth [leg. W. Grabbe].

GZG.STR.50286 - Tooth [Koken 1887].

GZG.STR.50287 - Tooth [Koken 1887].

GZG.STR.50008, GZG.STR.50009, GZG.STR.50010 - teeth [leg. W. Grabbe].

(4) Osterwald Member (possibly including uppermost Obernkirchen Member).

(4.1) Unspecified locality near Sehnde, Lower Saxony [Region D].

NLMH unnumbered - fragments, incl. fragm. ?angular, fragm. right postorbital, right ?jugal, 3 fragm. paravertebral osteoderms [exact provenance unknown, most probably Sehnde, ex coll. Hoyer].

RPMH “Wd. 002” - Praemaxillae, fragm. maxillae, and fragm. ?nasals, articulated.

NLMH unnumbered - fragm. right ?parietal [ex coll. Dahl]

RPMH “Wd. 022" - posterior end of right mandible. 
GZG.STR.50067 - left angular [ex coll. Woeckener, 1906].

GZG.STR.50150-50151, GZG.STR.50160, GZG.STR.50191-50193 - teeth.

GZG.STR.50096 - tooth [collected 1910].

GZG.STR.50070-50077 - teeth [ded. Weinhauer].

GZG.STR.50089-50095, GZG.STR.50152-50159 - teeth and tooth fragments [ex coll. Herzog, 1893].

GZG.STR.50161-50184 - teeth [ex coll. Woeckener, 1906].

GZG.STR.50185 - tooth [ded. Schacht, 1904].

NLMH unnumbered -6 tooth fragments [ex coll. Hoyer].

NLMH unnumbered - large tooth [ex coll. Hoyer].

NLMH unnumbered -8 small teeth [ex coll. Hoyer].

NLMH unnumbered -4 teeth [ex coll. Hoyer].

NLMH unnumbered - 28 teeth [ex coll. Dahl].

NLMH 101.938 - 11 teeth and tooth fragments [probably ex coll. Struckmann].

NLMH 101.762 - 4 fragm. paravertebral osteoderms, 1 ventral osteoderm.

RPMH “Wd. 011” - paravertebral osteoderm.

GZG.STR.50196 - fragm. osteoderms and other fragments.

(4.2) Abandoned clay-pit, Gretenberg near Sehnde, Lower Saxony [Loc. D-1].

GZG.STR.50045 - fragm. right postorbital(?).

GZG.STR.50046 - fragm. left squamosal.

GZG.STR.50048 - fragm. left jugal(?).

GZG.STR.50047 - fragm. right retroarticular process.

GZG.STR.50049 - frag. right dentary.

GZG.STR.50050, GZG.STR.50051, GZG.STR.50052, GZG.STR.50053 - teeth.

GZG.STR.50043 - > 15 fragm. paravertebral osteoderms.

GZG.STR.50054 - fragm. paravertebral osteoderm.

GZG.STR.50055 - 2 fragm. paravertebral osteoderms.

(4.3) Duinger Wald, near Duingen, Lower Saxony [Loc. C-15].

NLMH 102.076 - small tooth fragments.

(4.4) Lühnde, Lower Saxony [Region D].

NLMH unnumbered - 2 teeth [ex coll. Hoyer].

(5) Bückeberg Formation, unspecified sublevel ("Wealden").

(5.1) Abandoned clay-pit, ca. 300 m SE of Hohenbüchen, Lower Saxony [Loc. C-16].

GZG.STR.50031 - tooth [leg. D. Meischner].

GZG.STR.50032, GZG.STR.50033 - fragm. teeth [leg. D. Meischner].

GZG.STR.50029, GZG.STR.50030 - fragm. paravertebral osteoderms [leg. D. Meischner].

(5.2) Bückeberg, Obernkirchen, Lower Saxony [Loc. C-8b?].

NLMH 105.529 - large tooth. 
(5.3) Unspecified locality near Wennigsen, Lower Saxony.

GZG.STR.50024 - tooth.

(5.4) Unknown locality, most probably from the Osterwald Member of the Sehnde area.

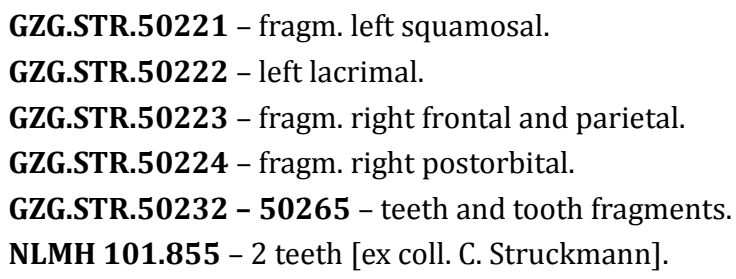

(5.5) Unknown locality.

GZG.STR.50266, GZG.STR.50267 - teeth.

\section{Goniopholididae? indet.}

(1) Osterwald Member.

(1.1) Gerdemann clay-pit, Gronau/Westfalen, Northrhine Westfalia [Loc. A-1].

GZG.STR.50011 - tooth [collected 1914].

Pholidosauridae von Zittel, 1902

Remarks. The monophyly and relationships of the Pholidosauridae have been widely and controversally discussed (e.g. Buffetaut 1982, Jouve et al. 2006, Jouve 2009, Pol et al. 2009). Some cladistic studies recovered them as paraphyletic and in a sister-group relationship to Thalattosuchia (e.g. Andrade et al. 2011). Buffetaut (1982) has proposed a close relationship between goniopholidids and pholidosaurids. This view was recently supported by Martin \& Buffetaut (2012), who recognized the presence of a maxillary depression (which is not homologous to the antorbital foramen common to archosaurs, Andrade 2009) in several genera of pholidosaurids, a character otherwise only known in goniopholidids. A cladistic analysis by these authors resulted in a nesting of a monophyletic pholidosaur[id] clade whithin the Goniopholididae. It has to be noted that - if this topology is supported by future studies - pholidosaurids should become re-ranked as a subfamily Pholidosaurinae within an expanded family Goniopholididae.

For the purpose of this overview, a monophyletic Pholidosauridae is accepted. 


\section{Pholidosaurus von Meyer, 1841}

Remarks. The type species, Pholidosaurus schaumburgensis von Meyer, 1841, was based upon an articulated dorsal vertebral series with the paravertebral armour in situ (GZG.BA.0047) from the Obernkirchen Sandstone near Bückeburg. Dunker $(1843 / 44,1849)$ made a well-preserved, though only ventrally exposed cranium (MB.R.2025.1) from the Obernkirchen Sandstone of the Bückeberg the type specimen of a new genus and species, Macrorhynchus meyeri. Meyer (in Dunker 1846) gave an extensive description of both taxa, and - as there was no overlapping material between both kept them separately. The next - and up to date most extensive - revision was provided by Koken (1887) based upon more material (see below for specimen details). In contrary to von Meyer, Koken emphasized the similarities between $P$. schaumburgensis and $M$. meyeri and concluded in referring both to the same genus, Macrorhynchus. However, he kept both species separated, based upon minor differences in skull proportions, dental features and ornamentation of skull-roof and rostrum.

Von Zittel (1902) correctly gave Pholidosaurus priority over Macrorhynchus. The synonymity of both genera has since been generally accepted, though, strictly spoken, it cannot be proven by overlapping material between the holotypes of P. schaumburgensis and P. meyeri and/or referred material. The most comprehensive association between cranial and postcranial material in a referred specimen from Obernkirchen (MB.R.1966, Koken 1887) includes three partial paravertebral osteoderms, however these are only exposed from the ventral side. Therefore they cannot be compared to the characteristic ornamentation of the osteoderms in the holotype of $P$. schaumburgensis. However, the hypothesis that the relation of osteoderms with the skull material is correct is also supported by a complete skeleton from the Purbeck Group of southern England (NHMUK R.3956, Andrews 1913), which is currently regarded as belonging to a further species, $P$. purbeckensis (Mansell-Pleydell, 1888) (see Salisbury 2002). The latter species is however very similar to P. schaumburgensis / P. meyeri and may turn out to be a junior synonym (Salisbury et al. 1999, Salisbury 2002).

A partial skull (NMHUK 28966) from the Wealden Group (probably Barremian) of the Isle of Wight (southern England) was orgininally referred to Pholidosaurus meyeri by Lydekker (1887), but was recently redescribed as a new genus and species, Leiokarinosuchus brookensis Salisbury \& Naish, 2011, whose systematic relationships are not yet established (Salisbury \& Naish 2011).

Pending a thorough revision of Pholidosaurus (Hornung in prep.), the generally accepted synonymies of the genus is followed here. Additionally the minor differences used by Koken (1887) to distinguish $P$. schaumburgensis and P. meyeri, based on referred specimens in the former, are considered to be dependant on individual variation, ontogeny and preservation, and only a single valid species is currently recognized from the Bückeberg Formation. 


\section{Pholidosaurus schaumburgensis von Meyer, 1841}

$$
\text { (=P. meyeri [Dunker, 1843/44]) }
$$

Holotype. GZG.BA.0047, articulated thorax with paravertebral armour (von Meyer 1841).

Locus typicis. Old comital quarry, Harrl hill, 1.7 km SE of Bückeburg, Lower Saxony, northern Germany (von Meyer 1841).

Stratum typicum. Obernkirchen Sandstone, Obernkirchen Member, Bückeberg Formation, late Berriasian, Early Cretaceous.

Temporal and geographical range. Berriasian of northern Germany. A closely related (? synonymous) species (P. purbeckensis) also in the Berriasian of southern England.

(1) Obernkirchen Sandstone, Obernkirchen Member.

(1.1) Old comital quarry, Harrl hill, 1.7 km SE of Bückeburg, Lower Saxony [Loc. C-6].

GZG.BA.0047 - articulated thorax (8 complete, 2 incomplete dorsal vertebrae) with paravertebral armour (8 pairs of osteoderms) in situ [HOLOTYPE, impr., leg. c. 1835, Fig. III.2b] (von Meyer 1841, von Meyer in Dunker 1846, Koken 1887, Hornung et al. 2012: fig. 2B).

GZG.BA.0511 - fragm. cranium [impr., leg. M. Ballerstedt, before 1925].

MB.R.2014.1-5 - fragm. cranium [cast of GZG.BA.0511, ded. M. Ballerstedt, 11/1925).

GZG.BA.0122a - fragm. left mandibular ramus [impr., leg. M. Ballerstedt, before 1925].

MB.R.2015.1-2 - left angular [cast of now missing part of GZG.BA.0122a, ded. M. Ballerstedt, 11/1925].

(1.2a) Bückeberg, active sandstone quarry, c. 5 km ESE Obernkirchen, Lower Saxony [Loc. C-8a].

NLMH 103.163 - cranium, anterior rostrum missing [impr., ded. K. Köster 2003/2005].

NLMH 103.269 - skull [impr., leg. K. Köster 1998].

(1.2b) Bückeberg, old sandstone quarries, c. 5 km ESE Obernkirchen, Lower Saxony [Loc. C-8b].

MB.R.2025.1 - cranium [holotype of Macrorhynchus meyeri, impr., leg. in 1838 (Koken 1887)] (Dunker 1843/1844, von Meyer in Dunker 1846).

MB.R.2026.1-4 - natural endocranial cast [belonging to MB.R.2025.1] (von Meyer in Dunker 1846, Koken 1887).

MB.R.1966 - partial cranium, partial left humerus, partial left ulna, 4 thoracal ribs, 3 fragm. paravertebral osteoderms [impr.] (Koken 1887).

MB.R.1968 - partial cranium [impr., ex coll. Degenhardt, ded. 1883] (Koken 1887).

MB.R.1969 - partial cranium [impr., ex coll. Degenhardt] (Koken 1887).

MB.R.1970 - partial cranium (right orbital and temporal region) [impr.] (Koken 1887).

MB.R.2080 - partial rostrum (cast of specimen from Naturkundemuseum Lübeck, original presumably destroyed, S. Sachs pers. com. 2011) (Jaffé 1912).

MB.R.2024 - fragm. left maxilla (original specimen unknown).

MB.R.2029 - distal end of rostrum [impr.] (Koken 1887).

MB.R.2019, MB.R.2027, MB.R.2071 - natural endocranial casts [MB.R.2071 is double-used: two not related dorsal vertebrae of Crocodylia indet. (see below) are registred under the same number] (Koken 1887).

MB.R.2020.1-10 - natural endocranial cast (10 fragments).

MB.R.2028, MB.R.2030, MB.R.2062, MB.R.2064 - natural casts of rostral cavities.

MB.R.2065, MB.R.2066, MB.R.2069.1-2, MB.R.2070.1-2 - natural casts of otic region (Koken 1887). 
MB.R.2067, MB.R.2068 - natural casts of otic labyrinth (Koken 1887).

MB.R.2060 - tooth.

MB.R.2063.1-2 - natural casts of alveoli.

MB.R.2073.1-4 - 4 tooth fragments from the lower jaw [impr].

MB.R.2031 - teeth and jaw fragments.

MB.R.2059.1-4 - teeth.

MB.R.2074.1-3 - 3 casts of a mandibular tooth.

MB.R.2022.1-2 - fragm. right mandibular ramus, limb bone [impr.].

RPMH unnumbered - articulated mandible and atlas-axis [impr.]

MB.R.1965 - articulated mandible and atlas-axis [impr., cast of RPMH specimen] (Koken 1887).

GZG unnumbered - articulated mandible and atlas-axis [impr., cast of RPMH specimen].

MB.R.2021 - thoracal rib [impr.]

(1.3) Bückeberg or Harrl hill, unknown specific locality, Lower Saxony.

MB unnumbered - cranium and mandible [impr., ex coll. M. Ballerstedt, ded. 11/1925].

GZG.BA.0087 - cranium [impr., leg. M. Ballerstedt, Fig. A.2].

GZG.BA.0072 - cranium [impr., leg. M. Ballerstedt].

GZG.BA.0068 - partial cranium and mandible [impr., leg. M. Ballerstedt].

GZG.BA.0096 - fragm. cranium [impr., leg. M. Ballerstedt].

GZG.BA.0071 - fragm. cranium [impr., leg. M. Ballerstedt].

GZG.BA.0135 - fragm. cranium [impr., leg. M. Ballerstedt].

GZG.BA.0137 - fragm. cranium [impr., leg. M. Ballerstedt].

GZG.BA.0069 - rostrum [impr., leg. M. Ballerstedt].

GZG.BA.0103 - rostrum [impr., leg. M. Ballerstedt].

GZG.BA.0510a - rostrum [impr., leg. M. Ballerstedt].

GZG.BA.0130 - left maxilla [impr., leg. M. Ballerstedt].

GZG.BA.1724 - fragm. rostrum [historical plaster cast].

GZG.BA.0074 - mandibular ramus [impr., leg. M. Ballerstedt].

GZG.BA.0119 - mandibular ramus [impr., leg. M. Ballerstedt].

GZG.BA.0120a - right mandibular ramus [impr., leg. M. Ballerstedt].

GZG.BA.0138 - right mandibular ramus [impr., leg. M. Ballerstedt].

GZG.BA.0234 - fragm. mandibular ramus [impr., leg. M. Ballerstedt].

GZG.BA.0514 - fragm. mandible [impr., leg. M. Ballerstedt].

GZG.BA.0515 - fragm. mandible [impr.].

GZG.BA.0516 - fragm. mandible [impr.].

GZG.BA.0518 - fragm. mandible [impr., leg. M. Ballerstedt].

GZG.BA.0520 - fragm. mandible [impr., leg. M. Ballerstedt].

GZG.BA.0521 - fragm. left mandibular ramus [impr., leg. M. Ballerstedt].

GZG.BA.0522 - fragm. right mandibular ramus [impr., leg. M. Ballerstedt].

GZG.BA.0743 - mandibular symphysis [impr., leg. M. Ballerstedt].

GZG.BA.0077 - vertebrae, ribs, paravertebral osteoderms [impr., leg. M. Ballerstedt].

GZG.BA.0102 - fragm. paravertebral osteoderms [impr.].

GZG.BA.0109, GZG.BA.0524, GZG.BA.0529, GZG.BA.0523, GZG.BA.0532, GZG.BA.0589 - paravertebral osteoderms [impr.]

GZG.BA.0190, GZG.BA.0312, GZG.BA.0525, GZG.BA.0526, GZG.BA.0527, GZG.BA.0528a, GZG.BA.0530, GZG.BA.0531, GZG.BA.0585, GZG.BA.0586a, GZG.BA.0587, GZG.BA.0588, GZG.BA.0590 - paravertebral osteoderms [impr., leg. M. Ballerstedt].

GZG.BA.0091 - [impr., leg. M. Ballerstedt]. 


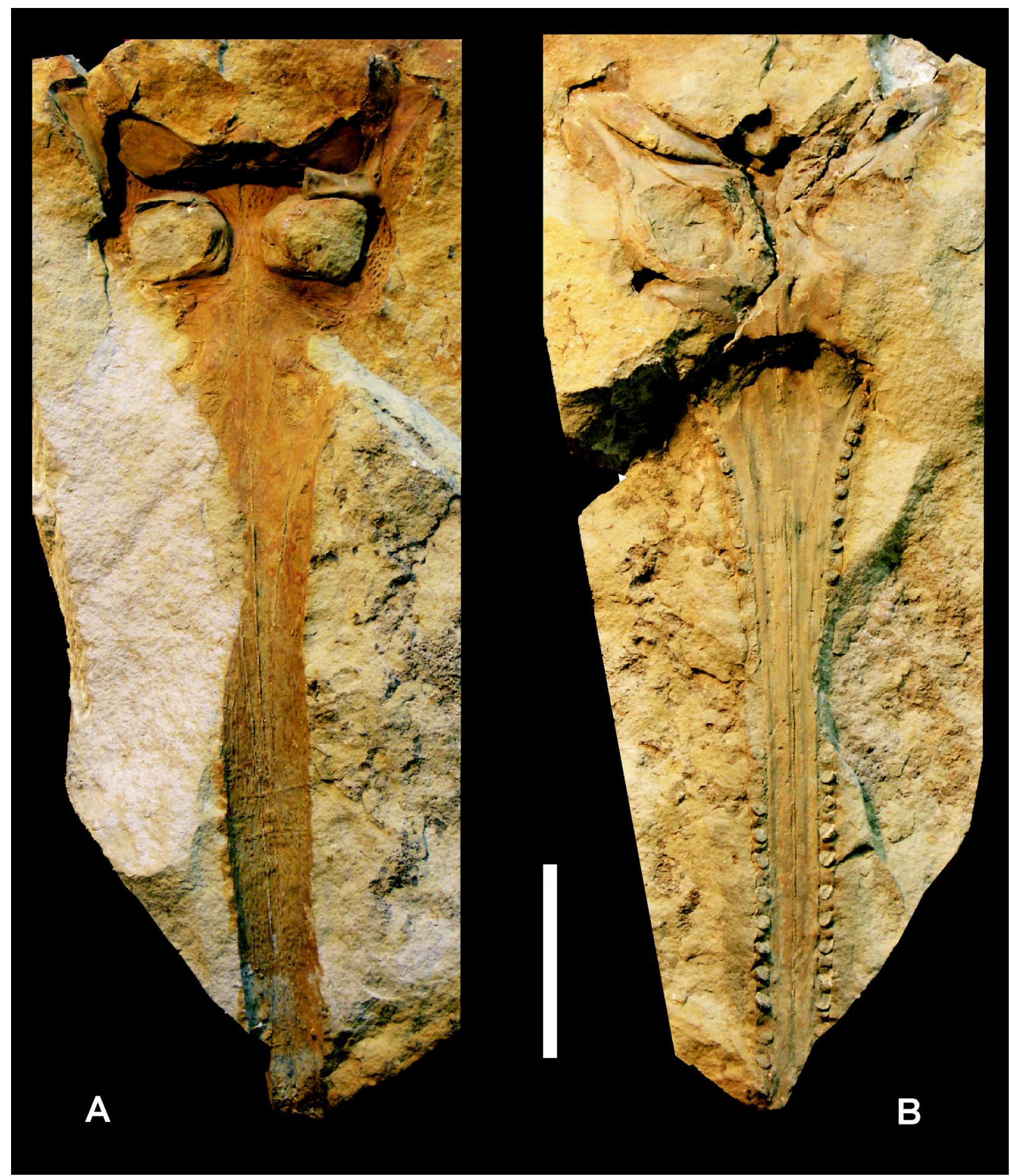

Fig. A.2 Pholidosaurus schaumburgensis von Meyer, 1841, GZG.BA.0087a-b, cranium, natural impressions of the (A) dorsal and (B) palatal surfaces. Obernkirchen Sandstone, Obernkirchen Member; Harrl hill or Bückeberg, leg. M. Ballerstedt. Scale bar equals $10 \mathrm{~cm}$. 
(1.4) Unknown locality.

NLMH unnumbered - most of the cranium [impr.].

(2) Wealden 3-4, Obernkirchen Member, unspecified level (“Mittlerer Wealden”), probably Dachplatte bonebed, underlying the Obernkirchen Sandstone.

(2.1) Abandoned mineshaft, Wackerfeld, Lower Saxony [Loc. C-22a].

GZG.STR.50228 - left jugal [leg. W. Grabbe].

\section{Pholidosauridae indet.}

Remarks. Fragmentary and/or isolated remains which show similarities to P. schaumburgensis but are insufficient for an unambiguous determination.

(1) Dachplatte bonebed, Obernkirchen Member.

(1.1) Vicinity of Obernkirchen, Lower Saxony.

GZG.STR.50282 - fragm. paravertebral osteoderm (Koken 1887).

(2) Obernkirchen Sandstone, Obernkirchen Member.

(2.1) Bückeberg, old sandstone quarries, c. 5 km ESE Obernkirchen, Lower Saxony [Loc. C-8b].

MB.R.2079.1-2 - tooth fragments.

(2.2) Bückeberg or Harrl hill, unknown specific locality, Lower Saxony.

GZG.BA.0136 - fragm. cranium [impr., leg. M. Ballerstedt].

GZG.BA.0240 - fragm. cranium [impr., leg. M. Ballerstedt].

GZG.BA.0509 - cranial fragments [impr., leg. M. Ballerstedt].

GZG.BA.0122a - fragm. mandible [impr., leg. M. Ballerstedt].

GZG.BA.0124 - fragm. mandible [impr., leg. M. Ballerstedt].

GZG.BA.0512 - fragm. mandible [impr.].

GZG.BA.0517 - fragm. ?mandible [impr.].

GZG.BA.0519 - fragm. mandible [impr.].

GZG.BA.1758 - dorsal vertebra [impr.].

(3) Wealden 3-4, Obernkirchen Member.

(3.1) Abandoned mine shaft, Krebshagen, Lower Saxony [Loc. C-22b].

GZG.STR.50005, GZG.STR.50006 - teeth [leg. Grabbe]. 
(3.2) Abandoned mine shaft, Wackerfeld, Lower Saxony [Loc. C-22a].

GZG.STR.50013-50017 - teeth [leg. Grabbe].

GZG.STR.50020, GZG.STR.50021, GZG.STR.50027 - teeth.

(3.4) Unspecified locality, Schaumburg-Lippe, Lower Saxony [Region C].

GZG.STR.50019 - tooth.

(4) Osterwald Member.

(4.1) Unspecified locality near Sehnde, Lower Saxony [Region D].

RPMH “Wd. 023" - fragm. right praemaxillary.

RPMH “Wd. 024" - fragm. right dentary (symphyseal region).

NLMH unnumbered - 11 tooth fragments [ex coll. Hoyer].

GZG.STR.50078, GZG.STR.50079 - tooth and tooth fragment [ded. Weinhauer].

GZG.STR.50097, GZG.STR.50144-50149, GZG.STR.50190 - teeth.

GZG.STR.50098, GZG.STR.50100-50103 - teeth and tooth fragments [ex coll. Herzog, 1893].

GZG.STR.50104-50142, GZG.STR.50186-50189 - teeth and tooth fragments [ex coll. Woeckener, 1906].

GZG.STR.50143 - paravertebral osteoderm.

NLMH unnumbered - fragm. paravertebral osteoderm [ex coll. Hoyer].

(4.2) Lühnde, Lower Saxony [Region D].

NLMH unnumbered - 2 fragm. teeth [ex coll. Hoyer].

(4.3) Abandoned clay-pit, Gretenberg near Sehnde, Lower Saxony [Loc. D-1].

GZG.STR.50040 - rostral end of mandibular symphysis.

GZG.STR.50042 - fragm. right dentary.

GZG.STR.50038 - ca. 25 fragments of paravertebral osteoderms.

GZG.STR.50039 - 2 fragm. ventral osteoderms.

(4.4) Unknown locality, probably from the Osterwald Member in the Sehnde area [Region D].

GZG.STR.50230 - fragm. rostrum.

GZG.STR.50273 - left quadrate.

GZG.STR.50268-50271 - tooth fragments.

(5) Bückeberg Formation, unspecified level.

(5.1) Unspecified locality near Stemmen, Lower Saxony [Loc. C-23].

GZG.STR.50004 - tooth and bone fragment.

(5.2) Abandoned clay-pit, ca. 300 m SE of Hohenbüchen, Lower Saxony [Loc. C-16]. 
GZG.STR.50028 - fragm. paravertebral osteoderm [leg. Meischner].

(5.3) Unspecified locality near Wennigsen, Lower Saxony.

GZG.STR.50025 - tooth [coll. Witte].

GZG.STR.50026 - tooth fragment [associated with a goniopholidid tooth fragment and fish remains, coll. Witte].

(5.4) Egestorf(?), Lower Saxony [Loc. C-20].

GZG.STR.50275 - tooth.

(5.5) Unknown locality.

GZG.STR.50231 - fragm. right frontal.

GZG.STR.50229 - paravertebral osteoderm.

\section{Pholidosauridae? indet.}

Remarks. A few dorsal osteoderms are similar in general morphology and sculpture to those of $P$. schaumburgensis, however, the surface is more densely covered by well defined though shallow pits arranged in indistinct transversal rows. One of them was already identified as a potentially distinct taxon by Koken (1887). Their lack of association to more complete remains and the insufficiently known range of variation of osteoderm sculpture in $P$. schaumburgensis hinder a more definite assessment.

(1) Dachplatte bonebed, Obernkirchen Member.

(1.1) Vicinity of Obernkirchen, Lower Saxony.

GZG.STR.50283 - fragm. paravertebral osteoderm (Koken 1887).

(2) Osterwald Member.

(2.1) Abandoned clay-pit, Gretenberg near Sehnde, Lower Saxony [Loc. D-1].

GZG.STR.50041 - fragm. paravertebral osteoderm.

(2.1) Unspecified locality near Sehnde, Lower Saxony [Region D].

RPMH “Wd. 009”, RPMH “Wd. 010” - paravertebral osteoderms. 
Atoposauridae Gervais, 1871

\section{Theriosuchus Owen, 1879}

\section{Theriosuchus sp.}

Remarks. GZG.BA.0139 represents most of a left angular articulating with the proximal end of the dentary. This specimen is congruent in various characters with the lower jaw of Theriosuchus pusillus Owen, 1879 (NHMUK 48330, NHMUK 48328, Salisbury 2002), the type species of the genus from the Purbeck Group of southern England. Most important is the presence of a shelf along the ventrolateral side of the angular, the apparent lack of an external mandibular fenestrum, the participation of the angular in forming the ventral half of a posteriorly directed retroarticular process (Raddatz 2011) and a short, vertical suture between angular and dentary on the lateral side of the mandible. The most important difference of GZG.BA.0139 to other members of Theriosuchus is the presence of a knob-like lateral swelling near the anterior end of the lateral shelf of the angular and its size: it is about three time as large as e.g. the paratype skull of T. pusillus (NHMUK 48330) and may therefore be the largest known atoposaurid. These characters further distinguishes it from the species of Theriosuchus present in the Upper Jurassic (Kimmeridgian) of northern Germany (Thies et al. 1997, Thies \& Broschinski 2001, Karl et al. 2006, Raddatz 2011).

The presence of a unusually large species of Theriosuchus is also supported by three paravertebral osteoderms from Sehnde, the largest of which is at $3 \mathrm{~cm}$ long and more than $3 \mathrm{~cm}$ wide (incompletely preserved). Despite its size other characters closely resemble those of $T$. spp.

To the contrary, GZG.STR.50293 represents a paravertebral osteoderm which is closely comparable in size, outline, and ornamentation to T. pusillus.

(1) Obernkirchen Sandstone, Obernkirchen Member.

(1.2) Old comital quarry, Harrl hill, c. 1.7 km SE of Bückeburg, Lower Saxony [Loc. C-6].

GZG.BA.0139 - left angular and partial dentary [impr., leg. M. Ballerstedt, in or before 1925].

MB.R.2008.1-2 - left angular and partial dentary [cast of GZG.BA.0139, ded. M. Ballerstedt 11/1925)

(2) Osterwald Member.

(2.1) Unspecified locality near Sehnde, Lower Saxony [Region D].

RPMH “Wd. 004" - three large, paravertebral osteoderms from the cervical or dorsal region.

GZG.STR.50293 - paravetebral osteoderm from the caudal region.

Eusuchia Huxley, 1875

Hylaeochampsidae Andrews, 1913 


\section{Gen. \& sp. indet.}

Remarks. An tiny, elongate, narrow, strongly procoelous, dorsal centrum with partially preserved neurapophysis is very similar in morphology to those of the enigmatic eusuchian Heterosuchus valdensis Seeley, 1870 from the Hastings Group of England and other hylaeochampsids (e.g. Buscalioni et al. 2011). Together with the other material listed below it may represent the oldest hylaeochampsid known and be among the oldest eusuchians.

(1) Osterwald Member.

(1.1) Unspecified locality near Sehnde, Lower Saxony [Region D].

GZG.STR.50085 - dorsal vertebra with incomplete neurapophysis, collected 1910

\section{Eusuchia? indet.}

Remarks. Osteoderms with ovate outline are dissimilar to the common osteoderms of goniopholidids and pholidosaurids and comparable to those from the accessory dorsolateral longitudinal rows in basal eusuchians (Salisbury et al. 2006).

(1) Osterwald Member.

(1.1) Abandoned clay-pit, Gretenberg near Sehnde, Lower Saxony [Loc. D-1].

GZG.STR.50037 - osteoderm.

\section{Crocodylia indet.}

Remarks. Fragmentary material which cannot be determined more precisely at present.

(1) Unspecified level, Bückeberg Formation.

(1.1) Unspecified locality near Osnabrück, Lower Saxony.

MB.R.2071 - 2 dorsal vertebral centra [collected in or before 1885, not related to an endocranial cast of Pholidosaurus schaumburgensis also cataloged as MB.R.2071].

(1.2) Unknown locality.

GZG.STR.50272 - Sacral rib.

(2) Obernkirchen Sandstone, Obernkirchen Member. 
(2.1) Abandoned mineshaft, Wackerfeld, near Stadthagen, Lower Saxony [Loc. C-22a].

GZG.STR.50285 - fragm. cervical vertebra [SYNTYPE of Goniopholis minor Koken, 1887].

GZG.STR.50274 - Metacarpal I.

(2.2) Bückeberg or Harrl hill, unknown specific locality, Lower Saxony.

GZG.BA.0118 - cranial fragment (occipital region) [impr., leg. M. Ballerstedt].

GZG.BA.0221, GZG.BA.1729 - left quadrates [impr., leg. M. Ballerstedt].

GZG.BA.0075 - fragm. mandible [impr., leg. M. Ballerstedt].

GZG.BA.0123 - right mandibular ramus [impr., leg. M. Ballerstedt].

GZG.BA.0598 - fragm. left mandibular ramus [impr., leg. M. Ballerstedt].

GZG.BA.0599 - fragm. mandibular ramus [impr].

GZG.BA.0601 - fragm. left mandibular ramus [impr., leg. M. Ballerstedt].

GZG.BA.0081, GZG.BA.1734 - teeth [impr., leg. M. Ballerstdt].

GZG.BA.1713 - teeth [impr.].

GZG.BA.0105 - cervical vertebra [impr., leg. M. Ballerstedt].

GZG.BA.0488, GZG.BA.0489, GZG.BA.0490, GZG.BA.0491, GZG.BA.0492, GZG.BA.0494, GZG.BA.1731 - thoracal ribs [impr., leg. M. Ballerstedt].

GZG.BA.0498, GZG.BA.1719, GZG.BA.1722 - dorsal vertebrae [impr., leg. M. Ballerstedt].

GZG.BA.0500 - dorsal neurapophysis [impr., leg. M. Ballerstedt].

GZG.BA.0496a, GZG.BA.0497, GZG.BA.1712a - sacral vertebrae with articulated sacral ribs [impr., leg. M. Ballerstedt].

GZG.BA.0495 - articulated series of 9 terminal caudal vertebrae [impr., leg. M. Ballerstedt].

GZG.BA.0501a - distal caudal vertebra [impr., leg. M. Ballerstedt].

GZG.BA.0499 - haemapophysis [impr., leg. M. Ballerstedt].

GZG.BA.502 - right scapula [impr., leg. M. Ballerstedt].

GZG.BA.0503a - ?coracoid [impr., leg. M. Ballerstedt].

GZG.BA.0085 - left humerus [impr., leg. M. Ballerstedt].

GZG.BA.0506 - left humerus [impr., leg. M. Ballerstedt].

GZG.BA.0507 - right humerus [impr., leg. M. Ballerstedt].

GZG.BA.0504 - right ischium [impr., leg. M. Ballerstedt].

GZG.BA.0505 - left femur [impr., leg. M. Ballerstedt].

GZG.BA.1725 - ?fibula [old plaster cast, original specimen unknown].

GZG.BA.0617 - paravertebral osteoderm [impr., leg. M. Ballerstedt].

(3) Obernkirchen Member.

(3.1) Sülbeck, near Nienstädt, Lower Saxony

GZG.STR.50284 - dorsal vertebra [SYNTYPE of Goniopholis minor Koken, 1887].

(4) Osterwald Member (and possibly uppermost Obernkirchen Member).

(4.1) Unspecified locality near Sehnde, Lower Saxony [Region D].

GZG.STR.50099 - tooth [ex coll. Herzog, 1893].

NLMH unnumbered - tooth fragment [ex coll. Dahl].

NLMH unnumbered - proximal end of fibula [ex coll. Dahl].

NLMH 101.937 - dorsal centrum with partial neurapophysis [provenance uncertain]. 
NLMH unnumbered - 3 distal caudal vertebral centra [ex coll. Hoyer].

NLMH 101.804 - caudal vertebral centrum.

GZG.STR.50068 - fragm. left jugal [ex coll. Woeckener, 1906].

GZG.STR.50069 - fragm. osteoderms [possibly same taxon as GZG.STR.50068, according to sculpture, ex coll. Woeckener, 1906].

GZG.STR.50081 - vertebral centrum.

GZG.STR.50082 - several fragments of vertebrae and other bones [collected 1916].

RPMH “Wd. 013”, RPMH “Wd. 014” - cervical vertebrae.

RPMH “Wd. 015”, RPMH “Wd. 016”, RPMH “Wd. 018” - caudal vertebrae.

RPMH “Wd. 017" - distal caudal vertebra.

RPMH “Wd. 019” - fragm. caudal vertebra.

GZG.STR.50197, GZG.STR.50198 - fragm. caudal centrum.

RPMH “Wd. 028” - fragm. radius.

(4.2) Gretenberg clay-pit, Sehnde, Lower Saxony [Loc. D-1]

GZG.STR.50056 - posterior cervical vertebra.

GZG.STR.50057 - proximal part of right(?) fibula.

GZG.STR.50058 - fragm. transversal process.

GZG.STR.50059 - fragm. paravertebral osteoderm.

GZG.STR.50060 - cervical centrum.

GZG.STR.50061 - dorsal centrum.

(4.3) Unknown locality, most probably from the Osterwald Member of the Sehnde area, Lower Saxony [Region D].

GZG.STR.50278 - frag. cervical vertebra.

GZG.STR.50219, GZG.STR.50220, GZG.STR.50277 - Vertebral centra.

GZG.STR.50276 - fragm. ischium.

\section{Crocodylia? indet.}

(1) Bückeberg Formation.

(1.1) Unknown locality, most probably from the Osterwald Member of the Sehnde area, Lower Saxony [Region D].

GZG.STR.50217 - gastral rib.

\section{PTEROSAURIA Kaup, 1834}

Remarks. A few fragments represent pterosaurs. The remains are too scanty for a precise identification, however, the jaw remains indicate the presence of at least two toothed taxa. GZG.STR.50292 consists of the small (ca. $2 \times 3 \mathrm{~cm}$ as preserved), rostral part of the fused, 
dorsoventrally flat praemaxillae, with the anterior tip missing. The posteriormost preserved alveolus is enlarged and suggests the presence of fang-like teeth (the teeth are missing except for two eroded fragments of small replacement teeth). The dorsal surface is mooth. Aside of the very delicate hollow structure a sharp, strongly raised mid-line crest on the oral side of the rostrum are typical characters of pterosaurs. The median ridge is exceptionally pronounced and protrudes ventrally well below the alveolar margin.

RPMH "Wd. 025" is a water-worn fragment of a relatively large left dentary (ca. $4 \mathrm{~cm}$ dorsoventral height). It represents a short section of the bone posterior to the mandibular symphysis at the posterior end of the tooth row. The oral margin shows the eroded remains of four shallow alveoli which are bordered lingually by a horizontal bony shelf. An interesting feature is a raised bony lamina posterior to the last alveolus along the external oral margin of the dentary. Pterosaur features include the extremely thin-walled structure of the bone with trabeculae visible in places.

Note. The skeletal material was not mentioned in Chapter $\mathrm{X}$ because the elements were not yet known/identified when this chapter was submitted for publication.

(1) Osterwald Member.

(1.1) Unspecified locality near Sehnde, Lower Saxony [Region D].

RPMH “Wd. 025” - fragm. left dentary (posterior region).

(1.2) Unknown locality, most probably from the Osterwald Member of the Sehnde area, Lower Saxony [Region D].

GZG.STR.50291 - fragm. wing-finger phalanx.

GZG.STR.50292 - fragm. rostrum (fused praemaxillae).

DINOSAURIA Owen, 1842

Saurischia Seeley, 1887

Theropoda Marsh, 1881

Altispinax von Huene, 1923

Altispinax dunkeri (Dames, 1884b)

Holotype. IGPM 1857 [cited by Carrano et al. [2012] as "N 84", probably based upon von Huene (1926a). However von Huene did not specify an accession number, but he refers to an arbitrary list of material summarized for his work (von Huene 1926a: 36ff.], lateral tooth-crown (Dames 1884b), Fig. A.3.

Locus typicus. Stated to be "Deister" by Dames (1884b), but is in fact Obernkirchen according to original label.

Stratum typicum. 'Dachplatte' (argillaceous interval between main coal seam and overlying 
Obernkirchen Sandstone), Obernkirchen Member, Bückeberg Formation, late Berriasian, Early Cretaceous (according to original label and Koken, 1887).

Temporal and geographical range. Berriasian of northern Germany.

Remarks. An isolated, medium-sized (tooth crown height $65 \mathrm{~mm}$ ) theropod tooth-crown (IGPM 1857) was made the holotype of a new species of Megalosaurus Buckland, 1824, M. dunkeri, by Dames (1884b).

Lydekker (1888a, 1890) listed a number of fragmentary NHMUK specimens (teeth and isolated bones, mostly from the Wealden Group, but also from the Purbeck Group of southern England) as belonging to $M$. dunkeri, primarily based upon stratigraphic grounds. He even doubted on the diagnostic value of IGPM 1857, citing presevational issues (Lydekker 1888b). Subsequently von Huene (1923: 453) supposed:

"The species described as M[egalosaurus]. dunkeri by Lydekker (Dames), from the English (and German) Lower Wealden is distinguished from Megalosaurus by its enormously high neural spines in the dorsal region. I therefore propose to establish a new genus, Altispinax, for it. M. oweni (Lydekker), from the British Upper Wealden, belongs to the same genus."

However, his characterisation of the genus (and reasoning for its separation from Megalosaurus) was contradictory for the fact, that none of the material that forms the hypodigms of Dames (1884b) or Lydekker (1888b, 1889b, 1890) for M. dunkeri and M. oweni Lydekker, 1889b includes vertebrae with tall neural spines (contra Olshevsky 1991: 22). It is also important to note, that in 1923 apparently von Huene has no doubt in referring the English material to M. dunkeri, following Lydekker's justification. In 1926 von Huene listed the material considered by Lydekker to $M$. dunkeri under this taxon name again and conluded, that if a series of three articulated dorsal vertebrae with elongated neural spines (NHMUK R1828) from the Wealden Group of England can once be proven to be conspecific with Lydekker's hypodigm, it should be removed from Megalosaurus as a new genus, Altispinax (von Huene 1926a: 77f., 1926b: 482f.). In this second approach, von Huene also expressed some doubts on the comparability of the English Wealden material to IGPM 1857 (esp. von Huene 1926b: 483) and explained that he refers "here" to Lydekker's material (esp. NHMUK R604, an assortment of two teeth and a few postcranial elements supposed to be found in association, Lydekker 1888b, 1890) instead of IGPM 1857. He even referred to the former incorrectly as "type-material" (von Huene 1926b: 483). Both, the conditional definition of Altispinax and the treatment of M. dunkeri by von Huene in 1926 were not in accordance with ICZN rules. He also did not further discuss the inclusion of M. oweni, he had referred to Altispinax in 1923 and apparently neither he nor Lydekker ever undertook a specimenbased comparison between IGPM 1857 and the English material.

What does this twisted history mean for the validity and definition of Altispinax?

The decision by Lydekker to deliberately create a hypodigm of largely unassociated, fragmentary material and to link it to a taxon based upon a single tooth of much different provenance, the reference to Lydekker by von Huene and the casual way in which he created and treated the genus 

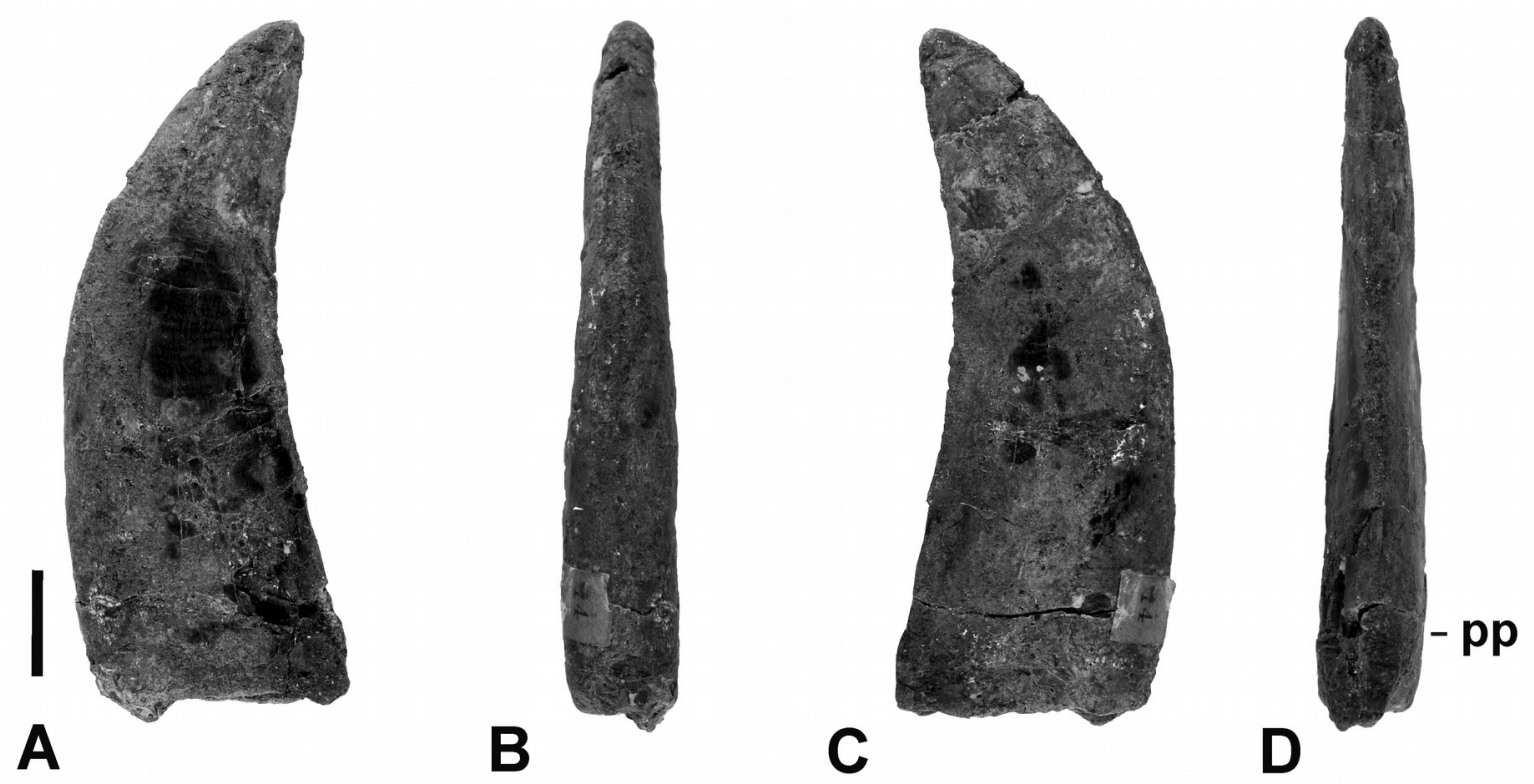

Fig. A.3 Altispinax dunkeri (Dames, 1884b), lateral tooth-crown, IGPM 1857 [HOLOTYPE]. Dachplatte bonebed, Obernkirchen Member; Obernkirchen. In (A) labial, (B) mesial, (C) lingual, and (D) distal aspect, pp palaeopathology (swelling and deformation of tooth base). Scale bar equals $10 \mathrm{~mm}$.

Altispinax led subsequently to some problems (Paul 1988, Molnar 1990, Olshevsky 1991, Rauhut 2000, Naish 2010).

However, despite violating some principles of application of the ICZN in the subsequent use, von Huene (1923) originally clearly specified what he conceived under Altispinax, i.e. "the species described as M. dunkeri by Lydekker (Dames)", and that "M. oweni (Lydekker) [...] belongs to the same genus".

The association of NHMUK R1828 with the material regarded to belong to M. dunkeri by Lydekker was therefore an original idea by von Huene and not by Lydekker (1888b, as claimed by Olshevsky 1991). However, he did not explain this concept before 1926 (von Huene 1926a, b) concurrently realizing that his linking of NHMUK R1828 with M. dunkeri in 1923 was not justified on irrefutable grounds, which is probably the reason why he tried to "reserve" Altispinax for M. dunkeri for an a posteriori application.

Nonetheless, von Huene's (1923) first establishment of Altispinax is definitely not a nomen nudum (contra Rauhut 2000). Von Huene clearly outlined his concept of the genus by defining its content (M. dunkeri, M. oweni) and referred to the definitions by Lydekker and Dames (both not including NMHUK R1828). Given his explicit statement "the species described as M. dunkeri by Lydekker (Dames)" further specified by "from the English (and German) Lower Wealden", his own incorrect and unjustified emendation regarding the tall neural spines is secondary in effect.

An error in the original definition does not render a taxon name available for subsequent use for different definitions as long as it does not qualify for being a nomen nudum (ICZN 1999) - in consequence any attempt to define the genus Altispinax based upon anything other (e.g. NHMUK R1828) than the holotype (IGPM 1857) and (currently non-existent) unequivocally referrable 
material of $M$. dunkeri Dames, $1884 \mathrm{~b}$ will necessarily create a nomen illegitimum. With respect to nomenclatorial stability, the adherence to original definitions (if they are sufficiently clear) is mandatory and the content of taxa may not be changed deliberately afterwards (as attempted by von Huene 1926b). This view apparently also guided Kuhn (1939), who righteously fixed M. dunkeri as type species of Altispinax, acting as first reviser. Therefore the creation of a new species, altispinax Paul, 1988, and its referral to a new genus, Becklespinax, for NHMUK R1828 by Olshevsky (1991) is justified (see also Naish 2010, contra Rauhut 2000). The same is true for Valdoraptor Olshevsky, 1991, established to contain Megalosaurus oweni Lydekker, 1889b, which was partly based upon diagnostic material (NHMUK 2559, Olshevsky 1991) with no direct stratigraphical, temporal or morphological overlap with B. altispinax or M. dunkeri.

Whether or not the genus name Altispinax should be applied to IGPM 1857 depends on the question whether it can be demonstrably distinguished from Megalosaurus. If this can be achieved, its oldest available synonym must be applied, i.e. Altispinax von Huene, 1923. Most authors mentioning this taxon expressed doubt whether this is possible at various degrees (Paul 1988, Olshevsky 1991, Rauhut 2000, Holtz et al. 2004, Carrano et al. 2012), however, generally referring to the short description by Dames (1884b) or the rather schematic figure by Koken (1887: pl. XXXI, fig. 2), often considering the holotype specimen lost.

The basal tetanuran genus Megalosaurus, as currently defined, only contain its type species, $M$. bucklandii Mantell, 1827 from the Middle Jurassic of England (Benson et al. 2008, Benson 2010). IGPM 1857 can be safely excluded from belonging to Megalosaurus on the basis of the presence of very fine, filiform, apico-basal striations where patches of the enamel surface is preserved. The enamel of M. bucklandii is smooth except for "transverse wrinkles" (Benson et al. 2008) common in tetanurans and also present in IGPM 1857. Otherwise the taxonomic meaning of these striae appear unclear: They are much finer than the enamel ridges present on teeth of Ceratosaurus spp. (Madsen 1976: fig. 9d, Madsen \& Welles 2000) or of some spinosaurids (e.g. Buffetaut 2011) and are only rarely figured or mentioned in theropod teeth. They are present at least in a large tooth from the Upper Jurassic of China (IVPP V 15310), which has been very tentatively related to the allosauroid genus Sinraptor Currie \& Zhao, 1993 by Xu \& Clark (2008). Other aspects in IGPM 1857 are more reminiscent of tyrannosauroids (e.g. Rauhut et al. 2010), dromaeosaurids (e.g. Currie et al. 1990), and some neovenatorids (Currie \& Azuma 2006), including the very strong labiolingual compression (crown base ratio [Smith et al. 2005] c. 0.41), flat to basally gently concave labial and lingual sides, and a relatively abrupt posterior recurving at about $50 \%$ of tooth-crown height. The denticles of the distal carina are very poorly preserved, the best examples are located near the apex (about 2.0 per $\mathrm{mm}$ ), they are labiolingually and apicobasally broad and slightly apically inclined. The interdenticular slits appear to be simple and straight. The mesial face of the tooth is strongly corroded, and, as already noted by Lydekker (1888b), therefore no conclusions can be drawn from the absence of a mesial carina.

A possible pathology appears to be present at the distal side of the bony tooth base, consisting of a callous swelling. This may be causally linked to an abnormality of the distal carina which reaches down to the base but sigmoidally curves gently first to the labial, then more distinctly to the lingual side along its basalmost $8 \mathrm{~mm}$ above the callus. 
Fig. A.4 Theropoda gen. \& sp. indet., manual phalanx III-2, GZG.BA.0098z. Artificial cast (only dorsal side of natural impression preserved). Obernkirchen Sandstone, Obernkirchen Member; Bückeberg or Harrl hill, leg. M. Ballerstedt. (A) Dorsal, (B) medial aspect. Scale bar equals $10 \mathrm{~mm}$.

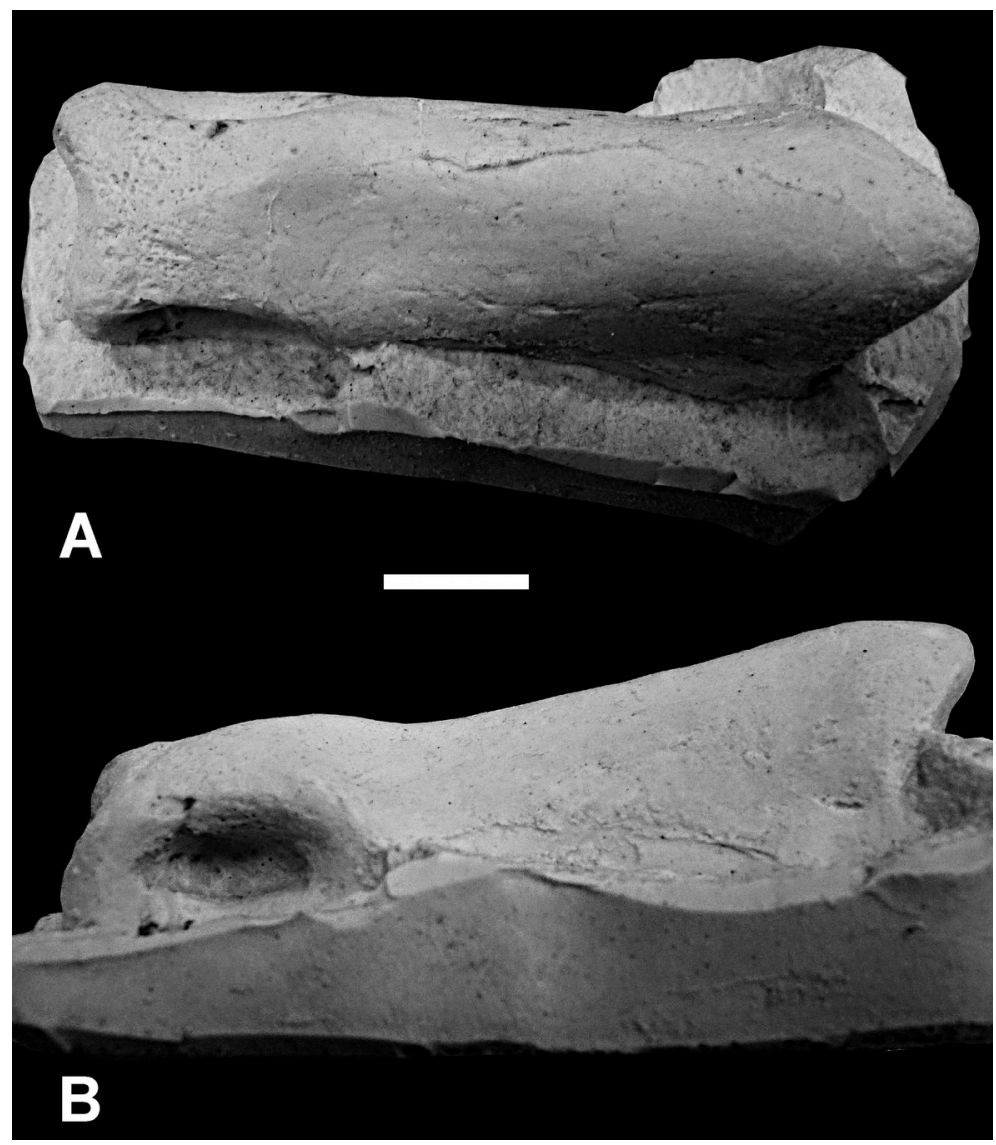

The abrupt recurvation at mid-crown height, as well as the enamel striae, distinguishes IGPM1857 from Dromaeosauroides bornholmensis Christiansen \& Bonde, 2003 from the late Berriasian of Bornholm, Denmark, based upon two isolated teeth (Christiansen \& Bonde 2003, Bonde 2012). However, despite their much smaller size (about 10-15\% of IGPM 1857 in height) the teeth associated with the holotype and a referred dentary of Nuthetes destructor Owen, 1854 (DORCM G913, NHMUK 48207, Milner 2002) from the Purbeck Limestone Group of southern England are quite similar in morphology to IGPM 1857. They are different in having more strongly recurved apices and smooth enamel. $N$. destructor is probably based upon juvenile specimens and the difference could be ontogeny related. However, until such a relationship is established based upon data evidence, both taxa should be kept separately.

Previous authors have stated the difficulties surrounding a diagnosis of $A$. dunkeri, and doubted on its validity, most explicitly Holtz et al. (2004) and Carrano et al. (2012), regarding it as a nomen dubium. However, the combination of characters stated above (enamel mesostructure and morphology) seem to be unique and may be suitable to diagnose the taxon. However its relationships to other theropods cannot be ascertained as its characters occur in various theropod clades (e.g. Carrano et al. 2012). Notably, the same problem concerns $N$. destructor, who was once referred to a lacertilian (Owen 1854), later to a megalosaurid (Owen 1861), redescribed as a dromaeosaurid (Milner 2002) and later discussed as a possible tyrannosauroid (Rauhut et al. 2010), or looping back to a basal tetanuran (Bonde 2012), a position closer to Owen's ideas. 
Altispinax dunkeri is therefore provisionally considered valid, but as a theropod incertae sedis.

Windolf (1998) noted a second, undescribed theropod tooth from the Bückeberg Formation (? Osterwald Member) near Sehnde, however, he made no comments on the whereabouts of this specimen and it was not located in any collection studied for this work.

(1) Obernkirchen Member, 'Dachplatte' bonebed.

(1.1) Uncertain exact locality near Obernkirchen, Lower Saxony.

IGPM 1857 - lateral tooth crown [HOLOTYPE, provenance erroneously reported to be "Deister" by Dames 1884b, clarified by original label, Fig. A.3] (Dames 1884b, Koken 1887, Lydekker 1888, von Huene 1923, 1926a, b, Molnar 1990, Olshevsky 1991, Holtz et al. 2004, Carrano et al. 2012).

\title{
Gen. \& sp. indet.
}

Remarks. A robust phalanx is very similar to the second phalanx in digit III of Allosaurus fragilis Marsh, 1877 (Madsen 1976: pls. 43-45). However, similar phalanges are known across a wide range of theropods and the specimen is therefore considered an indetermined theropod.

(2) Obernkirchen Sandstone, Obernkirchen Member.

(2.1) Bückeberg or Harrl hill, unknown specific locality, Lower Saxony.

GZG.BA.0098 - manual phalanx, probably III-2 [impr., leg. M. Ballerstedt, Fig, A.4].

\author{
Sauropodomorpha von Huene, 1932 \\ Sauropoda Marsh, 1878 \\ Macronaria Wilson \& Sereno, 1998 \\ Titanosauriformes Salgado et al. 1997
}

Brachiosauridae Riggs, 1903

\section{Gen. \& sp. indet.}

Remarks. An isolated, unworn tooth crown with damaged base shows traits of basal macronarian sauropod teeth, foremost a labiolingual compression of the lanceolate tip. The anterior margin bears a coarsely denticulated carina, a primitive trait among sauropods, Upchurch et al. (2004), and the axis is slightly twisted along its apico-basal axis. However, the concave lingual side is less deeply excavated, and the tooth crown is less compressed then in Camarasaurus spp. (e.g. Osborn \& Mook 1921) or derived brachiosaurids (Janensch 1935-36). It differs in the same characters from 
"Pleurocoelus valdensis" Lydekker, 1889b, a taxon based upon isolated teeth from the Early Cretaceous of England (Swinton 1962, Naish \& Martill 2001, Upchurch et al. 2011). It lacks also the tear-drop shape and recurved tip characteristical for Turiasauria (Royo-Torres \& Upchurch 2012). There is more congruence to Oplosaurus armatus Gervais, 1852, also based upon a single tooth from the Early Cretaceous of England (Naish \& Martill 2001, Upchurch et al. 2011), especially with respect to the convex labial face lacking distinct apico-basal grooves at least in the apical half. It differs however in a less concave lingual surface and the asymmetry in the distinctness of the mesial and distal carinae (which is much stonger and denticulated on the mesial side) and the enamel surface structure which is strongly wrinkled and even verrucous in places in contrast to the shiny, smooth enamel in 0 . armatus. Close similarities in morphology and surface structure exist to the teeth of Europasaurus holgeri Sander, Mateus, Laven \& Knötschke, 2006 from the Kimmeridgian of Lower Saxony (e.g. DMMh FV032), considered to be a basal macronarian (Sander et al. 2006) but found to be a basal brachiosaurid (D'Emic 2012).

Based upon the presence of denticles and a twisted apico-basal axis the specimen can be identified as a posterior maxillary tooth of a brachiosaurid (Chure et al. 2010, D'Emic 2012), a view supported by its similarity to teeth of E. holgeri.

(1) Osterwald Member.

(1.1) Unspecified locality near Sehnde, Lower Saxony [Region D].

NLMH 106.200 - fragm. unworn posterior maxillary tooth [ex coll. Dahl, Fig. A.5a-b].

Titanosauriformes Salgado et al. 1997

Gen. \& sp. indet.

Remarks. Five, slightly worn, caudal vertebral centra show at least one synapomorphy of Titanosauriformes (base of neurapophyses on the middle caudals shifted anteriorly, Salgado et al. 1997, Upchurch et al. 2004, D'Emic 2012), but do not allow for a more precise identification within this group.

(1) Osterwald Member.

(1.1) Mittelland Canal (near intersection with side canal to Hildesheim) near Sehnde, Lower Saxony [Region D].

RPMH unnumbered - five middle to distal caudal centra, probably from the same individual [collected in the 1920s, Fig. A.5c] (Windolf 1998). 

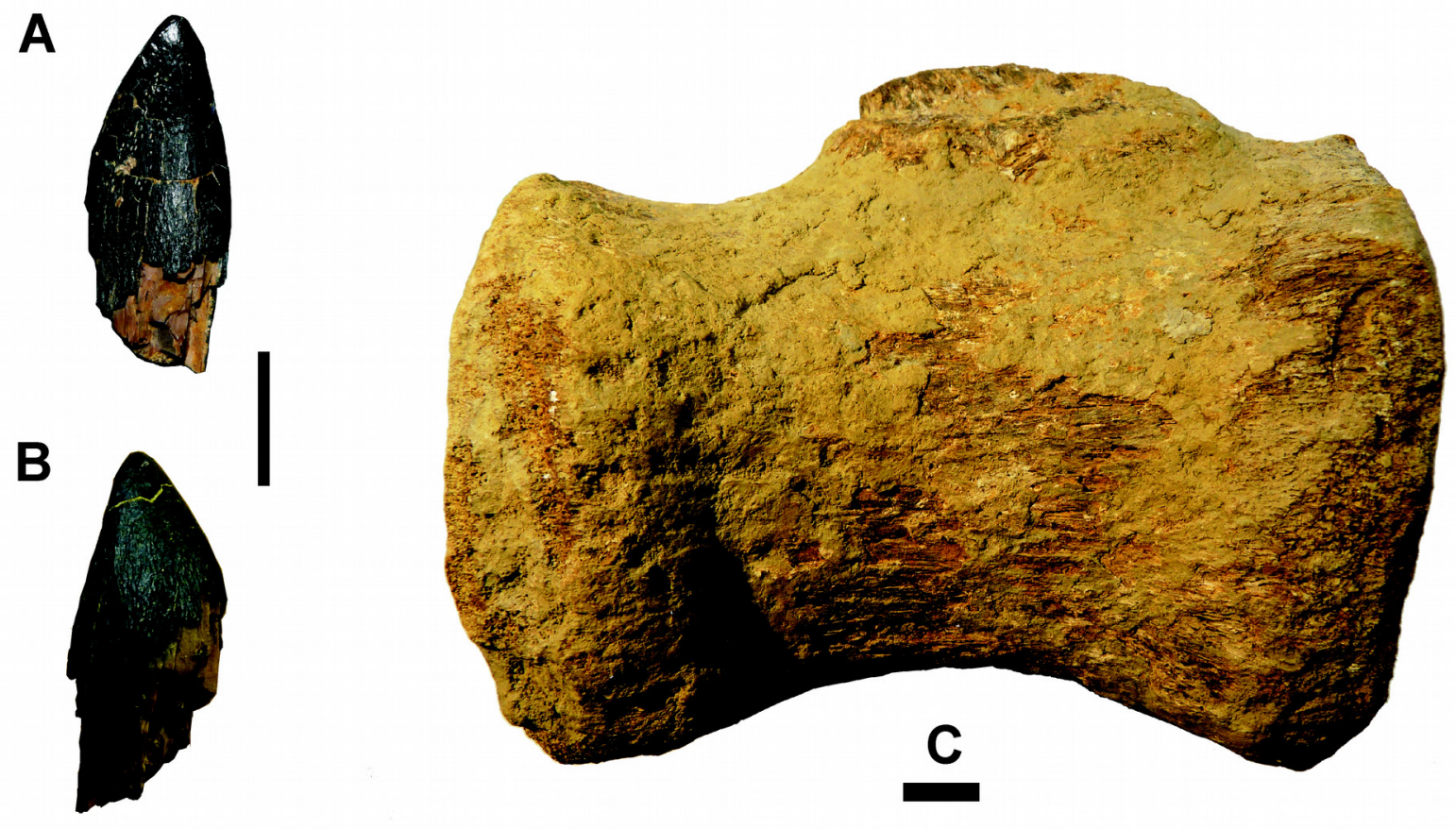

Fig. A.5 (A-B) Brachiosauridae indet., NLMH 106.200 maxillary tooth-crown in (A) lingual, and (B) labial aspect. Osterwald Member; Sehnde area, ex coll. Dahl. (C) Titanosauriformes indet., RPMH unnumbered, mid-caudal vertebral centrum, right lateral aspect. Osterwald Member; Mittelland Canal near Sehde. Scale bars equal $10 \mathrm{~mm}$.

\section{Macronaria indet.}

Remarks. A few fragmentary manus elements are very similar in morphology to those in Camarasaurus spp. and probably belong to a basal macronarian or a basal titanosauriform.

(1) Probably Osterwald Member.

(1.1) Unknown locality, most probably from the Osterwald Member of the Sehnde area, Lower Saxony [Region D].

GZG.STR.50213, GZG.STR.50214 - Two distal ends of metacarpals.

GZG.STR.50212 - Terminal manual phalanx (from one of digits II to V).

GZG.STR.50215 - fragm. terminal manual phalanx (from one of digits II to V)?

Ornithischia Seeley, 1888

Thyreophora Nopcsa, 1915

Ankylosauria Osborn, 1923 


\section{Hylaeosaurus Mantell, 1833 \\ ?Hylaeosaurus sp.}

Remarks. The material assigned to ?Hylaeosaurus sp. is described in detail in Chapter VII. It does not include the specimens described by Koken (1887), which are listed below as ?Ornithischia indet..

(1) Osterwald Member.

(1.1) Gerdemann clay pit, Gronau/Westfalen, Northrhine-Westphalia (Loc. A-1).

DLM 537 - osteoderm (right cervico-pectoral lateral spine) [Chapter VII, Fig. VII.3].

GPMM A3D.3 - partial right humerus [Chapter VII, Fig. VII.4] (Sachs 1997).

\section{Ornithopoda Marsh, 1881}

Iguanodontia Dollo, 1888

Remarks. The abundance of tracks referrable to large-bodied ornithopods in the Bückeberg Formation (and foremost the Obernkirchen Sandstone, Chapter IV), and a considerable degree of morphological variation among these tracks (e.g. Böhme et al. 2009, Chapter IV, and Appendix B) suggests a rich and diverse iguanodontian fauna. In contrast to the tracks, the osteological record of this group is much sparser. However, the few elements also show a range of characters supporting the presence of several taxa of iguanodontians in the Bückeberg Formation.

Ankylopollexia Sereno, 1986

Remarks. The left pubis GZG.BA.0099 is closely comparable to the corresponding element (e.g. McDonald 2011: fig. 5) in Camptosaurus dispar (Marsh, 1879). Important shared characters include a long, nearly straight, only very slightly dorsoventrally expanding prepubic process, a thickened, rounded dorsal margin in the posterior half of the prepubic process which is, in lateral aspect, posteroventrally confluent with the postpubic process in lateral and tapers ventrally to a thin blade. The medial surface is flat. As in $C$. dispar the postpubic process protrudes ventrolaterally from the pubic body and anteriorly to the ischiadic peduncle. The acetabular margin is formed by a thin, gently medially deflected plate of bone. Differences to $C$. dispar include the proportionally much longer and ventrally gently concave prepubic blade and the more robust, posterodorsally protruding iliac peduncle.

This element indicates the presence of a rather basal ankylopollexian in the Obernkirchen Sandstone. GZG.BA.0099 is plesiomorphic in retaining a separation of the base of the postpubic process from the ischiadic peduncle by a dorsally extending obturatoric foramen. This condition is present in Hypsilophodon foxii Huxley, 1869 (Galton 1974) and basal Iguanodontia: dryosaurids 
(Janensch 1955, Galton 1981), Tenontosaurus spp. (Foster 1990, Winkler et al. 1997). In the basalmost well-known styracosternan, Uteodon aphanoecetes (Carpenter \& Wilson, 2008) (McDonald, 2011), the postpubic process and the ischiadic peduncle share a common base, backsetting the obturatoric foramen ventrodistally with respect to the body of the pubis (Carpenter \& Wilson 2008: fig. 25). This trait is shared with many more derived styracosternans (e.g. Norman 1980, 2004, 2011, Horner et al. 2004, Paul 2007, Carpenter \& Ishida 2010), except for Mantellisaurus atherfieldensis (Hooley 1925) (Norman 1986, 2011). The distinct lateral off-set of the postpubic process from the main body of the pubis seems to be a character exclusively shared with $C$. dispar.

In conclusion GZG.BA.0099 probably indicates the presence of a primitive non-styracosternan ankylopollexian with affinities to the Late Jurassic $C$. dispar in the middle Berriasian of northern Germany. Alternatively, a mosaic-like distribution of primitive and derived characters in the poorly known iguanodontians of this time-span cannot be excluded and GZG.BA.0099 may belong to a more derived ankylopollexian which retained primitive traits in its pelvic architecture. Its size indicates a body length roughly comparable or slightly larger than C. dispar from Quarry 13 at Como Bluff, Wyoming (Morrison Formation), which reached about 6 m (Foster 2007).

Two terminal manual phalanges (GZG.STR.50216, GZG.STR.50280) resemble the reduced unguals in digits IV and V of $C$. dispar, and GZG.STR.50281 distal carpal IV in basal ankylopollexians.

\section{Gen. \& sp. indet.}

(1) Obernkirchen Sandstone, Obernkirchen Member

(1.1) Old comital quarry, Harrl hill, 1.7 km SE of Bückeburg, Lower Saxony [Loc. C-6]

GZG.BA.0099 - Partial left pubis (lacking most of the postpubic process) [impr., leg. M. Ballerstedt, 1921, mentioned in a letter to O. Abel, 2 Feb 1922 (cited after Karl \& Tichy 2004: 288f.), Fig. A.6a].

(2) Probably Osterwald Member.

(2.1) Unknown locality, most probably from the Osterwald Member of the Sehnde area, Lower Saxony [Region D].

GZG.STR.50216, GZG.STR.50280 - Two terminal manual phalanges (from digit IV or V).

GZG.STR.50281 - distal carpal IV.

\section{Styracosterna Sereno, 1986}

Remarks. The following ornithopod elements can be related to styracosternans with some confidence:

Two small, worn, ornithopod tooth-crowns are available from the Osterwald Member of the Sehnde region. They show general characteristics of ankylopollexian teeth: a squared cross-section of the base, mesially and distally grooved for the reception of the replacement teeth, a cingulum 


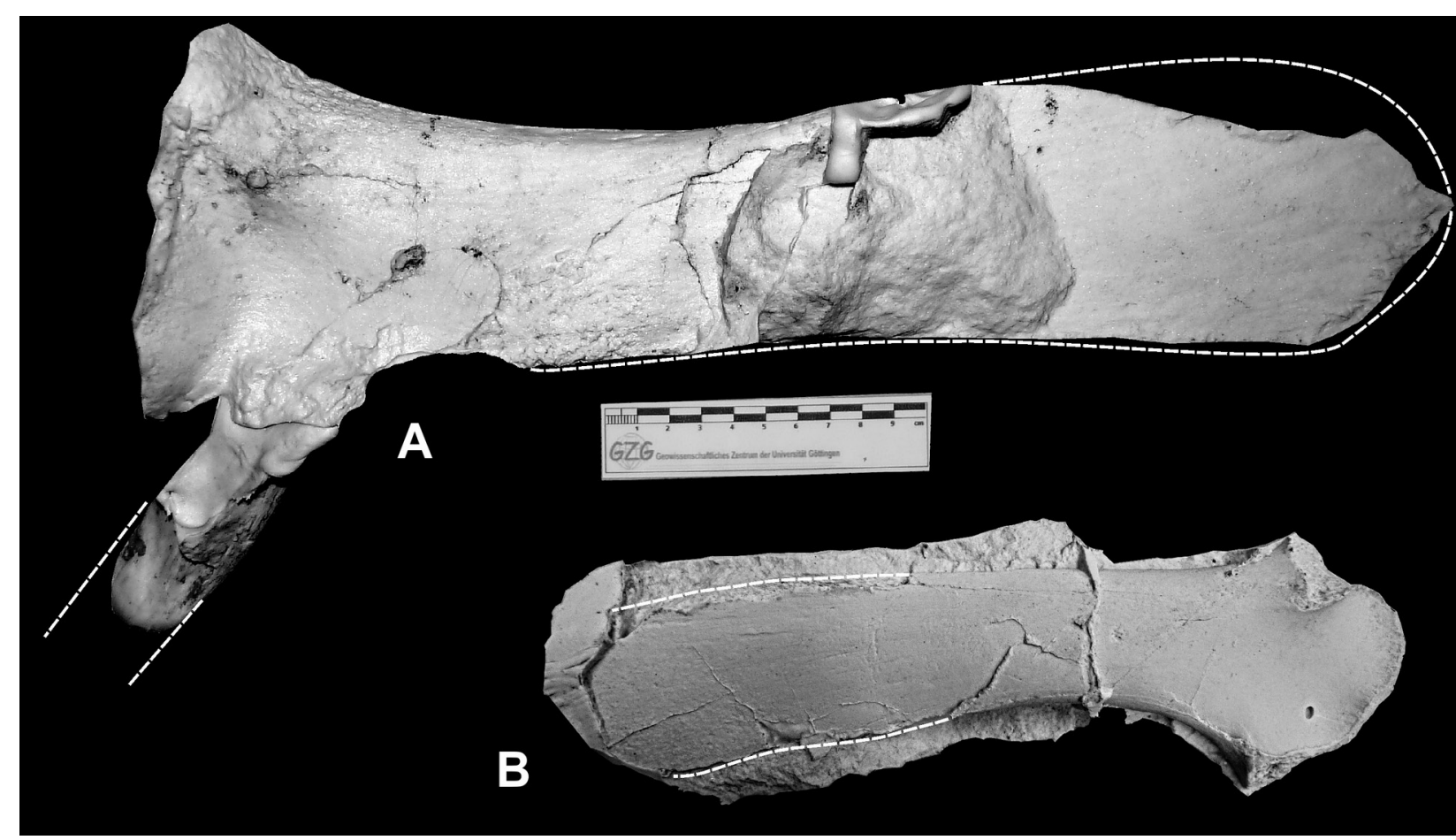

Fig. A.6 (A) Ankylopollexia indet., GZG.BA.0099z, left pubis, artificial cast of natural impression, medial aspect. Old comital quarry, Harrl hill (Loc. C-6); Obernkirchen Sandstone, Obernkirchen Member, leg. M. Ballerstedt 1921. (B) Styracosterna indet., GZG.BA.0097z, right scapula, artificial cast of natural impression, lateral aspect. Bückeberg or Harrl hill, Obernkirchen Sandstone, Obernkirchen Member, leg. M. Ballerstedt. Scale bar equals $10 \mathrm{~cm}$.

formed by the confluent mesial and distal labial edges, a mesiobasal ledge formed by an inrolled part of the mesiolabial edge of the tooth-crown, mesial and distal carinae with apically pointing, labiolingually directed, simple, tile-shaped denticles, a prominent primary ridge, dividing the labial face in two surfaces, which are angled to each other, and two to three thin accessory ridges mesially to the primary ridge. The tooth-crown is entirely covered by enamel. While most of these characters are plesiomorphic for ankylopollexians (Norman 2004), the presence of mesial and distal grooves for the reception of replacement teeth occurs in basal styracosternans (Cumnoria prestwichii [Hulke, 1880], Owenodon hoggii [Owen, 1874], Galton 2009, 2012, McDonald 2011), but not in Camptosaurus dispar (see Galton 1983, 2007). The teeth from Sehnde are therefore referred to Styracosterna. The better preserved specimen (RPMH unnumbered, Struckmann 1894) shows at least one character not known from other iguanodontians: The primary ridge is strongly distally displaced and recurved, so that it runs parallel to the curved distal edge of the tooth-crown. This is in contrast to the submedian, only gently recurved or straight primary ridge in other iguanodontians (Norman 2004). They differ further from Owenodon, the only other valid Berriasian - early Valanginian iguanodontian genus $(O$. hoggii based upon a dentary with teeth from the Purbeck Group, Dorset [NHMUK R.180], Norman \& Barrett 2002) by the presence of a secondary ridge in the latter (referred material of Owenodon sp. from the Berriasian-Valanginian of Cornet, Romania, Galton 2009, 2012). The second tooth-crown (GZG.STR.50295) is less well preserved and water-worn, the basic characters are the same as in the RPMH specimen though the recurvation of 
the primary ridge is not as distinct (more of the apical part is missing).

GZG.BA.0097 is a small (subadult?) right scapula with convex dorsal and concave ventral margins of the gently expanding scapular blade which terminates in a rounded tip and a dorsally projecting acromial process. These characters are found in many styracosternans including the basal U. aphanoecetes and Cumnoria prestwichii (Hulke, 1880) (Galton \& Powell 1980, Carpenter \& Wilson 2008, McDonald 2011).

A massive metatarsal II (GZG.BA.0092) closely resembles the same element (Norman 1980) in Iguanodon bernissartensis Boulenger, 1881 in morphology and size. An extensive rugosity along the proximal c. $60 \%$ of the lateral side of the bone and a small lip anterodistally to the proximal articular surface indicate a tight contact to metatarsal III. Closely attached metatarsals II-IV along most of their length is a diagnostic character of Styracosterna (Sereno 1986, Norman 2004).

A manual ungual of digit II (GZG.STR.50294) is referred to the Styracosterna based upon its dorso-ventral compression (see Norman 2004).

\section{Gen. \& sp. indet.}

(1) Obernkirchen Sandstone, Obernkirchen Member.

(1.1) Bückeberg or Harrl hill, unknown specific locality, Lower Saxony.

GZG.BA.0097 - right scapula [impr., leg. M. Ballerstedt, Fig. A.6b].

GZG.BA.0092 - left metatarsal II [impr., leg. M. Ballerstdt].

(2) Lowermost Osterwald Member.

(2.1) Unspecified locality near Sehnde, Lower Saxony [Region D].

RPMH unnumbered - worn right maxillary tooth-crown [originally preserved with root, (Struckmann 1894), which is missing today] (Struckmann 1894).

(3) Osterwald Member.

(3.1) Unspecified locality near Sehnde, Lower Saxony [Region D].

GZG.STR.50295 - worn left maxillary tooth-crown.

GZG.STR.50294 - fragm. manual ungual.

\section{Iguanodontia indet.}

Remarks. Fragmentary remains which cannot be referred with certainty to a subclade at present.

(1) Osterwald Member.

(1.1) Unspecified locality near Sehnde, Lower Saxony [Region D]. 
Fig. A.7 Styracosterna indet., maxillary tooth-crowns, labial aspect. (A) RPMH unnumbered, Sehnde area; bonebed near the base of Osterwald Member, original of Struckmann (1894), (B) GZG.STR.50295, Sehnde area; Osterwald Member. Scale bar equals $10 \mathrm{~mm}$.
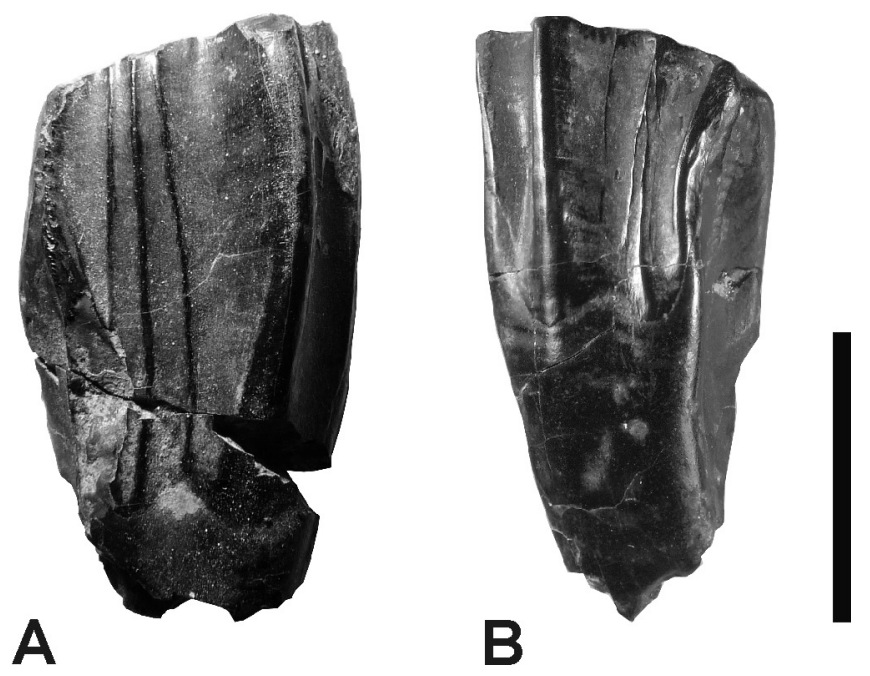

RPMH “Wd. 020" - dorsal centrum.

RPMH “Wd. 021" - mid-caudal centrum.

(2) Probably Osterwald Member.

(2.1) Unknown locality, most probably from the Osterwald Member of the Sehnde area, Lower Saxony [Region D].

GZG.STR.50279 - cervical centrum.

GZG.STR.50218 - distal caudal centrum.

\section{Marginocephalia Sereno, 1986}

Ceratopsia Marsh, 1890

Stenopelixidae Nopcsa, 1917

Remarks. The family Stenopelixidae was introduced by Nopcsa (1917: 211, as Stenopelyxidae, nom. corr. Kuhn 1966) for Stenopelix valdensis von Meyer, 1857. It was considered by him (Nopcsa $1917,1919)$ to belong to the Ceratopsia. The family was rarely cited by later authors, owing to the problematic phylogenetic position of $S$. valdensis. Cooper (1985) used it to include basal pachycephalosaurs but gave an inadequate diagnosis, based upon cranial characters which cannot be studied in the nominal genus. Kuhn (1966) and Olshevsky (1991) tentatively assumed a placement of $S$. valdensis in the Ceratopsia and conceived the Stenopelixidae as a possible synonym of Psittacosauridae Granger \& Gregory 1923.

Following a detailed study of the holotype (Butler \& Sullivan 2009), a cladistic analysis by Butler et al. (2011) found S. valdensis to be a basal ceratopsian, forming a clade with Yinlong downsi Xu et al. 2006 from the Late Jurassic of China. It is prudent to apply the name Stenopelixidae to this clade, representing the most basal ceratopsians, a placement very similar to the initial hypothesis by Nopcsa (1917). 


\section{Stenopelix von Meyer, 1857 \\ Stenopelix valdensis von Meyer, 1857}

(1) Obernkirchen Sandstone, Obernkirchen Member

(1.1) Old comital quarry, Harrl hill, 1.7 km SE of Bückeburg, Lower Saxony [Loc. C-6]

GZG.BA.0048 - nearly complete postcranial skeleton [old number GZG/GPIGö 741/2, leg. in 1855 (von Meyer 1857), Fig. III.2c-d] (von Meyer 1857, 1859, Koken 1887, Schmidt 1969, Sues \& Galton 1982, Windolf 1989, Gottmann 1999, Sullivan 2006, Butler \& Sullivan 2009).

\section{Ornithischia? Seeley, 1887}

Gen. \& sp. indet.

(= Hylaeosaurus sp. sensu Koken 1887)

Remarks. Koken (1887) reported two caudal centra from the Bückeberg Formation of Weenzen, which he referred to Hylaeosaurus sp., and figured the better preserved of both. This specimen is preserved at the NLMH, while the second is currently lost. The caudal centrum is poorly preserved and badly crushed. A referral to the Thyreophora, let alone to the genus Hylaeosaurus is not possible (compare also Pereda-Suberbiola 1993), while the overall morphology is reminiscent of thyreophorans as well as ornithopods. The specimen is therefore referred to as Ornithischia? indet.

(1) ?Osterwald Member.

(3.1) Duinger Wald near Duingen, Lower Saxony [Loc. C-15].

NLMH 105.502 - caudal vertebral centrum (Koken 1887).

\section{Dinosauria indet.}

Remarks. Indeterminate fragments.

(1) Obernkirchen Sandstone, Obernkirchen Member.

(1.1) Bückeberg or Harrl hill, unknown specific locality, Lower Saxony.

GZG.BA.0093a - fragm. thoracal rib [impr., leg. M. Ballerstedt].

GZG.BA.0621 - fragm. thoracal rib [impr., possibly fragment of same specimen as GZG.BA.0093a].

GZG.BA.0238 - fragm. thoracal rib [impr.]. 


\section{Dinosauria? indet.}

Remarks. Indeterminate fragments.

(1) Wealden 3-4, Obernkirchen Member.

(1.1) Abandoned mineshaft, Wackerfeld, Lower Saxony [Loc. C-22a].

GZG.STR.50210a-k - various bone fragments, incl. partial basicranium, jugal?, pterygoid?, thoracal rib, transversal process [leg. W. Grabbe].

GZG.STR.50211 - neurapophysis [probably belonging to GZG.STR.50210, but no detailed label available].

References on p. 364. 
Appendix B

Spatial and temporal distribution of archosaur fossils in the Bückeberg Formation 


\section{Appendix B: Spatial and temporal distribution of archosaur fossils in the Bückeberg Formation}

\section{Geographical distribution}

Geographically, the occurrence of archosaur fossils in the Bückeberg Formation is mostly determined by the distribution of outcrops across the northern German lowland. Over most of its distribution, the Bückeberg Formation is covered by younger sediments. Its isolated exposures are related to tectonically uplifted areas, which are connected to uprising salt structures. By the occurrence of archosaur fossils (bones and tracks), four areas of exposure across North-Rhine Westphalia and Lower Saxony are defined here (Regions A to D, Fig. B.1).

Region A: Gronau in Westfalen

A small occurrence of the upper Bückeberg Formation was exploited in the northwest of the town of Gronau in Westfalen, North-Rhine Westphalia, for brickwork clays. It has yielded a diverse vertebrate fauna, including archosaurs.

\section{Locality A-1: Abandoned Gerdemann clay-pit, Gronau in Westfalen}

Stratigraphy: Wealden 5-6, Osterwald Member, upper Bückeberg Formation, lowermost Valanginian.

Archosaur fauna: Ankylosauria (?Hylaeosaurus sp.), Goniopholididae indet.

Remarks: See Chapter VII for more details and references.

\section{Region B: Osnabrück region}

Intercalated sandstones in the Bückeberg Formation have been described by Riegel \& Lill (1988), Lill \& Riegel (1991), and Wilde \& Schultka (1996) as a local delta prograding in to the Lower Saxony Basin. Surface exposures and fossils are rare.

Locality B.1: Field near Hilter-Borgloh

Stratigraphy: Bückeberg Formation, Berriasian - lowermost Valanginian.

Archosaur fauna: Iguanodontia indet. (isolated footprint).

Reference: Anonymous (2005).

Fig. B.1: Geographical distribution of archosaur localities in the Bückeberg Formation. Geological information in Fig. B.1b after LBEG (2013). 

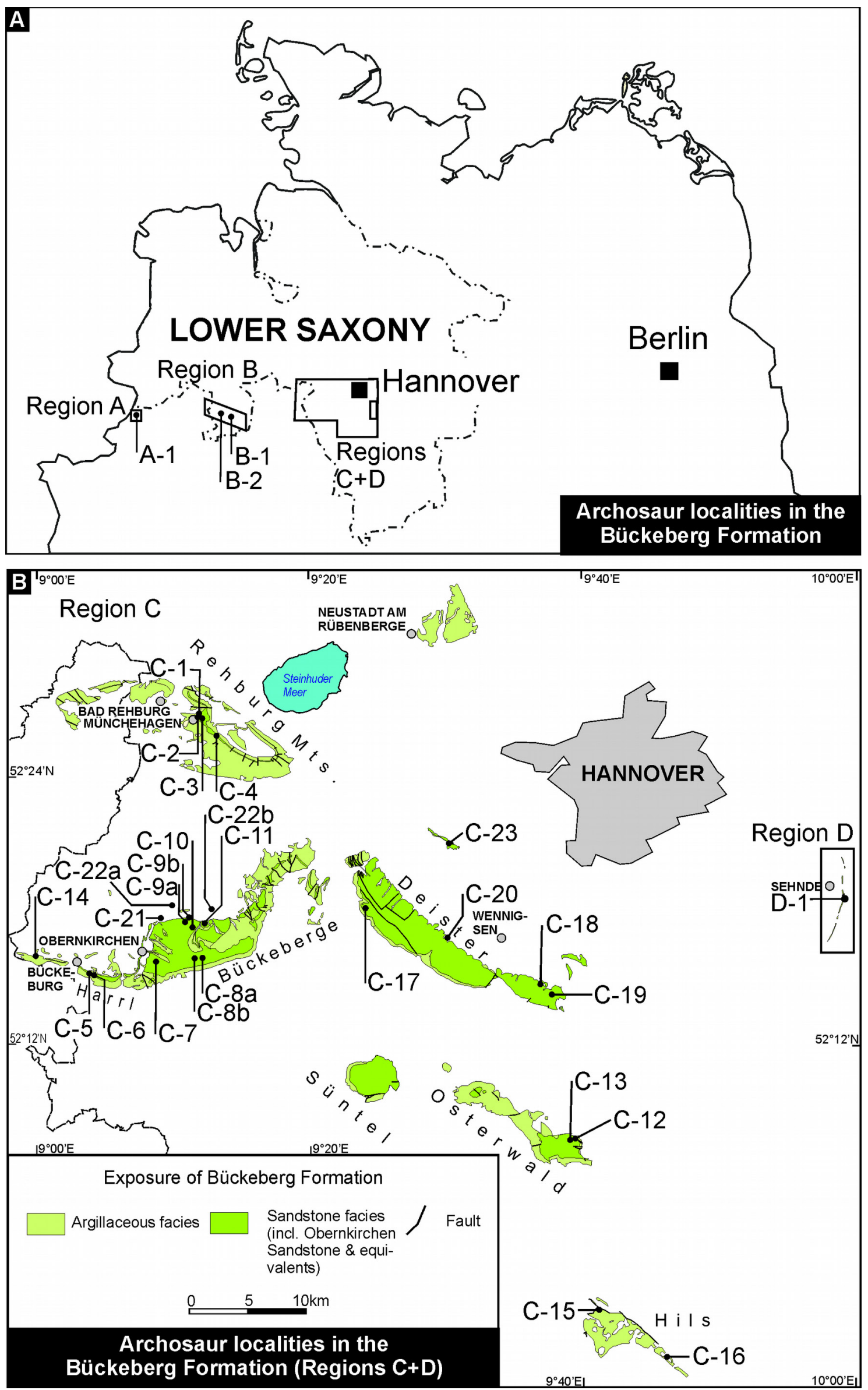
Stratigraphy: Bückeberg Formation, Bückeberg Formation, Berriasian - lowermost Valanginian. Archosaur fauna: Goniopholididae indet.

References: Koken (1887), Salisbury et al. (1999).

Region C: Mountainous areas between the River Weser and Hannover

The main surface exposure area of the Bückeberg Formation and the type region of the Obernkirchen Sandstone and its lateral equivalents. Outcrops occur in the Rehburg Mountains, the Bückeberge, the Harrl hill, the Deister, Süntel, Osterwald, Nesselberg, and Hils mountains. Due to economic reasons, most outcrops occur in the relatively thin sandstone units and the associated coal measures, while the much thicker claystone facies is far less frequently exposed.

Locality C-1: F. Wesling GmbH quarry, Münchehagen

Stratigraphy: Obernkirchen Sandstone (Rehburg Sandstone), Obernkirchen Member, Bückeberg Formation, upper Berriasian.

Archosaurs fauna: Ornithopoda indet. (tracks), Theropoda indet. (tracks).

References: See Chapter IV; Wings et al. (2012).

Locality C-2: Dinosaurier-Park Münchehagen open-air museum (abandoned quarry), Münchehagen

Stratigraphy: Obernkirchen Sandstone (Rehburg Sandstone), Obernkirchen Member, Bückeberg Formation, upper Berriasian.

Archosaurs fauna: Sauropoda inc. sed. (Rotundichnus muenchehagensis = Brontopodus isp., tracks), tridactyl tracks of unidentified biped.

References: See Chapter IV.

Locality C-3: Stadtländer quarry, Münchehagen

Stratigraphy: Obernkirchen Sandstone (Rehburg Sandstone), Obernkirchen Member, Bückeberg Formation, upper Berriasian.

Archosaurs fauna: Ornithopoda (tracks).

References: See Chapter IV.

Locality C-4: Wölpinghäuser Berg, Wölpinghausen

Stratigraphy: Obernkirchen Sandstone (Rehburg Sandstone), Obernkirchen Member, Bückeberg Formation, upper Berriasian.

Archosaurs fauna: Ornithopoda (tracks), Theropoda (tracks).

References: See Chapters II, IV, V.

Locality C-5: Abandoned quarry on the western side of Harrl hill, Bückeburg

Stratigraphy: Obernkirchen Sandstone, Obernkirchen Member, Bückeberg Formation, upper Berriasian. 
Archosaur fauna: Dinosauria (tracks, trampled horizon), ?Ornithopoda (tracks).

References: See Chapters III, IV.

Locality C-6: Hexenteich quarry (old comital quarry, abandoned), Harrl hill, Bückeburg

Stratigraphy: Obernkirchen Sandstone, Obernkirchen Member, Bückeberg Formation, upper Berriasian.

Archosaur fauna: Crocodylia (Pholidosaurus schaumburgensis, Goniopholis simus, Theriosuchus n. sp.), Ankylosauria (tracks, incl. Metatetrapous valdensis), Ornithopoda (Iguanodontia indet: tracks and skeletal remains), Ceratopsia (Stenopelix valdensis), Theropoda (tracks: „Bueckeburgichnus“ maximus).

References: See Chapters III, IV.

Locality C-7: Schauenstein glass factory, abandoned and infilled quarry, Obernkirchen)

Stratigraphy: Obernkirchen Sandstone, Obernkirchen Member, Bückeberg Formation, upper Berriasian.

Archosaur fauna: Ornithopoda (Iguanodontia indet: tracks).

Remarks: This outcrop is no longer existent. Dietrich (1927) conducted excavations there, collecting a large number of ornithopod footprints, including a supposedly tetradactyle morphotype, which was later named Wealdenichnites iguanodontoides by Kuhn (1958). The material was stored for a long time in the private museum of the quarry operator, the Heye glass factory. However, this museum was disbanded when the Heye company was sold to an international investor in the late 1990s, and Dietrich's material has been saved only partially through the efforts of the late R. B. de Groot, Obernkirchen. This is now (early 2013) partially housed at the GZG, Göttingen, which will take over the whole remainders of the material. The supposed ichnoholotype of $W$. iguanodontoides is not yet identified among the material, and it is possible that it is lost forever.

References: See Chapter IV.

C-8a: Obernkirchener Sandsteinbrüche GmbH quarry, Bückeberge, Obernkirchen

Stratigraphy: Obernkirchen Sandstone, Obernkirchen Member, Bückeberg Formation, upper Berriasian.

Archosaur fauna: Crocodylia (Pholidosaurus schaumburgensis), Ornithopoda (Iguanodontia indet: tracks, several morphotypes), Theropoda (tracks: several morphotypes).

References: See Chapter IV, Raddatz et al. (2012), Richter et al. (2012).

\section{C-8b: Abandoned old quarries, Bückeberge, Obernkirchen}

Stratigraphy: Obernkirchen Sandstone, Obernkirchen Member, Bückeberg Formation, upper Berriasian.

Archosaur fauna: Crocodylia (Goniopholis simus).

Remarks: A number of small quarries were operated during the $19^{\text {th }}$ century ca. $1-2 \mathrm{~km}$ southwest to the modern quarry. Today abandoned and largely refilled, they have produced several early finds of vertebrates. 
C-9a: „Dreier's quarry“, Nienstädt (abandoned, exact locality unknown)

Stratigraphy: Obernkirchen Sandstone, Obernkirchen Member, Bückeberg Formation, upper Berriasian.

Archosaur fauna: Dinosauria (tracks: tridactyl biped).

Remarks: Exact location unknown.

References: See Chapter IV.

C-9b: Infilled, unnamed quarry, c. $0.6 \mathrm{~km}$ NE of Liekwegen

Stratigraphy: Obernkirchen Sandstone, Obernkirchen Member, Bückeberg Formation, upper Berriasian.

Archosaur fauna: Dinosauria (tracks: tridactyl biped).

Remarks: The site is completely filled-up today. It is possible that this location is identical with location C-9a. Jürgens (1972) reported "iguanodontid" tracks in situ from this locality.

References: Jürgens (1972).

\section{C-10: Brandshof quarry, Liekwegen}

Stratigraphy: Obernkirchen Sandstone, Obernkirchen Member, Bückeberg Formation, upper Berriasian.

Archosaur fauna: Ornithopoda (Iguanodontia: tracks), Theropoda (tracks).

Remarks: Since the publication of Chapter IV (early 2012), a theropod track has been found in situ in this locality which formerly only historical accounts of ornithopod tracks were known.

References: See Chapter IV.

\section{C-11: „Maier's quarry“, Wendthagen}

Stratigraphy: Obernkirchen Sandstone, Obernkirchen Member, Bückeberg Formation, upper Berriasian.

Archosaur fauna: Dinosauria (tracks: biped).

Remarks: Exact location unknown, the first oral reports of dinosaur tracks were from here (c. 185060).

References: See Chapter IV.

\section{C-12: Vicinity of Ahrensberg, Osterwald Mountains}

Stratigraphy: Upper(?) Obernkirchen Member, Bückeberg Formation, upper(?) Berriasian. Archosaur fauna: Ornithopoda (Iguanodontia: tracks), Theropoda (tracks).

References: See Chapter IV.

\section{C-13: Kaiserblick, Osterwald Mountains}

Stratigraphy: Upper(?) Obernkirchen Member, Bückeberg Formation, upper(?) Berriasian. Archosaur fauna: Ornithopoda (Iguanodontia: tracks).

References: See Chapter IV. 
C-14: Unspecified coal mine near Minden

Stratigraphy: „Coal seam no. 4“, Bückeberg Formation, upper Berriasian.

Archosaur fauna: Crocodylia (Goniopholis sp.).

C-15: Duinger Wald, near Duingen, Hils mountains

Stratigraphy: Proximal sandstones, ?Obernkirchen Member, Bückeberg Formation, upper Berriasian - lowermost Valanginian.

Archosaur fauna: Crocodylia, Dinosauria.

References: Koken (1887).

C-16: Abandoned quarry, SE of Hohenbüchen, Hils mountains

Stratigraphy: Proximal sandstones, ?Obernkirchen Member, Bückeberg Formation, upper Berriasian - lowermost Valanginian.

Archosaur fauna: Crocodylia (Goniopholididae, Pholidosauridae).

C-17: Abandoned quarry at Rodenberger Höhe, c. 3 km ESE Rodenberg, Deister Mountains

Stratigraphy: Proximal sandstones, ?Obernkirchen Member, Bückeberg Formation, upper Berriasian - lowermost Valanginian.

Archosaur fauna: Dinosauria (tracks: tridactyl biped).

Remarks: Jürgens (1972) reported "iguanodontid" tracks in situ from this locality.

References: Jürgens (1972).

C-18: Uncertain locality, c. 1.5 km SSE of Wennigsen-Bredenbeck, Deister Mountains

Stratigraphy: Proximal sandstones, ?Obernkirchen Member, Bückeberg Formation, upper Berriasian - lowermost Valanginian.

Archosaur fauna: Ornithopoda (Iguanodontia: footprint).

Remarks: A single ornithopod hypichnium that was first mentioned by Windolf \& Held [1992, publication was not available] and kept in a local museum in Bredenbeck [0. Schirmer, pers. com. 2012/2013].

C-19: Vicinity of abandoned Grüner Weg coal mine, c. 1 km SW of Steinkrug, Deister Mountains Stratigraphy: Proximal sandstones, ?Obernkirchen Member, Bückeberg Formation, upper Berriasian - lowermost Valanginian.

Archosaur fauna: Crocodylia.

Remarks: Specimens located at NLMH, information kindly provided by O. Schirmer [pers. com. 2013].

\section{C-20 Uncertain locality near Egestorf, Deister Mountains}

Stratigraphy: Proximal sandstones, ?Obernkirchen Member, Bückeberg Formation, upper Berriasian - lowermost Valanginian.

Archosaur fauna: Crocodylia. 


\section{C-21: Uncertain locality near, Sülbeck, c. $1 \mathrm{~km}$ W of Nienstädt}

Stratigraphy: Upper Obernkirchen Member, Bückeberg Formation, upper Berriasian.

Archosaur fauna: Crocodylia.

References: Koken (1887).

\section{C-22: Abandoned coal mineshafts near Wackerfeld (a), and Krebshagen (b)}

Stratigraphy: Upper Obernkirchen Member, Bückeberg Formation, upper Berriasian.

Archosaur fauna: Crocodylia, Dinosauria.

\section{C-23 Uncertain locality near Stemmen}

Stratigraphy: Proximal sandstones, ?Obernkirchen Member, Bückeberg Formation, upper Berriasian - lowermost Valanginian.

Archosaur fauna: Crocodylia.

\section{Region D: Sehnde area}

In the area of Sehnde, southeast of Hannover, Jurassic and Cretaceous rocks are exposed mostly along a narrow strip west to the uplifted, N-S trending Sarstedt-Lehrte salt structure (Bettenstaedt \& Dietz 1957). From Jurassic and Lower Cretaceous strata, mostly brickwork clays have been quarried in a number of small outcrops, which are often highly fossiliferous. Another exposure was provided by construction of the Mittelland Canal in the 1920s and subsequent modifications of the canal in the following decades. These outcrops vanished in the second half of the $20^{\text {th }}$ century.

The Bückeberg Formation was first recognised by Römer (1874, as „Weald“) in this area and has been described to the most extent by Struckmann (1891) and Hoyer (1902).

In the Sehnde area, the Bückeberg Formation has a reduced thickness of ca. 30-60 m, overlying the Middle Jurassic (Aalenian) with an onlaping basal contact. The succession comprises the Wealden 5 and 6 (Osterwald Member, lowermost Valanginian), and an upper Wealden 4 age has been questionably brought into consideration for the most basal beds (Dietz 1973). It is therefore clear that the onlaping geometry is related to the major transgression within the Lower Saxony Basin near the base of Wealden 5, which can also be traced elsewhere (Pelzer 1998). The underlying stratigraphic gap indicates that, before this rise in waterlevel, the region belonged to the emergent Hildesheim Peninsula, a northern promontory of the Central German Rise which bounded the Hils Embayment to the E. The succession seems to have been laterally quite variable, which is aggravated in places by the extensive subsequent faulting due to salt tectonics. However, generally a threefold sequence was described (Struckmann 1891, Hoyer 1902) with a basal argillaceous, partly sideritic and marly unit, interbedded by thin coquinas, followed by a succession of fine-grained sandstones, partly calcareous and Fe-rich, in some beds with coalified wood and plant remains and coarser material (including small quartz pebbles). The upper section consists predominantly of (marly) claystones and thin limestones with few interbedded sandstones. The lack of extant outcrops hampers a detailed interpretation, however, the sequence indicates an initial transgressive phase with strongly reduced sedimentation rates over the pre-Cretaceous basement, followed by a 
highstand phase with establishment of a littoral sandy depositional system, which was clearly influenced by terrestrial input. It was followed by a new transgressive tract, possibly after a lowstand represented by a thin, residual conglomeratic sandstone (described by Hoyer 1902 from Lühnde and elsewhere). This transgression may mark the base of Wealden 6 .

The invertebrate and vertebrate fauna was generally rich, indicating overall brackish conditions. In some layers of the sandstones, oysters (Exogyra sp.) form abundant, mass-occurrences unknown from deeper levels in the formation. Vertebrate remains occur in the whole succession, but they may be concentrated in bonebeds. Most reknown is the basal bonebed from near the base of the succession (e. g. Struckmann 1891, Strebost et al. 1992), which was sampled by Göttlich (2003). He found teeth of hybodontoid sharks, ginglymodian actinopterygians (either of the genus Callipurbeckia or Scheenstia, formerly „Lepidotes“, Lopez-Arbarello 2012, and possibly of macrosemiids) and possibly of teleosteans (?Leptolepididae, ?Ichthyodectiformes). Among reptiles he recognised teeth of Goniopholis sp., however, the fragmentary tooth-crown right on his fig. 17 is more reminiscent of a pholidosaurid. Many other remains may in historical collections may be also from this bonebed. Interestingly, Göttlich (2003) found also two fragmentary belemnite rostra which he identified as to belong to the Cretaceous genus Acrotheutis. However, the specimens are poorly preserved, worn, and cannot be distinguished from several Jurassic belemnite genera, e.g. Holcobelus (see e. g. Mariotti et al. 2007). Given the fact that cephalopods are generally absent from the euryhaline Osterwald Member (Kemper 1961), and reworked Jurassic fossils have been reported from the basal layers of the Bückeberg Formation at Sehnde (Struckmann 1891), it is considered that these belemnites also originate from the Aalenian or older Jurassic strata underlying the Lower Cretaceous.

Windolf (1998) mentioned a number of supposed dinosaur fossils from the Sehnde area located at the RPMH or in private collections. They are reconsidered in Appendix A. However, what he recognised as sauropod caudal vertebrae were in fact partially cervical and dorsal vertebrae of a plesiosaur.

Vertebrate fossils from Sehnde are present in a number of historical collections now housed in the $\mathrm{NLMH}, \mathrm{RPMH}$, and GZG. All material is fragmentary, disarticulated, and often lacks a more precise locality information than "Wealden, Sehnde“. When it is given more precisely, it often refers to the now abandoned and water-filled Gretenberg [I] clay-pit, ca. $2 \mathrm{~km} \mathrm{SE}$ of Sehnde. However, other pits and outcrops also existed in the area (all refilled or water-filled today) and may have produced also vertebrate fossils. Due to the detailed lithological descriptions by Struckmann (1891) specimens can be in some cases more closely referred stratigraphically by its color or matrix lithology.

\section{D-1: Gretenberg I clay-pit, Sehnde}

Stratigraphy: Osterwald Member, Bückeberg Formation, lowermost Valanginian.

Archosaur fauna: Crocodylia (Goniopholididae., Pholidosauridae, Atoposauridae, Hylaeochampsidae), Ornithopoda (Iguanodontia). From the wider Sehnde area also Sauropoda (Macronaria) and Pterosauria.

Remarks: A large amount of specimens from the Sehnde area may originate from this prolific locality, although the they often lack detailed documentation. 


\section{Stratigraphic and facies distribution of archosaurs in the Bückeberg Formation}

Figure B.2 summarizes the known stratigraphic and facies record of major archosaur groups throughout the Bückeberg Formation. As it becomes clear, there are two abundance maxima: a lower in the upper Berriasian Obernkirchen Sandstone and an upper in the lowermost Valanginian Osterwald Member. At least at the level of major groups there appears to be no conspicuous stratigraphic seperation, while the material is generally insufficient to evaluate this at lower taxonomic levels.

Diversity and abundance maxima are concentrated in the peripheral areas of the basin near shorelines and in deltaic deposits. An exemption is given in the presence of terrestrial and semiaquatic taxa in the basinal facies of Wealden 5-6 in Region A, which may be related to subaqueous density flows transporting skeletal remains deeper into the basin. The underrepresentation of archosaur remains from the basinal facies is probably related to low sedimentation rates and longer transport distances for terrestrial animals. However, especially in Region $\mathrm{C}$ a sampling bias also plays an important role, as the deltaic sandstones and interbedded coals were and are more intensively quarried than the argillaceous facies. Specimens from the latter are also often problematic in their stratigraphic assessment as only micropaleontological analyses would be necessary to clarify their position in the lithologically rather monotonous succession. The same is true for the most proximal deposits, consisting of peri-fluvial sediments in the southern part of Region C, whose stratigraphic relationships to the more distal successions are mostly only insufficiently known.

Fig. B.2 Stratigraphical and facies distribution of major archosaur groups in the Bückeberg Formation. See Chapter I for sources on stratigraphy and lithofacies. 


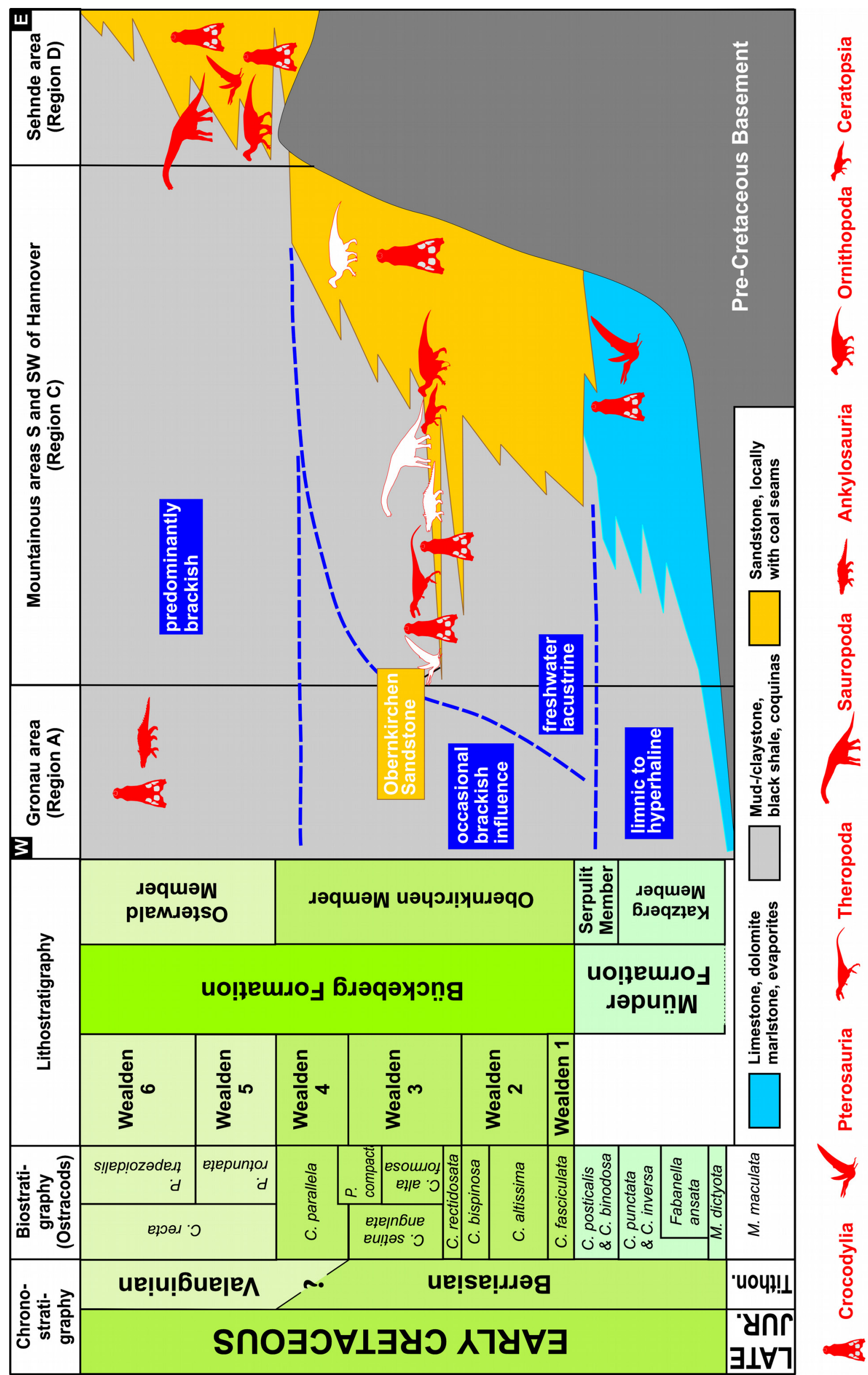




\section{References for Chapter XI, Outlook, and Appendices}

Abel, 0. 1935. Vorzeitliche Lebensspuren. Jena: Fischer, xv+664 pp.

Abbink, O., Targarona, J., Brinkhuis, H. \& Visscher, H. 2001. Late Jurassic to earliest Cretaceous palaeoclimatic evolution of the southern North Sea. Global and Planetary Change, 30(3-4): 231-256.

Agnolin, F. \& Varricchio, D. 2012. Systematic reinterpretation of Piksi barbarulna Varricchio, 2002 from the Two Medicine Formation (Upper Cretaceous) of Western USA (Montana) as a pterosaur rather than a bird. Geodiversitas 34(4): 883894.

Alcalá, L., Cobos, A., Espílez, E., Gascó, F., Mampel, L., Escorza, C. M. \& Royo-Torres, R. 2012. Icnitas de dinosaurios en la Formación Villar del Arzobispo de Ababuj (Teruel, España). Geogaceta, 51: 35-38.

Allain, R. \& Pereda Suberbiola, X. 2003. Dinosaurs of France. Comptes Rendus Palevol, 2(1): 27-44.

Allain, R., Taquet, P., Battail, B, Dejax, J., Richir, P., Véran, M., Limon-Duparcmeur, F., Vacant, R., Mateus, O., Sayarath, P., Khenthavong, B., \& Phouyavong, S. 1999. Un nouveau genre de dinosaure sauropode de la formation des Grès supérieurs (Aptien-Albien) du Laos. Comptes Rendus de l'Académie des Sciences, Sciences de la Terre et des Planètes, 329(8): 609-616.

Allain, R., Xaisanavong, T., Richir, P., \& Khentavong, B. 2012. The first definitive Asian spinosaurid (Dinosauria: Theropoda) from the early cretaceous of Laos. Naturwissenschaften, 99(5): 369-377.

Allen, P. 1998. Purbeck-Wealden (Early Cretaceous) climates. Proceedings of the Geologists' Association, 109: 197-236.

Allen, P. \& Wimbledon, W. A. 1991. Correlation of NW European Purbeck-Wealden (nonmarine Lower Cretaceous) as seen from the English type-areas. Cretaceous Research, 12(5): 511-526.

Amiot, R., Buffetaut, E., Lécuyer, C., Wang, X., Boudad, L., Ding, Z., Fourel, F., Hutt, S., Martineau, F., Medeiros, A., Mo, J., Simon, L., Suteethorn, V., Sweetman, S., Tong, H., Zhang, F., \& Zhou, Z. 2010. Oxygen isotope evidence for semi-aquatic habits among spinosaurid theropods. Geology, 38(2): 139-142.

Andrade, M.B. de \& Hornung, J.J. 2011. A new look into the periorbital morphology of Goniopholis (Mesoeucrocodylia: Neosuchia) and related forms. Journal of Vertebrate Paleontology, 31(2): 352-368.

Andrade, M.B. de, Edmonds, R., Benton, M.J. \& Schouten, R. 2011. A new Berriasian species of Goniopholis (Mesoeucrocodylia, Neosuchia) from England, and a review of the genus. Zoological Journal of the Linnean Society, 163: S66-S108.

Andrews, C.W. 1913. On the skull and part of the skeleton of a crocodile from the Middle Purbeck of Swanage, with the description of new species (Pholidosaurus laevis), and a note on the skull of Hylaeochampsa. Annals and Magazine of Natural History, 8: 485-494.

Ansorena, P., Diaz-Martinez, I. \& Perez-Lorente, F., 2008. Mina Victoria(Navajun) y valdeperillo (Cornago). Nuevos yacimentos de ichnitas de dinosaurio en el grupo de Urbion (Cuenca de Cameros, La Rioja, España). Zubia, 25-26: 7596.

Arp, G. \& Mennerich, C. 2008. Ostracod associations, palaeoenvironment and cyclicity of Purbeck-type sediments of the 
Münder Formation (Lower Cretaceous, Hils Syncline, N-Germany). In: Mischke, S. \& Holmes, J. A. (eds.): Applications of lacustrine and marginal-marine Ostracoda to palaeoenvironmental reconstruction, $15^{\text {th }}$ International Symposium on Ostracoda. Palaeogeography, Palaeoclimatology, Palaeoecology, 246(3-4): 230-249.

Aurell, M. \& Meléndez, A. 1993. Sedimentary evolution and sequence stratigraphy of the Upper Jurassic in the Central Iberian Chain, northeast Spain. International Association of Sedimentologists, Special Publication, 18: 343-368.

Austen, P. A. \& Batten, D. J. 2011. Plant Megafossils. In: Batten, D.J. (ed.): English Wealden fossils. Palaeontological Association Field Guide to Fossils: Number 14: 596-642, London: The Palaeontological Association.

Austen, P. A., Brockhurst, D. \& Honeysett, K. 2010. Vertebrate fauna from Ashdown Brickworks, Bexhill, East Sussex. Wealden News, 8: 13-23.

Avanzini, M., Piñuela, L. \& Garcia-Ramos, J.C. 2010. Preservational morphotypes of Crocodylopodus from the Late Jurassic of Asturias (Spain). New Mexico Museum of History and Science Bulletin, 51: 239-244.

Averianov, A. 0. 2000. Sunosuchus sp. (Crocodylomorpha, Goniopholididae) from the Middle Jurassic of Kirghisia. Journal of Vertebrate Paleontology, 20(4): 776-779.

Baele, J.-M., Godefroit, P., Spagna, P. \& Dupuis, C. 2012. A Short Introduction to the Geology of the Mons Basin and the Iguanodon Sinkhole. In: Godefroit, P. (ed.): Bernissart Dinosaurs and Early Cretaceous Ecosystems: 35-42, Bloomington: Indiana University Press.

Bakker, R. T. 1978. Dinosaur feeding behaviour and the origin of flowering plants. Nature, 274: 661-663.

Bakker, R. T. 1986. The Dinosaur Heresies. 481 pp., New York: Zebra Books (Kensington Publishing Corp.).

Ballerstedt, M. 1905. Über Saurierfährten der Wealdenformation Bückeburgs. Naturwissenschaftliche Wochenschrift, Neue Folge, 4(31): 481-485.

Ballerstedt, M. 1922. Über Schreckensaurier und ihre Fußspuren. Kosmos, 19(3): 77-80.

Barco, J. L. \& Ruiz-Omeñaca, J. I. 2001a. Primeros dientes de terópodo (Dinosauria, Saurisehia) en la Formación Villar del Arzobispo (Titónico-Berriasiense): yacimientos Cuesta Lonsal y Las Cerradicas 2(Galve, Teruel). In: G. Meléndez, Herrera, Z., Delveney, D. \& Azanza, B (eds.): XVII Jornadas de la Sociedad Española de Paleontología: Los fósiles y la paleogeografía. Publicacion del Seminario de Paleontología de Zaragoza (SEPAZ), 5: 239-246.

Barco,J.L. \& Ruiz-Omeñaca, J. I. 2001b. Primeros restos postcraneales de terópodo (Dinosauria, Saurischia) en la Formación Villar del Arzobispo (Titónico-Berriasiense): Un centro vertebral caudal del yacimiento Carretera (Galve, Teruel). In: G. Meléndez, Herrera, Z., Delveney, D. \& Azanza, B (eds.): XVII Jornadas de la Sociedad Española de Paleontología: Los fósiles y la paleogeografía. Publicacion del Seminario de Paleontología de Zaragoza (SEPAZ), 5: 247254.

Barco, J.L., Canudo, J.I., \& Ruiz-Omeñaca, J.I. 2004. Presencia de la icnoasociación Megalosauripus-Therangospodus en el Berriasiense (Cretácico inferior) de la Península Ibérica (Cuenca de Cameros, Soria): implicaciones paleobiogeográficas. Geo-Temas, 6(5): 15-18.

Barco, J.L., Canudo, J.L., Cuenca-Bescós, G. \& Ruíz-Omeñaca, J.I. 2005. Un nuevo dinosaurio saurópodo, Galvesaurus herreroi gen. nov., sp. nov., del tránsito Jurásico-Cretácico en Galve (Teruel, NE de España). Naturaleza Aragonesa, 15: 4-17. 
Barco, J. L., Canudo, J. I. \& Ruiz-Omeñaca, J. I. 2006. New data on Therangospodus oncalensis from the Berriasian Fuentesalvo tracksite (Villar del Río, Soria, Spain): an example of gregarious behaviour in theropod dinosaurs. Ichnos, 13: $237-248$.

Barrett, P. M. \& Maidment, S. C. R. 2011. Armoured Dinosaurs. In: Batten, D.J. (ed.): English Wealden fossils. Palaeontological Association Field Guide to Fossils: Number 14: 391-406, London: The Palaeontological Association.

Barrett, P. M. \& Upchurch, P. 2005. Sauropod diversity through time: possible macroevolutionary and palaeoecological implications. In: Curry Rogers, K. A. \& Wilson, J. A. (eds.): The Sauropods: Evolution and Palaeobiology: 125-156, Berkley: University of California Press.

Barrett, P. M., McGowan, A. J. \& Page, V. 2009. Dinosaur diversity and the rock record. Proceeding of the Royal Society, B, 276: 2667-2674.

Barrett, P. M., Benson, R. J. B. \& Upchurch, P. 2010. Dinosaurs of Dorset: Part II, the sauropod dinosaurs (Saurischia, Sauropoda) with additional comments on the theropods. Proceedings of the Dorset Natural History and Archaeological Society, 131: 113-126.

Barthel, K. W., Swinburne, N. H. M. \& Conway Morris, S. 1990. Solnhofen - A study in Mesozoic palaeontology. 245 pp., Cambridge: Cambridge University.

Batten, D. J. 2002. Palaeoenvironmental setting of the Purbeck Limestone Group of Dorset, southern England. Special Papers in Palaeontology, 68: 13-20.

Batten, D. J. 2011. Wealden Geology. In: Batten, D.J. (ed.): English Wealden fossils. Palaeontological Association Field Guide to Fossils: Number 14: 7-14, London: The Palaeontological Association.

Batten, D. J. \& Austen, P. A. 2011. The Wealden of south-east England. In: Batten, D.J. (ed.): English Wealden fossils. Palaeontological Association Field Guide to Fossils: Number 14: 15-51, London: The Palaeontological Association.

Beckles, S. H. 1851. On supposed casts of footprints in the Wealden. Quarterly Journal of the Geological Society of London, 7: 117.

Beckles, S. H. 1852. On the Ornithoidichnites of the Wealden. Quarterly Jounal of the Geological Society of London, 8: 396397.

Bennett, S. C. 2007. A review of the pterosaur Ctenochasma: taxonomy and ontogeny. Neues Jahrbuch für Geologie und Paläontologie, Abhandlungen, 245: 23-31.

Bennett, S. C. 2013. The morphology and taxonomy of the pterosaur Cycnorhamphus. Neues Jahrbuch für Geologie und Paläontologie, Abhandlungen, 267: 23-41.

Benson, R. B. J. 2010. A description of Megalosaurus bucklandii (Dinosauria: Theropoda) from the Bathonian of the UK and the relationships of Middle Jurassic theropods. Zoological Journal of the Linnean Society, 158: 882-935.

Benson, R. B. J. \& Barrett P. M. 2009. Dinosaurs of Dorset: Part I, the carnivorous dinosaurs (Saurischia, Theropoda). Proceedings of the Dorset Natural History and Archaeological Society, 130: 133-147.

Benson, R. B. J. \& Mannion, P. D. 2012. Multi-variate models are essential for understanding vertebrate diversification in 
deep time. Biology Letters, 8(1): 127-130.

Benton, M. J. \& Clark, J. M. 1988. Archosaur phylogeny and the relationships of the Crocodylia. In: Benton, M.J. (ed.): The phylogeny and classification of the Tetrapods, volume 1: 295-338, Oxford: Clarendon Press.

Benson, R. B. J., Barret, P. M., Powell, H. P. \& Norman, D. B. 2008. The taxonomic status of Megalosaurus bucklandii (Dinosauria, Theropoda) from the Middle Jurassic of Oxfordshire, UK. Palaeontology, 51(2): 419-424.

Benson R. B. J., Carrano M. T. \& Brusatte S. L. 2010a. A new clade of archaic large-bodied predatory dinosaurs (Theropoda: Allosauroidea) that survived to the latest Mesozoic. Naturwissenschaften, 97: 71-78

Benson, R. J. B., Butler, R. J., Lindgren, J. \& Smith. A. S. 2010b. Mesozoic marine tetrapod diversity: mass extinctions and temporal heterogeneity in geological megabiases affecting vertebrates. Proceedings of the Royal Society, B, 277: 829834.

Benson, R. B. J. \& Butler, R. J. 2011. Uncovering the diversification history of marine tetrapods: ecology influences the effect of geological sampling biases. In: McGowan, A. J. \& Smith, A. B. (eds.): Comparing the Geological and Fossil Record. Implications for Biodiversity Studies. Geological Society, Special Publication, 358: 191-208.

Benton, M. J. \& Spencer, P. S. 1995. Fossil reptiles of Great Britain. Joint Nature Conservation Committe, Geological Review Series, 10: xii-386.

Benton, M. J., Cook, E., Grigorescu, D., Popa, E. \& Tallódi, E. 1997. Dinosaurs and other tetrapods in an Early Cretaceous bauxite-filles fissure, northwestern Romania. Palaeogeography, Palaeoclimatology, Palaeoecology, 130: 275-292.

Benton, M. J., Minter, N. J. \& Posmoşanu, E. 2006. Dwarfing in ornithopod dinosaurs from the Early Cretaceous of Romania. In: Csiki, Z. (ed.): Mesozoic and Cenozoic Vertebrates and Paleoenvironments; Tributes to the Career of Prof. Dan Grigorescu: 79-87, Bucharest: Ars Docendi.

Benton, M. J., Dunhill. A. M., Lloyd, G. T. \& Marx, F. G. 2011. Assessing the quality of the fossil record: insights from vertebrates. In: McGowan, A. J. \& Smith, A. B. (eds): Comparing the Geological and Fossil Records: Implications for Biodiversity Studies. Geological Society, London, Special Publications, 358: 63-94.

Bettenstaedt, F. \& Dietz, C. 1957. Tektonische und erdölgeologische Untersuchungen im Raum Lehrte östlich Hannover. Geologisches Jahrbuch, 74: 463-521.

Billon-Bruyat, J.-P., Mazin, J.-M. \& Pouech, J. 2010 A stegosaur tooth (Dinosauria, Ornithischia) from the Early Cretaceous of southwestern France. Swiss Journal of Geoscience, 103(2): 143-153.

Blows, W. T. 1998. A Review of Lower and Middle Cretaceous Dinosaurs of England. In: Lucas, S. G., Kirkland, J. I. \& Estep, J. W. (eds.): Lower and Middle Cretaceous Terrestrial Ecosystems. New Mexico Museum of Natural History and Science Bulletin, 14: 29-38.

Bock, W. J. \& Bühler, P. 1996. Nomenclature of Cretaceous birds from Romania. Cretaceous Research, 17: 509-514.

Böhme, A., Stratmann, U., Wiggenhagen, M., van der Lubbe, T. \& Richter, A. 2009. New tracks on the rock: Parallel trackways of a new type of Iguanodontipus/Caririchnium-like morphology from the Lower Cretaceous sandstones of Obernkirchen, northern Germany. Journal of Vertebrate Paleontology, 29(3): 66A.

Bonde, N. 2004. An Early Cretaceous (Ryazanian) fauna of "Purbeck-Wealden" type at Robbedale, Bornholm, with 
references to other Danish fossil vertebrates. In: Arratia, G. \& Tintori, A. (eds.): Mesozoic Fishes 3: 507-528, München: F. Pfeil.

Bonde, P. 2012. Danish Dinosaurs: A Review. In: Godefroit, P. (ed.): Bernissart Dinosaurs and Early Cretaceous Ecosystems: 435-451, Bloomington: Indiana University Press.

Bonde, P. \& Christiansen, P. 2003. New dinosaurs from Denmark. Comptes Rendus Palevol, 2(1): 13-26.

Brinkmann, W. 1989. Vorläufige Mitteilung über die Krokodilier-Faunen aus dem Ober-Jura (Kimmeridgium) der Kohlegrube Guimarota, bei Leiria (Portugal) und der Unter-Kreide (Barremium) von Uña (Provinz Cuenca, Spanien. Documenta naturae, 56: 1 - 28.

Boulenger, G.A. 1881. Sur l'arc pelvien chez les dinosauriens de Bernissart. Bulletins de l'Academie Royale des Sciences, des Lettres et des Beaux Arts de Belgique, 3eme série, 1: 600-608.

Broin, F. de \& Taquet, P. 1966. Découverte d'un Crocodilien nouveau dans le Crétacé inférieur du Sahara. Comptes Rendus de l'Académie des Sciences à Paris, Série D, 262: 2326-2329.

Buckland, W. 1824. Notice on the Megalosaurus or great Fossil Lizard of Stonesfield. Transactions of the Geological Society of London, series 2, 1: 390-396.

Buffetaut, E. 1975. Sur l'anatomie et la position systématique de Bernissartia fagesii Dollo, L., 1883, crocodilien du Wealdien de Bernissart, Belgique. Bulletin de l'Institut royal des Sciences Naturelles de Belgique, Sciences de la Terre, $51(2): 1-20$.

Buffetaut, E. 1982. Radiation evolutive, paléoécologie et biogéographie des crocodiliens mésosuchiens. Memoires de la Societé Géologique de France, 142: 1-88.

Buffetaut, E. 1986. Une mâchoire de Goniopholis (Crocodylia, Mesosuchia) dans le Portlandien supérieur du Boulonnais. Mémoires de la Société académique du Boulonnais, 1(2): 64-71.

Buffetaut, E. 2011. An early spinosaurid dinosaur from the Late Jurassic of Tendaguru (Tanzania) and the evolution of the spinosaurid dentition. Oryctos, 10: 1-8

Buffetaut, E. \& Ford, R. L. E. 1979. The crocodilian Bernissartia in the Wealden of the Isle of Wight. Palaeontology, 22: 905912.

Buffetaut, E. \& Hutt, S. 1980. Vectisuchus leptognathus, n. g. n. sp., a slender-snouted goniopholid crocodilian from the Isle of Wight. Neues Jahrbuch für Geologie und Paläontologie, Monatshefte, 1980(7): 385-390.

Buffetaut, E. \& R. Ingavat, R. 1980. A new crocodilian from the Jurassic of Thailand, Sunosuchus thailandicus n. sp. (Mesosuchia, Goniopholididae), and the palaeogeographical history of south-east Asia in the Mesozoic. Geobios, 13: 879-889.

Buffetaut, E. \& Taquet, P. 1977. The giant crocodilian Sarcosuchus in the Early Cretaceous of Brazil and Niger. Palaeontology, 20: 203-208.

Buffetaut, E., Pouit, D., Rigollet \& L. Archambeau, J.-P. 1989. Poissons et reptiles continenteaux du Purbeckien de la région de Cognac (Charente). Bulletin de la Societé géologique de France, 8, 5(5): 1065-1069. 
Buffetaut, E., Suteethorn, V., Tong, H. \& Amiot, R. 2008. An Early Cretaceous spinosaurid theropod from southern China. Geological Magazin, 145: 745-748.

Buscalioni, A. D. \& Sanz, J. L. 1988. Phylogenetic relationships of the Atoposauridae (Archosauria, Crocodylomorpha). Historical Biology, 1: 233-250.

Buscalioni, A. D. \& Sanz, J. L. 1990. The small crocodile Bernissartia fagesii from the Lower Cretaceous of Galve (Teruel, Spain). Bulletin de l'Institut Royal des Sciences Naturelles de Belgique, Sciences de la Terre, 60: 129-150.

Buscalioni, A. D., Buffetaut, E. \& Sanz, J. L. 1984. An immature specimen of the crocodilian Bernissartia from the Lower Cretaceous of Galve (Province of Teruel, Spain). Palaeontology, 27(4): 809-813.

Buscalioni, A. D., Piras, P., Vullo, R., Signore, M. \& Barbera, C. 2011. Early eusuchia crocodylomorpha from the vertebraterich Plattenkalk of Pietraroia (Lower Albian, southern Apennines, Italy). Zoological Journal of the Linnean Society, 163: S199-S227.

Butler, R.J. \& Sullivan, R.M. 2009. The phylogenetic position of the ornithischian dinosaur Stenopelix valdensis from the Lower Cretaceous of Germany and the early fossil record of Pachycephalosauria. Acta Palaeontologica Polonica, 54(1): 21-34.

Butler, R. J., Upchurch, P. \& Norman, D. B. 2008. The phylogeny of the ornithischian dinosaurs. Journal of Systematic Palaeontology, 6: 1-40.

Butler, R. J., Galton, P. M., Porro, L. B., Chiappe, L. M., Henderson, D. M. \& Erickson, G. M. 2010. Lower limits of ornithischian dinosaur body size inferred from a diminutive new Upper Jurassic heterodontosaurid from North America. Proceedings of the Royal Society, B, 277: 375-381.

Butler, R.J., Jin Liyong, Chen Jun \& Godefroit, P. 2011a. The postcranial osteology and phylogenetic position of the small ornithischian dinosaur Changchunsaurus parvus from the Quantou Formation (Cretaceous: Aptian-Cenomanian) of Jilin Province, north-eastern China. Palaeontology, 54(3): 667-683.

Butler, R. J., Benson, R. B. J., Carrano, M. T., Mannion, P. D. \& Upchurch, P. 2011b. Sea level, dinosaur diversity, and sampling biases: investigating the 'common cause' hypothesis in the terrestrial realm. Proceedings of the Royal Society, B, 278: 1165-1170.

Canudo, J. I. 2006. La ambigüedad paleobiogeográfica de los dinosaurios ibéricos durante el Cretácico Inferior. In: Colectivo Arqueológico-Paleontológico Salense (eds.): Actas de las III Jornadas sobre Dinosaurios y su Entorno: 21-45, Salas de los Infantes.

Canudo, J. I. 2009. Dinosaurios Ibéricos, final del Jurásico y la Formación Morrison. Zubía, 27: 53-80.

Canudo, J. I. \& Ruiz-Omeñaca, J. I. 2003. Los restos directos de Dinosaurios Terópodos (excluyendo aves) en España. In: Pérez Lorente, F., Romero Molina, M. M. \& Rivas Carrera, P. (eds.): Dinosaurios y otros reptiles mesozoicos en España: 347-374, Logroño: Universidad de la Rioja, Instituto de Estudios Riojanos.

Canudo, J. I., Ruiz-Omeñaca, J. I., Barco, J. L., Royo Torres, R. 2002. ¿Saurópodos asiáticos en el Barremiense inferior (Cretácico Inferior) de España? Ameghiniana, 39(4): 443-452.

Canudo, J. I., Ruiz-Omeñaca, J. I. \& Cuenca-Bescós, G. 2004. Los primeros dientes de anquilosaurio (Ornithischia: Thyreophora) descritos en el Cretácico Inferior de España. Revista Española de Paleontología, 19(1): 33-46. 
Canudo, J. I., Aurell, M., Barco, J. L., Cuenca-Bescós, G. \& Ruiz-Omeñaca, J. I. 2005a. Los dinosaurios de la Formación Villar del Arzobispo (Titónico medio - Berriasiense inferior) en Galve (Teruel). Geogaceta, 38: 39-42.

Canudo, J. I., Barco, J. L., Cuenca-Bescós, G. \& Ruiz-Omeñaca, J. I. 2005b. Presence of two different theropod footprints in the Valanginian-Hauterivian (Lower Cretaceous) of Villanueva de Huerva (Zaragoza, Aragón, Spain). In: Le Loeuff, J., Vila, B., Marmi, J., Golobart. À. \& Oms, O. (eds.): International Symposium on Dinosaurs and other Vertebrates Palaeoichnology. Fumanya-St. Corneli (Cercs, Barcelona) October 4-8 ${ }^{\text {th }} 2005$ : 37-39.

Canudo J.I., Ruiz-Omeñaca J.I., Aurell M., Barco J.L. \& Cuenca-Bescós, G. 2006. A megatheropod tooth from the late Tithonian-lower Berriasian (Jurassic-Cretaceous transition) of Galve (Aragon, NE Spain). Neues Jahrbuch für Geologie und Paläontologie, Abhandlungen, 239: 77-99.

Canudo, J. I., Barco, J. L., Pereda Suberbiola, X., Ruiz-Omenaca, J. I., L Salgado, L., Torcida Fernandez-Baldor, F., Gasulla, J. M. 2009. What Iberian dinosaurs reveal about the bridge said to exist between Gondwana and Laurasia in the Early Cretaceous. Bulletin de la Societé Géologique de France, 180(1): 5-11.

Canudo, J. I., Gasca, J. M., Moreno-Azanza, M. \& Aurell, M. 2012. New information about the stratigraphic position and age of the sauropod Aragosaurus ischiaticus from the Early Cretaceous of the Iberian Peninsula. Geological Magazine, 149(2): 252-263.

Carpenter, K. \& Ishida, Y. 2010. Early and "Middle" Cretaceous Iguanodonts in Time and Space. Journal of Iberian Geology, 36(2): 145-164.

Carpenter, K. \& Kirkland, J. I. 1998. Review of Lower and Middle Cretaceous Ankylosaurs from North America. In: Lucas, S. G., Kirkland, J. I. \& Estep, J. W. (eds.): Lower and Middle Cretaceous Terrestrial Ecosystems. New Mexico Museum of Natural History and Science Bulletin, 14: 249-270.

Carpenter, K. \& Wilson, Y. 2008. A new species of Camptosaurus (Ornithopoda: Dinosauria) from the Morrison Formation (Upper Jurassic) of Dinosaur National Monument, Utah, and a biomechanical analysis of its forelimb. Annals of the Carnegie Museum, 76: 227-264.

Carpenter, K., Miles, C. \& Cloward, K. 1998. Skull of a Jurassic ankylosaur (Dinosauria). Nature, 393: 782-783.

Carrano, M.T., Benson, R.B.J. \& Sampson, S.D. 2012. The phylogeny of Tetanurae (Dinosauria: Theropoda). Journal of Systematic Palaeontology, 10(2): 211-300.

Castanera, D. \& Canudo, J. I. 2011. Los saurópodos del intervalo Jurásico-Cretácico de la Cordillera Ibérica: icnitas vs huesos. In: Pérez-García, A., Gascó, F., Gasulla, J.M., Escaso, F. (eds.): Viajando a mundos pretéritos: 101-109, Ayuntamiento de Morella.

Castanera, D., Barco, J.L., Díaz-Martínez, I., Pérez-Lorente, F., \& Canudo, J.I. 2011. New evidence of a herd of titanosauriform sauropods from the Lower Berriasian of the Iberian Range (Spain). Palaeogeography, Palaeoclimatology, Palaeoecology, 310: 227-237.

Castanera, D., Vila, B., Razzolini, N. L., Falkingham, P. L., Canudo J. I., Manning, P. L. \& Galobart, À. (2013) Manus Track Preservation Bias as a Key Factor for Assessing Trackmaker Identity and Quadrupedalism in Basal Ornithopods. PLoS ONE, 8(1): e54177.

Charig, A. \& Chapman, S. 1998. Iguanodon Mantell, 1825 (Reptilia, Ornithischia): proposed designation of Iguanodon 
bernissartensis Boulenger in Beneden, 1881 as the type species, and proposed designation of a lectotype. Bulletin of Zoological Nomenclature, 55: 99-104.

Charig, A. J. \& Milner, A. C. 1986. Baryonyx, a remarkable new theropod dinosaur. Nature 324(6095): 359-361.

Charig, A. J. \& Milner, A. C. 1997. Baryonyx walkeri, a fish-eating dinosaur from the Wealden of Surrey. Bulletin of the Natural History Museum of London, 53: 11-70.

Chatterjee, S. \& Rudra, D. K. 1996. KT events in India: impact, rifting, volcanism and dinosaur extinction. Memoirs of the Queensland Museum, 39(3): 489-532.

Christian, A. 2010. Some sauropods raised their necks - evidence for high browsing in Euhelopus zdanskyi. Biology Letters, 6(6): 823-825.

Christiansen, P. \& Bonde, N. 2003. The first dinosaur from Denmark. Neues Jahrbuch für Geologie und Paläontologie, Abhandlungen, 227(2): 287-299.

Chure, D. J. 1994. Koparion douglassi, a new dinosaur from the Morrison Formation (Upper Jurassic) of Dinosaur National Monument; the oldest troodontid (Theropoda: Maniraptora). Brigham Young University Geology Studies, 40: 11-15.

Chure, D. J., Britt, B. B., J. A. Whitlock, J. A. \& Wilson, J. A. 2010. First complete sauropod dinosaur skull from the Cretaceous of the Americas and the evolution of sauropod dentition. Naturwissenschaften, 97(4): 379-391.

Clemente, P. 2010. Review of the Upper Jurassic-Lower Cretaceous stratigraphy in western Cameros Basin, northern Spain. Revista de la Sociedad Geológica de España, 23(2-3): 101-143.

Cobos, A., Royo-Torres, R., Luque, L., Alcalá, L. \& Mampel, L. 2010: An Iberian stegosaurs paradise: The Villar del Arzobispo Formation (Tithonian-Berriasian) in Teruel (Spain). Palaeogeography, Palaeoclimatology, Palaeoecology, 293: 223236.

Colin, J.-P., El Albani, A., Fürsich, F. T., Martin-Closas, C., Mazin, J.-M., Billon-Bruyat, J.-P. 2004. Le gisement "Purbeckien” de vertébrés de Cherves-de-Cognac, Charente (SW France): nouvelles données biostratigraphiques. Comptes Rendus Palevol, 3: 9-16.

Company, J., Pereda Suberbiola, X. \& Ruiz-Omeñaca, J. I. 2010. New stegosaurian (Ornithischia, Thyreophora) remains from Jurassic-Cretaceous transition beds of Valencia province (Southwestern Iberian Range, Spain). Journal of Iberian Geology, 36(2): 243-252.

Cooper, M.R. 1985. A revision of the ornithischian dinosaur Kangnasaurus coetzeei Haughton, with a classification of the Ornithischia. Annals of the South African Museum, 95: 281-317.

Cope, E.D. 1869. Synopsis of the extinct Batrachia, Reptilia, and Aves of North America. Transactions of the American Philosophical Society, 14: 1-252.

Cope, E.D. 1875. Check-list of North American Batrachia and Reptilia with a systematic list of the higher groups and an essay on geographic distribution based on the specimens in the U.S. National Museum. Bulletin of the United States National Museum, 1: 1-104.

Cope, J. C. W., Ingham, J. K. \& Rawson, P. F. (eds.) 1999. Atlas of Palaeogeography and Lithofacies. The Geological Society Memoir, 13: 1-157. 
Cuny. G., Buffetaut, E., Capetta, H., Martin, M., Mazin, J.-M. \& Rose, J. M. 1991. Nouveaux restes de vertébrés du Jurassique terminal du Boulonnais (Nord de la France). Neues Jahrbuch für Geologie und Paläontologie, Abhandlungen, 180: 323347.

Currie, P. J. \& Azuma, Y. 2006. New specimens, including a growth series, of Fukuiraptor (Dinosauria, Theropoda) from the Lower Cretaceous Kitadani Quarry of Japan. Journal of the Paleontological Society of Korea, 22(1): 173-193.

Currie, P. J., Rigby, jr., J. K. \& Sloan, R. E. 1990. Theropod teeth from the Judith River Formation of southern Alberta, Canada. In: Carpenter, K. \& Currie, P. J. (eds.): Dinosaur Systematics: Perspectives and Approaches: 107-125, Cambridge: Cambridge University Press.

Dalla Vecchia, F. M. 2008. The impact of dinosaur palaeoichnology in palaeoenvironmental and palaeogeographic reconstructions: the case of the Periadriatic carbonate platforms. Oryctos, 8: 89-106.

Dames, W. 1884a. Über ein Humerusfragment eines Dinosauriers welches im Liegenden des Hauptflötzes im Marienschacht auf der Körssen bei Stadthagen gefunden wurde. Zeitschrift der Deutschen Geologischen Gesellschaft, 36: 186-187.

Dames, W. 1884b. ...Zahn von Megalosaurus aus dem Deister... Sitzungsberichte der Gesellschaft naturforschender Freunde zu Berlin, 1884: 186-188.

Debelmas, J. \& Strannoloubsky, A. 1957. Découverte d'un crocodilien dans le Néocomien de La Martre (Var), Dacosaurus lapparenti n. sp. Traveaux Laboratoire de Géologie de l'Université de Grenoble, 33: 89-99.

D'Emic, M.D. 2012. The early evolution of titanosauriform sauropod dinosaurs. Zoological Journal of the Linnean Society, 166: 624-671.

Diedrich, C. 2004. New important iguanodontid and theropod trackways of the tracksite Obernkirchen in the Berriasian of NW Germany and megatracksite concept of Central Europe. Ichnos, 11(3): 215-228.

Diedrich, C. 2011. Upper Jurassic tidal flat megatracksites of Germany - coastal dinosaur migration highways between European islands, and a review of dinosaur footprints. Palaeobiodiversity and Palaeoenvironments, 91: 129-155.

Dietrich, O. W. 1927. Über Fährten ornithopodider Saurier im Oberkirchner Sandstein Sandstein. Zeitschrift der Deutschen Geologischen Gesellschaft, 78: 614-621.

Dietz, C. 1973. Erläuterungen zur Geologischen Karte von Niedersachsen 1:25 000. Blatt Lehrte, Nr. 3625.83 pp., Hannover: NLfB.

Dollo, L. 1883. Premiere note sur les crocodiliens de Bernissart. Bulletin du Musee Royal d'Histoire Naturelle de Belgique 2: 309-340.

Dong, Z. 1990. Stegosaurs of Asia. In: Carpenter, K. \& Currie, P. J. (eds.): Dinosaur Systematics: Perspectives and Approaches: 255-268, Cambridge: Cambridge University Press.

Dragastan, O. N. \& Richter, D. K. 2011. Stromatolites and calcareous algae of Münder Formation (Tithonian-Berriasian) from NW Germany. Acta Palaeontologica Romaniae, 7: 139-168.

Dragastan, O., Coman, O., \& Ştiucă, E. 1988. Bauxite-bearing formations and facies in the Pădurea Craiului and Bihor 
Mountains (Northern Apuseni). Revue Roumaine de Géologie, Géophysique et Géographie, 32: 67-81.

Dunker, W. 1843-44. Über den norddeutschen sogenannten Wälderthon und dessen Versteinerungen. Programm der höheren Gewerbeschule in Cassel. 46 pp.

Dunker, W. 1846. Monographie der Norddeutschen Wealdenbildung: ein Beitrag zur Geognosie und Naturgeschichte der Vorwelt. Braunschweig: Oehme and Müller, 83 pp.

Dunker, W. 1849. Ueber den norddeutschen sogenannten Wälderthon und dessen Versteinerungen. Studien des Göttingischen Vereins Bergmännischer Freunde, 5(2): 105-185.

Dyke, G. J., Benton, M. J., Posmosanu, E. \& Naish, D. 2011. Early Cretaceous (Berriasian) birds and pterosaurs from the Cornet bauxite mine, Romania. Palaeontology, 54(1): 79-95.

El Albani, A., Fürsich, F. T., Colin, J.-P., Meunier, A., Hochuli, P. Martín-Closas, C., Mazin, J.-M., Billon-Bruyat, J.-P. 2004. Palaeoenvironmental recontruction of the basal Cretaceous vertebrate bearing beds in the Northern part of the Aquitaine Basin (SW France): sedimentological and geochemical evidence. Facies, 50: 195-215.

El-Shahat, A. \& West, I. M. 1983. Early and late lithification of aragonitic bivalve beds in the Purbeck Formation (Upper Jurassic - Lower Cretaceous) of southern England. Sedimentary Geology, 35: 15-41.

Ensom, P. C. 1995a. Dinosaur footprints in the Purbeck Limestone Group (?Upper Jurassic- Lower Cretaceous) of southern England. Proceedings of the Dorset Natural History Archaeological Society, 116: 77-104.

Ensom, P. C. 1995b. Dinosaur footprint records for the Purbeck Limestone Group, Dorset, since 1981. Proceedings of the Dorset Natural History and Archaeological Society, 116:151-152

Ensom, P. C. 2002a. The Purbeck Limestone Group of Dorset, Southern England: A guide to lithostratigraphic terms. Special Papers in Palaeontology, 68: 7-11.

Ensom, P. C. 2002b. Reptile eggshell, tiny vertebrate remains and globular calcified cartilage from the Purbeck Limestone Group of southern England,. Special Papers in Palaeontology, 68: 221-239.

Ensom, P. C. 2002c. Vertebrate trace fossils in the Purbeck Limestone Group of southern England. Special Papers in Palaeontology, 68: 203-220.

Ensom, P. C. 2010. Lithostratigraphic sections through the Purbeck Limestone Group (Tithonian-Berriasian) at five Regionally Important Geological/Geomorphological Sites (RIGS) on the Isle of Purbeck, and at Bacon Hole near West Lulworth, Dorset, southern England. Proceedings of the Dorset Natural History and Archaeological Society, 131: 127144.

Ensom, P. C. \& Delair, J. B. 2007. Dinosaur tracks from the lower Purbeck strata of Portland, Dorset, southern England. Geoscience in South-west England, 11: 309-325.

Escaso, F. Ortega, F., Dantas, P., Malafaia, E., Pimentel, N. L., Pereda-Suberbiola, X., Sanz, J. L., Kullberg, J. C., Kullberg, M. C. \& Barriga, F. 2007. New evidence of shared dinosaur across Upper Jurassic proto-North Atlantic: Stegosaurus from Portugal. Naturwissenschaften 94: 367-374

Ezcurra, M. D. \& Agnolín, F. L. 2012. A new global palaeobiogeographical model for the late Mesozoic and early Tertiary. Systematic Biology, 61(4): 553-566. 
Fiorillo, A. R. 1999. Non-mammalian microvertebrate remains from the Robison eggshell site, Cedar Mountain Formation (Lower Cretaceous), Emery County, Utah. In: Gillette, D. D. (ed.): Vertebrate Paleontology in Utah. Utah Geological Survey, Miscellaneous Publication, 99-1: 259-268.

Fischer, R. 1998. Die Saurierfährten im Naturdenkmal Münchehagen. Mitteilungen aus dem geologischen Institut der Universität Hannover, 37: 3-59.

Fortier, D., Perea, D. \& Schultz, C. 2011. Redescription and phylogenetic relationships of Meridiosaurus vallisparadisi, a pholidosaurid from the Late Jurassic of Uruquay. Zoological Journal of the Linnean Society, 163: S257-S272.

Foster, C.A. 1990. The postcranial skeleton of the ornithopod dinosaur Tenontosaurus tilletti. Journal of Vertebrate Paleontology, 10: 273-294.

Foster, J. 2007. Jurassic West: The Dinosaurs of the Morrison Formation and their World. Bloomington: Indiana University Press, $389 \mathrm{pp}$.

Fowler, D. 2007. Recently rediscovered baryonychine teeth (Dinosauria: Theropoda): new morphologic data, range extension and similarity to ceratosaurs. Journal of Vertebrate Paleontology, 27 (suppl. 3): 76A.

Fu, Q.-M., Ming, S.-Y. \& Peng, G.-Z. 2005. A new species of Sunosuchus from Zigong, Sichuan, China. Vertebrata PalAsiatica, 43(1): 76-83.

Fuentes Vidarte, C. 1996. Primeras huellas de aves en el Weald de Soria (España). Nuevo icnogenero, Archaeornithipus y nueva icnospecie A. meijidei. Estudios Geologicos, 52: 63-75.

Fuentes Vidarte, C. \& Meijide Calvo, M. 1996. Restos de pterosaurios en el "Weald" de Soria (España). Studia Geologica Salamanticensia, 32: 15-22.

Fuentes Vidarte, C. \& Meijide Calvo, M. 1998. Icnitas de dinosaurios teropodos en el Weald de Soria (Espa ña). Nuevo icnogenero Kalohipus. Estudios Geologicos, 54: 147-152.

Fuentes Vidarte, C., Meijide Calvo, M., Meijide Fuentes, F., \& Meijide Fuentes, M. 2004. Pteraichnus longipodus nov. icnosp. en la Sierra de Oncala (Soria, España). Studia Geologica Salmanticensia, 40: 103-114

Fuentes Vidarte, C., Meijide Calvo, M., Meijide Fuentes, F. \& Meijide Fuentes, M. 2005a. El conjunto faunísticode de la base del Cretácico inferior de Soria (Cuenca de Cameros, Grupo Oncala) a través del análisis icnológico. Celtiberia, 99: 367404.

Fuentes Vidarte, C., Meijide Calvo, M., Meijide Fuentes, F. \& Meijide Fuentes, M. 2005b. Fauna de vertebrados del Cretácico Inferior de yacimiento do "Zorralbo" en Golmayo (Soria, España). Revista Española de Paleontología, número extraordinario 10: 83-92.

Galton, P.M. 1974. The ornithischian dinosaur Hypsilophodon from the Wealden of the Isle of Wight. Bulletin of the British Museum (Natural History), Geology Series, 25: 1-152.

Galton, P.M. 1977. The ornithopod dinosaur Dryosaurus and a Laurasia-Gondwanaland connection in the Upper Jurassic. Nature, 268: 230-232.

Galton, P. M. 1980a. Armored dinosaurs (Ornithischia: Ankylosauria) from the Middle and Upper Jurassic of England. 
Géobios, 13: 825-837.

Galton, P. M. 1980b. Partial skeleton of Dracopelta zbyszewskii n. gen., and n. sp., an ankylosaurian dinosaur from the Upper Jurassic of Portugal. Géobios, 13: 451-457.

Galton, P. M. 1981a. Craterosaurus pottonensis Seeley, a stegosaurian dinosaur from the Lower Cretaceous of England, and a review of Cretaceous stegosaurs. Neues Jahrbuch für Geologie und Paläontologie, Abhandlungen, 161: 28-46.

Galton, P. M. 1981b. Dryosaurus, a hypsilophodontid dinosaur from the Upper Jurassic of North America and Africa: Postcranial skeleton. Paläontologische Zeitschrift, 55: 271-312.

Galton, P.M. 1983. The cranial anatomy of Dryosaurus, a hypsilophodontid dinosaur from the Upper Jurassic of North America and East Africa, with a review of the hypsilophodontids from the Upper Jurassic of North America. Geologica et Palaeontologica, 17: 207-243.

Galton, P.M. 1985. British plated dinosaurs (Ornithischia, Stegosauria). Journal of Vertebrate Paleontology, 5: 211-254.

Galton, P. M. 2007. Teeth of Ornithischian Dinosaurs (mostly Ornithopoda) from the Morrison Formation (Upper Jurassic) of the Western United States. In: Carpenter, K. (ed.): Horns and Beaks - Ceratopsian and Ornithopod Dinosaurs: 17-48, Bloomington: Indiana University Press.

Galton, P.M. 2009. Notes on Neocomian (Lower Cretaceous) ornithopod dinosaurs from England - Hypsilophodon, Valdosaurus, "Camptosaurus", "Iguanodon" - and referred specimens from Romania and elsewhere. Revue de Paléobiologie, 28(1): 211-273.

Galton, P.M. 2012. Hypsilophodon foxii and Other Smaller Bipedal Ornithischian Dinosaurs from the Lower Cretaceous of Southern England. In: Godefroit, P. (ed.): Bernissart Dinosaurs and Early Cretaceous Terrestrial Ecosystems: 225-282, Bloomington: Indiana University Press.

Galton, P.M. \& Powell, H.P. 1980. The ornithischian dinosaur Camptosaurus prestwichii from the Upper Jurassic of England. Palaeontology, 23(2): 411-443.

Galton, P. M. \& Taquet, P. 1982. Valdosaurus, a hypsilophodontid dinosaur from the Lower Cretaceous of Europe and Africa. Géobios, 15: 147-159.

Galton, P. M., Dyke, G. \& Kurochkin, E. 2009. Re-analysis of Lower Cretaceous fossil birds from the UK reveals an unexpected diversity. Journal of Vertebrate Paleontology, 29(Suppl. 3): S102.

García-Hernández, M., López-Garrido, A. C. \& Pérez-Lorente, F. 2003. Pisadas de dinosaurio en calizas del tránsito JurásicoCretácico del Prebético de la Sierra del Pozo (Provincia de Jaén. España). In: Pérez Lorente, F., Romero Molina, M. M. \& Rivas Carrera, P. (eds.): Dinosaurios y otros reptiles mesozoicos en España: 41-48, Logroño: Universidad de la Rioja, Instituto de Estudios Riojanos.

Gascó, F., Cobos, A., Royo-Torres, R., Mampel, L., \& Alcalá, L. 2012. Theropod teeth diversity from the Villar del Arzobispo Formation (Tithonian-Berriasian) at Riodeva (Teruel, Spain): Palaeobiodiversity and Palaeoenvironments, 92(2): 273285.

Gascón, J. H. \& Pérez-Lorente, F. 2012. El Rompido (Aguilar del Alfambra). Icnitas de dinosaurios en la Formación Villar del Arzobispo. Teruel. Geogaceta, 51: 39-42. 
Gervais, P. 1852. Zoologie et paléontologie française (animaux vertébrés). $1^{\text {st }}$ ed. Paris: A. Bertrand, 271 pp..

Gervais, P. 1871. Remarques au sujet des Reptiles provenant des calcaires lithographiques de Cerin, dans, le Bugey, qui sont conservés au Musée de Lyon. Comptes Rendus des séances de l'Academie de Sciences, 73: 603-607.

Gmelin, J.F. 1789. Tom. I. Pars III. In: Gmelin, J.F. (ed.): Caroli a Linné, systema naturae: 1033-1516, Lipsiae: Beer.

Göhlich, U. B. \& Chiappe, L. M. 2006. A new carnivorous dinosaur from the Late Jurassic Solnhofen archipelago. Nature, 440: 329-332.

Golonka, J. 2007. Phanerozoic paleoenvironment and paleolithofacies maps. Mesozoic. Geologia, 33(2): 211-264.

Göttlich, J. 2003. Diversitätsanalyse der Vertebratenreste aus einem "Wealden"-Bonebad bei Sehnde, Niedersachsen. Unpubl. B. Sc. thesis, University of Hannover: 42 pp., Hannover: University of Hannover.

Gottmann, A. 1999. Revision der taxonomischen Zuordnung von Stenopelix valdensis (Reptilia: Ornithischia) aus dem norddeutschen Wealden. Unpubl. Diploma thesis, Georg-August-Universität Göttingen.

Gramann, F., C. Heunisch, C., Klassen, H., Kockel, F., Dulce, G., Harms, F.-J., Katschorek, T., Mönnig, E., Schudack, M., Schudack, U., Thies, D. \& M. Weiss, M. 1997. Das Niedersächsische Oberjura-Becken-Ergebnisse interdisziplinärer Zusammenarbeit. Zeitschrift der Deutschen Geologischen Gesellschaft 148(2): 165-236.

Grange, D. R. \& Benton, M. J. 1996. Kimmeridgian metriorhynchid crocodiles from England. Palaeontology, 39(2): 497-515.

Gravesen, P., Rolle, F. \& Surlyk, F. 1982. Lithostratigraphy and sedimentary evolution of the Triassic, Jurassic, and Lower Cretaceous of Bornholm, Denmark. Danmarks Geologiske Undersøgelse, Serie B, 7: 1-51.

Grigorescu, D. 1993. Nonmarine Cretaceous of Romania. In: Mateer, N.J. \& Chen, P.-J. (eds.): Aspects of Nonmarine Cretaceous Geology: 142-164, Beijing: China Ocean Press.

Grigorescu, D. 2003. Dinosaurs of Romania. Comptes Rendus Palevol 2(1): 97-102.

Grupe, 0. 1931. Über Wurzelböden im Wealdensandstein der Bückeberge und ihre Bedeutung für den Rhythmus dynamischer Vorgänge. Zeitschrift der Deutschen Geologischen Gesellschaft, 83: 224-234.

Gutierrez, K. \& Sheldon, N. D. 2012. Paleoenvironmental reconstruction of Jurassic dinosaur habitats of the Vega Formation, Asturias, Spain. Geological Society of America Bulletin, 124(3-4): 596-610.

Haderer, F. \& Neef, C. 2004. Ein weiterer Nachweis der Theropodenfährte Bueckeburgichnus aus dem Obernkirchener Sandstein von Nordwestdeutschland. Bericht der Naturhistorischen Gesellschaft Hannover, 146: 1-6.

Harding, I. C., Smith, G. A., Riding, J. B. \& Wimbledon, W. A. P. 2011. Inter-regional correlation of Jurassic/Cretaceous boundary strata based on the Tithonian-Valanginian dinoflagellate cyst biostratigraphy of the Volga Basin, western Russia. Review of Palaeobotany and Palynology, 167 (1-2): 82-116.

Hartman, S., Lovelace, D., \& Wahl, W. 2005. Phylogenetic assessment of a maniraptoran from the Morrison Formation. Journal of Vertebrate Paleontology, 25(Suppl. 3): 67A-68A.

Haughton, S. H. 1915. On some dinosaur remains from Bushmanland. Transactions of the Royal Society of South Africa, 5: 259-264. 
Hay, O.P. 1930. Second bibliography and catalogue of the fossil vertebrata of North America, volume II. Carnegie Institution of Washington Publication No. 390. Washington DC.: Carnegie Institution of Washington, xiv+1074 pp.

Hernández Medrano, N., Pascual Arribas, C., Latorre Macarron, P. \& Sanz Pérez, E. 2006. Contribución de los yacimentos de icnitas Sorianos al registro general de Cameros. Zubía, 23-24: 79-120.

Hesselbo, S. P., Deconinck, J-F., Huggett, J. M., Morgans-Bell, H. S. 2009. Late Jurassic palaeoclimatic change from clay mineralogy and gamma-ray spectrometry of the Kimmeridge Clay, Dorset, UK. Journal of the Geological Society, London, 166: 1123-1134.

Hoedemaeker, P. J. \& Herngreen, G. F. W. 2003. Correlation of Tethyan and Borreal Berriasian-Barremian strata with emphasis on strata in the subsurface of the Netherlands. Cretaceous Research, 24: 253-275.

Hoffmann, F. 1830. Uebersicht der orographischen und geognostischen Verhältnisse vom nordwestlichen Deutschland. xxiv + 676 pp., Leipzig: J. A. Barth.

Holtz, jr., T. R., Molnar, R. E. \& Currie, P. J. 2004a. Basal Tetanurae. In: Weishampel, D. B., Dodson, P. \& Osmolska, H. (eds.): The Dinosauria. $2^{\text {nd }}$ ed.: 111-136, Berkeley: University of California Press.

Holtz, jr., T. R., Chapman, R. E. \& Lamanna, M. C. 2004b. Mesozoic Biogeography of Dinosauria. In: Weishampel, D. B., Dodson, P. \& Osmolska, H. (eds.): The Dinosauria. $2^{\text {nd }}$ ed.: 627-642, Berkeley: University of California Press.

Hooley, R. W. 1907. On the skull and greater portion of the skeleton of Goniopholis crassidens from the Wealden Shales of Atherfield (Isle of Wight). Quarterly Journal of the Geological Society of London, 69: 372-422.

Hooley, R. W. 1925. On the skeleton of Iguanodon atherfieldensis sp. nov., from the Wealden Shales of the Isle of Wight. Quarterly Journal of the Geological Society of London, 81: 1-61.

Horner, J. R., Weishampel, D. B. \& Forster, C. A. 2004. Hadrosauridae. In: Weishampel, D. B., Dodson, P. \& Osmolska, H. (eds.): The Dinosauria. $2^{\text {nd }}$ ed.: 438-463, Berkeley: University of California Press.

Hornung, J. J. \& Reich, M. 2012. The croc puzzle: a fairly complete specimen of Goniopholis (Mesoeucrocodylia: Goniopholididae) from the Bückeberg Formation (Berriasian) of Bückeburg, northern Germany. In: Richter, A., \& Reich, M. (eds.): Dinosaur Tracks 2011. An International Symposium, Obernkirchen, April 14-17, 2011. Abstract Volume and Field Guide to Excursions: 26, Göttingen: Universitäts-Verlag.

Hornung, J. J., Andrade, M. B. de \& Reich, M. 2009. Are Goniopholis crassidens and G. simus different species of crocodilians? New postcranial evidence solving a taxonomic riddle. Journal of Vertebrate Paleontology, 29 (Suppl. to 3): 117A.

Hornung, J. J., Böhme, A., Lubbe, T. van der, Reich, M. \& Richter, A. 2012. Vertebrate tracksites in the Obernkirchen Sandstone (late Berriasian, Early Cretaceous) of northwest Germany - their stratigraphical, palaeogeographical, palaeoecological, and historical context. Paläontologische Zeitschrift, 86(3): 231-267.

Hornung, J. J., Böhme, A., Schlüter, N. \& Reich, M. subm. Diversity, ontogeny, or both? A morphometric approach to iguanodontian ornithopod (Dinosauria: Ornithischia) track assemblages from the Berriasian (Early Cretaceous) of northwestern Germany. Dinosaur Tracks 2011. An International Symposium, Proceedings volume.

Howse, S.C.B. \& Milner, A.R. 1995. The pterodactyloids from the Purbeck Limestone Formation of Dorset. Bulletin of the Natural History Museum, London (Geology), 51(1): 73-88. 
Hoyer, W. 1902. Die geologischen Verhältnisse der Umgegend von Sehnde. Zeitschrift der Deutschen Geologischen Gesellschaft, 54: 84-143.

Hu, D., Hou, L., Zhang, L. \& Xu, X. 2009. A pre-Archaeopteryx troodontid theropod from China with long feathers on the metatarsus. Nature 461 (7264): 640-643.

Hua, S. 1999. Le Crocodilien Machimosaurus mosae (Thalattosuchia, Teleosauridae) du Kimmeridgien du Boulonnais (Pas de Calais, France) [The Crocodilian Machimosaurus mosae (Thalattosuchia, Teleosauridae) from the Kimmeridgian of the Boulonnais (Pas de Calais, France)]. Palaeontographica, A, A252(4-6): 141-170.

Hua, S., Buffetaut, E., Legall, C. \& Rogron, P. 2007. Oceanosuchus boecensis n. gen., n. sp., a marine pholidosaurid (Crocodylia, Mesosuchia) from the Lower Cenomanian of Normandy (western France). Bulletin de la Société Géologique de France, 178: 503-513.

Hua, S., Vignaud, P., Atrops, F., Clément A. 2000. Enaliosuchus macrospondylus Koken, 1883 (Crocodylia, Metriorhynchidae) du Valanginien de Barret-le-Bas (Hautes Alpes, France): un cas unique de remontée des narines externes parmi les crocodiliens. Géobios, 33: 467-474.

Huene, F. von 1922. Über einen Sauropoden im oberen Malm des Berner Jura. Eclogae Geologicae Helvetiae, 17: 80-94.

Huene, F. von 1923. Carnivorous Saurischia in Europe since the Triassic. Bulletin of the Geological Society of America, 34: 449-458.

Huene, F. von 1926a. The carnivorous Saurischia in the Jura and Cretaceous formations, principally in Europe. Revista del Museo de la Plata, 29: 35-167.

Huene, F. von 1926b. On several known and unknown reptiles of the order Saurischia from England and France. Annals and Magazine of Natural History, Series 9, 17: 473-489.

Huene, F. von 1932. Die fossile Reptil-Ordnung Saurischia, ihre Entwicklung und Geschichte. Monographien zur Geologie und Palaeontologie, Serie 1, 4: 1-361.

Huene, F. von 1946. Die großen Stämme der Tetrapoden in den geologischen Zeiten. Biologisches Zentralblatt, 65 (7/12): 266-275.

Hulke, J. W. 1874. Note on a very large saurian limb-bone adapted for progression upon land, from the Kimmeridge Clay of Weymouth, Dorset. Quaterly Journal of the Geological Society, London, 30: 16-17.

Hulke, J. W. 1880. Iguanodon prestwichii, a new species from the Kimmeridge Clay founded on numerous fossil remains lately discovered at Cumnor, near Oxford. Quarterly Journal of the Geological Society of London, 36: 433-456.

Hutt, S., Martill, D. M. \& Barker, M. J. 1996. The first European allosauroid dinosaur (Lower Cretaceous, Wealden Group, England). Neues Jahrbuch für Geologie und Paläontologie, Monatshefte, 1996: 635-644.

Hutt, S., Naish, D., Martill, D. M., Barker, M. J. \& Newberry, P. 2001. A preliminary account of a new tyrannosauroid theropod from the Wessex Formation (Early Cretaceous) of southern England. Cretaceous Research, 22: 227-242.

Huxley, T. H. 1869. On Hypsilophodon, a new genus of Dinosauria. Abstracts of the Proceedings of the Geological Society of London, 204: 3-4. 
Huxley, T. H. 1875. On Stagonolepis Robertsoni, and on the evolution of the Crocodilia. Quarterly Journal of the Geological Society of London, 3:423-438.

ICZN 1999. International Code of Zoological Nomenclature. $4^{\text {th }}$ edition. 306 pp. London: International Trust for Zoological Nomenclature.

ICZN 2000. Iguanodon Mantell, 1825 (Reptilia, Ornithischia): Iguanodon bernissartensis Boulenger in Beneden, 1881 designated at the type species, and a lectotype designated. Bulletin of Zoological Nomenclature, 57: 61-62.

Jaffé, G. 1912. Über Pholidosaurusreste aus dem Naturhistorischen Museum in Lübeck. Mitteilungen der Geographischen Gesellschaft und des Naturhistorischen Museums in Lübeck, (zweite Reihe) 25: 1-10.

Janensch, W. 1935-36. Die Schädel der Sauropoden Brachiosaurus, Barosaurus und Dicraeosaurus aus den TendaguruSchichten Deutsch-Ostafrikas. Palaeontographica, Supplement 7 (2): 1-34.

Janensch, W. 1955. Der Ornithopode Dysalotosaurus der Tendaguruschichten. Palaeontographica, Supplement 7 (3): $105-$ 176.

Jin, L., Chen, J., \& Godefroit, P. 2012. A new basal ornithomimosaur (Dinosauria: Theropoda) from the Early Cretaceous Yixian Formation, Northeast China. In: Godefroit, P. (ed.): Bernissart Dinosaurs and Early Cretaceous Ecosystems: 467487, Bloomington: Indiana University Press.

Jouve, S. 2009. The skull of Teleosaurus cadomensis (Crocodylomorpha; Thalattosuchia), and phylogenetic analysis of Thalattosuchia. Journal of Vertebrate Paleontology, 29: 88-102.

Jouve, S., Iarochene, M., Bouya B. \& Amaghzaz, M. 2006. A new species of Dyrosaurus (Crocodylomorpha, Dyrosauridae) from the early Eocene of Morocco: phylogenetic implications. Zoological Journal of the Linnean Society, 148: 603-656.

Jacobs, L. L., Strganac, C. \& Scotese, C. 2011. Plate Motions, Gondwana Dinosaurs, Noah's Arks, Beached Viking Funeral Ships, Ghost Ships, and Landspans. Anais da Academia Brasileira de Ciências, 83(1): 3-22.

Jurcsák, T. 1982. Occurences nouvelles des sauriens mésozoiques de Roumania. Vertebrata Hungarica: 21, 175-184.

Jurcsák, T. \& Kessler, E. 1991. The Lower Cretaceous fauna from Cornet, Bihor County, Romania. Nymphaea: 21, 5-32.

Jurcsák, T. \& Popa, E. 1979. Dinozaurieni ornitopozi din bauxitele de la Cornet (Munții Pădurea Craiului). Nymphaea: 10, 715.

Jurcsák, T. \& Popa, E. 1983a. La faune de dinosauriens du Bihor (Roumaine). In: Buffetaut, E., Mazin, J.-M., \& Salmon, E. (eds): Actes du Symposium Paléontologique G. Cuvier: 325-335. Montbéliard: Ville de Montbéliard.

Jurcsák, T. \& Popa, E. 1983b. Reptile zburătoare în bauxitele de la Cornet, notăpreliminară. Nymphaea: 10, 7-15.

Jurcsák, T. \& Popa, E. 1984. Pterosaurians from the Cretaceous of Cornet, Romania. In: Reif, W.-E. \& Westphal, F. (eds.): Third Symposium on Mesozoic Terrestrial Ecosystems, Short Papers: 117-118, Tübingen: Attempto.

Jürgens, U. 1972. Sedimentologie der Wealden-Sandsteine im Hannoverschen Bergland (NW-Deutschland), Unpublished Doctoral Thesis. 164 pp., Hamburg: Universität Hamburg. 
Kaever M. \& Lapparent, A.-F. de 1974. Les traces des pas le Dinosaures du Jurassique des Barkhausen (Basse Saxe, Allemagne). Bulletin de la Societé Géologique de France, 16: 516-525.

Karl, H.-V. \& Tichy, G. 2004. Zur frühen Geschichte der Paläocheloniologie von Schaumburg-Lippe. Die Rolle des Gymnasial-Professors Max Ballerstedt in der Naturwissenschaft. Berichte zur Wissenschaftsgeschichte, 27: 285-296.

Karl, H.-V., Gröning, E., Brauckmann, C., Schwarz, D. \& Knötschke, N. 2006. The Late Jurassic crocodiles of the Langenberg near Oker, Lower Saxony (Germany), and description of related materials (with remarks on the history of quarrying the "Langenberg Limestone” and “Obernkirchen Sandstone”). Clausthaler Geowissenschaften, 5: 59-77.

Karl, H.-V., Staesche, U., Tichy, G., Lehmann, J. \& Peitz, S. 2007. Systematik der Schildkröten (Anapsida: Chelonii) aus Oberjura und Unterkreide von Nordwestdeutschland. Geologisches Jahrbuch, Reihe B, B98: 5-89.

Karl, H.-V., Gröning, E., Brauckmann, C. \& Knötschke, N, 2008. First remains of the head of Steneosaurus (Crocodylomorpha: Teleosauridae) from the Late Jurassic of Oker (Lower Saxony, Germany). Studia Geologica Salamanticensia, 44(2): 187-201.

Kaup, J. J. 1834. Versuch einer Eintheilung der Säugethiere in 6 Stämme und der Amphibien in 6 Ordnungen. Isis von Oken, 3: 311-324.

Kemper, E. 1961. Die Ammonitengattung Platylenticeras (- Garnieria). Mit einem Beitrag zur Stratigraphie und Bionomie ihrer Schichten (Untere Kreide, mittleres Valendis). Beihefte zum Geologischen Jahrbuch, 47: 1-195.

Kemper, E. 1987. Das Klima der Kreidezeit. Geologisches Jahrbuch, Reihe A, A96: 5-186.

Kessler, E. 1984. Lower Cretaceous birds from Cornet (Romania). In: Reif, W.-E. \& Westphal, F. (eds.): Third Symposium on Mesozoic Terrestrial Ecosystems, Short Papers: 119-122, Tübingen: Attempto.

Kessler, E. \& Gall, E. 1995. A new theory concerning the origin and evolution of birds. In: Sun, A. \& Wang, Y.-Q. (eds.): Sixth Symposium on Mesozoic Terrestrial Ecosystems and Biota, Short Papers: 215-216, Beijing: China Ocean Press.

Kessler, E . \& Jurcsák, T. 1984. Fossil bird remains in the bauxite from Cornet (Romania, Bihor County) . Travaux du Musée d' Histoire Naturelle, Grigore Antipa, 25: 393 - 401.

Kessler, E. \& Jurcsák, T. 1986. New contributions to the knowledge of the Lower Cretaceous bird remains from Cornet (Romania). Travaux du Musée d' Histoire Naturelle, Grigore Antipa, 28: 289 - 295

Kirkland, J. I. \& Carpenter, K. 1994. North America's first pre-Cretaceous ankylosaur (Dinosauria) from the Upper Jurassic Morrison Formation of western Colorado. Brigham Young University Geological Studies, 40: 25-42.

Kirkland, J. I., Lucas, S. G. \& Estep, J. W. 1998. Cretaceous Dinosaurs of the Colorado Plateau. In: Lucas, S. G., Kirkland, J. I. \& Estep, J. W. (eds.): Lower and Middle Cretaceous Terrestrial Ecosystems. New Mexico Museum of Natural History and Science Bulletin, 14: 79-90.

Koken, E. 1883. Die Reptilien der norddeutschen unteren Kreide. Zeitschrift der Deutschen geologischen Gesellschaft, 35: 735-827.

Koken, E. 1887. Die Dinosaurier, Crocodiliden und Sauropterygier des norddeutschen Wealden. Palaeontologische Abhandlungen, 3(5): 1-111. 
Koken, E. 1896. Die Reptilien des norddeutschen Wealden. Nachtrag. Palaeontologische Abhandlungen, 7(=N.F. 3(2)): 119126.

Kuhn, 0. 1939. Saurischia. Fossilium Catalogus, I: Animalia, Pars 87. 126 pp., The Hague: W. Junk.

Kuhn, O. 1958. Die Fährten der vorzeitlichen Amphibien und Reptilien. 64 pp., Bamberg: Meisenbach.

Kuhn, 0. 1966. Die Reptilien. System und Stammesgeschichte. 154 pp., Krailingen: Oeben.

Kützing, F. T. 1849. Species algarum. vi+922 pp., Lipsiae: F. A. Brockhaus.

Lauprasert, K., Laojumpon, C., Saenphala, W., Cuny, G., Thirakhupt, K. \& Suteethorn, V. 2011. Atoposaurid crocodyliforms from the Khorat Group of Thailand: first record of Theriosuchus from Southeast Asia. Paläontologische Zeitschrift, 85(1): 37-47.

Le Loeuff, J., Buffetaut, E. \& Merser, C. 1996. Découverte d'un dinosaure sauropode tithonien dans la région de Cognac (Charente). Géologie de la France, 2: 79-81.

Le Loeuff, J., Gourrat, C., Landry, P., Hautier, L., Liard, R. Souillat, C., Buffetaut, E. \& Enay, R. 2006. A Late Jurassic sauropod tracksite from Southern Jura (France). Comptes Rendus Palevol, 5(5): 705-709.

Leonardi, G. 1984. Le impronte fossili di dinosauri. In: Bonaparte, F. (ed.): Sulle orme dei dinosauri: 165-186, Venezia: Erizzo.

Lill, K. \& Riegel, W. 1991. Ein fluviatil dominiertes Delta im „Unteren Wealden“(Berrias, Bueckeberg-Folge) von Borgloh/Kloster Ösede, Osnabrücker Hügelland, Niedersachsen). Bericht der Naturhistorischen Gesellschaft Hannover, 133: 221-255.

Lillegraven, J. A., Kraus, M. J. \& Bown, T. M. 1979. Paleogeography of the world of the Mesozoic. In: Lillegraven, J. A., KielanJaworowska, Z. \& Clemens, W. A. (eds.): Mesozoic Mammals: the First Two-thirds of Mammalian History: 277-308, Berkeley: University of California Press.

Lindgren, J., Currie, P. J., Rees, J., Siverson, M., Lindström, S. \& Alwmark, C. 2008. Theropod dinosaur teeth from the lowermost Cretaceous Rabekke Formation on Bornholm, Denmark. Geobios, 41: 253-262.

Loyd, G. T. 2012. A refined modelling approach to assess the influence of sampling on palaeobiodiversity curves: new support for declining Cretaceous dinosaur richness. Biology Letters, 8(1): 123-126.

Lloyd, G. T., Young, J. R. \& Smith, A. B. 2012. Taxonomic Structure of the Fossil Record is Shaped by Sampling Bias. Systematic Biology, 61(1): 80-89.

Lockley, M.G. 2000. An amended description of the theropod footprint Bueckeburgichnus maximus Kuhn 1958, and its bearing on the megalosaur tracks debate. Ichnos, 7(3): 217-225.

Lockley, M. G., Meyer, C. A. \& dos Santos, V. F. 1998. Megalosauripus and the problematic concept of megalosaur footprints. Gaia, 15: 313-337.

Lockley, M., Garcia-Ramos, J. C., Pinuela \& Avanzini, M. 2008. A review of vertebrate track assemblages from the Late Jurassic of Asturias, Spain with comparative notes on coeval ichnofaunas from the western USA: implications for faunal diversity in siliciclastic facies assemblages. Oryctos, 8: 53-70. 
Lockley, M. G. \& Meyer, C. 2000. Dinosaur Tracks and Other Fossil Footprints of Europe. 323 pp., New York: Columbia University Press.

van der Lubbe, T., Richter, A. \& A. Böhme 2009a. Velociraptor's sisters: First report of troodontid tracks from the Lower Cretaceous of northern Germany.Jounal of Vertebrate Paleontology, 29(3): 194A.

van der Lubbe, T., Richter, U. \& Knötschke, N. 2009b. Velociraptorine dromaeosaurid teeth from the Kimmeridgian (Late Jurassic) of Germany. Acta Palaeontologica Polonica, 54(3): 401-408.

Lydekker, R. 1887. Note on the Hordwell and other crocodilians. Geological Magazin, Decade 3, 4: 307-312.

Lydekker, R. 1888a. Note on a new Wealden iguanodont and other dinosaurs. Quarterly Journal of the Geological Society of London, 44: 46-61.

Lydekker, R. 1888b. Catalogue of the fossil Reptilia and Amphibia in the British Museum (Natural History). Part I. containing the orders Ornithosauria, Crocodylia, Dinosauria, Squamata, Rhynchochephalia, and Proterosauria. London: Trustees of the British Museum (Natural History), 309 pp..

Lydekker, R. 1889a. Notes on new and other dinosaur remains. Geological Magazin (Decade III), 4: 352-356.

Lydekker, R. 1889b. Note on some points in the nomenclature of fossil reptiles and amphibians, with preliminary notices of two new species. Geological Magazine, (Decade III), 6: 325-326.

Lydekker, R. 1890. Catalogue of the fossil Reptilia and Amphibia in the British Museum (Natural History). Part IV. containing the orders Anomodontia, Ecaudata, Caudata, and Labyrinthodontia; and Supplement. London: Trustees of the British Museum (Natural History), 295 pp..

Madsen, Jr., J. H. 1976. Allosaurus fragilis: A revised osteology. Utah Geological and Mineral Survey Bulletin, 109: 1-163.

Madsen, Jr., J. H. \& Welles, S. P. 2000. Ceratosaurus (Dinosauria, Theropoda) a revised osteology. Utah Geological Survey Miscellaneous Publication, 00-2:1-80.

Makovicky, P. J. \& Norell, M. A. 2004. Troodontidae. In: Weishampel, D. B., Dodson, P. \& Osmolska, H. (eds.): The Dinosauria. $2^{\text {nd }}$ ed.: 184-196, Berkeley: University of California Press.

Malafaia, E., Ortega, F., Escaso, F., Dantas, P., Pimentel, N., Gasulla, J. M., Ribeiro, B., Barria, F. \& Sanz, J. L. 2010. Vertebrate fauna at the Allosaurus fossil-site of Andrés (Upper Jurassic), Pombal, Portugal.

Mallison, H. 2011. Defense capabilities of Kentrosaurus aethiopicus Hennig, 1915, Palaeontologia Electronica, 14(2): 1-25.

Mannion, P. D. \& Upchurch, P. 2010. A quantitative analysis of environmental associations in sauropod dinosaurs. Paleobiology, 36: 253-282.

Mannion, P. D., Upchurch, P., Carrono, M. T. \& Barrett, P. M. 2011. Testing the effect of the rock record on diversity: a multidisciplinary approach to elucidating the generic richness of sauropodomorph dinosaurs throgh time. Biological Reviews, 86: 157-181.

Mannion, P. D., Upchurch, P., Mateus, O., Barnes, R. N. \& Jones, M. E. H. 2012. New information on the anatomy and systematic position of Dinheirosaurus lourinhanensis (Sauropoda: Diplodocoidea) from the Late Jurassic of Portugal, 
with a review of European diplodocoids. Journal of Systematic Palaeontology, 10(3): 521-551.

Mansell-Pleydell, J. C. 1888. Fossil reptiles of Dorset. Proceedings of the Dorset Natural History and Antiquarian Field Club, 9: 1-40.

Mantell, G. 1825. Notice on the Iguanodon, a newly discovered fossil reptile, from the sandstone of Tilgate Forest, in Sussex. Philosophical Transactions of the Royal Society, 115: 179-186.

Mantell, G. 1827. Illustrations of the geology of Sussex: a general view of the geological relations of the south-eastern part of England, with figures and descriptions of the fossils of Tilgate Forest. London: Lupton Relfe. xii + 92 pp..

Mantell, G. 1833. Observations on the remains of the Iguanodon, and other fossil reptiles, of the strata of Tilgate Forest in Sussex. Proceedings of the Geological Society of London, 1: 410-411.

Mantell, G. 1848. A brief notice of organic remains recently discovered in the Wealden formation. Quarterly Journal of the Geological Society of London, 5: 37-43.

Mantell, G. 1852. On the structure of the Iguanodon and on the fauna and flora of the Wealden Formation. Proceedings of the Royal Institution of Great Britain, 1: 141-146.

Marinescu, F. 1989. Lentila de bauxită 204 de la Brusturi - Cornet (Jud. Bihor), zăcământ fosilifer cu dinozauri. Ocrotirea Naturale Mediulului Inconjur, 33: 125-133.

Mariotti, N., Santantonio, M. \& Weis, R. 2007. Aalenian-Early Bajocian belemnite assemblage from peri-mediterranean Tethyan sediments (Calabria, southern Italy). Geologica Romana, 40: 1-19.

Marsh, 0. C. 1877. Notice on some new dinosaurian reptiles from the Jurassic Formation. American Journal of Science, Series 3, 14: 514-516.

Marsh, O. C. 1878. Principal characters of American Jurassic dinosaurs. Part I. American Journal of Science, Series 3, 16: 411-416.

Marsh, 0. C. 1879. Notice of new Jurassic reptiles. American Journal of Science, Series 3, 501-505.

Marsh, O. C. 1881. Principal characters of American Jurassic dinosaurs. Part V. American Journal of Science, Series 3, 21: 417-423.

Marsh, O. C. 1890. Additional characters of the Ceratopsidae, with notice of new Cretaceous dinosaurs. American Journal of Science, series 3: 39: 418-426.

Marsh, O.C. 1894. The typical Ornithopoda of the American Jurassic. American Journal of Science, series 3, 48: 85-90.

Marshall, L. G. 1981. The Great American Interchange: An invasion induced crisis for South American mammals. In: Niticki, M. H. (ed.): Biotic Crises in Ecological and Evolutionary Time: 133-229, New York: Academic Press.

Marshall, L. G. 1988. Land Mammals and the Great American Interchange. American Scientist, 76: 380-388.

Martill, D. M. \& Etches, S. in press. A new monofestratan pterosaur from the Kimmeridge Clay Formation (Upper Jurassic, Kimmeridgian) of Dorset, England. Acta Palaeontologica Polonica, in press. 
Martill, D. M., Sweetman, S. C. \& Witton, M. P. 2011. Pterosaurs. In: Batten, D.J. (ed.): English Wealden fossils. Palaeontological Association Field Guide to Fossils: Number 14: 370-390, London: The Palaeontological Association.

Martin, J. E. \& Benton, M.J. 2008. Crown Clades in Vertebrate Nomenclature: Correcting the Definition of Crocodylia. Systematic Biology, 57(1): 173-181.

Martin, J. E. \& Buffetaut, E. 2012. The maxillary depression of Pholidosauridae: an anatomical study. Journal of Vertebrate Paleontology, 32(6): 1442-1446.

Martin, J. E., Rabi, M. \& Csiki, Z. 2010. Survival of Theriosuchus (Mesoeucrocodylia: Atoposauridae) in a Late Cretaceous archipelago: a new species from the Maastrichtian of Romania. Naturwissenschaften, 97: 845 - 854.

Martin, T. \& Krebs, B. (eds.) 2000. Guimarota - A Jurassic Ecosystem. München: Pfeil, 155 pp..

Marty, D. 2008. Sedimentology, taphonomy, and ichnology of Late Jurassic dinosaur tracks from the Jura carbonate platform (Chevenez-Combe Ronde tracksite, NW Switzerland): insights into the tidal-flat palaeoenvironment and dinosaur diversity, locomotion, and palaeoecology. GeoFocus, 21: 1-278.

Marty, D. \& Meyer, C. A. 2012. From sauropods to cycads - The Late Jurassic terrestrial record of the Swiss Jura Mountains. In: Witzmann, F. \& Aberhan, M. (eds.): Centenary Meeting of the Paläontologische Gesellschaft. Programm, Abstracts and Field Guides. Terra Nostra, 2012(3): 119-120.

Marty, D., Strasser, A. \& Meyer, C. A. 2009. Formation and Taphonomy of Human Footprints in Microbial Mats of PresentDay Tidal-flat Environments: Implications for the Study of Fossil Footprints. Ichnos, 16: 127-142.

Mateus, 0. 2006. Late Jurassic dinosaurs from the Morrison Formation, the Lourinhã and Alcobaça Formations (Portugal), and the Tendaguru Beds (Tanzania): a comparison. In: Foster, J. R. \& Lucas, S. G. R. M., (eds.): Paleontology and Geology of the Upper Jurassic Morrison Formation. New Mexico Museum of Natural History and Science Bulletin, 36: 223-231.

Mateus, O. \& Antunes, M.T. 2001. Draconyx loureiroi, a new Camptosauridae (Dinosauria: Ornithopoda) from the Late Jurassic of Lourinhã, Portugal. Annales de Paleontologie, 87(1): 61-73.

Mateus, O. \& Milàn, J. 2008. Ichnological evidence for giant ornithopod dinosaurs in the Upper Jurassic Lourinhã Formation, Portugal. Oryctos, 8: 47-52.

Mateus, 0. \& Milàn, J. 2009. A diverse Upper Jurassic dinosaur ichnofauna from central-west Portugal. Lethaia, 43(2): 245257.

Mateus, O., Walen, A. \& Antunes, M.T. 2006. The large theropod fauna of the Lourinhã Formation (Portugal) and its similarity to the Morrison Formation, with a description of a new species of Allosaurus. In: Foster, J.R. \& Lucas, S. G. R.M. (eds.): Paleontology and Geology of the Upper Jurassic Morrison Formation. New Mexico Museum of Natural History and Science Bulletin, 36: 123-129.

Mateus, O., Maidment, S. \& Christiansen, N. 2009. A new long-necked 'sauropod-mimic' stegosaur and the evolution of the plated dinosaurs. Proceedings of the Royal Society of London, B, B276: 1815-1821

Mateus, O., Milàn, J., Romano, M. \& Whyte, M. A. 2011. New finds of stegosaur tracks from the Upper Jurassic Lourinh ã Formation, Portugal. Acta Palaeontologica Polonica, 56(3): 651-658.

Matthew, W. D. \& Brown, B. 1922. The family Deinodontidae, with a notice of a new genus from the Cretaceous of Alberta. 
Bulletin of the American Museum of Natural History, 46: 367-385.

Mazin J.-M. \& Billon-Bruyat, J.-P. 2002. Le gisement paléontologique de Cherves-de-Cognac. Pour la Science 293: 30-31.

Mazin, J.-M., Billon-Bruyat, J.-P. \& Pouech, J. 2005. The Purbeckian crocodilians from Cherves-de-Cognac (Berriasian, southwestern France). In: Barrett, P. M. (ed.): $53^{\text {rd }}$ SVPCA 2005, Abstracts: p. 17, London.

Mazin, J.-M., Billon-Bruyat, J.-P., Pouech, J. \& Hantzpergue, P. 2006. The Purbeckian site of Cherves-de-Cognac (Berriasian, Early Cretaceous, southwest France): A continental ecosystem accumulated in an evaporitic littoral depositional environment. In: Barrett, P. M. \& Evans, S. E. (eds.): $9^{\text {th }}$ International Symposium, Mesozoic Terrestrial Ecosystems and Biota: Manchester 2006: 84-88, Manchester.

Mazin, J.-M., Pouech, J., Hantzpergue P. \& Lenglet, T. 2008. The purbeckian site of Cherves-de-Cognac (Berriasian, Early Cretaceous, SW France): a first synthesis. In: J.-M. Mazin, J. Pouech, P. Hantzpergue, V. Lacombe (eds.): Mid-Mesozoic Life and Environments, Cognac (France), June $24^{\text {th }}-28^{\text {th }}$ 2008. Documents des Laboratoires de Géologique de Lyon, 164: 68-71.

McDonald, A. T. 2011. The taxonomy of species assigned to Camptosaurus. Zootaxa, 2783: 52-68.

McDonald, A. T. 2012. Phylogeny of Basal Iguanodonts (Dinosauria: Ornithischia): An Update. PLoS ONE, 7(5): e36745. doi:10.1371/journal.pone.0036745

McDonald, A. T., Kirkland J. I., DeBlieux, D. D., Madsen, S. K., Cavin, J., Milner, A. R. C. \& Panzarin, L. 2010a. New Basal Iguanodonts from the Cedar Mountain Formation of Utah and the Evolution of Thumb-Spiked Dinosaurs. PLoS ONE 5(11): e14075.

McDonald, A. T., Barrett, P. M. \& Chapman, S. D. 2010b. A new basal iguanodont (Dinosauria: Ornithischia) from the Wealden (Lower Cretaceous) of England. Zootaxa, 2569: 1-43.

McKenna, M. C. 1973. Sweepstakes, filters, corridors, Noah's Arks, and Beached Viking Funeral Ships in palaeogeography. In: Tarling, D. H. \& Runcorn, S. K. (eds.): Implications of Continental Drift to the Earth Sciences: 295-308, New York: Academic Press.

Meijide Calvo, M., Meijide Fuentes, F., Fuentes Vidarte, C., \& Meijide Fuentes, M. 2001. Huellas de pterosaurio en la Sierra de Oncala (Soria, España). Nueva icnospecies Pteraichnus parvus. In: Colectivo Arqueológico-Paleontológico de Salas (ed.): Resúmenes de las II Jornadas Internacionales sobre Paleontología de Dinosaurios y su Entorno: 397-406, Salas de los Infantes, Burgos.

Meijide Fuentes, F., Fuentes Vidarte, C., Meijide Calvo, M. \& Meijide Fuentes, M. 2001. Primer rastro de un dinosaurio saurópodo subadulto en el weald de Soria (España): Brontopodus oncalensis, nov. icnosp. In: Colectivo ArqueológicoPaleontológico de Salas (ed.): II Jornadas Internacionales sobre Paleontología de Dinosaurios y su Entorno: [w/o pagination], Salas de los Infantes.

Meijide Fuentes, F., Fuentes Vidarte, C. \& Meijide Calvo, M. 2001. Nueva ichnospecie para el Weald de la Comarca de Cameros Parabrontopodus distercii, nov. ichnoesp.. In: Colectivo Arqueológico-Paleontológico de Salas (ed.): Actas I Jornadas Internacionales sobre Paleontología de los Dinosaurios y su Entorno: 407-415, Salas de los Infantes.

Meléndez, N. \& Gómez-Fernández, J. C. 2000. Continental deposits of the eastern Cameros Basin (northern Spain) during Tithonian-Berriasian time. In: Gierlowski-Kordesch, E. H. \& Kelts, K. R. (eds.): Lake Basins through Space and Time. AAPG Studies in Geology, 46: 263-278. 
Melville, A. G. 1849. Notes on the vertebral column of the Iguanodon. In: Mantell, G. A.: Additional observations on the osteology of the Iguanodon and Hylaeosaurus. Philosophical Transactions of the Royal Society, 139: 285-300.

Metcalf, S. J., Vaughan, R. F., Benton, M. J., Cole, J., Simms, M. J. \& Dartnall, D. L. 1992. A new Bathonian (Middle Jurassic) microvertebrate site, within the Chipping Norton Limestone Formation at Hornsleasow Quarry, Gloucestershire. Proceedings of the Geologists' Association, 103: 321-342.

Meyer, C. A. 1993. A sauropod megatracksite from the Late Jurassic of Northern Switzerland. Ichnos, 2: 1-10.

Meyer, C. A. \& Thüring, B. 2003. Dinosaurs of Switzerland. Comptes Rendus Palevol, 2: 103-117.

Meyer, H. von 1841. Pholidosaurus schaumburgensis, ein Saurus aus dem Sandstein der Wald-Formation NordDeutschlands. Neues Jahrbuch für Mineralogie, Geognosie, Geologie und Petrefakten-Kunde, 1841: 443-445.

Meyer, H. von 1851. Ctenochasma Roemeri. Palaeontographica, 2(3): p. 82.

Meyer, H. von 1857. Beiträge zur näheren Kenntniss fossiler Reptilien. Neues Jahrbuch für Mineralogie, Geognosie, Geologie und Petrefakten-Kunde, [1857]: 532-543.

Meyer, H. von 1859. Stenopelix Valdensis, ein Reptil aus der Walden-Formation Deutschland's. Palaeontographica, 7: 2534.

Miller, K. G.., Mountain, G. S., Wright, J. D. \& Browning, J. V. 2011. A 180-Million-year record of sea level and ice volume variations from continental margin and deep-sea isotopic records. Oceanography, 24(2): 40-53.

Milner, A. C. 2002. Theropod dinosaurs of the Purbeck Limestone Group, southern England. Special Papers in Palaeontology, 68: 191-201.

Milner, A. R. 2004. The turtles of the Purbeck Limestone Group of Dorset, southern England. Palaeontology, 47: 14411467.

Molnar, R. E. 1980. An ankylosaur (Ornithischia: Reptilia) from the Lower Cretaceous of southern Queensland. Memoires of the Queensland Museum, 20: 77-87.

Molnar, R. E. 1992. Problematic Theropoda: “Carnosaurs”. In: Weishampel, D. B., Dodson, P. \& Osmolska, H. (eds.): The Dinosauria. $1^{\text {st }}$ Paperback Printing: 306-317, Berkeley: California University Press.

Moratalla, J. J. [1993]. Restos indirectos de dinosaurios del registro español: Paleoicnología de la Cuenca de Cameros (Jurásico superior). 729 pp. Unpublished PhD thesis, Madrid: Universidad Autónoma de Madrid.

Moratalla, J. J. 2009. Sauropod tracks of the Cameros Basin (Spain): Identification, trackway patterns and changes over the Jurassic-Cretaceous. Geobios, 42(6): 797-811.

Moratalla, J. J. \& Sanz, J. L. 1997. Cameros Basin Megatracksite. In: Currie, P. J. \& Padian, K. (eds.): Encyclopedia of Dinosaurs: 88-90, New York: Academic Press.

Mudroch, A., Richter, U., Joger, U., Kosma, R., Idé, O. \& Maga, A. 2010. Didactyle Tracks of Paravian Theropods (Maniraptora) from the ?Middle Jurassic of Africa. PloS ONE 6(2): e14642. 
Murphy, N. L., Trexler, D. \& Thompson, M. 2007. “Leonardo," a Mummified Brachylophosaurus (Ornithischia: Hadrosauridae) from the Judith River Formation of Montana. In: Carpenter, K. (ed.): Horns and Beaks. Ceratopsian and Ornithopod Dinosaurs: 117-134, Bloomington/Indianapolis: Indiana University Press.

Mutterlose, J. 1997. Münchehagen quarry. In: Mutterlose, J., Wippich, M. G. E. \& Geisen, M. (eds.): Cretaceous Depositional Environments of NW Germany. Bochumer Geologische und Geotechnische, Arbeiten, 46: 123-128.

Myers, T. S., Tabor, N. J., Jacobs, L. L., Mateus, O. 2012. Palaeoclimate of the Late Jurassic of Portugal: comparison with the Western United States. Sedimentology, 59(6): 1695-1717.

Naish, D. 2003. A definitive allosauroid (Dinosauria; Theropoda) from the Lower Cretaceous of East Sussex. Proceedings of the Geologists' Association, 114, 319-326.

Naish, D. 2011. Theropod Dinosaurs. In: Batten, D.J. (ed.): English Wealden fossils. Palaeontological Association Field Guide to Fossils: Number 14: 526-559, London: The Palaeontological Association.

Naish, D. \& Martill, D. M. 2001. Saurischian Dinosaurs 1: Sauropoda. In: Martill, D.M. \& Naish, D. (eds.) Dinosaurs of the Isle of Wight. Palaeontological Association Field Guide to Fossils: Number 10: 185-241, London: The Palaeontological Association.

Naish, D. \& Martill, D. M. 2007. Dinosaurs of Great Britain and the role of the Geological Society of London in their discovery: basal Dinosauria and Saurischia. Journal of the Geological Society, London 164: 493-510.

Naish, D. \& Martill, D. M. 2008. Dinosaurs of Great Britain and the role of the Geological Society of London in their discovery: Ornithischia. Journal of the Geological Society, London 165: 613-623.

Naish, D. \& Sweetman, S. C. 2011. The first record of maniraptoran dinosaurs in the Lower Cretaceous Wealden Supergroup in south-east England. Cretaceous Research, 32: 464-471.

Naish, D., Hutt, S. \& Martill, D. M. 2001. Saurischian dinosaurs 2: Theropods. In: Martill, D. M. \& Naish, D. (eds.): Dinosaurs of the Isle of Wight. Palaeontological Association Field Guide to Fossils: Number 10: 242-309, London: The Palaeontological Association.

Néraudeau, D., R. Allain, R., Ballevre, M., Batten, D. J., Buffetaut, E., Colin, J. P., Dabard, M. P., Daviero-Gomez, V., El Albani, A., Gomez, B., Grosheny, D., Loeuff, J., Leprince, A., Martin-Closas, C., Masure, E., Mazin, J. M., Philippe, M., Pouech, J., Tong, H., Tournepiche, J. F., \& Vullo, R. 2012. The Hauterivian-Barremian lignitic bone bed of Angeac (Charente, south-west France): stratigraphical, palaeobiological and palaeogeographical implications. Cretaceous Research, 37: 1-14

Noe-Nygaard, N. \& Surlyk, F. 1988. Washover fan and brackish bay sedimentation in the Berriasian-Valanginian, Bornholm, Denmark. Sedimentology, 35(2): 263-273.

Noe-Nygaard, N., Surlyk, F. \& Piasecki, S. 1987. Bivalve Mass Mortality Caused by Toxic Dinoflagellate Blooms in a Berriasian-Valanginian Lagoon, Bornholm, Denmark. Palaios, 2(3): 263-273.

Nopcsa, F. 1915. Die Dinosaurier der siebenbürgischen Landesteile Ungarns. Mitteilungen aus dem Jahrbuche der Kgl. Ungarischen Geologischen Reichsanstalt, 23: 1-26.

Nopcsa, F. 1917. Über Dinosaurier. [Nr. 1. Notizen über die Systematik der Dinosaurier]. Centralblatt für Mineralogie, Paläontologie und Geologie, 1917: 203-213. 
Nopcsa, F. 1918. Leipsanosaurus n. gen. Ein neuer Thyreophore aus der Gosau. Földtani Közlöny, Budapest, 48(1918): 324328.

Norman, D. B. 1980. On the ornithischian dinosaur Iguanodon bernissartensis from the Lower Cretaceous of Bernissart (Belgium). Institut Royale des Sciences Naturelles de Belgique. Mémoires, 178: 1-103.

Norman, D. B. 1986. On the anatomy of Iguanodon atherfieldensis (Ornithischia: Ornithopoda). Bulletin de l'Institut Royale des Sciences Naturelles de Belgique, Sciences de la Terre, 56: 281-372.

Norman, D. B. 1987a. Wealden dinosaur stratigraphy. In: Currie, P. J. \& Koster, E. H. (eds.): Fourth Symposium on Mesozoic Terrestrial Ecosystems, short papers: 165-170.

Norman, D. B. 1987b. A mass-accumulation of vertebrates from the Lower Cretaceous of Nehden (Sauerland), West Germany. Proceedings of the Royal Society of London, B, 230(1259): 215-255.

Norman, D. B. 2004. Basal Iguanodontia. In: Weishampel, D. B., Dodson, P. \& Osmolska, H. (eds.): The Dinosauria. $2^{\text {nd }}$ ed.: 413-437, Berkeley: University of California Press.

Norman, D. B. 2011a. Ornithopod Dinosaurs. In: Batten, D.J. (ed.): English Wealden fossils. Palaeontological Association Field Guide to Fossils: Number 14: 407-475, London: The Palaeontological Association.

Norman, D. B. 2011b. On the osteology of the lower Wealden (Valanginian) ornithopod Barilium dawsoni (Iguanodontia: Styracosterna). Special Papers in Palaeontology, 86 . pp. 165-194.

Norman, D. B. \& Barrett, P. 2002. Ornithischian Dinosaurs from the Lower Cretaceous (Berriasian) of England. Special Papers in Palaeontology, 68: 161-189.

Nyhuis, C. \& Herbig, H.-G. 2009. Ichthyolithe aus dem Berriasium von Gronau/Westfalen (westliches Niedersächsisches Kreidebecken)—Rekonstruktion einer trophischen Kette aus sturmkondensierten Bonebeds. In: Martin, T. \& Kaiser, S. I. (eds.): Paläontologie - Schlüssel zur Evolution. 79. Jahrestagung der Paläontologischen Gesellschaft. Kurzfassungen der Tagungsbeiträge. Terra Nostra. Schriften der Alfred-Wegener-Stiftung, 2009 (3): 85.

Olshevsky, G. 1991. A Revision of the Parainfraclass Archosauria Cope, 1869, Excluding the Advanced Crocodylia. Mesozoic Meanderings, 2: 1-196.

Ortega F., Escaso, F. \& Sanz, J.L. 2010. A bizarre, humped Carcharodontosauria (Theropoda) from the Lower Cretaceous of Spain. Nature, 467: 203-206.

Osborn, H. F. 1923. Two Lower Cretaceous dinosaurs from Mongolia. American Museum Novitates, 95: 1-10.

Osborn, H. F. \& Mook, C. C. 1921. Camarasaurus, Amphicoelias, and other sauropods of Cope. Memoires of the American Museum of Natural History, new series, 3(3): 247-287.

Ostrom, J. H. 1978. The osteology of Compsognathus longipes Wagner. Zitteliana, 4: 73-118.

Owen, R. 1842. Report on British fossil reptiles. Part II. Reports and Transactions of the British Association for the Advancement of Science, 11: 60-204.

Owen, R. 1854. On some reptilian and mammalian remains from the Purbecks. Quarterly Journal of the Geological Society of London, 10: 420-433. 
Owen, R. 1858. Note on the Bones of the Hind-foot of the Iguanodon, discovered and exhibited by S. H. Beckles, F.G.S. Quarterly Journal of the Geological Society, 14(1-2): 174-175.

Owen, R. 1861. Monograph of the fossil Reptilia of the Wealden and Purbeck formations. Part V. Lacertilia (Nuthetes etc.). Monographs of the Palaeontographical Society, 13: 31-39.

Owen, R. 1874. Monograph on the fossil Reptilia of the Mesozoic formations, Part I. Pterosauria. Monograph of the Palaeontographical Society, 27(126): 1-14.

Owen, R. 1875. Monographs on the fossil Reptilia of the Mesozoic formations. Part II. (Genera Bothriospondylus, Cetiosaurus, Omosaurus). Monograph of the Palaeontographical Society, 29(133): 15-93

Owen, R. 1878. Monograph of the fossil Reptilia of the Wealden and Purbeck formations. Supplement, No. VIII. Crocodilia (Goniopholis, Petrosuchus, and Suchosaurus). Monographs of the Palaeontographical Society, 32: 1-15.

Owen, R. 1879. Monograph of the fossil Reptilia of the Wealden and Purbeck formations. Supplement, No. IX. Crocodilia (Goniopholis, Brachydectes, Nannosuchus, Theriosuchus, and Nuthetes). Monographs of the Palaeontographical Society, 33: 1-19.

Pascual Arribas \& Hernández Medrano 2010. Nuevos datos sobre el yacimiento icnítico de Las Cuestas I (Santa Cruz de Yanguas, Soria, España). Studia Geologica Salamanticensia, 46(2): 121-157.

Pascual Arribas, C., Hernández Medrano, N., Latorre Macarrón, P. \& Sanz Pérez, E. 2008. Estudio de un rastro de huellas de saurópodo del yacimiento de Las Cuestas I (Santa Cruz de Yanguas, Soria, España). Implicaciones taxonómicas. Studia Geologica Salmanticensia, 44(1): 13-40.

Pascual C., Canudo J. I., Hernández N., Barco J. L. \& Castanera D. 2012. First record of stegosaur dinosaur tracks in the Lower Cretaceous (Berriasian) of Europe (Oncala group, Soria, Spain). Geodiversitas, 34(2): 297-312.

Patrulius, D., Marinescu, F., \& Baltreş, A. 1983. Dinosauriens ornithopodes dans les bauxites Néocomiennes de l'Unité de Bihor (Monts Apuseni). Anuarul Institutului de Geologie si Geofizica, 59: 109-117.

Paul, G. S. 1988. Predatory Dinosaurs of the World. New York: Simon \& Schuster, 464pp..

Pelzer, G. 1998. Sedimentologie und Palynologie der Wealden-Fazies im Hannoverschen Bergland. Courier Forschungsinstitut Senckenberg, 207: 1-211.

Pelzer, G. \& Wilde, V. 1987. Klimatische Tendenzen während der Ablagerung der Wealden-Fazies in Nordwesteuropa. Geologisches Jahrbuch, Reihe A, A96: 239-263.

Pereda Suberbiola, X. 1993. Hylaeosaurus, Polacanthus, and the systematics and stratigraphy of Wealden armoured dinosaurs. Geological Magazine, 130: 767-781.

Pereda Suberbiola, X. \& Galton, P. M. 2001. Thyreophoran ornithischian dinosaurs from the Iberian Peninsula. In: Colectivo Arqueológico-Paleontológico de Salas (ed.): Actas I Jornadas Internacionales sobre Paleontología de Dinosaurios y su entorno: 147-161, Salas de los Infantes.

Pereda Suberbiola, X., Torcida, F., Izquierdo, L. A., Huerta, P., Montero, D. \& Pérez, G. 2003. First rebbachisaurid dinosaur (Sauropoda, Diplodocoidea) from the early Cretaceous of Spain: palaeobiogeographical implications. Bulletin de la 
Societé geólogique de France, 174(5): 471-479.

Pereda Suberbiola, X., Ruiz-Omeñaca, J.I., Hernández, J.M. \& Pujalte, V. 2006. Primera cita de un dinosaurio ornitópodo en el Cretácico Inferior (Berriasiense) del So de la Cuenca Vasco-Cantábrica (Palencia, España). Revista de la Sociedad Geológica de España, 19(3-4): 219-231.

Pereda Suberbiola, X., Ruiz-Omeñaca, J. I., Torcida Fernández-Baldor, F., Maisch, M. W., Huerta, P., Contreras, R., Luis Ángel Izquierdo, L. A., Montero Huerta, D., Urién Montero, V., Welle, J. 2011. A tall-spined ornithopod dinosaur from the Early Cretaceous of Salas de los Infantes (Burgos, Spain). Comptes Rendus PalEvol 10(7): 551-558.

Pereda Suberbiola, X., Galton, P. M., Mallison, H. \& Novas, F. 2013. A plated dinosaur (Ornithischia, Stegosauria) from the Early Cretaceous of Argentina, South America: an evaluation. Alcheringa, 37(1): 65-78.

Pérez-Lorente, F. 2003. Icnitas de dinosaurios del Cretácico en España. In: Pérez-Lorente, F., Romero Molina, M. M. \& Rivas Carrera, P.: Dinosaurios y otros reptiles mesozoicos en España: 49-108, Logroño: Universidad de La Rioja.

Pérez-Lorente, F., Cuenca-Bescós, G., Aurell, M., Canudo, J. I., Soria, A. R. \& Ruiz-Omeñaca, J. I. 1997. Las Cerradicas tracksite (Berriasian, Galve, Spain): Growing evidence for quadrupedal ornithopods. Ichnos, 5: 109-120.

Pérez-Moreno, B. P., Sanz, J. L., Sudre, J. \& B. Sigé, B. 1993. A theropod dinosaur from the Lower Cretaceous of southern France. Revue de Paléobiologie, Volume Speciale 7: 173-188.

Pérez-Moreno, B. P., Sanz, J. L., Buscalioni, A. D., Moratalla, J. J., Ortega, F. \& Rasskin-Gutman, D. 1994, A unique multitoothed ornithomimosaur dinosaur from the Lower Cretaceous of Spain. Nature, 370: 363-367.

Petersen, H. I., Bojesen-Koefoed, J. A. \& Nytoft, H. P. 1996. Depositional environment and burial history of a Lower Cretaceous carbonaceous claystone, Bornholm, Denmark. Bulletin of the Geological Society of Denmark, 43: 133-142.

Piasecki, S. 1984. Dinoflagellate cyst stratigraphy of the Lower Cretaceous Jydegård Formation, Bornholm, Denmark. Bulletin of the Geological Society of Denmark, 32: 145-161.

Pieńkowski, G., Schudack, M. E., Bosák, P., Enay, R., Feldman-Olszewska, A., Golonka, J., Gutowski, J., Herngreen, G. F. W., Jordan, M., Krobicki, B., Lathuiliere, B., Leinfelder, R. R., Michalik, J., Mönnig, E., Noe-Nygaard, N., Palfy, J., Pint, A., Rasser, M. W., Reisdorf, A. G., Schmid, D. U., Schweigert, G., Surlyk, F., Wetzel, A. \& Wong, T. E. 2008. Jurassic. In: McCann, T. (ed.): The Geology of Central Europe. Volume 2: 823-923, Bath: The Geological Society.

Pol, D. \& Rauhut, O. W. M. 2012. A Middle Jurassic abelisaurid from Patagonia and the early diversification of theropod dinosaurs. Proceedings of the Royal Society, B, [published online/ahead of print: doi: 10.1098/rspb.2012.0660].

Pol, D., Turner, A. H. \& Norell, M. A. 2009. Morphology of the Late Cretaceous crocodylomorph Shamosuchus djadochtaensis and a discussion of neosuchian phylogeny as related to the origin of Eusuchia. Bulletin of the American Museum of Natural History, 324: 1-103.

Pollard, J. E. \& Radley, J. D. 2011. Trace Fossils. In: Batten, D.J. (ed.): English Wealden fossils. Palaeontological Association Field Guide to Fossils: Number 14: 652-676, London: The Palaeontological Association.

Posmoşanu, E. 2002. Preliminary report on the revision of the dinosaur (Ornithopoda) collection from the Lower Cretaceous bauxite deposits, Cornet - Romania. The $7^{\text {th }}$ European Workshop of Vertebrate Palaeontology, Sibiu, Romania, 2-7 July 2002. Abstract Volume and Excursuions Field Guide: 36, Sibiu. 
Posmoşanu, E. 2003a. New data on Lower Cretaceous dinosaurs from Romania. $1^{\text {st }}$ EAVP Meeting, Abstract of papers and posters, 49: Basel.

Posmoşanu, E. 2003b. Iguanodontian dinosaurs from the Lower Cretaceous bauxite site from Romania. Acta Palaeontologica Romaniae, 4: 431-439.

Posmoşanu, E. 2003c. The palaeoecology of the dinosaur fauna from a Lower Cretaceous bauxite deposit from Bihor (Romania). In: Petculescu, A. \& Stiuca, E. (eds.): Advances in Vertebrate Paleontology: Hen to Panta: 121-124, Bucarest: Romanian Academy, "Emil Racoviță" Institute of Speleology.

Posmoşanu E. \& Cook, E. 2000. Vertebrate taphonomy and dinosaur palaeopathology from a Lower Cretaceous bauxite lens, northwest Romania. Oryctos, 3: 39-51.

Pouech, P., Mazin, J.-M. \& Billon-Bruyat, J.-P. 2006. Microvertebrate biodiversity from Cherves-de-Cognac (Lower Cretaceous, Berriasian: Charente, France) In: Barrett, P. M. \& Evans, S. E. (eds.): $9^{\text {th }}$ International Symposium, Mesozoic Terrestrial Ecosystems and Biota: Manchester 2006: 96-100, Manchester.

Probst, E. \& Windolf, R. 1993. Dinosaurier in Deutschland. 320 pp., München: Bertelsmann.

Quinif, Y. \& Licour, L. 2012. The Karstic Phenomenon of the Iguanodon Sinkhole and the Geomorphological Situation of the Mons Basin during the Early Cretaceous. In: Godefroit, P. (ed.): Bernissart Dinosaurs and Early Cretaceous Ecosystems. Bloomington: Indiana University Press: 51-62.

Raddatz, M. 2011. New remains of an atoposaurid crocodile from the Upper Jurassic (Mittlere Süntel Formation) of the Langenberg Quarry, Oker (Lower Saxony, northwestern Germany). 98 pp. Unpublished Diploma thesis, HalleWittenberg: Martin-Luther-Universität.

Raddatz, M., Bachmann, G. H. \& Richter, A. 2012. A new track horizon in the old Obernkirchen Sandstone quarry of the Bückeberg (Lower Saxony, Germany). In: Richter, A., \& Reich, M. (eds.): Dinosaur Tracks 2011. An International Symposium, Obernkirchen, April 14-17, 2011. Abstract Volume and Field Guide to Excursions: 50, Göttingen: Universitäts-Verlag.

Racey, A. \& Goodall, J. G. S. 2009. Palynology and stratigraphy of the Mesozoic Khorat Group of NE Thailand. In: Buffetaut, E., Cuny, G., Le Loeuff, J. \& Suteethorn, V. (eds.): Late Palaeozoic and Mesozoic Ecosystems in SE Asia. Geological Society, London, Special Publications, 315: 67-81.

Rauhut, O. W. M. [2000a]. The interrelationships and evolution of basal theropods (Dinosauria, Saurischia). 440 pp. Unpublished Ph.D. thesis, Bristol: University of Bristol.

Rauhut, O. W. M. 2000b. The dinosaur fauna from the Guimarota mine. In: Keller, T. \& Krebs, B. (eds.): Guimarota - A Jurassic Ecosystem: 75-82, München: Dr. Friedrich Pfeil.

Rauhut, O. W. M. 2003. A tyrannosauroid dinosaur from the Upper Jurassic of Portugal. Palaeontology, 46(5): 903-910.

Rauhut, O. W. M. 2011. Theropod dinosaurs from the Late Jurassic of Tendaguru (Tanzania). Special Papers in Palaeontology, 86: 195-239.

Rauhut, O. W. M. \& Werner, C. 1995. First record of the family Dromaeosauridae (Dinosauria: Theropoda) in the Cretaceous of Gondwana (Wadi Milk Formation, northern Sudan). Paläontologische Zeitschrift, 69(3-4): 475-489. 
Rauhut, O. W. M., Milner, A. C. \& Moore-Fay, S. 2010. Cranial osteology and phylogenetic position of the theropod dinosaur Proceratosaurus bradleyi (Woodward, 1910) from the Middle Jurassic of England. Zoological Journal of the Linnean Society, 158: 155-195.

Rauhut, O. W. M., Foth, C., Tischlinger, H., Norell, M. A. 2012. Exceptionally preserved juvenile megalosauroid theropod dinosaur with filamentous integument from the Late Jurassic of Germany. Proceedings of the National Academy of Sciences, 109(29): 11746-11751.

Rawson, P. F. \& West, I. A. 1999. [Map J11d] [Purbeck facies]. In: Cope, J. C. W., Ingham, J. K. \& Rawson, P. F. Atlas of Palaeogeography and Lithofacies. The Geological Society Memoir, 13: 124-126.

Rees, J., Lindgren, J., \& Evans, S.E., 2005. Amphibians and small reptiles from the Berriasian Rabekke Formation on Bornholm, Denmark. GFF, 127: 233-238.

Rees, P. McA., Noto, C. R., Parrish, J. M. \& Parrish, J. T. 2004. Late Jurassic Climates, Vegetation, and Dinosaur Distributions. Journal of Geology, 112: 643-653.

Richter, A., Böhme, A. \& van der Lubbe, T. 2009. “Chicken Run”: A new unusual, heavily dinoturbated tracksite from the Lower Cretaceous sandstones of Obernkirchen,northern Germany. Journal of Vertebrate Paleontology, 29(3): p. 171A.

Richter, A., Hornung, J. J., Böhme, A. \& Stratmann, U. 2012. Obernkirchen Sandstone Quarries - A Natural Workstone Lagerstaette and a Dinosaur Tracksite. In: Richter, A., \& Reich, M. (eds.): Dinosaur Tracks 2011. An International Symposium, Obernkirchen, April 14-17, 2011. Abstract Volume and Field Guide to Excursions: 73-100, Göttingen: Universitäts-Verlag.

Riegel, W. \& Lill, K. 1988. Geologische und sedimentologische Untersuchungen im Berrias von Borgloh/Kloster Ösede (Osnabrücker Hügelland, Niedersachsen). Nachrichten der Deutschen Geologischen Gesellschaft 39: 78-79.

Rogers, R. R. \& Kidwell, S. M. 2007. A Conceptual Framework for Genesis and Analysis of Vertebrate Skeletal Concentrations. In: Rogers, R. R., Eberth, D. A. \& Fiorillo, A. R. (eds.): Bonebeds - Genesis, Analysis, and Paleobiological Significance: 1-64, Chicago: Chicago University Press.

Royo-Torres, R. \& Canudo, J. I. 2003. Restos directos de dinosaurios saurópodos en España (jurásico superior - cretácico superior). In: Pérez-Lorente, F., Romero Molina, M. M. \& Rivas Carrera, P. (eds.): Dinosaurios y otros reptiles mesozoicos en España: 313-334, Logroño: Universidad de La Rioja.

Royo-Torres, R. \& Upchurch, P. 2012. The cranial anatomy of the sauropod Turiasaurus riodevensis and implications for its phylogenetic relationships. Journal of Systematic Palaeontology, 10(3): 553-583.

Royo-Torres, R., Cobos, A. \& Alcalá, L. 2006. A giant European dinosaur and a new sauropod clade. Science, 314: 19251927.

Royo-Torres, R., Cobos, A., Luque, L., Aberasturi, A., Espílez, E., Fierro, I., González, A., Mampel, L. \& Alcalá, L. 2009. High European sauropod dinosaur diversity during Jurassic Cretaceous transition in Riodeva (Teruel, Spain). Palaeontology, 52: 1009-1027.

Ruiz-Omeñaca, J. I. \& Canudo, J. I. 2003. Dinosaurios (Saurischia, Ornithischia) en el barremsiense (cretácio inferior) de la Península Ibérica. In: Pérez-Lorente, F., Romero Molina, M. M. \& Rivas Carrera, P.: Dinosaurios y otros reptiles mesozoicos en España: 269-312, Logroño: Universidad de La Rioja. 
Ruiz-Omeñaca, J. I., Canudo, J. I., Aurell, M., Bádenas, B., Barco, J. L., Cuenca-Bescós, G. \& Ipas, J. 2004. Estudios Geologicos, 60: $179-202$.

Salgado, L., Coria, R. \& Calvo, J. O. 1997. Evolution of titanosaurid sauropods. I. Phylogenetic analysis based on the postcranial evidence. Ameghiniana, 34: 3-32.

Salisbury, S. W. 2002. Crocodilians from the Lower Cretaceous (Berriasian) Purbeck Limestone Group of Dorset, southern England. Special Papers in Palaeontology, 68: 121-144.

Salisbury, S. W. \& Naish, D. 2011. Crocodilians. In: Batten, D.J. (ed.): English Wealden fossils. Palaeontological Association Field Guide to Fossils: Number 14: 305-369, London: The Palaeontological Association.

Salisbury, S. W., Willis, P. M. A., Peitz, S. \& Sander, P. M. 1999. The crocodilian Goniopholis simus from the Lower Cretaceous of north-western Germany. Special Papers in Palaeontology, 60: 121-148.

Salisbury, S. W., Molnar, R. E., Frey, E. \& Willis, P. M. A. 2006. The origin of modern crocodyliforms: new evidence from the Cretaceous of Australia. Proceedings of the Royal Society of London, Series B, 273: 2439-2448.

Sánchez-Hernández, B. 2005. Galveosaurus herreroi, a new sauropod dinosaur from Villar del Arzobispo Formation (Tithonian-Berriasian) of Spain. Zootaxa, 1034: 1-20.

Sánchez-Hernández, B., Benton, M. J. \& Naish, D. 2007. Dinosaurs and other fossil vertebrates from the Late Jurassic and Early Cretaceous of the Galve area, NE Spain. Palaeogeography, Palaeoclimatology, Palaeoecology, 249: 180-215.

Sánchez-Hernández, B., Przewieslik, A. G. \& Benton, M. J. 2009. A reassessment of the Pteraichnus ichnospecies from the Early Cretaceous of Soria Province, Spain. Journal of Vertebrate Paleontology, 29(2): 487-497.

Sander, P. M., Mateus, O., Laven, T. \& Knötschke, N. 2006. Bone histology indicates insular dwarfism in a new Late Jurassic sauropod dinosaur. Nature, 441: 739-741.

Santisteban, C., Gaete, R., Galobart, A. \& Suñer, M. 2003. Rastros de dinosaurios en el jurássico terminal (facies Purbeck) de Corcodilla (Los Serranos, Valencia). In: Pérez-Lorente, F., Romero Molina, M. M. \& Rivas Carrera, P.: Dinosaurios y otros reptiles mesozoicos en España: 33-40, Logroño: Universidad de La Rioja.

Santos, V. F., Moratalla, J. J. \& Royo-Torres, R. 2009. New sauropod trackways from the Middle Jurassic of Portugal. Acta Palaeontologica Polonica, 54(3): 409-422.

Sanz, J. L. \& Ortega, F. 2004. Las aves de Las Hoyas (huellas de fósiles). Historia Natural, 2004(4): 14-21.

Sanz, J. L., Buscalioni, A. D., Casanovas, M. L. \& Santafé, J. V. 1987. Dinosaurios del Cretácico Inferior de Galve (Teruel, España). Estudios geológicos, vol. extr. Galve-Tremp: 45-64.

Sanz, J. L., Buscalioni, A. D., Pérez Moreno, B. P., Moratalla, J. \& Jimenez Garcia, S. 1992. Los dinosaurios de Castilla-León. In: Museo de Salamanca (ed.): Vertebrados fósiles de Castilla y León: 45-57, Salamanca: Museo de Salamanca.

Sarjeant, W. A. S., Delair, J. B. \& Lockley, M. G. 1998. The footprints of Iguanodon: a History and taxonomic study. Ichnos, 6(3): 183-202.

Schmidt, H. 1969. Stenopelix valdensis H. v. Meyer, der kleine Dinosaurier des norddeutschen Wealden. Paläontologische Zeitschrift, 43: 194-198. 
Schnyder, J., Ruffell, A., Deconinck, J.-F. \& Baudin, F. 2006. Conjunctive use of spectral gamma-ray logs and clay mineralogy in defining late Jurassic-early Cretaceous palaeoclimate change (Dorset, U.K.). Palaeogeography, Palaeoclimatology Palaeoecology 229: 303-320.

Schnyder, J., Baudin, F. \& Deconinck, J.-F. 2009. Occurrence of organic-matter-rich beds in Early Cretaceous coastal evaporitic setting (Dorset, UK): a link to long-term palaeoclimate changes? Cretaceous Research 30: 356-366.

Schwarz, D. 2002. A new species of Goniopholis from the Upper Jurassic of Portugal. Palaeontology, 45(1): 185-208.

Schwarz, D. \& Salisbury, S. W. 2005. A new species of Theriosuchus (Atoposauridae, Crocodylomorpha) from the Late Jurassic (Kimmeridgian) of Guimarota, Portugal. Geobios, 38: 779-802.

Schwarz-Wings, D., Rees, J. \& Lindgren, J. 2009. Lower Cretaceous Mesoeucrocodylians from Scandinavia (Denmark and Sweden). Cretaceous Research, 30: 1345-1355.

Seeley, H. G. 1874. On the base of a large lacertian cranium from the Potton Sands, presumably dinosaurian. Quarterly Journal of the Geological Society of London, 30: 690-692.

Seeley, H. G. 1887a. On the classification of the fossil animals commonly named Dinosauria. Proceedings of the Royal Society of London, 43: 165-171.

Seeley, H. G. 1887b. On Aristosuchus pusillus (Owen), being further notes on the fossils described by Sir R. Owen as Poikilopleuron pusillus, Owen". Quarterly Journal of the Geological Society of London, 43: 221-228.

Selenka, E. 1867. Die fossilen Krokodilinen des Kimmeridge von Hannover. Palaeontographica, 16(3): 137-144.

Senter, P., Barsbold, R., Britt, B. B., \& Burnham, D. B. 2004. Systematics and evolution of Dromaeosauridae (Dinosauria, Theropoda). Bulletin of the Gunma Museum of Natural History, 8: 1-20.

Senter, P., Kirkland, J. I., Deblieux, D. D., Madsen, S., \& Toth, N. 2012. New Dromaeosaurids (Dinosauria: Theropoda) from the Lower Cretaceous of Utah, and the Evolution of the Dromaeosaurid Tail. PLoS ONE, 7(5): e36790.

Sereno, P. C. 1986. Phylogeny of the bird-hipped dinosaurs (Order Ornithischia). National Geographic Research, 2: 234256.

Sereno, P. C. \& Brusatte, S. L. Basal abelisaurid and carcharodontosaurid theropods from the Lower Cretaceous Elrhaz Formation of Niger. Acta Palaeontologica Polonica, 53(1): 15-46.

Sereno, P., Larsson, H. C., Sidor, C.A. \& Gado, B. 2001. The Giant Crocodyliform Sarcosuchus from the Cretaceous of Africa. Science, 294: 1516-1519.

Smith, J. B., Vann, D. R. \& Dodson, P. 2005. Dental Morphology and Variation in Theropod Dinosaurs: Implications for the Taxonomic Identification of isolated Teeth. The Anatomical Record, Part A, 285A: 699-736.

Spagna, P., Yans, J., Schnyder, J. \& Dupuis, C. 2012. The Paleoenvironment of the Bernissart Iguanodons: Sedimentological Analysis of the Lower Cretaceous Wealden Facies in the Bernissart Area. In: Godefroit, P. (ed.): Bernissart Dinosaurs and Early Cretaceous Ecosystems. Bloomington: Indiana University Press: 87-96.

Steel R. 1973. Crocodylia. In: Kuhn O (ed.): Handbuch der Palaeoherpetologie. Band 16. 116 pp, Stuttgart: Gustav Fischer 
Verlag.

Sternberg, C. M. 1932. Dinosaur tracks from Peace River, British Columbia. National Museum of Canada Bulletin, 68: 59-85.

Stevens, K. A. \& Parrish, J. A. 1999. Neck posture and feeding habits of two Jurassic sauropod dinosaurs. Science, 284: 798800.

Stevens, K. A. \& Parrish, J. A. 2005. Neck Posture, Dentition, and Feeding Strategies in Jurassic Sauropod Dinosaurs. In: Tidwell, V. \& Carpenter, K. (eds.) Thunder-Lizards. The Sauropodomorph Dinosaurs. Bloomington: Indiana University Press: 212-232.

Stokes, W. L. 1957. Pterodactyl tracks from the Morrison Formation. Journal of Paleontology, 31: 952-954.

Strebost, M., Jurkschat, T. \& Zawischa. D. 1992. Der Lias am Mittellandkanal bei Sehnde. Arbeitskreis Paläontologie Hannover, 20 (3): 57-67.

Struckmann, C. 1891. Die Wealdenbildungen von Sehnde bei Lehrte. Neues Jahrbuch für Mineralogie, Geologie und Paläontologie, [1891] (1): 117-131.

Struckmann, C. 1894. Ueber einen Zahn des Iguanodon aus dem Wealden von Sehnde bei Lehrte. Zeitschrift der Deutschen Geologischen Gesellschaft, 46: 828-831.

Surlyk, F., Milàn, J., Noe-Nygaard, N. 2008. Dinosaur tracks and possible lungfish aestivation burrows in a shallow coastal lake; lowermost Cretaceous, Bornholm, Denmark. Palaeogeography, Palaeoclimatology, Palaeoecology, 267: 292-304.

Sweetman, S. C. 2004. The first record of velociraptorine dinosaurs (Saurischia, Theropoda) from the Wealden (Early Cretaceous, Barremian) of southern England. Cretaceous Research, 25: 353-364.

Sweetman, S. C. 2011. Vertebrate microfossils. In: Batten, D.J. (ed.): English Wealden fossils. Palaeontological Association Field Guide to Fossils: Number 14: 192-204, London: The Palaeontological Association.

Swinton, W. E. 1962. Fossil amphibians and reptiles. $3^{\text {rd }}$ ed. London: British Museum (Natural History), 118 pp..

Tagart, E. 1846. On markings in the Hastings sand beds near Hastings, supposed to be the footprints of birds. Quaterly Journal of the Geological Society of London, 2: 267.

Tallodi-Posmoșanu, E. \& Popa, E. 1997. Notes on a camptosaurid dinosaur from the Lower Cretaceous bauxite, Cornet Romania. Nymphaea, 23-25: 35-44.

Taplin, L. E. \& Grigg, G. C. 1989. Historical Zoogeography of the Eusuchian Crocodilians: A Physiological Perspective. American Zoologist, 29(3): 885-991.

Taylor, K. G. \& Ruffell, A. H. 1993. Early Cretaceous environments. Journal of the Geological Society, London, 150: 413-414.

Taylor, M. A., Norman, D. B. \& Cruickshank, A. R. I. 1993. Remains of an ornithischian dinosaur in a pliosaur from the Kimmeridgian of England. Palaeontology, 36: 357-360.

Taylor, M. P. \& Naish, D. 2007. An unusual new neosauropod dinosaur the Lower Cretaceous Hastings Beds Group of East Sussex, England. Palaeontology, 50: 1547-1564. 
Thies, D. \& Broschinski, A. 2001. Teeth of a small durophagous crocodile from the Late Jurassic (Kimmeridgian) of North Germany. Geologische Beiträge Hannover, 2: 65-70.

Thies, D., Windolf, R. \& Mudroch, A. 1997. First record of Atoposauridae (Crocodylia: Metamesosuchia) in the Upper Jurassic (Kimmeridgian) of Northwest Germany. Neues Jahrbuch für Geologie und Paläontologie, Abhandlungen, 205(3): 393-411.

Thompson, R. S., Parish, J. C., Susannah C. R. Maidment, S. C. R. \& Barrett, P. M. 2011. Phylogeny of the ankylosaurian dinosaurs (Ornithischia: Thyreophora). Journal of Systematic Palaeontology, 10(2): 301-312.

Torcida Fernández-Baldor, F., Canudo, J. I., Huerta, P., Montero, D., Pereda Suberbiola, X. \& Salgado, L. 2011. Demandasaurus darwini, a new rebbachisaurid sauropod from the Early Cretaceous of the Iberian Peninsula. Acta Palaeontologica Polonica, 56(3): 535-552.

Tütken, T. 2011. The Diet of Sauropod Dinosaurs. Implications of Carbon Isotope Analysis on Teeth, Bones, and Plants. In: Klein, N., Remes, K., Gee, C. T. \& Sander, P. M. (eds.): Biology of the Sauropod Dinosaurs. Understanding the Life of Giants. Bloomington: Indiana University Press: 57-82.

Tykowski, R. S., Rowe, T. B., Ketcham, R. A., \& Colbert, M. W. 2002. Calsoyasuchus valliceps, a new crocodyliform from the Early Jurassic Kayenta Formation of Arizona. Journal of Vertebrate Paleontology, 22(3): 593-611.

Underhill, J. 2002. Evidence for structural controls on the deposition of the late Jurassic-early Cretaceous Purbeck Limestone Group, Dorset, southern England. Special Papers in Palaeontology, 68: 21-40.

Upchurch, P., Barrett, P. M. \& Dodson, P. 2004. Sauropoda. In: Weishampel, D. B., Dodson, P. \& Osmolska, H. (eds.): The Dinosauria. $2^{\text {nd }}$ ed.: 259-324, Berkeley: University of California Press.

Upchurch, P., Mannion, P. D. \& Barrett, P. M. 2011. Sauropod Dinosaurs. In: Batten, D.J. (ed.): English Wealden fossils. Palaeontological Association Field Guide to Fossils: Number 14: 476-525, London: The Palaeontological Association.

Upchurch, P., Mannion, P. D., Benson, R. B. J., Butler, R. J. \& Carrano, M. T. 2011. Geological and anthropogenic controls on the sampling of the terrestrial fossil record: a case study from the Dinosauria. In: McGowan, A. J. \& Smith, A. B. (eds.): Comparing the Geological and Fossil Record. Implications for Biodiversity Studies. Geological Society, Special Publication, 358: 209-240.

Virchow, H. 1919. Atlas und Epistropheus bei den Schildkröten. Sitzungsberichte der Gesellschaft Naturforschender Freunde zu Berlin, 1919(8): 303-332.

Voigt, S., Wagreich, M., Surlyk, F., Walaszczyk, I., Uličny, D., Čech, S., Voigt, T., Wiese, F., Wilmsen, M., Niebuhr, B., Reich, M., Funk, H., Michalík, J., Jagt, J. W. M., Felder, P. J., \& Schulp, A. S. 2008. Cretaceous. In: McCann, T. (ed.) The Geology of Central Europe. Volume 2: 923-997, Bath: The Geological Society.

Vullo, R., Pouech, J., Neraudeau, D., Mazin, J.-M. \& Billon-Bruyat, J.-P. 2008. Faunal change among continental tetrapods during the Early Cretaceous in the northern Aquitaine Basin (Charentes, SW France). In: J.-M. Mazin, J. Pouech, P. Hantzpergue, V. Lacombe (eds.): Mid-Mesozoic Life and Environments, Cognac (France), June $24^{\text {th }}-28^{\text {th }} 2008$. Documents des Laboratoires de Géologique de Lyon, 164: 86-90.

Waite, R. 2010. The palaeoecology of high-spired gastropods and the lost palaeosols: depositional reconstructions on a shallow carbonate platform (Late Kimmeridgian, Swiss Jura Mountains). GeoFocus, 23: 1-149. 
Weigelt, J. 1927. Rezente Wirbeltierleichen und ihre paläobiologische Bedeutung. Leipzig: Weg, XVI+227 pp.

Weishampel, D. B., Barrett, P. M., Coria, R. A., Le Loeuff, J., Xing, X., Xijin, Z., Sahni, A., Gomani, E. M. P. \& Noto, C. R. 2004. Dinosaur Distribution. In: Weishampel, D. B., Dodson, P. \& Osmolska, H. (eds.): The Dinosauria. $2^{\text {nd }}$ ed.: 517-606, Berkeley: University of California Press.

Wellnhofer, P. 1970. Die Pterodactyloidea (Pterosauria) der Oberjura-Plattenkalke Süddeutschlands. Bayerische Akademie der Wissenschaften, Mathematisch-Wissenschaftlichen Klasse, Abhandlugen, 141: 1-133.

Wellnhofer, P. 1971. Die Atoposauridae (Crocodylia, Mesosuchia) der Oberjura-Plattenkalke Bayerns. Palaeontographica, A, A138(5-6): 133-165.

Wellnhofer, P. 1975. Die Rhamphorhynchoidea (Pterosauria) der Oberjura-Plattenkalke Süddeutschlands. Palaeontographica, A, A148: 1-33, 132-186; A149: 1-30.

Wellnhofer, P. 1978. Pterosauria. Handbuch der Paläoherpetologie. Teil 19. Pterosauria. Stuttgart: Gustav Fischer Verlag: 82 pp.

Wellnhofer, P. 2009. Archaeopteryx. Der Urvogel von Solnhofen. München: Dr. Friedrich Pfeil: 256 pp..

West, I.M. 1975. Evaporites and associated sediments of the basal Purbeck Formation (Upper Jurassic) of Dorset. Proceedings of the Geologists' Association, London, 86: 205-225.

West, I.M. \& El Shahat, A. 1985. Dinosaur footprints and early cementation of Purbeck bivalve beds. Proceedings of Dorset Natural History and Archaeological Society, 106: 169-170.

Whetstone, K. N. \& P. J. Whybrow, P. J. 1983. A "cursorial" crocodilian from the Triassic of Lesotho (Basutoland), Southern Africa. Occasional Papers of the Museum of Natural History, University of Kansas, 106: 1-37

Whitlock, J. A. 2011. Inferences of Diplodocoid (Sauropod: Dinosauria) Feeding Behaviour from Snout Shape and Microwear Analyses. PLoS ONE 6(4): e18304.

Wilde, V. \& Schultka. S. 1996. Die sandige Wealden-Fazies (Bückeberg-Formation, Berrias, Unterkreide) am Westrand eines Schüttungskörpers bei Osnabrück (NW-Deutschland). Neues Jahrbuch für Geologie und Paläontologie, Abhandlungen, 199(2): 249-268.

Wilson, J. A. \& Sereno, P. C. 1998. Early evolution and higher-level phylogeny of the sauropod dinosaurs. Society of Vertebrate Paleontology Memoir, 5: 1-68.

Wilson, J. A. \& Upchurch, P. 2009. Redescription and reassessment of the phylogenetic affinities of Euhelopus zdanskyi (Dinosauria: Sauropoda) from the Early Cretaceous of China. Journal of Systematic Palaeontology, 7(2): 199-239.

Wiman, C. 1929. Die Kreide-Dinosaurier aus Shantung. Palaeontologica Sinica, Series C, 6: 1-67.

Windolf, R. 1989. Dinosaurier-Lexikon. Das aktuelle Wissen über die Dinosaurier von ihren Anfängen bis zum Aussterben. Korb: Goldschneck-Verlag: $152 \mathrm{pp}$.

Windolf, R. 1997. Theropoden-Zähne aus dem Oberen Jura Niedersachsens. In: Sachs, S., Rauhut, O. W. M. \& Weigert, A. (eds.): 1. Treffen der deutschsprachigen Paläoherpetologen. Extended Abstracts. Terra Nostra, 9: 33-34. 
Windolf, R. 1998. Dinosaurierfunde in Niedersachsen. Arbeitskreis Paläontologie Hannover, 26: 1-7.

Wings, 0. 2012. The Langenberg-Quarry in Oker - A special window into the terrestrial Late Jurassic of Northern Germany. In: Witzmann, F. \& Aberhan, M. (eds.): Centenary Meeting of the Paläontologische Gesellschaft. Programm, Abstracts and Field Guides. Terra Nostra, 2012/3: p. 200.

Wings, O., Falk, D., Knötschke, N. \& Richter, A. 2012: The Early Cretaceous Dinosaur Trackways in Münchehagen (Lower Saxony, Germany) - the Natural Monument 'Saurierfährten Münchehagen' and the adjacent Wesling Quarry. In: Richter, A., \& Reich, M. (eds.): Dinosaur Tracks 2011. An International Symposium, Obernkirchen, April 14-17, 2011. Abstract Volume and Field Guide to Excursions: 113-142, Göttingen: Universitäts-Verlag.

Winkler, D. A., Murry, P. A. \& Jacobs, L. L. 1990. Early Cretaceous (Comanchean) vertebrates of central Texas. Journal of Vertebrate Paleontology, 10: 95-116.

Winkler, D. A., Murry, P. A. \& Jacobs, L. L. 1997. A new species of Tenontosaurus (Dinosauria: Ornithopoda) from the Early Cretaceous of Texas. Journal of Vertebrate Paleontology, 17: 330-348.

Woodhams, K. E. \& Hines, J. S. 1989. Dinosaur footprints from the Lower Cretaceous of East Sussex, England. In: Gillette, D. D. \& Lockley, M. G. (eds.): Dinosaur tracks and traces: 301-307, Cambridge: Cambridge University Press.

Woodward, A. S. 1910. On a skull of Megalosaurus from the Great Oolite of Minchinhampton (Gloucestershire). Quarterly Journal of the Geological Society, London, 66: 111-115.

Wright, J.L. 1999. Ichnological evidence for the use of the forelimb in iguanodontians. In: Unwin, D. M. (ed.). Cretaceous Fossil Vertebrates. Special Papers in Palaeontology, 60: 209-219.

Wright, J.L., Unwin, D.M., Lockley, M.G. \& Rainforth, E.C. 1997. Pterosaur tracks from the Purbeck Limestone Formation of Dorset, England. Proceedings of the Geologists' Association, 108: 39-48.

Wright, J. L., Barrett, P. M., Lockley, M. G. \& Cook, E. 1998. A review of Early Cretaceous terrestrial vertebrate track-bearing strata of England and Spain. In: Lucas, S. G., Kirkland, J. I. \& Estep, J. W. (eds.): Lower and Middle Cretaceous Terrestrial Ecosystems. New Mexico Museum of Natural History and Science Bulletin, 14: 143-153.

Wu, W. \& Godefroit, P. 2012. Anatomy and Relationships of Bolong yixianensis, an Early Cretaceous Iguanodontoid Dinosaur from Western Liaoning, China. In: Godefroit, P. (ed.): Bernissart Dinosaurs and Early Cretaceous Ecosystems: 293-333, Bloomington: Indiana University Press.

Wu, X., Brinkman, D. B., Russell, A. P. 1996. Sunosuchus junggarensis sp. nov. (Archosauria: Crocodyliformes) from the Upper Jurassic of Xingjiang, China. Canadian Journal of Earth Sciences, 33: 606-630.

Xu, X. \& Clark, J. M. 2008. The presence of a gigantic theropod in the Jurassic Shishogu Formation, Junggar Basin, western China. Vertebrata PalAsiatica, 46(2): 157-160.

Xu, X., Forster, C.A., Clark, J.M., \& Mo, J. 2006. A basal ceratopsian with transitional features from the Late Jurassic of northwestern China. Proceedings of the Royal Society B: Biological Sciences, 273(1598): 2135-2140.

Xu, X., You, H., Du, K, Han, F. 2011. An Archaeopteryx-like theropod from China and the origin of Avialae. Nature 475 (7357): 465-470.

Yadagiri, P. \& Ayyasami, K. 1979. A new stegosaurian dinosaur from Upper Cretaceous sediments of south India. Journal of 
the Geological Society of India, 20(11): 521-530.

Yans, J., Dejax, J., Pons, D., Dupuis, C. \& Taquet, P. 2005. Implications paléontologiques et géodynamiques de la datation palynologique des sédiments à faciès wealdien de Bernissart (bassin de Mons, Belgique). Comptes Rendus Palevol, 4 : 135-150.

Young, M. T. \& Andrade, M. B. de 2009. What is Geosaurus? Redescription of Geosaurus giganteus (Thalattosuchia: Metriorhynchidae) from the Upper Jurassic of Bayern, Germany. Zoological Journal of the Linnean Society, 157(3): 551-585.

Young, M. T., Brusatte, S. L., Ruta, M. \& Andrade, M. B. de 2010. The evolution of Metriorhynchoidea (Mesoeucrocodylia, Thalattosuchia): an integrated approach using geometric morphometrics, analysis of disparity, and biomechanics. Zoological Journal of the Linnean Society, 158: 801-859.

Zheng, X.-T., You, H.-L., Xu, X \& Dong, Z.-M. 2009. An Early Cretaceous heterodontosaurid dinosaur with filamentous integumentary structures. Nature 458 (7236): 333-336.

Zaher H., Pol D., Carvalho A. B., Nascimento P. M., Riccomini C., Larson, P., Juarez-Valieri, R., Pires-Domingues, R., da Silva, jr., N. J. \& Almeida Campos, D. de 2011. A Complete Skull of an Early Cretaceous Sauropod and the Evolution of Advanced Titanosaurians. PLoS ONE, 6(2): e16663.

Ziegler, P. A. 1990. Geological Atlas of Western and Central Europe. $2^{\text {nd }}$ Edition. 239 pp., Bath: Geological Society Publishing House / Shell International Petroleum Maatschappij B. V.

Zinke, J. 1998. Small theropod teeth from the Upper Jurassic coal mine of Guimarota (Portugal). Paläontologische Zeitschrift, 72(1-2): 179-189.

Zittel, K. A. von 1902. Text-Book of Palaeontology by Karl A. von Zittel. Volume II. Translated by C.R. Eastman, London: McMillan \& Co., 283 pp. 
References for Chapter XI, Outlook, and Appendices 


\section{JAHN JOCHEN HORNUNG}

12.10.1976 Geboren in Freiburg im Breisgau

01.06.1996 Abitur, Leibniz-Gymnasium, Neustadt/Weinstr.

Okt. 1996 - Okt. 1997

Zivildienst

Okt. 1997 - Jan. 2004

Studium der Geologie und Paläontologie, Johannes-Gutenberg-Universität Mainz.

28.01.2004 Abschluss des Studiums mit Diplom.

Feb. 2004 - April 2006 Wissenschaftlicher Mitarbeiter, Institut für Geologie, Universität Hannover.

Okt. 2007 - Juli 2013

Promotionsstudium, Geowissenschaftliches Zentrum der Georg-August-Universität Göttingen. 